Contract No. W-7405-eng-26

\title{
CHEMICAL TECHNOLOGY DIVISION \\ ANNUAL PROGRESS REPORT \\ for Period Ending May 31, 1964
}
F. L. Culler
- Division Director
J. C. Bresee
- Assistant Director
D. E. Ferguson
- Assistant Director
R. G. Wymer
- Chemical Development
Section A Chief
R. E. Blanco
- Chemical Development Section B Chief
K. B. Brown
- Chemical Development Section C Chief
M. E. Whatley
- Unit Operations Section Chief
H. E. Goeller
- Process Design Section Chief
R. E. Brooksbank - Pilot Plant Section Chief

\section{OCTOBER 1964}

\author{
OAK RIDGE NATIONAL LABORATORY \\ Oak Ridge, Tennessee \\ operated by \\ UNION CARBIDE CORPORATION \\ U. 5. ATOMIC ENERGY COMMISSION
}




\section{DISCLAIMER}

This report was prepared as an account of work sponsored by an agency of the United States Government. Neither the United States Government nor any agency Thereof, nor any of their employees, makes any warranty, express or implied, or assumes any legal liability or responsibility for the accuracy, completeness, or usefulness of any information, apparatus, product, or process disclosed, or represents that its use would not infringe privately owned rights. Reference herein to any specific commercial product, process, or service by trade name, trademark, manufacturer, or otherwise does not necessarily constitute or imply its endorsement, recommendation, or favoring by the United States Government or any agency thereof. The views and opinions of authors expressed herein do not necessarily state or reflect those of the United States Government or any agency thereof. 


\section{DISCLAIMER}

Portions of this document may be illegible in electronic image products. Images are produced from the best available original document. 


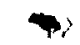

0

,) 


\section{Summary}

\section{POWER REACTOR FUEL PROCESSING}

In the development of new power reactor concepts, fuels that can be used for long periods and at very high temperatures are continually being developed. To achieve these goals, materials are employed for which the chemistry encountered in fuel processing is often not well understood. The development program is directed toward the demonstration of chemical methods and engineering practices to permit the recovery of the uranium, thorium, and plutonium from the spent fuels. Two approaches are being followed: the development of both mechanical and chemical head-end methods designed to produce suitable aqueous feeds for solvent extraction and the development of nonaqueous processes such as chloride volatility, which may either precede or circumvent solvent extraction or fluoride volatility processes.

\subsection{Process Development for Uranium Carbide Fuels}

Last year it was reported that unirradiated samples of uranium carbides hydrolyze rapidly in water and in solutions of acids and bases at 80 to $100^{\circ} \mathrm{C}$. Hot-cell evaluations of this process with uranium monocarbide samples irradiated from 600 to $16,000 \mathrm{Mwd} /$ ton showed that irradiation passivates uranium carbide toward hydrolysis in water and in base solutions (but not in acids) and that the degree of passivation is a function of the amount of irradiation. Fuel containing 20\% PuC $-80 \%$ UC behaved similarly. To circumvent this difficulty, two alternative methods were explored and tested with unirradiated and irradiated fuel samples.

The first method employed pyrohydrolysis of uranium carbide with steam at 700 to $800^{\circ} \mathrm{C}$ at
1 atm; when air is excluded, $\mathrm{UO}_{2}$ is produced, but with air present, the product is $\mathrm{U}_{3} \mathrm{O}_{8}$. The off-gas consists of $\mathrm{H}_{2}, \mathrm{CO}$, and $\mathrm{CO}_{2}$. Only $0.03 \%$ of the carbon remains unreacted. In hot-cell tests, $0.5 \%$ of the cesium and $0.04 \%$ of the ruthenium were volatilized but were condensed quantitatively in the steam condensate. The uranium oxide ash remaining after hydrolysis is easily dissolved in nitric acid, and the resulting solution can be solvent extracted without further treatment. Similar results were obtained with $\mathrm{PuC}$ and $20 \%$ PuC-UC fuel samples that had been irradiated to $20,000 \mathrm{Mwd} /$ ton. When irradiated $\mathrm{PuC}-80 \% \mathrm{UC}$ was burned directly in $\mathrm{O}_{2}, 36 \%$ of the fission product cesium and $2 \%$ of the ruthenium were volatilized, probably as oxides.

Alternatively, uranium monocarbide can be dissolved in $13 M \mathrm{HNO}_{3}$ to produce a dilute solution of uranyl nitrate in nitric acid. However, this solution contains about $40 \%$ of the carbon (from the UC) as soluble organic acids and possibly other compounds. These contaminants can be oxidized completely by extended treatment with permanganate. Then, after removing the excess acid by distillation, the solution may be processed with little difficulty by Purex solvent extraction. In tests of the procedure, uranium recovery was better than $99.99 \%$; however, $0.15 \%$ of the plutonium was not recovered during stripping.

Our continuing studies of the hydrolysis reactions and reaction products of the carbides of uranium have required samples with varying ratios of uranium to carbon. The Metals and Ceramics Division accordingly prepared heat-treated specimens ranging in initial composition from $\mathrm{UC}_{1.0}$ to $\mathrm{UC}_{1.85}$. After heat treatment at temperatures of 1275 to $1780^{\circ} \mathrm{C}$, these starting materials were converted to mixtures of monocarbide-sesquicarbide (UC to $\mathrm{UC}_{1.5}$ ) or sesquicarbide-dicarbide $\left(\mathrm{UC}_{1.5}\right.$ to $\mathrm{UC}_{1.85}$ ). No uranium sesquicarbide was formed 
when an as-cast specimen of dicarbide (with a combined-C/U atom ratio of 1.86 ) was heat treated under conditions in which the sesquicarbide should have formed had the as-cast specimen been a mixture of $\mathrm{UC}$ and $\mathrm{UC}_{2.0}$.

The hydrolysis of uranium sesquicarbide $\left[\mathrm{U}_{4}\left(\mathrm{C}_{2}\right)_{3}\right]$ between 25 and $99^{\circ} \mathrm{C}$ produced hydrogen, gaseous aliphatic hydrocarbons (containing mainly 2 to 8 carbon atoms, with a trace of methane), a water-insoluble wax, and a hydrous U(IV) oxide. Uranium monocarbide-sesquicarbide mixtures produced less methane and more $\mathrm{C}_{2}$ - to $\mathrm{C}_{8}$-hydrocarbons than expected, indicating that polymerization involving single carbon units from the monocarbide had occurred. Hydrolysis of sesquicarbide-dicarbide mixtures yielded the products expected from the behavior of the separate compounds. The compositions of the gaseous products from the heat-treated specimens containing uranium sesquicarbide were markedly different from those of as-cast monocarbide-dicarbide mixtures with the same carbon to uranium atom ratios.

One of the more interesting effects was that the gases produced by the hydrolysis of irradiated monocarbide in acids contained increasing concentrations of hydrogen and $\mathrm{C}_{2}-\mathrm{C}_{8}$ hydrocarbons and decreasing concentrations of methane as the irradiation level increased. That irradiation affects UC is further substantiated by the passivity of irradiated carbide to simple hydrolysis in water.

\subsection{Studies on the Dissolution of $\mathrm{PuO}_{2}-\mathrm{UO}_{2}$}

Fundamental studies of the dissolution of certain single- and mixed-fuel oxides, begun last year with unirradiated $\mathrm{UO}_{2}, \mathrm{PuO}_{2}$, and $\mathrm{PuO}_{2}-\mathrm{UO}_{2}$ fuel pellets obtained from a number of manufacturers, were continued.

Total dissolution times for pelleted $\mathrm{UO}_{2}-\mathrm{PuO}_{2}$ mixtures, prepared differently, were determined. When the pellets represented a homogeneous solid solution, they could be dissolved in nitric acid alone. When complete solid solution had not been achieved during pellet fabrication, a mixed dissolvent (nitric and hydrofluoric acids) was required. It was found that complete dissolution of pellets in which solid solution had been attained took two or three times as long as would be predicted on the basis of the area of the pellet and the initial dissolution rate.

\subsection{Dissolution of Sol-Gel-Derived $\mathrm{ThO}_{2}-\mathrm{UO}_{2}$}

Dissolution studies were made with both unirradiated and irradiated $\mathrm{ThO}_{2}-4 \% \mathrm{UO}_{2}$ prepared by the sol-gel process. Unirradiated mixed-oxide samples were only 70 to $73 \%$ dissolved in $7 \mathrm{hr}$ in boiling $13 \mathrm{MHNO}_{3}-0.04 \mathrm{M} \mathrm{Al}\left(\mathrm{NO}_{3}\right)_{3}$. Because of the long dissolution time, "heel" dissolution appears to be required. With a heel, $87 \%$ of the sol-gel-derived thoria dissolved in $20 \mathrm{hr}$, the dissolver product being $0.8 \mathrm{M}$ in thorium. Irradiated samples dissolved much faster, at least initially, than unirradiated specimens. In $7-\mathrm{hr}$ tests about $95 \%$ of the irradiated oxide dissolved.

\subsection{Studies on the Zirflex Process}

Several modifications and improvements to the $Z$ irflex process for the chemical removal of Zircaloy cladding from oxide-core fuels were evaluated. When ammonium fluoride-ammonium nitrate solutions are used to selectively dissolve Zircaloy from irradiated $\mathrm{UO}_{2}$, some small fraction of the $\mathrm{UO}_{2}$ is dissolved. Uranium can be recovered from Zirflex decladding waste solution by a slow (2- to 7-day) precipitation of uranium peroxide with $1 \mathrm{M} \mathrm{H}_{2} \mathrm{O}_{2}$, followed by filtration.

The addition of ammonium tartrate and ammonium hydroxide to $Z$ irflex waste solution produced solutions $(\mathrm{pH} 8)$ that were stable for more than a year, at $25^{\circ} \mathrm{C}$. The zirconium concentration was $0.15 \mathrm{M}$ at a tartrate-to-zirconium ratio of 0.1 , and $0.5 \mathrm{M}$ at a ratio of 0.5 . The addition of potassium tartrate and potassium hydroxide produced a waste $(\mathrm{pH} 12)$ that was stable for $70 \mathrm{hr}$ at a tartrate-to-zirconium ratio of 1.4. Addition of ammonium tartrate and ammonium hydroxide to the $\mathrm{NH}_{4} \mathrm{~F}$ dissolvent caused no reduction of the Zircaloy- 2 dissolution rate.

\subsection{Studies on the Adsorption of Protactinium}

The recovery of ${ }^{233} \mathrm{~Pa}$ from nitric acid solution of short-cooled irradiated thorium may be possible by the use of unfired Vycor glass as an adsorber. Laboratory studies showed that unfired Vycor preferentially and efficiently adsorbs protactinium from simulated acid-Thorex dissolver solutions, with distribution coefficients of 3800 to 300 , 
depending on the concentration of other ions in the solution. More than $98 \%$ of the protactinium can be removed.

Other inorganic ion exchangers or adsorbers were tested. Linde molecular sieves (5X,10X, and $15 \mathrm{X})$ gave distribution coefficients from 1000 to 2000; silica gel, 3000 to 6000; and Bio-Rad ZP-1, a zirconium phosphate ion exchanger, about 17,000 . Protactinium can be removed from the Vycor with oxalic acid solutions.

The first tests to determine the feasibility of recovering uranium from solutions of irradiated thorium by adsorption directly onto high-surfacearea thorium dioxide were discouraging.

\subsection{Recovery of Advanced Reactor Fuels by Solvent Extraction}

Some advanced reactor fuels must be dissolved in nitric-hydrofluoric acid mixtures, but the resulting solutions are not amenable to standard solvent extraction methods. Accordingly, laboratory experiments were made in order to define the variation in the distribution coefficient of uranium between tributyl phosphate or dibutyl butylphosphonate and nitric-hydrofluoric acid systems containing niobium and aluminum.

Countercurrent batch extraction experiments, with a feed solution $0.1 M$ in $\mathrm{Nb}, 0.1 M$ in U, $1 M$ in $\mathrm{F}^{-}$, $3 M$ in $\mathrm{NO}_{3}{ }^{-}$, plus trace amounts of fission products, resulted in satisfactory uranium recovery and decontamination from fluotide, niobium, zirconium, ruthenium, and rare-earth elements.

\subsection{Studies on Chloride Volatility}

Laboratory studies indicated the feasibility of collecting volatile $\mathrm{ZrCl}_{4}$ and $\mathrm{UCl}_{5}$ (resulting from the chlorination of $\mathrm{U}-\mathrm{Zr}$ alloy fuel) in boiling water. The chloride can be removed from this solution, and the solution can be reduced in volume, by adding hydrogen peroxide and boiling. The resulting solution is stable at room temperature. It may be as concentrated as $5 M$ in zirconium, and the uranium can be satisfactorily recovered by solvent extraction with tributyl phosphate. To indicate the possible application of chloride volatility to graphite-matrix fuels, the ash from the burning of UC-ThC-graphite fuel was satisfactorily chlorinated, and the thorium and uranium chloride was dissolved in $6 \mathrm{~N} \mathrm{HCl}$. After concentrating, the uranium was recovered by solvent extraction.

Other work in the chloride system included thermodynamic calculations on the reduction of volatile $\mathrm{UCl}_{4}$ with $\mathrm{CO}$ to produce the nonvolatile $\mathrm{UCl}_{3}$; quantitative reduction and recovery of the uranium is not feasible. Phase-equilibrium data for the system $\mathrm{HCl}-\mathrm{H}_{2} \mathrm{O}-\mathrm{ZrOCl}_{2}$ were determined for the range 0.2 to $3.5 \mathrm{M} \mathrm{ZrOCl}_{2}$. Calculations were made which indicate that the equilibrium capacity of chlorine for transporting plutonium as $\mathrm{PuCl}_{4}$ is affected only slightly by the presence of uranium chloride vapor. This capacity increases from $3 \times 10^{-6}$ mole to $10^{-2}$ mole of plutonium per mole of chlorine as the temperature increases from 700 to $1000^{\circ} \mathrm{K}$.

\subsection{Corrosion Studies}

Corrosion studies to evaluate potential structural materials for use with the various aqueous and nonaqueous fuel processes under development were continued. This work is being done by the Reactor Chemistry Division.

Hastelloy-F, Haynes 25, and type $309 \mathrm{SCb}$ stainless steel were found to be suitable for the process that includes the burning and nitric acid leaching of graphite and carbide fuels because the corrosion rates for the three alloys were $\leqq 1 \mathrm{mil} /$ month. When trace amounts $\left(\leq_{0.05} \mathrm{M}\right)$ of $\mathrm{HF}$ are added to $7 \mathrm{MHNO}_{3}$, Corronel 230 is the best material $(<2 \mathrm{mils} / \mathrm{month}) ;$ Haynes 25 and type $309 \mathrm{SCb}$ stainless steel were marginal $>5$ mils/month); and Hastelloy $\mathrm{F}$ was unsatisfactory (>13 mils/month).

No suitable material was found for high-temperature $\left(800^{\circ} \mathrm{C}\right)$ oxidation followed by chlorination with $\mathrm{Cl}_{2}$ or $\mathrm{CCl}_{4}$ at $500^{\circ} \mathrm{C}$. However, oxidation followed by chlorination with hexachloropropene at $180^{\circ} \mathrm{C}$ was satisfactory in either Nichrome $\mathrm{V}$ or Haynes 25. "A" nickel showed rates of less than $1 \mathrm{mil} /$ month for exposure to both $\mathrm{O}_{2}-1 \% \mathrm{HF}$ at $600^{\circ} \mathrm{C}$ and steam $-1 \% \mathrm{O}_{2}$ at $25^{\circ} \mathrm{C}$. The rate for type $304 \mathrm{~L}$ stainless steel in the latter environment was $0.2 \mathrm{mil} / \mathrm{month}$.

Only Duriron and tantalum had satisfactory corrosion rates when exposed to $90 \% \mathrm{H}_{2} \mathrm{SO}_{4}-10 \%$ $\mathrm{HNO}_{3}$ at $150^{\circ} \mathrm{C}$; the rate was 0.2 to $0.3 \mathrm{mil} /$ month.

Hastelloy $\mathrm{B}$ was exposed to $3 \mathrm{M} \mathrm{ZrOCl}_{2}-3 \mathrm{M}$ $\mathrm{HCl}$ under an atmosphere of $\mathrm{H}_{2}-\mathrm{HCl}$ in order to 
test its durability as a structural material for a process in which $\mathrm{ZrCl}_{4}$ vapor is absorbed in concentrated $\mathrm{HCl}$. Although overall corrosion rates were less than $2 \mathrm{mils} / \mathrm{month}$, the alloy underwent a pitting type of attack, indicating unfitness for this service.

\subsection{Mechanical Processing Development}

This year, the adequacy of the 250-ton fuel shear for processing first-core power-reactor fuels was demonstrated, and the safety of shearing Zircaloy2-clad fuel was verified. Batch-leaching of both sheared $\mathrm{UO}_{2}$ and $\mathrm{ThO}_{2}-\mathrm{UO}_{2}$ fuels, held in a perforated basket, was found to be feasible. Demonstrations of the disassembly and/or shearing of prototypes of second- and later-core fuels indicated that they cannot be sheared intact. Disassembly of the advanced fuels can be achieved by "pulling" the tubes, so tests were made to evaluate the feasibility of disassembling to tubes and shearing loose tube bundles. Both operations worked adequately.

Evaluation of the shear-leach process will be continued by studying the feasibility of shearing and leaching second-generation fuels in largescale engineering tests. Similar studies will be made with liquid-metal-bonded fuels. Work on the mechanical processing of massive graphite fuel rods will also be started next year.

\section{FLUORIDE VOLATILITY PROCESSING}

The purpose of the volatility program in the United States is to develop an alternative to conventional aqueous processes for recovering uranium from spent nuclear fuels. All fluoride-volatility methods use the volatility of $\mathrm{UF}_{6}$ to achieve a high degree of separation of the uranium from its fission products. Other advantages of volatility processes, compared with aqueous processes, are (1) the formation of a dry, highly concentrated waste, (2) the greater ease of processing certain refractory fuels, (3) fewer processing steps between the original fuel element and $\mathrm{UF}_{6}$, and (4) increased nuclear safety. Thus, dependence on a physical property, volatility, rather than a chemical one, makes possible the recovery of uranium for return to production channels.
Volatility processes are being studied at all the national laboratories; here, the primary emphasis has been on a molten-salt fluoride-volatility process for use with spent zirconium-base fuels containing highly enriched uranium. The process consists basically of three steps: (1) dissolution of the metal (or oxide) by hydrofluorination in a molten salt, (2) volatilization of the uranium from the melt as UF ${ }_{6}$ by contacting the salt with gaseous fluorine, and (3) the purification of the product $\mathrm{UF}_{6}$ from contaminants by passing the impure stream through beds of $\mathrm{NaF}$ and $\mathrm{MgF}_{2}$. A pilot-plant-scale demonstration of the process for $\mathrm{Zr}-\mathrm{U}$ alloy fuels was completed during the year.

A few years ago, the study of the application of the process to Al-U alloy fuels began. In addition, some work has been done on developing processes for highly enriched $\mathrm{UO}_{2}$ fuels containing zirconia, thoria, beryllia, or stainless steel.

Studies have also been made at the Laboratory aimed at the volatilization and recovery of uranium and plutonium from low-enrichment fuels that had previously been dissolved in molten salt; these studies will be emphasized during the coming year. A proposal has been made to install a fluidizedbed fluoride-volatility pilot plant in building 3019 as an extension of the work being conducted at Argonne National Laboratory. Primarily, the work at this facility would be with stainless-steel- or zirconium-clad $\mathrm{UO}_{2}$.

\subsection{Processing of Uranium-Zirconium Alloy Fuel}

For the past $3 \frac{1}{2}$ years the Chemical Technology Division has been engaged in the demonstration of the molten-salt fluoride-volatility process for $\mathrm{U}-\mathrm{Zr}$ alloy fuels on a pilot-plant scale. In this demonstration, highly enriched $U-Z r$ alloy fuel elements were dissolved by $\mathrm{HF}$ in $37.5-37.5-25$ mole $\% \mathrm{NaF}-\mathrm{LiF}-\mathrm{ZrF}_{4}$ at 650 to $500^{\circ} \mathrm{C}$. The resulting salt, in which the alloyed uranium had been converted to $\mathrm{UF}_{4}$, was contacted with fluorine at $500^{\circ} \mathrm{C}$. This converted the $\mathrm{UF}_{4}$ to the volatile hexafluoride, which was further purified by passage through $\mathrm{NaF}$ and $\mathrm{MgF}_{2}$ absorber beds. The purified $\mathrm{UF}_{6}$ was condensed and returned to production channels. This trapping is discussed in the abstract titled, "Sorbent Studies."

During the past year, this demonstration was terminated, following the successful completion 
of a series of five runs made with high-burnup $\mathrm{U}-\mathrm{Zr}_{\mathrm{r}}$ alloy fuel that had decayed for 6 to 13 months. The capability for sustained operation was demonstrated with losses of only a fraction of a percent and with excellent decontamination. Operations with this short-decayed fuel were the smoothest and most trouble free of any of the runs made. Decontamination factors (DF's) were among the highest ever reported for a radiochemical process, including those for three cycles of solvent extraction. For specific fission products, $D F^{\prime}$ 's ranged from greater than $10^{6}$ to greater than $10^{10}$. Of particular interest was a zirconiumniobium DF higher than $5 \times 10^{10}$, achieved in one of the runs.

After completion of the zirconium program, which consisted of 40 runs, the pilot plant equipment was partially decontaminated to permit measurements of the extent of corrosion of the hydrofluorinator. Wall thicknesses were measured remotely by a pulse-echo technique developed for the Homogeneous Reactor Test. The maximum corrosion rate of $0.14 \mathrm{mil}$ per hr of $\mathrm{HF}$ flow occurred in the bottom 17 in. of the hydrofluorinator, a new section installed after 29 runs. In the enlarged vapor section, the conical section, and in the remainder of the bottom section of the vessel, the maximum corrosion rates after 40 runs were from 0.024 to $0.028 \mathrm{mil}$ per $\mathrm{hr}$ of $\mathrm{HF}$ flow (approximately 0.7 mil per run). In all areas, the maximum loss (excluding pits) was less than $10 \%$ of the original wall thickness. In general, the corrosion rates based on exposure to the $\mathrm{HF}$ and the molten salt after 40 runs were less than those previously obtained in all areas except for the newly installed bottom.

The lower $9 \mathrm{ft}$ of the hydrofluorinator and the bottom part of the conical section were thoroughly inspected after the 40 runs; a telescope and mirrors were used. A few pits, estimated to be not more than 20 mils in diameter and 20 mils deep, were seen in the lower section. Several small fissures were noted in the conical section. These fissures were estimated to be not more than 10 mils wide, and they did not appear to be deep. No areas of extensive pitting or cracking were seen. After the corrosion measurements had been made, the plant was prepared for the program to demonstrate the processing of Al-U alloy fuels. This subject is discussed briefly in the next abstract.
Completed during the year was a processimprovement study made on a semiworks scale to demonstrate the feasibility of dissolving and fluorinating in the same vessel and of using a partial salt-recycle procedure for maintaining the initial proportion of $\mathrm{ZrF}_{4}$ when using the 37.537.5-25 mole \% NaF-LiF- $\mathrm{ZrF}_{4}$ mixture. Five dissolution-fluorination cycles were made in an alloy 79-4 vessel without difficulty when 6-in. sections of $\mathrm{Zr}-\mathrm{U}$ alloy plate-type specimens were used. Maximum corrosion rates for the INOR-8 (reported previously) and alloy 79-4 vessels during alternating exposure to $\mathrm{HF}$ and fluorine in molten salt, followed by cleaning with aqueous solutions, were 0.87 and $0.53 \mathrm{mil} / \mathrm{hr}$, respectively, based on fluorine exposure time only. Without the cleaning step, the corresponding rates were 0.7 and $0.4 \mathrm{mil} / \mathrm{hr}$.

Supplementing work reported last year, a brief study was made of the corrosivity and zirconiumdissolution characteristics of a 36.9-27.0-27.0-9.1 mole \% NaF-LiF- $\mathrm{ZrF}_{4}-\mathrm{BeF}_{2}$ mixture at $500^{\circ} \mathrm{C}$, compared with the initial composition used in pilot-plant studies (37.5-37.5-25.0 mole \% $\mathrm{NaF}$ $\mathrm{LiF}-\mathrm{ZrF}_{4}$ at $650^{\circ} \mathrm{C}$ ). The studies were made at Batelle Memorial Institute (BMI) on a laboratory scale. Corrosion rates for non-heat-treated INOR-8 specimens were very low in both salt compositions, ranging from slight weight gains to $0.3 \mathrm{mil} / \mathrm{month}$. Initial zirconium dissolution rates were practically the same in all tests, but the overall rate of zirconium dissolution averaged $50 \%$ higher in the $\mathrm{NaF}-\mathrm{LiF}-\mathrm{ZrF}_{4}$ mixture.

\subsection{Processing of Uranium-Aluminum Alloy Fuel}

Aluminum-uranium fuel elements presently comprise the largest potential load source for a plant processing metallic fuel elements containing highly enriched uranium. Thus, the application of moltensalt fluoride-volatility methods to the processing of aluminum-based fuel was of major interest as the development of the process for $z$ irconium-based fuels neared completion. Process development efforts have progressed from phase-equilibrium studies through laboratory- and engineering-scale dissolution and fluorination studies to a pilot-plant dissolution of dummy fuel elements containing only aluminum. Corrosion studies have been conducted concurrently. 
As reported last year, the $\mathrm{KF}-\mathrm{ZrF}_{4}-\mathrm{AlF}_{3}$ salt system was selected on the basis of the solubility of $\mathrm{AlF}_{3}$, liquidus temperatures, and the commercial availability of $2 \mathrm{KF} \cdot \mathrm{ZrF}_{4}$ at a price of only about $50 \notin$ per $1 b$. Two general types of process flowsheets were developed. In the preferred "recycle" flowsheet, A1-U alloy is dissolved in sufficient 66-22-12 mole \% $\mathrm{KF}-\mathrm{ZrF}_{4}-\mathrm{AlF}_{3}$ with $\mathrm{HF}$ at 575 to $600^{\circ} \mathrm{C}$ to yield a melt that is 32 mole \% in $\mathrm{AlF}$ prior to fluorination. After fluorination at about $600^{\circ} \mathrm{C}$, part of the salt is discharged to waste, and technical grade $\mathrm{KF}$ and $2 \mathrm{KF} \cdot \mathrm{ZrF}_{4}$ are added to restore the initial proportions. In the "step" flowsheet, Al-U alloy is dissolved in 60-40 mole \% $\mathrm{KF}-\mathrm{ZrF}_{4}$ with $\mathrm{HF}$ at 575 to $600^{\circ} \mathrm{C}$, after which additional $\mathrm{KF}$ is added. The hydrofluorination$\mathrm{KF}$-addition cycle is repeated until a final $\mathrm{AlF}_{3}$ content of 28 mole \% is achieved. At that point, the uranium is removed from the melt by fluorination at about $575^{\circ} \mathrm{C}$, and the waste salt is discarded.

The results obtained from all studies of the two flowsheets showed no major obstacle to the use of the process at full scale. For the recycle flowsheet, penetration rates determined in the laboratory increased from 8 to $43 \mathrm{mils} / \mathrm{hr}$ as the $\mathrm{AlF}$ concentration changed from 12 to 29 mole $\%$. Engineering-scale tests on 4 - to 10-in. lengths of 19-plate fuel elements gave penetration rates of about $8 \mathrm{mils} / \mathrm{hr}$ and typically required less than $10 \mathrm{hr}$ for complete dissolution. Removal of more than $99.9 \%$ of the uranium by fluorination was demonstrated in both the laboratory and engineering tests. All studies indicated that the corrosivity of this salt mixture $\left(\mathrm{KF}-\mathrm{ZrF}_{4}-\mathrm{AlF}_{3}\right)$ toward INOR-8 is less than that of the $\mathrm{NaF}$ $\mathrm{LiF}-\mathrm{ZrF}_{4}$ blend used for dissolving $\mathrm{Zr}-\mathrm{U}$ alloy. On the other hand, the nearness of the operating temperature to that of the melting point of aluminum is a subject of concern. However, in a laboratory test when the salt was deliberately heated above the melting point of aluminum, the aluminum reacted rapidly and completely to form a black, slaglike material which was, in the main, unidentifiable, except for some evidence of an $\mathrm{Al}-\mathrm{Zr}$ intermetallic. Also, the net reaction heat in the $\mathrm{Al}-\mathrm{ZrF}_{4}$ reaction and in melting the aluminum, $8.4 \mathrm{kcal}$ per mole of aluminum, is not considered excessive. In one engineering-scale test, the temperature of the salt rose above the melting point of aluminum but caused no operational difficulties. For these reasons, the melting of a fuel element during full-scale operation should not lead to any serious consequences.

\subsection{Sorbent Studies}

One of the process steps responsible for the unusually high decontamination factors achieved in fused-salt fluoride-volatility processes is that of the selective sorption of volatile fission product fluorides by inorganic fluorides. In the current process, the $\mathrm{UF}_{6}$ and other volatiles pass through a bed of $\mathrm{NaF}$ at $400^{\circ} \mathrm{C}$ immediately downstream from the fluorinator; next, the $\mathrm{UF}_{6}$ and certain volatiles are sorbed by $\mathrm{NaF}$ at $100^{\circ} \mathrm{C}$. Molybdenum hexafluoride is separated from the $U_{F}{ }_{6}$ by desorption at about $150^{\circ} \mathrm{C}$, and the $\mathrm{UF}_{6}, \mathrm{NpF}_{6}$, and $\mathrm{TcF}_{6}$ are desorbed as the temperature of the $\mathrm{NaF}$ bed is raised to $400^{\circ} \mathrm{C}$. The neptunium and technetium fluorides are then sorbed by $\mathrm{MgF}_{2}$ at $100^{\circ} \mathrm{C}$. The sorption process has been the subject of two complementary studies, one in the laboratory and the other at an engineering scale. The laboratory study of the sorption of volatile fluorides on alkali metal fluorides and $\mathrm{MgF}_{2}$ used gasometric measurements, small (less than $1 \mathrm{~g}$ ) samples of sorbent, static conditions, and undiluted gases. Its purposes were to improve current volatility processing steps involving $\mathrm{NaF}$ and $\mathrm{MgF}_{2}$ and to develop new or alternative sorption systems. The engineering-scale study has been aimed at determining and characterizing the rate of removal of $\mathrm{UF}_{6}$ from nitrogen or fluorine by fixed beds of NaF pellets.

In the laboratory study, the gasometric method that was used permitted a rapid and quantitative study of physical-chemical effects in sorptions and desorptions, the determination of stoichiometric ratios, and the measurement of the dissociation pressures where definite complexes were involved.

In the $\mathrm{UF}_{6}-\mathrm{NaF}$ system, the existence of three compounds, namely, $\mathrm{UF}_{6} \cdot \mathrm{NaF}, \mathrm{UF}_{6} \cdot 2 \mathrm{NaF}$, and $\mathrm{UF}_{6} \cdot \mathrm{HF} \cdot 2 \mathrm{NaF}$, was demonstrated, and their dissociation pressures were measured. These dissociation-pressure data indicate that under process conditions only the second compound is of importance. Cyclic sorption tests demonstrated that spalling and powdering of $\mathrm{NaF}$ pellets result from volume changes that occur when $\mathrm{UF}_{6}$ and $\mathrm{NaF}$ react to form $\mathrm{UF}_{6} \cdot \mathrm{NaF}$. A net increase in capacity for $\mathrm{UF}_{6}$ resulted from modification to the structure 
of the $\mathrm{NaF}$ after previous sorption cycles involving either $\mathrm{UF}_{6}$ or $\mathrm{HF}$.

Further study of the $\mathrm{MoF}_{6}-\mathrm{NaF}$ and $\mathrm{WF}_{6}-\mathrm{NaF}$ sorptive systems showed that compounds analogous to the $\mathrm{UF}_{6}$ system exist. The dissociationpressure data obtained for $\mathrm{MoF}_{6} \cdot 2 \mathrm{NaF}$ indicated that an optimum operating temperature for the No. 1 $\mathrm{NaF}$ sorber should exist between 150 and $200^{\circ} \mathrm{C}$, which would result in a maximum separation from $\mathrm{MoF}_{6}$ at an acceptable $\mathrm{UF}_{6}$ loss. Also, the reactions of $\mathrm{UF}_{6}$ and $\mathrm{WF}_{6}$ with $\mathrm{LiF}, \mathrm{KF}, \mathrm{RbF}$, and $\mathrm{CsF}$ were characterized.

Work on $\mathrm{MgF}_{2}$ demonstrated that $\mathrm{UF}_{6}$ retention was due to hydrolysis (from moisture in the $\mathrm{MgF}_{2}$ ) as well as to physical adsorption. The formation of the nonvolatile $\mathrm{UO}_{2} \mathrm{~F}_{2}$ through hydrolysis could be minimized by a more thorough preconditioning of the $\mathrm{MgF}_{2}$ with fluorine at high temperatures, to drive off water. The physically sorbed $\mathrm{UF}_{6}$ could be recovered by desorption at $350^{\circ} \mathrm{C}$.

In the engineering-scale study, the relationship between the life and capacity of $\mathrm{NaF}$ pellets and their physical properties was determined by cyclic sorption and desorption of $\mathrm{UF}_{6}$ on deep beds of pellets. The capacity of the beds for the sorption of $\mathrm{UF}_{6}$ from a $\mathrm{UF}_{6}$-nitrogen stream was measured by trapping the $\mathrm{UF}_{6}$ that passed through a bed under specified conditions of flow rate, temperature, composition, pellet history, etc. Also, the variation with time of the concentration of $\mathrm{UF}_{6}$ in the effluent from fixed beds was determined by use of a gas chromatograph. Pellet life was determined by visual and microscopic observation of the amount of powder formed after altemating sorptions and desorptions of the $\mathrm{UF}_{6}$.

Both pellet life and capacity depended primarily on the void fraction; a high void fraction $(0.50$ or more) tended to reduce pellet life to less than four cycles before degradation became severe, whereas pellets with a low void fraction $(0.35$ or less) could be recycled more than 20 times. However, the pellets that had a low fraction of voids also had a lower sorption capacity for $\mathrm{UF}_{6}$.

\subsection{Removal of Tellurium Hexafluoride from Pilot Plant Effluent Gas}

The removal of tellurium activity $\left({ }^{127 m} \mathrm{Te}\right.$, ${ }^{129 \mathrm{~m}} \mathrm{Te}$, and ${ }^{132} \mathrm{Te}$ ) from the effluent gas leaving the Volatility Pilot Plant is a problem, particularly when processing short-decayed fuel. Only partial removal is possible by reaction with the aqueous potassium hydroxide in the spray tower usually employed for fluorine disposal. A laboratory investigation showed that beds of nickel mesh held at temperatures of 400 to $500^{\circ} \mathrm{C}$ are quite effective in removing tellurium from $\mathrm{TeF}$-helium mixtures. Although good material balances were not obtained, the results indicated that the use of such beds downstream from the caustic scrubber would reduce contamination of the atmosphere from the effluent gas.

\subsection{Application to Stainless Steel}

Preliminary studies indicate that molten mixtures of $\mathrm{KF}-\mathrm{ZrF}_{4}$ may have sufficient capacity for dissolving $\mathrm{FeF}_{2}$ to warrant consideration of the molten-salt volatility process for use with fuels that contain stainless steel. As an example, 60-40 mole $\% \mathrm{KF}-\mathrm{ZrF}_{4}$ dissolved sufficient $\mathrm{FeF}_{2}$ to give a final concentration of 22 mole $\%$ at $575^{\circ} \mathrm{C}$. However, in hydrofluorination tests with type $304 \mathrm{~L}$ stainless steel in both the $\mathrm{KF}-\mathrm{ZrF}_{4}$ and $\mathrm{KF}-\mathrm{ZrF}_{4}-$ $\mathrm{AlF}_{3}$ salt systems, dissolution rates of only about $1 \mathrm{mil} / \mathrm{hr}$ were obtained.

Studies of the corrosivity of 52-37-11 mole \% $\mathrm{NaF}-\mathrm{LiF}-\mathrm{ZrF}_{4}$, a melt previously suggested for use in recovering the uranium from the EBR-1, core- 2 meltdown residue (about $88 \% \mathrm{U}, 2 \% \mathrm{Zr}$, and $10 \%$ type 347 stainless steel), were made on a laboratory scale at Battelle Memorial Institute (BMI) under hydrofluorination conditions. The rates of attack on INOR-8, HyMu 80 (alloy 79-4), 85-10-5 wt \% Ni-Mo-Fe, $\mathrm{Ni}-5 \% \mathrm{Fe}, \mathrm{Ni}-1 \% \mathrm{Al}$, and weld filler metal 61 were unusually high. Of the melts studied at BMI under the volatility program, only one, 50.5-37.0-12.5 mole \% NaF-LiF-BeF ${ }_{2}$, was more corrosive than the one mentioned above. Despite these unfavorable results, preliminary data from earlier ORNL laboratory studies indicated that 37-37-26 mole \% NaF-LiF- $\mathrm{rFF}_{4}$ should be satisfactory for processing stainless steel.

An extensive study was made of important variables in the fluoride-catalyzed destructive oxidation of type 304L stainless steel. This is of interest as a decladding method for stainlesssteel-clad reactor fuels, particularly for use in the fluidized-bed volatility process, but possibly also for fused-salt processing. Gaseous hydrogen fluoride was used as the catalyst because of the ease with which a uniform concentration can be maintained, even in a fluidized bed, in contrast to 
the difficulty caused by the use of a less volatile material like $\mathrm{FeF}_{3}$. Hydrogen fluoride concentrations of up to 80 mole \% in oxygen were used, with maximum oxidation rates of 50 to $60 \mathrm{mils} / \mathrm{hr}$ when the HF concentration was about 40 mole $\%$ and the temperature was $650^{\circ} \mathrm{C}$. Lower rates, 10 to 30 $\mathrm{mils} / \mathrm{hr}$, were obtained at 575 to $600^{\circ} \mathrm{C}$. Two batches of type $304 \mathrm{~L}$ stainless steel gave reproducibly different results, thus clearly indicating the importance of metallurgical differences. The product consisted of the oxides of iron, nickel, and chromium, with usually less than a $1 \%$ fluoride content. The low consumption of $\mathrm{HF}$ indicates that a gas recycle step would be desirable in a commercial application.

\subsection{Application to Oxide Fuels}

In processing low-enrichment $\mathrm{UO}_{2}$ fuels by the molten-salt fluoride-volatility method, a salt system with a high $\mathrm{UF}_{4}$ solubility would be advantageous in minimizing salt costs. In laboratory tests, uranium was successfully fluorinated and volatilized from a salt containing 31.5 wt \% uranium. The mixture was equivalent to that obtained by dissolving fuel from Commonwealth Edison's Dresden Reactor in 37.5-37.5-25 mole \% LiF-NaF$\mathrm{ZrF}_{4}$. Some preliminary phase-equilibrium studies of the $\mathrm{LiF}-\mathrm{NaF}-\mathrm{ZrF}_{4}-\mathrm{UF}_{4}$ system have been conducted.

\subsection{Volatilization and Recovery of Plutonium Hexafluoride}

The feasibility of volatilizing $\mathrm{PuF}_{6}$ from fused salts by fluorination was demonstrated in laboratory work directed toward adapting the fused-salt fluoride-volatility method to the processing of lowenrichment reactor fuels. An equilibrium relationship between plutonium concentrations in the gas and molten salt was controlling, with the result that the salt had to be contacted with a relatively large volume of fluorine. Such a large volume of gas in the usual batch fluorinator would require a fast gas-sparging rate to volatilize the plutonium in a reasonable time. An alternative being considered is the use of a gas-phase-continuous fluorination contactor (e.go, a spray tower) to obtain a high gas-salt volume ratio.

The salt-gas equilibrium was affected by changes in salt composition, salt purity, temperature, and fluorine pressure. Other factors, such as plutonium concentration in the salt, mechanical agitation, and the use of special fluorinating agents and catalysts, appeared to have almost no effect on the equilibrium. Although the controlling equilibrium apparently requires the use of a special fluorinator design if long process times are to be avoided, the lack of dependence on plutonium concentration and the almost complete removal of plutonium from a salt that had an initial concentration of $2 \mathrm{ppm}$ indicate that high plutonium recoveries are possible.

Sorption tests conducted in conjunction with the volatilization work showed that several of the alkali-metal and alkaline-earth fluorides effectively trapped or removed $\mathrm{PuF}_{6}$ from fluorine gas. Variation of the temperature in the range of 100 to $400^{\circ} \mathrm{C}$ had little effect on the sorptive behavior. The sorptive effects suggested the formation of chemical complexes analogous to $\mathrm{UF}_{6} \cdot 2 \mathrm{NaF}$. However, the completeness of sorption at $400^{\circ} \mathrm{C}$ indicated that the formation of the complexes of $\mathrm{PuF}_{6}$ and $\mathrm{NaF}$ is not reversible, as is that of the $\mathrm{UF}_{6}-\mathrm{NaF}$ complex.

\subsection{Fluorination with Gas Phase Continuous}

Laboratory development work was initiated to show the feasibility of a spray, or gas-phasecontinuous, molten-salt fluorination reactor for volatilizing $\mathrm{UF}_{6}$ and $\mathrm{PuF}_{6}$ as a means of reducing corrosion, and of achieving the large ratio of fluorine gas to molten salt, which is necessary for fast plutonium recoveries. This type of moltensalt-gas contactor may also be useful with a continuous processing scheme. Preliminary tests consisting in dropping powdered fluorides (47.547.5-5 mole \% NaF- $\mathrm{ZrF}_{4}-\mathrm{UF}_{4}$ ) through a 5-ft-high fluorine tower at about $600^{\circ} \mathrm{C}$ resulted in volatilizing more than $99.9 \%$ of the uranium when the powder particles were between 60 and $150 \mu$ in diameter. A correlation equation was obtained for the dependence of uranium volatilization on temperature, size of the drop, and residence time in the high-temperature zone. 


\subsection{Measurement of Uranium Hexafluoride Concentrations in Streams of Other Gases}

Instruments for measuring the concentration of $\mathrm{UF}_{6}$ gas in multicomponent process streams are useful for both pilot plant operations and smallerscale experiments. Since suitable instruments are not commercially available, several types are being studied to determine their stability, range, and the reproducibility of their results. Of the three types showing promise, the gas chromatograph was found to have a linear response to $\mathrm{UF}_{6}$ concentrations in the ranges 1 to 65 mole $\%$ and 0.2 to 20 mole \%; the limit of detection was 0.01 mole $\%$ when operating in the low range. The response to mixed $\mathrm{UF}_{6}$ and $\mathrm{MoF}_{6}$ streams (in mixed gases) is being determined. The infrared analyzer used is accurate to about the same range as the chromatograph. A third instrument, called the Constriction Response Analyzer (developed at the Oak Ridge Gaseous Diffusion Plant), measures a pressure signal that is proportional to the stream density. Calibration by wet analysis indicates that the limit of detection is less than $0.1 \%$ of $\mathrm{UF}_{6}$.

\subsection{General Corrosion Studies}

Corrosion problems related to the molten-salt fluoride-volatility process have been studied on a laboratory scale at Battelle Memorial Institute (BMI) under a subcontract. Some of the results are reported elsewhere in this report. One of the major undertakings was an eight-run experiment in which 52-37-11 and 37.5-37.5-25 mole \% $\mathrm{NaF}-\mathrm{LiF}-\mathrm{ZrF}_{4}$ were used, with and without dissolution of type 347 stainless steel and Zircaloy-2, respectively, to determine the effect of melt composition, fuel-metal dissolving, salt purity, heat treatment, variation between lots of INOR-8, etc., upon corrosion rates. The experimental work has been completed, but evaluation of the results has not.

Preliminary results of another BMI study to determine the feasibility of electrochemically protecting the INOR-8 hydrofluorinator indicated that anodic protection is not possible. Cathodic protection gave positive results but did not eliminate the high rate of attack normally experienced at the salt-vapor interface, particularly with melts such as $52-37-11$ mole $\% \mathrm{NaF}-\mathrm{LiF}-\mathrm{ZrF}_{4}$. However, dilution of the HF with helium apparently markedly reduces the attack at the interface.

In support of the BMI studies, a FORTRAN digital computer program was prepared at ORNL for calculating and automatically plotting corrosion rates for specimens of container metal and dissolution rates for the simulated fuel.

A first attempt was made to correlate the overall collection of weight-loss data from BMI experiments on corrosion during the hydrofluorination step. A factor-screening procedure based on statistical techniques was used with their digital computer. The program is being revised for use here.

\section{WASTE TREATMENT AND DISPOSAL}

The Waste Treatment and Disposal program was designed to develop a comprehensive waste management system for all nuclear wastes and to determine the cost of this operation. Methods are being developed for conversion of high-level radioactive wastes to solids prior to permanent disposal in a suitable location such as a salt mine. These calcined or glassy solids would be contained in 88-in.-long by 6- to 24-in.-diam stainless steel pots (pipes), from whence are derived the names Potcal or Potglass processes. The Potcal and Potglass processes will be demonstrated in the Waste Solidification Demonstration pilot plant now being built at Hanford. Low-level radioactive wastes are treated to remove radioactivity prior to their discharge to the environment. Two improved low-activity-waste processes have been developed for testing in a pilot plant: the scavenging-precipitation ion-exchange process and the scavenging-precipitation foam-separation process. The solid and liquid radioactive residues from treating low-level wastes, evaporator concentrated from miscellaneous sources at nuclear installations, and concentrates from second and third cycles of solvent extraction from processing nuclear fuels constitute a third waste type, intermediate-level radioactive wastes. Methods being developed for disposing of intermediate-levelactivity wastes include incorporation in asphalt or concrete and burial in a controlled area. The economic and safety analyses made on these waste treatment methods, as well as others being developed within the AEC program, provide the 
AEC with a sound basis for national and international comparison of alternative systems and serve as a guide for the direction of experimental work.

\subsection{Solidification of High-Level Radioactive Waste}

Engineering Studies. - The engineering program included pump tests and development of three high-activity-waste solidification methods, the RL-Potglass (rising level) process, the ConPotglass (continuous) process, and the Potcal process. All wastes were simulated nonradioactive solutions.

The RL-Potglass process was tested in 8-in.diam, 88-in.-high type 304L stainless steel pots with FTW-65 Purex (formaldehyde-treated waste, expected in 1965) and TBP-25 (aluminum) wastes. In the RL process the aqueous waste is fed directly to the pot, the liquid is vaporized, and the solid residue is melted to a glassy solid. With proper melt formulation, the temperature should be $900^{\circ} \mathrm{C}$ or lower. As the level rises, three phases are present: liquid glass at the bottom, a small solid interface, and a small aqueous solution pool. The wastes contained one or more of the following glass-forming additives: phosphate, lead, lithium, aluminum, or sodium. Molar compositions of the feed were $3.9 \mathrm{NO}_{3}{ }^{-}, 0.25 \mathrm{Fe}^{3+}, 0.78 \mathrm{Na}^{+}, 0.43 \mathrm{SO}_{4}{ }^{2-}$, $0.79 \mathrm{PO}_{4}^{3-}, 0.86 \mathrm{Li}^{+}$, and $0.65 \mathrm{Al}^{3+}$ for $\mathrm{FTW}^{3}-65$ waste, and $1.7 \mathrm{Al}^{3+}, 2.1 \mathrm{Na}^{+}, 0.25 \mathrm{~Pb}^{2+}, 6.0$ $\mathrm{HNO}_{3}$, and $2.0 \mathrm{PO}_{4}{ }^{3-}$ for TBP-25 waste. In initial tests, at $900^{4}$ to $1000^{\circ} \mathrm{C}$, processing rates were 7 to 10 liters $/ \mathrm{hr}$. Dust entrainment was a problem but was successfully controlled by periodic flushing of off-gas lines. Total corrosion penetration per run was up to 150 mils, with an average of around 80 to $100 \mathrm{mils}$. Although this corrosion rate will be tolerable for a single-use container with 320-mil-thick wall, further development is required to produce lower melting and hence less corrosive melts (Sect. 3.3).

The Con-Potglass process was tested in an 8-in.-diam., 40-in.-long horizontal unit wherein aqueous wastes (compositions above) are converted directly to molten glass. The aqueous feed falls directly on a solid interface which partially covers the molten pool. Average feed rates were 5 to 10 liters/hr, but faster rates are expected with furnaces with higher heating rates.
Dusting and off-gas line plugging were satisfactorily controlled by use of an updraft condenser. Corrosion is high in the present stainless steel units, but a program objective is to develop "neutral" glasses with acceptable corrosion rates (see "Laboratory Studies", this chapter); otherwise, a platinum-lined unit will be required.

A pump-loop test was completed, and a Chempump model GAT $\left(1 \frac{1}{2} \times 3 / 4 \mathrm{~S}\right)$ feed pump was recommended for use in the pilot plant at Hanford Atomic Products Operation.

The development of the Potcal process, using resistance furnaces and 8-in.-diam pots, was successfully completed. Final tests were on reacidified FTW-65 wastes, in which the $\mathrm{Na}_{2} \mathrm{SO}_{4}$ to $\mathrm{Fe}^{3+}$ ratio was 6.0 rather than 1.5 as in $\mathrm{FTW}-65$ waste. The average feed rate was about 15 liters/hr, and corrosion was satisfactory. A 16-in.-diam unit has now been designed and installed for determining processing rate as a function of diameter and for perfecting the use of induction heating. The waste solution is fed from a pump circulation loop to the 16-in. pot, which is heated by a $150-\mathrm{kw} 3000$-cycle induction furnace. In a test of the 16-in. unit with FTW-65 waste, the average feed rate was 24 liters $/ \mathrm{hr}$, which confirms the mathematical prediction that the average rate is independent of pot diameter. Pot failure occurred when the run was $80 \%$ complete. Failure was induced by inadequate thermocouples, which permitted an undetected, excessive temperature rise. RL-Potglass runs will also be made in 8-in.-diam pots with induction heating. Data from these tests will be utilized in the design of process equipment for the Hanford Waste Demonstration Prototype, which will use induction heating.

Pilot-Plant Design. - Cooperation with Hanford on the design of the pot calcination equipment for the Hanford Waste Demonstration Prototype continued. Remote mechanical equipment, developed at the Georgia Nuclear Laboratories, was modified for installation in the Hanford cells, and the pot calciner design was simplified to reduce fabrication costs and improve the process economics. The process equipment designed for the cells was reviewed, and methods for increasing the cooling rates in the calcination furnace were developed to prevent overheating of the calcine upon completion of calcination. Preliminary planning of the Hanford test program for the Potcal and Potglass processes was initiated. 
Laboratory Studies. - A new series of solid compositions was developed for the fixation of sulfate-containing Purex waste by substitution of lithium for sodium as a fluxing additive. The lithium series generally have lower melting temperature, greater insolubility, and improved physical and mechanical properties compared with their sodium counterparts. The volatility of sulfate, which is the great problem with this waste type, is not increased as a result of the substitution. The volatilization of sulfuric acid is undesirable since it is corrosive and also constitutes a side stream that requires treatment and disposal. Studies on the fixation solids from Purex wastes that do not contain sulfate resulted in the formulation of a number of low-melting ( $\mathrm{mp} \leqq 700^{\circ} \mathrm{C}$ ) products, of which some were true glasses.

Calcination of sulfate-deficient Purex waste (essentially $\mathrm{NaNO}_{3}$ and $\mathrm{Na}_{2} \mathrm{SO}_{4}$ ) was rendered feasible by the addition of aluminum in a $1: 1$ molar ratio to the excess of sodium over sulfate. In the absence of additives, this waste type cannot be satisfactorily calcined because of the entrainment of gross amounts of solids as well as the volatilization of sodium, cesium, and sulfate. The addition of aluminum is desirable since it acts as a glass former in phosphate ceramic systems.

Since mercury does not form a thermally stable compound, it causes operating problems by depositing in the off-gas system during the fixation process. Hence, a process was developed to remove mercury prior to waste solidification. More than 99\% was removed from Purex FTW-65 waste by displacement with copper. Aluminum turnings were effective in removing more than $98 \%$ of the mercury from concentrated FTW-65 waste.

Corrosion tests confirmed the feasibility of using titanium as constructional material for the evaporator and type $304 \mathrm{~L}$ stainless steel for the fixation and storage container ("pot"). Titanium showed negligible corrosion ( $\leq 0.01 \mathrm{mil} / \mathrm{month}$ ) rates in FTW-65 solutions both with and without fluxing additives. Total penetration of type 304L stainless steel after $29 \mathrm{hr}$ of exposure with a phosphate "glass" at $1050^{\circ} \mathrm{C}$ was $15.4 \mathrm{mils}$ (includes $3 \mathrm{hr}$ for evaporation to dryness). Maximum design operating temperature is $900^{\circ} \mathrm{C}$. The corrosion rate of type $304 \mathrm{~L}$ steel at $300^{\circ} \mathrm{C}$ in salt

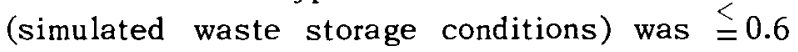
$\mathrm{mil} /$ month.

\subsection{Treatment of Low-Level Radioactive Waste}

Scavenging-Precipitation lon-Exchonge Process. - Modifications in the scavenging-precipitation ion-exchange process evaluated on a laboratory scale included (1) the addition of Grundite clay to the regenerant waste of the cation resin column to sorb cesium activity and the recycle of this slurry into the scavenging-precipitation step; (2) the use of alumina to remove phos phates from untreated neutral waste; and (3) the use of an anion exchanger for the removal of ruthenium and cobalt activity remaining after cation exchange treatment. Micro-pilot-plant tests showed that, with Grundite clay added, the average decontamination factors obtained after precipitation and cation exchange for cesium, strontium, cobalt, and ruthenium were $630,6000,3$, and 3 respectively; decontamination factors in the precipitation step alone were $7,5,3$, and 3 respectively. Not only did Grundite clay effectively fix cesium activity, but it also improved slightly the decontamination factors for cobalt and ruthenium over those obtained without Grundite. Chromatographicgrade alumina removed $50 \%$ or more of the phosphates (up to $3 \mathrm{ppm}$ in the raw waste) for at least 15,000 bed volumes of waste processed. Two strong-base anion resins, Dowex $21 \mathrm{~K}$ and Illco TAD-1, possibly are effective in removing one or more forms of ruthenium remaining after the scavenging-precipitation ion-exchange process, but not all forms; no selectivity for cobalt is apparent. Laboratory studies with Grundite clay showed that the optimum $\mathrm{pH}$ range (close to $\mathrm{pH}$ 11.8) for cesium sorption is narrow and that the amount of cesium sorbed is independent of particle size ( 50 to $<200$ mesh) but is greater if the clay is added before $\mathrm{pH}$ adjustment. A test on an exhausted alumina column showed that phosphates are removed slowly by the use of $1 M \mathrm{NaOH}$; $1 \mathrm{M} \mathrm{HNO}_{3}$ removed the relatively small amount of fission product activity sorbed. Jar tests showed that untreated neutral waste may be clarified prior to ion exchange treatment by the addition of 10 to $20 \mathrm{ppm}$ of alum or $5 \mathrm{ppm}$ of copperas and $70 \mathrm{ppm}$ of lime, in that order.

The low-level radioactive waste pilot-plant development program included a test of a filtration-ion-exchange process, performance tests in the new 4-ft-diam agitated clarifier, demonstration of an improved scavenging-precipitation ionexchange process, and installation of equipment 
for the demonstration of the two-step scavengingprecipitation foam-separation process.

The improved scavenging-precipitation ionexchange process was tested in three pilot-plant runs with ORNL low-level radioactive waste. Improvements were as follows: (1) Addition of an alumina column to remove phosphate as an initial step and thus eliminate this variable, which can cause considerable fluctuation in the efficiency of the standard flowsheet. Phosphate concentration was reduced from about $2 \mathrm{ppm}$ to $<1$ ppm, a satisfactorily low level. (2) Use of a new 4-ft-diam agitated clanfier. This clarıfier has a processing rate of $47 \mathrm{gal} \mathrm{ft}^{-2} \mathrm{hr}^{-1}$ compared with 27 for the older unit The hardness in the clarifier effluent, using the scavengingprecipitation ion-exchange head-end conditions (0.01 $M \mathrm{NaOH}, 5$ ppm $\mathrm{Fe}^{2+}$ ), was 7 ppm (computed as $\mathrm{CaCO}_{3}$ ) at a flow rate of $10 \mathrm{gpm}$, compared with 30 to $70 \mathrm{ppm}$ for the older unit (w1thout phosphate removal). With the foam-separation headend conditions $\left(0.005 \mathrm{M} \mathrm{Na}_{2} \mathrm{CO}_{3}, 0.005 M\right.$ $\mathrm{NaOH}, 4 \mathrm{ppm} \mathrm{Fe}^{2+}$ ), the effluent hardness (on tap-water feed) was less than $2 \mathrm{ppm}$ at $5 \mathrm{gpm}$. (3) Use of a recycle flowsheet in which the ion exchange regenerant solution is combined with Grundite clay (to sorb cesium) and recycled to the feed stream. This eliminates an evaporator and causes all activity to exit the system in the solid sludge. Overall decontamination factors for the recycle system averaged $17,11,1200$, $1400,2.6$, and 580 , for gross beta, gross gamma, cesium, strontium, ruthenium, and rare earths, respectively, which reduced the water to less than $2.0 \%$ of the $168-\mathrm{hr} \mathrm{MPC}_{\mathrm{w}}$ for occupational exposure. Final treatment with an anion exchange column increased the ruthenum and cobalt DF's to about 14 and 11 respectively.

An initial test was made of an 1on exchange process in which the water was clarified with an anthracite filter and the hardness and radionuclides removed by weak-acid (IRC 50) and strong-acid (Dowex 50) resin beds in sequence, thus eliminating the scavenging-precipitation step. About 1000 bed volumes $(33,000 \mathrm{gal})$ of waste were treated (effluent hardness rose to $50 \%$ of feed concentration). Decontamination factors for gross beta, gross gamma, cesium, strontium, cobalt, and rare earths were $25,1.4$, $35,2766,1.0$, and 134 respectively. Activity effluent concentrations were $0.05,1.4,1.5$, 0.09 , and $0.25 \%$ of the $168-\mathrm{hr} M \mathrm{MC}_{\mathrm{w}}$ for ${ }^{137} \mathrm{Cs}$,
${ }^{90} \mathrm{Sr},{ }^{103-106} \mathrm{Ru},{ }^{95} \mathrm{Zr}-\mathrm{Nb}$, and ${ }^{60} \mathrm{Co}$ respectively. Algae from the settling basin passed through both the filter and the ion exchange column. Hence, a more efficient clarification system, such as scavenging-precipitation, is required.

Equipment for the demonstration of the scavenging-precipitation foam-separation process was installed in the pilot plant and awaits testing. The feed to the foam-separation equipment comprises waste that has been treated with Grundite clay for cesium removal in the scavenging-precipitation step. The foam-separation equipment includes a $2-\mathrm{ft}^{2}$ 8-ft-high countercurrent foam column for decontaminating the low-level radioactive waste, three $2-\mathrm{ft}^{2}$ foam columns in series for recovering the surfactant from decontaminated waste, an a1r recirculation system to provide a1r for foam generation, a centrifuge foam breaker, and three orifice-type foam breakers. The max1mum design throughput rate for the equipment is $5 \mathrm{gpm}$.

The net cost for the revised scavenging-precip1tation 1on-exchange process using alumina and the Grundite-regenerant recycle is $66 \phi$ per 1000 gal for treating about 2000 resin bed volumes of waste with minimum decontamination factors of 1000 and 100 for strontium and cesium respectively. If phosphate removal is not required, the total cost is about $60 \phi$ per 1000 gal. If strontrum is limiting, instead of cesium, and 6000 resin bed volumes are treated per cycle, the total cost is about $56 \phi$ per 1000 gal.

Scavenging-Precipitation Foam-Separation Process. - Flowsheet conditions for decontaminating low-level radioactive process waste water by the two-step scavenging-precipitation foam-separation process were tested with tap water and wastewater feeds on a laboratory scale. This process consists in precipitating and eliminating most of the hardness (calcium and magnesium) in a suspended-bed sludge column and producing further decontamination in a countercurrent foam column. Nonradioactive and tracer runs were performed to determine the effect of flow rates, foam recycle, the presence of phosphates, and the use of solid cesium sorbents or soluble cesium complexers on decontamination factors (DF's). Overall strontium DF's of about $10^{2}$ to $10^{4}$ were achieved, those for cesium were in the range 8 to 15 . The DF's obtained for cerrum, cobalt, ruthenium, and $z 1 r$ conium-niobium were $>10^{2}, 5$ to 10,3 to 10 , and 2 to 23 respectively. The distribution of calcium, 
magnesium, iron, and the surfactant, dodecylbenzene sulfonate (DBS), throughout the system was studied. Use of the foam column parameter, $V / L D$ (where $V$ and $L$ are gas and liquid flow rates, respectively, and $D$ is an average bubble diameter), as a basis for process control was developed. The action of bacteria living in waste water on alkylbenzene sulfonates and phosphates was determined semiquantitatively.

Development work on the one-step scavengingprecipitation foam-separation process produced strontium DF's in the range 200 to 400 , but chemical costs and potential mechanical difficulties make the process noncompetitive with other available methods for waste-water decontamination. In this process the precipitate is removed from the water by flotation in the foam concurrently with the soluble ions. All operations, including precipitation of hardness cations and other contaminants as phosphates, scavenging with ferric ion, and adding the flotation agent, were performed simultaneously. The solid and ionic contaminants were then removed by a combination of frothing and foaming in a single column. Further work on this process has been suspended.

\subsection{Disposal of Intermediate-Level Radioactive Waste}

Incorporation of intermediate-level radioactive waste in asphalt and burial in a controlled area is a promising disposal method. Initial tests with emulsified asphalt and cement showed that the volume reduction with asphalt is 2.0 , compared with only 0.6 for cement, and that the leach rate from asphalt in water, as measured by leach tests with incorporated sodium and ${ }^{137} \mathrm{Cs}$, was about $3 \times 10^{-4} \mathrm{~g}$ of product per $\mathrm{cm}^{2}$ per day, compared with about $4 \times 10^{-2}$ for cement.

\subsection{Engineering, Economics, and Safety Evaluations}

Studies have been made of the comparative costs of permanent storage of solidified highlevel radioactive wastes in concrete vaults, rooms mined in granite formations, and salt mines, and of implications arising from the presence of fission product tritium in fuel processing wastes.

The costs of permanent storage of calcined radioactive wastes in concrete vaults were five to seven times greater than those for storage in salt, and costs for storage in rooms mined out of granite formations were twice those for storage in salt mines. This economic advantage, as well as the greater safety it is believed to offer, makes salt the preferred choice. The vaults were assumed to be similar to those used for secondary containment of tanks built for storage of liquid radioactive wastes, in that they would be underground structures of reinforced concrete with $10 \mathrm{ft}$ of earth cover and a floor-to-ceiling height of $15 \mathrm{ft}$. For maximum safety, they would be sealed completely from the surface, and space requirements were calculated assuming dissipation of the heat of radioactive decay by conduction through the earth cover. Space requirements for storage in granite formations are about the same as those for storage in salt deposits. However, excavating costs are higher for granite because heavier equipment is required, drilling is more difficult and slower, and costs of explosives are higher.

Tritium is a unique constituent of fuel processing wastes in that it does not lend itself to decontamination from the wastes by the conventional methods applied to other fission product contaminants. About $75 \%$ of the tritium in the irradiated fuel is currently discharged to the environment in low-level aqueous wastes, but future plants situated less remotely than those of today may be restricted in the quantity they can release to their immediate environs. It is estimated that, under present regulations, relatively little tritium could be released to surface streams, but plants processing fuel at rates equivalent to as much as $100,000 \mathrm{Mw}$ (thermal) of reactor power might disperse the tritium safely to the atmosphere. Larger plants must consider containment of the tritium by internal recycle of aqueous streams. Additional work is needed, however, to establish environmental tolerances for tritium as well as the feasibility of recycling the necessary process streams within the plants.

\section{TRANSURANIUM ELEMENT PROCESSING}

The High Flux Isotope Reactor (HFIR) and Transuranium Processing Plant (TRU) are being built to produce large quantities of the heavy actinide elements for research purposes. The reactor is scheduled to begin operations in the latter half of 1965, and TRU will be ready for full-scale operations in 1966. The design of 
TRU, which is now under construction and about $60 \%$ complete, was under the direction of the Chemical Technology Division. Process development work and the design, fabrication, and testing of equipment for the facility is divided between the Chemical Technology Division and the Metals and Ceramics Division, with the latter being responsible for the remote target fabrication equipment. Only that portion of the program under direction of the Chemical Technology Division, including the development work on the chemical process systems, the design, development, and procurement of the chemical equipment, and progress on construction of the Transuranium Processing Facility, is reported here.

\subsection{Development of Chemical Processes}

Investigations continued in the developing, testing and improving of the Tramex process (tertiary amine extraction from highly salted $\mathrm{LiCl}$ solutions) for separating transplutonium elements from fission products, corrosion products, and aluminum. The Tramex process is useful for recovering the transplutonium elements as a group and will be used for isolating ${ }^{243} \mathrm{Am}$ plus ${ }^{244} \mathrm{Cm}$ from the Savannah River processing raffinates, for isolating transplutonium elements from irradiated HFIR targets in TRU, and for the recovery of ${ }^{242} \mathrm{Cm}$ and ${ }^{241} \mathrm{Am}$ from irradiated cermets of $\mathrm{AmO}_{2}$ and aluminum. Process conditions are essentially unchanged. The principal difference is the addition of methanol to the feed solution to inhibit acid losses caused by radiolysis.

A series of five batch countercurrent solvent extraction tests of the Tramex flowsheet was made with solutions containing ${ }^{242} \mathrm{Cm}$ at power densities varying from 5 to $10 \mathrm{w} /$ liter. No adverse effect on the extraction process was noted due to alpha radiation, and the results indicate that the Tramex process can achieve high recovery of transplutonium elements and high decontamination from fission products.

During the past year, extensive work was directed at minimizing or preventing the loss of acid from Tramex feed caused by radiolysis at high activity levels. The acid concentration is critical since the precipitation of hydrolyzable ions occurs in neutral solutions; at concentrations above $0.1 \mathrm{~N}$, distribution coefficients are too low for satisfactory extraction. Acid losses of $0.1 \mathrm{~N}$ per day have been noted on Tramex feed at power densities of $10 \mathrm{w} /$ liter. Several potential solutions to this problem were investigated. The best solution found to this problem was the addition of reducing agents to prevent acid loss due to oxidation of the chloride ion. The addition of 2 to 10 vol \% methanol completely stabilizes Tramex feeds for long periods of time at high activity levels. No adverse affects due to the presence of as much as 10 vol \% methanol were noted on actinide distribution coefficients, extraction kinetics, or fission product behavior. Phase separation is faster with methanol present, and hydrochloric acid distribution coefficients are stabilized at acid concentrations below $0.15 \mathrm{M}$.

Since HFIR targets which still contain significant amounts of $\mathrm{PuO}_{2}$ may be processed, the dissolution of $\mathrm{PuO}_{2}$ in $\mathrm{HCl}$ and the behavior of plutonium in the Tramex process were investigated. Plutonium oxide calcined at $800^{\circ} \mathrm{C}$ could be successfully dissolved only in $6 \mathrm{M} \mathrm{HCl}$ that contained $\mathrm{CuF}_{2}$ as catalyst. This dissolver solution is not acceptable since the equipment made of $Z$ ircaloy -2 corrodes severely in fluoride solutions. Other solutions will be sought. In a laboratory-scale mixer-settler demonstration of the Tramex process, a plutonium recovery of $95 \%$ was obtained when $1 M \mathrm{HCl}$ was used as the strip solution.

In numerous small-scale laboratory tests, the potential problems of fires or explosions resulting from the use of Alamine $336 \cdot \mathrm{HNO}_{3}-\mathrm{DEB}$ in the Tramex process were studied. Such hazards could exist if the solvent were heated in the presence of nitrate. It was possible to initiate two types of undesirable reactions; however, extreme conditions such as a continuous spark in the vapor phase and distillation to near dryness were necessary. Results indicate that it is safe to adjust Tramex feed to $10 \mathrm{M} \mathrm{LiCl}$ by evaporation even if some solvent is present, but precautions must be taken to make certain that no solvent is present when $\mathrm{LiNO}_{3}$ or $\mathrm{A} 1\left(\mathrm{NO}_{3}\right)_{3}$ solutions must be heated.

Bidentate extractants were evaluated as a means of recovering americium, curium, and rare earths from nitrate raffinate solutions. Tetraamyl methylenediphosphonate [TA(MDP)] and dihexyl methylenediphosphonate [DH(MDP)] strongly extracted trivalent actinides and lanthanides from nitric acid solution. Although intragroup separations of the actinide elements are not feasible, these extractants would be useful for the recovery of tri- 
valent actinides and lanthanides from acid waste solutions such as Purex waste or ${ }^{242} \mathrm{Pu}$ raffinate.

Since HFIR targets will be made from pressed pellets of aluminum powder and actinide oxide, it is essential that the aluminum phase be continuous in order to guarantee satisfactory heat transfer during irradiation. With oxide particles in the mesh-size range 20 to 200 , the aluminum phase is continuous, even when the larger nonpyrophoric aluminum powders are used. A modified sol-gel method was used to prepare $79 \mathrm{~g}$ of ${ }^{239} \mathrm{PuO}_{2}$ for use in prototype HFIR targets which are being irradiated in the ETR. In addition, about $90 \mathrm{~g}$ of ${ }^{242} \mathrm{PuO}_{2}$ containing $79.88 \mathrm{~g}$ of ${ }^{242} \mathrm{Pu}$ was prepared for incorporation into seven target elements to be irradiated in a reactor at the Savannah River Laboratory. The ${ }^{239} \mathrm{Pu}$ prototype targets operate at the same heat ratings as HFIR targets, demonstrating the heat removal properties of this target design; the ${ }^{242} \mathrm{Pu}$ targets will produce significant quantities of the transplutonium elements and will provide additional irradiation experience with HFIR target elements.

The modified sol-gel method was also successfully used to produce large particles of $\mathrm{AmO}_{2}$. Calcination at $600^{\circ} \mathrm{C}$ produced oxide with a density of $10.0 \mathrm{~g} / \mathrm{cc}( \pm 10 \%)$. Initial attempts to produce americium sols were not successful; however, this effort is continuing with lanthanum as a stand-in for americium.

Chromatographic elution from cation resin with a-hydroxyisobutyrate solution is still the most reliable method available for separating transcurium isotopes, and either this system or elution from anion exchange resin with $4.4 \mathrm{M} \mathrm{LiNO}_{3}$ can be used to separate americium from curium. In either process, scaleup to several-milligram quantities is difficult because of disturbance of the resin bed by radiolytically produced gas. Two methods of controlling radiolytic gas were investigated, using ${ }^{242} \mathrm{Cm}$ solutions at activity levels as high as $150 \mathrm{w} /$ liter. Pressurized columns that employed spring-loaded resin beds were operable, minimizing the disturbance of the resin bed sufficiently to allow good separations of americium from curium. Methanol was very effective in reducing radiolytic gas formation in either the $a$ hydroxyisobutyrate or $\mathrm{LiNO}_{3}$ system; the use of methanol may make it possible to separate einsteinium and fermium from gram quantities of californium. A successful americium-curium separation was made at ${ }^{242} \mathrm{Cm}$ alpha-activity levels that correspond to a ${ }^{252} \mathrm{Cf}$ loading of 1.5 to $2.0 \mathrm{~g}$ per liter of resin.

As an aid in developing improved ion exchange separation methods, stability constants $\left(K_{s}\right)$ for various actinide complexes are being determined to evaluate ligands of potential interest. To date, the stability constants for $\mathrm{Am}, \mathrm{Cm}, \mathrm{Bk}$, and $\mathrm{Cf}$ have been determined for diethylenetriaminepentaacetic acid and for 1,2, diaminocyclohexyl tetraacetic acid.

The $\mathrm{LiCl}-a n i o n$ exchange process was successfully used to concentrate and purify $22 \mathrm{mg}$ of ${ }^{242} \mathrm{Cm}$ and $10 \mathrm{~g}$ of ${ }^{241} \mathrm{Am}$ for use in laboratory development studies.

\subsection{Development of Process Equipment}

Experimental engineering studies are continuing in order to develop equipment and procedures and to obtain information necessary to design of the processing cells. The development of individual processing equipment components, including samplers, diaphragm pumps, ion exchange columns, and valves, is well advanced. Tests of handling and maintenance concepts in a full-scale cell mockup are partially complete. Mockup tests in the last year included tests of disconnect wells and tube bundles, equipment racks, equipment transfer, the replacement of alpha windows, manipulator evaluations, cell-lighting main tenance, and remote maintenance methods. Prototypes and fully designed components of most of the process equipment and the maintenance apparatus are scheduled to be built and thoroughly tested in the cell mockup during the next year.

Small pulsed columns $\left(1 \frac{1}{2}\right.$ in. in diameter and $6 \mathrm{ft}$ high) are to be used in the TRU Facility. Development studies have been continued with columns $3 / 4$ in. in diameter in order to determine the operating conditions for good efficiency and flow capacity. For both the Tramex flowsheet and the phosphonic acid flowsheet, the best pulse conditions are a pulse frequency of $40 \mathrm{cpm}$ and amplitude of $0.2 \mathrm{in.}$ While it is necessary to operate at $50^{\circ} \mathrm{C}$ or greater for the Tramex flowsheet because of the high viscosity of the phases, the phosphonic acid flowsheet is satisfactory at $25^{\circ} \mathrm{C}$. The effects of variations of flow ratio, of use of surfactant, and of plate spacing were also studied. Removal of nitrate 
from an aqueous feed solution was successfully demonstrated in a pulsed column $4 \mathrm{ft}$ high.

\subsection{Design and Fabrication of Process Equipment}

Process equipment, including solvent extraction columns, ion exchange systems, and tanks, is being designed and built for use in the Transuranium Processing Plant. Design is over $70 \%$ complete (as of July 1, 1964), and fabrication of many components has been started. Detailed designs of most of the major equipment components, including the process tanks, seven of the ten equipment racks, and the intercell piping system, are complete. The constructional material for the waste and off-gas headers in the cell bank was changed from Hastelloy $\mathrm{C}$ to Zircaloy-2, which is more resistant to corrosion, and the design was modified to provide for remote replacement of the headers.

Fabrication of the first-cycle solvent-extraction equipment rack and the first of four 12-unit sampler stations has been completed. The fabrication of five additional equipment racks and the intercell piping plugs is proceeding.

Procurement of basic Zircaloy-2 materials was undertaken during this year, and all major items are now on hand. Vendors for the evaporators and waste- and product-storage tanks are being chosen; estimated delivery date for these vessels is about January 1, 1965.

\subsection{Construction of Transuranium Processing Plant}

The construction of the Transuranium Processing Plant was started July 1, 1963, and is about $50 \%$ complete and on schedule. Procurement of government-furnished material and equipment, including shielding windows, cubicle floor pans, conveyor housing, and all high-quality piping assemblies, is on schedule. A new formulation for hydrous, high-density concrete, containing limonite and ferrophos (a by-product from iron smelting), was developed for the cell-shielding walls to replace the magnetite, which could not be obtained in the required quantities.

\section{CURIUM PROCESSING}

The Isotopes Division and the Chemical Technology Division are working together to produce experimental heat sources for use in thermoelectric converters using two curium isotopes, ${ }^{242} \mathrm{Cm}$ and ${ }^{244} \mathrm{Cm}$. The Chemical Technology Division will chemically separate and isolate gram amounts of curium; the Isotopes Division will prepare and encapsulate the heat sources. Irradiated targets of ${ }^{241} \mathrm{AmO}_{2}$ in an aluminum matrix will be processed to separate ${ }^{242} \mathrm{Cm}$ from aluminum, fission products, and eventually from ${ }^{241} \mathrm{Am}$, although the first products will contain the residual ${ }^{241} \mathrm{Am}$ as well as ${ }^{242} \mathrm{Cm}$. Process methods, facilities, and source materials are used for both the Curium Program and the closely related Transuranium Element Program (see Chap. 4).

\subsection{Development of the Process}

The proposed method for isolating ${ }^{242} \mathrm{Cm}$ is to dissolve irradiated targets of ${ }^{241} \mathrm{AmO}_{2}-\mathrm{Al}$ in hydrochloric acid, adjust to Tramex (see Sect. 4.1) feed conditions by adding $\mathrm{LiCl}$ and evaporating to concentrate and to remove excess acid, separate ${ }^{241} \mathrm{Am}-{ }^{242} \mathrm{Cm}$ from aluminum and fission products by the Tramex process, and convert the product from a hydrochloric acid solution to a nitric acid solution by repeated nitric acid additions and evaporations to distill off chloride. The proposed method for recovering ${ }^{244} \mathrm{Cm}$ from the Savannah River concentrate is also based on the Tramex process. The concentrate will first be converted from nitrate to chloride by the Clanex (Co-Lanthanide-Actinide-Nitrate Extraction) process, in which americium, curium, and rare earths are extracted into Alamine $336 \cdot \mathrm{HNO}_{3}$-diethylbenzene (DEB) from neutral lithium nitrate solution and then stripped into dilute hydrochloric acid (Tramex process development is reported as part of Sect. 4.1). With Tramex tests americium losses are low $(0.01 \%)$ and fission product decontamination factors are equal to or greater than $10^{4}$. No serious radiation-induced effects were noted in 1 - to $10-\mathrm{ml}$ batch extraction tests at activity levels up to the proposed processing level of $10 \mathrm{w} /$ liter.

Both the Tramex and Clanex processes are expected to operate satisfactorily at full activity level in the Curium Recovery Facility (CRF). 
However, two Tramex cycles may be required to routinely give satisfactory fission product decontamination factors of greater than $10^{4}$ or $10^{5}$, which are required.

Conversion of Tramex product from $8 \mathrm{M} \mathrm{HCl}$ to a nitric acid solution by alternate additions of concentrated nitric acid and evaporations was successfully demonstrated in 1/10-scale tantalum equipment with simulated Tramex product. Chloride concentration of the product was reduced to 1 to 2 ppm after the second bolloff of the nitric acid, however, the final product was $15 M$ in $\mathrm{HNO}_{3}$, compared with the desired maximum acidity of $2 \mathrm{M}$.

Since a hazard would exist if residual organic solvent were present when curium product is converted from chloride to nitrate and because a sufficiently low nitric acid concentration cannot be readily obtained, a modified Tramex flowsheet was developed to produce chloride-free curium in $1 M \mathrm{HNO}_{3}$. In this process Alamine $336 \cdot \mathrm{HCl}$ containing the extracted americium and curium is converted to the nitrate salt in a conversion contactor, and the solvent can then be stripped with $1 M \mathrm{HNO}_{3}$. Laboratory results indicate that a satisfactory americium-curium product in nitric acid can be obtaned, free from zirconium and rare-earth contaminants, however, ruthenıum decontamination was poor and must be improved

Separation of americium and curium by precipitation of pentavalent americium as $\mathrm{KAmO}_{2} \mathrm{CO}_{3}$ from potassium carbonate solutions at concentrations equivalent to 40 to $130 \mathrm{w} /$ liter was demonstrated. The precipitated product contained 94 to $98 \%$ of the americium and carried from 2.0 to $3.8 \%$ of the curium. This procedure will probably be used in the CRF to separate ${ }^{241} \mathrm{Am}$ and ${ }^{242} \mathrm{Cm}$ Plans are to use the ion exchange methods discussed in Sect 4.1 for separating ${ }^{243} \mathrm{Am}$ from ${ }^{244} \mathrm{Cm}$. However, either method can be applied to both separations.

\subsection{Development of Alternative Processes: Separation of Lanthanides and Actinides}

The Talspeak process, which is a new method of separating lanthanides from trivalent actinides (especially americium and curium) consists in preferential extraction of the lanthanides with a dilute solution of di-(2-ethylhexyl)phosphoric acid (HDEHP) in an aromatic hydrocarbon from an aqueous solution of sodium diethylenetriaminepentaacetate in a carboxylic acid, such as lactic acid. The actinides may then be recovered from the aqueous raffinate by oxalate precipitation or by extraction with a more concentrated solution of HDEHP in an aliphatic diluent followed by stripping with dilute nitric acid. High concentrations of corrosive acids and salts are not required, and the separation is resistant to the effects of irradiation. Preliminary flowsheets have been devised on the basis of results from batch tests with various monoacidic phosphates and phosphonates, diluents, carboxylic acids, and aminopolyacetic acids. Curium has been successfully separated from fission product rare earths in continuous mixer-settler tests.

\subsection{The Curium Recovery Facility}

The Curium Recovery Facility (CRF) will be used to recover multigram amounts of ${ }^{243} \mathrm{Am}$ and ${ }^{244} \mathrm{Cm}$ for use in research and to purify gram amounts of ${ }^{242} \mathrm{Cm}$ and ${ }^{244} \mathrm{Cm}$ for use in thermoelectric converters. This facility is installed in cells 3 and 4 of the High Level Chemical Development Facility, Buılding 4507.

A dissolver and its auxiliary equipment were designed, fabricated, and installed in cell 3 . Th1s will be used to prepare feed from irradiated ${ }^{241} \mathrm{Am}$ targets. Cell 3 will also be used for the chemical separation of americium from curium This separation by ion exchange or precipitation will be performed in glass equipment mounted in removable containment boxes. The feed for this processing will come from the cell-4 solvent extraction process. Mixer-settlers for a single extraction cycle are installed in cell 4 . This cell also contains a product evaporator for converting from chloride to nitrate solution. A description of this equipment was given in the previous annual report. Facilities for transferring feed solutions and irradiated targets into the building and facilities to remove product streams from the building were designed and constructed. The installation of the CRF complex will be completed by the end of FY 1964.

Flowsheet and equipment tests were made on simulated target dissolutions, Tramex and Clanex feed adjustments, mixer-settler operation, and conversion of product from hydrochloric acid to nitric acid solutions.

During cold testing, repairs and changes were made to the equipment as required. Most of these were relatively minor. However, it was necessary to replace unsatisfactory polyethylene welds and 
disconnects, to replace unsatisfactory tantalumplated process tanks with glass-lined vessels, to eliminate air locks associated with equipment piping, to repair cracks which developed in the Homolite mixer-settlers, and to repair the manipulators. The Homolite mixer-settlers were replaced by $Z$ ircaloy mixer-settlers with quartz windows, and the glass-lined tanks will be replaced with tantalum-lined tanks when they become available.

As soon as equipment and flowsheet tests have been completed, gram quantities of ${ }^{243} \mathrm{Am}$ and ${ }^{244} \mathrm{Cm}$ will be separated from the Savannah River concentrate, which is now stored in an underground tank at the CRF. Runs will then be made in order to produce 4- to $8 \mathrm{-g}$ amounts of ${ }^{242} \mathrm{Cm}$.

Future plans call for installing a second extraction cycle and permanent equipment for americium-curium separation. Installation of this equipment will probably be started late in FY 1965 and continue through FY 1966.

\section{DEVELOPMENT OF THE THORIUM FUEL CYCLE}

The Thorium Fuel Cycle work is part of Oak Ridge National Laboratory's Thorium Utilization Program. The overall objective is the development of the fuel cycle technology required for economical power production in thorium-fueled reactors. Much of the work carried out in this program by the Chemical Technology Division has been in close cooperation with the Metals and Ceramics Division. Oxide fuels and the preparation of microspheres of those fuels are being emphasized, but some work on preparation of thorium-uranium carbides and other systems, such as cermets, is being carried out to exploit the versatility of the sol-gel process.

During the year, the Kilorod Program was successfully completed; approximately 1000 tubes filled with $\mathrm{ThO}_{2}-{ }^{233} \mathrm{UO}_{2}$ were produced in using the sol-gel process for oxide preparation and vibratory compaction as a means of remotely fabricating $\mathrm{ThO}_{2}-{ }^{23} \mathrm{UO}_{2}$ fuels. Also during the year, the preliminary (Title I) design of the Thorium-Uranium Fuel Cycle Development Facility was completed, and detailed (Title II) design was started.

\subsection{The Kilorod Facility}

Development of a reactor fuel cycle based on thorium and ${ }^{233} \mathrm{U}$ has been hindered by the radioactivity resulting from the decay of the daughter products of the ${ }^{232} \mathrm{U}$ normally present in ${ }^{233} \mathrm{U}$. Because of this associated activity, an economical thorium- ${ }^{233} \mathrm{U}$ fuel cycle requires rapid, simple chemical and mechanical processes easily adaptable to remote operation. The sol-gel process developed by ORNL for preparing dense mixed oxides of thorium and uranium uniquely meets these requirements; and, coupled with the loading of fuel tubes by vibratory packing of sized oxide, it provides a complete system for making fuel elements, starting with solutions or crystals of nitrate salts of thorium and uranium. During the past year, a pilot plant demonstration $(10 \mathrm{~kg}$ per day) showed the feasibility of this procedure for the remote fabrication of fuel.

In the pilot plant demonstration, experience was obtained in the handling of ${ }^{23}{ }^{3} \mathrm{U}$ containing $38 \mathrm{ppm}$ of ${ }^{232} \mathrm{U}$, and radiation data were collected which will make it possible to improve the design of facilities for handling larger quantities of ${ }^{233} \mathrm{U}$ having higher concentrations of ${ }^{232} \mathrm{U}$ and its daughters. During the demonstration, about 1000 fuel rods (hence the name, Kilorod Program) were produced to fulfill a request for elements to be used in reactor parametric studies at Brookhaven National Laboratory.

The Kilorod Program was a cooperative program between the Chemical Technology Division and the Metals and Ceramics Division. The Chemical Technology Division carried out the feed-material preparation and sol-gel process operations, while the Metals and Ceramics Division carried out all operations related to fuel-rod fabrication.

Three distinct and straightforward operations were involved in the Kilorod Program. These operations were: (1) preparation of feed materials, (2) the sol-gel process, and (3) fuel-rod fabrication. The preparation of feed materials consisted in preparing ${ }^{233} \mathrm{UO}_{2}\left(\mathrm{NO}_{3}\right)_{2}$ solution by removal of the daughter products of ${ }^{23} \mathrm{U}$ from ${ }^{23}{ }^{3} \mathrm{U}$ by a onecycle solvent extraction process in which the applicability of the new extractant, $2.5 \%$ di-secbutylphenylphosphonate in diethylbenzene was demonstrated, and in preparing $\mathrm{ThO}_{2}$ by denitration of thorium nitrate crystals with superheated steam at 450 to $500^{\circ} \mathrm{C}$. 
In the sol-gel process, $\mathrm{UO}_{2}\left(\mathrm{NO}_{3}\right)_{2}$ and $\mathrm{ThO}_{2}$ feed stocks are blended at $80^{\circ} \mathrm{C}$ to form a stable sol. The sol is dried to a gel at $80^{\circ} \mathrm{C}$ and then calcined and reduced in an $\mathrm{Ar}-4 \% \mathrm{H}_{2}$ atmosphere at $1150^{\circ} \mathrm{C}$ to produce a sintered, fragmented $\mathrm{UO}_{2}-$ $\mathrm{ThO}_{2}$ product. Fuel-rod fabrication is carried out by grinding and sizing the fragments and loading the sized powder into fuel tubes which are vibratorily packed. Following compaction, the end of the rod is closed by welding, after which it is inspected for leak-tightness and uniformity of packing, thus completing the process.

All chemical and mechanical processes behaved satisfactorily。 Fifty kilograms of ${ }^{233} \mathrm{U}$ was purified by the new solvent extraction system, and the product surpoassed the specifications. A thousand kilograms of ${ }^{23}{ }^{3} \mathrm{UO}_{2}-\mathrm{ThO}_{2}$ was prepared by the sol-gel process. All of the material produced was suitable for preparing fuel rods. Nine hundred rods, each containing $890 \mathrm{~g}$ of mixed oxide, and 200 shorter rods, each containing $310 \mathrm{~g}$ of mixed oxide, were prepared.

The pilot plant demonstration showed that the entire process used in the Kilorod Program may readily be scaled to larger operations. In fact, a more radioactive batch of sol-gel-derived oxides was prepared as a safety test, and the workers were not exposed to a level of radiation appreciably higher than when the less radioactive, more recently purified ${ }^{233} \mathrm{U}$ had been used. In this safety test, aged ${ }^{233} \mathrm{U}$ was used to simulate 14-day-old feed containing 1000 ppm of ${ }^{232} \mathrm{U}$. Thus, the present equipment and working areas can provide radiological safety even when considerably higher concentrations of ${ }^{232} \mathrm{U}$ and its decay products are encountered.

\subsection{Development of the Sol-Gel Process}

Exploratory experiments show that a small but controllable amount of porosity can be "built into" particles of thorium-uranium oxide in order to improve their solubilization prior to fuel recovery. More work is necessary, however.

\subsection{Application of the Sol-Gel Process to the Preparation of $\mathrm{ThC}_{2}-\mathrm{UC}_{2}$}

Microspheres of thorium and thorium-uranium dicarbides are attractive fuel materials for hightemperature, gas-cooled nuclear reactors. A variation of the sol-gel process has been developed on a laboratory scale for producing these materials. In this approach, a hydrosol of thorium oxide which may contain up to 10 at. $\%$ uranium oxide is prepared by the sol-gel process. A proprietary lyophilic, high-surface-area carbon product is dispersed in the oxide sol, and the resultant oxide-carbon sol is formed into gel spheres and air dried. The spheres are converted to dicarbide by firing at about $1800^{\circ} \mathrm{C}$ in vacuum or in an argon stream for about an hour.

Conversions of the oxide to the carbide are more than $99 \%$ complete when firing is carried out in vacuum. The conversion reaction in vacuum obeys pseudo-first-order kinetics, with an activation energy of about $112 \mathrm{kcal}$ per g-mole of $\mathrm{ThO}_{2}$ and a specific reaction rate constant of $3.2 \mathrm{hr}^{-1}$ at $1575^{\circ} \mathrm{C}$. Both 2-ethylhexanol and 1-methylpentanol are satisfactory water extractants for use in forming carbon-containing sols; and nonionic surfactants, such as 2-octanol, increase the perfection of the spherical shapes.

An outstanding feature of the sol-gel process for the preparation of uranium carbides is the ease of preparation of intimately mixed oxides and carbon so that they will react readily and completely to desired carbide compositions. This ease of mixing results from the fact that sols are mixed, rather than dry powders. Another feature is the relative ease and simplicity of forming near-perfect spheres. This is accomplished by the same method (see Sect. 6.4) as that used for preparing microspheres of the oxides.

The apparent densities of the dicarbide spheres (thorium or $5 \% \mathrm{U}-95 \% \mathrm{Th}$ ) increased from 30 to $90 \%$ of the theoretical densities as the free carbon content decreased from 22 to $2 \%$. The particles showed excellent resistance to breakage in handling and in rapid thermal cycling.

\subsection{Production of Microspheres}

A new technique for producing high-quality microspheres ( 5 to $2000 \mu$ in diameter) of oxides and carbides of thorium and uranium-thorium mixtures was developed. Microspheres appear useful as fuel particles in fueled graphite elements used in high temperature gas-cooled reactors and for other fueled matrices such as BeO. The method requires a minimum of handling and has a potential for a high rate of production. Development has been carried through the laboratory scale 
and has been scaled up to batches as large as a kilogram.

In principle, the technique consists in dispersing sols of oxides or oxides containing finely divided carbon to droplets in an immiscible nonaqueous liquid in which water is only somewhat soluble. Gelling occurs when the water is extracted from the sol by the immiscible liquid. Alcohols such as 2-ethylhexanol were the best of a number of dispersing and water-extracting agents. For optimum sphere-forming performance with different sols, surfactants were added to the alcohol to achieve the proper interfacial tension between sol and alcohol. After the gel spheres are formed, they are converted to oxides or carbides by calcination. The technique has been developed to the point where nearly perfect spheres were produced reproducibly at the rate of about $50 \mathrm{~g} / \mathrm{hr}$; a tapered column was used. The desired size can be controlled to within $\pm 50 \mu$, with less than $20 \%$ being rejected. Oxide spheres having densities greater than $99 \%$ of theoretical can be made, with less than $0.1 \%$ of the spheres having cracks or fissures. Microspheres of both oxide and carbide were successfully coated with pyrolytic graphite.

\section{SEPARATIONS CHEMISTRY RESEARCH}

\subsection{Studies in Descriptive Chemistry}

New separations methods and reagents are being developed, particularly for use in radiochemical processing. The current study is principally on solvent extraction, and it includes a systematic experimental laboratory-scale survey of the behavior and potential utility of extractants in nuclear fuel processing, waste treatment, fission product recovery, transuranium element recoveries, and other heavy-metal separations. Attention is increasing toward other separations methods, for example, extraction chromatography for highresolution separations.

Extraction of Metal Nitrates by Amines. - In a continuing study of the amine extraction characteristics of fission- and corrosion-product metals in nitrate solutions, a detailed study of niobium showed higher extractions with a primary amine than with the other classes of amines. Extractions increased with increasing aqueous nitric acid concentration; for example, the extraction coefficient was above 1 from $\geqq 10 \mathrm{MHNO}_{3}$ when $0.3 \mathrm{M}$
Primene JMT in toluene was used. The extraction coefficient was nearly proportional to the amine concentration. The extraction behavior indicated slow equilibration among at least two extractable and at least one inextractable niobium species in the aqueous phase and suggested that the most extractable species is a tetranitrato complex. In a survey investigation of extraction of other metal nitrates, extraction coefficients were $<1$ for mercuric nitrate, $<0.01$ for selenium nitrate, and $<0.001$ for antimony nitrate with $0.1 M$ trilaurylamine when the nitric acid concentration was 0.1 to $10 \mathrm{M}$. Conductance was found to be an accurate measure of excess nitric acid extracted by trilaurylamine in toluene. A new theoretical model was shown to correlate a wide range of uranyl nitrate extractions.

Extraction of Metal Chlorides by Amines. - As part of a program on surveying the extraction of metals from various systems with representative amines, data were obtained for the extraction of technetium, silver, cadmium, and palladium from $\mathrm{HCl}$ and $\mathrm{LiCl}-0.2 M \mathrm{HCl}$ solutions over the range 0.5 to $10 M$ total chloride. All the metals were extracted effectively, particularly at the lower chloride concentrations, and, in most cases, the extraction power of the amine for the metal varied in the order: Aliquat 336 (quaternary amine) $\geqq$ Alamine 336 (tertiary amine) > Amberlite LA-1 (secondary amine) $>$ Primene JM (primary amine).

Performance of Degraded Diluents. - Continued studies on aliphatic and aromatic diluents were concentrated on the improvement of their stabilities by sulfuric acid pretreatment, and on the stabilities and degradation reactions of diethylbenzene isomers. A sulfuric acid pretreatment previously used for improving the stability of aliphatic Amsco 125-82 was successfully applied to two additional commercial aliphatic diluents. Both were degraded severely when $1 M$ tri-n-butyl phosphate (TBP) solutions were refluxed with $2 M$ $\mathrm{HNO}_{3}$, with the diluents used as received, but both were markedly more stable after treatment with $98.5 \%$ sulfuric acid at $50^{\circ} \mathrm{C}$ for $90 \mathrm{~min}$. Studies of the nitration of diethylbenzene (DEB) isomers in the presence or in the absence of ${ }^{60} \mathrm{Co}$ gamma radiation confirmed the previously reported stability of meta-DEB. Sufficiently purified para- and orthoDEB appeared to be only a little less stable. In some tests, meta and para isomers showed about the same high resistance to degradation as does 
n-dodecane. As with other diluents, (1) irradiation while mixing DEB with $\mathrm{HNO}_{3}$ accelerated degradation without significantly changing the type and distribution of products; (2) the presence of TBP increased the rate of DEB degradation; and (3) hafnium extraction correlated fairly well with the final nitrogen content. The principal degradation products included ketones (ethylacetophenone isolated), and nitrogen-containing products (concentrated but not yet identified).

Sorption by Immobilized Extractants. - The potential use of extractants in quasi-solid form is being studied. These quasi-solids are obtained by absorption of liquid or dissolved extractant in a porous solid support, either for achieving highresolution column separations (extraction chromatography) or for circumventing insolubility or other physical difficulties that would interfere with liquid-liquid equilibration. Tests of uranyl-ion recovery by tri-n-octylphosphine oxide on microporous polyethylene and of americium-lanthanide separations by di(2-ethylhexy1)phosphoric acid on several supports confirmed some of the advantages expected from sorption by immobilized extractants, but they also showed some difficulties - slow or incomplete equilibration - suggesting that a portion of the extractant was in relatively inaccessible positions.

New Extraction Reagents. - A continued search for new separations reagents, particularly solvent extraction reagents, has included a series of $\mathrm{N}$ alkyl amides, phosphorus esters, phosphoramides, carboxylic acids (see Sect. 8.3), and substituted phenols.

Eight new high-molecular-weight $\mathrm{N}$-alkyl amides were synthesized and examined as solvent extraction reagents. Varied substitution on the $a$-carbon atom of the carboxylic acid provided varying degrees of u ranium-thorium selectivity. In $2 \mathrm{M} \mathrm{HNO}_{3}$, several amides gave uranium/thorium separation factors more than 100 times higher, with uranium extractions somewhat lower, than with tri-nbutyl phosphate (TBP)。 Separation factors for uranium/zirconium and uranium/ruthenium and total acid extraction were similar to those with TBP. High coefficients were obtained for americium and europium extraction from $\mathrm{LiNO}_{3}$ solutions but were accompanied by high lithium ex. traction and volume changes. Separation factors for europium/americium were less than 2 .
About 50 neutral organophosphorus compounds (esters and phosphoramides) were examined as extractants for cerium, europium, and americium. Some were strong extractants, but none was able to separate europium from americium by factors greater than 3. Di-(sec-butyl) (methylphenyl)phosphonate was usable in a diluent comprised of $75 \%$ aliphatic and $25 \%$ aromatic compounds, in contrast to the more than $75 \%$ aromatic constituent required by di-(sec-butyl) phenylphosphonate (DSBPP). The uranium extraction and separation from thorium were unaffected by the change in reagent structure. The high selectivity for thorium over uranium reported previously for cage-structure phosphates was shown to be due to acidic impurities.

Seven new phenols, especially synthesized to test certain variations of structure, were examined for their ability to extract cesium from dilute solutions of sodium hydroxide. One of these, 4chloro-2-( $\alpha$-methylbenzyl)phenol, showed high cesium extraction and good physical performance, comparable with the best of the previously identified cesium extractants. Two polymeric reagents, a dimer and a tetramer of 4-chloro-2-( $a$-hydroxyethy1)phenol, gave exceptionally high cesium extraction coefficients, although they had very limited solubility in hydrocarbon diluent.

\subsection{Development of Separations Processes}

Processes are being developed for specific separation and recovery applications, both where no practicable process yet exists and where existing processes can be measurably improved. Where warranted, development is carried to the point that large-scale performance can be predicted.

Cesium Recovery from Ores. - The effectiveness of the phenol extraction (Phenex) process for recovering cesium from alkaline-ore leach liquors was further confirmed in mixer-settler tests. In a simple continuous system, the cesium was selectively extracted with substituted phenols in a hydrocarbon diluent and stripped with dilute acid. Efficient cesium recovery and efficient separation of cesium from other components of the liquors, including other alkali metals, were obtained. A variety of high-purity cesium compounds can be produced since the cesium is easily stripped from the solvent with many different mineral or organic acids, from which the corresponding salts are readily prepared. 
In applying the process to the treatment of pollucite ore, which is the most important source of cesium, more than $97 \%$ of the cesium was solubilized by roasting the ore with 2 parts of $\mathrm{NaCl}$ and 1 part of $\mathrm{Na}_{2} \mathrm{CO}_{3}$ per part of ore for $1 \mathrm{hr}$ at $750^{\circ} \mathrm{C}$ and leaching with water. Cesium was extracted from the liquor in a countercurrent system with a $1 M$ solution of 4-sec-butyl-2-( $\alpha$ methylbenzyl)phenol (BAMBP) in kerosene. In one demonstration run the extract was scrubbed with water and stripped with hydrochloric acid to give a cesium chloride product solution containing less than $0.02 \%$ combined alkali-metal impurities, based on cesium. In a second demonstration run the extract was scrubbed with $0.01 M$ tartaric acid and stripped with carbon dioxide and water to give a cesium carbonate product solution with less than $0.01 \%$ combined alkali-metal impurities. Total chemical reagent costs for the process, including the cost of the roasting chemicals, are estimated at approximately $32 \phi$ per pound of cesium.

The process offers many advantages over those currently used. Its development is considered especially timely, in view of the anticipated large increase in the cesium market. Scale-up from the present laboratory-scale work to larger-scale operations can be accomplished on the basis of present technology.

Beryllium Recovery from Ores. - A tentative solvent extraction process using primary amines was outlined for recovering beryllium from sulfuric acid digests of low-grade beryllium ores. Extractions of beryllium with these amines are rapid, in contrast to the very slow extractions obtained with di(2-ethylhexyl)phosphoric acid. Of a variety of amines tested, only the primary amines extracted significant amounts of beryllium, and 1-(3-ethylpenty1)-4-ethyloctylamine was the most effective. Beryllium extraction coefficients, low at $\mathrm{pH} 1$, are usably high at $\mathrm{pH} 2$ to 3 . Aluminum is extracted to some extent, but good separations are achieved by saturating the solvent with beryllium and by scrubbing the extract with 0.01 to $0.03 M$ $\mathrm{H}_{2} \mathrm{SO}_{4}$. Iron extraction is minimized by reducing to the ferrous state. The beryllium is readily stripped from the extract with 0.5 to $1 \mathrm{M} \mathrm{H}_{2} \mathrm{SO}_{4}$.

In a batch countercurrent demonstration of the process, $92 \%$ of the beryllium was recovered from a synthetic leach liquor $(0.5 \mathrm{~g}$ of bery 11 ium and $5 \mathrm{~g}$ of aluminum per liter, $\mathrm{pH} 2.5)$ in six extraction and four scrub stages with $0.3 M$ 1-(3-ethylpentyl)-4- ethyloctylamine in Solvesso 100 . The product contained less than $0.3 \% \mathrm{Al}$, based on beryllium. In a similar demonstration run with an actual ore leach liquor, the extraction efficiency was lower, but $96 \%$ recovery of beryllium still was obtained by operating at a higher organic to aqueous flow ratio.

Thorium Recovery from Granitic Rocks. - The three holes drilled in the Conway granite formations in New Hampshire during 1962 have been extended from their original depths of 500 to $600 \mathrm{ft}$ to $1000 \mathrm{ft}$. The thorium content and process amenability of these deeper samples were nearly the same as for surface and previous drill-core samples. Consequently, the in-place reserves of thorium and uranium in the Conway formation, that can be estimated with confidence, are now 35 and 8 to 12 million tons, respectively, with about twothirds being recoverable by ordinary processing techniques.

Biochemical Separations. - A new program has been started to recover and separate transfer ribonucleic acids ( $t$-RNA's) from $E$. coli bacteria in quantities sufficient to permit chemical, physical, and biological investigations of the specific t-RNA's. The latter studies should ultimately provide definitive data regarding the base sequence concept of information coding in nucleic acids.

Several methods for the recovery of $t$-RNA have been studied. The preferred method involves breaking the bacteria cells in a phenol-water mixture, fractionating the crude nucleic acids in a sodium acetate-isopropanol mixture, and final purifying of the $t$-RNA by selective elution from a DEAE-cellulose column. Recoveries ranged from 0.8 to $1.9 \mathrm{~g}$ of $t$-RNA per kilogram of wet bacteria. Purity was measured by ${ }^{14} \mathrm{C}$ amino acid incorporation.

Attempts are now being made to devise a liquid ion exchange system, suitable for reverse-phase column chromatography, to fractionate the purified $t$-RNA mixture into its components. It is estimated that 25 to 40 different specific $t$-RNA's exist. Preliminary tests with quaternary ammonium compounds in oxygenated diluents are encouraging.

\subsection{Fundamental Studies on the Equilibria and Kinetics of Solvent Extraction}

Continuing fundamental investigations are aimed at understanding both the equilibria and the mechanisms of separations systems. Current 
studies are concentrated almost entirely on solvent extraction systems, together with some utilization of solvent extraction in studying the physical chemistry of aqueous solutions.

Extraction of Alkaline Earths and Alkali Metals by Di(2-ethylhexyl)phosphoric Acid. - The study of sodium and strontium extraction by mixtures of di(2-ethylhexyl)phosphoric acid (HDEHP) and its sodium salt is completed through the range from the completely ac1d form to the completely salt form of the extractant. The correlation of the extraction data over this entire range of extractant composition with a single extraction model appears successful. An experimental confirmation of proportionality between the logarithm of the hydrogen-1on concentration and the apparent $\mathrm{pH}$ as measured by glass electrode in $4 \mathrm{M} \mathrm{NaNO}_{3}$ solution, required in the correlation study, was obtained in the range $\mathrm{pH} 4$ to 7 . Simultaneous extraction of alkaline earths by HDEHP showed extractability in the order $\mathrm{Ca}>\mathrm{Mg}>\mathrm{Sr}>\mathrm{Ba}$ at low loading, changing to $\mathrm{Ca}>\mathrm{Mg}>\mathrm{Ba}>\mathrm{Sr}$ at higher loading.

Use of Dielectric Measurements in the Study of Interactions Between Extraction Components. - In a previously reported study of interactions between the components of synergistic extraction mixtures, infrared spectrophotometry showed association between HDEHP and trioctylphosphine oxide (TOPO) but could not be applied to mixtures of HDEHP with tri-n-butyl phosphate (TBP) because of a fortuitous overlapping of absorption bands. Dielectric measurements have now been used to show that there is little if any association between HDEHP and TBP. Dielectric measurements reconfirmed association between HDEHP and TOPO and showed association between TBP and the complex sodium salt NaDEHP.3HDEHP.

Extraction of Alkali Metals by Substituted Phenols. - Equilibrium measurements of cesium extraction by 4-sec-butyl-2( $\alpha$-methylbenzyl)phenol (BAMBP) in both $n$-octane and dissopropylbenzene confirmed the dependence of the extraction coefficient on the reciprocal of hydrogen-ion concentration and on the third power of the extractant concentration. Extraction isotherms with BAMBP in n-octane and in carbon tetrachloride reach a plateau at a mole ratio of $\mathrm{Cs}: \mathrm{BAMBP}=1: 4$ in the extract species, presumably cesium phenolate associated with three undissociated phenol molecules. At an aqueous hydroxide concentration of 1 to $2 \mathrm{M}$, the extraction of cesium (and also of the other alkalies) increases abruptly, reaching a mole ratio of approximately $1: 1$ in extraction from $6 M \mathrm{CsOH}$. Water extraction also increased abruptly, consistent with the hypothesis of a shift from solvation of the alkali phenolate by phenol molecules to hydration.

Investigation of Phenol-Alkali Metal Extraction Species by Nuclear Mognetic Resonance and Infrared Spectroscopy. - Infrared spectra of BAMBP in carbon tetrachloride show absorptions attributed to phenolic $-\mathrm{OH}$ groups in three different situations. unassociated, dimerized by hydrogen bonding, and polymerized by hydrogen bonding. The indicated proportion of monomeric phenol varies from nearly zero in undiluted BAMBP to nearly $100 \%$ below $0.05 M$. W 1 th cesium extraction (Cs:BAMBP $<1: 4$ ), monomer and dimer absorptions decrease and polymer absorption increases, the phenolic proton nuclear magnetic resonance (NMR) line is broadened and shifted far downfield. With further cesium extraction (Cs:BAMBP >1:4) and concomitant water extraction, the infrared absorption ascribed to polymer increases markedly, the shift of the phenolic proton NMR line is reversed, and the spectrum approaches that of water. The extent of the shift with other alkalies varies in the same order as their extractabilities: $\mathrm{Cs}>\mathrm{Rb}>\mathrm{K}$. The results indicate that inter-phenol hydrogen bonds are stronger in the presence than in the absence of alkali ion, especially when it is the cesium ion.

Kinetics of the Transfer of Sulfate During Ex. traction by Amines. - Previous evidence (through transfer-rate measurements of tagged sulfate from amine solution to aqueous sulfate solution) of the participation of both neutral complex transfer and complex anion transfer in uranyl sulfate extraction was confirmed and extended. This was done by comparison with rates with the tracer sulfate initially in the aqueous phase and by comparison of rates with the tracer sulfate initially present in various single organic-phase species. Besides qualitative confirmation that there is exchange of anions when uranium is extracted from moderately concentrated sulfate solutions $\left(\mathrm{UO}_{2}\left(\mathrm{SO}_{4}\right)_{2}{ }^{2}-\right.$ predominating) and that there is no exchange when it is extracted from very low sulfate solutions ( $\mathrm{UO}_{2}{ }^{2+}$ and $\mathrm{UO}_{2} \mathrm{SO}_{4}$ predominating), these tests gave a quantitative measure of the average sulfateto-uranium ratio in the species actually transferred. about 1 in the latter case and about 2 in the former. Computer correlation showed that the self- 
diffusion of the tracer sulfate conformed reasonably well to first-order rate.

Kinetics of the Extraction of Iron by $\mathrm{Di}(2$. ethylhexyl)phosphoric Acid. - A kinetics study has been started to investigate the reasons for and mechanisms of the markedly slow equilibration rates in the extraction of certain metal ions with dialkylphosphoric acid. Besides its importance in the fundamental study of solvent extraction, an understanding of the slow extractions should aid in safeguarding against difficulties in extraction processes and (more important) provide a basis for devising special separations to exploit rate differences. The first system being examined is the extraction of $\mathrm{Fe}$ (III) from acid sodium perchlorate solutions with HDEHP in $n$-octane. This extraction has now been shown to follow first-order rate, $\log [\mathrm{Fe}]_{\mathrm{A}}=-k t$, with rate directly proportional to a changing power of extractant concentration and inversely proportional to acidity ( $k \propto$ $\left.[\mathrm{HDEHP}]_{0}^{0.3-1.4}, k \propto 1 /\left[\mathrm{H}^{+}\right]_{\mathrm{A}}\right)$. The principal objectives of the current study are to determine whether controlling resistance lies at the interface or in the adjacent liquid layers and whether or not it involves chemical reaction.

Determination of the Activity Coefficients of Aqueous Acids by Amine Extraction. - It was found possible to measure acid activities in aqueous acid-salt mixtures by equilibration of an aqueous acid-salt mixture and an aqueous acidonly solution through an intervening amine phase. Amines of lower relative base strength are required for use with stronger acids and higher acid concentrations. Acid extraction isotherm curves show the acidity ranges for which different amines should be applicable.

Activity Coefficients of the Solvent Phases. Osmotic coefficients and solute activity coefficients were determined by direct precise measurement of vapor-pressure depression over solutions of triphenylmethane, azobenzene, and bibenzyl in dry benzene and/or in water-saturated $n$-hexane, in order to establish them as isopiestic standards. Bibenzyl has the advantage of higher solubility than most other possible reference solutes examined, nearly $3 \mathrm{~m}$ in hexane and $10 \mathrm{~m}$ in benzene, permitting its use in measurements at correspondingly high concentrations of test solutes. An improved manometer and capacitive mercurylevel detector for the differential vapor-pressure apparatus worked well in mockup, promising still better sensitivity and precision in the vaporpressure-depression measurements.

The average aggregation number $\bar{n}$ of 4-sec-butyl2-( $\alpha-$ methylbenzyl)phenol (BAMBP) was measured as a function of its concentration in wet hexane, for use in the studies of alkali-metal extraction by BAMBP. Isopiestic balancing against azobenzene at $25^{\circ} \mathrm{C}$ showed the average aggregation increasing approximately in proportion to concentration from monomer at very low concentration to trimer at about $1 M$.

The average aggregation number $\bar{n}$ of tri-noctylamine (TOA) and its sulfates at concentrations between 0.08 and $0.3 M$ in dry benzene was measured as a function of the sulfate-to-amine ratio. Isopiestic balancing against triphenylmethane at $25^{\circ} \mathrm{C}$ showed that the solute is monomeric at all ratios from 0 (free-base amine) to 0.5 (normal sulfate). Aggregation commenced abruptly at 0.5 and increased to an $\bar{n}$ of $\sim 2$ at $0.75, \sim 3.5$ at 1 (bisulfate), and $\sim 12$ at 1.5 (50\% excess sulfuric acid). At least up to 1 (bisulfate), $\bar{n}$ was independent of amine concentration in the range 0.08 to $0.3 \mathrm{M}$. In further tests, so far completed with the bisulfate only, aggregation was essentially unaffected by the addition of water to the system at water activity levels up to 0.9 of saturation, which is approaching the water activity levels in typical extraction systems of interest.

The activity coefficient of water in TOA-benzene and -phenylcyclohexane solutions, measured by isopiestic balancing and by direct liquid-liquid equilibration, decreased with increasing water concentration. Correlations appeared best when the water concentration was expressed as mole ratio $\mathrm{H}_{2} \mathrm{O}: \mathrm{R}_{3} \mathrm{NH}^{+}$, suggesting that the water may be associated mainly with the alkylammonium cation rather than with the free-base amine or the sulfate or bisulfate anions. The activity coefficient was nearly independent of the sulfate to amine ratio up to 0.5 (normal sulfate), then increased with increasing ratio up to 1 (bisulfate).

\section{RECOVERY OF FISSION PRODUCTS BY SOLVENT EXTRACTION}

\subsection{Cesium}

In continued studies of the phenol extraction process for recovering cesium from Purex waste, 4sec-butyl-2-(a-methylbenzyl)phenol (BAMBP) was shown to be adequately stable toward chemical and 
radiative degradation under expected flowsheet conditions. Feasibility of the process was further confirmed in a bench-scale continuous demonstration run in mixer-settler equipment. Cesium recovery was better than $99 \%$ 。 Use of synergistic reagent mixtures (e.g., BAMBP in combination with D2EHPA) was studied, but these solvents did not appear as favorable for cesium recovery as BAMBP alone.

\subsection{Strontium and Rare Earths}

The slow extractions of rare earths with $\operatorname{di}(2-$ ethylhexyl)phosphoric acid (D2EHPA) from tartratecomplexed Purex waste at a $\mathrm{pH}$ of about 5 are due to the presence of chromium, iron, and aluminum in the waste. Apparently, the aqueous phase contains unextractable metal-rare-earth-tartrate complexes which dissociate slowly to yield extractable rare-earth species.

Studies of cerium oxidation, followed by extraction with D2EHPA to obtain cerium separation from other rare earths, indicated that both persulfate and ozone are suitable oxidants.

\subsection{Recovery of Strontium with Carboxylic Acids}

A tentative process was outlined for recovering strontium from Purex waste by extracting with carboxylic acids, scrubbing with dilute $\mathrm{HNO}_{3}$, and stripping with $\mathrm{HNO}_{3}$. In a batch countercurrent test with citrate-complexed, simulated Purex FTW solution at a pH of about 8 , more than $99 \%$ of the strontium was recovered in five extraction and two scrub stages. About $70 \%$ of the rare earths was recovered with the strontium.

\subsection{Technetium}

Efficient extraction of technetium from alkaline waste supernatants was demonstrated with Aliquat 336 (a quaternary amine). However, an acceptable method for stripping the technetium from the solvent has not been found.

\subsection{Engineering Studies}

Engineering studies of a solvent extraction process using a substituted phenol (BAMBP) for the recovery of cesium from simulated Purex-type waste have been made. The flow capacity of pulsed columns for the extraction, scrub, and strip sections of the flowsheet were measured as a function of pulse conditions and flow ratio. Batch phase-separation tests were made for comparison with other known systems and to provide a basis for evaluation of mixer-settlers as contactors for this system.

\section{CHEMISTRY OF PROTACTINIUM}

A major part of the year was devoted to recovering and purifying the remainder of $50 \mathrm{~g}$ of ${ }^{231} \mathrm{~Pa}$ obtained from the British for use in preparing about $1 \mathrm{~g}$ of ${ }^{232} \mathrm{U}$ for cross-section measurements. Three methods were studied for separating protactinium from uranium, thorium, and niobium, the three most serious contaminants. Although all showed promise, the anion exchange procedure utilizing mixed hydrochloric-hydrofluoric acid solutions and fluoride complexing was used because we have had more experience with it. About $40 \mathrm{~g}$ of ${ }^{231} \mathrm{~Pa}$ has been recovered.

The study of the chemistry of protactinium in sulfuric acid solutions was continued, using the solvent extraction method. The unusual dependence of the protactinium distribution coefficient on protactinium concentration, possibly due to polymerization of protactinium, was studied under a variety of conditions. At protactinium concentrations that are quite low the extraction coefficient was nearly constant; but as the concentration was increased, the coefficient increased very sharply and then either leveled or slowly decreased at higher concentrations. Fluoride ion has less effect on protactinium extraction from sulfuric acid than from hydrochloric acid.

\section{RADIATION EFFECTS ON CATALYSTS}

The effect of beta radiation on the catalytic decomposition of formic acid vapor was studied by the use of copper, nickel, silica gel, activated alumina, zinc oxide, urania, thoria, silica-alumina, and chromia-alumina as catalysts. A beta-particle source containing 80 curies of ${ }^{90} \mathrm{SrTiO}_{3}$ was designed and constructed for these studies. Apparent activation energies were measured, and changes in product yields were sought. Analyses were carried out with a gas chromatograph used as 
an integral part of the catalyst irradiation apparatus. No permanent effects of beta 1 rradiation were found with any of the catalysts. Transient effects were found with silica gel, zinc oxide, and urania.

\section{HIGH-TEMPERATURE CHEMISTRY}

The purpose of this program is to develop and exploit various spectrophotometric techniques for studying the properties of aqueous solutions, primarily of uranium, transuranium, rare-earth, and transition-group elements. The principal effort is directed at construction of a spectrophotometer that can be used to study spectra of these elements in solutions up to $330^{\circ} \mathrm{C}$. To and in characterizing these solutions, a special autoclave has been built for measuring liquid densities at high temperatures and pressures. Since the high-temperature spectrophotometer has not yet been constructed, preliminary spectral studies of $\mathrm{UO}_{2}{ }^{2+}$ and $\mathrm{Pu}^{4+}$ ions have been made up to $95^{\circ} \mathrm{C}$ in existing spectrophotometers equipped with punched-card outputs.

Computer codes for the IBM 7090 have been written for calculating reaction rates from spectral data taken as a function of time and for resolving complex spectra into individual absorption peaks.

\subsection{High-Temperature, High-Pressure Spectrophotometer System}

Work has continued on the development of equipment and techniques for studying aqueous solutions at high temperatures and pressures. The prototype high-temperature, high-pressure spectrophotometric absorption cell, constructed as part of the subcontract development work, has performed satisfactorily in tests at this Laboratory. Conditions employed included temperatures up to $350^{\circ} \mathrm{C}$ and pressures to 3400 psi, applied simultaneously. Construction of the entire system should be completed in FY 1965.

\subsection{Spectral Studies of Ionic Systems at Elevated Temperatures}

A series of absorption measurements has been made of uranyl perchlorate solutions of fixed ionic strength at uranium concentrations between 0.01 and $0.75 M$ and at acidities from $3 \mathrm{M} \mathrm{HClO}_{4}$ to solutions having hydroxyl numbers of about 1.0 over the temperature range 25 to $95^{\circ} \mathrm{C}$. As the acidity is lowered through the stoichiometric point into the region where the uranyl ion becomes progressively more hydrolyzed, significant spectral changes are observed. As the acidity is lowered, the effect of increased temperature in promoting hydrolysis becomes increasingly more pronounced. Spectral studies have been made to the precipitation temperature points at the various hydroxyl numbers. Work is in progress on the smoothing and resolution of the spectra in order to determine the effect of the experimental variables on the fundamental spectral band parameters.

\subsection{Spectrophotometric Studies of Pu(IV) in Aqueous Nitrate Media}

The first phase of the analysis of the data from studies of the polymerization, precipitation, and depolymerization behavior of plutonium(IV) in nitrate systems over the temperature range 25 to $95^{\circ} \mathrm{C}$ has been completed. Calculations were made of the rates of the polymerization and depolymer1zation reactions. Enough data were analyzed to permit the formation of three-dimensional surfaces interrelating the rates and extent of depolymer.zation and the nitric acid concentration up to $15 \mathrm{M} \mathrm{HNO}_{3}$. The effects of several complexing agents on the depolymerization rate were determined.

\subsection{Computer Programs for Spectrophotometric Studies}

The generalized computer program developed to obtain reaction rate data by the analysis of spectrophotometric absorption data from dynamic multicomponent systems is operating on the IBM 7090. Curve-fitting interpolation methods have been studied for obtaining absorbance-tıme functions, which will permit the accurate calculation of time-independent spectra from the time-dependent experimental results. The computed reaction rate curves for all components of the reacting system are automatically plotted on the Calcomp plotter, as are the experimental and computed absorbancetime functions. The instantaneous reaction rates, obtained from the slopes of the concentration-time curves, are numerically evaluated as a function of time in order to facilitate the study of the kinetics of multicomponent systems. 
Work has been carried out to increase the usefulness of the set of computer programs and subroutines for the least-squares convolute smoothing of the noise and random fluctuations from digitized spectral data.

\section{MECHANISMS OF SEPARATIONS PROCESSES}

This program is designed to provide a quantitative description of the mechanisms of separations processes which can be used to optimize plant operations when applicable. Activities of water, nitric acid, and tributyl phosphate (TBP) over two- and three-component systems containing water, nitric acid, uranyl nitrate, and TBP are being measured in order to express solvent extraction data for these systems in terms of mathematical equations. The transpiration method for the dynamic measurement of vapor pressure was used to obtain the partial pressures of water and nitric acid over the three-component system $\mathrm{H}_{2} \mathrm{O}-\mathrm{UO}_{2}\left(\mathrm{NO}_{3}\right)_{2} \cdot 6 \mathrm{H}_{2} \mathrm{O}-\mathrm{HNO}_{3}$. These results were combined with literature data on the activities of water and nitric acid over the two-component systems $-\mathrm{H}_{2} \mathrm{O}-\mathrm{UO}_{2}\left(\mathrm{NO}_{3}\right)_{2} \cdot 6 \mathrm{H}_{2} \mathrm{O}$ and $\mathrm{H}_{2} \mathrm{O}-\mathrm{HNO}_{3}-$ to obtain appropriate relations for calculation of the activities of $\mathrm{UO}_{2}\left(\mathrm{NO}_{3}\right)_{2} \cdot 6 \mathrm{H}_{2} \mathrm{O}$ after an integration of the Gibbs-Duhem equation.

The activities of water and TBP were measured over the three-component, two-phase system $\mathrm{H}_{2} \mathrm{O}-\mathrm{UO}_{2}\left(\mathrm{NO}_{3}\right)_{2} \cdot 6 \mathrm{H}_{2} \mathrm{O}$-TBP - and the data were fitted to an empirical equation. Partition data for this system were fitted to an equation with the same independent variable. The solution of these two simultaneous linear equations expresses the activity coefficient of TBP as a function of the concentration of uranium in the organic phase.

\section{ION EXCHANGE: RADIATION DAMAGE TO ION EXCHANGE RESINS}

The objectives of this program are to develop new ion exchange processes, to determine how such processes are limited by radiation and thermal degradation of the exchangers, and to develop methods of engineering analysis for application in AEC problems.

Analysis of data from experiments in which water flowed through the Dowex 50W resin and in which the resin was exposed to about $0.75 \times 10^{9} \mathrm{r}(2 \mathrm{whr}$ per gram of dry resin) indicated that the rate of loss of strong-acid capacity was about 20 to $25 \%$ per watt-hour per gram of dry resin - about double the rate reported in the literature for air-dried resin exposed in a static system. The radiation induced more than $4 \%$ de-cross-linking of the resin matrix in the presence of water, rather than further cross-linking, as has been reported for air-dried resin.

\section{CHEMICAL ENGINEERING RESEARCH}

\subsection{The Stacked-Clone Contactor}

This high-performance liquid-liquid extraction device has been developed through the stage of identifying an optimum configuration of the functioning components. Studies on the basic design included variations in hydroclone shape and length, and in the dimensions of the underflow chambers, vortex finders, and feed ports. Each configuration was tested for flow capacity and stage efficiency with the system uranyl nitratesodium nitrate-18\% TBP in Amsco at a flow ratio $(\mathrm{A} / \mathrm{O})$ of about 3 . Operability at higher flow ratios (A/O $\leqq 40)$ was also evaluated, as was the effect of temperature on flow capacity and efficiency.

Due to the high rate at which data are generated, a computer program is being employed to calculate stage efficiencies. The calculational method has been revised to include an improved means of representing equilibrium data.

The current stacked-clone device performs equally well in either extraction or stripping modes at maximum stage efficiencies of $80 \%$ and capacities up to 4.0 liters $/ \mathrm{min}$. Flow ratios at least as high as 20 are feasible. This design represents a useful and practical prototype high-speed contactor for radiochemical processing.

\subsection{Mechanism of Coalescence in Solvent Extraction Systems}

It has been ascertained that alpha particles and fission fragments affect the rate of coalescence in immiscible liquid-liquid systems. Statistical studies of the lifetime of single drops of dispersed phase resting on a plane interface show that the fraction undergoing immediate coalescence on contact is highly increased by fission fragments and, in some cases, alpha particles. The mechanism for this phenomenon has not been established, but the 
possibility that it is caused by bubble nucleation in the film that separates the droplet from its bulk phase has been eliminated by studies with solvents with different vapor pressures and under different total pressures.

\subsection{In-Line Detection of Particles in Gas Streams by Scattered Light}

The development of a device which uses scattered light from the particles of an aerosol in a radioactive gas stream to provide an analysis of both concentration and size distribution has progressed to the point of cold testing a cell with optical windows and electronic gear. It was found that the light source and some optical components must be upgraded to better define the small optically sensitive volume which is to be exclusively illuminated and observed. The pulses from the scattered light are to be detected by a photomultiplier tube and sorted by a pulse-height analyzer such as is used in radiochemical analysis.

\subsection{Studies on Magnetically Induced Electrolytic Dissolution of Stainless Steel Fuel Elements}

A feasibility study of an electrolytic dissolver for stainless steel using an electromagnetically induced emf was made. The dissolver and the process are very uneconomical due to inherent inefficiencies in electromagnetic coupling between the primary coil and the dissolving stainless steel pieces constituting the secondary. The required circuit parameters and performance of a feasible design were evaluated by experiments with a scaled analog of the device.

\subsection{Solvent Extraction Engineering Studies}

The loss of pulse in the jackleg of a pulsed column was calculated on an analog computer for a range of pulse frequency, column height, and jackleg length and diameter. Good agreement with experimental data was obtained. The pulse loss was not significant at a column-to-jackleg-diameter ratio of 8 or greater.

The flooding points due to insufficient pulsation of a pulsed column were calculated as a function of pulse velocity and flow ratio for the four most common methods of introducing and withdrawing fluids from pulsed columns. This is part of the general correlation of flow capacity as a function of fluid properties and column parameters.

A laboratory-size mixer-settler having positive interface control and magnetically coupled mixers was successfully demonstrated with a Purex-type system.

\subsection{Transients in Gas-Absorption Towers}

Experimental data on the transient response of an air-water system in a packed tower subjected to a pulsed input of $\mathrm{SO}_{2}$ are being used to develop mathematical models of the system. The $\mathrm{SO}_{2}$ can be absorbed from the air phase at absorption factors around unity. Data at these conditions do not fit the simple slug-flow model which described earlier experimental results with the $\mathrm{CO}_{2}$-air-water system.

\section{DECONTAMINATION OF EQUIPMENT}

The decontamination program has as its goal the development of improved methods for the removal of fission products and uranium compounds from contaminated metal surfaces in nuclear reactors. Equipment that can be adequately decontaminated without significant corrosion damage may be maintained directly instead of remotely and also can be restored to service without extensive and costly replacement of corroded parts.

The laboratory program has been concerned chiefly with continuing the development and testing of decontamination reagents for gas-cooled reactors such as the EGCR, at Oak Ridge, and the AVR, in Germany. A new room-temperature decontamination method has been developed for carbon steel. The method is based on a 5-min dip in $0.02 M$ oxalic acid followed by a 5 -min dip in the same solution containing $0.05 M$ hydrogen peroxide. Carrier-free ${ }^{131} \mathrm{I}$ and ${ }^{137} \mathrm{Cs}$ were volatilized, deposited on metals at various temperatures, and then decontaminated from metal surfaces in the laboratory. By this method, also, stainless steel from an in-pile helium loop was fairly easily decontaminated from fission products.

In several tests of the deposition of fission products, conducted in the Oak Ridge Research Reactor, the level of the activity deposited from graphite-clad fuel balls was too low to permit meaningful measurements. Noncorrosive fluoridecontaining reagents were further developed for 
decontaminating stainless steel exposed to contaminated helium at about $1200^{\circ} \mathrm{F}$.

Other contributions to decontamination research include a fluoride-containing reagent developed for the simultaneous decontamination of Zircaloy-2, carbon steel, and stainless steel and oxalateperoxide reagents formulated for the decontamination of nickel vessels in the Fluoride Volatility Pilot Plant.

\section{REACTOR EVALUATION STUDIES}

This program is a joint effort by the Reactor, the Metals and Ceramics, and the Chemical Technology Divisions in which optimization studies are prepared for various reactor types and their associated fuel cycles respectively. In the past year, four activities were in progress in the Chemical Technology Division; they included (1) completion of the fuel-shipping-cask drop tests and correlation of the data obtained, (2) preparation of computer costing codes (MYRA and NORA) for fuel shipping optimization, (3) preparation of a criticality report for use in fuel-processing plant design, and (4) an economic study comparing the PWR reactor and fuel cycle costs with those of six advanced converter reactors.

\subsection{Studies of the Cost of Shipping Spent Fuel}

Computer codes were developed for calculating shipping and fuel-processing costs for irradiated reactor fuels, including inventory or use charges, for given input values of burnup, specific power, size of reactor discharge batch, and other variables and parameters. Also calculated is the maximum temperature of the fuel element during shipping (for pin-type fuel elements only). The codes will select the cooling, shipping, and reprocessing schedule that gives the minimum total of these costs. The code for calculating the shipping cost is called MYRA, and the combined shippingprocessing code is called NORA.

\subsection{Cost Studies for Processing Converter-Reactor Fuel}

Fuel shipping and processing costs were estimated for uranium-fueled PWR, SGR, and $\mathrm{D}_{2} \mathrm{O}$ moderated reactors and thorium-fueled HTGR,
$\mathrm{D}_{2} \mathrm{O}$-moderated, seed-blanket, and spectral-shift reactors in a 1975-80 nuclear power economy $[20,000 \mathrm{Mw}$ (electrical)] under ground rules established for comparative evaluation of advancedconverter reactors. These costs were then combined with fabrication costs estimated by the Metals and Ceramics Division and nuclear parameters specified by the Reactor Division to give total fuel cycle costs. Costs were calculated for fixed-charge rates of $15,22.5$, and $30 \%$, including depreciation, cost-of-money, taxes and insurance, to cover the possible range for privately owned facilities. The processing costs (capital plus operating, but not including losses or inventory charges) varied widely when expressed in dollars per metric ton, but stayed mostly within the range of 0.15 to $0.3 \mathrm{mill} / \mathrm{kwhr}$ (electrical).

\subsection{Manual for Shipping Spent Reactor Fuel}

A report that discusses the design of casks for the shipping of radioactive material is being prepared. It is based on studies and investigations concerning criticality, heat transfer, structural integrity, shielding, and peripheral areas of regulations and accidents,

\subsection{Drop Tests on Containers for Shipping Solutions of Reactor Fuels}

Drop tests have been performed on modified 55 -gal drums used to simulate holders for the "bird cages" in which irradiated fissile material is shipped. The drums were dropped on their sides. Results indicate that drums that hold the fissile material (contained in an 8-in.-diam pipe, or "bird") by means of two rows of angle-iron spokes welded to a barring ring (that fits snugly inside the drum) will withstand a 30 -ft fall.

\subsection{Criticality Control in Fuel-Cycle Plants}

A study to provide design information on methods of criticality control in advanced fuel cycle plants was completed. The criticality parameters for combinations of ${ }^{235} \mathrm{U},{ }^{233} \mathrm{U}$, and ${ }^{23}{ }^{9} \mathrm{Pu}-{ }^{24}{ }^{\circ} \mathrm{Pu}$ with ${ }^{238} \mathrm{U}$ and ${ }^{232} \mathrm{Th}$ applicable to geometry, mass, concentration, and fixed and soluble poison control were extended to the systems of interest by multigroup neutron diffusion and transport calculations. 


\section{CHEMICAL APPLICATIONS OF NUCLEAR EXPLOSIONS}

\subsection{Project Coach}

Work in this program is centered about Project Coach, a planned underground nuclear detonation of a 5- to 10-kiloton nuclear device in a beddedsalt formation near Carlsbad, New Mexico. The purpose of this project is to produce milligram or larger quantities of transcurium elements. The elements will be recovered by mining thousands of tons of debris and chemically reclaiming the radioisotopes.

Samples from the Gnome detonation were investigated in the laboratory to develop recovery methods for the project. The method investigated included water-leaching the debris to remove salt, thus leaving a water-insoluble residue that contained $99 \%$ of the actinides; then, acid-leaching the water-insoluble residue to put the actinides into solution; and finally, concentrating the actinides by precipitating them along with calcium oxalate, the carrier. The process shows promise of giving a concentration factor of about 1000 , with an actinide-element recovery of 70 to $90 \%$.

Petrographic analyses were performed on the water-insoluble residue, which was found to consist of opaque, magnetic materials: quartz, anhydrite, and several unidentified substances. A large sample of salt from the proposed Coach site was analyzed with respect to particle size, water-insoluble residue, and acid-soluble constituents. Sedimentation and filtration data pertinent to the engineering design of liquid-solid separations for the water- and acid-leach operations were obtained.

\subsection{Prompt-Sampler Studies for Recovering Samples and Irradiated Specimens from Nuclear Explosions}

A jet sampler and a bubble-tapping sampler are under study, each having its special purpose in helping to derive benefits from underground nuclear explosions. A hypervelocity jet arrangement is being tested at the Pitman-Dunn Institute for Research (PDIFR) at Frankford Arsenal, Philadelphia, for recovering specimens after they have been irradiated with neutrons about $1 \mathrm{~m}$ from an underground-exploded nuclear device. The jet sampler is designed to recover an irradiated specimen before it can be engulfed in the nuclear and environmental debris from the explosion. In tests with high explosives, to simulate nuclear explosion pressures that are expected to operate the jet sampler, sufficient velocity of the specimens was obtained but not sufficient range and recovery.

The bubble-tapping sampler is expected to sample the gaseous and particulate explosion products from an underground nuclear explosion cavity. Technical feasibility and cost studies for a bubble-tapping sampler experiment for possible inclusion in a nuclear test are also in progress at PDIFR. This sampler is expected to permit the sampling of gases and particles from the explosion for hours afterward, thus providing more knowledge about underground detonations.

\section{ASSISTANCE PROGRAMS}

During the past year, several engineering efforts for others have been carried out by the Chemical Technology Division. These include a continuation of the Eurochemic Assistance Program; liaison on the construction and startup of the High Radiation Level Analytical Laboratory for the Analytical Chemistry Division; preparation of a preliminary design and cost estimate for a proposed Alpha Laboratory Facility (also for the Analytical Chemistry Division); consultation to the Operations Division on the construction and startup of the two plant-waste-improvement projects; design and fabrication of equipment for the Health Physics experiments on waste disposal in salt and waste disposal by hydrofracturing; design of a ${ }^{233} \mathrm{U}$ storage facility for installation in Building 3019; design and installation of a shielded alpha-gamma facility in laboratory 1, Building 3508; and preparation of a proposal for processing Elk River reactor fuel to further development of the $T h-{ }^{23} \mathrm{U}$ fuel cycle.

\subsection{Eurochemic Assistance Program}

The Laboratory continued to coordinate the exchange of technical information between Eurochemic and the AEC production sites and National Laboratories for the AEC Division of International Affairs. E. M. Shank completed his second year at Mol, Belgium, as U.S. Technical Advisor to 
Eurochemic during the construction and startup of the Eurochemic fuel-processing plant. Construction of the plant and its auxiliary facilities is now about $60 \%$ complete.

\subsection{Construction and Startup of the High Radiation Level Analytical Facility}

The Chemical Technology Division continued to supply the necessary technical liaison between the Laboratory, the AEC, the designers (Vitro Corporation), and the construction contractor (Foster and Creighton Company) during construction of the High Radiation Level Analytical Laboratory. Construction was completed in the middle of April 1964, and the facility was turned over at that time to the Laboratory for $f_{i n a l}$ tie-in work by ORNL crafts and H. K. Ferguson Company, and shakedown operations by the Analytical Chemistry Division. The facility will be placed in "hot" service later this year.

\subsection{Alpha Laboratory Facilities}

The three-laboratory Interim Alpha Facility in the basement of Bulding 3019 was completed and placed in service. Glove boxes and equipment were installed by the Metals and Ceramics Division for the fabrication of ${ }^{242} \mathrm{Pu}$ target rods for 1 rradiation in the Savannah River reactors and later in the High Flux Isotope Reactor. Other work scheduled for this area in the near future includes development of the sol-gel processes for $\mathrm{PuO}_{2}$, testing of the Tramex process in laboratory pulsed columns, and chemical studies on americium and curium oxides.

A preliminary design and cost study was made for a new Alpha Laboratory Facility for joint use by the Analytical Chemistry, Chemical Technology, Reactor Chemistry, and Metals and Ceramics Divisions. The laboratory would contain twentyeight 16- by 32-ft alpha laboratories, four supporting "cold" laboratories, a 32- by 64-ft-deep bay area for large alpha experiments, and supporting office and service facilities. The facility, which would be administered by the Analytical Chemistry Division, is estimated to cost about $\$ 5,000,000$.

\subsection{Projects for Improving the Plant Waste System}

The Chemical Technology Division continued to supply consultation to the General Engineering and Construction and the Operations Divisions during construction and startup of the two plantwaste-system improvement projects. The first of these, the Melton Valley waste collection and transfer system, was completed in February 1964 and is ready to be put into service. The second, the intermediate- and high-level-waste evaporator and high-level-waste storage tanks, was nearly completed at the end of the year. The structure to house the two 50,000-gal stanless steel acidwaste tanks and the evaporator and its auxiliaries was completed in February 1964, and installation of equipment and piping was $50 \%$ completed. The facility is scheduled to be completed by December 1964 and to go into "hot" operation early in 1965, after the shakedown operations.

\subsection{Demonstration of the Disposal of Solid, High-Level Radioactive Waste in Salt Mines}

Assistance was provided by the Division on the waste disposal in salt experiment being conducted by the Health Physics Division. The respons1bilities included development, design, and handling of the radioactive materials (Engineering Test Reactor assemblies) to be used in the first series of experments.

\subsection{Disposal of Radioactive Waste by Hydrofracture}

The engineering on the Health Physics Division experiments on the disposal of intermediate-level radioactive aqueous wastes by hydrofracturing is being coordinated by the Process Design Section of this Division. In this program, the aqueous wastes are mixed with cement and clay, and then they are pumped at high pressure into an approximately 1000 -ft-deep hole in the ORNL test area in lower Melton Valley. When sufficient pressure is exerted, the rock strata are fractured at the bottom of the hole, and the waste is distributed in a thin slab around the hole, where it sets up as a concrete sheet 
The responsibilities of the Division in this project included the design, fabrication, and installation of the cement, clay, and waste-storage areas, and the mixing cell and its equipment. The Halliburton Company was responsible for the highpressure pumping equipment and the well operations. During the last year, the facility design and installation was completed, and four hydrofracturing injection experiments were made, first with inactive synthetic waste and then with lowand intermediate-level plant waste.

\subsection{Storage Facility for ${ }^{23} \mathrm{U}$, Building 3019}

A facility is being designed for the handling and critically safe storage of several hundred kilograms of ${ }^{233} \mathrm{U}$ in the pipe tunnel of Building 3019 . The handling and sampling will be done in the former solvent room in the makeup area of Building 3019. This facility will establish the Laboratory as a national depository for ${ }^{233} \mathrm{U}$ produced at Savannah River and elsewhere, and possibly for ${ }^{235} \mathrm{U}-{ }^{233} \mathrm{U}$ to be produced in power reactors [Consolidated Edison (core A) and Elk River]. Storage will be in conventional tanks packed with standard Pyrex Raschig rings, which contain 5\% boron to provide the neutron poison for criticality control.

Interim storage was also provided for about $60 \mathrm{~kg}$ of ${ }^{233} \mathrm{U}$ obtained from Savannah River as dry ${ }^{23}{ }^{3} \mathrm{U}_{3} \mathrm{O}_{8}$. The cans of $\mathrm{U}_{3} \mathrm{O}_{8}$ were stored in eight vertical 5 -in.-diam holes in the 5 -ft-thick concrete wall between cells 3 and 4 of Building 3019.

\subsection{Shielded Alpha-Gamma Facility}

A large $\left(100 \mathrm{ft}^{3}\right)$ glove box facility surrounded by $2 \mathrm{ft}$ of concrete shielding and equipped with master-slave manipulators and a zinc bromide window was designed and is being installed in laboratory 1, Building 3508, for research and development on alpha-gamma-emitting materials on a larger scale than can be handled in lightly shielded glove boxes. This facility is scheduled to be complete and ready for use in July 1964 .

\subsection{Shielding of I sotopic Power Sources for Space Missions}

Electronic payloads on missions lasting as long as five years will need to be protected from the radiations emitted by isotopic SNAP units. Calculations made for the isotopes and power source sizes of current interest indicate that separation distance, rather than shielding, offers the best solution.

\subsection{Proposal for the Elk River Reactor Fuel Cycle}

A proposal was made to the AEC for processing and reconstituting the fuel from the Elk River reactor in order to further the development of the

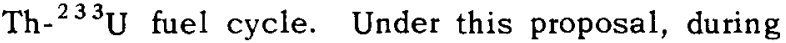
the period 1965-1967, fuel from the reactor would be received, stored, and mechanically and chemically processed in the fuel disassembly facility in cell $\mathrm{A}$, Building 3026 . The ${ }^{235} \mathrm{U}^{23}{ }^{23} \mathrm{U}$ would be decontaminated and recovered in the Thorex pilot plant in Building 3019 by the Acid Thorex Process, and new $\mathrm{ThO}_{2}-\mathrm{UO}_{2}$ fuel rods would be made by the sol-gel-vibratory-compaction process and then assembled into fuel assemblies in the Kilorod Facility for return to Elk River. In late 1967 and thereafter, the same effort would be continued in the Thorium-Uranium Fuel Cycle Development Facility; in these later operations, low-decontamination close-coupled processing would be demonstrated with used thorium and ${ }^{233} \mathrm{U}$ of high ${ }^{232} \mathrm{U}$ content.

\section{CHEMICAL PROCESSING FOR THE MOLTEN-SALT REACTOR EXPERIMENT}

The Molten-Salt Reactor Experiment is a $10-\mathrm{Mw}$ single-region reactor using an $\mathrm{LiF}-\mathrm{BeF}_{2}-\mathrm{ZrF}_{4}-\mathrm{UF}_{4}$ (65-29-5-1 mole \%) fuel salt at $1200^{\circ} \mathrm{F}$. The reactor is nearing completion in Building 7503 in Melton Valley. A chemical plant has been designed for installation in the same building in a cell adjacent to the drain cell. The chemical plant has two purposes: (1) to remove oxides (in fuel salt as $\mathrm{ZrO}_{2}$ ), which might eventually cause uranium precipitation; and (2) to recover uranium from spent fuel or contaminated flush salt. Equipment for this plant is being built. Construction will be started in July 1964, with completion scheduled for January 1965. 


\section{WATER RESEARCH PROGRAM}

Oak Ridge National Laboratory is carrying out a program of basic research on the properties of water and its solutions under the auspices of the Office of Saline Water, Department of the Interior. This program has as its long-range goal the development of methods for the economical purification of water in such amounts and of such purity that it may be used for drinking and for irrigation. Work in the program is under the direction of K. A. Kraus and is interdivisional. The work discussed in this abstract is reported in part in the Saline Water Conversion Report, 1963, U.S. Department of the Interior. All work done by the Chemical Technology Division is reported directly to the Office of Saline Water, and this abstract summarizes the work reported so far. No further information on this subject appears in this report.

Studies carried out in the Chemical Technology Division have been along several lines. One has been a basic study of the properties of membranes which have potential use as salt-rejection membranes. Electrokinetic measurements of membrane properties are carried out, and equilibrium measurements are made of the preferential uptake or exclusion of salt from membranes (e.g., $\mathrm{ZrO}_{2}$ ) which have been prepared and chemically treated in such a way as to produce charged pores. The relationship of surface composition and solution composition to the adhesion of inorganic crystalline salts precipitated from solution onto metals and metal oxide surfaces is being investigated in another study. The importance of scale formation in distillation methods used for water desalination provides incentive for this study. A third area of study has been the determination of distributive selectivity and activity coefficients of salt in amide-water-salt systems. From such studies it is hoped that insight into the mechanism of salt exclusion by organic membranes may be gained. In addition, engineering evaluations of the feasibility of possible desalination processes are carried out as required. 
-

-

, 


\section{Contents}

SUMMARY

1. POWER REACTOR FUEL PROCESSING 1

1.1 Process Development for Uranium Carbide Fuels 1

$\begin{array}{ll}1.2 & \text { Studies on the Dissolution of } \mathrm{PuO}_{2}-\mathrm{UO}_{2}\end{array}$

1.3 Dissolution of Sol-Gel-Derived $\mathrm{ThO}_{2}-\mathrm{UO}_{2} \quad 9$

$\begin{array}{lll}1.4 & \text { Studies on the Zirflex Process } & 10\end{array}$

$\begin{array}{lll}1.5 & \text { Studies on the Adsorption of Protactinium } & 13\end{array}$

1.6 Recovery of Advanced Reactor Fuels by Solvent Extraction 17

$\begin{array}{lll}1.7 & \text { Studies on Chloride Volatility } & 17\end{array}$

$\begin{array}{lll}1.8 & \text { Corrosion Studies } & 20\end{array}$

1.9 Mechanical Processing Development 21

2. FLUORIDE VOLATILITY PROCESSING 29

2.1 Processing of Uranium-Zirconıum Alloy Fuel 29

2.2 Processing of Uranium-Alumınum Alloy Fuel 40

2.3 Sorbent Studies $\quad 49$

2.4 Removal of Tellurium Hexafluoride from Pilot Plant Effluent Gas $\quad 52$

2.5 Application to Stannless Steel $\quad 54$

2.6 Application to Oxide Fuels $\quad 57$

2.7 Volatilization and Recovery of Plutonium Hexafluorıde $\quad 58$

2.8 Fluorination with Gas Phase Continuous $\quad 61$

2.9 Measurement of Uranium Hexafluoride Concentrations in Streams of Other Gases 65

$\begin{array}{ll}2.10 \text { General Corrosion Studies } & 67\end{array}$

3. WASTE TREATMENT AND DISPOSAL

3.1 Solidification of High-Level Radioactive Waste $\quad 74$

3.2 Treatment of Low-Level Radioactive Waste $\quad 92$

3.3 Disposal of Intermediate-Level Radioactive Waste 109

3.4 Engineering, Economics, and Safety Evaluations 110

4. TRANSURANIUM ELEMENT PROCESSING 115

4.1 Development of Chemical Processes 115

$\begin{array}{ll}4.2 & \text { Development of Process Equipment } \\ \end{array}$ 
4.3 Design and Fabrication of Process Equipment 129

4.4 Construction of the Transuranium Processing Plant 135

5. CURIUM PROCESSING 136

5.1 Development of the Process 136

5.2 Development of Alternative Processes: Separatıon of Lanthanıdes and Actınides 141

5.3 The Curium Recovery Facility 144

6. DEVELOPMENT OF THE THORIUM FUEL CYCLE

6.1 The Kilorod Facility 153

6.2 Development of the Sol-Gel Process 163

6.3 Application of the Sol-Gel Process to the Preparation of $\mathrm{ThC}_{2}-\mathrm{UC}_{2} \quad 163$

$\begin{array}{lll}6.4 & \text { Production of Microspheres } & 169\end{array}$

7. SEPARATIONS CHEMISTRY RESEARCH 177

$\begin{array}{ll}7.1 & \text { Studies in Descriptive Chemistry } \\ 7.2 & 177\end{array}$

7.2 Development of Separations Processes 188

7.3 Fundamental Studies on the Equilibria and Kinetics of Solvent Extraction 195

8. RECOVERY OF FISSION PRODUCTS BY SOLVENT EXTRACTION 209

$\begin{array}{ll}8.1 \text { Cesium } & 209\end{array}$

8.2 Strontium and Rare Earths 211

8.3 Recovery of Strontium with Carboxylic Acids 213

$\begin{array}{lll}8.4 & \text { Technetium } & 214\end{array}$

$\begin{array}{lll}8.5 & \text { Engineering Studies } & 214\end{array}$

9. CHEMISTRY OF PROTACTINIUM 216

9.1 Protactinium Recovery 216

9.2 Process Development 216

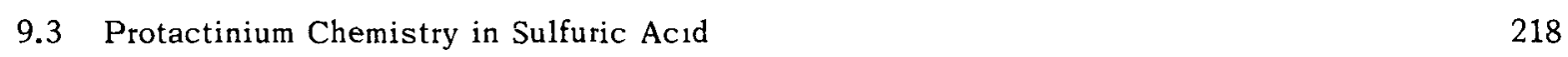

9.4 Specific Activity of ${ }^{232} \mathrm{U} \quad 219$

10. RADIATION EFFECTS ON CATALYSTS 220

10.1 Decomposition of Formic Ac1d on Metal and Oxide Catalysts 220

11. HIGH-TEMPERATURE CHEMISTRY 224

11.1 High-Temperature, High-Pressure Spectrophotometer System 224

11.2 Spectral Studies of Ionic Systems at Elevated Temperatures $\quad 225$

11.3 Spectrophotometric Studies of $\mathrm{Pu}(\mathrm{IV})$ in Aqueous Nitrate Media 226

11.4 Computer Programs for Spectrophotometric Studies 229

12. MECHANISMS OF SEPARATIONS PROCESSES

12.1 Activities of Water, Nitric Acid, and Uranyl Nitrate in the Three-Component System 231

12.2 Vapor-Pressure and Partition Data for the Two-Phase System $\mathrm{H}_{2} \mathrm{O}-\mathrm{UO}_{2}\left(\mathrm{NO}_{3}\right)_{2}$-TBP 232

13. ION EXCHANGE: RADIATION DAMAGE TO ION EXCHANGE RESINS 233 
14.2 Mechanism of Coalescence in Solvent Extraction Systems 239

14.3 In-Line Detection of Particles in Gas Streams by Scattered Light 242

14.4 Studies on Magnetically Induced Electrolytic Dissolution of Stainless Steel Fuel Elements

14.5 Solvent Extraction Engineering Studies $\quad 244$

14.6 Transients in Gas-Absorption Towers 246

15. DECONTAMINATION OF EQUIPMENT

$\begin{array}{lll}15.1 & \text { Progress and Status } & 247\end{array}$

$\begin{array}{ll}15.2 & \text { Experimental Work }\end{array}$

16. REACTOR EVALUATION STUDIES 249

16.1 Studies of the Cost of Shipping Spent Fuel 249

16.2 Cost Studies for Processing Converter-Reactor Fuel 252

16.3 Manual for Shipping Spent Reactor Fuel 254

16.4 Drop Tests on Containers for Shıpping Solutions of Reactor Fuels 254

16.5 Criticality Control in Fuel-Cycle Plants 255

17. CHEMICAL APPLICATIONS OF NUCLEAR EXPLOSIONS 256

$\begin{array}{lll}17.1 & \text { Project Coach } & 256\end{array}$

17.2 Prompt-Sampler Studies for Recoverıng Samples and Irradıated Specımens from
Nuclear Explosıons

18. ASSISTANCE PROGRAMS 259

18.1 Eurochemic Assistance Program 259

18.2 Construction and Startup of the High Radiation Level Analytical Fac1lity 260

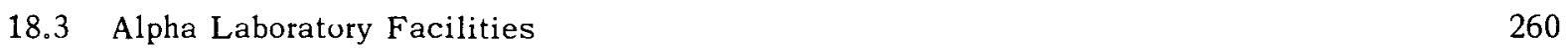

18.4 Projects for Improving the Plant-Waste System 261

18.5 Demonstration of the Disposal of Solid, High-Level Radioactive Waste in Salt Mines 262

18.6 Disposal of Radioactive Waste by Hydrofracture 262

18.7 Storage Facility for ${ }^{23} \mathrm{U}$, Bullding 3019

$\begin{array}{lll}\text { 18.8 Shrelded Alpha-Gamma Fac1lity } & 265\end{array}$

18.9 Shielding of Isotopic Power Sources for Space Missions 265

18.10 Proposal for the Elk River Reactor Fuel Cycle 266

19. CHEMICAL PROCESSING FOR THE MOLTEN-SALT REACTOR EXPERIMENT 267

20. WATER RESEARCH PROGRAM 268

PUBLICATIONS, SPEECHES, AND SEMINARS 269

$\begin{array}{ll}\text { ORGANIZATION CHART } & 281\end{array}$ 


\section{Power Reactor Fuel Processing}

Laboratory and engineering-scale development of processes for recovering fissionable and fertile material from irradiated power reactor fuels is continuing. Considerable emphasis was placed on basic chemical studies, however, major efforts are on chemical applications, engineering development, and small-scale hot-cell testing of the more promising fuel-recovery processes.

Work on carbide and graphite-type fuels included basic studies on the chemical properties of uranium monocarbide and sesquicarbide, development of three potential aqueous processes for uranıum and uranium-plutonium carbide fuels, and development of both combustion-volatility and -dissolution processes, using both fixed beds and fluidized beds, for Rover fuel. The work on the Rover fuel-recovery processes is presented in ORNL-3627, suppl. 1 (classified).

The dissolution-rate studies on $\mathrm{UO}_{2}-\mathrm{PuO}_{2}$ and $\mathrm{PuO}_{2}$ were extended to determine the total dissolution time. Similar studies were started on the dissolution of $\mathrm{ThO}_{2}-\mathrm{UO}_{2}$ prepared by the sol-gel process. Dissolution was slower than for pellet. ized fuel, but irradiated specimens of both types of $\mathrm{ThO}_{2}-\mathrm{UO}_{2}$ dissolved much more rapidly than unirradiated samples.

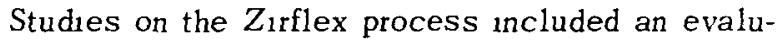
ation of uranium peroxide precipitation for reclaiming uranium from declad solutions and a survey of methods of producing neutral and alkaline $Z_{1}$ rflex wastes stabilized to keep zirconium in solution.

The work on the adsorption of protactinium on inorgan1c 1on exchange materials was extended to include the evaluation of zirconium phosphate, silica gel, and molecular sieves. Solvent extraction studies were made in order to determine the effect of fluoride, niobium, and aluminum on the extraction of uranium by tributyl phosphate (TBP) and dibutyl butyl phosphonate (DBBP).

Chloride volatility studies included an evaluation of the absorption of $\mathrm{ZrCl}_{4}$ and $\mathrm{UCl}_{5}$ in boiling water and subsequent elimination of chloride with $\mathrm{H}_{2} \mathrm{O}_{2}$, chlorination of uranium from the ash resulting from the combustion of graphite and car. bide fuels, reduction of $\mathrm{UCl}_{5}$ to $\mathrm{UCl}_{3}$ with carbon monoxide, and the volatilization of $\mathrm{PuCl}_{4}$ in a stream of chlorine gas.

Under the mechanical processing program, the evaluation of the 250-ton fuel shear was completed. In addition, fuel disassembly methods for second-generation fuels were studied, the safety of shearing $Z_{1 r c a l o y-2-c l a d}$ fuels was demonstrated, and batch leaching tests on stainlesssteel- and Zircaloy-2-clad $\mathrm{UO}_{2}$ and $\mathrm{ThO}_{2}-\mathrm{UO}_{2}$ were made.

\subsection{PROCESS DEVELOPMENT FOR URANIUM CARBIDE FUELS}

In order to provide a suitable fuel material for high-temperature gas-cooled reactors and for hightemperature fast reactors, uranium (and thorium) carbides are being studied and evaluated as fuel. Two reactors will be charged with such fuel in the near future. The first, the Consumer's Pub11c Power (Hallam, Nebraska) reactor will use uranium monocarbide fuel in stainless steel tubes with sodium bonding in the second core, the second, the High-Temperature Gas-Cooled Reactor (HTGR, Peachbottom, Pennsylvania) will use uranium and thorıum dicarbides in a graphite matrix in the form of 4-1n.-diam fuel rods. The use of $\mathrm{PuC}-\mathrm{UC}$ and $\mathrm{PuC}$ fuels is also being contemplated.

Unfortunately, the low-temperature hydrolysis process developed with unirradiated fuel and reported last year ${ }^{1}$ has been found to be unsuitable

${ }^{1}$ F. L. Culler, Jr., et al., Chem. Technol, Div. Ann. Progr. Rept. May 31, 1963, ORNL-3452, pp. 2-3. 
for irradiated uranium carbide because reactor irradiation passivates the fuel against hydrolysis in water or $\mathrm{NaOH}$ solutions. Therefore, other processes were investigated. The pyrohydrolysis of irradiated fuel with steam was feasible at $750^{\circ} \mathrm{C}$. In this process, $\mathrm{UO}_{2}$, virtually free of carbon, was formed. The $\mathrm{UO}_{2}$ dissolved directly in nitric acid to produce a Purex solvent extraction feed. An alternative process involves dissolution

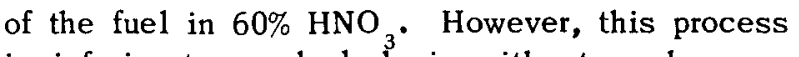
is inferior to pyrohydrolysis with steam because about half the carbide carbon remains in solution in the form of organic compounds that are soluble in nitric acid; these must then be destroyed by strong oxidants prior to solvent extraction.

\section{Aqueous Chemistry of Irradiated Uranium Monocarbide}

In the hydrolysis-dissolution process as initially developed with unirradiated stoichiometric uranium monocarbide, ${ }^{1.2}$ the fuel is hydrolyzed in water at $80^{\circ} \mathrm{C}$ to a slurry of uranium dioxide, with nearly quantitative conversion of the carbide carbon to volatile hydrocarbons. ${ }^{3}$ Dissolution of the uranium oxide in nitric acid then produces a feed solution containing virtually no organic impurities. If desired, the trace impurities can be removed by permanganate treatment of the feed solution before processing by solvent extraction; however, the presence of small amounts of organic impurities does not adversely affect extraction.

Unfortunately, this year's work showed that reactor irradiation of $\mathrm{UC}$ adversely affects its reactions with water and with aqueous solutions of $\mathrm{NaOH}, \mathrm{HCl}$, and $\mathrm{H}_{2} \mathrm{SO}_{4^{*}}{ }^{2-6}$ Nobium-clad helrumbonded specimens ${ }^{7^{2}}$ irradiated to 0.6 and 1.6 at.

\footnotetext{
${ }^{2}$ M. J. Bradley and L. M. Ferris, Processing of Utanium Carbide Reactor Fuels. I. Reaction with Water and HCl, ORNL-3101 (Aug. 1, 1961).

${ }^{3}$ M. J. Bradley and L. M. Ferris, Inorg. Chem. 1, 683 (1962).

${ }^{4}$ M. J. Bradley et al., Inorg. Chem. 3, 454 (1964).

${ }^{5}$ M. J. Bradley et al., The Reactions of NeutronIrradiated Uranium Monocarbide with Water and Aqueous Solutions of $\mathrm{NaOH}, \mathrm{HCl}$, and $\mathrm{H}_{2} \mathrm{SO}_{4}$, presented at the $52 \mathrm{~d}$ National Meeting of the American Institute of Chemical Engineers, Memphis, Tenn., Feb. 4, 1964.

${ }^{6}$ M. J. Bradley et al., Reactions of Reactor-Irradiated Uranium Monocarbide with Water and Aqueous Solutions of $\mathrm{NaOH}, \mathrm{HCl}$, and $\mathrm{H}_{2} \mathrm{SO}_{4}$, in preparation.
}

$\%$ burnup (6000 and 16,000 Mwd per metric ton of uranium respectively) were inert to water at 80 and $100^{\circ} \mathrm{C}$ in $24-\mathrm{hr}$-exposure tests. The outer portion of a sodium-bonded specimen irradiated to 0.6 at. \% burnup did hydrolyze; however, the core of the specimen was also inert to water. Specimens irradiated to the relatively low level of 0.06 at. \% burnup hydrolyzed completely, although more slowly than unirradiated carbide. Reactor irradiation also markedly decreased the rate of reaction with $\mathrm{NaOH}$. In a 51-hr test, practically no gas was evolved when a $2-\mathrm{g}$ piece 1rradiated to 0.6 at. $\%$ burnup was contacted with $6 \mathrm{MNaOH}$, although the specimen did disintegrate to a -50 -mesh powder. Unirradiated carbide ${ }^{6}$ under the same conditions reacted completely in about $10 \mathrm{hr}$. Irradiation had little effect on the rates of reaction with $\mathrm{HCl}$ or $\mathrm{H}_{2} \mathrm{SO}_{4}$. Complete reaction of 2-g pieces with $2 M \mathrm{HCl}$ required 1 to $3 \mathrm{hr}$, but only $20 \mathrm{~min}$ to $1 \mathrm{hr}$ in $6 \mathrm{M} \mathrm{HCl}$. The rate of gas evolution with $6 \mathrm{M} \mathrm{H}_{2} \mathrm{SO}_{4}$ from the sodium-bonded specimen ( 0.6 at. \% burnup) was about the same as that from unirradiated carbide (about $12 \mathrm{hr}$ for complete reaction of $2-$ to $4-g$ pieces); a heliumbonded specimen ( 0.06 at. \% burnup) reacted more slowly, requiring four days for complete reaction.

When hydrolysis did occur, the neutron-irradiated uranium monocarbide produced much more hydrogen and less methane than unirradiated samples (Table 1.1).

Irradiated 20\% PuC-UC specimens exhibited a similar passivity toward hydrolysis. After $26 \mathrm{hr}$ in water at $80^{\circ} \mathrm{C}$, partial hydrolysis of $20 \% \mathrm{PuC}-$ $80 \%$ UC ( $800 \mathrm{Mwd} /$ metric ton) occurred, and $69 \%$ of the cesium was leached by the water. With another specimen irradiated to $20,000 \mathrm{Mwd} / \mathrm{metric}$ ton, no hydrolysis occurred during a 6-hr test; $6 \%$ of the cesium was found in the water after this test.

Irradiated uranium monocarbide dissolved readily in boiling 4 to $13 \mathrm{MNO}_{3}$ at rates that were approximately those obtained with unirradiated carbide specimens. The solutions produced had the typical red-brown color associated with dissolved organic compounds derived from the nitric acid oxidation of carbides or graphite. ${ }^{1}$

${ }^{7}$ M. J. Bradley et al., The Effect of Irradiation on the Hydrolysis of Utanium Carbides. I. Preparation of Uranium Monocarbide Pellets for Itradiation, ORNL3403 (March 1963). 
Table 1.1. Effect of Reactor-Irradiation Level on the Reaction of Uranium Monocarbide with Water and Aqueous Solutions of $\mathrm{NaOH}, \mathrm{HCl}$, and $\mathrm{H}_{2} \mathrm{SO}_{4}$

\begin{tabular}{|c|c|c|c|c|c|c|}
\hline \multirow{2}{*}{ Reagent } & \multirow{2}{*}{$\begin{array}{l}\text { Burnup } \\
\text { (at. \%) }\end{array}$} & \multirow{2}{*}{$\begin{array}{l}\text { Volumes of Gas Evolved } \\
\text { [ml(STP)/g of carbide] }\end{array}$} & \multicolumn{3}{|c|}{ Gaseous Products (vol \%) } & \multirow{2}{*}{$\begin{array}{c}\text { Carbon in Gas } \\
(\% \text { of total) }\end{array}$} \\
\hline & & & $\mathbf{H}_{2}$ & $\mathrm{CH}_{4}$ & $C_{2}-C_{8}$ & \\
\hline \multirow{3}{*}{$\mathrm{H}_{2} \mathrm{O}$} & 0 & 90 & 9 & 88 & 3 & 98 \\
\hline & 0.06 & 96 & 28 & 67 & 5 & 86 \\
\hline & 0.6 & $40^{a, b}$ & 70 & 26 & 4 & 12 \\
\hline \multirow[t]{3}{*}{$6 M \mathrm{NaOH}$} & 0 & 112 & 26 & 71 & 3 & 98 \\
\hline & 0.06 & 99 & 53 & 42 & 4 & 60 \\
\hline & 0.6 & 4 & & & & \\
\hline \multirow{3}{*}{$6 \mathrm{M} \mathrm{H}_{2} \mathrm{SO}_{4}$} & 0 & 91 & 13 & 84 & 2 & 94 \\
\hline & 0.06 & 103 & 48 & 44 & 8 & 78 \\
\hline & 0.6 & $93^{a}$ & 66 & 26 & 8 & 54 \\
\hline \multirow[t]{4}{*}{2 or $6 \mathrm{M} \mathrm{HCl}$} & 0 & 92 & 15 & 83 & 3 & 97 \\
\hline & 0.06 & 97 & 23 & 75 & 2 & 87 \\
\hline & 0.6 & 91 & 31 & 64 & 5 & 81 \\
\hline & 1.6 & 98 & 40 & 56 & 4 & 83 \\
\hline
\end{tabular}

${ }^{a}$ Sodium bonded during irradiation.

${ }^{b}$ Only outer portion $(\sim 40 \%$ ) reacted; helium-bonded specimens with this burnup were inert,

\section{Pyrohydrolysis Process for Uranium and Plutonium Carbide Fuels}

The unexpected irradiation-induced passivity of irradiated uranium and plutonium monocarbides and other metallic carbides to hydrolysis in water at 80 to $100^{\circ} \mathrm{C}$ prompted the laboratory-scale development of pyrohydrolysis. ${ }^{8}$ In this process, uranium monocarbide is reacted with excess steam at $750^{\circ} \mathrm{C}$ in the absence of air to produce carbonfree uranium dioxide. The noncondensable offgas consists principally of hydrogen and carbon oxides. Dissolution of the uranium dioxide in nitric acid produces a fuel solution that may be processed directly by Purex solvent extraction. Shearing of the fuel rods to expose the carbide and low-temperature steaming to destroy the sodium bond would be required in the case of Hallam fuel.

${ }^{8}$ J. R. Flanary et al., Hot-Cell Studies of Aqueous Dissolution of Irradiated Carbide Reactor Fuels, in preparation.
Laboratory experiments with both unirradiated and irradiated uranium monocarbide fuel samples showed that this process is feasible if the pyrohydrolysis is carried out with air-free steam at $750^{\circ} \mathrm{C}$. Further laboratory work is planned to determine whether the process is also applicable to fuels that have a graphite matrix.

Reaction rates of unirradiated uranium monocarbide with air-free superheated steam were determined as a function of temperature and are shown as plots of dry off-gas volume vs time in Fig. 1.1. The reaction went to completion in $1 \mathrm{hr}$ at $750^{\circ} \mathrm{C}$, and in about $3 \mathrm{hr}$ at $700^{\circ} \mathrm{C}$. At $650^{\circ} \mathrm{C}$, the reaction was incomplete after $6 \mathrm{hr}$. The uranium dioxide produced by the pyrohydrolysis was a granular, free-flowing, dark-brown powder with an oxygen-to-uranium ratio of 2.03. The $\mathrm{UO}_{2}$ contained only $0.03 \%$ residual carbon.

About $425 \mathrm{~cm}^{3}$ (STP) of dry off-gas was evolved per gram of uranium monocarbide reacted. ${ }^{3}$ Analysis of the gaseous products from hydrolysis at $750^{\circ} \mathrm{C}$ indicated that the overall reaction of 1 mole of uranium monocarbide with 3.7 moles of 


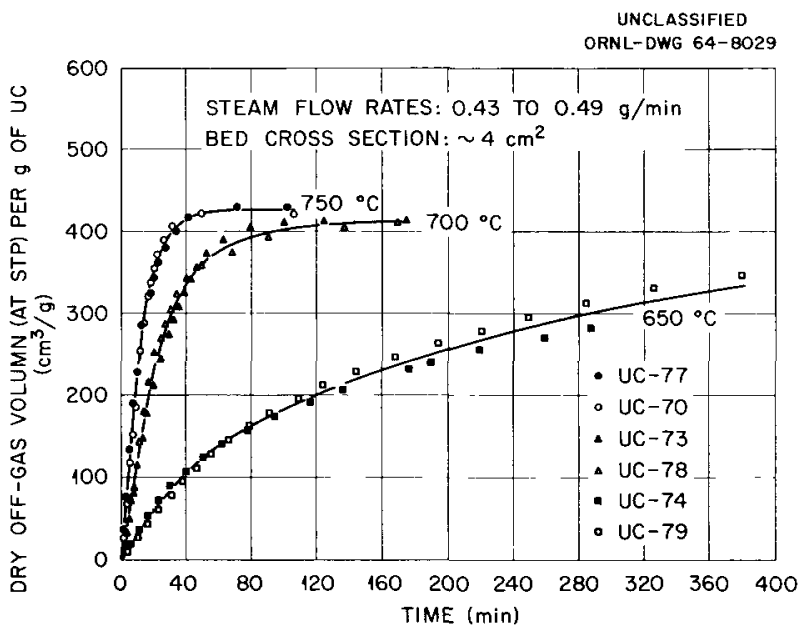

Fig. 1.1. Effect of Temperature on Reaction of Uranium Monocarbide with Steam.

steam yields 1 mole of uranium dioxide, 3.7 moles of hydrogen, 0.68 mole of carbon dioxide, and 0.1 mole of carbon monoxide.

During the first half of the reaction period at $750^{\circ} \mathrm{C}$, the gas was rich in hydrogen (86 vol \%). As the reaction proceeded, the proportion of hydrogen decreased to 73.1 vol \%. Conversely, the carbon dioxide increased from 2.4 to 25.5 vol \%, and the carbon monoxide decreased from 6 to 0 vol \%. These data indicate that the reaction proceeds stepwise. The relatively fast reaction

$$
\mathrm{UC}+2 \mathrm{H}_{2} \mathrm{O} \rightarrow \mathrm{UO}_{2}+\mathrm{C}+2 \mathrm{H}_{2}
$$

occurs first, and then the free carbon is converted to carbon oxides at slower rates according to the reactions

$$
\begin{gathered}
\mathrm{C}+\mathrm{H}_{2} \mathrm{O} \rightarrow \mathrm{CO}+\mathrm{H}_{2}, \\
\mathrm{C}+2 \mathrm{H}_{2} \mathrm{O} \rightarrow \mathrm{CO}_{2}+2 \mathrm{H}_{2} .
\end{gathered}
$$

In a run at $650^{\circ} \mathrm{C}$, the gas composition was constant throughout the reaction, indicating that at this temperature, reaction (1) proceeds about as rapidly as reactions (2a) and (2b).

The uranium dioxide product was easily dissolved in excess $6.5 M \mathrm{HNO}_{3}$ to produce a fuel solution containing $1.36 \mathrm{MUO} \mathrm{UO}_{2}\left(\mathrm{NO}_{3}\right)_{2}$ and $3 M$ $\mathrm{HNO}_{3}$, suitable for recovery of the uranium by Purex solvent extraction without further treatment.
In a batch solvent extraction test under simulated Purex conditions, more than $99.99 \%$ of the uranium and plutonium was recovered. The small amount of finely divided carbon in the fuel solution had no adverse effect on solvent extraction performance.

Pyrohydrolys is was also successfully demonstrated with prototype uranium monocarbide fuel samples irradiated up to $16,000 \mathrm{Mwd} /$ metric ton and with $20 \% \quad \mathrm{PuC}-80 \%$ UC irradiated up to $20,000 \mathrm{Mwd} / \mathrm{metric}$ ton, indicating that the method probably can be applied to all types of highly irradiated metallic carbide fuels without hindrance from irradiation-induced effects.

In the hot-cell tests (Fig. 1.2), 1-g pieces of stoichiometric uranium monocarbide irradiated to $7500 \mathrm{Mwd} /$ metric ton were contacted in heliumpurged equipment with excess steam at atmospheric pressure at 700 to $750^{\circ} \mathrm{C}$ for 2 to $3 \mathrm{hr}$. At $750^{\circ} \mathrm{C}$, the overall reaction was complete in $1 \mathrm{hr}$, which agrees closely with the tests with unirradiated fuel samples (Fig. 1.1). The nearly nonradioactive, dry off-gas contained 83 vol \% $\mathrm{H}_{2}, 11 \% \mathrm{CO}_{2}$, and $6 \% \mathrm{CO}$, compared with 80,16 , and $4 \%$, respectively, in the off-gas from unirradiated monocarbide pyrohydrolyzed under identical conditions. The steam condensate from these runs contained $0.48 \%$ of the cesium, $0.04 \%$ of the ruthenium, and $0.006 \%$ of the zirconium in the irradiated specimens. The dry off-gas samples taken for analysis were almost completely free of radioactivity. In preliminary runs where air was not excluded from the reactor, up to $42 \%$ of the cesium was volatilized during pyrohydrolysis at $800^{\circ} \mathrm{C}$.

Very similar results were obtained when $20 \%$ $\mathrm{PuC}-80 \%$ UC irradiated to $20,000 \mathrm{Mwd}$ /metric ton was pyrohydrolyzed at $750^{\circ} \mathrm{C}$; the resulting mixed oxide dissolved readily in nitric acid, and the resulting fuel solution was successfully tested by batch solvent extraction.

\section{Nitric Acid Dissolution of Uranium and Plutonium Carbide Fuels}

In the direct nitric acid dissolution process for uranium monocarbide fuel, ${ }^{8}$ the exposed fuel is first steamed at low temperature to convert the sodium bond (if present) to sodium hydroxide; then, the monocarbide is rapidly dissolved in strong nitric acid to produce a uranyl nitrate-nitric acid 

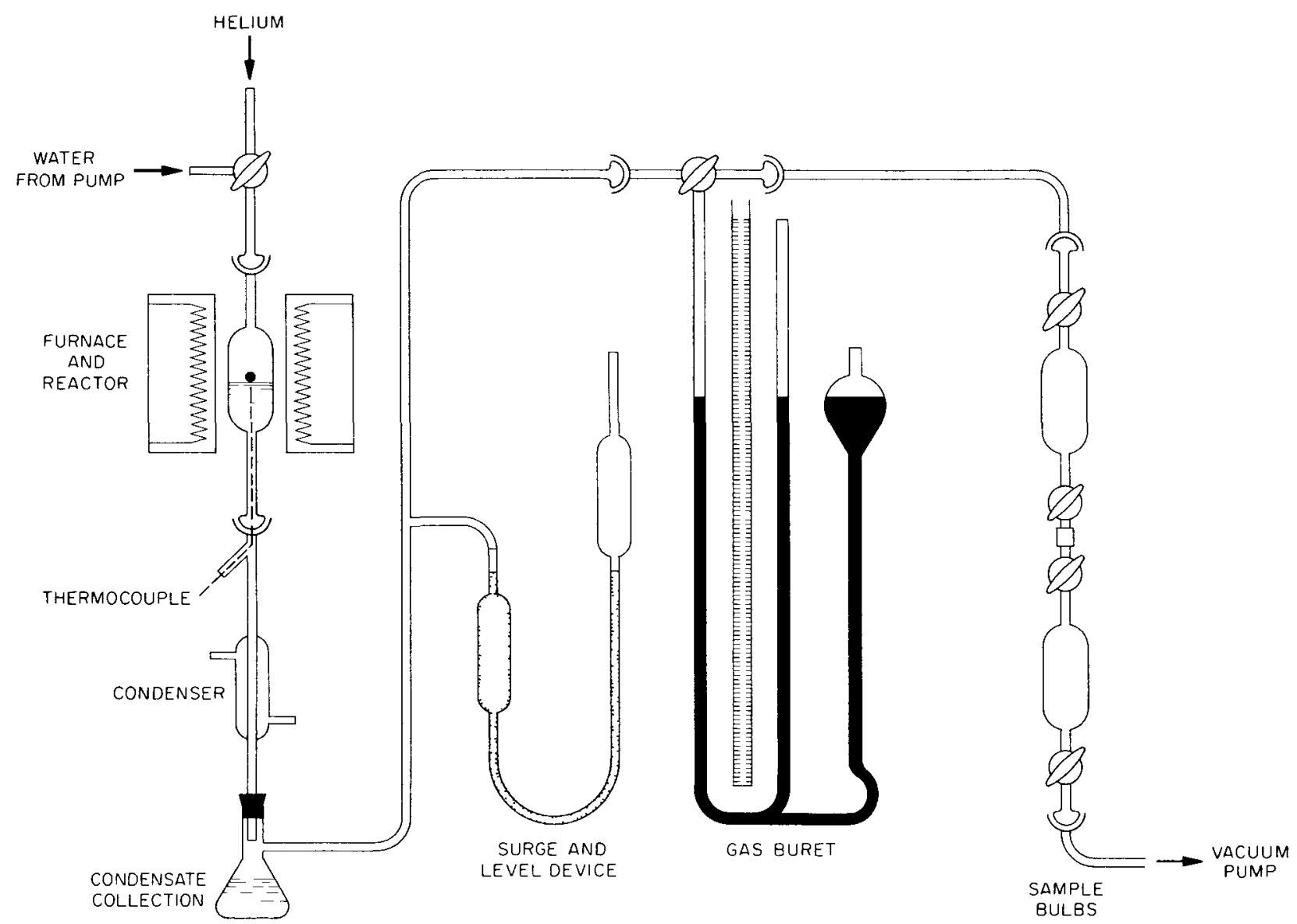

Fig. 1.2. Steam Combustion Apporatus for Processing of Uranium Carbide Fuel.

solution that contains nearly half the original carbide as soluble organic acids. ${ }^{1}$ This feed solution must be extensively treated to remove the organic impurities before it can be satisfactorily processed by Purex solvent extraction.

In hot-cell tests, this process was evaluated with irradiated uranium monocarbide $(6000 \mathrm{Mwd} /$ metric ton), plutonium carbide (1000 Mwd/metric ton), and 20\% PuC-80\% UC (20,000 Mwd/metric ton). No difficulties ascribable to irradiationinduced effects arose. Although the treated fuel solutions performed reasonably well in batch solvent extraction tests, analyses indicated that the organic impurities were not completely eliminated by oxidative degradation. Further study of other physical or chemical methods for rejecting the organic acids from the fuel solution or to prevent their formation during dissolution are indicated.
Samples $(50 \mathrm{~g})$ of uranium monocarbide containing 4.8 to $5.0 \% \mathrm{C}$ irradiated to $6000 \mathrm{Mwd} /$ metric ton which were refluxed in a $300 \%$ excess of boiling $13.2 \mathrm{M} \mathrm{HNO}_{3}$ for 6 hr produced solidsfree, dark-red solutions. In one run, however, a small (unweighable) black residue was detected after a 20 -hr reflux. This black residue retained less than $0.01 \%$ of the uranium and plutonium in the fuel sample. Excess acid was removed by distillation. The $13 \mathrm{MHNO}_{3}$ condensate contained $8 \%$ of the ruthenium ( $1.6 \%$ of the total gamma activity) originally in the fuel sample.

The solution was then adjusted to $1.36 M$ in $\mathrm{UO}_{2}\left(\mathrm{NO}_{3}\right)_{2}, 3 \mathrm{M}$ in $\mathrm{HNO}_{3}$, and $0.2 \mathrm{M}$ in $\mathrm{KMnO}_{4}$, after which it was refluxed for $2 \mathrm{hr}$. After filtration, to remove the precipitated manganese dioxide, the solution had the characteristic yellow color of uranyl nitrate. The solution was finally made $0.1 \mathrm{M}$ in $\mathrm{NaNO}_{2}$ to stabilize plutonium in the 
(IV) state and then was subjected to solvent extraction under simulated Purex conditions. Uranium recovery was better than $99.99 \%$; however, $0.15 \%$ of the plutonium was retained in the solvent after stripping. The phase-separation time of 20 to $30 \mathrm{sec}$ appeared normal for the Purex system, as did the observed uranium and plutonium separation factor from gross gamma activity of $3.4 \times 10^{4}$.

Samples of plutonium carbide $(1000 \mathrm{Mwd} /$ metric ton) and $20 \% \mathrm{PuC}-80 \% \mathrm{UC}(20,000 \mathrm{Mwd} /$ metric ton) were also evaluated. With both fuels, dissolution in $60 \% \mathrm{HNO}_{3}$ produced green-black solutions that were free of solids. During distillation of excess acid, up to $0.56 \%$ of the total ruthenium was volatilized and collected in the acid condensate. After oxidative degradation to eliminate the organic acid impurities, the resulting radioactive solutions still contained up to $32 \%$ of the carbon (as soluble organic acids) originally present in the fuel samples. In a batch extraction of a feed solution $0.13 M$ in $\mathrm{Pu}\left(\mathrm{NO}_{3}\right)_{4}$ and $4.5 M$ in $\mathrm{HNO}_{3}$, the plutonium was almost completely extracted with seven aliquots of $30 \%$ TBP in Adakane. However, $0.4 \%$ of the plutonium was retained by the solvent after stripping five times with $0.01 M \mathrm{HNO}_{3}$. Excessive holdup of plutonium (up to $1 \%$ ) in the stripped solvent was also observed when treated feed solutions derived from nitric acid dissolution of unirradiated uranium monocarbide, with $\mathrm{Pu}(\mathrm{IV})$ tracer added, were tested by batch solvent extraction. In contrast, batch extraction and stripping of feed solutions derived from comparably irradiated carbide specimens by pyrohydrolysis permitted nearly quantitative uranium and plutonium recovery. Thus, the holdup of plutonium in the stripped solvent is attributed to the organic impurities not destroyed by oxidation. These impurities are extracted and remain in the solvent after stripping and appear to act as strong complexing agents for $\mathrm{Pu}(\mathrm{IV})$.

\section{Preparation and Hydrolysis of Uranium Sesquicarbide}

Basic chemical studies on the preparation and hydrolysis of various unirradiated fuel carbides were continued. During the past year, hydrolysis of the uranium monocarbide-uranium sesquicarbide and the uranium sesquicarbide-uranium dicarbide binary systems was studied. ${ }^{9,10}$

Uranium carbide buttons with compositions between $\mathrm{UC}_{1.0}$ and $\mathrm{UC}_{1.85}$ were prepared by arc melting high-purity uranium metal and spectroscopic-grade carbon. ${ }^{11}$ Subsequent heat treatment of these specimens at temperatures from 1275 to $1765^{\circ} \mathrm{C}$ (typically $60 \mathrm{hr}$ at $1600^{\circ} \mathrm{C}$ ) resulted in the formation of monocarbide-sesquicarbide (UC-UC ${ }_{1.5}$ ) or sesquicarbide-dicarbide ( $\mathrm{UC}_{1.5}-\mathrm{UC}_{1.85}$ ) mixtures. ${ }^{9.10}$ No special stressing was required. No uranium sesquicarbide was formed when an ascast specimen with a combined-C/U atom ratio of 1.86 was heat treated under conditions where uranium sesquicarbide should have formed if the as-cast specimen were a mixture of $\mathrm{UC}$ and $\mathrm{UC}_{2.0^{\circ}}$. This further confirms prior work which shows that UC $1.85 \pm 0.03$ is the composition of the dicarbide. ${ }^{1,11}$

${ }^{9}$ M. J. Bradley and L. M. Ferris, Hydrolysis of Uranium Carbides Between 25 and 100\%. III. Utanium Sesquicarbide and Mixtures of the Sesquicarbide with Monocarbide or Dicarbide, presented at the 147 th American Chemical Society National Meeting, Philade1phia, Pa., Apr. 6, 1964.

${ }^{10} \mathrm{M}$. J. Bradley and L. M. Ferris, Inorg. Chem. 3, 730 (May 1964).

${ }^{11}$ M. J. Bradley and L. M. Ferris, Inorg. Chem. 3, 189 (Feb. 1964).

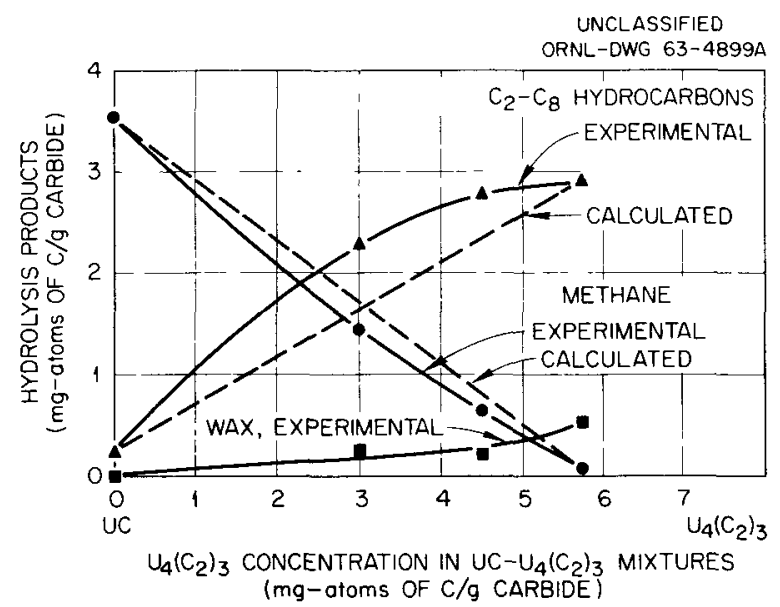

Fig. 1.3. Hydrolysis Products from Uranium Monocarbide-Sesquicarbide Mixtures, Showing Deviation of Experimental Values from Those Calculated for a UC$U_{4}\left(C_{2}\right)_{3}$ Binary. 


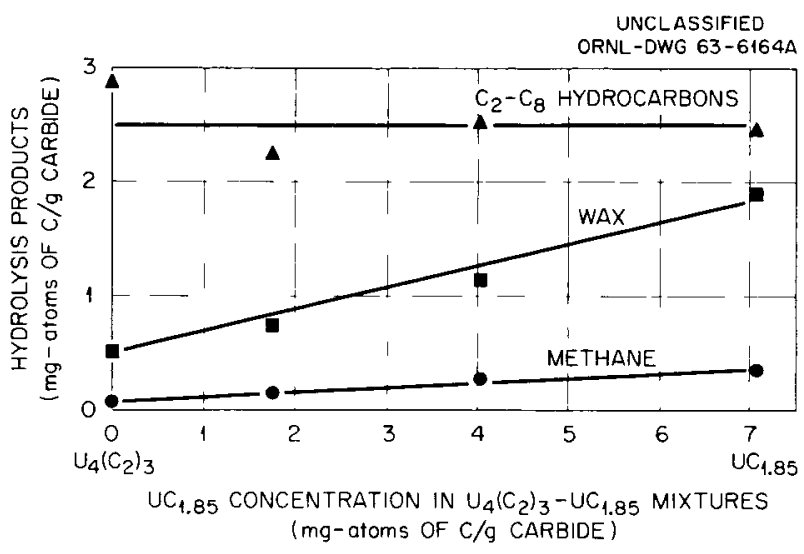

Fig. 1.4. Hydrolysis Products from Uranium Sesquicarbide-Dicarbide Mixtures; Experimental Values Are the Same as Those Calculated for a $U_{4}\left(C_{2}\right)_{3}-U C_{1.85}$ Binary.
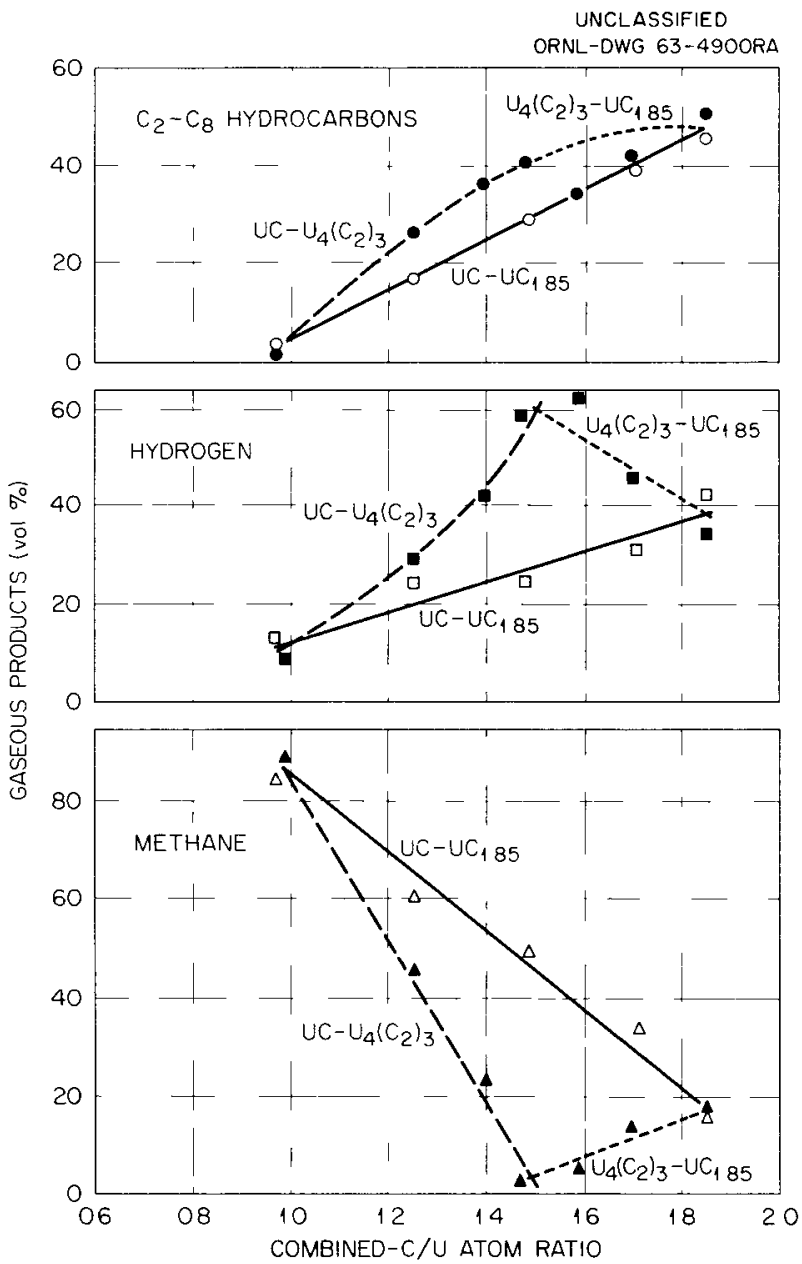

Fig. 1.5. Comparison of Gaseous Products from the Hydrolysis of Uranium Monocarbide-Dicarbide (UC$\left.U C_{1.85}\right)$, Monocarbide-Sesquicarbide $\left[U C-U_{4}\left(C_{2}\right)_{3}\right]$, and Sesquic arbide-Dicarbide $\left[U_{4}\left(C_{2}\right)_{3}-U C C_{1.85}\right]$ Mixtures.
The reaction of uranium sesquicarbide $\left[\mathrm{U}_{4}\left(\mathrm{C}_{2}\right)_{3}\right]$ with water ${ }^{6,7}$ at 25 to $99^{\circ} \mathrm{C}$ produced a gas containing hydrogen (59 vol \%) and hydrocarbons (methane, 2 vol \%; ethane, $26 \%$; $\mathrm{C}_{3}$ - to $\mathrm{C}_{8}$-alkanes, $6 \%$; alkenes, $7 \%$; alkynes, $0.5 \%$; and unidentified unsaturates, $0.8 \%$ ), a water-insoluble wax, and a hydrous U(IV) oxide. Fifty percent of the carbon was found in the gas and 10\% in the wax. Uranium monocarbide-sesquicarbide mixtures (UC to $\mathrm{UC}_{1.5}$ ) produced less methane and more $\mathrm{C}_{2}$ - to $\mathrm{C}_{8}$-hydrocarbons than expected, indicating that polymerization involving single carbon units from the monocarbide had occurred (Fig. 1.3). Hydrolysis of sesquicarbide-dicarbide mixtures ( $\mathrm{UC}_{1.5}$ to $\mathrm{UC}_{1.85}$ ) yielded the products expected from the behavior of the separate compounds, principally $\mathrm{C}_{2}$ - to $\mathrm{C}_{8}$-hydrocarbons, some hydrogen, and a little methane (Fig. 1.4). The compositions of the gaseous products from the heat-treated specimens containing uranium sesquicarbide were markedly different from those of as-cast monocarbide-dicarbide mixtures ${ }^{11}$ with the same $\mathrm{C} / \mathrm{U}$ atom ratios (Fig. 1.5).

\subsection{STUDIES ON THE DISSOLUTION OF $\mathrm{PuO}_{2} \cdot \mathrm{UO}_{2}$}

High-fired $\mathrm{UO}_{2}, \mathrm{UO}_{2}-\mathrm{PuO}_{2}$, and $\mathrm{PuO}_{2}$ are leading contenders for use as fuel in secondgeneration power reactors. Therefore, a thorough study of the dissolution characteristics of this type of fuel in $\mathrm{HNO}_{3}$ and $\mathrm{HNO}_{3}-\mathrm{HF}$ was begun last year to determine the effect of density, manufacturing conditions, and source.

The initial dissolution rate data previously reported [Chem. Technol. Div. Ann. Progr. Rept. May 31, 1963, ORNL-3452, pp. 9-10] have been extended to include measurement of the complete dissolution time (Table 1.2) of commercially prepared high-density fuel pellets. Because of roughening of the pellet surfaces during dissolution, $\mathrm{UO}_{2}$ pellets dissolved in about a third of the time predicted from their initial rate, assuming uniform dissolution of a smooth pellet. By use of an appropriate roughening constant, the time for the dissolution of $\mathrm{UO}_{2}$ pellets in any concentration of nitric acid may be calculated to within about $20 \%$. 
Table 1.2. Dissolution of Plutonium Oxide-Uranium Oxide Sintered Pellets in $10 \mathrm{M} \mathrm{HNO}_{3}$ Pellets from NUMEC

Diameter: $\sim 0.6 \mathrm{~cm}$

Length: $\sim 0.6 \mathrm{~cm}$

\begin{tabular}{|c|c|c|c|c|c|c|c|}
\hline \multirow{2}{*}{$\begin{array}{c}\text { Pellet } \\
\text { Composition } \\
\left(\% \mathrm{PuO}_{2}\right)\end{array}$} & \multirow{2}{*}{$\begin{array}{c}\text { Oxide } \\
\text { Preparation } \\
\text { Method }^{a}\end{array}$} & \multirow{2}{*}{ 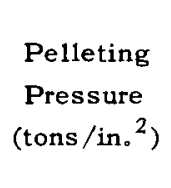 } & \multicolumn{2}{|c|}{$\begin{array}{l}\text { Sintering in } \\
\mathrm{N}_{2}-6 \% \mathrm{H}_{2}\end{array}$} & \multirow{2}{*}{$\begin{array}{c}\text { Percent } \\
\text { Theoretical } \\
\text { Density }\end{array}$} & \multirow{2}{*}{$\begin{array}{c}\text { Time for } \\
\text { Dissolution } \\
\text { (min) }\end{array}$} & \multirow{2}{*}{$\begin{array}{c}\mathrm{PuO}_{2} \text { Undissolved } \\
(\%)\end{array}$} \\
\hline & & & $\begin{array}{c}\text { Temperature } \\
\left({ }^{\circ} \mathrm{C}\right)\end{array}$ & $\begin{array}{l}\text { Time } \\
(\mathrm{hr})\end{array}$ & & & \\
\hline 0.5 & Coprecipitated & & 1600 & 1 & 94 & 60 & 0 \\
\hline 5.0 & Me. blended & & 1600 & 16 & 95 & 80 & 0 \\
\hline 5.0 & Coprecipitated & 12.7 & 1600 & 1 & 95 & 240 & 0 \\
\hline 17.8 & Me. blended & 13.4 & 1600 & 16 & 80 & 120 & 0 \\
\hline 17.8 & Coprecipitated & 21.2 & 1600 & 16 & 93 & 360 & 0 \\
\hline 20.0 & Me. blended & & 1600 & 48 & 81 & 60 & 0 \\
\hline 20.0 & Me. blended & 16.3 & 1600 & 16 & 93 & 60 & 9 \\
\hline 20.0 & Coprecipitated & 11.7 & 1300 & 2 & 87 & 30 & 21 \\
\hline 35.0 & Coprecipitated & 11.7 & 1600 & 16 & 88 & 450 & 0 \\
\hline
\end{tabular}

${ }^{a}$ Coprecipitated $=\mathrm{Pu}(\mathrm{OH})_{4}$ and $\left(\mathrm{NH}_{4}\right)_{2} \mathrm{U}_{2} \mathrm{O}_{7}$ continuously coprecipitated; Me. blended $=$ mechanically blended $\mathrm{PuO}{ }_{2}$ and $\mathrm{UO}_{2}$.

The dissolution rate of pellets fabricated by the Nuclear Materials and Equipment Corporation (NUMEC) and containing both $\mathrm{PuO}_{2}$ and $\mathrm{UO}_{2}$ depended upon the amount of $\mathrm{PuO}_{2}$ present and the method of fabrication. Autoradiographs were used by NUMEC to indicate the degree of homogeneity, as a function of fabrication method. Pellets that appeared to be a homogeneous mixture of $\mathrm{UO}_{2}$ and $\mathrm{PuO}$ dissolved rapidly and completely in nitric acid. The variation in dissolution rate with the concentration of nitric acid is defined approximately by the empirical equation:

$$
R_{\mathrm{PuO}_{2}-\mathrm{UO}_{2}}=K\left(\mathrm{HNO}_{3}\right)^{2+2 \mathrm{~m}} \text {, }
$$

where $m$ is the mole fraction of $\mathrm{PuO}_{2}$ in the pellet. With nonhomogeneous pellets, the uranium was selectively dissolved, leaving part of the $\mathrm{PuO}_{2}$ undissolved. Mechanically blended pellets dissolved faster than those prepared by the coprecipi- tation of plutonium and uranium. With pellets that did not completely dissolve in $10 \mathrm{M} \mathrm{HNO}_{3}$, solutions of Purex feed composition $(350 \mathrm{~g} / \mathrm{liter}$, $1.2 \mathrm{~N} \mathrm{H}^{+}$) were prepared by dissolving the pellets in $5.5 \mathrm{~N} \mathrm{HNO}_{3}-0.05 \mathrm{MHF}$ in less than $20 \mathrm{hr}$.

Most of the variation in the time required for the complete dissolution is due to the difference in the final dissolution rates for the last few weight percent of a pellet. In simulated cyclic dissolver experiments, $150-\mathrm{g}$ batches of $\mathrm{UO}_{2}$ pellets were dissolved in $4.5,6$, or $10 \mathrm{~N} \mathrm{HNO}_{3}$ for half the time calculated for complete dissolution. About $40 \%$ of the $\mathrm{UO}_{2}$ remained as a heel. An additional batch of pellets was then added, and the cycle was repeated. Although there was considerable variation in the sizes of pieces remaining at the end of each cycle, there was no further accumulation of heel in the dissolver after three consecutive dissolutions. In $10 \mathrm{MNO}_{3}$, the pellets dissolved quite uniformly from all surfaces, whereas in 4.5 or $6 \mathrm{MHNO}_{3}$, dissolution was more 

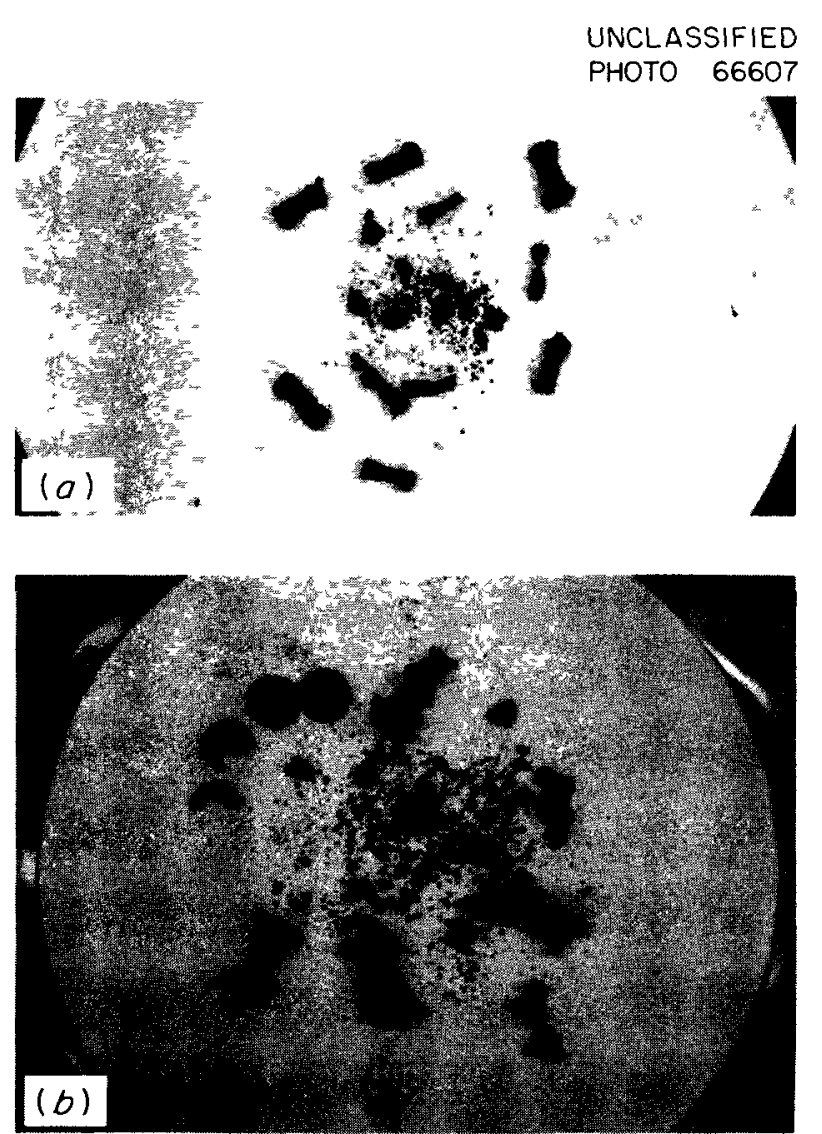

Fig. 1.6. Variation in the Shape of Partially Dissolved $\mathrm{UO}_{2}$ Pellets in High and Low Concentrations of Nitric Acid. (a) Dissolution in $10 \mathrm{MHNO}_{3}$; (b) dissolution in $6 \mathrm{MNO}_{3}$.

rapid from the sides of the pellets. In the dilute nitric acid, the pellets first became dumbbell shaped; finally, flat disks (the ends of the cylinder) remained after the pellet had almost completely dissolved (Fig. 1.6).

\subsection{DISSOLUTION OF SOL-GEL- DERIVED $\mathrm{ThO}_{2}-\mathrm{UO}_{2}$}

The sol-gel process produces refractory solid solutions of $\mathrm{ThO}_{2}-\mathrm{UO}_{2}$ ceramic fuels at near theoretical density. The dissolution characteristics of sol-gel-derived $\mathrm{ThO}_{2}-\mathrm{UO}_{2}$ differ from similar material prepared by other methods. Therefore a systematic laboratory-scale ${ }^{12}$ study is being made to compare the dissolution of sol-gel-derived $\mathrm{ThO}_{2}-\mathrm{UO}_{2}$ with the dissolution of arc-fused and pressed and sintered $\mathrm{ThO}_{2}-\mathrm{UO}_{2}$ pellets.

Both unirradiated and 1rradiated samples [4000 to $40,000 \mathrm{Mwd} /$ metric ton $(\mathrm{U}+\mathrm{Th})$ at heat ratings of 17,000 to $45,000 \mathrm{Btu} \mathrm{hr}^{-1} \mathrm{ft}^{-1}$ ] were successfully dissolved in boiling $13 M \mathrm{HNO}_{3}-0.04 M \mathrm{HF}$ containing $\mathrm{Al}\left(\mathrm{NO}_{3}\right)_{3}$ in concentrations up to $0.1 M$. Experiments using unirradiated oxide indicated that "heel" dissolution, in which some oxide is left undissolved at the end of each of a serres of successive dissolutions, is necessary to achieve acceptable rates. Using this not uncommon dissolution technique, it appears that the standard Thorex process can be used for sol-gel oxides.

The unirradiated $\mathrm{ThO}_{2}-4 \% \mathrm{UO}_{2}$ used in these studies was prepared by the sol-gel process and was a powder having the following particle size distribution: $60 \%,-6+16$ mesh; $15 \%,-50+140$ mesh; $25 \%,-200$ mesh. The density of the particles closely approached the theoretical, and the specific surface area was between 20 and 1000 $\mathrm{cm}^{2} / \mathrm{g}$.

The dissolution behavior of several batches of this material in boiling $\left(118\right.$ to $\left.120^{\circ} \mathrm{C}\right) 13 \mathrm{M} \mathrm{HNO}_{3}$ containing up to $0.1 \mathrm{MHF}$ and $0.1 \mathrm{M} \mathrm{Al}\left(\mathrm{NO}_{3}\right)_{3}$ was determined in 7-hr tests. With solutions containing no aluminum nitrate, the amount of oxide dissolved increased from about $71 \%$ to $76 \%$ as the hydrofluoric acid concentration in solution was increased from $0.04 M$ to $0.08 M$, but a further increase in hydrofluoric acid concentration to $0.1 \mathrm{M}$ caused no additional increase in the amount dissolved. Addition of $0.04 \mathrm{M} \mathrm{Al}\left(\mathrm{NO}_{3}\right)_{3}$ to solutions containing $0.04 M \mathrm{HF}$ had little effect on the amount of oxide dissolved in $7 \mathrm{hr}$; however, the presence of $0.1 M \mathrm{Al}\left(\mathrm{NO}_{3}\right)_{3}$ in solutions containing only $0.04 M \mathrm{HF}$ reduced the amount dissolved in $7 \mathrm{hr}$ to 60 to $65 \%$. There was preferential leachıng of the uranium oxide. These results are in good qualitative agreement with those obtained previously with $\mathrm{ThO}_{2}-4 \% \mathrm{UO}_{2}$ fuel pellets whose

\footnotetext{
${ }^{12}$ L. M. Ferris and J. W. Ullmann, Dissolution of Sol. Gel-Derived and Arc-Fused ThO ${ }_{2}^{-U O}{ }_{2}$ Fuel Particles in $\mathrm{HNO}_{3}-\mathrm{HF}$ Solutions: Laboratory Development (in press).
} 
densities were about $95 \%$ of the theoretical density. ${ }^{13-17}$

The time required to completely dissolve a batch of sol-gel $\mathrm{ThO}_{2}-\mathrm{UO}_{2}$ in boiling $13 \mathrm{M}_{\mathrm{HNO}_{3}}-0.04 \mathrm{M}$ $\mathrm{HF}-0.04 \mathrm{M} \mathrm{Al}^{2}\left(\mathrm{NO}_{3}\right)_{3}^{2}$ was about $75 \mathrm{hr}$, the product solution was about $1 M$ in thorium. The amounts dissolved as a function of time were 70,84 , and $92 \%$ in 7,24 , and $36 \mathrm{hr}$ respectively. The time required for complete dissolution was about twice that required for pellets that were about $95 \%$ of theoretical density. Although not tested, it seems reasonable to assume that the dissolution time could be reduced somewhat by accepting a lower thorium concentration in the product solution.

In all the above experiments, -50-mesh particles were almost completely dissolved in 2 to $3 \mathrm{hr}$. The undissolved residue from the short-term dissolutions was found by sieve analysis to consist primarily of the $-6+16$ mesh particles.

Since a 75-hr dissolving cycle is economically unattractive, tests of steady-state (or "heel") dissolution were made using boiling $13 \mathrm{M} \mathrm{HNO}_{3}-$ $0.04 M \mathrm{HF}-0.04 \mathrm{MAl}\left(\mathrm{NO}_{3}\right)_{3}$ for $20 \mathrm{hr}$, followed by fresh fuel additions $(2 \mathrm{~g})$. In the first series, steady state was achreved after about two cycles. The solutions from each cycle were about $0.8 \mathrm{M}$ in Th and $0.5 M$ in $\mathrm{H}^{+}$. About $87 \%$ of the oxide present at the start of each cycle was dissolved, allowing a constant "heel" of $13 \%$. Over six cycles, $97 \%$ of the oxide charged to the system was dissolved. In the second series, steady state was also achieved in about two cycles. The product solutions in this series were only about $0.4 \mathrm{M}$ in Th, but the heel represented only about $4 \%$ of the input. Over the six cycles, more than $99 \%$ of the oxide charged was dissolved.

One other series of heel dissolvings was made, also using 2-g fuel charges and volumes of reagent

\footnotetext{
${ }^{13}$ R. E. Blanco et al., Aqueous Processing of Thorium Fue1s. Part II, ORNL-3418 (May 23, 1963).

${ }^{14}$ R. E. Blanco, L. M. Ferris, and D. E. Ferguson, Aqueous Processing of Thotium Fuels. Part I, ORNL3219 (Feb. 28, 1962).

${ }^{15}$ L. M. Ferris and A. H. Kibbey, Sulfex-Thorex and Darex-Thorex Processes for the Dissolution of Consolidated Edison Power Reactor Fuel: Laboratory Development, ORNL-2934 (Oct. 26, 1960).

${ }^{16}$ L. M. Ferris and A. H. Kibbey, Miscellaneous Experiments Relating to the Processing of CETR Fuel by Sulfex-Thorex and Darex-Thorex Processes, ORNL-3143 (Aug. 16, 1961).

${ }^{17}$ W. D. Bond, Dissolution of Sintered ThoriumUranium Oxide Fuel in Nitric Acid-Fluoride Solutions, ORNL-2519 (Oct. 28, 1958)
}

sufficient to produce $1 M$ Th solutions if all the oxide were dissolved in each cycle. In this series, however, the dissolution time for each cycle was only $7 \mathrm{hr}$. With this dissolution time, steady state may have been achieved in six cycles, but the data are inconclusive. The heel increased from $23 \%$ to 60 to $80 \%$ over the six cycles. The thorium concentration in the product solutions increased correspondingly from 0.6 to $0.9 \mathrm{M}$. These results, obtaned in the laboratory, are in reasonable agreement with those obtained on an engineering scale using a basket leacher. ${ }^{18}$

Limited dissolution studies by the General Electric Company, Vallecitos, using irradiated solgel oxide have given some indication that irradiated fuel dissolves more rapidly than unirradiated. The General Electric group, as part of a radiation performance evaluation subcontract, dissolved irradiated $\mathrm{ThO}_{2}-\mathrm{UO}_{2}$ sol-gel oxide for burnup determinations using approximately the same conditions that we had used for unirradiated samples. The specimens dissolved at Vallecitos had been irradiated to 4000 to $40,000 \mathrm{Mwd}$ per metric ton $(\mathrm{U}+\mathrm{Th})$ at heat ratings of 17,000 to 45,000 Btu $\mathrm{hr}^{-1} \mathrm{ft}^{-1}$. In $7-\mathrm{hr}$ dissolution tests, 90 to 95\% of the irradiated oxide dissolved, ${ }^{19-21}$ compared with only 70 to $73 \%$ for the unirradiated fuel. Some evidence for insoluble residues was found, more systematic studies with irradiated fuel are planned.

\subsection{STUDIES ON THE ZIRFLEX PROCESS}

The $Z_{1}$ rflex process, ${ }^{22-24}$ developed at Hanford and here, involves the chemical decladding of

\footnotetext{
${ }^{18}$ M. E. Whatley et al., Unit Operations Section Monthly Report for March 1964 (in press).

${ }^{19}$ R. W. Darmitzel, Post-Irradiation Examination of ORNL Fuel Cycle Capsules, GEAP-4397 (September 1963).

${ }^{20}$ D. T. Ikeuye, D. L. Zimmerman, and R. W. Darmitze1, ORNL-RML Services Program Progress Report for January 1964, GEAP-4472 (1964).

${ }^{21}$ D. T. Ikeuye, D. L. Zimmerman, and R. W. Darmitze1, ORNL-RML Services Program Progress Report for $F$ ebruary 1964, GEAP-4500 (1964).

${ }^{22}$ T. A. Gens, Laboratory Development of Methods for Precipitating Utanium Peroxide from Zirflex Waste Solutions and Converting the Waste to Alkaline Solutions, ORNL-TM-780 (February 1964).

${ }^{23}$ L. M. Ferris, $Z_{\text {irflex Process for PWR Blanket }}$ Fuel. II. Revised Flowsheet, ORNL-2940 (October 1960).

${ }^{24}$ P. W. Smith, The $Z_{1 r f l e x}$ Process Terminal Develop. ment Report, HW-65979 (August 1960).
} 
Zircaloy-2-clad $\mathrm{UO}_{2}$ fuels in ammonium fluorideammonium nitrate solution. Subsequent modifications of the process, involving the addition of small amounts of hydrogen peroxide to the dissolvent, have extended its application to the total dissolution of zirconium-uranium alloy fuels as well. For zirconium-uranium alloy fuels, the process was called "Modified Zirflex."25,26 Work this year included studies on the recovery of the small amount of uranium that dissolves during the decladding of oxide fuels and the preparation of stable, neutral waste solutions from Zirflex solvent extraction raffinates to minimize corrosion of the waste-storage tanks.

In the Zirflex decladding process, up to $0.5 \%$ of the uranium dissolves in the solution as slightly soluble $\mathrm{NH}_{4} \mathrm{UF}_{5}$, formed in small amounts when the $\mathrm{NH}_{4} \mathrm{~F}_{-}^{4}\left(\mathrm{NH}_{4}\right)_{2} \mathrm{ZrF}_{6}$ solutions contact the uranium oxide after the cladding has been dis. solved.

In the Modified $Z$ irflex process, uranium-zirconium alloy fuel is totally dissolved in $\mathrm{NH}_{4} \mathrm{~F}$ $\mathrm{NH}_{4} \mathrm{NO}_{3}-\mathrm{H}_{2} \mathrm{O}_{2}$ solution. The peroxide converts the $\mathrm{NH}_{4}^{3} \mathrm{UF}_{5}^{2}$ to more soluble hexavalent uranium salts. The uranium can be recovered by solvent extraction, either directly from the product solution or from a solution prepared by adding nitric acid and aluminum nitrate. ${ }^{25,26}$ Studies were made in order to find whether the solvent extraction waste solutions could be made alkaline, since corrosion of the waste storage tanks would be reduced thereby. As the $\mathrm{pH}$ is increased, zirconium hydroxide normally precipitates from $\mathrm{NH}_{4} \mathrm{~F}$ solutions at about $\mathrm{pH} 7$. Since this precipitate might trap and retain fission products, local overheating (hot spots) and increased corrosion rates might result.

\section{Recovery of Uranium from Zirflex Declodding Solutions}

When Zirflex decladding solutions were less than $0.001 M$ in dissolved uranium, the uranium was

\footnotetext{
${ }^{25}$ T. A. Gens, Modified Zirflex Process for Dissolution of $1-10 \%$ U-Zr Alloy Fuels in Aqueous $\mathrm{NH}_{4} \mathrm{~F}$. $\mathrm{NH}_{4} \mathrm{NO}_{3}-\mathrm{H}_{2} \mathrm{O}_{2}:$ Laboratory Development, ORNL-2905 (March 1960).

${ }^{26}$ F. G. Kitts, Evaluation of an Engineering Demonstration of the Modified Zirflex and Neuflex Processes for the Preparation of Solvent Extraction Feeds from Unirradiated Zirconium-Base Reactor Fuels, ORNL3465 (March 1964).
}

quantitatively recovered by precipitation as uranium peroxide. In these experiments, simulated Zirflex decladding solutions were made $1 M$ in $\mathrm{H}_{2} \mathrm{O}$ and allowed to stand at $25^{\circ} \mathrm{C}$. Within a few hours, the slow formation of solid $\mathrm{UO}_{4} \cdot 4 \mathrm{H}_{2} \mathrm{O}$, as identified by $\mathrm{x}$-ray analyses, was observed (Fig. 1.7). Nearly quantitative precipitation of the uranium occurred in three days. After about a week, a similar slow precipitation of zirconium compounds began. Thus, it appears that uranium from Zirflex waste solution that is $\leq 0.001 M$ in uranium can be recovered by filtration or centrifugation before any significant precipitation of zirconium compounds occurs.

\section{Recovery of Uranium from Modified-Zirflex Decladding Solutions}

One of the main disadvantages of the Modified Zirflex process is that the addition of nitric acid and aluminum nitrate to the $Z$ irflex dissolver solution prior to solvent extraction produces a very large volume of corrosive $\mathrm{HNO}_{3}-\mathrm{HF}-\mathrm{Al}\left(\mathrm{NO}_{3}\right)_{3}$ solvent extraction feed. An alternative uraniumrecovery possibility would involve the separation of about $97 \%$ of the uranium (as insoluble $\mathrm{NH}_{4} \mathrm{UF}_{5}$ ) by filtration or centrifugation, followed by recovery of the remaining $3 \%$ of the uranium by precipitation as $\mathrm{UO}_{4} \cdot 4 \mathrm{H}_{2} \mathrm{O}$. This two-step procedure is

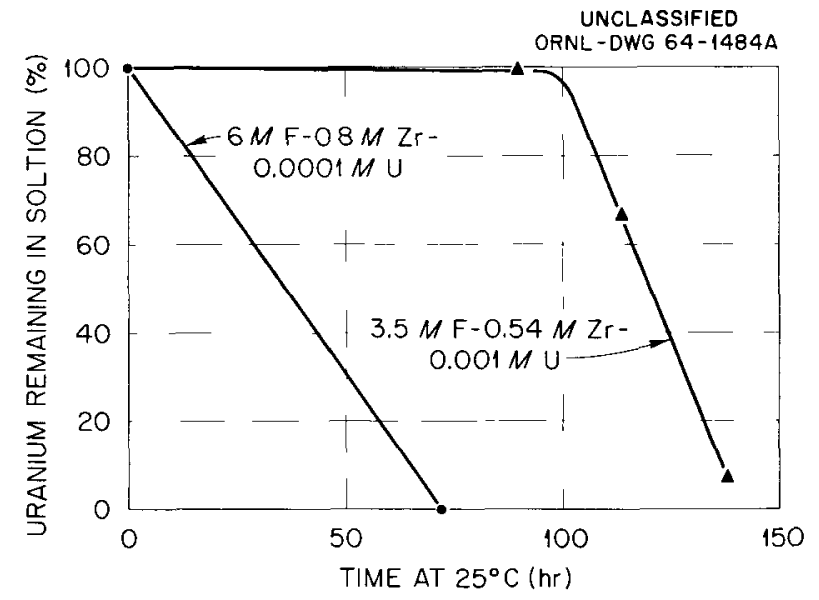

Fig. 1.7. Dissolved Uranium Can Be Recovered from Zirflex Wastes by Making the Solutions $\mathrm{I} M$ in $\mathrm{H}_{2} \mathrm{O}_{2}$ and Precipitating Uranium Peroxide, if the Solutions Are Less Than About $0.001 M$ in Uranium. 
required because the $\mathrm{NH}_{4} \mathrm{UF}_{5}$ is slightly soluble in the $Z$ irflex dissolver solution. The two products, $\mathrm{NH}_{4} \mathrm{UF}_{5}$ and $\mathrm{UO}_{4} \cdot 4 \mathrm{H}_{2} \mathrm{O}$, could be dissolved in nitric acid-aluminum nitrate solution, which could then be used as solvent extraction feed.

\section{Preparation of Alkaline Zirflex Waste Solutions}

Zirflex wastes were made alkaline without precipitating zirconium hydroxide when an $a$ hydroxy organic acid, such as tartaric, was added to form a soluble, complex zirconium salt. When tartrate was added to the dissolvent, less fluoride was necessary for zirconium dissolution. This resulted in more concentrated waste solutions containing less fluoride than ordinary Zirflex solutions.

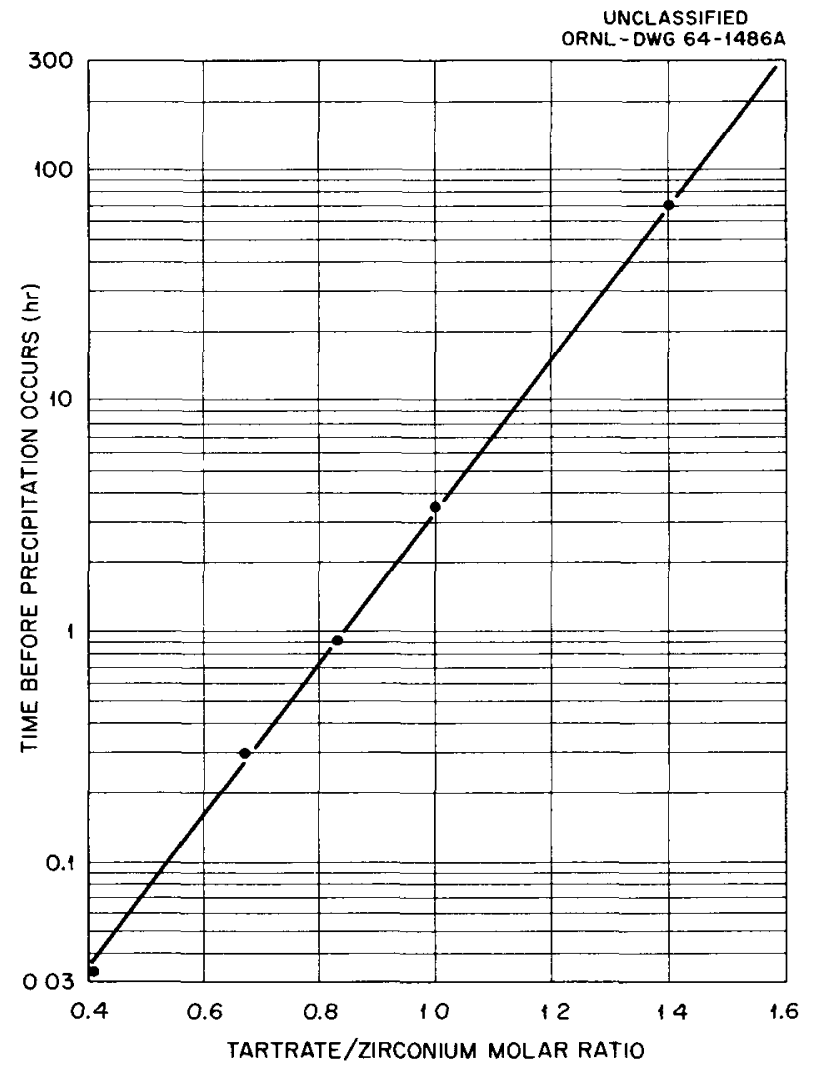

Fig. 1.8. Addition of Potassium Tartrate and Potossium Hydroxide to Zirflex Wastes Produces Strongly Alkaline Solutions Whose Stability at $25^{\circ} \mathrm{C}$ Depends on the Tartrate-to-Zirconium Mole Ratio. The alkaline solutions were $0.2 M$ in $\mathrm{Zr}, 1.3 M$ in $\mathrm{F}^{-}, 2.7 M$ in $\mathrm{K}^{+}$, and $0.4 \mathrm{M}$ in $\mathrm{CO}_{3}{ }^{2-}$, and were at $\mathrm{pH} 12$.
Strongly alkaline solutions $\left(0.2 M \quad \mathrm{Z}_{\mathrm{r}}-1.3 \mathrm{M}\right.$ $\mathrm{F}-1.9 \mathrm{M} \mathrm{KOH}-0.4 \mathrm{M} \mathrm{K}_{2} \mathrm{CO}_{3}$ and varying amounts of potassium tartrate, $\mathrm{pH} 12$ ) were prepared from simulated Zirflex waste solutions not bearing fission products. The length of time that the solutions were stable at $25^{\circ} \mathrm{C}$ was a logarithmic function of the tartrate-to-zirconium molar ratio in the solutions (Fig. 1.8). At a molar ratio of 0.4 , the solution was stable for only $2 \mathrm{~min}$; at a ratio of 1.4 the solution was stable for $70 \mathrm{hr}$. Extrapolation of the curve indicates that a tartrate-to-zirconium ratio of 2 would be required to stabilize the solution for one year.

Weakly alkaline solutions ( $\mathrm{pH} 8$ to 9 ) were prepared from simulated $\mathrm{Zirflex}$ waste by adding ammonium tartrate followed by ammonium hydroxide. The solutions were stable at $25^{\circ} \mathrm{C}$ for more than a year. A molar ratio of tartrate to zirconium of 0.1 was sufficient to stabilize a $0.15 M \mathrm{Zr}$ solution, while a ratio of 0.5 was needed for a $0.5 \mathrm{M} \mathrm{Z}$ r solution (Fig. 1.9).

When tartrate was added to the $\mathrm{NH}_{4} \mathrm{~F}$ dissolvent, less fluoride was necessary for the dissolution of Zircaloy-2. Therefore, a lower molar ratio of $\mathrm{F} / \mathrm{Zr}$, dependent on the molar ratio of tartrate to

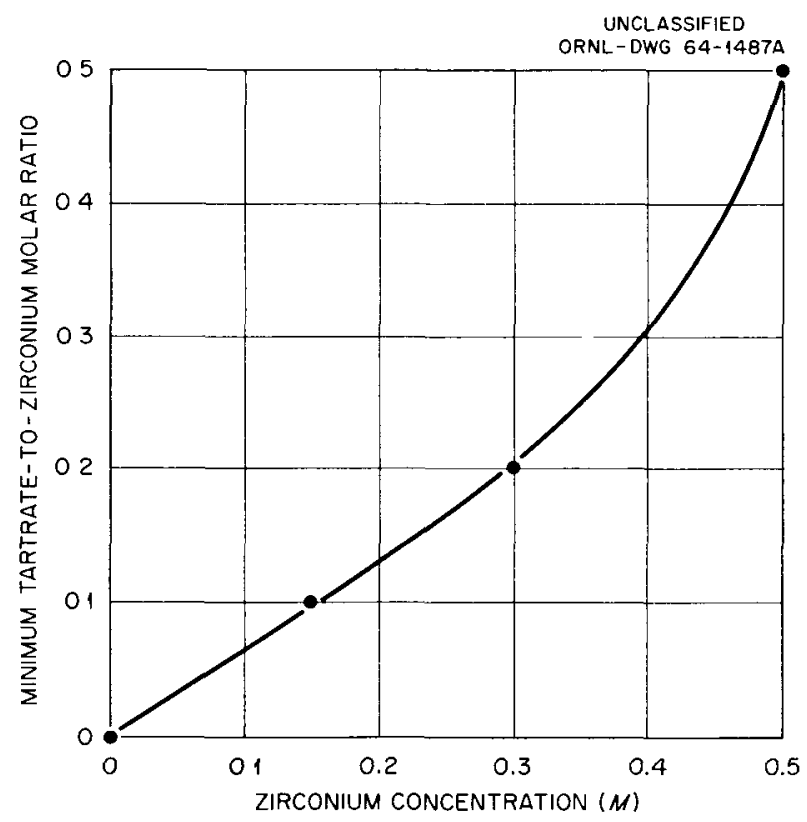

Fig. 1.9. Addition of Ammonium Tartrate and Ammonium Hydroxide to Zirflex Wastes Produces Weakly Alkaline Solutions in Which the Zirconium Solubility at $25^{\circ} \mathrm{C}$ Depends on the Tartrate-to-Zirconium Mole Ratio. In the alkaline solutions, $\mathrm{F} / \mathrm{Zr}=8, \mathrm{CO}_{3} / \mathrm{Zr}=0$ to 4 , and $\mathrm{pH}=8$ to 9 . 
zirconium, was required to dissolve a given quantity of zirconium. For example (Fig. 1.10), the initial dissolution rate of $Z_{11}$ icaloy-2 in refluxing $6 M \mathrm{NH}_{4} \mathrm{~F}-0.35 M$ ammonium tartrate was nearly $20 \mathrm{mg} \mathrm{min}{ }^{-1} \mathrm{~cm}^{-2}$, about equal to the rate in refluxing $6 M \mathrm{NH}_{4} \mathrm{~F}$ containing no ammonium tartrate. As dissolution proceeded, the reaction practically stopped in refluxing $6 \mathrm{MNH}_{4} \mathrm{~F}$ as the $\mathrm{F} / Z_{\mathrm{r}}$ ratio approached 6 , whereas in the $6 \mathrm{M}$ $\mathrm{NH}_{4} \mathrm{~F}-0.35 \mathrm{M}$ ammonium tartrate the dissolution rate was str11 about $1 \mathrm{mg} \mathrm{min}-1 \mathrm{~cm}^{-2}$ when the $\mathrm{F} / \mathrm{Z}_{\mathrm{r}}$ ratio had decreased to 5 . With greater concentrations of tartrate (and, correspondingly, less fluonde), the dissolution rates at low $\mathrm{F} / \mathrm{Zr}$ ratios continued to increase. In refluxing $3 \mathrm{M} \mathrm{NH}_{4} \mathrm{~F}-1.5$ $M$ ammonium tartrate, the rate was st1ll $2 \mathrm{mg} \mathrm{min}^{-1}$ $\mathrm{cm}^{-2}$ when the $\mathrm{F} / \mathrm{Zr}$ ratio had decreased to 4 . As the amount of fluoride and the final $F / Z r$ ratio are decreased, the solubility of zirconium in the waste solution is increased. For example, when Zircaloy-2 was dissolved in boiling $6 \mathrm{M} \mathrm{NH}_{4} \mathrm{~F}-$

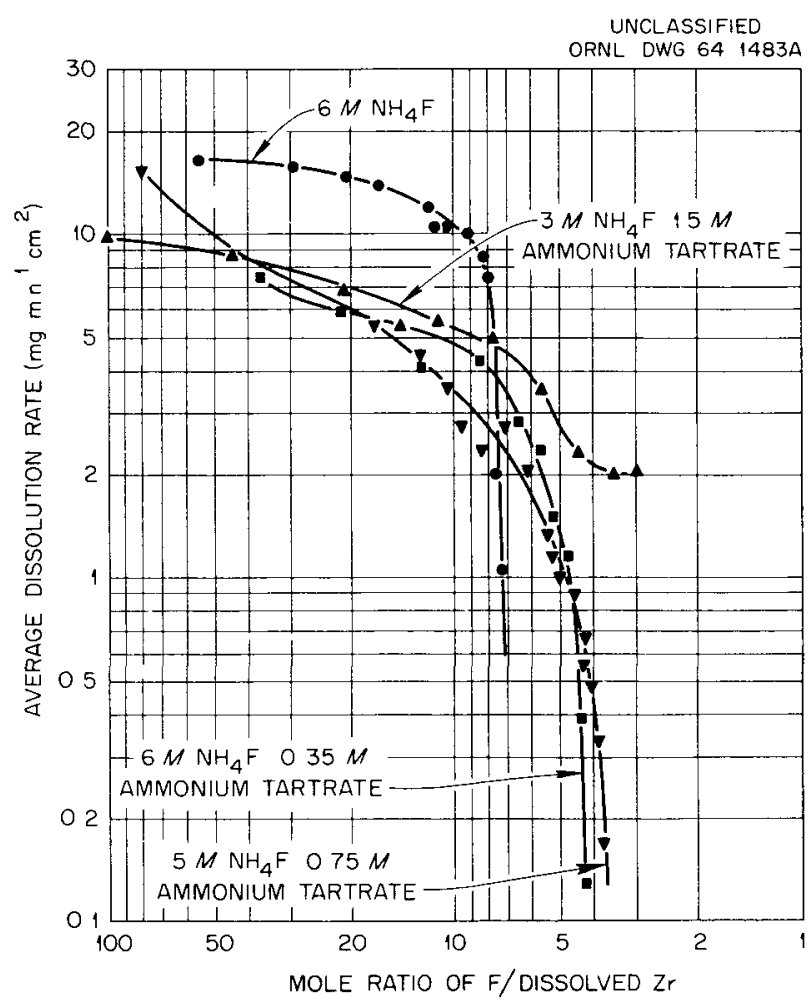

Fig. 1.10. Dissolution Rates of Zircaloy-2 in Refluxing Ammonium Fluoride-Tartrate Solutions, in Contrast to Rates in Solutions of Ammonium Fluoride Alone, Remain High at F/Zr Mole Ratios Below 6.
$0.35 \mathrm{M}$ ammonium tartrate and the overhead vapors were removed in a downdraft condenser, the dissolver product solutions were stable at $2 \mathrm{M} \mathrm{Zr}$ and an $F / Z r$ ratio of 3 . The tartrate-containing product solutions were also stable when made alkaline with ammonium hydroxide.

\subsection{STUDIES ON THE ADSORPTION OF PROTACTINIUM}

Because of the long half-11fe (27 days) of ${ }^{233} \mathrm{~Pa}$, thorium-uranium fuels must either be cooled eight or nine months before processing in order to assure complete recovery of all avallable ${ }^{233} \mathrm{U}$, or special methods must be developed to permit recovery of the ${ }^{233} \mathrm{~Pa}$. An unattractive alternative of these two possibilities is to process the fuel after a nominal three or four months of cooling and then to reprocess the waste again after another five or six months to recover the residual ${ }^{233} \mathrm{U}$.

Removal of the protactinium on inorganic adsorbents is one method that shows promise. Most of this work has been on the use of unf $f_{1}$ red Vycor glass, but more recent studies have employed zirconium phosphate, silica gel, and molecular sieves.

\section{Adsorption of Protactinium on Unfired Vycor Glass}

The distribution coefficients (DC's) of ${ }^{233} \mathrm{~Pa}$ between 60- to 80 -mesh unfired $V_{y} \operatorname{cor}^{1,27}$ and aqueous solutions contaning 4 to $100 \mathrm{~g}$ of thorium per liter, 0.5 to $12 \mathrm{M}$ in $\mathrm{HNO}_{3}$, plus tracer quant1ties of protactinium were measured and found to obey the following empirical equation

$\mathrm{DC}=(378 \pm 72)+(384 \pm 9) \mathrm{X}-(1.27 \pm 0.13) \mathrm{XY}$

$$
-(1.13 \pm 1.02) \mathrm{Y},
$$

where $\mathrm{X}$ is $\mathrm{M} \mathrm{HNO}_{3}$ and $\mathrm{Y}$ is grams of thorium per liter (Fig. 1.11).

When $\mathrm{HNO}_{3}$ solutions containing $100 \mathrm{~g}$ of thorium per liter were made 0.01 to $0.04 M$ in $\mathrm{HF}$, there resulted a slight increase in the protactinium DC in

${ }^{27}$ J. G Moore, The Effect of Nitric Acid, Thorium, Fluoride, and Aluminum on Protactinium Adsorption by Unfired Vycor Glass, ORNL-3599A (Apr11 1964). 


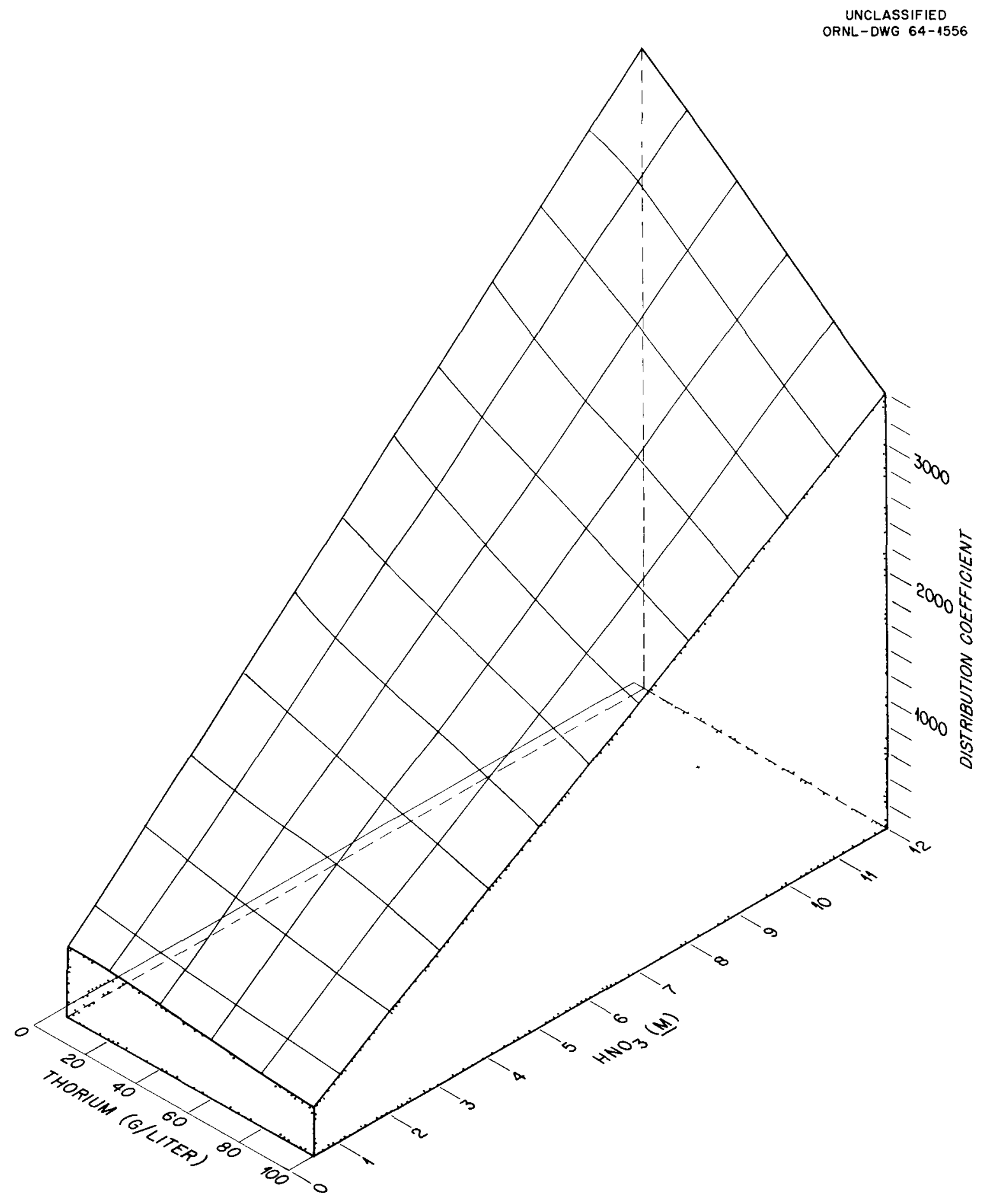

Fig. 1.11. Distribution of ${ }^{233} \mathrm{~Pa}$ Between Unfired Vycor and Thorium-Nitric Acid Solutions. 
solutions containing 0.5 to $3.5 \mathrm{MHNO}_{3}$. At higher acidities, the coefficient decreased with increasing fluoride content. The largest decrease was observed at $10 \mathrm{MHNO}$, where the coefficient dropped from about 3000 with no fluoride present, to 300 when the fluoride concentration was $0.04 \mathrm{M}$ (Fig. 1.12).

When $\mathrm{A} 1\left(\mathrm{NO}_{3}\right)_{3}$ was added to solutions that are $0.04 M$ in $\mathrm{F}, 0.5$ to $10 M$ in $\mathrm{HNO}_{3}$, and contain up to $100 \mathrm{~g}$ of thorium per 1iter, the protactinium DC was increased. Concentrations of $\mathrm{Al}\left(\mathrm{NO}_{3}\right)_{3}$ up to $0.4 M$ were used. However, the maximum coeff 1 cient was still only about half that obtained with no fluoride or aluminum present. For example, the coefficient was about 3000 for $10 M \mathrm{HNO}_{3}$ without fluoride ( $F_{1}$ g. 1.12), 300 when it was $0.04 M$ in $\mathrm{HF}$, and 1500 when it was $0.4 M$ in $\mathrm{Al}\left(\mathrm{NO}_{3}\right)_{3}$ (F1g. 1.13).

The amount of protactinium that was unadsorbable from nitric acid solutions containing thorium (4 to $\left.100 \mathrm{~g} / \mathrm{l}_{1 \text { ter }}\right), \mathrm{HF},\left(0\right.$ to $0.04 \mathrm{M}$ ), and $\mathrm{Al}\left(\mathrm{NO}_{3}\right)_{3}$ $(0.4 M)$ decreased with increasing nitric acid concentration. The values ranged from a maximum of about $7 \%$ unadsorbable from $0.5 \mathrm{MHNO}_{3}$ solutions to less than $2 \%$ from all solutions that were more than $3 \mathrm{M}_{\text {in }} \mathrm{HNO}_{3}$.

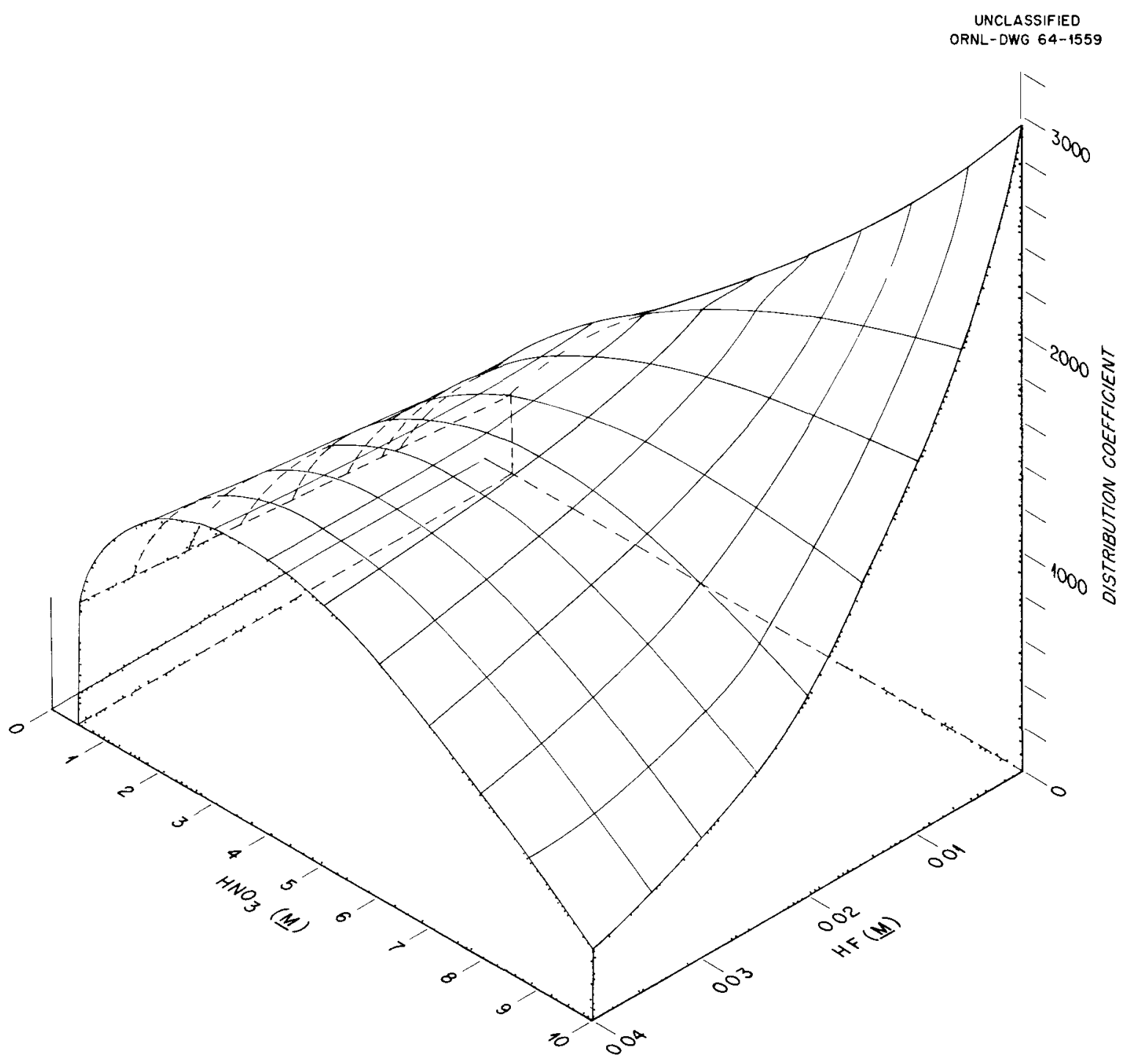

Fig. 1.12. Effect of HF on the Adsorption of ${ }^{233} \mathrm{~Pa}$ from Nitric Acid Solutions Containing $100 \mathrm{~g}$ of Thorium per Liter. 
Experimental data show no major effect of protactinium concentration. The tracer experiments reported above confirm previously reported studies made with solutions containing $50 \mathrm{mg}$ of ${ }^{231} \mathrm{~Pa}$ per liter. Both sets of data verify the potentialities of a process for removing protactinium from nitric acid solutions of short-decayed thorium fuels by adsorption on pulverized unfired Vycor glass. Hot-cell experiments are scheduled to determine the effects of high concentrations of ${ }^{233} \mathrm{~Pa}$, fission products, and radioactivity on the process.

\section{Adsorption of Protactinium on Other Inorganic Exchangers}

Initial laboratory experiments with tracer protactinium showed that B10-Rad ZP-1 (a zırconium phosphate exchanger), silica gel, and Linde molecular sieves $5 \mathrm{X}, 10 \mathrm{X}$, and $13 \mathrm{X}$ will also adsorb protactınıum from nitric acid solutions. Tenmolar nitric acid solutions of thorsum $(4 \mathrm{~g} /$ liter $)$ and ${ }^{233} \mathrm{~Pa}\left(2.3\right.$ to $9.0 \times 10^{5}$ counts $\left.\mathrm{min}^{-1} \mathrm{ml}^{-1}\right)$ were contacted for $24 \mathrm{hr}$ with $5 \mathrm{~g}$ of 60 - to 80 -mesh adsorbent per liter of solution. A distribution coefficient of 17,400 was obtained with the BroRad ZP-1, compared with 3800 obtained with unfired Vycor. Silica gels produced coefficients in the same range as those found for unfired Vycor, ranging from 3300 for commercial silica gel to about 6000 for laboratory-prepared material. The minimum coefficients were obtaned with the Linde molecular sieves $5 \mathrm{X}, 10 \mathrm{X}$, and $13 \mathrm{X}$; they were 900,2400 , and 1900 respectively. In view of the high coefficients obtained with the silica gels and ZP-1, additional studies will be made for comparison with unfired Vycor.

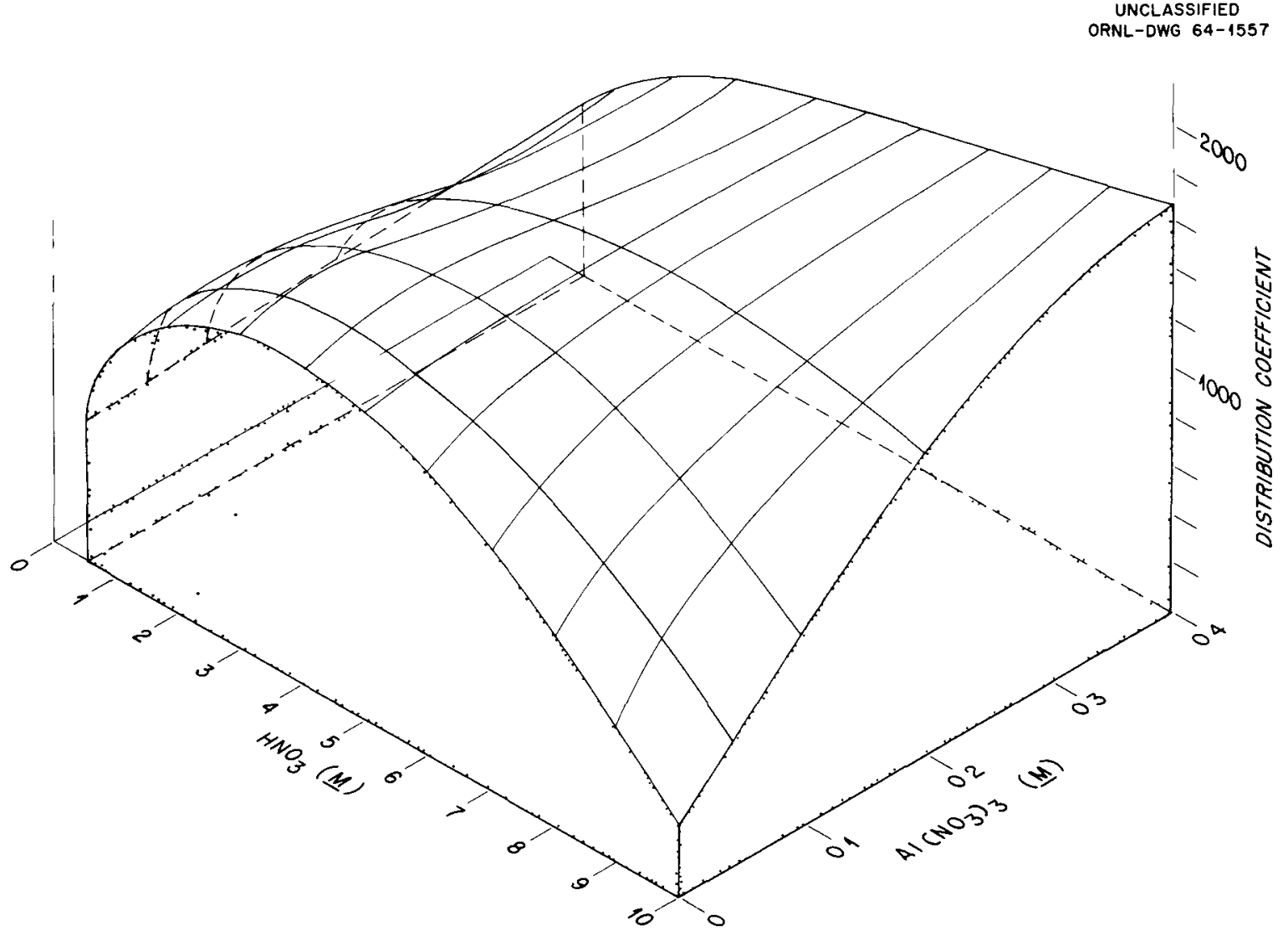

Fig. 1.13. Effect of Aluminum on the Adsorption of ${ }^{233} \mathrm{~Pa}$ from Nitric Acid Solutions Containing $100 \mathrm{~g}$ of Thorium per Liter and $0.04 M$ in MF. 


\subsection{RECOVERY OF ADVANCED REACTOR FUELS BY SOLVENT EXTRACTION}

Some advanced reactor fuels, particularly highfired $\mathrm{UO}_{2}-\mathrm{PuO}_{2}$ and $\mathrm{PuO}_{2}$, cannot be dissolved in nitric acid but can be dissolved in a mixture of nitric and hydrofluoric acids (see Sect. 1.2). Laboratory experiments were run to define the variation in distribution coefficient (DC) of uranium between tributyl phosphate (TBP) or dibutyl butylphosphonate (DBBP) and mixtures of $\mathrm{HNO}_{3}$ and $\mathrm{HF}$, and the effect of the presence of niobium and/ or aluminum. With 30 vol \% solvent in n-dodecane diluent, the uranium distribution coefficient in the $\mathrm{U}-\mathrm{HNO}_{3}-\mathrm{HF}$ system may be calculated from the following empirical equations:

$$
\begin{aligned}
& \mathrm{DC}_{(30 \% \text { т в P })}=0.064\left(\mathrm{HNO}_{3}\right)^{1.83}(\mathrm{HF})^{-1.38}, \\
& \mathrm{DC}_{(30 \% \text { D B B })}=0.94\left(\mathrm{HNO}_{3}\right)^{1.45}(\mathrm{HF})^{-1.41} .
\end{aligned}
$$

The distribution coefficients calculated from these equations agree to within about $20 \%$ with exper1mental results obtained for 0.5 to $10 \mathrm{M} \mathrm{HNO}_{3}$ and 0.5 to $4 M \mathrm{HF}$. These equations also give good estimates of the uranium distribution in systems containing aluminum and/or niobium if the total nitrate concentration is substituted for nitric acid concentration and if the total fluoride concentratron is reduced by 5 moles of fluoride per mole of niobium. For aluminum, the total fluoride is re. duced by an amount twice the molarity of the aluminum.

Very little niobium was extracted under any of the conditions tested. The distribution coefficient varied from 0.01 to 0.04 with $38 \%$ TBP, and from 0.2 to 0.06 with $3 \%$ DBBP in 1 to $6 \mathrm{~N} \mathrm{HNO}_{3}$ and 0.5 to $2 M \mathrm{HF}$. Niobium extraction increased slightly with increasing fluoride and decreased slightly with increasing nitric acid concentration. Factors such as increasing nitrate and decreasing fluoride, which increase the extraction of uranium, also increase the separation of niobium.

Free hydrofluoric acıd (1.e., fluoride uncomplexed with metal 1ons) is readily extracted by either TBP or DBBP. The DC of fluoride was 0.25 and 0.45 with $0.85 M \mathrm{HF}$ and 0.13 and 0.19 with $4.5 M$ $\mathrm{HF}$, respectively, for the two solvents. This high extraction indicates that a scrub with a complexing agent, such as aluminum nitrate, will be required to remove fluoride from the organic phase in a countercurrent solvent extraction system.
Countercurrent batch extraction experiments with low-1rradiated fuel have resulted in decontamination factors from fluoride of 200; niobium, 200; zırconium, 2000, ruthenium, 30 ; and rareearth elements, 350 with TBP, and 450, 2000, $9000, \geq 100$, and 2000 , respectively, with DBBP. Flowsheet conditions were:

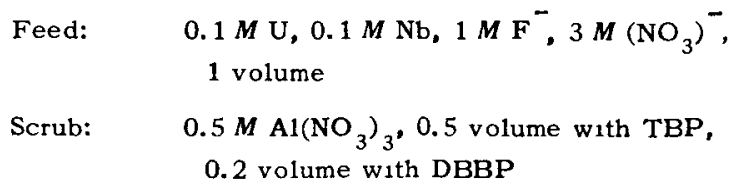

Extractant: $30 \%$ solvent in $n$-dodecane, 3 volume with TBP, 0.3 volume with DBBP

\subsection{STUDIES ON CHLORIDE VOLATILITY}

Work was continued on the use of chlorination as a means of recovering uranium from spent nuclear fuels. Chlorination was studied as a method for converting fuels containing thorium dispersed in graphite or zirconium into water-soluble chlondes. The proposed methods, which avold the use of aqueous solutions of fluorides, are intended mainly for use in combination with the Darex process, ${ }^{28}$ since the only fuels of major importance for which the Darex process is presently unsuited are those containing zirconium or graphite. In addition, a low-decontamination process based on chlorination and volatilization of chlorides offers an altemative to aqueous head-end processes for fuels such as uranium oxide.

\section{Chlorination of Refractory Fuels}

Laboratory experiments on the chlorination of refractory fuels demonstrated the recovery of uranium from spent uranıum-zirconium alloy fuels ${ }^{29}$ (Fig. 1.14). Briefly, the experuments were as follows: The volatilized chlorination products

\footnotetext{
${ }^{28}$ W. E. Clark, J. R. Flanary, and F. G. Kitts, The Darex Process." The Treatment of Stainless Steel Reactor Fuels with Dilute Aqua Regia, ORNL-2712 (May 1962).

${ }^{29}$ T. A. Gens, Laboratory Development of a Combined Chloride Volatility-Aqueous Processing Method for Uranium-Zirconium Nuclear Fuels, ORNL-TM-645 (October 1963).
} 


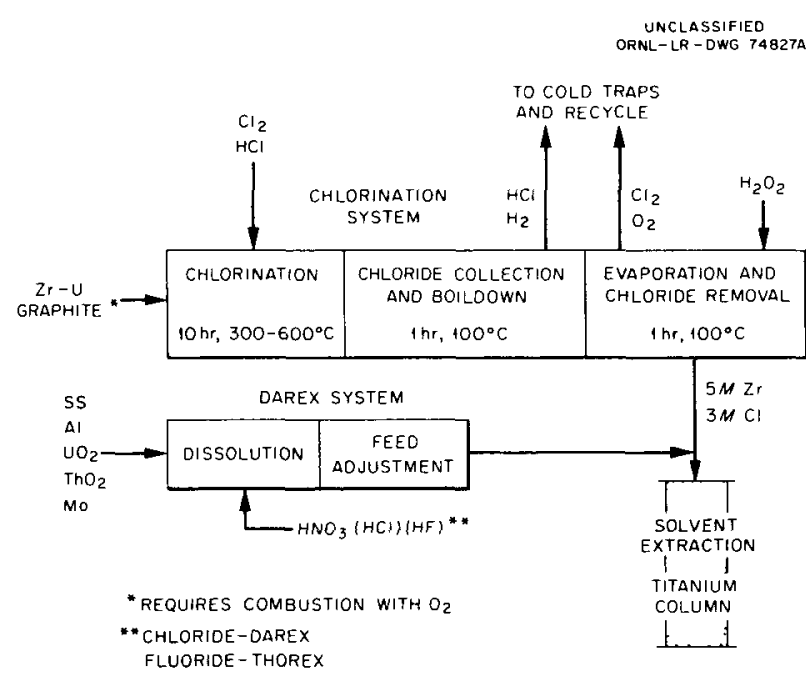

Fig. 1.14. Combination Flowsheet for High-Temperature Chlorination and Darex Processes.

(mainly zirconium tetrachloride and uranium pentachloride) were collected in boiling water; the resulting solution was concentrated; the freezing point was lowered by removing chloride with hydrogen peroxide; and the uranium was recovered from the $5 M Z_{r}$ product solution by solvent extraction with tributyl phosphate.

A study was made to determine the boiling points, incipient crystallization temperatures, and chloride, water, and zirconium concentrations of $\mathrm{ZrOCl}-\mathrm{HCl}$ solutions when the solutions were concentrated to between 0.2 and $3.5 \mathrm{M} \mathrm{ZrOCl}_{2}$ by distilling off hydrochloric acid at atmospheric pressure. The $\mathrm{ZrOCl}_{2}-\mathrm{HCl}$ mixtures formed constant-boiling solutions whose properties depend on the zirconyl chloride concentration. The temperature at which crystallization started during slow cooling increased irregularly from 41 to $95^{\circ} \mathrm{C}$. Based on this study, the properties of $\mathrm{ZrOCl}_{2}-\mathrm{HCl}$ solutions, which have been concentrated by distilling off hydrochloric acid at atmospheric pressure, can be predicted at $\mathrm{ZrOCl}_{2}$ concentrations up to $3.5 \mathrm{M}$.

Laboratory tests were also made on the recovery of uranium from uranium carbide-thorium carbidegraphite fuels by burning, chlorinating the ash, dissolving the product in $6 \mathrm{~N} \mathrm{HCl}$, concentrating the chloride solution, and recovering the uranium by solvent extraction ${ }^{30}$ (Fig. 1.15). The main objective of this work, which was to perform the combustion, chlorination, and dissolution in a single vessel, thereby avoiding a transfer of the combustion ash, was tentatively accomplished. The method is acceptable only if corrosion rates of $20 \mathrm{mils} / \mathrm{month}$ are accepted for the burnerchlorinator operation and if titanium equipment is used for the first cycle of solvent extraction.

\section{Chloride Volatility Low-Decontamination Process Development}

The volatilization of uranium chlorides during the chlorination of nuclear fuels provides a partial decontamination method for uranium fuels. ${ }^{31}$ If the volatile uranium chlorides are selectively converted to less-volatile chlorides, further decontamination from volatile fission product chlorides might be accomplished. Experimental and theoretical investigation of the behavior of plutonium during the chlorination of $\mathrm{U}_{3} \mathrm{O}_{8}-\mathrm{PuO}_{2}$ with $\mathrm{CCl}_{4}$ is also being started.

The equilibrium yields of solid uranium trichloride from the reduction of gaseous uranium tetrachloride with carbon monoxide in an inert carrier gas were calculated from published freeenergy data ${ }^{32}$ as a function of temperature and pressure (Fig. 1.16). The calculated yields were too small for practical use under all conditions investigated.

The equilibrium capacity of chlorine gas for forming (and carrying) plutonium tetrachloride vapor during the chlorination of $\mathrm{U}_{3} \mathrm{O}_{8}-\mathrm{PuO}_{2}$ with $\mathrm{CCl}_{4}$ was also calculated from published freeenergy data at $1 \mathrm{~atm}$ of pressure. This analysis was made for temperatures between 500 and $1050^{\circ} \mathrm{K}$ and varying amounts of chlorine and inert gases. ${ }^{33}$

\footnotetext{
${ }^{30}$ T. A. Gens, Laboratory Development of a Process for Chlorinating the Combustion Ash from Graphite Fuels Containing $\mathrm{ThC}_{2}$ and $U \mathrm{C}_{2}$ and Recovering the Uranium by Solvent Extraction from a Solution of the Chlorination Products, ORNL-TM-789 (in press).

${ }^{31} \mathrm{~J}$. H. Goode, Laboratory Study of the Separation and Recovery of Uranium and Plutonium from Fission Products by Chloride Volatility, ORNL-TM-828 (in press).

${ }^{32}$ T. A. Gens and G. J. Atta, Thermodynamic Calculations Relating to Chloride Volatility Processing of Nuclear Fuels. I. The Gas-Phase Reduction of Utanium Tetrachloride to the Trichloride with Carbon Monoxide, ORNL-TM-829 (in press).

${ }^{33}$ T. A. Gens, Thermodynamic Calculations Relating to Chloride Volatility Processing of Nuclear Fuels. II. The Capacity of Chlorine for Carrying Plutonium Tetrachloride Vapor During Chlorination of $\mathrm{U}_{3} \mathrm{O}_{8}-\mathrm{PuO}_{2}$ with $\mathrm{CCl}_{4}$ (in preparation).
} 


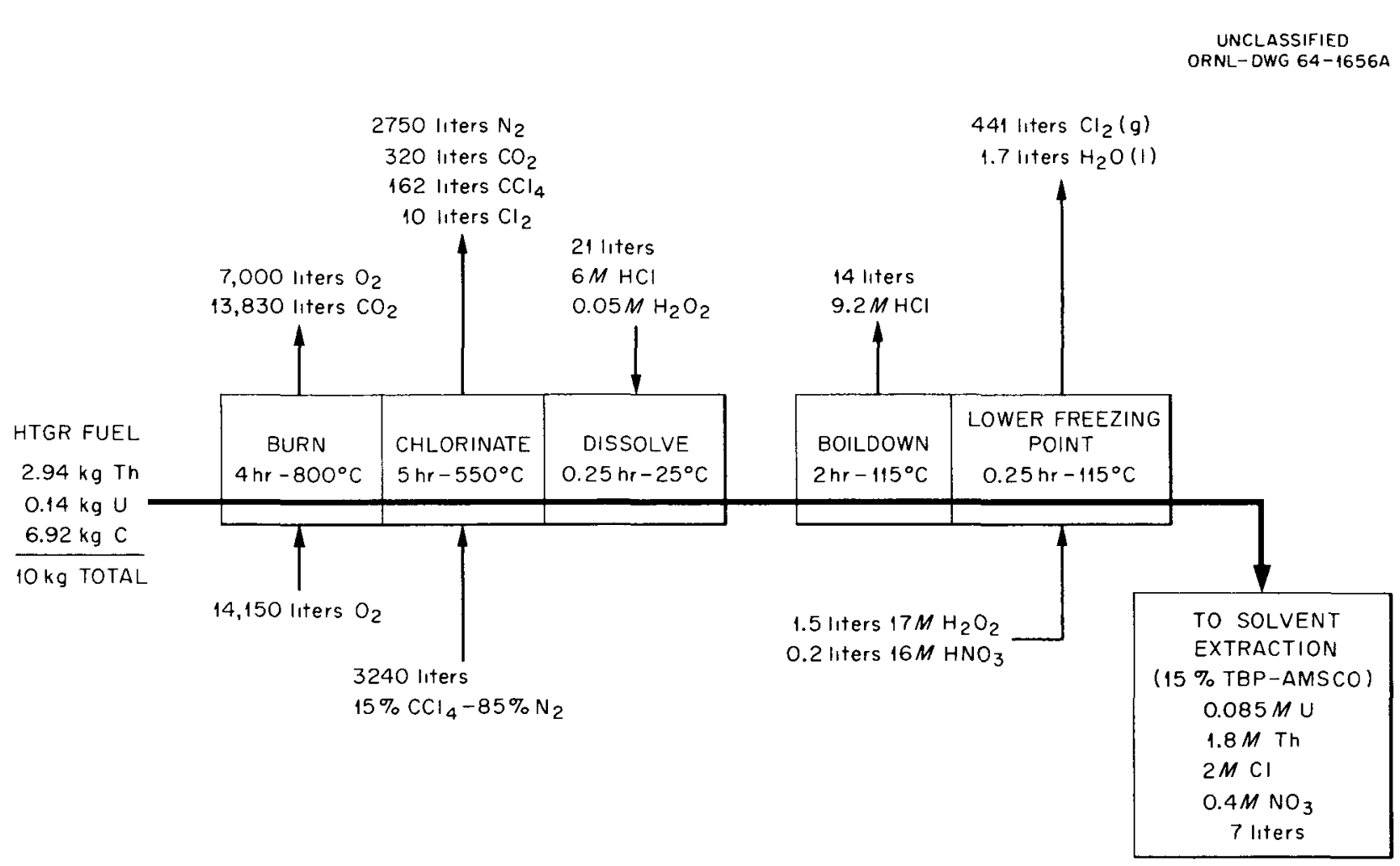

Fig. 1.15. Combustion-Chlorination-Aqueous Dissolution-Solvent Extraction Process for HTGR-Type Fuels.

Under all conditions studied, the capacity of chlorine for forming volatile plutonium tetrachloride is slightly greater when the chlorine is introduced during the chlorination of $\mathrm{U}_{3} \mathrm{O}_{8}$ with carbon tetrachloride than during the chlorination of plutonium trichloride directly (Fig. 1.17). The capacity increases from about $3 \times 10^{-6}$ to $10^{-2}$ mole of plutonium tetrachloride per mole of chlorine as the temperature increases from 700 to $1000^{\circ} \mathrm{K}$. If inert gas is present, the capacity is slightly greater.

\section{Chloride Volatility Hot-Cell Tests}

Ten hot-cell experiments were made in order to evaluate the recovery and decontamination of uranium from uranium dioxide fuels by chloride volatility. The uranium dioxide was first converted to $\mathrm{U}_{3} \mathrm{O}_{8}$ by heating in oxygen at 500 to $800^{\circ} \mathrm{C}$. Then the oxide was chlorinated with $85 \%$ $\mathrm{Cl}-15 \% \mathrm{CCl}_{4}$ at $500^{\circ} \mathrm{C}$, thus forming the volatile $\mathrm{UCl}_{5}-\mathrm{UCl}_{6}$. $\quad{ }^{4}$ The chlorides were finally purified and decontaminated from fission products by fractional distillation and sublimation. Uranium recovery varied from 90 to $98 \%$. The losses were caused by incomplete chlorination and/or sublimation of higher chlorides during the purification step. Volatilization of the plutonium was accomplished by use of large excess volumes of the $\mathrm{Cl}_{2}-\mathrm{CCl}_{4}$; but its behavior was unpredictable, probably due to physical adsorption on the equipment of the small amounts of plutonium in the fuel samples. The overall gamma decontamination factors were generally low, less than 50 , similar to values obtained by others. Such decontamination may be satisfactory for a close-coupled low-decontamination process. 


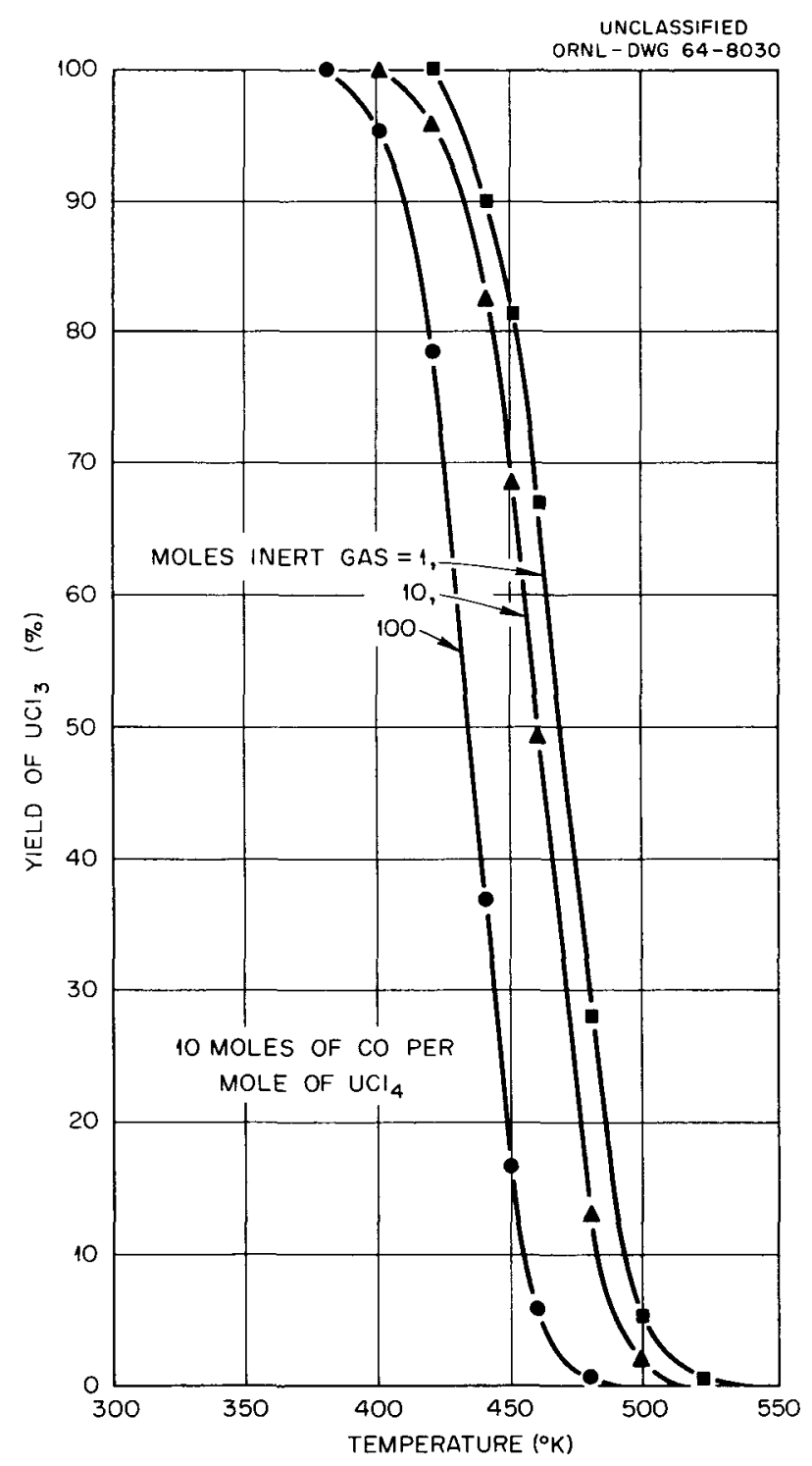

Fig. 1.16. Reduction of $\mathrm{UCl}_{4}$ to $\mathrm{UCl}_{3}$ with Carbon Monoxide, as a Function of Temperature and Pressure.

\subsection{CORROSION STUDIES}

Corrosion studies in support of the various fuel processing development programs were carried out by P. D. Neumann and other members of the Reactor Chemistry Division. Structural materials for both aqueous and nonaqueous processes were evaluated.

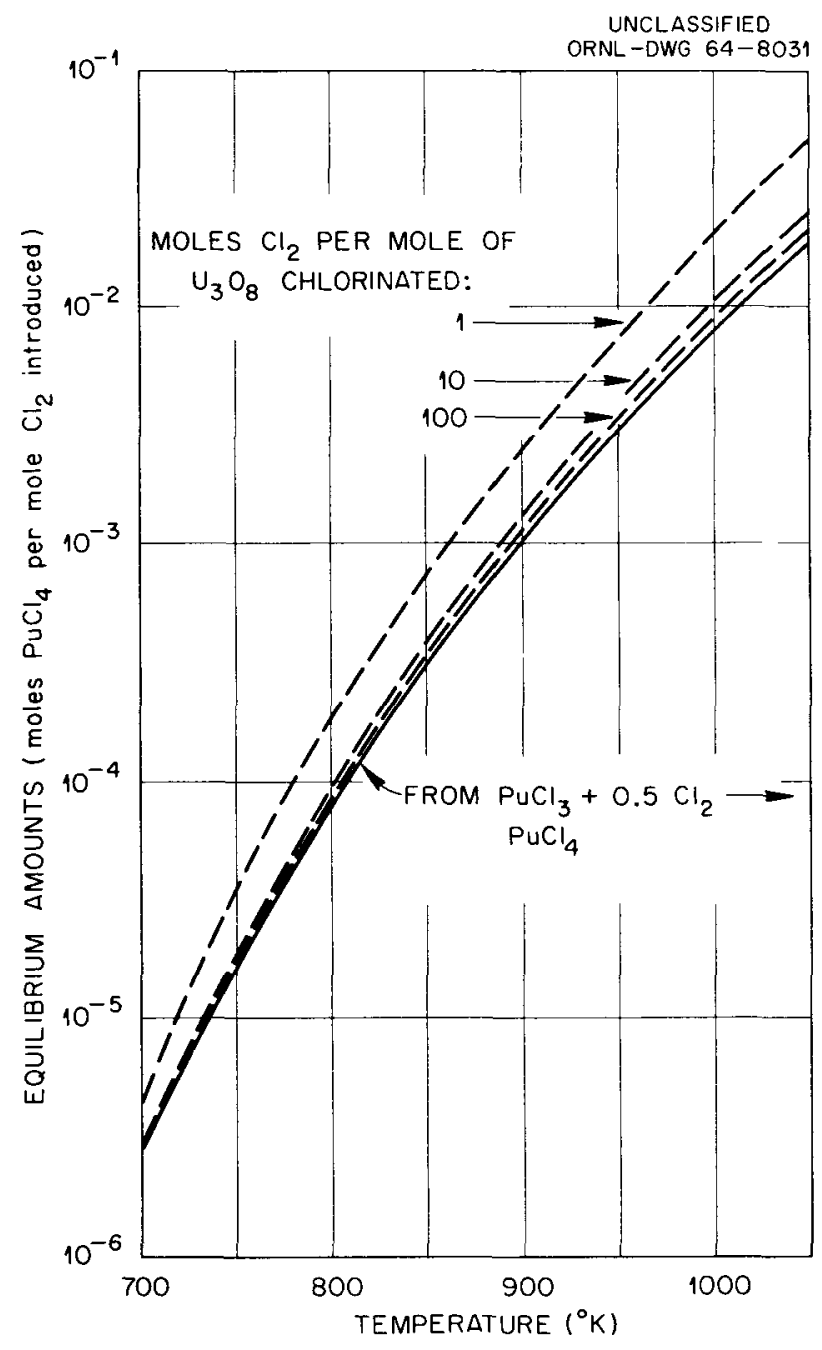

Fig. 1.17. Carrying Capacity of Chlorine for $\mathrm{PuCl}_{4^{\prime}}$ as a Function of Temperature.

\section{Corrosion Tests for Oxidation and Chloride Volatility Processes}

Head-end processes for graphite or carbide fuels generally consist in burning the fuel in oxygen, air, or steam and then dissolving the "ash" in nitric acid. Tests have shown that such processes can be satisfactorily conducted in equipment made of stainless steel or high-nickel alloys. The corrosion rate of type $309 \mathrm{SCb}$ stainless steel for eight cycles of alternate exposure to oxygen at $800^{\circ} \mathrm{C}$ for $5 \mathrm{hr}$, followed by leaching in boiling $5 \mathrm{MHNO}_{3}$ for $\frac{1}{2} \mathrm{hr}$, was $\leq 0.03 \mathrm{mil} /$ month. If the 
ash, such as plutonium dioxide or thorium dioxide, requires the addition of small amounts of hydrogen fluoride to the nitric acid dissolvent, Corronel 230 is the preferred alloy. Substitution of the Thorex dissolvent (13 $M \mathrm{HNO}_{3}-0.04 M \mathrm{HF}$ ) for the $5 M$ $\mathrm{HNO}_{3}$ in the burn-dissolve cycle resulted in a corrosion rate of less than $1 \mathrm{ml} /$ month for Corronel.

Increased burning temperatures can be expected to increase the corrosion rates of nickel and nickel alloys in processes that call for burning and dissolving. Nickel exposed in pure oxygen at $800^{\circ} \mathrm{C}$ formed an adherent, protective film, but the $f_{1} 1 \mathrm{~m}$, when formed at higher temperatures, spalled irregularly. High-temperature alloys such as $\mathrm{N}$ chrome, Corrone1 230, Inconel, and types 309 and 310 stainless steel can be expected to withstand dry oxidation at temperatures varying from 800 to $1100^{\circ} \mathrm{C}$. The addition of 1 vol $\%$ of hydrogen fluoride to the oxygen, accompanied by lowerng the exposure temperature to $600^{\circ} \mathrm{C}$, resulted in corrosion rates on "A" nickel which increased from about $0.1 \mathrm{mil} / \mathrm{month}(24-\mathrm{hr}$ test) to $0.4 \mathrm{mil}$ / month (1008-hr exposure).

Superheated steam, with or without the addition of small amounts of oxygen, is a possible reagent for oxidizing $Z_{11}$ rcaloy-2 or for decomposing carbide fuels. Type 304L stanless steel and "A" nickel exposed in steam at $825^{\circ} \mathrm{C}$ and atmospheric pressure corroded at rates that averaged 0.2 and $0.7 \mathrm{mll} /$ month, respectively, based on $1008 \mathrm{hr}$ of exposure. "A" nickel tested in steam -1 vol $\% \mathrm{O}_{2}$ under these same conditions showed a weight gain equivalent to a corrosion rate of $1.8 \mathrm{ml} / \mathrm{s} /$ month based on $168 \mathrm{hr}$ of exposure.

No material tested showed satisfactory resistance to any processing cycle involving high-temperature chlorination by chlorine or carbon tetrachloride at 500 to $600^{\circ} \mathrm{C}$, followed by oxidation at $800^{\circ} \mathrm{C}$ and aqueous dissolution. Cycle sequences were changed to let either chlorination or oxidation be the first step and to use e1ther hydrochlonic or nitric acid as the aqueous dissolvent. The corrosion rates of all materials tested were $\geq 20 \mathrm{~m} 1 \mathrm{ls} / \mathrm{month}$. Materials tested included "A" nickel, N1chrome V, Haynes 25, and Corronel 230. In cycles involving oxidation at $800^{\circ} \mathrm{C}$, chlorination by hexachloropropene at about $180^{\circ} \mathrm{C}$, and dissolution in $5 \mathrm{MHO}_{3}$, both Nichrome $\mathrm{V}$ and Haynes 25 showed negligible corrosion.

\section{Corrosion Tests for Aqueous Processes}

Carbide and graphite fuels also can be disintegrated by treatment with nitric acid of high concentrations, or they can be chemically oxidized at $150^{\circ} \mathrm{C}$ ("burned") by the use of "nitrating acid," which consists of mixed, concentrated $\mathrm{H}_{2} \mathrm{SO}_{4}-10 \% \mathrm{HNO}_{3}$. For such service, only Duriron and tantalum gave satisfactory corrosion resistance - $\leq 0.3 \mathrm{mil} / \mathrm{month}$. Other materials tested included type $309 \mathrm{SCb}$ stainless steel, Carpenter $20 \mathrm{SCb}$, Corronel 230, $\mathrm{N}_{1}$-o-nel, and Nichrome V. Of the alloys that "failed," type $309 \mathrm{SCb}$ had the lowest corrosion rate, $7.7 \mathrm{mils}$ / month for $96 \mathrm{hr}$ of exposure.

In boiling $7 \mathrm{M} \mathrm{HNO}_{3}-0.05 \mathrm{M} \mathrm{HF}$, Corronel 230 was the most satisfactory of four alloys tested. Maxımum rates for Corronel, type $309 \mathrm{SCb}$, Hastelloy $\mathrm{F}$, and Haynes 25 alloys were 1.9, 13.7, 28.2 , and $6.1 \mathrm{mils} /$ month, respectively, for $48 \mathrm{hr}$ of exposure in the initial dissolvent. When the

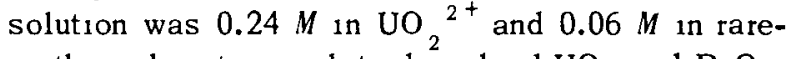
earth oxides, to simulate dissolved $\mathrm{UO}_{2}$ and $\mathrm{PuO}_{2}$, maxımum rates were $0.3,0.4,0.5$, and $0.6 \mathrm{mil}$ / month, respectrvely, based on $504 \mathrm{hr}$ of exposure.

In tests to evaluate the feasibility of absorbing the off-gases from hydrochlorination of zirconium fuels, Hastelloy $B$ was exposed for $1008 \mathrm{hr}$ in bolling $3 \mathrm{M} \mathrm{HCl}-3 \mathrm{MZrOCl}_{2}$. The maximum overall rate was only $1.7 \mathrm{mils} / \mathrm{month}$, but pitting occurred to such a degree that the alloy cannot be recommended for this service.

In miscellaneous tests, Duriron alloy, DC-8, corroded in $5 \mathrm{MHNO}_{3}-2 \mathrm{MHCl}$ (initial Darex dissolvent) at a maximum rate which increased from $3.0 \mathrm{mlls} /$ month, based on $24 \mathrm{hr}$ of exposure, to $3.5 \mathrm{~m} 1 \mathrm{~s} / \mathrm{month}$, based on $72 \mathrm{hr}$ of exposure. In the "midpoint" Darex solution $\left(4 M \mathrm{H}^{+}, 4.3 M\right.$ $\mathrm{NO}_{3}{ }^{-}, 0.15 M \mathrm{Cr}^{3+}, 1.9 M \mathrm{Cl}^{-}, 0.55 M \mathrm{Fe}^{3+}$, $0.06 \mathrm{M} \mathrm{N}^{2+}$ ), the maximum rate increased from 0.5 to $0.7 \mathrm{~m} 1 /$ month, based on 24 and $48 \mathrm{hr}$ of exposure respectively.

\subsection{MECHANICAL PROCESSING DEVELOPMENT}

The major efforts during the past year on mechanical processing of fuels included an evaluation of disassembly methods for second-generation 
power reactor fuels, completion of shearing tests on first-generation fuels, a safety analysis of zirconium-clad fuel shearing, and the development of suitable equipment for the batch-leaching of sheared $\mathrm{UO}_{2}$ and $\mathrm{ThO}_{2}-\mathrm{UO}_{2}$ fuels.

The shear-leach process, ${ }^{34}$ (Fig. 1.18) developed as an alternative to chemical decladding followed by fuel dissolution, includes (1) the shearing of multitubular fuel assemblies or individual tubes into $1 / 2-$ to 2 -in. lengths to expose the fuel material and (2) leaching of the fuel from the disrupted cladding with nitric acid or Thorex dissolvent. With some of the second-generation fuels, at least

\footnotetext{
${ }^{34}$ C. D. Watson et al., The Shear-Leach Process for Spent Nucleat Fuels, ORNL-3625 (to be published).
}

partial fuel element disassembly prior to shearing was required. The feasibility of the shear-leach process has now been fully demonstrated for stainless-steel-clad and Zircaloy-2-clad $\mathrm{UO}_{2}$ and ThO ${ }_{2}-\mathrm{UO}_{2}$ fuels. Further work will be required to show its adequacy for NaK-bonded U-Mo or UC fuels and for fuels made from materials that are insoluble in nitric acid or catalyzed nitric acid.

Since the cladding is not dissolved, the leached cladding can be stored as a solid waste for about one-twentieth the cost of its liquid counterpart. The process not only offers an economic advantage in waste storage but is a useful adjunct to existing chemical processing plants, allowing the processing of a wider variety of spent fuel in conventional stainless steel equipment.

UNCLASSIFIED

ORNL-OWG $63-3131$

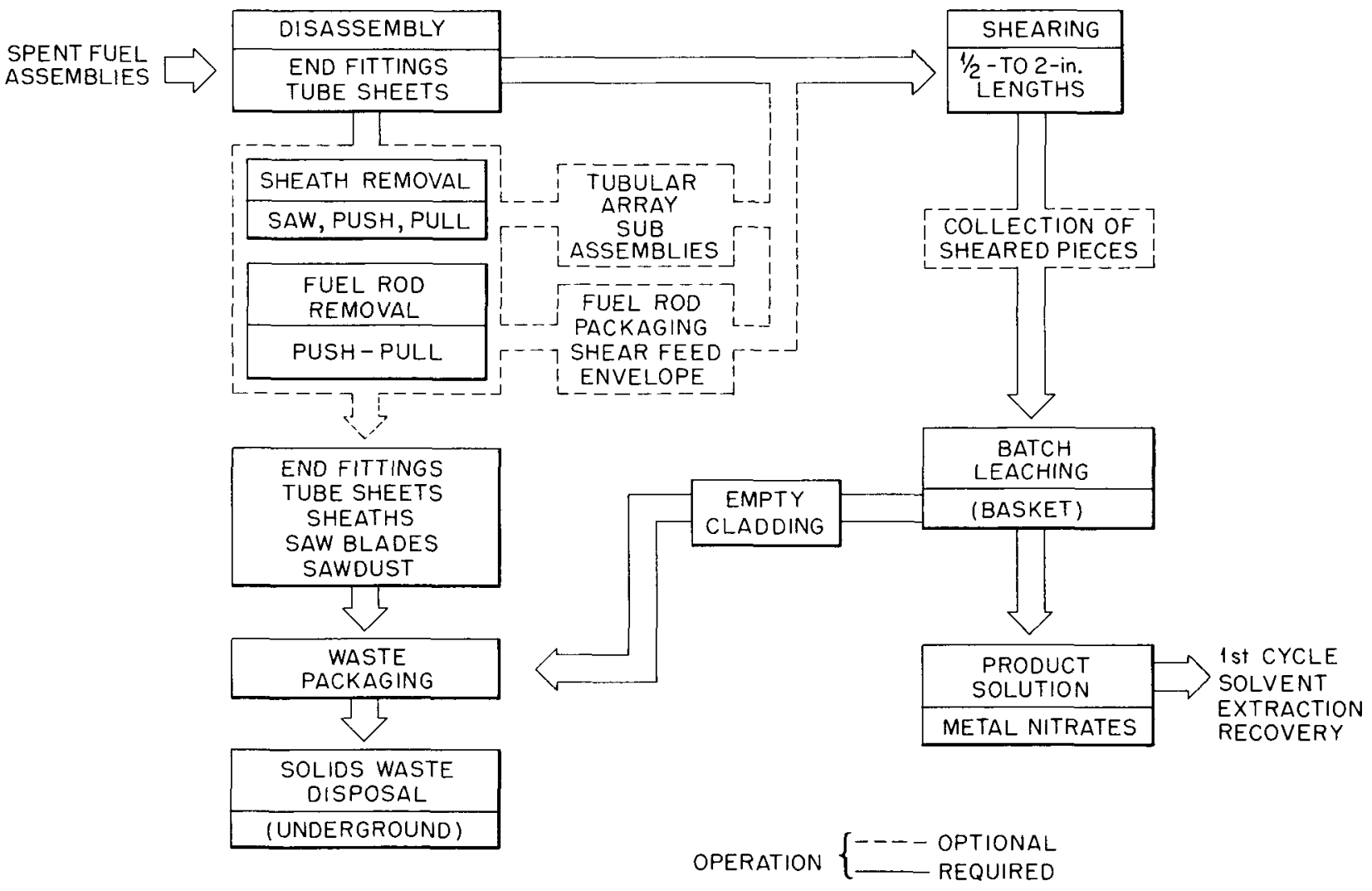

Fig. 1.18. Flowsheet of Shear-Leach Process. 


\section{Fuel-Disassembly Tests}

In the processing of first- and second-generation multitubular fuel arrays, the end adapters are removed prior to shearing. In tests of this operation, the ends were satisfactorily removed by abrasivedisk sawing and by drilling out spot welds that secured the assembly outer sheath to the end adapters. Either method is easily adapted for hotcell use by means of inexpensive commercial equipment. For first-generation fuels, the tubes are held together with brazed ferrules, and the assemblies can be sheared directly. Some secondgeneration fuels (e.g., Consolidated Edison Core B) contain fuel rods that are held in brazed "egg crates" or grids spaced at $1-\mathrm{ft}$ intervals along the fuel assembly. Trial pullings of individual rods showed that the operation is feasible and that a force of 24 to $130 \mathrm{lb}$ would be required. Similar tests in which rods were pushed from an assembly were equally successful. Both methods appear to be practical. Pushing or pulling of selected fuel tubes at appropriate locations permits a parent assembly to be subdivided by abrasive-disk sawing. For example, if a vertical and a horizontal row of tubes intersecting at the center of the assembly are removed, the assembly can then be quartered by sawing through the assembly longitudinally at the vacated sites.

\section{Evaluation of 250-ton Prototype Fuel Shear}

The 250-ton prototype fuel shear consists of a stainless steel housing that contains a horizontally moving ram which carries a stepped blade across a $V$-shaped fixed blade. The shear is also equipped with a horizontally actuated feeding mechanism, gags to hold the spent fuel during shearing, and gibs to adjust the clearance between blades. The design of the shear permits remote replacement of the feed envelope, gags, fixed and moving blades, and the adjustable wearing surfaces or gibs. It is provided with a network type of lubrication system and a separate system of 40 nozzles for remote decontamination with aqueous solutions. All the main features of the shear have been tested to evaluate the adequacy of the design.

Fuel.Feeding Mechanism. - The hydraulic feeding mechanism, which is sealed to the outer end of the envelope, pushes the fuel into the shear at a preset rate against a variable-length stop. This stop, which sets the length to be sheared, was tested with wood, $\mathrm{UO}_{2}$, $\mathrm{ThO}_{2}-\mathrm{UO}_{2}$, and porcelainfilled prototype fuel assemblies, as well as with loosely stacked rods. The envelope and feeding mechanism performed excellently, with the exception of the fuel stop, which was damaged twice. Placement of the stop or its equivalent in the exterior feeding mechanism is recommended.

Gags. - In the 250-ton shear, two gags placed side by side were evaluated for holding multitubular assemblies, subassemblies, and loosely packed fuel tubes. The results of these tests show that two gags, a resilient-faced outer one and a hard-faced inner one, operating in the proper sequence are necessary for satisfactory shearing of nuclear fuel. A single gag does not permit proper feeding of the spent fuel while simultaneously serving as a holding device. The gags are, in principle, an unbroken smooth extension of the feed envelope and must be dimensioned accordingly.

Fixed and Moving Blades. - The fixed blade and fixed-blade holder, or anvil, are $V$-shaped, with the open end of the $V$ facing the leading step of the moving blade. The width is the same as that of the combined outer and inner $V$-shaped gags and opposes the thrust of the gags. This design of the fixed blade appears to be the best general shape to accommodate all fuel types. The life of the fixed blade is estimated to be several reactor cores. A step-shaped moving blade is considered to be the best general-purpose blade. Optimum clearance between the two blades appears to be about 3 mils. During a 38 -min test in which a porcelain-filled ORNL Mark I assembly was sheared 169 times $(1 / 2-i n$. cuts), an increase in blade temperature from $39^{\circ} \mathrm{C}$ to $62^{\circ} \mathrm{C}$ occurred within $10.5 \mathrm{~min}$ (50 cuts). The temperature remained at about $62^{\circ} \mathrm{C}$ for the remainder of the shearing.

Decontamination and Lubrication. - In a single test in which the shear interior was contaminated with about $300 \mathrm{~g}$ of $\mathrm{UO}_{2}$ and $\mathrm{ThO}_{2}-\mathrm{UO}_{2}$ fines, the shear was satisfactorily cleaned with four water washes of about 30 liters each. The total shear holdup was approximately $1450 \mathrm{~g}$ of $\mathrm{UO}_{2}$ and $\mathrm{ThO}_{2}-\mathrm{UO}_{2}$, resulting from 1450 cuts of $\mathrm{UO}_{2}$-filled and 215 cuts of ThO ${ }_{2}-\mathrm{UO}_{2}$-filled ORNL Mark I fuel assemblies. Approximately $1150 \mathrm{~g}$ of the contaminants had been removed from the shear by vacuum cleaning before washing. 
Lubrication of the shear is probably not required, but water containing about $0.1 \%$ of fine molybdenum disulfide is recommended.

\section{Shearing Tests}

Sofety of Shearing Zircaloy-2. - Zirconium-clad prototype fuel was sheared for the first time in the ORNL 250-ton shear. A fuel bundle consisting of 77 loose Zircaloy- 2 tubes $(0.42$ in. in diameter, with a 30-mil wall) filled with $\mathrm{UO}_{2}$ pellets was sheared into 0.5-, 1.5-, and 2.0-in. lengths. The maximum shearing force required varied from 71 to 92 tons, compared with 63 tons for shearing a stainless steel fuel bundle (ORNL Mark I assembly). Shearing was accomplished without difficulty and with no apparent risk of igniting the parent assembly. Some sparking was observed during shearing of the Zircaloy-2 tubes, but particle specimens larger than $3 / 8$-in., 149 to $297 \mu$, and 74 to $149 \mu$ (examined at $500 \times$ by M. L. Pickelsimer of the Metals and Ceramics Division) showed no evidence of oxygen contamination, annealing of the grain structure, or of temperatures sufficiently great to have formed a detectable oxide skin. More than $95 \%$ of the dislodged Zircaloy- 2 particles in the two smallest fractions measured, 44 to $74 \mu$ and $<44 \mu$, were magnetic. This has not yet been explained, and an investigation of this magnetism is continuing. The particles in these two fractions were determined by the $\mathrm{x}$-ray absorption-edge method to consist of 48 to $73 \%$ zirconium; a small amount of iron was also detected.

Some of the sheared cladding was cracked circumferentially, and a large number of pieces were split longitudinally into several sections. This fracturing of the Zircaloy-2 cladding allowed a much greater percentage of the core material to become dislodged than was the case with stainless steel cladding (Fig. 1.19).

Effect of Tubing Wall Thickness on Shearing. Fuel tubes or rods were withdrawn from a Consolidated Edison Core B assembly and stacked loosely in an orderly array in feed envelopes for shearing tests on loose rods. These fuel rods are 0.3 in. in
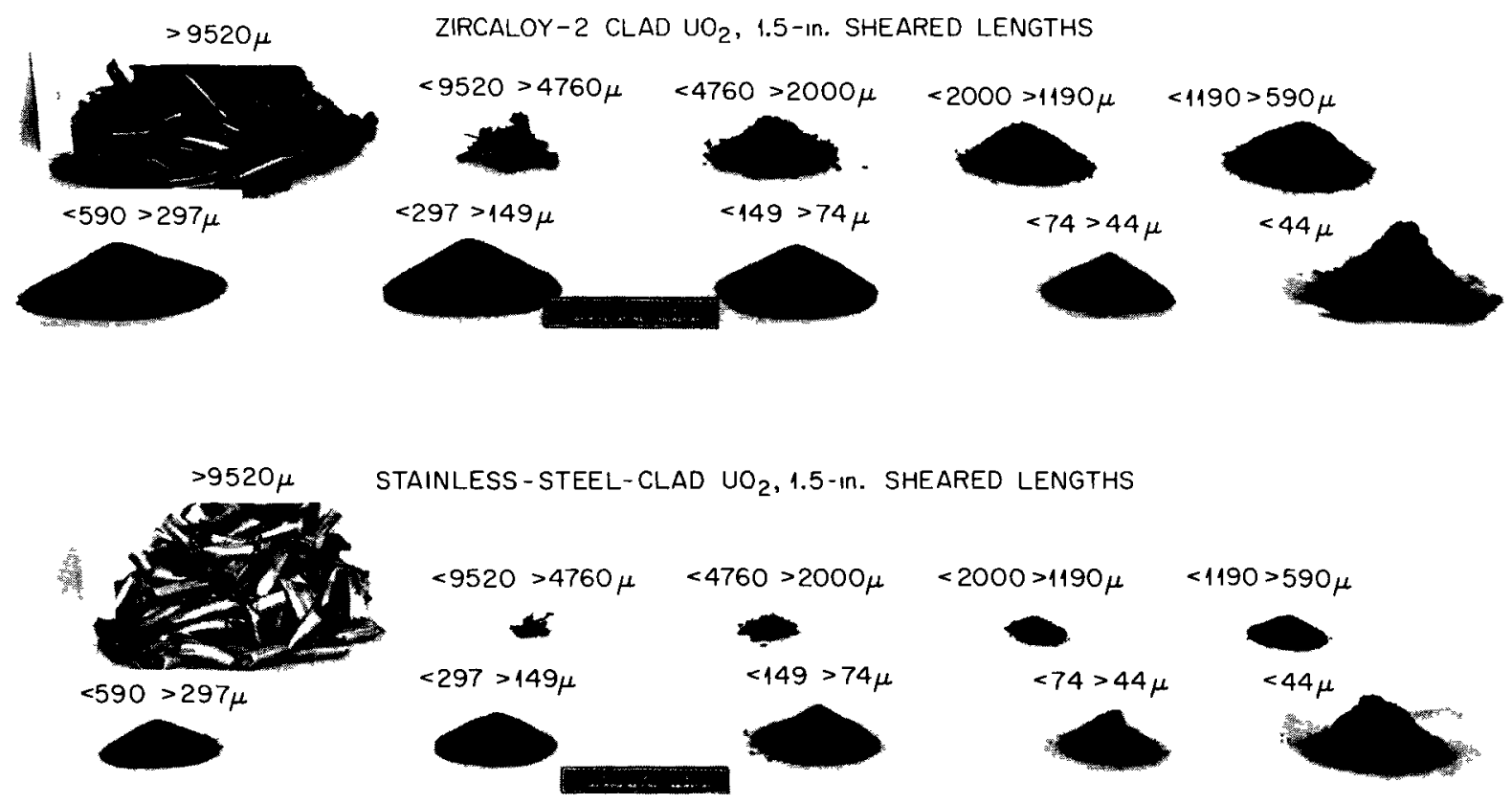

Fig. 1.19. Comparison of Particle-Size Fractions Produced from Shearing Zircaloy-2. and Stainless-Steel-Clad $\mathrm{UO}_{2}$ Prototype Fuel Assemblies. 
diameter and $12 \mathrm{in.}$ long, with 11-mil walls. Two arrays were evaluated: the first was 2.75 by 2.75 in. and contained 93 tubes; the other was 3.75 by 3.75 in. and contained 156 tubes. The bundles were easily gagged and sheared. The results of tests with fuel rods filled with porcelain and sheared into 1-in. lengths showed that the bundles of small tubes were easily restrained and held during shearing; the thin ( 11 mils) wall was sheared as easily as tubing with $30-$ to $35-\mathrm{mil}$ walls, and terminal lengths of $\leq 1.5$ in. were easily attained.

Shearing of Intact and Subdivided Fuel Assem. blies. - First-generation unsheathed fuel assemblies of brazed tubular construction up to a maximum size of 3.6 by 3.6 in. were easily sheared intact. Larger sizes have not yet been tried. Attempts to shear intact, second-generation, 6- by 6-in. sheathed fuel containing egg crates (Consolidated Edison Core B) into which the fuel rods are inserted were unsuccessful because the sheath prevented proper holding of the fuel during shearing. In subsequent tests with the same assembly, two rows of tubes were removed, and the parent assembly was sawed longitudinally into subassemblies, as explained in "Fuel-Disassembly Tests," this chapter. Subassemblies of $2.6-$ by 2.6 -in. and 3.6by $3.6-i n$. configurations were then easily sheared. Further tests with second-generation fuels are planned.

\section{Batch Leaching Studies}

Batch leaching studies were conducted on bench and engineering scales with sheared, unitradiated, prototype $\mathrm{ThO}_{2}-\mathrm{UO}_{2}$ and $\mathrm{UO}_{2}$ fuel to determine the time required for leaching $99.9 \%$ of the fuel and to evaluate the feasibility of leaching in a perforated basket. Typical data are given in Table 1.3 for both shearing and leaching.

Bench-Scale Leaching of Clad $\mathrm{ThO}_{2} \cdot \mathrm{UO}_{2}$ and $\mathrm{UO}_{2}$ Pellets. - Leaching studies were performed in which unirradiated sheared stainless-steel-clad $\mathrm{ThO}_{2}-\mathrm{UO}$ and $\mathrm{UO}$ pellets were leached in $12 \mathrm{M}$ $\mathrm{HNO}_{3}^{2}-0.04 \quad M \quad \mathrm{NaF}-0.10 M \mathrm{Al}_{2}^{2}\left(\mathrm{NO}_{3}\right)_{3}$ and $7 M$ $\mathrm{HNO}_{3}$ respectively. Variables studied in the $\mathrm{ThO}_{2}^{3}-\mathrm{UO}_{2}$ leaching were, in order of importance, air sparging for agitation of $\mathrm{ThO}_{2}-\mathrm{UO}_{2}$ fines released from the fuel basket, length of sheared fuel pieces, and fuel basket design. The 4-in.-diam batch leacher used in these experiments is shown in Fig. 1.20.

The minimum time observed for $99.9 \%$ dissolution of pelletized $\mathrm{ThO}_{2}-\mathrm{UO}_{2}$ was $6.7 \mathrm{hr}$. In this test, $1 / 2$-in. sheared lengths of stainless-steel-clad $\mathrm{ThO}_{2}$ $\mathrm{UO}_{2}$ were leached in a perforated basket, employing an air sparge. Without an air sparge, the average dissolution time for both $\frac{1}{2}-$ and 1 -in. lengths was about $12 \mathrm{hr}$ (Fig. 1.21). The leaching time required for $1 \frac{1}{2}$-in. lengths of fuel was considerably longer than for $1 / 2$ - or 1 -in. lengths under the same conditions. The extrapolated time for $99 \%$ dissolution was $14 \mathrm{hr}$, compared with $8 \mathrm{hr}$ for the shorter lengths. Terminal thorium-plus-uranium concentrations in all runs was about $125 \mathrm{~g} /$ liter.

Four runs in which sheared metal-clad UO fuel was leached in $7 \mathrm{M} \mathrm{HNO}_{3}$ resulted in $99.9 \% \mathrm{UO}_{2}$ dissolution in less than $2 \mathrm{hr}$. Material sheared to $1 \frac{1}{2}$-in. lengths leaches appreciably faster than that cut into 2-in. lengths. Also, $\mathrm{UO}_{2}$ was leached more rapidly from $Z$ ircaloy- 2 cladding than from stainless steel cladding, possibly because the sheared ends of the Zircaloy- 2 are almost fully open, while the ends of the more ductile stainless steel are partially closed.

Table 1.3. Typical Shear-Leach Data for Prototype Power-Reactor Fuels

\begin{tabular}{|c|c|c|c|c|c|c|c|c|c|}
\hline Fuel & Cladding & $\begin{array}{l}\text { Shearıng } \\
\text { Force } \\
\text { (tons) }\end{array}$ & $\begin{array}{l}\text { Recommended } \\
\text { Sheared } \\
\text { Length } \\
\text { (1n.) }\end{array}$ & $\begin{array}{l}\text { Core } \\
\text { Dislodged } \\
(\%)\end{array}$ & $\begin{array}{c}\text { Clad } \\
\text { Dislodged } \\
(\%)\end{array}$ & $\begin{array}{l}\text { Packing } \\
\text { Density } \\
\left(\mathrm{g} / \mathrm{cm}^{3}\right)\end{array}$ & $\begin{array}{c}\text { Vold } \\
\text { Fraction } \\
(\%)\end{array}$ & $\begin{array}{l}\text { Time to Batch } \\
\text { Leach } 99.9 \% \\
\text { (hr) }\end{array}$ & Notes \\
\hline $\begin{array}{l}\mathrm{UO}_{2} \\
\text { (pellets) }\end{array}$ & $\begin{array}{l}\text { Stanless steel } \\
\text { or Zircaloy-2 }\end{array}$ & $50-90$ & $\begin{array}{l}1 \\
1 \frac{1}{2}\end{array}$ & $\begin{array}{l}36 \\
28\end{array}$ & $\begin{array}{l}2 \\
2 \frac{1}{2}\end{array}$ & 4.8 & $\begin{array}{l}50 \\
55\end{array}$ & $2^{1 / 2}$ & \\
\hline $\begin{array}{l}\mathrm{UO}_{2}-\mathrm{ThO}_{2} \\
\text { (pellets) }\end{array}$ & Stainless steel & $50-75$ & $1^{1 / 2}$ & $\begin{array}{l}85 \\
36\end{array}$ & $\begin{array}{l}8 \\
2\end{array}$ & 4.4 & $\begin{array}{l}48 \\
50\end{array}$ & $\begin{array}{l}8 \\
12\end{array}$ & $\begin{array}{l}\text { Sparged } \\
\text { Not sparged }\end{array}$ \\
\hline $\begin{array}{c}\mathrm{UO}_{2}-\mathrm{ThO}_{2} \\
(\mathrm{sol} \text { gel })^{2}\end{array}$ & Stainless steel & $50-75$ & $1^{1 / 2}$ & $\begin{array}{l}85 \\
36\end{array}$ & $\begin{array}{l}8 \\
2\end{array}$ & 4.4 & $\begin{array}{l}48 \\
50\end{array}$ & $\begin{array}{l}20 \\
65\end{array}$ & $\begin{array}{l}25 \% \text { heel } \\
\text { No heel }\end{array}$ \\
\hline
\end{tabular}




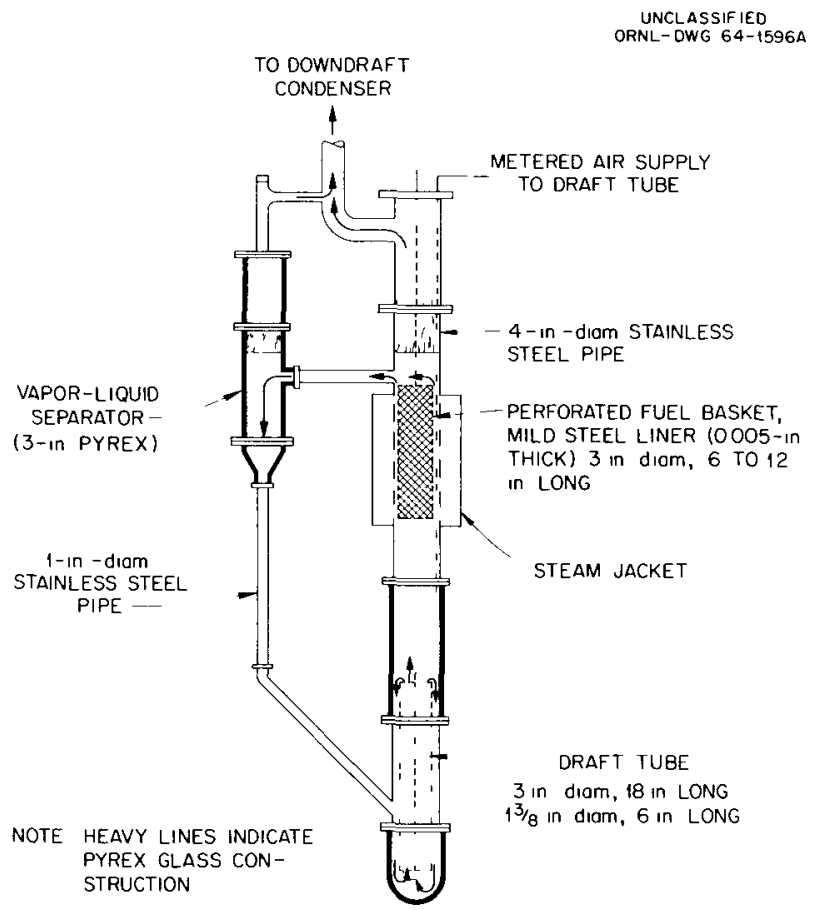

Fig. 1.20. Recirculating 10-Liter Batch Leacher. Liquid height: about $4 \mathrm{ft}$.

Air sparging was not used since the reaction was very energetic and did not require suspension of $\mathrm{UO}_{2}$ fines. The bed of $\mathrm{UO}_{2}$ fines was about 2 in. deep in the bottom of the leacher at some time during each run. Because of the high reactivity of $\mathrm{UO}_{2}$ fines with $\mathrm{HNO}_{3}$, the fuel basket was immersed in the dissolvent at room temperature and then heated to $105^{\circ} \mathrm{C}$. (The leaching basket employed in these runs is the tall one in Fig. 1.22).

Engineering-Scale Leaching of $\mathrm{Clad}_{\mathrm{ThO}_{2}} \cdot \mathrm{UO}_{2}$ and $\mathrm{UO}_{2}$ Pellets. - Unirradiated $1 / 2-$ and $1-i n$. long sheared sections of stainless-steel-clad $\mathrm{ThO}_{2}-\mathrm{UO}_{2}$ (17.3 kg of $96.88 \% \quad \mathrm{ThO}_{2}-3.12 \% \mathrm{UO}_{2}$ and $6.4 \mathrm{~kg}$ of stainless steel) were batch leached in an engineering-scale batch leacher in which boiling $\left(117.5^{\circ} \mathrm{C}\right)$ dissolvent $10.7 \mathrm{M}$ in $\mathrm{HNO}_{3}, 0.04$ $M$ in $\mathrm{Al}^{3+}$, and $0.04 M$ in $\mathrm{F}^{-}$was in convection circulation. The effect of sheared length on dissolution time was measured. Dissolution of the $\mathrm{ThO}_{2}-\mathrm{UO}_{2}$ was $99.9 \%$ complete in $18 \frac{1}{2} \mathrm{hr}$ for $1 / 2$-in. sections, and in $18 \mathrm{hr}$ for 1 -in. sections. The final product solution contained $160 \mathrm{~g}$ of thorium per liter and was $9.6 \mathrm{M}$ in $\mathrm{HNO}_{3}$; it had a volume of 92 liters and was almost the same for each case. Except for the amount of fines dislodged from the basket during dissolution of the consumable steel liner ( $4110 \mathrm{~g}$ of iron for $1 / 2-i n$. sections and $1650 \mathrm{~g}$ for 1-in. sections), there was no appreciable difference in the batch leaching of $1 / 2$ - or 1 -in sheared sections.

An engineering-scale batch leaching of $25 \mathrm{~kg}$ of fuel containing $19.1 \mathrm{~kg}$ of $\mathrm{UO}_{2}$ and $5.85 \mathrm{~kg}$ of stainless steel sheared to 1-1n. sections, with boiling $\left(108^{\circ} \mathrm{C}\right) 7.11 \mathrm{M} \mathrm{HNO}_{3}$ as the dissolvent, resulted in more than $99.9 \%$ dissolution of the $\mathrm{UO}_{2}$ in $2 \mathrm{hr}$. The final product composition was: $183^{2} \mathrm{~g} /$ liter uranium, $5 \mathrm{M} \mathrm{HNO}_{3}, 2.08 \mathrm{~g} /$ liter $\mathrm{Fe}^{3+}$, $0.019 \mathrm{~g} /$ liter $\mathrm{Cr}^{3+}$, and $0.103^{3} \mathrm{~g} /$ liter $\mathrm{Ni}^{2+}$. The volume of $\mathrm{UO}_{2}$ fines carried out of the basket during dissolution of the consumable liner was about $1150 \mathrm{ml}$ (estimated weight, $7170 \mathrm{~g}$ ).

Bench-Scale Leaching of Sized Sol-Gel-Derived $\mathrm{ThO}_{2}$ aUO $2^{\circ}$ - Dissolution rates of $\mathrm{ThO}_{2}-\mathrm{UO}_{2}$ prepared by the sol-gel process were measured for the two extremes ( 6 to 16 mesh and -200 mesh)

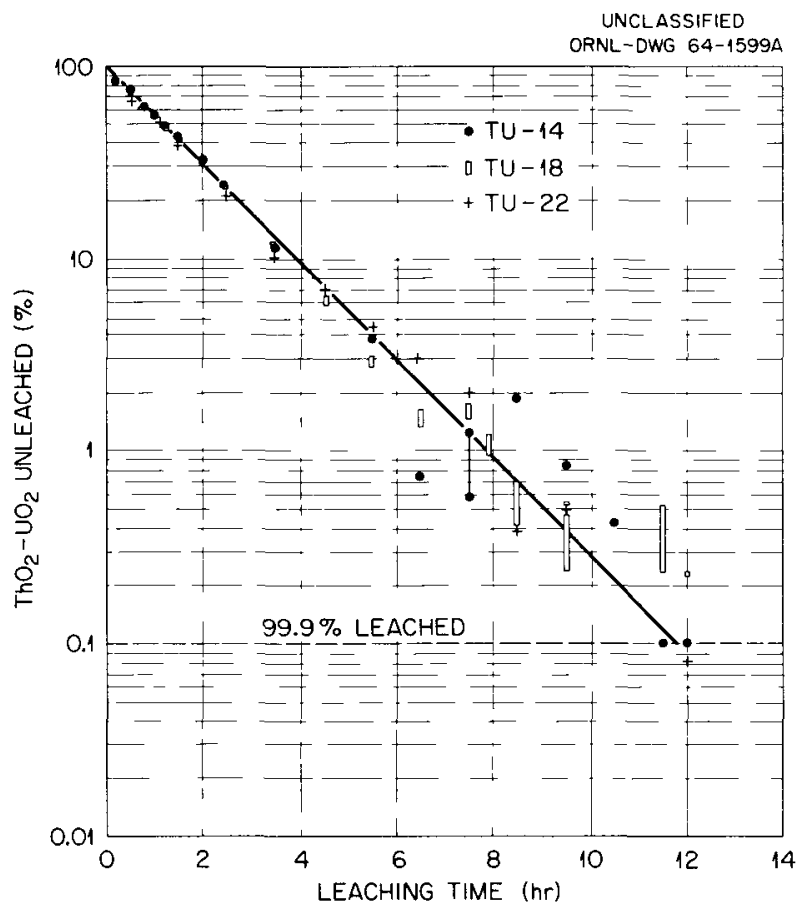

Fig. 1.21. $\mathrm{ThO}_{2}-\mathrm{UO}_{2}$ Remaining Unleached vs Time. Comparison of leaching rate of $1-\mathrm{mn}$. sheared lengths (duplicate runs TU.14 and TU.18) and $1 / 2$-in. sheared lengths (run TU-22), with no air sparge. Basket material: $0.020-i n$-diam holes, $24 \%$ free orea. 
of the size distribution usually employed in vibratorily packed fuel. The distribution recommended for $1 / 2$-in.-diam fuel tubes is $60 \% 6$ to 16 mesh, $15 \% 70$ to 140 mesh, and $25 \%-200$ mesh.

Dissolution of nominal 6- to 16 -mesh sol-gel material followed the relationship $R=0.718 e^{-0.099 t}$ (for $t>12 \mathrm{hr}$ ), where $R$ is the fraction remaining at any time $t$ in hours. Since the fines dissolve much more rapidly, $99.9 \%$ of the size distribution specified for $1 / 2-i n$. tubes will dissolve in about $60 \mathrm{hr}$. A $1500-\mathrm{g}$ batch of -200 -mesh sol-gel material was also leached in 10 liters of refluxing dissolvent. At an air-sparge rate of $0.05 \mathrm{scfm}$, $99.92 \%$ dissolution was achieved in $14 \mathrm{hr}$. The composition of the dissolver solution in both runs was approximately $0.55 M \mathrm{Th}-0.017 M \mathrm{U}-9.5 M$ $\mathrm{HNO}_{3}-0.04 M \mathrm{NaF}-0.10 M \mathrm{Al}\left(\mathrm{NO}_{3}\right)_{3}$.

Dissolution of Sol-Gel-Derived $\mathrm{ThO}_{2} \cdot \mathrm{UO}_{2}$ by Heel Operation. - The slow dissolution rate of sol-gel-derived $\mathrm{ThO}_{2}-\mathrm{UO}_{2}$ suggested that dissolving to a heel, in comparatively short cycles, would almost certainly be preferable to complete core dissolution of each batch.

A series of eight $20-\mathrm{hr}$ dissolution cycles, in which a $1400-\mathrm{g}$ charge of sol-gel $\mathrm{ThO}_{2}-\mathrm{UO}_{2}$ was added to the residue in the leaching basket at the end of each cycle, produced a maximum heel of $356 \mathrm{~g}$, equivalent to $25 \%$ of the individual charge, at the end of six cycles. The size distribution of the $\mathrm{ThO}_{2}-\mathrm{UO}_{2}$ heel contained in the basket at the end of the fifth and eighth cycles was as follows:

$\begin{array}{rcc}\text { Mesh Size } & \begin{array}{c}\text { Fifth Cycle } \\ (\%)\end{array} & \begin{array}{c}\text { Eighth Cycle } \\ (\%)\end{array} \\ 6 \text { to } 10 & 50 & 33 \\ 10 \text { to } 20 & 45 & 60 \\ 20 \text { to } 50 & 5 & 7\end{array}$

The amount of undissolved $\mathrm{ThO}_{2}-\mathrm{UO}_{2}$ found outside the basket at the end of a 20 -hr cycle was so small that it could have been discarded.
Batch Leaching of Sheared Stainless.Steel-Clad Sol.Gel $\mathrm{ThO}_{2} \cdot \mathrm{UO}_{2} \cdot$ - Previous batch leaching work showed that pelleted $\mathrm{ThO}_{2}-\mathrm{UO}_{2}$ was leached from stainless-steel-clad $\mathrm{ThO}_{2}^{2}-\mathrm{UO}_{2}^{2}$ fuel more rapidly for $1 / 2-$ in. sheared lengths (about $7 \mathrm{hr}$ ) than for 1-in. lengths (about $12 \mathrm{hr}$ ), with other conditions optimized.

Stainless-steel-clad sol-gel $\mathrm{ThO}_{2}-\mathrm{UO}_{2}$ was 99.9\% leached in about $32 \mathrm{hr}$ for $\frac{1}{2}$-in. sheared lengths and $51 \mathrm{hr}$ for 1 -in. sheared lengths. The ratio of these numbers is virtually the same as the $7-\mathrm{hr}$ to 12 -hr ratio for pelletized $\mathrm{ThO}_{2}-\mathrm{UO}_{2}-$ about $60 \%$. These absolute time values for sol-gel $\mathrm{ThO}_{2}-\mathrm{UO}_{2}$ are somewhat optimistic, since terminal thorium concentration was only about $75 \mathrm{~g} / \mathrm{liter}$, compared with a value of $125 \mathrm{~g} /$ liter for all previous leaching runs.

Fuel-Basket Design Specifications. - A fuel basket must be designed to receive sheared fuel from the shear and transport it to the leacher, support the cut fuel within the leacher while the core material is being leached, and remove the empty metal cladding from the leacher.

The five baskets tested and representative sections of the cylindrical bottom and surfaces are shown in Fig. 1.22. When relatively weak perforated sheet metal was employed (the first and third baskets), the bottom was reinforced with heavier perforated sheet. The percentage of free area in the bottoms of these two baskets is the product of the value of each lamination, or about $6 \%$.

Principal variables examined included hole size and shape and percentage of free area of the basket material. Most of the runs that were made to determine the optimum basket design were made with 1-in. sheared lengths of stainless-steel-clad $\mathrm{ThO}_{2}-\mathrm{UO}_{2}$ in a nonsparged system.

The five types of perforated sheet evaluated for basket liner use were ranked on the basis of time required for sheared fuel to be $99 \%$ leached. The first three materials shown in Fig. 1.22 gave about equal performance within the accuracy of the dissolution-time measurements made. 


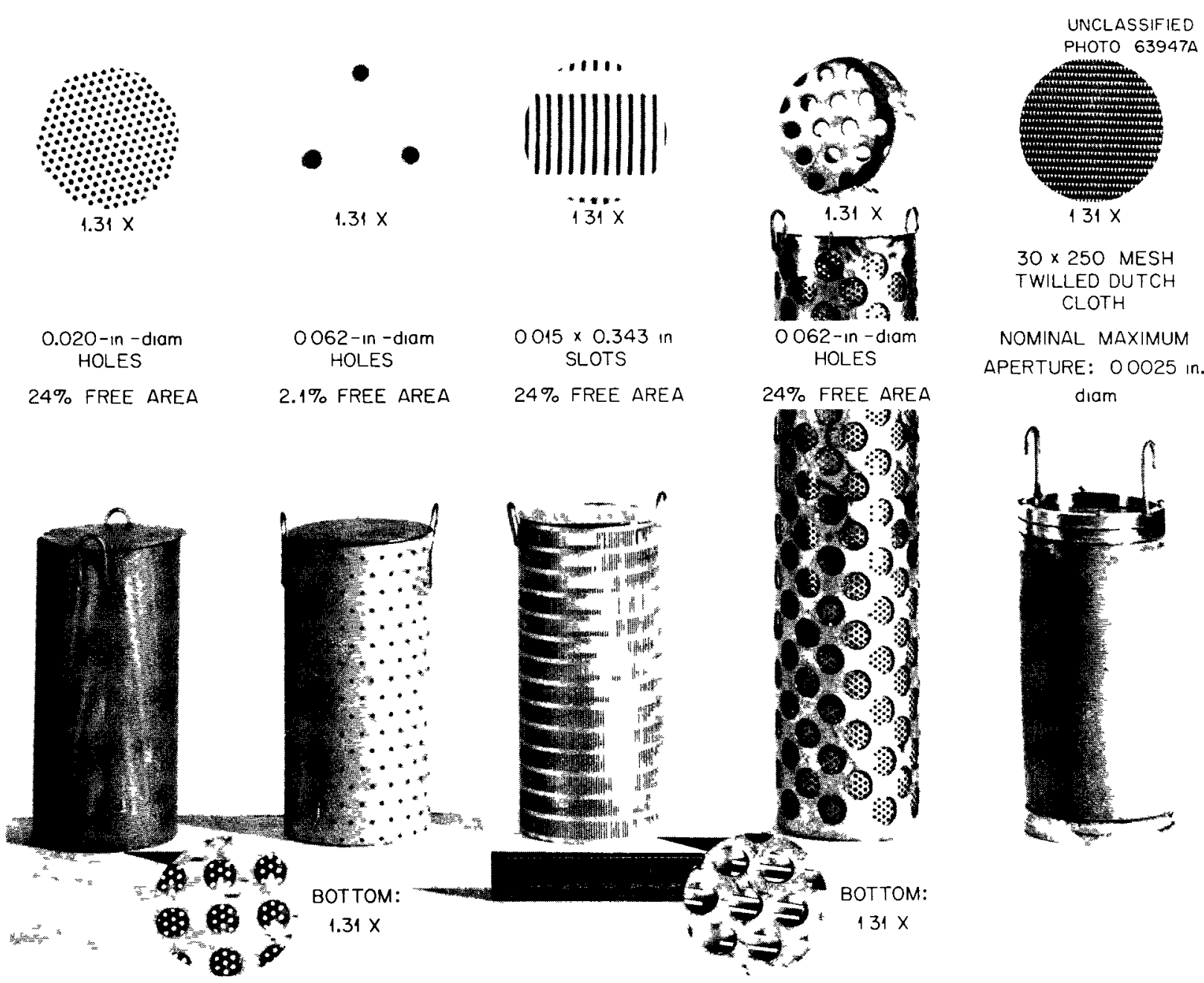

Fig. 1.22. Perforated Leaching Baskets, in Order of Effectiveness. All baskets 3 in. in outer diameter and $6 \mathrm{in}$. high, except the fourth, which is $3 \mathrm{in}$. in outer diameter and $12 \mathrm{in}$. high. 


\section{Fluoride Volatility Processing}

The purpose of the volatility program in the United States is to develop an alternative to conventional aqueous processes for recovering uranium from spent nuclear fuels. Current major volatility processes depend upon either volatiliz• ing uranium as $\mathrm{UF}_{6}$ from nonaqueous solutions of the reactor fuel, structural materials, and fission products, or volatilizing certain structural materials, such as zirconium and aluminum, from the uranium as their chlorides. In some cases, structural metals and the accompanying uranium are first converted to their chlorides with a chlorinating agent; fluorine is then used to convert the nonvolatile uranium chloride to the volatile $\mathrm{UF}_{6}$.

Some of the potential advantages of volatility processes, compared with aqueous processes, are (1) the formation of a dry, highly concentrated waste, (2) the greater ease of processing certain refractory fuels, (3) fewer processing steps between the original fuel element and $\mathrm{UF}_{6}$, and (4) increased nuclear safety.

At ORNL, the emphasis has been on a moltensalt fluoride-volatility process which consists basically of three steps: (1) dissolution of the metal (or oxide) by hydrofluorination in a molten salt, (2) volatilization of uranium from the melt as $\mathrm{UF}_{6}$ by contacting the salt with gaseous fluorine, and (3) the purification of the product UF from contaminants by passing the impure gas stream through beds of $\mathrm{NaF}$ and $\mathrm{MgF}_{2}$ pellets.

The first fuel processed here by the molten-salt fluoride-volatility process was the molten salt from the Aircraft Reactor Experiment. The next effort was the development of a process for use with alloys of zirconium and highly enriched uranium. A few years ago, the study of the application of the process to Al-U alloy fuels began; this work was prompted by the large potential load of such fuels to be processed. In addition, some work has been done on developing processes for fuels containing zirconia-urania, thoria-urania, beryllia-urania, and stainless steel.

Studies have also been made here aimed at the volatilization and recovery of uranium and plutonium from low-enrichment fuels, but the principal effort has been at Argonne National Laboratory, by use of a fluidized-bed approach. The application of fluidized-bed methods to fuels containing highly enriched uranium has also been studied there. The nitrofluor process is being studied at Brookhaven National Laboratory for possible application to fuels containing both low- and highenrichment uranium.

Work on the molten-salt fluoride-volatility process for $\mathrm{Zr}-\mathrm{U}$ alloy fuels at ORNL is nearly complete, and its application to Al-U alloy fuels is being studied.

In the future, process development efforts will emphasize the application of the molten-salt fluoride-volatility approach to low-enrichment fuels. Also, a proposal was made to install a fluidized-bed fluoride-volatility pilot plant in Building 3019, primarily for studies on stainlesssteel- or $z$ irconium-clad $\mathrm{UO}_{2}$.

\subsection{PROCESSING OF URANIUM-ZIRCONIUM ALLOY FUEL}

Many nuclear reactors are fueled with $U-Z_{r}$ alloy, but such fuels are difficult and expensive to process by conventional aqueous methods. Therefore, in order to develop an alternative method for recovering enriched uranium from spent zirconium-alloy fuel elements, the Chemical Technology Division has adapted the molten-salt fluoride-volatility process to this purpose. Studies have been made at laboratory and engineering scales, and during this past year a series of 
tests in the ORNL Volatility Pilot Plant was successfully completed.

\section{Operability of Molten-Salt Fluoride-Volatility Process for Zirconium-Uranium Alloy Fuels Proved by Tests in Pilot Plant}

An extensive series of tests of the process for recovering uranium from spent $\mathrm{U}-\mathrm{Zr}_{\mathrm{r}}$ alloy fuels was conducted in the ORNL Volatility Pilot Plant with the objectives of (1) proving the process at that scale and (2) gathering sufficient information to serve as the basis for the design of a commercial plant. The process was as described in the introduction to this chapter.

The test series of five runs was successfully completed, and the two objectives mentioned above were met. Therefore, the program was terminated. The results of the first two runs were reported last year, ${ }^{1}$ but all five are summarized here. These five pilot plant experiments were made with highly irradiated, short-decayed (6 to 13 months) fuel.

In this series, the capability for sustained operation was demonstrated. Chemical purity of the product was acceptable, and losses were satisfactorily low. Decontamination from fission products was extremely good, and the maintenance of high decontamination factors was demonstrated. Corrosion of the dissolver, although high when compared with that in conventional processes, was not crucial. Attack was reasonably uniform, and the rate of corrosion is predictable, so adequate allowances can be made in designing a similar vessel.

Description of Process for Zirconium-Uranium Alloy Fuel as Studied in the Pilot Plant. - The flowsheet depicting equipment and flow patterns that were used for processing $U-Z_{r}$ alloy fuel elements is shown in Fig. 2.1. This flowsheet encompasses the dissolution of fuel elements in a molten fluoride salt, fluorination to separate the uranium (as $U F_{6}$ ) from the salt and from most of the fission products, and further purification and recovery of the UF .

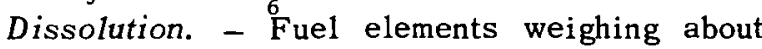
$42 \mathrm{~kg}$ (total) are lowered into the dissolver and are then covered with a molten salt (37.5-37.5-25

\footnotetext{
${ }^{1}$ Chem. Technol. Div. Ann. Progr. Rept. May 31, 1963, ORNL-3452, p. 33.
}

mole \% LiF-NaF- $-\mathrm{rF}_{4}$ ) at $650^{\circ} \mathrm{C}$. Anhydrous $\mathrm{HF}$ is sparged through the salt, converting the fuel element to $\mathrm{ZrF}_{4}$ and $\mathrm{UF}_{4}{ }_{4}$. As the zirconium content of the melt builds up toward its final concentration of 45 mole \%, the temperature is reduced to $500^{\circ} \mathrm{C}$. Complete dissolution requires 12 to $17 \mathrm{hr}$.

Submicron-size solids generated during dissolution are scrubbed from the off-gas by liquid $\mathrm{HF}$. These solids and any $\mathrm{H}_{2} \mathrm{O}$ resulting from oxide dissolution are retained in the $\mathrm{HF}$ catch tank for discharge at the end of the run. Unreacted HF is recirculated. Noncondensibles (hydrogen and inert purge gases) are scrubbed by $2 N \mathrm{KOH}$ solution before being discharged to the off-gas system.

After dissolution is complete, the salt is transferred to the fluorinator for uranium removal.

Fluorination. - Salt in the fluorinator is kept at $500^{\circ} \mathrm{C}$. Fluorine is admitted into a draft tube in the lower section of the fluorinator, thus supplying pumping action to circulate the salt. In $2 \mathrm{hr}$, the fluorine converts the $\mathrm{UF}_{4}$ to $\mathrm{UF}_{6}$, which volatilizes from the salt. Most of the fission products remain in the salt, which is later transferred to a waste can for burial.

During fluorination and subsequent product purification, excess fluorine is reacted with $\mathrm{KOH}$ solution in a spray tower before the off-gas is discharged.

Product Purification and Recovery. - The gas stream from fluorination, containing $\mathrm{UF}_{6}$, is routed through the movable-bed absorber, which contains $\mathrm{NaF}$ pellets. The first portion of this sorber is held at $400^{\circ} \mathrm{C}$. At this temperature, some fission and corrosion products, such as fluorides of niobium and chromium, are sorbed, but UF ${ }_{6}$ passes through. The gas stream then enters a portion of the $\mathrm{NaF}$ bed held at $100^{\circ} \mathrm{C}$. At this temperature, $\mathrm{UF}_{6}$ is retained by the $\mathrm{NaF}$. Technetium, neptunium, and molybdenum fluorides are also retained, but all other impurities present at this point leave the sorber through the outlet line near the middle of the vessel. This stream passes through another $\mathrm{NaF}$ bed (at room temperature) before discharge to the caustic scrubber.

After the concurrent fluorination and sorption are complete, the portion of the bed containing $\mathrm{UF}_{6}$ is heated to $150^{\circ} \mathrm{C}$ to remove $\mathrm{MoF}_{6}$; a fluorine sweep is also used. The entire bed is then heated to $400^{\circ} \mathrm{C}$ (with a fluorine sweep) to remove UF through the outlet line at the top of the vessel. 


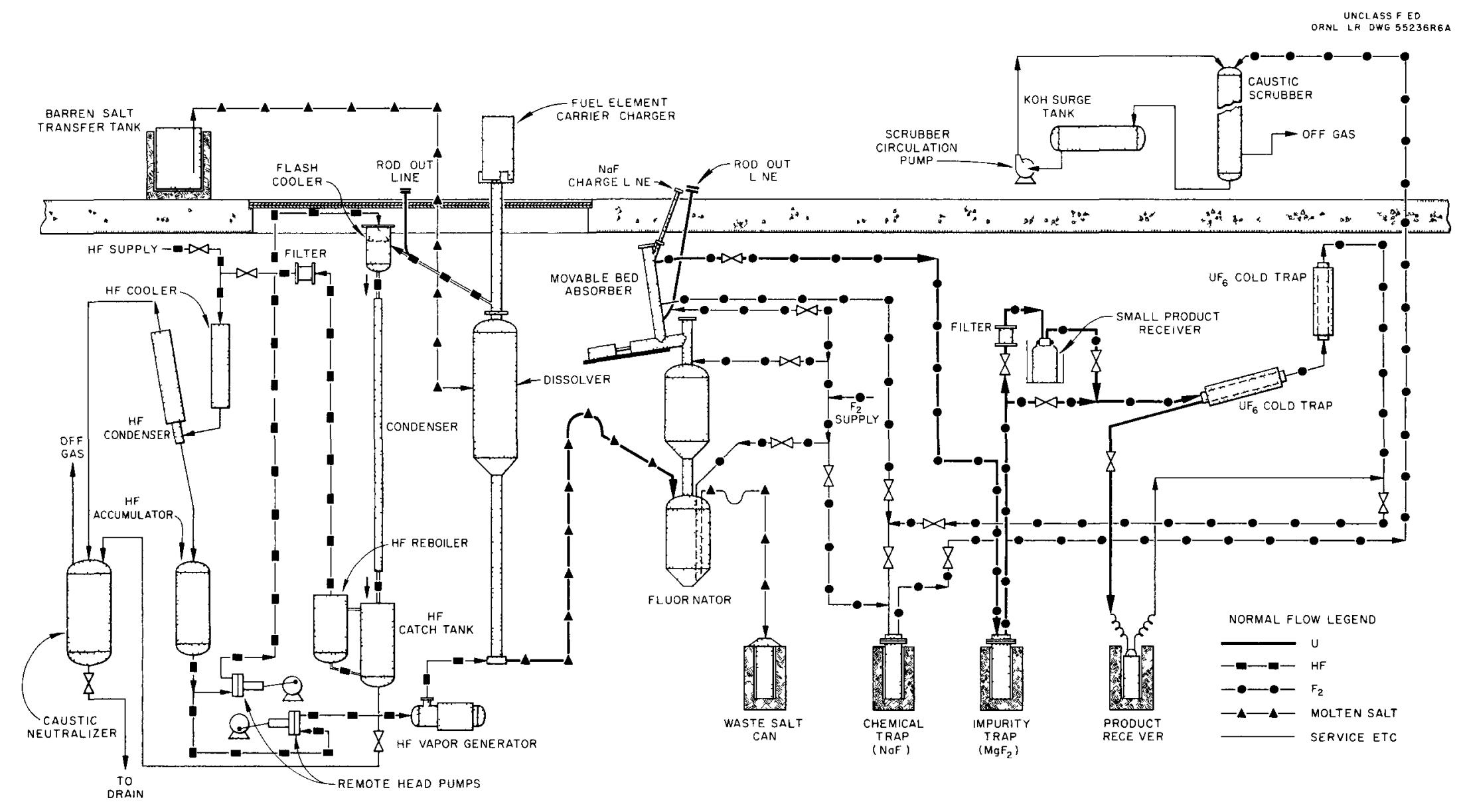

Fig. 2. I. Process Flow Diagram of Volatility Pilot Plant. 
Technetium and neptunium fluorides are removed by sorption at $100^{\circ} \mathrm{C}$ in a bed of $\mathrm{MgF}_{2}$ pellets, leaving a stream of pure $\mathrm{UF}_{6}$ in fluorine and inert purge gas (nitrogen).

The $\mathrm{UF}_{6}$ product $(0.5$ to $1 \mathrm{~kg})$ is recovered by freezing either in a small product receiver sized for an individual run or in large cold traps capable of handling $15 \mathrm{~kg}$ of $\mathrm{UF}_{6}$.

After the $\mathrm{UF}_{6}$ has been recovered, the $\mathrm{NaF}$ in the lower portion of the movable-bed absorber (about $7 \mathrm{~kg}$ ) is discharged into the waste salt in the fluorinator. Fresh $\mathrm{NaF}$ is then charged to the top of the absorber.

Results of the Five Runs. - Five runs were made, according to the method described above, to study fission product decontamination and to demonstrate sustained operability. For each run, two fuel elements were dissolved; thus, about $0.5 \mathrm{~kg}$ of uranium and $42 \mathrm{~kg}$ of zirconium were processed per run. The fuel was highly enriched uranium, highly burned, with decay times ranging from 6 to 13 months. Decontamination was excellent, and the ease of operation increased steadily throughout the series. Data and details of the runs are summarized below, according to the unit operations.

Dissolution. - Dissolution of the fuel elements was started with the salt at $650^{\circ} \mathrm{C}$, about $50^{\circ} \mathrm{C}$ above its melting temperature. During the course of dissolution, the temperature was lowered to $500^{\circ} \mathrm{C}$, about $60^{\circ} \mathrm{C}$ above the final melting point. Flow of $\mathrm{HF}$ was maintained at $125 \mathrm{~g} / \mathrm{min}$ until the element surface area was reduced due to dissolution of fuel plates.

The change in surface area when fuel plates were penetrated resulted in a "tail-out" of the dissolution. To illustrate this, the time required for dissolution of $90 \%$ of the fuel elements ranged from 9.5 to $12.7 \mathrm{hr}$, averaging 10.7; for complete dissolution, times ranged from 12.2 to $16.5 \mathrm{hr}$ and averaged 14.8. Hence, data for the first $90 \%$ of each dissolution are more meaningf $u 1$ than data for complete dissolution.

Based on $90 \%$ completion, average metal dissolution rates ranged from 2.9 to $3.9 \mathrm{~kg} / \mathrm{hr}$. These dissolution rates are equivalent to an $\mathrm{HF}$ utilization of 36 to $45 \%$ per pass (HF loss from the recirculation was undetectable). Considering system discharge at the end of each run, overall HF utilization usually fell in the 60 to $70 \%$ range.

Fluorination. - Two different fluorine flow rates were used in each fluorination. The major portion of the uranium was removed in $1.67 \mathrm{hr}$ (1.5 in the final run) with a fluorine flow rate of $6 \mathrm{std}$ liters/min; the remainder was removed in $0.33 \mathrm{hr}$ with fluorine flowing at 13 liters/min. The concentration of uranium in the waste salt after fluorination did not exceed 4 ppm; presumably, for commercial processing, an economic balance would dictate less fluorination, thus resulting in a somewhat higher uranium concentration in the waste salt.

The total nonrecoverable losses of uranium include any that was unfluorinated and any that remained with the $\mathrm{NaF}$ discharged into the waste salt. With the exception of run R-9, in which the loss was $0.14 \%$, the loss of nonrecoverable uranium in every run was less than $0.1 \%$.

Fluorine utilization ranged from 7 to $11 \%$. Although of interest, these values are of little significance in processing enriched fuels. For example, only $3 \mathrm{lb}$ of fluorine was used for the R-11 fluorination.

Product Quality. - The combined product UF from the five-run series was completely satisfactory for return to production channels. However, only the UF from run R-7 met published specifications for total and individual cationic impurities. $^{2}$ Table 2.1 lists for each run the principal impurities in that product, the maximum total cationic impurities (based on analytical limits), and selected values of the specifications.

The specification of $200 \mathrm{ppm}$ molybdenum, maximum, was met in some runs; however the R-9 and R-11 products had $120 \%$ of the maximum allowed. Obviously, the molybdenum-removal procedure (heating the $\mathrm{UF}_{6}-\mathrm{NaF}$ complex to $150^{\circ} \mathrm{C}$ with a sweep of fluorine) was not uniformly effective. We now believe that the time at $150^{\circ} \mathrm{C}$, the fluorine sweep, or both, were inadequate, and that sorbing the $U F_{6}$ at $150^{\circ} \mathrm{C}$ rather than at $100^{\circ} \mathrm{C}$ will solve this problem.

The nuclides ${ }^{99} \mathrm{Tc}$ and ${ }^{237} \mathrm{~Np}$ were satisfactorily trapped by the $\mathrm{MgF}$ bed, as evidenced by the low amounts found in the product in all runs. The high sodium content of $\mathrm{R}-8$ is attributed to $\mathrm{NaF}$ remaining in the lines from earlier work. With the exception of the unexplained high values for copper and nickel, all other individual cationic impurity levels were satisfactory.

\footnotetext{
${ }^{2}$ Federal Register 25, 2817 (1960).
} 
The total cationic impurities in the products in individual runs met the published specification of less than $300 \mathrm{ppm}$ only in run R-7. In the last three runs, the major contaminant was molybdenum, therefore, a reduction in molybdenum contamination by the procedural change suggested above would materially reduce the amount of total cationic impurities. Note that the totals shown in Table 2.1 include the analytical $11 \mathrm{mits}$ for those cations that were below the limit of detection and are, therefore, maximum.

Decontamination from fission products was better using this molten-salt fluoride-volatility process for $\mathrm{U}-\mathrm{Zr}$ alloy fuels than has ever been achieved by any other known process, even three cycles of solvent extraction (see Table 2.2).
The decontamination factors (DF's) in one run of up to more than $5 \times 10^{10}$ for ${ }^{95} \mathrm{Zr}^{95} \mathrm{Nb}$ are particularly noteworthy. In all cases, the fission products in the product $\mathrm{UF}_{6}$ were close to or below the limits of analytical detection (if below, the limit of detection was used in calculating DF's). High decontamination was maintained throughout the series, any trend evident in DF's was in the direction of general improvement with succeeding runs.

Radiation Exposure. - Records were maintained of the daily radiation exposure (as shown on pocket ionization chambers) of each worker in the program. During the operations, the highest weekly total exposure for any individual was

Table 2.I. Cationic Impurities in UF 6 Product

Specifications. Mo, 200 ppm, max, total 1mpurities, 300 ppm, max, both based on $U$

\begin{tabular}{lrrrrrrrr}
\hline & \multicolumn{8}{c}{ Product Impurity Leve1 (ppm, based on U) } \\
\cline { 2 - 7 } & Na & Mo & Ni & Fe & Cu & ${ }^{99}$ Te & ${ }^{237}$ Np & $\begin{array}{c}\text { Total } \\
\text { Cations }\end{array}$ \\
\hline R-7 & 130 & & & & & $<1$ & 3 & $<171$ \\
R-8 & 326 & 43 & & 67 & 150 & 5 & 48 & $<714$ \\
R-9 & 114 & 239 & 183 & & 79 & 31 & 40 & $<701$ \\
R-10 & 104 & 115 & 58 & 27 & & $<2$ & 7 & $<348$ \\
R-11 & 100 & 241 & & & 45 & 18 & 24 & $<498$ \\
\hline
\end{tabular}

Table 2.2. Overall Decontamination Factors

\begin{tabular}{|c|c|c|c|c|c|c|c|}
\hline \multirow{3}{*}{ Run No. } & \multirow{3}{*}{$\begin{array}{c}\text { Decay Time } \\
\text { (months) }\end{array}$} & \multirow{2}{*}{\multicolumn{2}{|c|}{$\begin{array}{c}\text { Nonvolatile } \\
\text { Isotopes }\end{array}$}} & \multicolumn{4}{|c|}{ Volatile Isotopes } \\
\hline & & & & \multirow{2}{*}{${ }^{106} \mathrm{Ru}$} & \multirow{2}{*}{${ }^{125} \mathrm{Sb}$} & \multirow{2}{*}{$\mathrm{Te}^{a}$} & \multirow{2}{*}{${ }^{95} \mathrm{Zr}-^{95} \mathrm{Nb}$} \\
\hline & & ${ }^{90} \mathrm{Sr}$ & ${ }^{137} \mathrm{Cs}$ & & & & \\
\hline $\mathbf{R}-7$ & 13 & $>10^{9}$ & $>5 \times 10^{9}$ & $>10^{8}$ & $>10^{7}$ & $>10^{7}$ & $>10^{9}$ \\
\hline $\mathbf{R}-\mathbf{8}$ & 6 & $>10^{9}$ & $>5 \times 10^{9}$ & $>5 \times 10^{8}$ & $>10^{8}$ & $>10^{9}$ & $>10^{10}$ \\
\hline R-9 & 8.5 & $>10^{10}$ & $>10^{9}$ & $>10^{9}$ & $>10^{6}$ & $>10^{9}$ & $>10^{10}$ \\
\hline$R=10$ & 9 & $>10^{10}$ & $>5 \times 10^{9}$ & $>10^{9}$ & $>10^{6}$ & $>10^{9}$ & $>10^{10}$ \\
\hline R-11 & 10 & $>10^{9}$ & $>5 \times 10^{9}$ & $>10^{9}$ & $>10^{7}$ & $>10^{9}$ & $>5 \times 10^{10}$ \\
\hline
\end{tabular}

a ${ }^{127 m} \mathrm{Te},{ }^{129 m} \mathrm{Te}$, and ${ }^{132} \mathrm{Te}$. 
$90 \mathrm{mr}$. The highest quarterly total exposure (as shown on $\mathrm{f}_{1} 1 \mathrm{~m}$ badges) was $650 \mathrm{mr}$.

Of the group, the operators were exposed to the highest radiation dosage. In the week in which the operators received the highest total exposure, the average was $44 \mathrm{mr}$ per operator. The highest exposure, $650 \mathrm{mr}$ in one quarter, was only $22 \%$ of the MPD (maximum permissible dose). During the quarter of highest exposure, the average film badge reading was $426 \mathrm{mr}$ per operator, equivalent to only $14 \%$ of the MPD.

Equipment Performance. - The equipment was reasonably trouble-free throughout the series. All difficulties were relatively minor, and there was no need to enter cell 1 (the high radiation area) at any time. A few minor design changes were made, and there were some equipment fallures, none of these prevented successful completion of a run. The design changes consisted in (1) replacing the chemical trap (NaF) and the impurity trap $\left(\mathrm{MgF}_{2}\right)$ with $\mathrm{U}$-bend pipe sections to reduce the quantity of pellets required for filling from about $10 \mathrm{~kg}$ to about $1 \mathrm{~kg}$, (2) replacing leakıng copper tubing on a refrigeration unit with flexible tubing, and (3) enclosing the flanges on the access lines to the movable-bed absorber in a glove box.

In general, equipment performance was excellent. From a process standpoint, each prece of equipment performed its designed function well. Mechanically, there were a few malfunctions, but all were relatively minor and easily repaired. The minor design changes were made either to reduce holdup in the system or to increase safety. Most of the equipment malfunctions could be tolerated until a run was complete, permitting correction between runs, the worst consequence of any of the fallures was delay of the run for a few hours while repairs were made.

Terminal Operations. - After the series of runs described above, the uranium remaining in the system was recovered in order to obtain a final material balance. The recovery was accomplished by a dummy run, barren salt flushes, and aqueous rinses. The plant was then partially decontaminated in order to inspect the dissolver.

Inspection of the dissolver was necessary to ensure that the equipment was in satisfactory condition for use in another program. The dissolver was inspected remotely, the interior was examined visually for defects, and wall thickness was measured for determination of corrosion loss.
The plant cleanout and decontamination and the dissolver inspection (including corrosion measurements) are described below.

Plant Cleanout and Decontamination. - Residual uranium was recovered from the equipment that held molten salt, this was done by making a run using Zircaloy without uranium and then flushing with barren salt. The remainder of the system was water rinsed. The plant cleanout resulted in the recovery of $900 \mathrm{~g}$ of uranium. This residue completed the material balance for all the uranium charged to the plant.

The dissolver and the fluorinator were partially decontaminated with an aqueous solution of hot ammonium oxalate $(0.35 M)$, and then with two batches of a low-sudsing detergent in water. The dissolver only was then flushed with $0.1 \mathrm{M}$ $\mathrm{Al}\left(\mathrm{NO}_{3}\right)_{3}$ solution, followed by a 5-1-1 wt \% solution of $\mathrm{NaOH}-\mathrm{H}_{2} \mathrm{O}_{2}$-sodium tartrate, water rinses, and drying.

At the start of the cleanout program, the $\operatorname{rad}_{1}$ ation background at different working areas in cell 1 ranged from 25 to $500 \mathrm{r} / \mathrm{hr}$, and specific "hot spots" read as high as $2200 \mathrm{r} / \mathrm{hr}$. The dummy run and barren salt flushes had no effect on the hot spots, but did reduce the background readings by a factor of 2 to 3 . The ammonium oxalate solution reduced background to 10 to $20 \%$ of original intensity and reduced the worst original hot spot from 2200 to $11 \mathrm{r} / \mathrm{hr}$. After completion of the partial decontamination, the highest measured intensity was $15 \mathrm{r} / \mathrm{hr}$ inside the lower section of the dissolver. Outside the equipment, some of the vessels showed a contact reading of 1 to $2 \mathrm{r} / \mathrm{hr}$. Background intensities in cell working areas ranged from 50 to $200 \mathrm{mr} / \mathrm{hr}$.

Dissolver Inspection and Corrosion Measurements. - Following the partial decontamination described above, the interior of the dissolver was examined visually, and the metal loss due to corrosion was determined. ${ }^{3}$ The inspection showed that the dissolver was still in good condition and that it would be safe to process additional fuel elements.

Corrosion loss, based on wall-thickness comparisons, was measured using a pulse-echo technique originally developed for the Aqueous Homo-

\footnotetext{
${ }^{3}$ E. L. Youngblood et al., Corrosion of the Volatility Plot Plant INOR-8 Hydrofluorinator and Nickel 201 Fluorinator During Forty Zirconium Fuel Processing Runs, ORNL-3523 (being prepared).
} 
geneous Reactor. ${ }^{4}$ The dissolver was filled with water, and an ultrasonic transducer was lowered in from the penthouse. All operations, including positioning of the transducer, were performed remotely from the penthouse.

Pulse-echo measurements were made in each quadrant of the dissolver at 3 -in. intervals. Total losses during 40 runs are shown in Fig. 2.2 in terms of mils of thickness lost for each level of the vessel. The crosshatched area represents the range of readings in the four quadrants. For example, at the bottom of the vessel, the reading in one quadrant indicated a metal loss of 27 mils, while at the same level the reading in another quadrant showed none. (The lower portion of the vessel was replaced after 29 runs, so measurements of this portion indicate loss during the last 11 runs only.)

In Fig. 2.2, the numbers beside the crosshatched areas represent the corrosion rate in mils per hour of exposure to molten salt and HF (measured losses do not include small pits). With the exception of the new section at the bottom, the average rates range from 0.012 to $0.017 \mathrm{mil}$ per hour of $\mathrm{HF}$ exposure, or less than $1 / 2 \mathrm{mil} / \mathrm{run}$. Corresponding rates for maximum measured losses range from 0.024 to $0.028 \mathrm{mil} / \mathrm{hr}$, or about 0.7 mil/run.

A high corrosion rate is indicated for the new section at the bottom of the dissolver. However, the quadrant of maximum loss was opposite a quadrant in which a thickness gain was measured (counted as zero loss in calculating averages). Since the pulse-echo transducer must be centered for accurate readings, these probable spurious readings could have been caused by the installation of the new section being slightly off-center.

The measured corrosion rate during fuel dissolution is not seriously high. The vessel was designed for a life of about 100 runs (a 100-mil corrosion allowance). This estimate now appears conservative, and the remaining life after 40 runs may be about 100 more runs.

Corrosion measurements had been made earlier after $7,14,21$, and 29 dissolutions. ${ }^{5-7}$ Comparison of the earlier measurements with current data reveals a trend toward a decreasing cor-

\footnotetext{
${ }^{4}$ R. W. McClung and K. V. Cook, Development of Ultrasonic Techniques for the Remote Measurement of the HRT Core Vessel Wall Thickness, ORNL-TM-103 (Mar. 15, 1962).
}

rosion rate with increasing exposure time. Although such factors as the possibility of better temperature control during later runs may have contributed to the trend, the initial corrosion rate is apparently higher than the rate after some processing.

After thickness measurements were completed, the interior of the lower portion of the dissolver, up to and including part of the conical section, was remotely inspected with a telescope and murror. A few pits, estimated to be smaller than $20 \mathrm{mils}$ in diameter and 20 mils deep, were seen in the lower section; a photograph of one of these pits is shown in Fig. 2.3. Some small fissures such as the one shown in Fig. 2.4 were found in the conical section. These fissures were estimated to be not more than 10 mils wide, and they did not appear to be deep. No area of extensive pitting or cracking was found. The pits did not appear to be any deeper or wider than those found in earlier examinations. Thus, neither pitting nor fissuring constitutes a serious problem.

\section{Alloy 79.4 More Corrosion-Resistant than INOR-8 in Engineering.Scale Tests of Combination HydrofluorinatoroFluorinator}

Completed during the year was a processimprovement study made on a semiworks scale to demonstrate the feasibility of dissolving and fluorinating in the same vessel and of using a partial salt-recycle procedure for supplying the initial $\mathrm{ZrF}$, content necessary when using the 37.5-37.5-25 mole \% NaF-LiF-ZrF mixture.

A comparison of the corrosion rates of Alloy 79-4 and INOR-8 in single-vessel service was the most recent objective of the study. ${ }^{8}$ To this

\footnotetext{
${ }^{5}$ E. C. Moncrief and A. P. Litman, Corrosion of the Volatility Pilot Plant INOR-8 DISsolver After Seven Cold Dissolution Runs, ORNL-CF-60-11-80 (Nov. 30, 1960).

${ }^{6}$ A. P. Litman, Corrosion of Volatility Pilot Plant Mark I INOR-8 Hydrofluorinator and Mark III L Nickel Fluorinator After Fourteen Dissolution Runs, ORNL3253 (Feb. 9, 1962).

${ }^{7}$ E. C. Moncrief, Corrosion of the Volatility Pllot Plant INOR-8 Hydrofluormator and L Nickel Fluormator After 21 Nonradioactive Dissolution Runs, ORNL-TM186 (Mar. 29, 1962).

${ }^{8}$ Nominal compositions and commercial designations: Alloy $79-4$ - $79 \% \mathrm{~N}_{1}, 4 \%$ Mo, bal Fe; HyMu 80 (Carpenter Steel Co.); Moly Permalloy (Allegheny Ludlum Steel Corp.).

INOR-8 - $17 \%$ Mo, $7 \% \mathrm{Cr}, 5 \% \mathrm{Fe}$, bal N1; Hastelloy N (Union Carbide Corp., Stellite Div.); Inconel 608 (The International Nickel Co., Hunt ington Alloy Products Div.).
} 


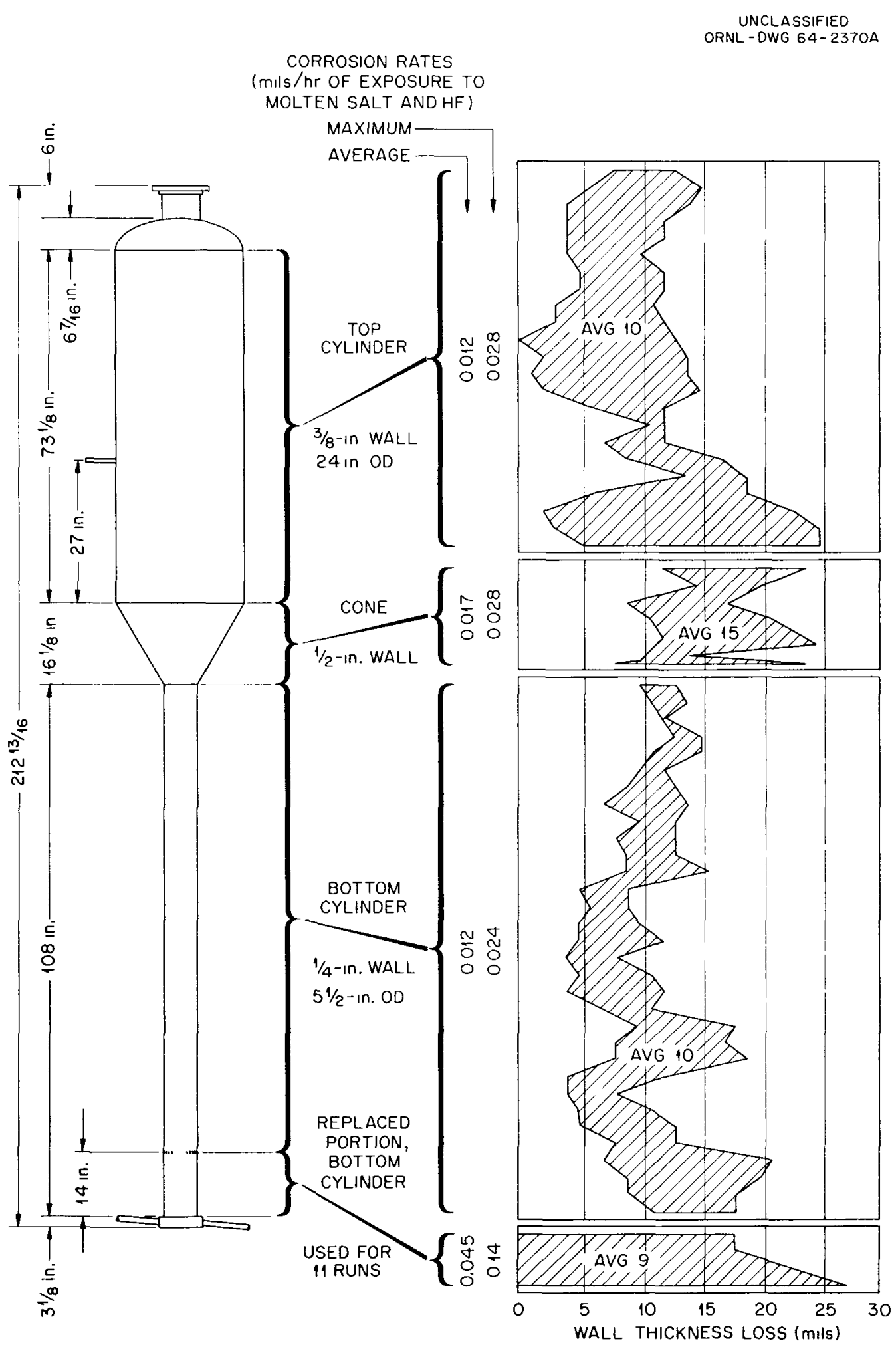

Fig. 2.2. Losses in Wall Thickness of the INOR-8 Hydrofluorination Vessel, Volatility Pilot Plant, After 40 Zirconium Hydrofluorination Runs. 


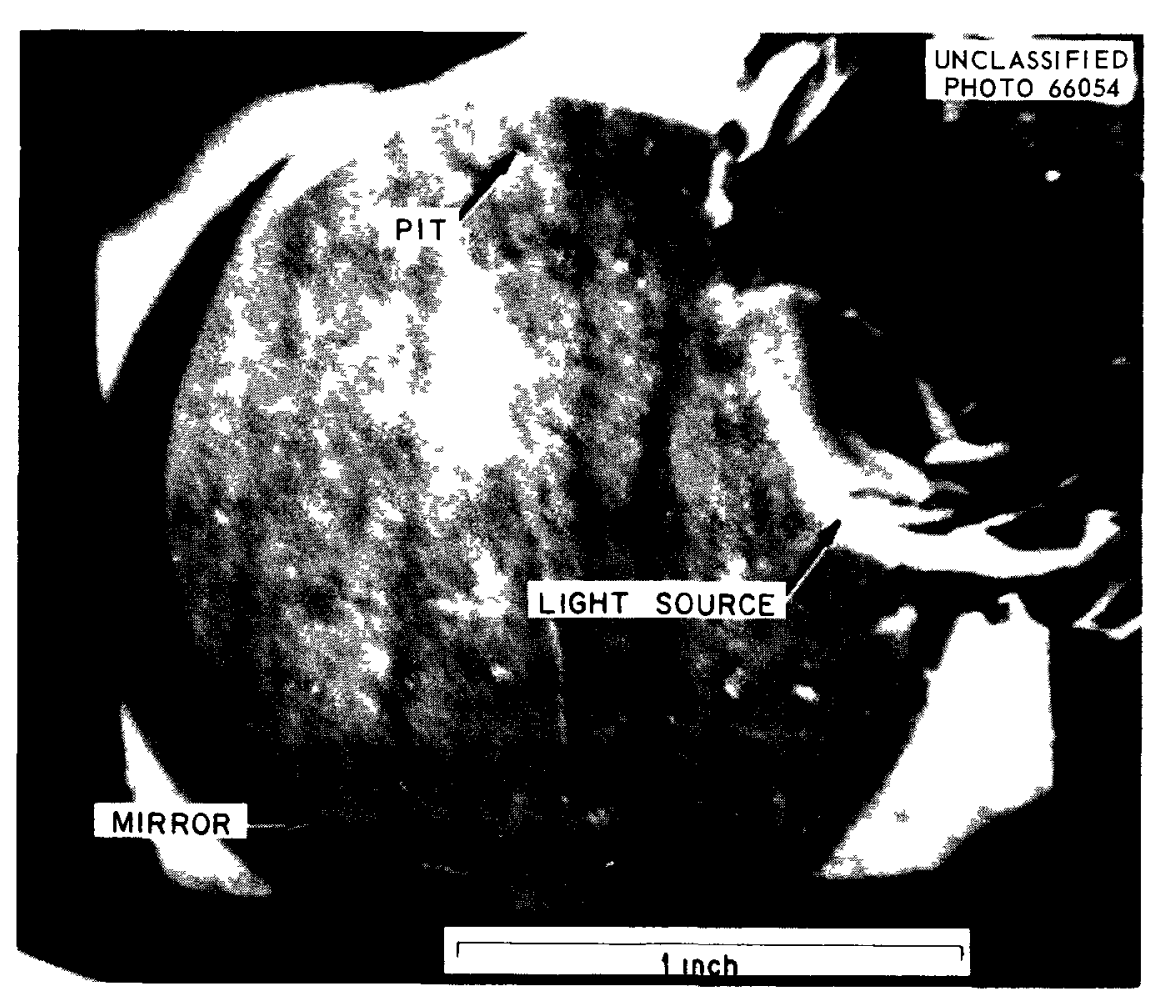

Fig. 2.3. Pit Observed in 5/2-in..OD Section of the Hydrofluorinator After 40 Runs. Photographed with aid of a mirror.

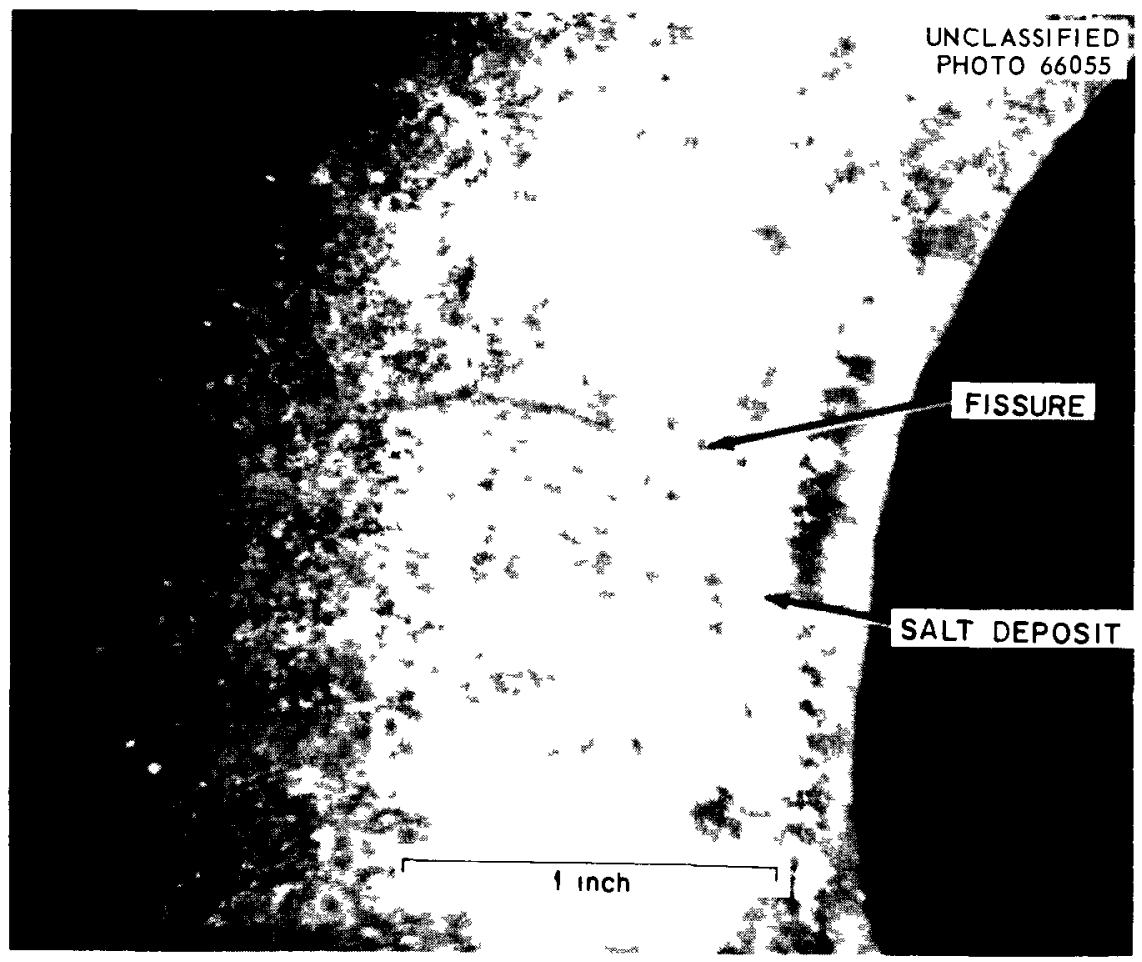

Fig. 2.4. Fissure in the Conical Section of the Hydrofluorinator After 40 Runs. 
end, two engineering-scale vessels, one fabricated of each alloy, were exposed to molten salt under alternating hydrofluorination and fluorination conditions. The INOR-8 vessel, as previously reported, ${ }^{9}$ corroded at a rate of $0.87 \mathrm{mil}$ per hour of fluorine exposure, whereas the maximum rate of corrosion for the Alloy 79-4 vessel was 0.53 mil per hour of fluorine exposure. These rates include the corrosion due to decontamination with aluminum nitrate solution; excluding this corrosion, the rates were 0.7 and $0.4 \mathrm{mil} / \mathrm{hr}$ respectively. For single-vessel processing, the expression of total corrosion in terms of fluorine exposure is useful for two reasons: (1) most of the corrosion occurs during the fluorination step, and (2) the ratio of hydrofluorination time to fluorination time remains nearly constant for any particular fuel alloy.

Five process runs were made in the Alloy 79-4 vessel, using $\mathrm{Zr}-\mathrm{U}$ alloy fuel elements similar to those used in the Pressurized Water Reactor as seed. An initial salt composition of 35-35-30 mole \% NaF-LiF- $\mathrm{ZrF}_{4}$ was used; temperatures were 550 to $575^{\circ} \mathrm{C}$. Five dissolution-fluorination cycles and two additional fluorinations were made in a 5-in.-ID Alloy 79-4 vessel, using the saltrecycle scheme. Dissolution rates of about $1 \mathrm{mg}$ $\mathrm{cm}^{-2} \min ^{-1}$ were obtained during all tests. Rates were consistent with those from previous dis-

${ }^{9}$ Chem. Technol. Div. Ann. Progr. Rept. May 31 , 1963, ORNL-3452, pp. 45-46. solutions at similar conditions. No operational difficulties were experienced during any of the dissolutions or fluorinations.

The results are shown in Table 2.3, where they are compared with those previously reported for INOR-8 exposure. The values in the last column represent recent data. Corrosion at the interface was significantly greater in the INOR-8 vesse1 than in the Alloy 79-4 unit. Also, the test bars that had not been exposed to the solution used for decontamination showed a much lower rate as measured by micrometers at the end of the test period. Metallography of the bars at BMI showed neither pitting nor intergranular attack in the case of the INOR- 8 , but did reveal pitting attack on the Alloy 79-4 surface. The comparison in Table 2.3 would show $0.29 \mathrm{mil}$ per hour of fluorine exposure for INOR-8 and $0.19 \mathrm{mil}$ per hour of fluorine exposure for Alloy 79-4 if intergranular attack were included.

\section{NaF-LiF-ZrF ${ }_{4}-\mathrm{BeF}_{2}$ at $500^{\circ} \mathrm{C}$ Apparently Less Desirable thon NaF-LiF-ZrF 4 at $650^{\circ} \mathrm{C}$ for Hydrofluorination Melt}

Supplementing work reported last year, ${ }^{8}$ a study was made of the corrosivity and zirconium-dissolution characteristics of 36.9-27.0-27.0-9.1 mole \% NaF-LiF- $\mathrm{ZrF}_{4}-\mathrm{BeF}_{2}$ at $500^{\circ} \mathrm{C}$, compared with the initial composition used in pilot plant

Table 2.3. Corrosion Rates Measured During Cyclic Hydrofluorination and Fluorination of Zr.U Alloy in INOR-8 and Alloy 79-4 Vessels

\begin{tabular}{|c|c|c|c|c|}
\hline & \multicolumn{2}{|c|}{ Test Bars } & \multicolumn{2}{|c|}{ Vessels } \\
\hline & INOR-8 & $79-4$ & INOR-8 & $79-4$ \\
\hline \multicolumn{5}{|l|}{ Exposure, hr: } \\
\hline To molten salt & 1060 & 1060 & 699 & 520 \\
\hline To $H F$ & 142 & 142 & 83 & 79 \\
\hline To $\mathrm{F}_{2}$ & 66 & 66 & 36 & 34 \\
\hline $\begin{array}{l}\text { To } \mathrm{Al}\left(\mathrm{NO}_{3}\right)_{3} \text { solution } \\
\text { (decontamination) }\end{array}$ & & & 78 & 58 \\
\hline $\begin{array}{l}\text { Corrosion rates, } \\
\mathrm{mil} / \mathrm{hr} \text { of } \mathrm{F}_{2} \text { exposure }\end{array}$ & $0.29^{a}$ & $0.14^{a}$ & $0.87^{b}$ & $0.53^{b}$ \\
\hline
\end{tabular}

${ }^{a}$ By micrometry.

${ }^{b}$ By Vidigage. 
studies (37.5-37.5-25.0 mole \% NaF-LiF- $\mathrm{ZrF}_{4}$ at $650^{\circ} \mathrm{C}$ ). The study was made on a laboratory scale by BMI under subcontract. ${ }^{10}$ Corrosion rates for non-heat-treated INOR-8 specimens were very low in both salt compositions; initial zirconium-dissolution rates were practically the same in all tests, but the overall rate of zirconium dissolution averaged $50 \%$ higher in the NaF-LiF$\mathrm{ZrF}_{4}$ mixture.

\footnotetext{
${ }^{10}$ P. D. Miller et al., Corrosion Resistance of NickelBase Alloys in a NaF-L ${ }_{2} F \cdot \mathrm{BeF}_{2}-\mathrm{ZrF}_{4}$ Mixture Under Hydrofluorinator Conditions at $500^{\circ} \mathrm{C}, W_{I}$ th and $W_{1}$ thout $Z_{1 t c a l o y} 2$ Dissolving - Patt II, BMI-X-253 (Aug. 23, 1963).
}

We concluded that the melt containing beryllium, which permitted the $500^{\circ} \mathrm{C}$ operation, apparently has no advantages over the standard melt; a disadvantage would be the special precautions required when handling beryllium compounds.

The experiment in which the melt containing $\mathrm{BeF}_{2}$ was used was the first one in which all the fuel element structural metal was added at the beginning of the run. The pieces of metal were contained in a basket that had a perforated bottom below which the HF entered. Figure 2.5 illustrates a typical arrangement of fuel element metal, the basket, and the corrosion specimens. In previous runs, the metal to be dissolved was added intermittently as the run progressed. With

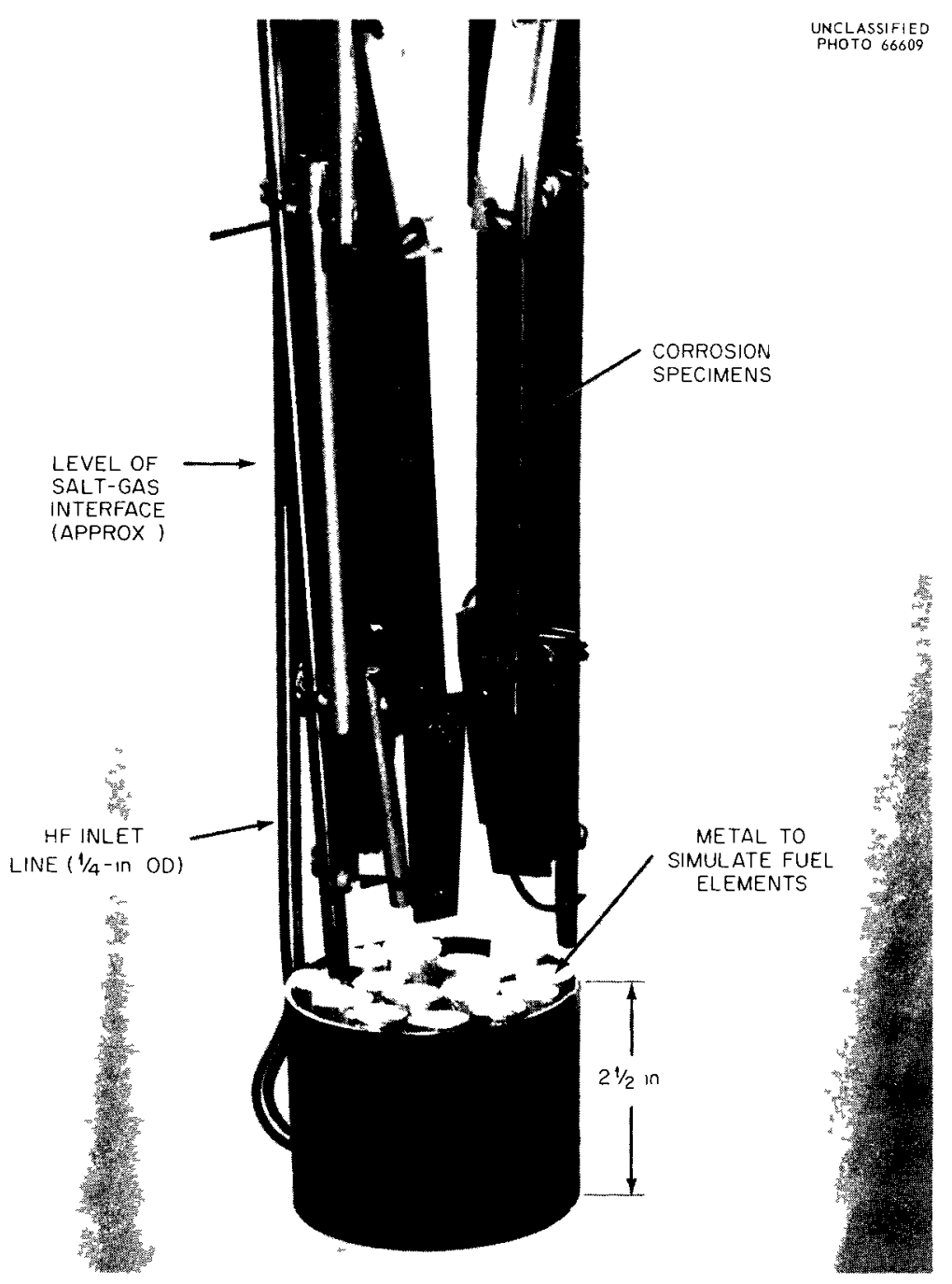

Fig. 2.5. Corrosion Specimens and Metal Used to Simulate Fuel Elements Are Mounted as a Unit Prior to Insertion Into 4-in.-ID Test Vessel Containing Molten Fluorides. 
the new method, better simulation of process conditions was accomplished by first determıning corrosion rates for selected constructional materials while dissolving zirconium in the standard melt. After dissolution had stopped, the corrosion specimens were removed, new ones were introduced, and their rates of corrosion were determined without zirconium dissolution. This second phase of the experiment was intended to simulate conditions near the end of a plant-scale run.

Specimens exposed to molten salt and HF during this study were made from INOR-8, HyMu 80 (Alloy 79-4), $\mathrm{N}_{1}-10 \% \mathrm{Mo}-5 \% \mathrm{Fe}, \mathrm{N}_{1}-5 \% \mathrm{Fe}$, $\mathrm{N}_{1}-1 \% \mathrm{Al}$, and nickel filler metal 61. According to weight-loss measurements of specimens exposed in the first phase of the experiment with $Z_{1 \text { rcaloy- }}$ dissolving, no specimen corroded at more than $0.1 \mathrm{mil} / \mathrm{month}$. No attack was measurable by micrometry on any specimen, nor was intergranular attack noted for any specimens except the $\mathrm{N}_{1}-1 \%$ $\mathrm{Al}$ and the $\mathrm{N} 1-5 \% \mathrm{Fe}$ specimens that were exposed at the interface location. These showed maximum corrosion rates of 78 and $23 \mathrm{mils} / \mathrm{month}$, respectively, based on sound metal remaining. During the second phase (with HF but no Zircaloy-2 present), corrosion rates as measured by weight loss were slightly higher. Maximum values were $0.14 \mathrm{mil} /$ month for INOR-8 (vapor), 027 for HyMu 80 (interface), 020 for Alloy 2 (vapor), 2.6 for $\mathrm{N}_{1}-1 \% \mathrm{Al}$ (11quid), 3.4 for $\mathrm{N}_{1}-5 \% \mathrm{Fe}$ (1nterface), and 1.6 for nickel filler metal 61 (liquid). The only corrosion rate measurable by micrometry was $45 \mathrm{mils} /$ month for the $\mathrm{N}_{1}-1 \% \mathrm{Al}$ specimens located at the interface and in the liquid, and 13.5 and $2.7 \mathrm{mils} /$ month for the $\mathrm{Ni}-5 \% \mathrm{Fe}$ spec1mens at the interface and in the liquid respectively. No intergranular attack was found during the second phase except on the $\mathrm{N}_{1-1}-1 \% \mathrm{Al}$ and N1-5\% Fe specimens, which had maximum attacks of 32 and $14 \mathrm{mils} /$ month, based on sound metal remaining.

As part of another study, ${ }^{11}$ three comparable experiments were later conducted at BMI, starting with $375-375-25$ mole $\% \mathrm{NaF}-\mathrm{LiF}_{1}-\mathrm{ZrF}_{4}$ at $650^{\circ} \mathrm{C}$. As in the study above, Zircaloy- 2 was dissolved first in each case, followed by a nondissolution phase. The highest rate of corrosion for any comparable INOR-8 specimen was $03 \mathrm{mil} / \mathrm{month}$, as measured by weight loss. No measurable

\footnotetext{
${ }^{11}$ See first part of sect. 2.10 of this report.
}

dimensional losses or intergranular attack was noted.

The dissolution rates of $Z_{1}$ rcaloy- 2 for the first $24 \mathrm{hr}$ of the experiment in which $\mathrm{NaF}-\mathrm{L}_{1} \mathrm{~F}-\mathrm{ZrF}_{4}-$ $\mathrm{BeF}_{2}$ was used, and for the three expenments with $\mathrm{NaF}-\mathrm{L}_{1} \mathrm{~F}-\mathrm{ZrF}_{4}$, were very close -0.26 to $0.30 \mathrm{mg} \mathrm{cm}^{-2} \mathrm{~min}^{-1}$. However, whereas the overall dissolution rate for Zircaloy-2 for the exper1ment containing $\mathrm{BeF}_{2}$ and conducted at $500^{\circ} \mathrm{C}$ was $5.3 \mathrm{~g} / \mathrm{hr}$, the overall rates for the three tests using $\mathrm{NaF}-\mathrm{L}_{1} \mathrm{~F}-\mathrm{ZrF}_{4}$ at $650^{\circ} \mathrm{C}$ were $9.2,79$, and $67 \mathrm{~g} / \mathrm{hr}$.

\subsection{PROCESSING OF URANIUM-ALUMINUM ALLOY FUEL}

Aluminum-clad Al-U alloy fuel elements presently comprise the largest potential load source for a plant processing metallic fuel elements containing highly enriched uranium. Thus, the application of molten-salt fluoride-volatility methods to the processing of aluminum-based fuel became of major interest as the development of the process for $z_{1}$ rconum-based fuels neared completion. The development of a molten-salt process for aluminum-uranium alloys was, of course, contingent upon finding a mixture of fluondes suitable for use as a solvent with HF. Desirable characteristics of the salt melt for the process include the following: (1) liquidus temperature below $600^{\circ} \mathrm{C},{ }^{12}$ (2) an adequate capacity for dissolving the $\mathrm{AlF}_{3}$ derived from the dissolution of aluminum with $\mathrm{HF}$, (3) low cost, (4) adequate physical properties such as low vapor pressure and viscosity, and (5) ability to be contained in the present INOR- 8 hydrofluonnator and nickel fluorinator. As reported last year, $\mathrm{KF}-\mathrm{ZrF}_{4}-\mathrm{AlF}_{3}$ was chosen as the mixture that most nearly meets the above requirements. ${ }^{13}$ This chorce was based on phase equilibrium studies made by Reactor Chemistry Division personnel, laboratory- and engineering-scale dissolution and fluonnation studies, and laboratory corrosion tests. Aside from the differences in salt systems and in the details of "stepping" through the

\footnotetext{
12 Melting points for compositions of interest, ${ }^{\circ} \mathrm{C}$ : pure aluminum, 600; type 1100 aluminum, 643 to $657,13 \%$ $\mathrm{U}-87 \% \mathrm{~A} 1,640$ (eutect1c), and $18 \% \mathrm{U}$ in type 1100 aluminum ("meat" of ORR and MTR fue1), 730 (approx).

${ }^{13}$ Chem. Technol. Div Ann Progt. Rept May 31, 1963, ORNL-3452, suppl. 1.
} 
composition diagram, the process for Al-U alloy fuels is identical to the one for $\mathrm{Zr}-\mathrm{U}$ fuels described in Sect. 2.1.

During the past year, the preliminary phase diagram for $\mathrm{KF}-\mathrm{ZrF}_{4}-\mathrm{AlF}_{3}$ was refined, principally by the new visual polythermal method, to better define the $600^{\circ} \mathrm{C}$ isothermal. Purification of the components $\mathrm{ZrF}_{4}$ and $\mathrm{AlF}_{3}$ by volatilization and of the KF by oxide precipitation and distillation was necessary to obtain melts that were suff 1 crently clear for visual study. The effect of oxide additions to the melt in the region of the compound $\mathrm{KF} \cdot \mathrm{ZFF}_{4}$ was evaluated. The results of the phase studies performed as a part of the development of process for aluminum-uranium alloy were reported. ${ }^{14}$ Other laboratory studies were made in order to determine the extent of the aluminum-dissolution reaction that was attributable to $\mathrm{HF}$ and the extent that was attributable to the reduction of $\mathrm{ZrF}_{4}$ in the melt by aluminum. The effect of melt composition on the rate of aluminum dissolution was explored in the $\mathrm{KF}-\mathrm{ZrF}_{4}-\mathrm{AlF}_{3}$ system. Two modifications of the process were developed, and these were tested successfully on both a laboratory and an engineering scale. Successful fluorination tests were also made on both scales. Corrosion studies under hydrofluorination conditions were made at Battelle Memorial Inst1tute (BMI) and in the laboratory here. Rates of attack on INOR-8 were very low - almost the same as those found in laboratory studies of the standard $\mathrm{Zr}-\mathrm{U}$ alloy process.

Based on all the favorable results, demonstration studies were begun in the pilot plant. At the end of the period, one run had been completed in which two simulated fuel elements (aluminum only) were successfully dissolved and processed through the fluorination step. Plans call for a study of corrosion under fluorination conditions at BMI and continuation of pilot plant demonstration runs to culminate in the processing of highly irradiated, short-cooled fuel elements from the Oak Ridge Research Reactor. Other laboratoryand engineering-scale studies will be confined to providing assistance required by the pilot plant.

\footnotetext{
${ }^{14}$ B. J. Sturm, R. E. Thoma, and E. H. Guinn, MoltenSalt Solvents for Fluoride-Volatility Processing of Aluminum-Matrix Nuclear Fuel Elements, ORNL-3594 (in press).
}

\author{
Phase Equilibrium Dota Refined ${ }^{15}$ for \\ $\mathrm{KF}-\mathrm{ZrF}_{4}-\mathrm{AlF}_{3}$
}

The phase diagram for the system $\mathrm{KF}-\mathrm{ZrF}_{4}$ $\mathrm{AlF}_{3}$ as presented in last year's report is shown in Fig. 2.6. Additional data were obtained, principally by the visual polythermal method, that better defined the $600^{\circ} \mathrm{C}$ isotherm (see Fig. 2.7). Impurities in the reagents resulted in cloudy melts that interfered with visual studies. One of the regions of interest was near the compound $\mathrm{KF}$. $\mathrm{ZrF}_{4}$. Thermal analysis showed that $\mathrm{KF} \cdot \mathrm{ZrF}_{4}$ sometimes crystallized in a metastable form that froze at $453^{\circ} \mathrm{C}$. During freezing, the metastable form often changed exothermally into a more stable form that froze at $478^{\circ} \mathrm{C}$. Oxide, in the concentration range of 0 to $2500 \mathrm{ppm}$, raised the visually determined liquidus temperature (the temperature at which a cooling melt becomes cloudy) above the stable freezing point by about $1^{\circ} \mathrm{C}$ per $20 \mathrm{ppm}$ of oxygen. This effect on the liquidus persisted throughout the concentration range of 42 to 55 mole $\% \mathrm{ZrF}_{4}$ but was not noted at 37.5 mole \%. Since the oxygen contaminant in the $\mathrm{KF}$ was apparently the reason for the false liquidus point, a procedure was developed to improve the purity of the KF. Commercial KF is usually very hygroscopic and thus is contaminated with either moisture or $\mathrm{KOH}$. The best $\mathrm{KF}$ previously avallable had a $\mathrm{KOH}$ content corresponding to about 1200 ppm, by weight, of oxygen. Because $\mathrm{KOH}$ in molten $\mathrm{KF}$ reacts with various fluondes to prec1pitate metal oxides,

$$
2 \mathrm{MF}_{\mathrm{x}}+\mathrm{xKOH} \rightarrow 2 \mathrm{MO}_{\mathrm{x} / 2} \downarrow+\mathrm{xHF} \uparrow+\mathrm{xKF}
$$

the production of better quality $\mathrm{KF}$ was possible by its vacuum distillation from the remaining molten mixture. The use of $\mathrm{FeF}_{3}$ and $\mathrm{FeF}_{2}$ to precipitate the oxide yielded $\mathrm{KF}$ that contained $900 \mathrm{ppm}$ of oxygen after its distillation from the melt, the use of $\mathrm{UF}_{4}$ gave a product containing only $500 \mathrm{ppm}$. More accurate determinations of the liquidus temperature in the $\mathrm{KF}-\mathrm{ZrF}_{4}-\mathrm{AlF}_{3}$ system were made with the higher quality $\mathrm{KF}$.

\footnotetext{
${ }^{15}$ Work performed by B. J. Sturm and R. E. Thoma, Reactor Chemistry Division.
} 


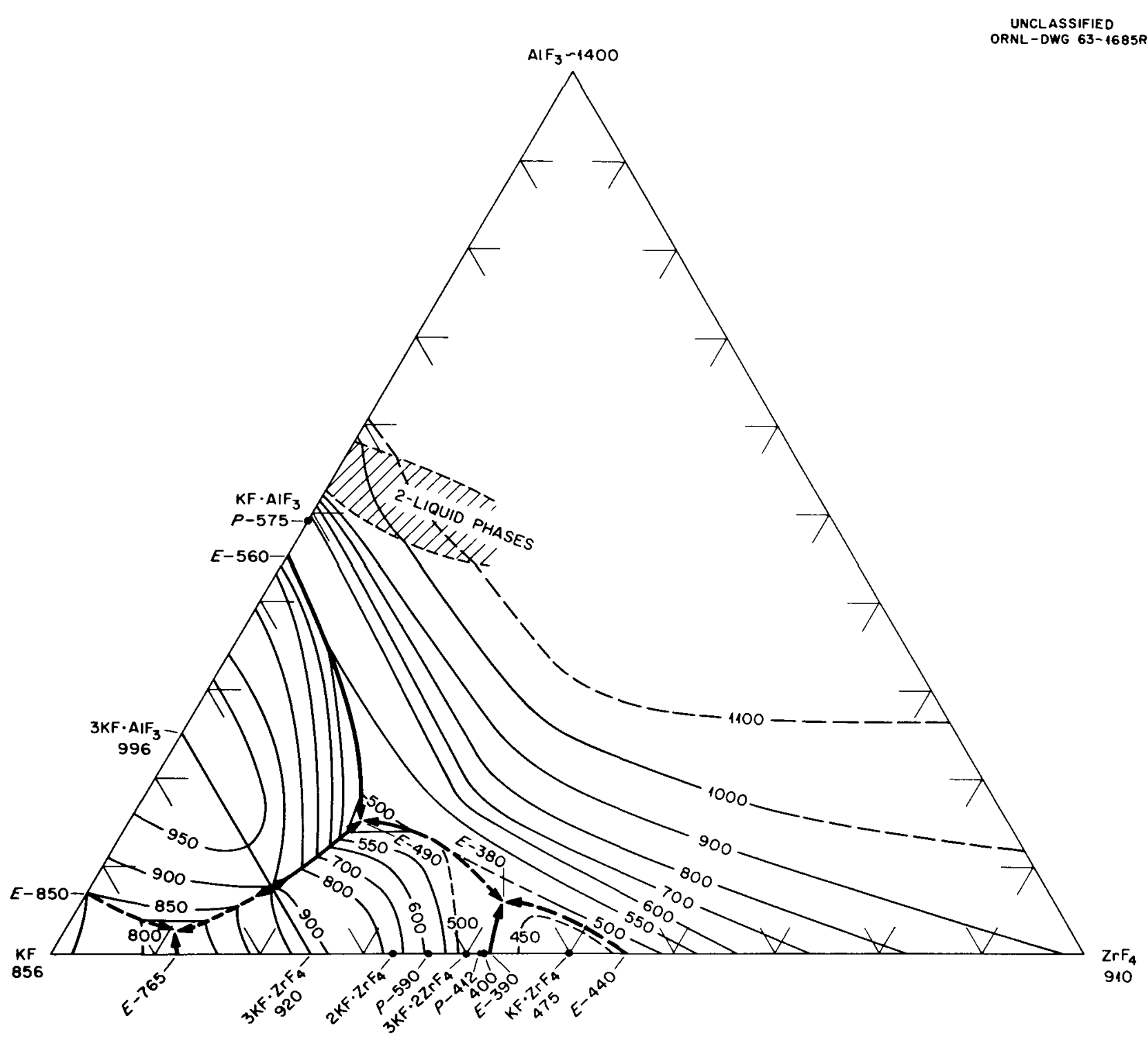

Fig. 2.6. The System KF- $\mathrm{ZrF}_{4}-\mathrm{AlF}_{3}$.

\section{Dissolution Rate Studies Show Effect of Melt Composition and Provide More Information on the Chemical Reactions}

Dissolution Rates. - Supplementing the laboratory studies previously reported, ${ }^{16}$ more determinations were made of rates of dissolution of

\footnotetext{
${ }^{16}$ Chem. Technol. Div. Ann. Ptogt. Rept. May 31, 1963, ORNL-3452, suppl. 1, p. 11 .
}

aluminum in $\mathrm{KF}-\mathrm{ZrF}_{4}-\mathrm{AlF}_{3}$ with $\mathrm{HF} .{ }^{17}$ The tests consisted simply in the partial reaction of $3-\mathrm{g}$ specimens of aluminum in 60 to $70 \mathrm{~g}$ of salt held in a $0.93-$ in.-ID nickel reactor and sparged with $\mathrm{HF}$ at a flow rate of about $100 \mathrm{ml}(\mathrm{STP}) / \mathrm{min}$. The rates were calculated according to the weight-loss

\footnotetext{
${ }^{17}$ M. R. Bennett and G. I. Cathers, Adaptation of the Fused-Salt Fluoride-Volatility Process to the Recovery of Uranium from Aluminum-Uranium Alloy Fuel, ORNL3596 (June 1964).
} 
method and, in some cases, according to micrometry. Conditions of the experiment and the data obtained are summarized elsewhere. ${ }^{17}$ To better indicate the portion of the $\mathrm{KF}-\mathrm{ZrF}_{4}-\mathrm{AlF}_{3}$ system surveyed in dissolution rate tests, the values for the dissolution rates vs the midpoint of the composition path for each experiment are shown in Fig. 2.7. Results of runs made at initial melt compositions near $60-40$ mole \% $\mathrm{KF}-\mathrm{ZrF}_{4}$ showed that the hydrofluorination reaction was highly dependent on the $\mathrm{KF} / \mathrm{ZrF}_{4}$ ratio (Sect. AB, Figs. 2.7 and 2.8). High dissolution rates were observed when initial melts contained about 60 mole $\% \mathrm{KF}$. In a second series of tests, the addition of $\mathrm{AlF}_{3}$ to the initial mixtures was necessary to achieve a liquidus below the $600^{\circ} \mathrm{C}$ operating temperature (Sect. BC, Figs. 2.7 and 2.8). Maximum dissolution rates were obtained in this series at a $\mathrm{KF} / \mathrm{ZFF}_{4}$ ratio of $0.65 / 0.35$. Also, as indicated on Fig. 2.7, these first two series of tests
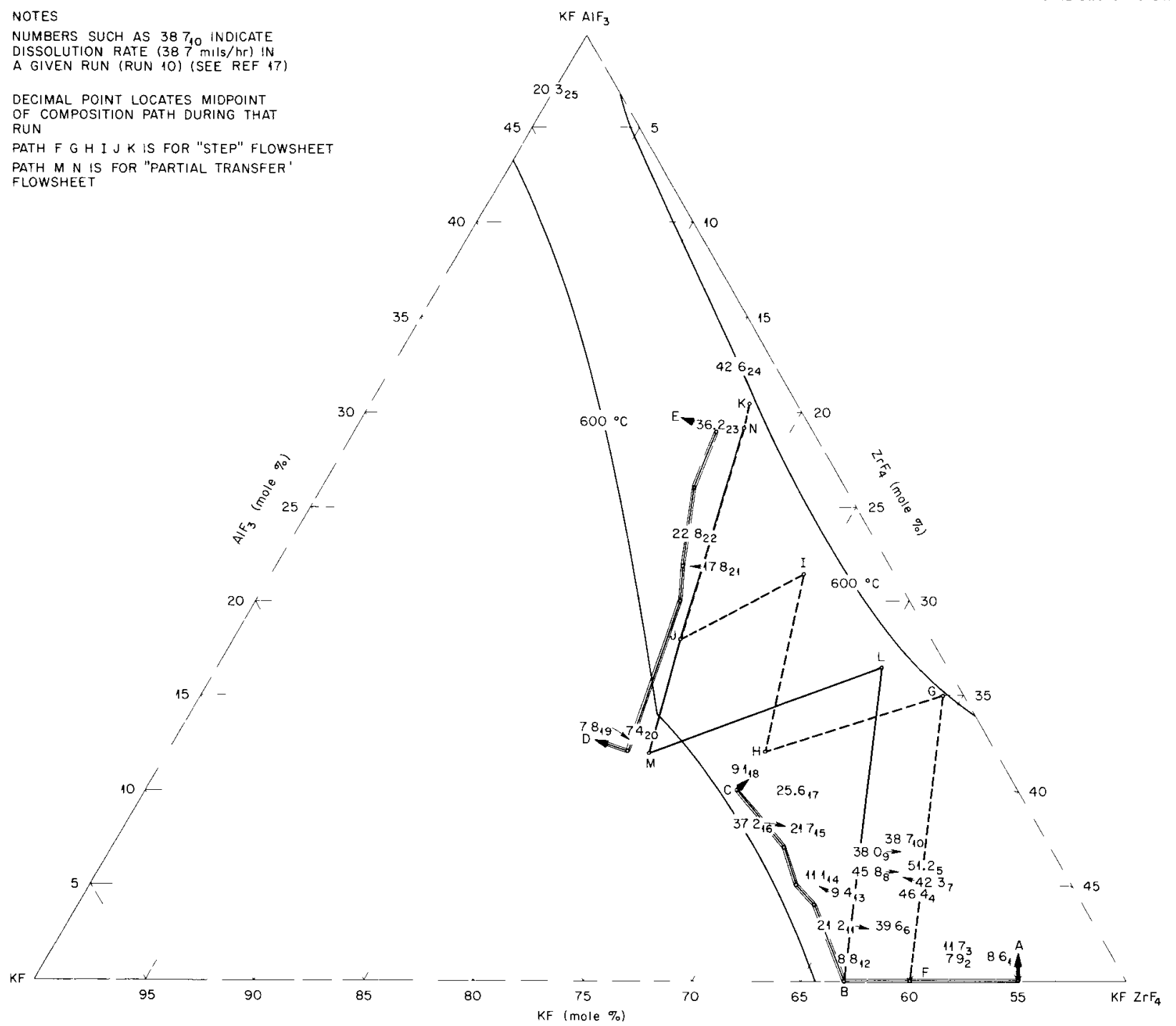

Fig. 2.7. Molten-Salt Fluoride-Volatility Process for Al-U Alloy Fuels: Reference Diagram Summarizing Current Information on the Location of the $600^{\circ} \mathrm{C}$ Liquidus Isotherm, Dissolution Rates for Aluminum Using HF (Lab. oratory-Scale), and Process Flowsheet Alternatives. 


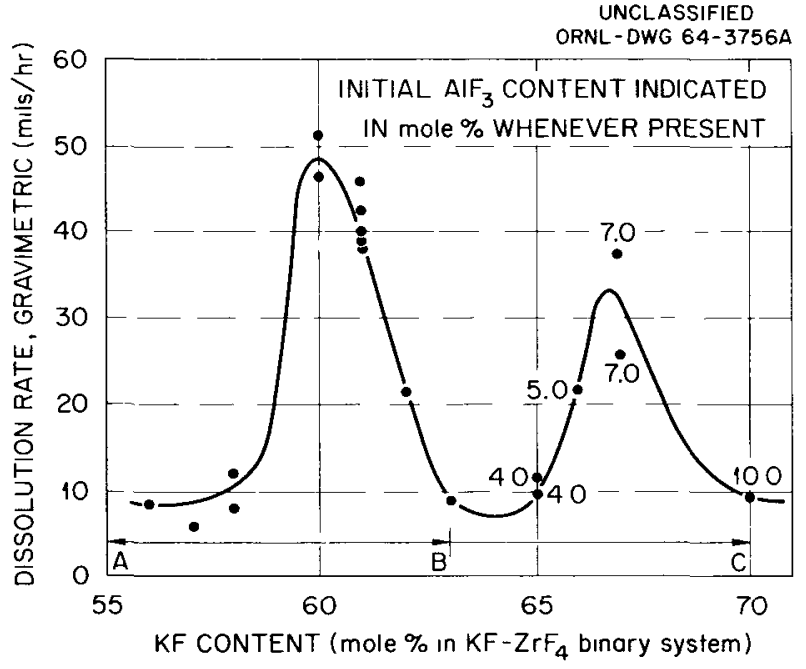

Fig. 2.8. Maximum Aluminum Dissolution Rates Are Obtained At Two Compositions in the KF- $\mathrm{ZrF}_{4}$ System.

were in the portion of the phase diagram used in the first half of the "step" flowsheet (see next section). A third series of dissolution-rate tests was conducted in an area proposed for the "partial transfer" and the last dissolution of the "step" flowsheet (Sect. DE, Fig. 2.7). On the basis of data from all previous hydrofluorination tests, an increasing $\mathrm{AlF}_{3}$ concentration at a constant $\mathrm{KF} / \mathrm{ZrF}_{4}$ ratio would have been expected to result in lower reaction rates. This effect was not observed; instead, the dissolution rate in the last series of tests definitely increased with $\mathrm{AlF}_{3}$ content (Fig. 2.9).

Reaction Mechanisms. - The dissolution rates of 40 to $50 \mathrm{mils} / \mathrm{hr}$ differed greatly in significance, depending upon the composition of the melt. At about $60-40$ mole $\% \mathrm{KF}-\mathrm{ZrF}_{4}$, when the maximum rates were observed, only about $30 \%$ of the hydrogen had been evolved at the time of withdrawal of the dissolution specimen. In runs 19 to 24 , where the initial $\mathrm{ZnF}_{4}$ content varied from 21 to 16.5 mole \%, usually 95 to $100 \%$ of the hydrogen had been evolved when the dissolution specimen was withdrawn. This difference in behavior, typifying the two types of dissolution process, was further justification for choice of the "recycle" process. The high dissolution rates observed in runs 1 to 18 were always accompanied by the formation of black, dispersed material in the molten salt as well as by a delay in hydrogen evolution. However, with further hydrofluorination, all the hydrogen was evolved, and the black material was dissolved. Although never positively identified, the black material was strongly reducing and was believed to be either amorphous zirconium or zirconium hydride formed by the reactions:

$$
\begin{gathered}
4 \mathrm{Al}+3 \mathrm{ZrF}_{4} \longrightarrow 3 \mathrm{Zr} \text { (amorphous) }+4 \mathrm{AlF}_{3}, \\
\mathrm{Zr}+\frac{\mathrm{x} / 2}{2} \mathrm{H}_{2} \longrightarrow \mathrm{ZrH}_{\mathrm{x}} .
\end{gathered}
$$

The material balance over one run (Table 2.4) indicated that over $50 \%$ of the aluminum was dissolved by the first reaction; the average composition of the zirconium hydride formed was $\mathrm{ZrH}_{1,34}$.

\section{"Step" and "Partial Transfer" Process Flowsheets Developed}

Two methods for obtaining a reasonable capacity for the $\mathrm{AlF}_{3}$ that results from the hydrofluorination of aluminum in the fuel elements were developed. Both methods were based on the phase diagram

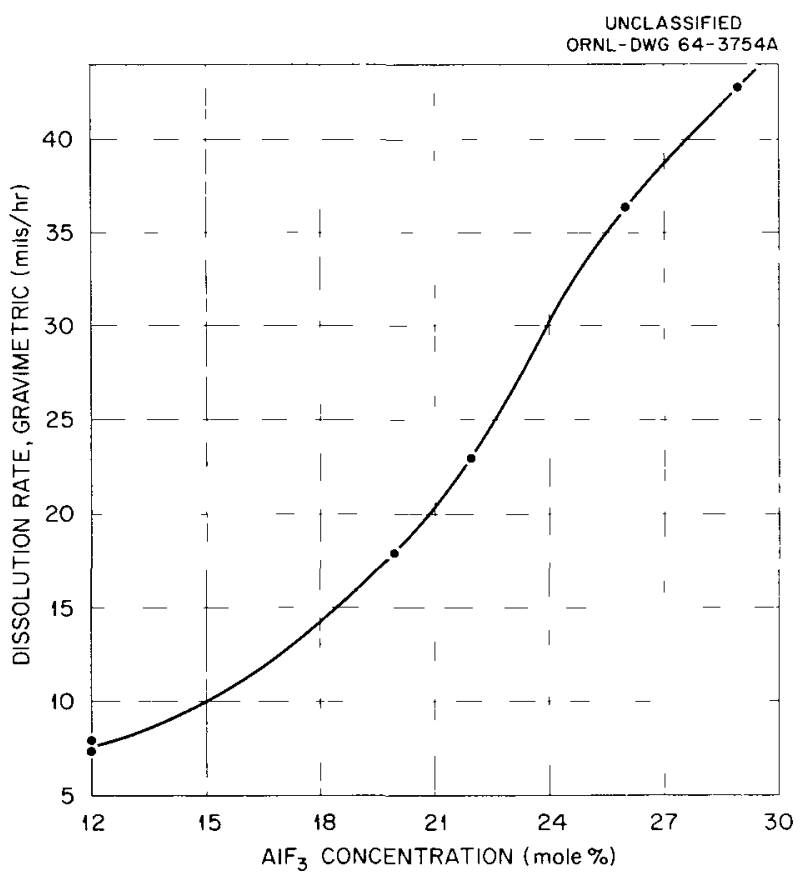

Fig. 2.9. Aluminum Dissolution Rate Increases with AlF $_{3}$ Content Between Salt Compositions of 67-21-12

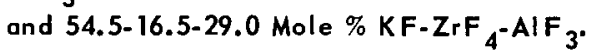


Table 2.4. Material Balance in an Aluminum Dissolution Run

Showing Reduction of $\mathrm{ZrF}_{4}$

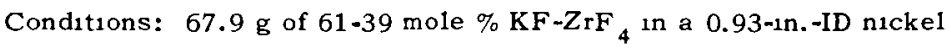

reactor sparged with $\mathrm{HF}$ at rate of $100 \mathrm{~m} 1$ (STP)/min for

$1 \mathrm{hr}$, no digestion period after dissolution

\begin{tabular}{|c|c|c|}
\hline & Grams & Moles \\
\hline Aluminum in test & 3.254 & \\
\hline Aluminum actually dissolved in $1 \mathrm{hr}$ & 2.286 & 0.0848 \\
\hline Hydrogen evolved & & 0.0315 \\
\hline HF used from weighed source & 7.739 & \\
\hline HF recovered in cold trap & 5.516 & \\
\hline HF used in reaction & 2.223 & 0.111 \\
\hline \multicolumn{3}{|c|}{ Results Calculated from Above Data } \\
\hline \\
\hline \multicolumn{3}{|c|}{ Fraction of theoretical hydrogen evolved $-56.8 \%$} \\
\hline \multicolumn{3}{|c|}{ Moles of reduced $\mathrm{Zr}$ produced -0} \\
\hline \multicolumn{3}{|c|}{ Moles of $\mathrm{H}_{2}$ produced but not evolved -0.0240} \\
\hline \multicolumn{3}{|c|}{ 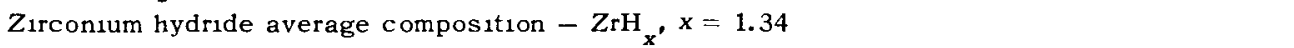 } \\
\hline \multicolumn{3}{|c|}{ Concentration of amorphous $\mathrm{Zr}$ in salt $-4.8 \%$} \\
\hline
\end{tabular}

for the $\mathrm{KF}-\mathrm{ZrF}_{4}-\mathrm{AlF}_{3}$ system, the use of commercial $63-37$ mole $\% \mathrm{KF}-\mathrm{ZrF}_{4}$ salt, and recycle of the salt from one dissolution to the next. The specific flowsheets and compositions, as de. scribed below, were based on the charge of an integral number of Oak Ridge Research Reactor fuel elements to the Volatility Pilot Plant hydrofluorinator for each dissolution step.

The step flowsheet (path FGHIJK on Fig. 2.7) is a slightly modified version of the plan proposed last year. ${ }^{16}$ The current plan is to begin with 60-40 mole \% $\mathrm{KF}-\mathrm{ZrF}_{4}$ and dissolve one element to obtain 51-34-15 mole \% KF- $\mathrm{ZrF}_{4}-\mathrm{AlF}_{3}$. This salt is diluted with $\mathrm{KF}$ to $60.6-273-12.1$ mole $\%$, and a second element is dissolved. The resulting salt, 54.2-24.3-21.5 mole \%, is also diluted with KF to yield a salt of the composition 61.620.4-18.0 mole \%. Two more elements are then dissolved, yielding a final salt of 52.2-17.3-30.5 mole \% $\mathrm{KF}-\mathrm{ZrF}_{4}-\mathrm{AlF}_{3}$ with approximately 3000 ppm of uranium (from irradiated elements). After fluorination, the salt is discarded.

The partial transfer process (path MN on Fig. 27 ) uses $66-22-12$ mole $\% \mathrm{KF}-\mathrm{ZrF}_{4}-\mathrm{AlF}_{3}$ as the initial melt. It 1 s obtained by a modified step procedure, as described above, for dissolving one element in 63-37 mole \% $\mathrm{KF}-\mathrm{ZrF}_{4}$ and then diluting with KF to the desired composition (path BLM). Two elements are dissolved in the initial melt, producing 53.1-17 7-29.2 mole \% salt containing about $2600 \mathrm{ppm}$ of uranium. The uranium is removed from this salt by fluorination. Then, about two-thirds of the salt (by weight) is discarded. The other one-third is recycled and diluted with 63-37 mole \% KF- ZrF ${ }_{4}$ and $\mathrm{KF}$ to $66-22-12$ mole \%, to become the salt charge for the next cycle. The location of point $M$ may have to be changed slightly, since, as shown on Fig. 2.7, the most recent phase-diagram studies indicate a liquidus above $600^{\circ} \mathrm{C}$ for that particular composition.

A comparison of the step and partial transfer flowsheets can be made using the following ratios:

Partial Transfer Step

Uranium processed per cycle

$1.0 \quad 1.3$

Estimated corrosion per cycle

$1.0 \quad 1.2$

Estimated time per cycle

1.0

2.7

Number of consecutive

6

13

process operations per cycle

(not including salt makeup) 
These ratios are based on a single-vessel plant with an auxiliary vessel for salt makeup or for holding molten salt, the same plant could be operated in either mode or in a variety of combinations between the two shown. The higher cycle time and larger number of operations make the step process less attractive than the partial transfer.

Engineering tests of both procedures were made in an INOR-8 vessel. The test of the step flowsheet consisted of three dissolutions and one fluorination. Short lengths of full cross-section Low-Intensity Test Reactor (LITR) prototype fuel elements were dissolved. The elements were $3 \times 3.1 \times 10 \mathrm{in}$. long, and the part of the dissolverfluorinator containing them was $5 \frac{1}{4}$ in. in inner diameter. Overall penetration rates varıed from 3.5 to $9 \mathrm{mils} / \mathrm{hr}$, and overall $\mathrm{HF}$ utilization ranged from 9.5 to $44.8 \%$. After the last dissolution, the uranium was removed from the melt by sparging with fluorine at $575^{\circ} \mathrm{C}$. Fluorination for $3 \mathrm{hr}$ lowered the uranium concentration to $65 \mathrm{ppm}$. The half-time value for fluorination was $28 \mathrm{~min}$, the overall efficiency of fluorine utilization was $3.3 \%$.

Six dissolution-fluorination cycles were made in another engineering test of the partial transfer flowsheet, following an initial step dissolutiondilution to obtain the desired starting composition. Again, short lengths of full cross-section LITR [except for one Oak Ridge Research Reactor (ORR) type] prototype elements were dissolved, with overall penetration rates of 3 to $6 \mathrm{mils} / \mathrm{hr}$ and $\mathrm{HF}$ utıllzation of 151 to $367 \%$. After each of the first four partial transfer dissolutions, the uranium was removed from the entire melt by fluorine sparging at the rate of 2 to 3 std liters $/ \mathrm{min}$. The half-tıme values for removal of urantum varied between 20 and $46 \mathrm{~min}$, and fluorine utilization varied between 0.4 and $31 \%$. After each of the final two dissolutions, the melts were divided into two parts, one part was fluorinated at the rate of $3 \mathrm{std}$ liters/min and the other part at 6 std liters/min. Apparently, fluorine flow rate was not the controlling factor for uranium removal in this system, since in one case a higher flow resulted in higher removal, but in the other, a lower removal.

Operationally, the runs were exceptionally smooth. Processing of the Al-U alloy by either flowsheet was so nearly similar to previous experiments with $\mathrm{Zr}-\mathrm{U}$ alloy that no changes in operating technique were necessary. Only three operational difficulties occurred during the testing of both flowsheets. One of these, a fallure of the autoresistance-heated pipe used for transferring salt and admitting $\mathrm{HF}$ gas, was similar to one that occurred during zirconium processing. The other two difficulties were peculiar to the Al-U alloy process and involved temperature excursions. In one case, the temperature of the center of the element rose to about $1100^{\circ} \mathrm{C}$, although the temperature of the bulk salt remained below 550. When the flow of HF was stopped, the temperature inside the element returned to nearly that of the bulk salt, and the remainder of the run was uneventful. In the second case, a temperature above $700^{\circ} \mathrm{C}$ was recorded in the salt for about $15 \mathrm{~min}$, but, with no HF flow, it returned to normal, and the run was continued.

In addition to the fluorination studies that were a part of the engineering-scale test of the process for Al-U alloys (see preceding discussion), laboratory tests were made in order to determine the completeness and rate of removal of uranium from $\mathrm{KF}-\mathrm{ZrF}_{4}-\mathrm{AlF}_{3}$ melts. The tests were made in a 0.93-1n. -ID nickel reactor, using 50 to $70 \mathrm{~g}$ of salt and fluorine sparging rates of about $100 \mathrm{ml}$ (STP)/ min. Results of the tests are summarized in Table 2.5 and show that more than $999 \%$ of the uranium was easily volatilized from the melts. The relatively high values for uranium retained in three of the runs $(15,20$, and $30 \mathrm{ppm})$ were attributed to insufficient times of fluorination.

\section{Corrosivity to INOR-8 of KF-ZrF ${ }_{4}-\mathrm{AlF}_{3}$ for Dissolving Aluminum at $600^{\circ} \mathrm{C}$ is Equal to or Slightly Less than That of NaF-LiF.ZrF for Dissolving Zirconium at $650^{\circ} \mathrm{C}$}

Of importance in evaluating the suitability of any new application of the molten-salt fluoridevolatility process is the relative corrosivity of the proposed melt to the contanner materials. Three separate studies were made for the alum1num process, each of which involved exposure of at least INOR-8 to molten fluorides and HF. In a laboratory experiment at BMI, which has been previously reported, ${ }^{18,19}$ corrosion was found

\footnotetext{
${ }^{18}$ P. D. Millet et al, Corrosion Resistance of NickelBase Alloys Under Hydrofluorinator Conditions with Aluminum Dissolving, BMI-X-215 (Jan. 7, 1963).

${ }^{19}$ Chem. Technol. Div Ann. Progir. Rept. May 31, 1963, ORNL-3452, supp1. 1, pp. 12-13.
} 
Table 2.5. Laboratory Demonstration of Nearly Complete Removal of Uranium from KF- $\mathrm{ZrF}_{4}-\mathrm{AlF}_{3}$ Melts with Fluorine at $600^{\circ} \mathrm{C}$

Conditions: 50 to $70 \mathrm{~g}$ salt in a $0.930-1 n$. -ID nickel reactor, fluorine sparging rate, $\sim 100 \mathrm{~m} 1(\mathrm{STP}) / \mathrm{mm}$

Step process: Dissolution of Al-U alloy in $60-40$ mole $\% \mathrm{KF}-\mathrm{ZrF}_{4}$ at $600^{\circ} \mathrm{C}$ to attain composition of $51-34-15$ mole $\% \mathrm{KF}-Z_{\mathrm{rF}}-\mathrm{AlF}_{3}$, followed by addition of KF and dissolution of more alloy to attain final composition of $51.5-20.5-28$ mole $\% \mathrm{KF}-\mathrm{ZFF}_{4}-\mathrm{AlF}_{3}$, fluorination may be undertaken at $600^{\circ} \mathrm{C}$ either after first phase or at end

Recycle process: Dissolution of Al-U alloy in 67-21-12 mole \% $\mathrm{KF}-\mathrm{ZrF}_{4}-\mathrm{AlF}_{3}$ to attain salt composition of $51.8-16.2-32$ mole $\% \mathrm{KF}-\mathrm{ZrF}_{4}-\mathrm{AlF}_{3}$, followed by fluorination at $600^{\circ} \mathrm{C}$

\begin{tabular}{|c|c|c|c|c|c|}
\hline \multirow[b]{2}{*}{ Run } & \multirow[b]{2}{*}{ Type of Process } & \multicolumn{2}{|c|}{ Fluorination } & \multicolumn{2}{|c|}{ U Concentration } \\
\hline & & $\begin{array}{l}\text { Temp } \\
\left({ }^{\circ} \mathrm{C}\right)\end{array}$ & $\begin{array}{c}\text { Time } \\
(\mathrm{hr})\end{array}$ & $\begin{array}{l}\text { In1t1a1 } \\
(\mathrm{ppm})\end{array}$ & $\begin{array}{l}\text { Final } \\
\text { (ppm) }\end{array}$ \\
\hline A & Step process -1 st phase ${ }^{a}$ & 575 & $\begin{array}{l}0.5 \\
1.0\end{array}$ & 1530 & $\begin{array}{l}1.2 \\
0.8\end{array}$ \\
\hline $\mathrm{B}$ & Step process -1 st phase $\mathrm{e}^{b}$ & 600 & 1.0 & 1570 & 7 \\
\hline $\mathrm{C}$ & Step process -1 st phase ${ }^{a}$ & 625 & $\begin{array}{l}0.5 \\
1.0\end{array}$ & 1480 & $\begin{array}{l}15 \\
1.2\end{array}$ \\
\hline $\mathrm{D}$ & Complete step process ${ }^{a}$ & 575 & $\begin{array}{l}0.5 \\
1.0\end{array}$ & 3200 & $\begin{array}{l}1.2 \\
1.4\end{array}$ \\
\hline $\mathrm{E}$ & Complete step process ${ }^{b}$ & 600 & 1.0 & 5300 & 30 \\
\hline $\mathrm{F}$ & Complete step process ${ }^{a}$ & 625 & $\begin{array}{l}05 \\
1.0\end{array}$ & 3500 & $\begin{array}{l}2.0 \\
0.8\end{array}$ \\
\hline $\mathrm{G}$ & Recycle process ${ }^{b}$ & 600 & 1.0 & 3900 & 2.2 \\
\hline $\mathrm{H}$ & Recycle process ${ }^{b}$ & 600 & 1.0 & 2300 & 20 \\
\hline
\end{tabular}

${ }^{a}$ Sa1t prepared by addition of $U_{F}$. .

${ }^{b}$ Salt prepared by dissolution of 3.6 wt $\%$ U-Al alloy.

to be unusually low when nickel-base alloys were exposed to 63.8-31.4-4.8 mole \% $\mathrm{KF}-\mathrm{ZrF}_{4}-\mathrm{AlF}_{3}$ at $600^{\circ} \mathrm{C}$ while dissolving type 1100 aluminum with HF. The aluminum was added periodically, and the concentration of $\mathrm{AlF}_{3}$ was increased to 15.6 mole $\%$ in $200 \mathrm{hr}$.

Another laboratory experiment was conducted at BMI with the new procedure (see third part of Sect. 2.1). In this experiment, also made at $600^{\circ} \mathrm{C}$, corrosion was first determined during $101 \mathrm{hr}$ while type 1100 aluminum was dissolving, next, rates of corrosion were determined over a 200-hr period by using the salt from the $f_{1}$ rst portion of the run but without the dissolution of aluminum. ${ }^{20}$ The melt used in the first (dissolution) phase of the experiment was made by adjusting a commercial salt with $\mathrm{ZrF}_{4}$ to a nominal composition of $62.8-37.2$ mole $\% \mathrm{KF}^{-}-\mathrm{rF}_{4}$. The usual $\mathrm{HF}-\mathrm{H}_{2}$ purification of the initial salt was not employed. The salt, as used, contaned 63.8-36.2 mole \% $\mathrm{KF}-\mathrm{ZrF}_{4}$ and $131,29,766$, and $312 \mathrm{ppm}$ of $\mathrm{Fe}, \mathrm{Cr}, \mathrm{N} 1$, and $\mathrm{S}$ respectively. Again the corrosion rates were very low. No losses of

\footnotetext{
${ }^{20}$ P. D. Miller et al, Corrosion Resistance of NickelBase Alloys Under Hydrofluorinator Conditions with Aluminum Dissolving - Part II, BMI-X-260 (Oct. 18, 1963).
} 
metal were detectable by micrometry on any of the nickel-base alloys exposed during either phase of the experiments. By weight loss, the maximum corrosion rates for INOR-8 and HyMu 80 (Alloy 79-4) were 02 and $0.8 \mathrm{mll} /$ month, respectively, during the first phase, and $0.5 \mathrm{mil} / \mathrm{month}$ during the second. Of interest were the intergranular effects noted in the second study, compared with the first. No intergranular attack was observed in the INOR-8 or HyMu 80 specimens in the earlier study, nor did specimens of a new heat of INOR-8 show any intergranular attack in any of the specimens exposed in any position or part of the experiment. However, another heat of INOR-8 (M1671) that had been tested before showed intergranular modification under all conditions except when coupons were exposed above the salt during the nondissolution part of the exper1ment. For the latter heat, the maximum intergranular attack was 1.5 mils in $101 \mathrm{hr}$ during the first part and 3 mils in $200 \mathrm{hr}$ during the second part. Based on sound metal remaining, the maximum corrosion rates were $10.8 \mathrm{mils} /$ month and 8.2 mils/month respectively. Specimens of INOR-8 tubing showed almost no intergranular effects. HyMu 80 specimens showed a slightly greater incidence of intergranular attack, Alloy $2(85 \%$ $\mathrm{N} 1-10 \% \mathrm{Mo}-5 \% \mathrm{Fe}$ ) and weld filler metal 61 were attacked slightly more, and $\mathrm{N}_{1}-1 \% \mathrm{Al}$ and $\mathrm{N}_{1}-5 \%$ Fe specimens were severely attacked.

The third corrosion study was made in our laboratory in an attempt to obtain a direct comparison of the corrosion of Hastelloy $N$ (INOR-8) when exposed to $\mathrm{HF}$ and the melts for dissolving Al-U and $\mathrm{Zr}-\mathrm{U}$ alloys. Gravimetry indicated that $\mathrm{KF}$ $\mathrm{ZrF}_{4}-\mathrm{AlF}_{3}$, as proposed for the Al-U alloy process, is slightly less corrosive to Hastelloy $N$ than the NaF-LiF- $\mathrm{ZrF}_{4}$ melt used for dissolving $z_{11-}$ conium. During the tests, which were made at $600^{\circ} \mathrm{C}$, specimens were exposed to $\mathrm{HF}$ and to helium for 14 and about $35 \mathrm{hr}$ respectively. A single specimen was exposed in both the salt and gas phases of a particular salt composition without fuel dissolution. When the computations were arbitrarily based only on the area of each specimen actually submerged in salt, corrosion rates of 0.006 and $0.013 \mathrm{mil} / \mathrm{hr}$ were found at $67-21-12$ and 51.8-16.2-32 mole \% $\mathrm{KF}-\mathrm{ZrF}_{4}-\mathrm{AlF}_{3}$, respectively, for the Al-U alloy process case, and 0.022 and $0.018 \mathrm{mll} / \mathrm{hr}$ at $37.5-37.5-25$ and $27.5-27.5-45$ mole $\% \mathrm{~L}_{1} \mathrm{~F}-\mathrm{NaF}-\mathrm{ZrF}_{4}$, respectively, for the $\mathrm{Zr}-\mathrm{U}$ alloy process. The salt compositions represented the initial and final conditions for the hydrofluorination (dissolution) step of the two processes.

\section{First Test Was Completed Successfully in the Pilot Plant by Using Fuel Elements Simulated with Aluminum}

On the basis of the favorable results reported above, the process development efforts on the processing of U-Al alloy fuel have been extended to pilot plant scale. One run was successfully completed.

The first aluminum run in the pilot plant consisted in the dissolution of simulated fuel elements containing only aluminum. Two dummy elements, each $21 \mathrm{in}$. long and weighing $4 \mathrm{~kg}$, were dissolved in molten $\mathrm{KF}-\mathrm{ZrF}_{4}$ in $30 \mathrm{hr}$. Even though there was no uranium present, the remainder of the process was followed to test the system.

The composition of the salt at the beginning of metal dissolution was $63-37$ mole $\% \mathrm{KF}-\mathrm{ZrF}_{4}$, 1ts final composition was 16.4-52.7-30.9 mole \% $\mathrm{AlF}_{3}-\mathrm{KF}-\mathrm{ZrF}_{4}$. Salt temperature was mantaned at 600 to $620^{\circ} \mathrm{C}$ throughout the dissolution. Preliminary data indicating the effect of $\mathrm{HF}$ flow rate on dissolution rate were obtained by varying $\mathrm{HF}$ flow in the range of 80 to $125 \mathrm{~g} / \mathrm{min}$, results were inconclusive. Dissolution was complete in $30 \mathrm{hr}$, but a flow of $\mathrm{HF}$ was continued at 40 $\mathrm{g} / \mathrm{min}$ for $1 \mathrm{hr}$ to remove any finely divided solids that might have been present in the melt.

After dissolution was accomplished, the remainder of the flowsheet was followed, with minor variations, to test the operability of the system. No difficulties were encountered.

One major change was made in the flowsheet on the basis of laboratory studies. In the past, during fluorination $\mathrm{UF}_{6}$ was sorbed by $\mathrm{NaF}$ at $100^{\circ} \mathrm{C}$. At this temperature, $\mathrm{MoF}_{6} 1 \mathrm{~s}$ also sorbed, and it must be removed before $U_{6}$ can be recovered. In the revised process, $\mathrm{UF}_{6}{ }_{6}$ is sorbed by $\mathrm{NaF}$ at $150^{\circ} \mathrm{C}$. At $150^{\circ} \mathrm{C}, \mathrm{MoF}_{6}$ should not be held by the NaF, and only a negligible quantity of $\mathrm{UF}_{6} 1 \mathrm{~s}$ displaced to the chemical trap. The $\mathrm{UF}_{6}$ may be recovered from the chemical trap.

Results of the first run were quite satisfactory, and they indicated that there are no inherent difficulties with either the process or the equipment that would prevent continuation of the development program in the pilot plant. 


\subsection{SORBENT STUDIES}

In the fluoride-volatility process, fixed beds of $\mathrm{NaF}$ pellets are used for separating $\mathrm{UF}_{6}$ from a gas stream which may also contain fluorides of corrosion products, fission products, or both. Data on the rate of removal of $\mathrm{UF}_{6}$ from gas streams by fixed beds of $\mathrm{NaF}$ are necessary for the design of sorber systems. The usefulness of current solid sorbents, $\mathrm{NaF}$ and $\mathrm{MgF}_{2}$, could be substantially increased if their capacity, specificity, and stability were improved. Also, other sorbents may be superior.

Work on these problems has been concentrated in seven areas: (1) the development of a correlation between sorption-desorption conditions and the resultant deterioration of $\mathrm{NaF}$ pellets and changes in capacity for sorbing $\mathrm{UF}_{6}$, (2) an extension of the study on the rates of sorption of $\mathrm{UF}_{6}$ by single layers of $\mathrm{NaF}$ pellets to include a broader temperature range and two additional pellet types, (3) determination of the sorptiondesorption characteristics of impurity gases, (4) a study of other possible sorbent systems, (5) a study of pellet production from NaF powder, (6) the elimination of the undesirable retention of uranium on $\mathrm{MgF}_{2}$, and (7) the evaluation of the separation of $\mathrm{PuF}_{6}$ and $\mathrm{UF}_{6}$ by sorptive methods. Results of studies made thus far on item 7 are reported in Sect. 2.7 of this report.

For part of this work, a gasometric apparatus was specially constructed, and it permitted the rapid study of quantitative and controlled gassolid reactions such as sorptions, desorptions, alternating sorption-desorptions, syntheses, and dissociation-pressure measurements. ${ }^{21}$ The gasometric apparatus, used with small, welldispersed samples, permitted a broad attack on many of the specific problems with a minimum of effort.

\section{A Correlation Between Sorption-Desorption Conditions and Both Deterioration of NaF Pellets and Changes in Capacity for UF 6}

During repeated sorptions and desorptions of $\mathrm{UF}_{6}$ on NaF pellets, the pellet structure is broken

\footnotetext{
${ }^{21} \mathrm{~S}$. Katz, Apparatus for the Gasometric Study of Solid-Gas Reactions: Sodium Fluoride with Hydrogen Fluoride and Uranium Hexafluorıde, ORNL-3497 (Oct. $15,1963)$.
}

down, and a finely divided, low-density powder is produced. The capacity of the NaF pellets to sorb $\mathrm{UF}_{6}$ is appreciably reduced after the first sorption-desorption cycle and gradually increases in subsequent cycles. From kinetics studies on pellets in both single layers and in beds under a variety of operating conditions with dilute $\mathrm{UF}_{6}$, and from static studies in the gasometer with undiluted $\mathrm{UF}_{6}$, an explanation has been developed for the effects of variations in operating conditions on both the physical behavior of the pellets and on their capacity for $\mathrm{UF}_{6}$.

As purchased from the Harshaw Chemical Company, the NaF pellet $(1 / 8 \mathrm{in}$. in diameter by $1 / 8$ in. high) has a surface area of 1 to $2 \mathrm{~m}^{2} / \mathrm{g}$. The void fraction is about 0.45 , which theoretically limits the weight of $\mathrm{UF}_{6}$ sorbed to $33 \%$ of the pellet weight. In process applications at $100^{\circ} \mathrm{C}$, the quantity of $\mathrm{UF}_{6}$ sorbed during the first cycle represents about $15 \%$ of the uranium contained in the theoretical composition $\mathrm{UF}_{6} \cdot 2 \mathrm{NaF}$, and on the second cycle, about $10 \%$ of theoretical, with a gradual increase thereafter. The $1: 2$ molar ratio, $\mathrm{UF}_{6} \cdot 2 \mathrm{NaF}$, has been established as the limit, according to studies with highly dispersed $\mathrm{NaF}$.

The initial sorption of $\mathrm{UF}_{6}$ by the $\mathrm{NaF}$ pellet is dependent upon temperature, $\mathrm{UF}_{6}$ concentration, void fraction, and specific surface area. The temperature dependence of the rate of sorption at a point in the pellet has been shown to be of the Arrhenius type; this produces a decrease in total sorption capacity for a pellet as the temperature is increased. The dependence of sorption capacity on the concentration of $\mathrm{UF}_{6}$ arises as a result of different transfer mechanisms for diluted and pure $\mathrm{UF}_{6}$. For impure $\mathrm{UF}_{6}$, transfer is by diffusion through stagnant diluent gas; for pure $\mathrm{UF}_{6}$, transfer is by forced flow resulting from decreased pressure within the pellet. The sorption capacity for pure $\mathrm{UF}_{6}$ is about $30 \%$ of theoretical and has little dependence on sorption temperature. The dependence of sorption capacity on the void fraction results from the requirement that the sorbed $\mathrm{UF}_{6}$ must occupy a volume dictated by the density of the $\mathrm{UF}_{6} \cdot 2 \mathrm{NaF}\left(4.13 \mathrm{~g} / \mathrm{cm}^{3}\right.$ at $26^{\circ} \mathrm{C}$ ). Figure $2.10 \mathrm{a}$ shows the bulk-volume relationship between the same weights of $\mathrm{NaF}$ pellets, reagent-grade $\mathrm{NaF}$, and $\mathrm{NaF}$ which had previously been in the form $\mathrm{UF}_{6} \cdot 2 \mathrm{NaF}$. Rate of sorption is initially dependent upon the available surface; thereafter, it is also affected by the 
thickness of the surface layer of the complex, which, in turn, is inversely proportional to the specific surface area.

During desorption of $\mathrm{UF}_{6}$ from the $\mathrm{NaF}$ pellet, mechanical damage may occur. Its extent is a function of original void volume, temperature of desorption, rate of $\mathrm{UF}_{6}$ removal, and the temperature to which the remaining $\mathrm{NaF}$ is subjected. In the absence of fluorine, the $\mathrm{U}^{5+}$ complex is formed, blocking the movement of the $\mathrm{UF}_{6}$ in the pellet and further reducing the capacity of the $\mathrm{NaF}$ for $\mathrm{UF}_{6}$.

To establish the effect of initial void fraction on the deterioration of pellets and on their capac- ity for $\mathrm{UF}_{6}$, tests were conducted on pellets from two shipments of $\mathrm{NaF}$, lots $\mathrm{P}-2$ and $\mathrm{P}-4$, with initial void fractions of 0.45 and 0.34 respectively. The tests consisted in alternately sorbing and desorbing $\mathrm{UF}_{6}$ between fixed beds of $\mathrm{NaF}$ pellets. In each test, the pellets were loaded to capacity with $\mathrm{UF}_{6}$ at $100^{\circ} \mathrm{C}$ and then desorbed at $400^{\circ} \mathrm{C}$, using fluorine as a carrier gas in both steps. The pressure drop was measured after each run for comparison with initial pressure drop data, and samples were withdrawn for analysis. Photographs of both P-2 and P-4 pellets after eight complete cycles are shown in Figs. $2.10 \mathrm{~b}$ and $2.10 \mathrm{c}$ respectively. The P-2 pellets had deteriorated badly;

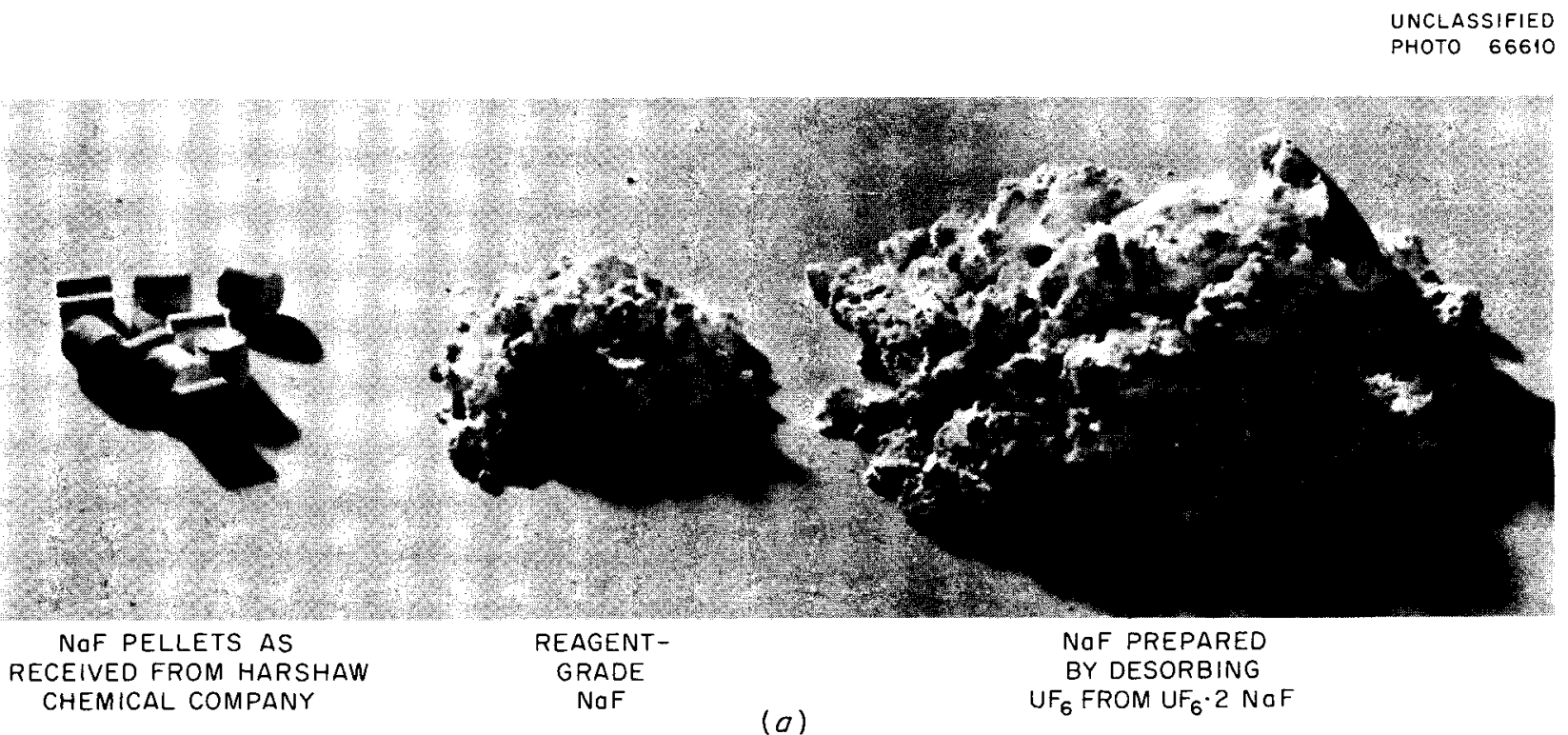

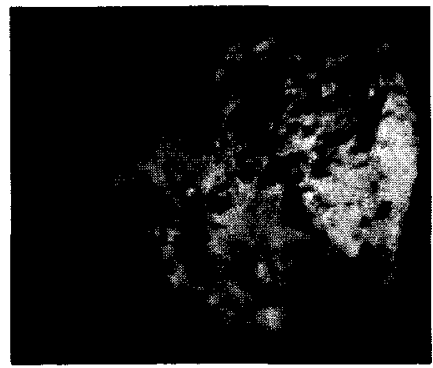

(b)

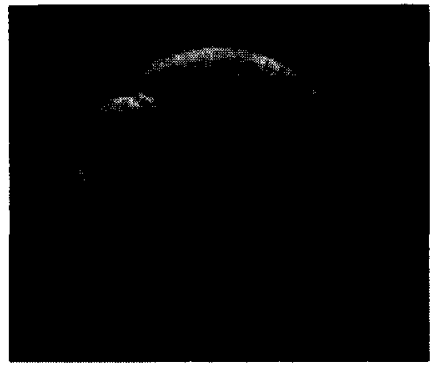

(c)

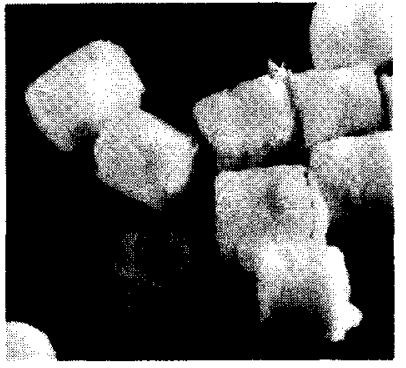

(d)

Fig. 2.10. Appearance of NaF in Sorption Tests. (a) Volumes of identical weights of NaF from different sources; (b) pellet with void fraction of 0.45 after eight sorption cycles; (c) same as (b) except void fraction of $0.34 ;(d)$ after two or three cycles with pure $U F_{6}$, surface layer often sloughs off and remains intact. 
about $5 \%$ of the $\mathrm{NaF}$ had separated from the pellet as a low-density powder, and about $20 \%$ of the initial pellet material was present as a weakly adherent, low-density material at the pellet surface. The remainder of the pellet was essentially unchanged. In contrast, the P-4 pellets showed little change after eight cycles. Their appearance was similar to that of the $\mathrm{P}-2$ pellets after two cycles. The same type of deterioration is believed to have occurred in each case; however, the rate of deterioration was much lower with the denser material.

As shown in Fig. 2.11, resistance to flow of nitrogen through a bed of $\mathrm{P}-2$ pellets increased slightly after nine cycles. No increase was noted for the P-4 material. The increased pressure drop resulting from pellet deterioration is not believed to be a problem, but entrainment of the finely divided $\mathrm{NaF}$ from the bed could cause difficulties.

Mechanical damage to the $\mathrm{NaF}$ pellets is significantly lower when the $\mathrm{UF}_{6}$ is desorbed rapidly at a relatively low temperature. Holding the NaF$\mathrm{UF}_{6}$ complex at $320^{\circ} \mathrm{C}$ for $1 \mathrm{hr}$ reduces the subsequent capacity of the dispersed $\mathrm{NaF}$ powder for $\mathrm{UF}_{6}$ by about $10 \%$. The usual changes in appearance during the first desorption are a rounding of the corners and a roughening of the surface of the pellets.

Sorption of $\mathrm{UF}_{6}$ during the second and third cycles is about $10 \%$ of theoretical. This reduction in capacity is caused by the increase in the area

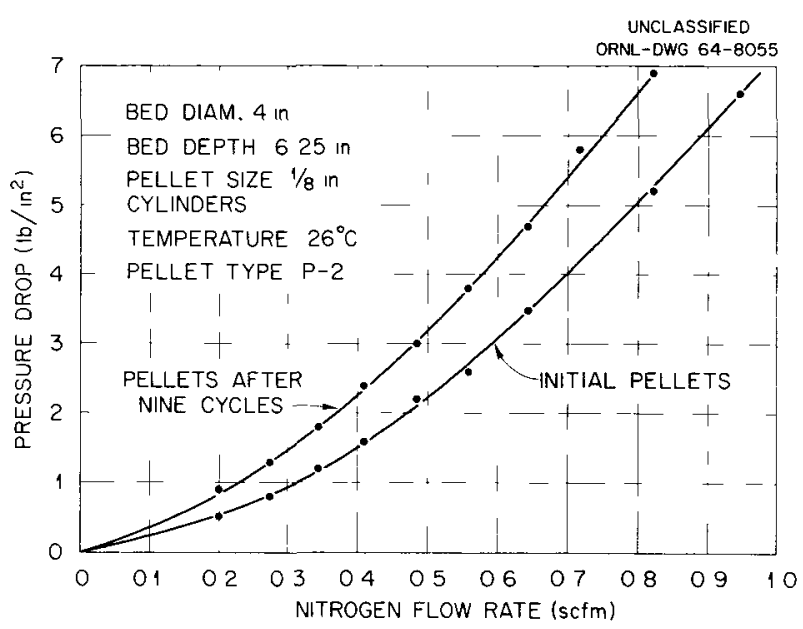

Fig. 2.11. Slightly Greater Resistance to Gas Flow Noted in Bed of NaF Pellets (45\% Voids in Individual Pellets) After Nine Cycles of UF 6 Sorption-Desorption. of the external surface of the $\mathrm{NaF}$ pellet that occurred during the first cycle. The increased rate of reaction in the outer layer blocks the pores sooner than with pellets which had not previously been exposed to $\mathrm{UF}_{6}$; this effect is most pronounced with undiluted $\mathrm{UF}_{6}$. Thus, since the $\mathrm{UF}_{6}$ reacts more rapidly, less time is available for the transport of gaseous $\mathrm{UF}_{6}$ beyond the vicinity of the surface of the pellet. With more cycles of sorption-desorption, mechanical damage and overall pellet dimensions increase. Both conditions are minimal when desorption temperatures are low and $\mathrm{UF}_{6}$ withdrawal rates are high. Mechanical damage results in loose powder; in fact, cycles involving pure $\mathrm{UF}_{6}$ often cause an intact surface layer to slough off as shown in Fig. 2.10d. The sorption capacity of the dispersed powder is reduced because of sintering if the powder is heated to about $490^{\circ} \mathrm{C}$, or higher, during the desorption process. The net effect of these factors is usually a gradual increase in the sorption capacity after the third cycle.

\section{Extension of Mathematical Model for Sorption of UF ${ }_{6}$ by $\mathrm{NaF}$}

Previous work on this problem 22,23 consisted in the correlation, by use of a mathematical model, of data on the sorption of $\mathrm{UF}_{6}$ from a flowing stream of $\mathrm{UF}_{6}$ and nitrogen by single layers of $\mathrm{NaF}$ pellets. The pellets were from a particular shipment received from the Harshaw Chemical Company. The mathematical model considered the effects of temperature, concentration of $\mathrm{UF}_{6}$, gas flow rate, and pellet characteristics. The data were taken in the temperature range 29 to $100^{\circ} \mathrm{C}$ and showed that the sorption rate and capacity of a pellet for sorbing $\mathrm{UF}_{6}$ were strongly influenced by the specific surface area and void fraction of the pellet.

This work was extended to include pellets from three other shipments, with void fraction and specific surface areas different from those of the first shipment tested. In addition, the temperature range was extended so that data are available to

\footnotetext{
${ }^{22}$ Chem. Technol. Div. Ann. Progr. Rept, May 31, 1963, ORNL-3452, p. 48.

${ }^{23}$ L. E. McNeese, An Experimental Study of Sorption of Uranium Hexafluoride by Sodium Fluoride Pellets and a Mathematical Analysis of Diffusion with Simultaneous Reaction, ORNL-3494 (Nov. 14, 1963).
} 
$225^{\circ} \mathrm{C}$. In general, these additional data support the conclusions drawn from the earlier study.

\section{Preparation of Compounds Formed by Reaction of $\mathrm{UF}_{6}, \mathrm{MoF}_{6}$, and $\mathrm{WF}_{6}$ with $\mathrm{NaF}$, and Measurement of Dissociation Pressures}

The compounds $\mathrm{UF}_{6} \cdot 2 \mathrm{NaF}, \mathrm{MoF}_{6} \cdot 2 \mathrm{NaF}$, and $\mathrm{WF}_{6} \cdot 2 \mathrm{NaF}$ were prepared in the gasometer, and the dissociation-pressure curves were determined. The equations for the dissociation pressures were:

$$
\begin{array}{r}
\log P_{\mathrm{mm}}=9.25-\left(4.18 \times 10^{3}\right) / T \\
\text { for } \mathrm{UF}_{6} \text { over } \mathrm{UF}_{6} \cdot 2 \mathrm{NaF},
\end{array}
$$

$\log P_{\mathrm{mm}}=8.80-\left(3.99 \times 10^{3}\right) / T$ for $\mathrm{WF}_{6}$ over $\mathrm{WF}_{6} \cdot 2 \mathrm{NaF}$,

$\log P_{\mathrm{mm}}=8.27-\left(2.87 \times 10^{3}\right) / T$

$$
\text { for } \mathrm{MoF}_{6} \text { over } \mathrm{MoF}_{6} \cdot 2 \mathrm{NaF} \text {, }
$$

where $P_{\mathrm{mm}}$ is pressure in $\mathrm{mm}$ of mercury, and $T$ is temperature in ${ }^{\circ} \mathrm{K}$.

\section{Reactions of $U F_{6}$ and $W_{6}$ with LiF, KF, RbF, and $\mathrm{CsF}$}

Reactions of $\mathrm{UF}_{6}$ and $\mathrm{WF}_{6}$ with lithium, potassium, rubidium, and cesium fluorides were characterized in the gasometer at temperatures from 100 to $450^{\circ} \mathrm{C}$. Lithium fluoride did not react with $W_{6}$ at temperatures below $435^{\circ} \mathrm{C}$; no reaction occurred with $\mathrm{UF}_{6}$ until a temperature of $370^{\circ} \mathrm{C}$ was attained, when a $\mathrm{U}^{5+}$ compound was formed.

When $\mathrm{UF}_{6}$ and $\mathrm{WF}_{6}$ each contacted $\mathrm{KF}, \mathrm{RbF}$, and $\mathrm{CsF}$ separately, compounds approximating $3 \mathrm{KF} \cdot 2 \mathrm{UF}_{6}, \mathrm{WF}_{6} \cdot 2 \mathrm{KF}, \mathrm{UF}_{6} \cdot 1.7 \mathrm{RbF}, \mathrm{WF}_{6} \cdot 2.1 \mathrm{RbF}$, $\mathrm{UF}_{6} \cdot 0.8 \mathrm{CsF}$, and $\mathrm{WF}_{6} \cdot \mathrm{CsF}$ were prepared. These compounds evolved little of the metal hexafluorides upon heating to $400^{\circ} \mathrm{C}$. No favorable separation system was evident.

\section{Production of Pellets from NaF Powder}

At present, pelleted $\mathrm{NaF}$ used in the volatility process is purchased from Harshaw Chemical Company for about $\$ 5$ per $1 \mathrm{~b}$. Since powdered $\mathrm{NaF}$ is available for less than $20 \phi$ per $\mathrm{lb}$, a study of pellet production from $\mathrm{NaF}$ powder is in prog- ress on a subcontract basis with the Paducah Gaseous Diffusion Plant. Pellets are produced by agglomerating a mixture of powdered $\mathrm{NaF}$ and water, followed by drying and fluorination at 250 to $350^{\circ} \mathrm{C}$. To date, pellets prepared by this method have satisfactory sorption characteristics, but they lack the structural stability necessary for repeated use in flxed-bed sorbers. Work will be continued on methods for increasing their stability.

\section{The Undesirable Retention of Uranium on Magnesium Fluoride Sorbent}

The undesirable retention of uranium on the $\mathrm{MgF}_{2}$ used to separate $\mathrm{TcF}_{6}$ from gross amounts of $\mathrm{UF}_{6}$ was shown to be caused by physical sorption, if the $\mathrm{MgF}_{2}$ were pretreated with fluorine at high temperatures. ${ }^{24}$ The deposition of $\mathrm{UF}_{6}$ on $\mathrm{MgF}_{2}$ was studied as a function of preheating, prefluorination, and prehydrofluorination of the pellets. Because the as-received pellets contained about $10 \mathrm{wt} \%$ water, a rigorous preheating and prefluorination was necessary to prevent chemical conversion of the $\mathrm{UF}_{6}$ to a nonvolatile form, probably $\mathrm{UO}_{2} \mathrm{~F}_{2}$. Physical sorption at the $100^{\circ} \mathrm{C}$ sorption temperature is responsible for most of the uranium adsorbed on carefully pretreated $\mathrm{MgF}_{2}$ pellets, and the amount of $\mathrm{UF}_{6}$ retained per kilogram of $\mathrm{MgF}_{2}$ can be reduced to less than $1 \mathrm{~g}$ by heating to $350^{\circ} \mathrm{C}$, thus permitting the adsorber to be discarded when necessary.

\subsection{REMOVAL OF TELLURIUM HEXAFLUORIDE FROM PILOT PLANT EFFLUENT GAS}

The radioactivity due to tellurium $\left({ }^{127 \mathrm{~m}} \mathrm{Te}\right.$, ${ }^{129 \mathrm{~m}} \mathrm{Te}$, and ${ }^{132} \mathrm{Te}$ ) in effluent gases from fluoride-volatility processing represents a possible source of atmospheric contamination. The tellurium is probably in the form of very volatile $\mathrm{TeF}_{6}$ (bp $38^{\circ} \mathrm{C}$ ), although some lower-valent fluorides of less volatility might conceivably originate through reduction. The caustic-spray absorption system used for fluorine disposal in

\footnotetext{
${ }^{24}$ S. Katz, Reduction of Uranium Hexafluoride Retention on Beds of Magnesium Fluoride Used for Removal of Technetium Hexafluoride, ORNL-3544-A (Jan. $16,1964)$.
} 
the Oak Ridge Volatility Pilot Plant (VPP) has been shown capable of removing some of the tellurium but not enough to ensure that none accompanies the residual effluent (helium or nitrogen). ${ }^{25}$ Since tellurium and sulfur are Group VI elements, and since nickel readily reacts with most sulfur compounds at temperatures higher than $300^{\circ} \mathrm{C}$, passage of the gas stream through a bed of nickel at 400 to $500^{\circ} \mathrm{C}$ seemed to be a likely possibility as a more effective method of removing tellurium. Laboratory results confirmed this, and a high-temperature nickel bed will probably be tested under process conditions in the VPP.

The laboratory tests consisted in passing a mixture of $\mathrm{TeF}_{6}$ and helium through a 6-1n.-long bed of nickel mesh in a 1-1n.-diam nickel tube held in a furnace. The $\mathrm{TeF}_{6}$ and helium gas flows were monitored by flowmeter, but the total quantity of $\mathrm{TeF}_{6}$ used was determined by weight loss of the source tank. For convenience of separation and analysis, the bed was made up of six separate sections of mesh, each section being 1 in. long.

Run conditions and results from this study are shown in Table 2.6. In the first three runs at 400,500 , and $600^{\circ} \mathrm{C}$, the respective material balances of $88.5,72.9$, and $63.0 \%$ indicated losses,

\footnotetext{
${ }^{25}$ Chem. Technol. Div. Progr. Rept May 31 1963, ORNL-3452, p. 44.
}

therefore, three consecutive bubbler traps containing a $5 \% \mathrm{KOH}$ solution at $90^{\circ} \mathrm{C}$ were employed in the next three runs in attempts to determine the $\mathrm{TeF}_{6}$ loss through the column. However, the insignificant amounts of tellurium found in the caustic indicated that either there were no losses or that the caustic traps were almost totally ineffective.

The tellurium distribution in each bed indicated degrees of reaction. The first three runs showed some evidence of breakthrough at $600^{\circ} \mathrm{C}$ and perhaps at 500. These temperatures were believed to be fictitiously high due to the method of thermocouple installation. With a more reliable thermocouple technique, the second group of three runs, all conducted below $500^{\circ} \mathrm{C}$, gave little evidence of breakthrough. The effect of too low a temperature (below $400^{\circ} \mathrm{C}$ ) is seen in the first section of the fourth run (Table 2.6).

The mechanism for tellurium retention in a hot nickel bed is probably a combination of chemical reduction and the diffusion of elemental tellurium into the nickel. All the possible reduction products, $\mathrm{Te}_{2} \mathrm{~F}_{10}, \mathrm{TeF}_{4}$, and tellurium have significant volatilities (decreasing in the order given) so that movement of tellurium through a bed after reduction is not surprising, particularly at $600^{\circ} \mathrm{C} .^{26}$ ${ }^{26}$ I. G. Ryss, The Chemistry of Fluorine and Its
Inorganic Compounds, AEC-Tr-3927 (Pt. 1), pp. 161-205 (February 1960).

Table 2.6. Retention of Tellurium in Beds of Nickel Mesh of 400 to $600^{\circ} \mathrm{C}$

Conditions: Mixtures of 15 to $25 \% \mathrm{TeF}_{6}$ passed through beds of nickel mesh ( $1 \mathrm{in}$. in diameter and $6 \mathrm{kn}$. long) at $100 \mathrm{ml}(\mathrm{STP}) / \mathrm{min}$ for $0.5 \mathrm{hr}$

\begin{tabular}{|c|c|c|c|c|c|c|c|c|c|}
\hline \multirow{3}{*}{$\begin{array}{l}\text { Temp } \\
\left({ }^{\circ} \mathrm{C}\right)^{a}\end{array}$} & \multicolumn{8}{|c|}{ Tellurium Retention (\% input) } & \multirow{3}{*}{$\begin{array}{c}\text { Material } \\
\text { Balance } \\
(\%)\end{array}$} \\
\hline & \multicolumn{6}{|c|}{ Bed Section (in order of use) } & \multirow{2}{*}{$\begin{array}{c}\text { Reactor } \\
\text { Wall }^{b}\end{array}$} & \multirow{2}{*}{$\begin{array}{c}\text { Aqueous } \\
\mathrm{KOH} \text { Trap }\end{array}$} & \\
\hline & 1 & 2 & 3 & 4 & 5 & 6 & & & \\
\hline 400 & 61.8 & 24.8 & 1.9 & 0 & 0 & 0 & & & 88.5 \\
\hline 500 & 17.7 & 11.6 & 4.7 & 7.2 & 134 & 10.0 & 87 & & 72.9 \\
\hline 600 & 8.7 & 4.4 & 4.7 & 3.8 & 0 & 0 & 41.4 & & 63.0 \\
\hline 400 & 0 & 24.5 & 38.5 & 1.8 & 0.2 & 0 & & 0.7 & 65.7 \\
\hline 450 & 20.7 & 44.7 & 1.4 & 0 & 0 & 0 & & 0 & 66.8 \\
\hline 480 & 43.6 & 13.0 & 1.0 & 0.7 & 0 & 0 & & 0 & 58.3 \\
\hline
\end{tabular}

\footnotetext{
at Temperatures in the last three runs were believed more accurate than others due to 1 mprovements in application of thermocouples.

${ }^{b}$ Determined by total dissolution.
} 
Tellurium tetrafluoride is reportedly easily hydrolyzed (in contrast to $\mathrm{Te}_{2} \mathrm{~F}_{10}$ and $\mathrm{TeF}_{6}$ ), and therefore, some retention of tellurium in the aqueous traps should have occurred.

Although the material balances make the adequacy of the method somewhat questionable, a high-temperature nickel bed will probably be quite effective under process conditions, where only a trace of activity will be present. Additional effectiveness can probably be achieved by increasing the residence time beyond the value of about $0.5 \mathrm{~min}$ used in the above tests.

\subsection{APPLICATION TO STAINLESS STEEL}

\section{Solubility of $\mathrm{FeF}_{2}$ in 60-40 Mole \% KF. ZrF $\mathrm{rF}_{4}$ Is About 22 Mole \%, but Stainless Steel Dissolution Rate Is Low}

The solubility of the fluorides of iron, chromium, and nickel in solvent melts such as NaF-LiF-ZrF is low at 450 to $600^{\circ} \mathrm{C}$ because of the large differences between the melting temperatures of the difluorides of these metals and that of the solvents. The disadvantages of low solubility (10 to $15 \%$ ) may be offset if other properties, for example, the rapid dissolution of stainless steel claddings or the suitability of a recycled salt as solvent, prove to be especially favorable. Accordingly, preliminary studies of the solubility of $\mathrm{FeF}_{2}$ were made with $\mathrm{KF}-\mathrm{ZrF}_{4}$ mixtures of composition similar to those employed in the reprocessing of aluminum-based fuel. Although only preliminary data have been obtained, the saturating concentration of $\mathrm{FeF}_{2}$ in the $\mathrm{KF}-\mathrm{ZrF}_{4}$ (60-40 mole \%) solvent at $575^{\circ} \mathrm{C}$ may be approximately 22 mole \%. These data suggested that molten mixtures of $\mathrm{KF}$ and $\mathrm{ZtF}_{4}$ might have sufficient capacity for dissolving $\mathrm{FeF}_{2}$ to warrant consideration of their use in the application of the volatility process to fuels that are dispersed in a stainless steel matrix.

Dissolution-rate tests were conducted to determine the practicality of using $\mathrm{KF}-\mathrm{ZrF}_{4}$ for processing stainless-steel-clad fuels. In two tests with $\mathrm{HF}$ in $64-36$ mole $\% \mathrm{KF}-\mathrm{ZrF}_{4}$ and 51.8-16.232 mole $\% \mathrm{KF}-\mathrm{ZrF}_{4}-\mathrm{AlF}_{3}$ at $600^{\circ} \mathrm{C}$, dissolution rates of 1.3 and $0.8 \mathrm{mil} / \mathrm{hr}$, respectively, were measured by gravimetry for type $304 \mathrm{~L}$ stainless steel. The second system was tested on the assumption that the high proportion of $\mathrm{KF}$ would increase the dissolution rate; however, the multivalent components $\left(\mathrm{ZrF}_{4}\right.$ and $\left.\mathrm{AlF}_{3}\right)$ apparently had an overriding effect. Previously reported work in the $\mathrm{KF}-\mathrm{ZrF}_{4}$ system at $650^{\circ} \mathrm{C}$ resulted in higher dissolution rates. Use of the 50-50 mole $\%$ salt in two tests gave rates of about $7.0 \mathrm{mils} /$ hr (2.0 and $\left.2.2 \mathrm{mg} \mathrm{cm}^{-2} \mathrm{~min}^{-1}\right) .^{22}$ For 60-40 mole $\%$ salt, rates of 2.3 and $2.8 \mathrm{mils} / \mathrm{hr}(0.9$ and 1.0 $\mathrm{mg} \mathrm{cm}{ }^{-2} \mathrm{~min}^{-1}$ ) were measured.

The dissolution rates found at 600 and $650^{\circ} \mathrm{C}$ are not necessarily insufficient for stainlesssteel-clad $\mathrm{UO}_{2}$ fuel. However, several other determinations will have to be made before the processing of stainless steel can be considered practicable. These include the solubility of $\mathrm{FeF}_{3}$ (formed in the fluorination step) as opposed to that of $\mathrm{FeF}_{2}$, the corrosivity of $\mathrm{FeF}_{3}$, and the effect of large quantities of $\mathrm{UF}_{4}$ on solubilities, as, for example, in the case of low-enrichment fuel where a high concentration of $\mathrm{UF}_{4}$ appears desirable.

\section{2-37-11 Mole \% NaF-LiF-ZrF 4 , Once Considered for Dissolving the EBR-1 Core-2 Residue with $H F$, Found To Be Exceptionally Corrosive}

The melt consisting of $52-37-11$ mole $\% \mathrm{NaF}-$ $\mathrm{LiF}-\mathrm{ZrF}_{4}$ has been considered for use in dissolving the EBR-1 core- 2 meltdown residue with $\mathrm{HF}$ at $650^{\circ} \mathrm{C}$. The residue has this approximate composition: $88 \%$ uranium, $10 \%$ type 347 stainless steel, $2 \%$ zirconium, and an appreciable amount of occluded "NaK" (the heat-transfer medium in the fuel element, a mixture of sodium and potassium).

In short-term tests reported previously, INOR-8 coupons were corroded at about $0.06 \mathrm{mil} / \mathrm{hr}(43$ mils/month). ${ }^{27-29}$ To verify these results, a laboratory study was made at Battelle Memorial Institute (BMI) under subcontract. ${ }^{30}$ The test was made without fuel dissolution in order to obtain maximum corrosion rates; exposure of

\footnotetext{
${ }^{27}$ G. I. Cathers, M. R. Bennett, and R. L. Jolley, Chem. Eng. Progr. Symp. Ser. 60(47) 31-36 (1964).

${ }^{28}$ Chem. Technol. Div. Ann. Progr. Rept. May 31, 1961, ORNL-3153, pp. 34-35.

${ }^{29}$ Chem. Technol. Div. Ann. Progr. Rept. June 30, 1962, ORNL-3314, pp. 45-46.

${ }^{30}$ P. D. Miller et al., Corrosion Resistance of NickelBase Alloys in a NaF-LiF-ZrF Salt Mixture Considered for EBR-1 Fuel Recovery, BMI-X-247 (July $31,1963)$.
} 
corrosion coupons to $\mathrm{HF}$ and molten salt was for $212 \mathrm{hr}$. The melt was very highly corrosive, with the maximum attack occurring at the saltvapor interface for all alloys tested. On the basis of the sound metal remaining, determined by micrometry and metallography, maximum corrosion rates of 56 , greater than $83,65,51$, greater than 83 , greater than 83 , and $120 \mathrm{~m} 1 \mathrm{~s} /$ month were measured for unannealed INOR-8, annealed INOR-8, annealed Alloy 79-4 (HyMu 80), $\mathrm{N}_{1}-10 \%$ $\mathrm{Mo}-5 \% \mathrm{Fe}, \mathrm{N} 1-5 \% \mathrm{Fe}, \mathrm{N} 1-1 \% \mathrm{Al}$, and nickel filler metal 61 respectively. (The designation "greater than" indicates complete penetration of that particular specimen.)

The above rates of attack may be compared with rates obtained from experiments conducted later with both 52-37-11 mole \% NaF- $\mathrm{L}_{1} \mathrm{~F}-\mathrm{ZrF}_{4}$ for stanless steel and the standard melt for processing zirconium fuels, $37.5-37.5-25$ mole $\% \mathrm{NaF}$ $\mathrm{L}_{1} \mathrm{~F}-\mathrm{ZrF}_{4}$, with and without metal dissolving in each case (see first part of Sect. 2.10). When stanless steel was dissolved in the 52-37-11 melt, both the annealed INOR- 8 and the unannealed Alloy 79-4 coupons located at the saltvapor interface were again penetrated, indicating corrosion rates greater than $83 \mathrm{~m} 1 \mathrm{ls} / \mathrm{month}$. During the nondissolution phase, rates of attack were 15,32 , and $56 \mathrm{mils} / \mathrm{month}$ for unannealed INOR-8, annealed INOR-8, and unannealed Alloy 79-4, all located at the interface. At the beginning of the nondissolution phase of the experiment, the nickel, chromium, and iron contents of the melt were $0.7,17$, and 6.1 mole $\%$ respectively. For the most part, the concentrations of these elements in the melt represented the stanless steel that was dissolved during the first phase of the test.

The extreme corrosiveness of the 52-37-11 melt 1s apparent when the above results are compared with those obtained in the later experiments with 37.5-37.5-25 mole \% NaF- $\mathrm{L}_{1} \mathrm{~F}-\mathrm{ZrF}_{4}$. In neither the dissolution nor the nondissolution phases of the zirconium-flowsheet experiments was any corrosion of INOR-8 or Alloy 79-4 interfacelocated coupons detectable by either micrometry or metallography after exposures of 104 to 210 hr. According to weight-loss determinations, the maximum rate of attack for any comparable spec1men of the two alloys was $0.5 \mathrm{~m} 1 / /$ month.

Recently, processing of the EBR-1 core- 2 meltdown residue was eliminated from the developmental program planned for the Volatility Pilot
Plant (VPP). However, if the residue is ever processed in the VPP on a production basis, earlier ORNL laboratory-scale studies indicated that the salt mixture, $37-37-26$ mole $\%$ NaF-LiF$\mathrm{ZrF}_{4}$, should be considered for use during the hydrofluorination step.

\section{Destructive Oxidation of Stainless Steel in Presence of HF Appears Feasible as a Head.End Process}

The destructive oxidation of stainless steel in the presence of a fluoride catalyst is the basis of a head-end process for reactor fuels using stainless steel as a cladding materiąl or as a matrix ingredient. The resistance of stainless steel to chemical attack is usually a difficult problem in processing such fuels. Use of the oxidation process in conjunction with either the fused-salt or the fluidized-bed volatility process appears possible, and it could also be used as a head-end step for aqueous processes. Exposure of type 304L stainless steel to a $40 \% \mathrm{HF}-\mathrm{O}_{2}$ gas mixture at 575 to $650^{\circ} \mathrm{C}$ results in extremely fast attack rates, the products are the oxides - not the fluorides - of 1ron, nickel, and chromium. As a result of work done during this report period, a process featuring gas recycle is proposed as a convenient and general head-end method for utılizing the destructive oxidation process ( $F_{1}$. 2.12). In such a process, the fuel would be simply exposed to a circulating stream of HF and oxygen (or air), with only oxygen required as make-up material. For a molten-salt volatility process, molten salt would be introduced for dissolution of the $\mathrm{UO}_{2}$ or other uranium material by hydrofluorination. Use of a fluidized bed for the oxidation step also appears possible in volatility processing. For adaptation of this head-end process to aqueous processing, the oxidation products would be fluidized, flushed, or mechanically transferred to another vessel for dissolution and preparation for solvent extraction.

The chorce of HF as the catalyst was based on the results of studies on the dissolution of stainless steel in fused salts in the presence of $\mathrm{HF}$ and oxygen. ${ }^{31}$ Work at Brookhaven National Laboratory showed that stainless steel rapidly degrades when exposed to a mixture of solid $\mathrm{FeF}_{3}$

\footnotetext{
${ }^{31}$ Chem Technol. Div. Monthly Progr. Rept. Feb. 1957, ORNL-2270, pp. 71-74.
} 


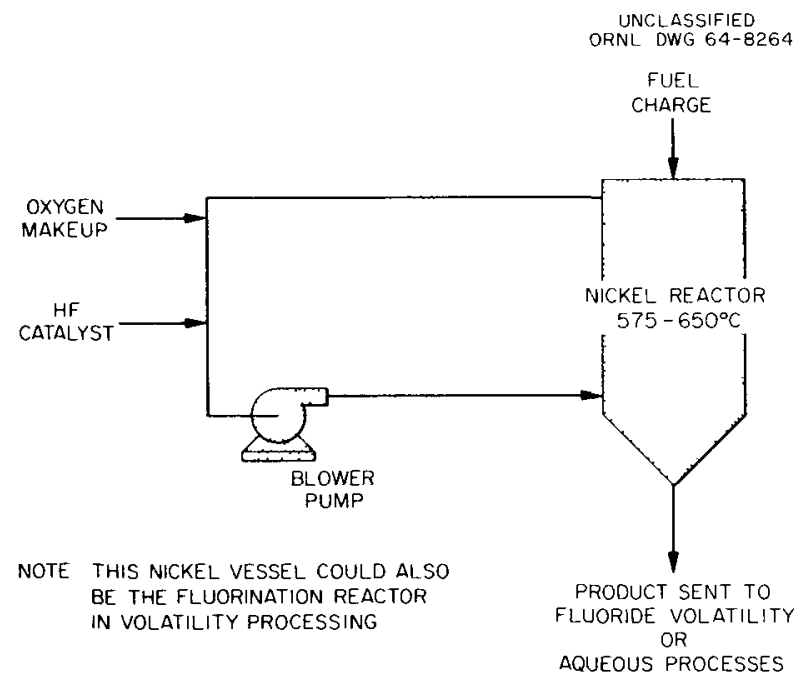

Fig. 2.12. Head-End Process for Stainless Steel Fuels Using the Destructive Oxidation Method.

and oxygen in a bed of fluidized alumina. ${ }^{32}$ The use of gaseous $\mathrm{HF}$ as a catalyst may have process advantages, as, for example, in the uniform distribution of the catalyst. Also, only a little fluoride should remain in the bed and hence should not cause a corrosion problem if the bed is leached with aque ous acids.

The most important factors were HF concentration, temperature, and a metallurgical difference between two batches of type 304L stainless steel samples. Gas flow rate and the presence of nitrogen and moisture were less important factors. The tests were conducted by suspending cylindrical specimens ( $1 \mathrm{in}$. long and $1 / 4 \mathrm{in}$. in diameter) in a 2-in.-diam nickel reactor for an hour. The oxide scale was removed by immersion in boiling $0.3 \mathrm{M}$ ammonium oxalate prior to determination of the reaction rate by weight loss.

The maximum oxidation rate at $650^{\circ} \mathrm{C}$ occurred in approximately 40 mole \% $\mathrm{HF}$ at flow rates of 100 and $200 \mathrm{ml}(\mathrm{STP}) / \mathrm{min}$ (Fig. 2.13). The oxygen utilization varied inversely with flow rate, with $28 \%$ utilization being obtained at a flow rate of $100 \mathrm{ml} / \mathrm{min}$. A distinct difference was obtained between two batches of metal (Fig. 2.14). Batch A gave high oxidation rates with almost no evidence of pitting; batch $B$

\footnotetext{
${ }^{32}$ Information from L. P. Hatch, Chemistry and Chemical Engineering Division, Brookhaven National Laboratory, December 1963.
}

at corresponding temperatures gave lower rates and a high degree of pitting. Moisture or an inert gas usually lowered the oxidation rate. The product contained $\mathrm{Fe}_{2} \mathrm{O}_{2}$ and $\mathrm{Cr}_{2} \mathrm{O}_{3}$ in all cases. The fluoride content was less than $1 \%$, indicating that the $\mathrm{HF}$ catalyst is not appreciably consumed.

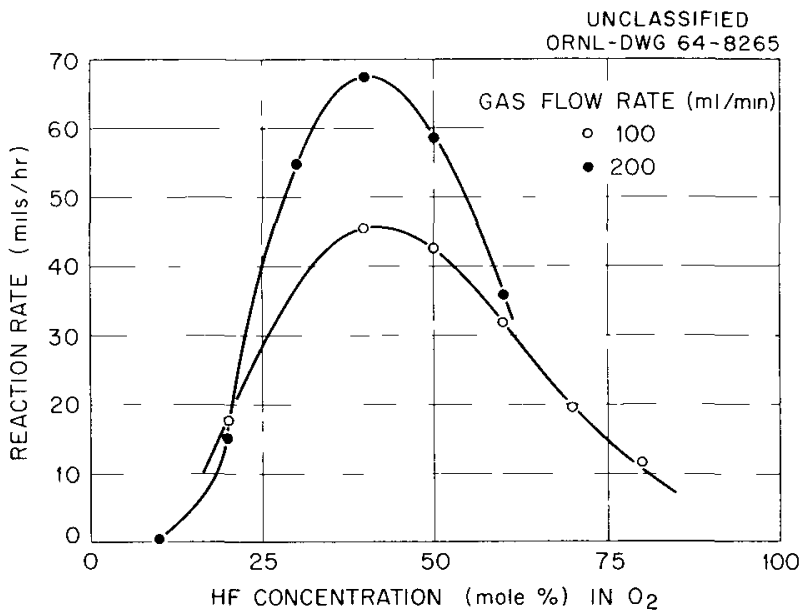

Fig. 2.13. Variation of Destructive Oxidation Rate for Type 304L Stainless Steel with HF Concentration in Oxygen at $650^{\circ} \mathrm{C}$.

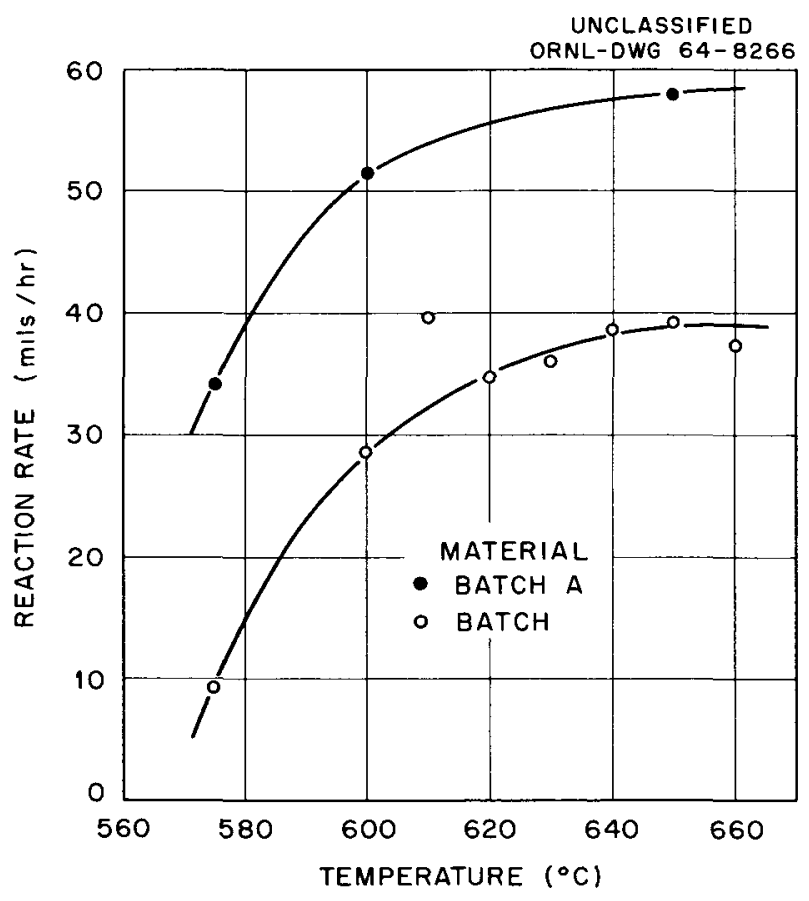

Fig. 2.14. Effect of Temperature on Fluoride-Catolyzed Destructive Oxidation of 304L Stainless Steel [40 Mole \% HF in $\mathrm{O}_{2}$ at a Flow Rate of $200 \mathrm{ml}(\mathrm{STP})$ / $\min ]$. 
The probable mechanism is that the HF (or other fluorides) destroys the passivity of the stainless steel through the formation of $\mathrm{CrF}_{3}$, which in turn is converted to oxide. This agrees with a thermodynamic evaluation and with the action of moisture in decreasing the rate. In one run, where $40 \% \mathrm{~F}$, in oxygen was used in place of HF, almost total conversion to fluoride occurred, but the attack rate was only $3 \mathrm{mils} / \mathrm{hr}$.

Further development of the destructive oxidation method will proceed with other types of stainless steel, and the process will be evaluated as to its adaptability as a head-end treatment for volatility or aqueous processes. Nickel, or possibly a highnickel alloy, is being considered as a constructional material for the reactor vessel. Preliminary information indicated corrosion rates of less than $0.1 \mathrm{mil} / \mathrm{month}$ for nickel at $650^{\circ} \mathrm{C}$ for a $1 \% \mathrm{HF}-\mathrm{O}_{2}$ mixture, and about $2 \mathrm{mils} / \mathrm{month}$ for a $40 \% \mathrm{HF}-\mathrm{O}_{2}^{2}$ mixture.

\subsection{APPLICATION TO OXIDE FUELS}

\section{LiF-NaF-ZrF ${ }_{4}$ Mixture Appears Useful as the Basis for a Molten-Salt Volatility Process for Low-Enrichment $\mathrm{UO}_{2}$ Fuels Clad in Zirconium}

To fully exploit the molten-salt fluoride-volatility process, it must be applied to fuels containing $\mathrm{UO}_{2}$ of low enrichment. A fuel consisting of $\mathrm{UO}_{2}$ clad in zirconium, as used in Commonwealth Edison's Dresden Reactor, was chosen for the initial study. Previous studies on low-enrichment uranium have been concerned with the volatilization and recovery of plutonium from fluoride salt melts. The processing of low-enrichment $\mathrm{UO}_{2}$ power reactor fuels by the fused-salt volatility method appears feasible on the basis of high $\mathrm{UO}_{2}$ dissolution rates and the possible volatilization and recovery of both plutonium and uranium. Two important factors are the nature of the cladding material and the uranium concentration obtainable in the molten salt. For $\mathrm{UO}_{2}$ fuels clad in Zircaloy-2, the process for dissolving zirconium in molten salts with $\mathrm{HF}$ is well established; the only question is that of the upper practicable limit for the concentration of uranium in the solvent salt. Heretofore, the concentration of $\mathrm{UF}_{4}$ in the melt was so low that it was of little or no consequence with respect to the phase behavior of the mixture.
Preliminary solubility measurements were made in $\mathrm{KF}-\mathrm{ZrF}_{4}$ and $\mathrm{LiF}-\mathrm{NaF}-\mathrm{ZrF}_{4}$ mixtures. Successful fluorination tests were made with a salt intended to simulate the maximum amount of $\mathrm{UF}_{4}$ expected. Future work will be guided primarily by the phase-diagram information to be secured for specific fuels. It will include both dissolution and fluorination tests of actual flowsheet-indicated processes; in addition, problems of corrosion and plutonium volatility will be studied.

The solubility measurements were made by adding equimolar increments of $\mathrm{UF}_{4}$ and $\mathrm{ZrF}_{4}$ to 64-36 mole \% KF- $\mathrm{ZrF}_{4}$ and to 37.5-37.5-25.0 mole $\% \mathrm{LiF}-\mathrm{NaF}-\mathrm{ZrF}_{4}$. The resulting mixtures approximately simulated the progressive change in solvent composition during dissolution of Dresden Reactor fuel. According to the liquidus curves (Fig. 2.15) expressing the results of these measurements, the maximum $\mathrm{UF}_{4}$ solubilities in these melts at $600^{\circ} \mathrm{C}$ are 11 and 15 mole \% respectively. Lowering $\mathrm{ZrF}_{4}$ concentration in $\mathrm{LiF}-\mathrm{NaF}-\mathrm{ZrF}_{4}$ was conducive to even greater $\mathrm{UF}_{4}$ solubility.

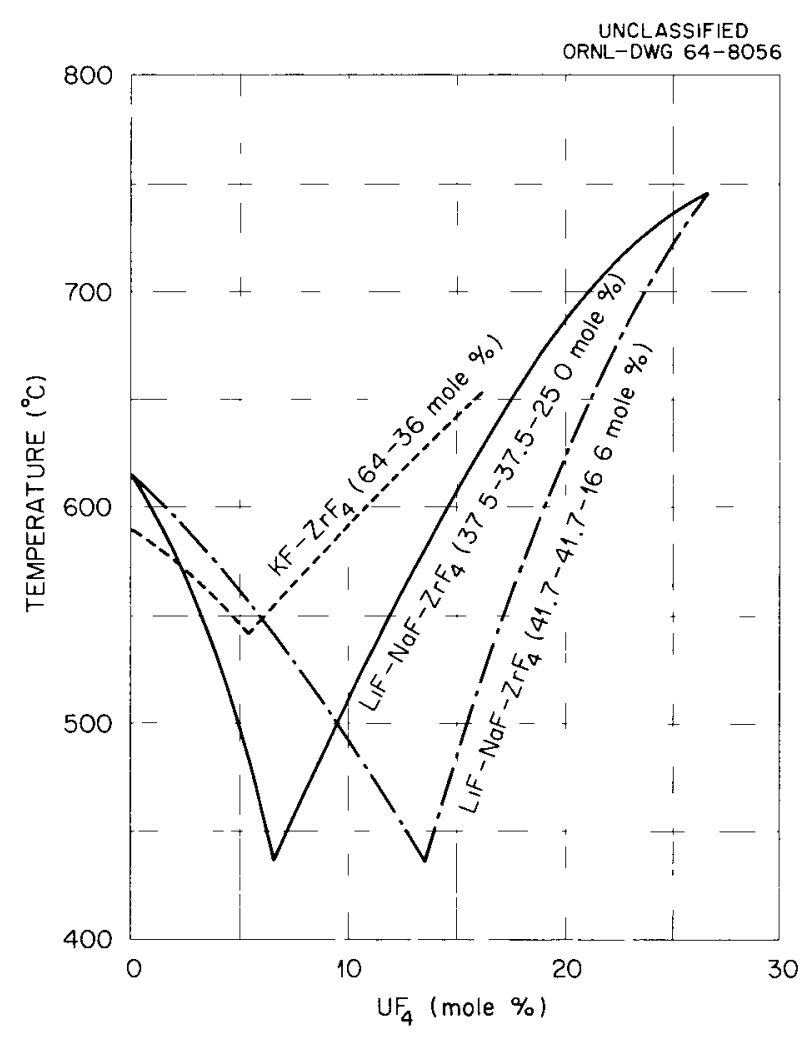

Fig. 2.15. Liquidus Curves in the Systems KF-ZrF $4^{-}$ $U F_{4}$ and LiF.NoF-ZrF $4-U F_{4}$. 
For example, the solubility in 41.7-41.7-16.6 mole \% LiF-NaF- $\mathrm{ZrF}_{4}$ was 19 mole \%.

To determine the feasibility of removing the uranium from a melt where it is present in high concentrations, an exploratory fluorination test was made with the $\mathrm{LiF}-\mathrm{NaF}-\mathrm{ZrF}_{4}$ system. The test salt was 25.7-25.7-30.8-17.8 mole \% LiF$\mathrm{NaF}-\mathrm{ZrF}_{4}-\mathrm{UF}_{4}$ (equivalent to $31.5 \mathrm{wt} \% \mathrm{U}$ ). This melt was calculated on the basis of processing Dresden fuel in 37.5-37.5-25 mole \% LiF-NaF$\mathrm{ZrF}_{4}$ to a final combined $\mathrm{ZrF}_{4}$ and $\mathrm{UF}_{4}$ content of approximately 45 mole \%. Thus, the proposed process is similar to the present one for zirconium fuels, which uses equimolar $\mathrm{LiF}-\mathrm{NaF}$ and progresses from 25 to 45 mole $\% \mathrm{ZrF}_{4}$.

Uranium was successfully recovered by fluorination, indicating the feasibility of high concentration of uranium in a process for Zircaloyclad fuel. Fluorination of a $62.5-\mathrm{g}$ batch of the test salt at $600^{\circ} \mathrm{C}$ for $1 \mathrm{hr}$ with a fluorine rate of $100 \mathrm{ml}$ (STP)/min volatilized $99.8 \%$ of the uranium ( $570 \mathrm{ppm}$ of residual uranium in the salt). A second hour of fluorination increased the recovery to $99.99+\%$ ( $8 \mathrm{ppm}$ in the salt). During fluorination, the sound of the bubbles of fluorine entering the melt did not change, which indicated an absence of thickening or the precipitation of solids in the melt. A high fluorine utilization was obtained as a result of the high uranium concentration. During the first hour of fluorination the fluorine utilization was $31 \%$; it dropped to $0.03 \%$ during the second hour - the best example yet observed of this phenomenon.

\subsection{VOLATILIZATION AND RECOVERY OF PLUTONIUM HEXAFLUORIDE}

Extension of the use of fused-salt volatility processing to low-enrichment fuel requires the volatilization and recovery of plutonium as well as uranium. In previous work at a tracer concentration level of only $2 \mathrm{ppm}$ of plutonium in the salt, the feasibility of fluorinating and volatilizing the plutonium as the hexafluoride was demonstrated, and a sorption method for trapping the $\mathrm{PuF}_{6}$, separately from $\mathrm{UF}_{6}$, was tested. ${ }^{33}$ Further laboratory tests with $1000 \mathrm{ppm}$ of plutonium in the salt

\footnotetext{
${ }^{33}$ G. I. Cathers and R. L. Jolley, Recovery of $P u F_{6}$ by Fluorination of Fused Fluoride Salts, ORNL-3298 (Sept. 28, 1962).
}

generally confirmed the results obtained at $2 \mathrm{ppm}$. However, the rate-controlling factor was not the speed of reaction between $\mathrm{PuF}_{4}$ and fluorine, as previously described, but rather a chemical equilibrium between the salt and gas phases. Due to this equilibrium, an adequate plutonium recovery is possible only with use of a high volume ratio of gas to salt. Maintenance of a high ratio is probably practicable only by using a high sparging rate in a batch reactor, or by using a salt spray or gasphase-continuous fluorine contactor with an intrinsically high volume ratio of gas to salt (see Sect. 2.8).

In the experimental work at a plutonium salt concentration of $1000 \mathrm{ppm}$, an evaluation was made of factors that might affect the volatilization rate and thus permit a more rapid recovery. The results indicated that the composition, purity, temperature of the salt, and the pressure of the gas over the salt were important. Agitation of the salt and the use of fluorination catalysts and different fluorinating agents had no significant effect.

\section{Experimental Work}

The tests with a concentration of $1000 \mathrm{ppm}$ of plutonium were made in a glove box; small nickel reactors were used $(1 \mathrm{in}$. in diameter and 8 in. high), with about $50 \mathrm{~g}$ of salt and a gas (usually fluorine) sparge rate of $100 \mathrm{ml}$ (STP)/min. Plutonium was added to the salt in the form of $\mathrm{PuF}_{3}$. The volatilized $\mathrm{PuF}_{6}$ was trapped in various solid fluoride test beds; each bed weighed about $8 \mathrm{~g}$ and was held in a $1 / 2$-in.-diam nickel tube. The rate of volatilization of plutonium from the molten salt was followed by sampling the salt at intervals over a 4- to 6 -hr period. Total material balances and recoveries were determined from the complete system.

\section{Equilibrium Relationship}

The analytical expression used in interpretation of the results is:

$$
\ln X_{s} / X_{s, 0}=-K F / S
$$

where $X_{s, 0}$ is the original mole fraction of plutonium in the salt, and $X_{s}$ is the mole fraction after sparging $S$ moles of salt with $F$ moles of fluorine 
gas. The equilibrium constant $K$ is defined by the relation:

$$
K=X_{g} / X_{s},
$$

where $X_{g}$ is the mole fraction of $\mathrm{PuF}_{6}$ in the gas phase in equilibrium with the salt. The linear semilogarithmic expression describing the relation between plutonium concentration and moles of fluorine is similar in form to an integrated first-order kinetic equation, the basis for use of half-time values in previous work.

\section{Results}

Volatilization Tests. - The equilibrium constants and material balances for representative tests are given in Table 2.7. Two batches of the principal type of salt used, 31-24-45 mole \% LiF$\mathrm{NaF}-\mathrm{Z}_{\mathrm{rF}}$, gave different results, possibly as the result of a difference in purification method and, hence, of different oxide contents. Values of $K$ for batch $\mathrm{A}$ were generally in the range 0.43 to 0.49 at $600^{\circ} \mathrm{C}$ with fluorine, both with and without violent stirring of the salt. In contrast, values of

Table 2.7. Plutonium Volatilization During Fluorination of Fused Fluorides

Normal run: About $50 \mathrm{~g}$ salt containing $1000 \mathrm{ppm}$ plutonium fluorinated at atmospheric pressure in a 1-1n.-diam reactor at a gas-sparge rate of $100 \mathrm{ml}(\mathrm{STP}) / \mathrm{min}$

\begin{tabular}{|c|c|c|c|}
\hline $\begin{array}{l}\text { Salt composition } \\
(\text { mole } \%)\end{array}$ & Conditions & $\begin{array}{c}\text { Equilibrium } \\
\text { Constant } \\
(K)\end{array}$ & $\begin{array}{c}\text { Plutonium } \\
\text { Material } \\
\text { Balance } \\
(\%)\end{array}$ \\
\hline $30 \mathrm{~L}_{1} \mathrm{~F}-25 \mathrm{NaF}-45 \mathrm{ZrF}_{4}{ }^{a}$ & $\mathrm{~F}_{2}, 600^{\circ} \mathrm{C}$ & 0.49 & 97.8 \\
\hline $30 \mathrm{~L}_{1 \mathrm{~F}}-25 \mathrm{NaF}-45 \mathrm{ZrF}_{4}{ }^{a}$ & $\mathrm{~F}_{2}, 600^{\circ} \mathrm{C}$ & 0.43 & 100.0 \\
\hline $30 \mathrm{~L}_{1} \mathrm{~F}-25 \mathrm{NaF}-45 \mathrm{Z}_{\mathrm{rF}_{4}}{ }^{a}$ & $\mathrm{~F}_{2}, 600^{\circ} \mathrm{C}$, stirring & 0.43 & 97.9 \\
\hline $30 \mathrm{LiF}_{1}-25 \mathrm{NaF}-45 \mathrm{ZrF}_{4}{ }^{a}$ & $\mathrm{~F}_{2}, 600^{\circ} \mathrm{C}$, stirring & 0.45 & 98.1 \\
\hline $30 \mathrm{LiF}_{1}-25 \mathrm{NaF}-45 \mathrm{ZrF}_{4}{ }^{a}$ & $\mathrm{~F}_{2}, 500^{\circ} \mathrm{C}$ & 0.29 & 95.1 \\
\hline $30 \mathrm{~L}_{1} \mathrm{~F}-25 \mathrm{NaF}-45 \mathrm{ZrF}_{4}{ }^{b}$ & $\mathrm{~F}_{2}, 600^{\circ} \mathrm{C}$, stirring & 0.30 & 99.3 \\
\hline $30 \mathrm{~L}_{1} \mathrm{~F}-25 \mathrm{NaF}-45 \mathrm{ZrF}_{4}{ }^{b}$ & $\mathrm{C} 1 \mathrm{~F}_{3}, 600^{\circ} \mathrm{C}$ & 0.33 & 98.7 \\
\hline $30 \mathrm{~L}_{1} \mathrm{~F}-25 \mathrm{NaF}-45 \mathrm{ZrF}_{4}{ }^{b}$ & $\mathrm{~F}_{2}, 600^{\circ} \mathrm{C}, 2$ mole $\% \mathrm{PbF}_{2}$ & 0.33 & 98.6 \\
\hline $30 \mathrm{LiF}-25 \mathrm{NaF}-45 \mathrm{ZrF}_{4}{ }^{b}$ & $\mathrm{~F}_{2}, 650^{\circ} \mathrm{C}$ & 0.26 & 98.8 \\
\hline $30 \mathrm{~L}_{1} \mathrm{~F}-25 \mathrm{NaF}-45 \mathrm{ZrF}_{4}{ }^{b}$ & $\mathrm{~F}_{2}, 600^{\circ} \mathrm{C}, 1 / 2 \times$ N.D. ${ }^{\mathrm{c}}$ & 0.28 & 95.7 \\
\hline $30 \mathrm{~L}_{1} \mathrm{~F}-25 \mathrm{NaF}-45 \mathrm{Z}_{\mathrm{r}} \mathrm{F}_{4}{ }^{b}$ & $\mathrm{~F}_{2}, 600^{\circ} \mathrm{C}, 2 \times \mathrm{N} . \mathrm{D} .^{\mathrm{c}}$ & 0.27 & 100.8 \\
\hline $30 \mathrm{~L}_{1} \mathrm{~F}-25 \mathrm{NaF}-45 \mathrm{ZrF}_{4}{ }^{b}$ & $\mathrm{~F}_{2}-0.5 \mathrm{~atm}, 600^{\circ} \mathrm{C}$ & 0.32 & 93.9 \\
\hline $30 \mathrm{~L}$ F $-25 \mathrm{NaF}-45 \mathrm{ZrF}_{4}{ }^{b}$ & $\mathrm{~F}_{2}-3.5 \mathrm{~atm}, 600^{\circ} \mathrm{C}$ & 0.22 & 75.7 \\
\hline $30 \mathrm{~L}_{1} \mathrm{~F}-25 \mathrm{NaF}-45 \mathrm{Z}_{\mathrm{rF}_{4}}{ }^{b}$ & $\mathrm{~F}_{2}-5.0 \mathrm{~atm}, 600^{\circ} \mathrm{C}$ & 0.21 & 96.2 \\
\hline $42 \mathrm{NaF}-58 \mathrm{ZrF}_{4}$ & $\mathrm{~F}_{2}, 600^{\circ} \mathrm{C}$ & 0.46 & 82.2 \\
\hline $55 \mathrm{~L}_{1 \mathrm{~F}}-45 \mathrm{ZrF}_{4}$ & $\mathrm{~F}_{2}, 600^{\circ} \mathrm{C}$ & 0.33 & 100.6 \\
\hline $26 \mathrm{AlF}_{3}-54 \mathrm{KF}-20 \mathrm{ZrF}_{4}$ & $\mathrm{~F}_{2}, 600^{\circ} \mathrm{C}$ & 0.15 & 90.7 \\
\hline
\end{tabular}

a Batch A.

${ }^{b}$ Batch B.

${ }^{c}$ Signifies use of either half or twice the normal depth (N.D.) of salt. 
about 0.30 were obtained for batch $B$. The largest variation in behavior was obtained when different salt compositions were used (Fig. 2.16). The highest $K$ values were measured with $31-24-45$ mole \% LiF-NaF- $\mathrm{ZrF}_{4}$, the lowest with 26-54-20 mole \% $\mathrm{AlF}_{3}-\mathrm{KF}-\mathrm{ZrF}_{4}$. These values correspond to " $\mathrm{ki}$ netic half-time values" of 2.7 and $4.9 \mathrm{hr}$, respectively, for a fluorine flow rate of $100 \mathrm{ml}(\mathrm{STP}) / \mathrm{min}$. Temperature apparently affected the equilibrium constant, but a quantitative interpretation is not possible with the limited data obtained. The Arrhenius plot gave some indication that $600^{\circ} \mathrm{C}$ would be the most favorable fluorinating temperature (Fig. 2.17). Increasing the fluorine pressure increased the rate of $\mathrm{PuF}_{6}$ volatilization. Thus,

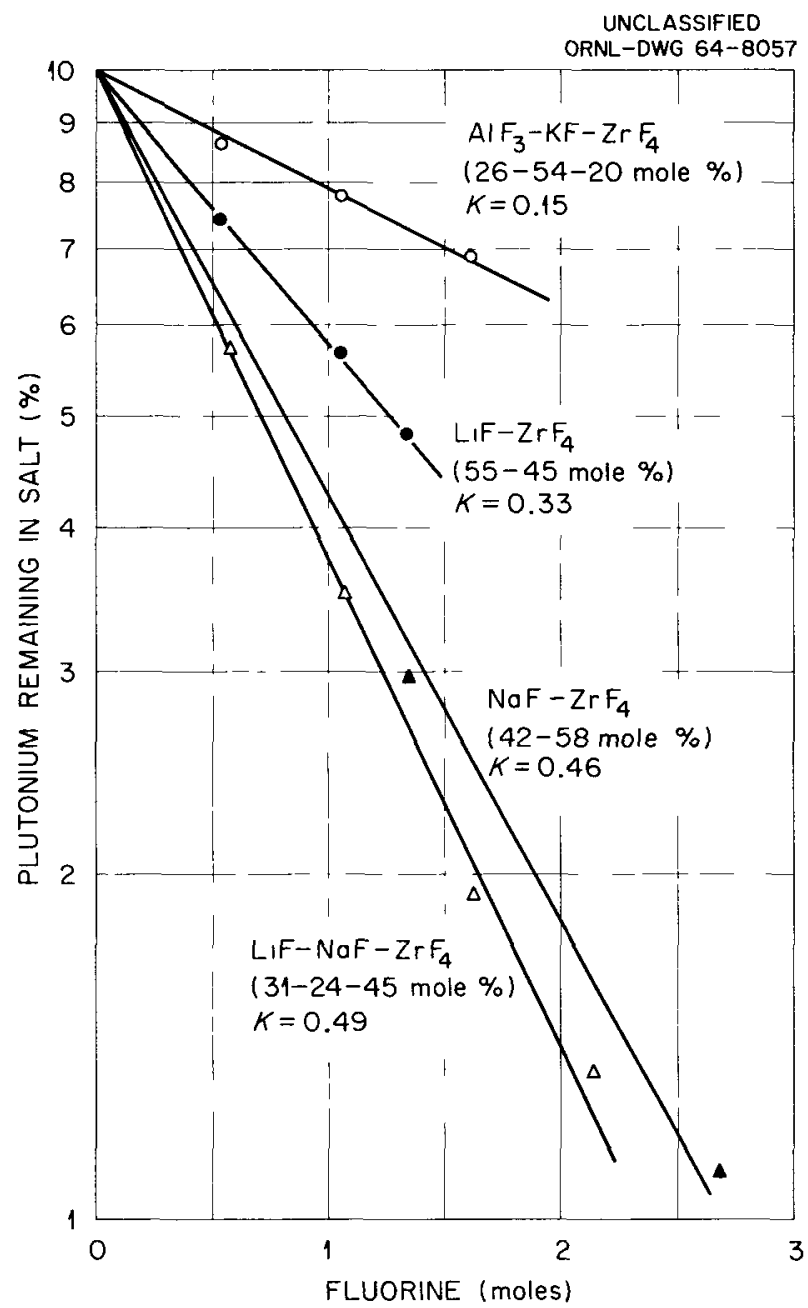

Fig. 2.16. Dependence of PuF 6 Volatilization on Composition of Fused Salt. higher pressure increased the fluorine-gas density and produced a higher concentration of $\mathrm{PuF}_{6}$ in the gas despite some decrease in the $K$ value.

Factors other than rapid stirring that had little or no effect on the rate of $\mathrm{PuF}_{6}$ volatilization included the use of other fluorinating agents and fluorination catalysts. The gaseous interhalogen $\mathrm{ClF}_{3}$ behaved no differently from fluorine. The interhalogen $\mathrm{BrF}_{5}$ did not volatilize any $\mathrm{PuF}$, presumably due to its dissociation to $\mathrm{BrF}_{3}$, which reduced any $\mathrm{PuF}_{6}$ that may have formed. Reagents such as $\mathrm{PbF}_{2}, \mathrm{CoF}_{2}$, or $\mathrm{UF}_{4}$ added to the salt to act as fluorination intermediates or redox catalysts had little effect.

Sorption of Plutonium by Hexafluoride Fluoride Beds. - Beds of $\mathrm{CaF}_{2}, \mathrm{MgF}_{2}, \mathrm{LiF}, \mathrm{NaF}$, and $\mathrm{KF}$ were used in the volatilization tests to achieve the high recoveries reported in Table 2.7. All except $\mathrm{KF}$ were tested at temperatures as high as $400^{\circ} \mathrm{C}$, and all were effective in sorbing and trapping the $\mathrm{PuF}_{6}$. The surface areas of the first four materials were, respectively, $14,60,42$, and $1.7 \mathrm{~m}^{2} / \mathrm{g}$. Only fused LiF, with a specific surface area of $0.02 \mathrm{~m}^{2} / \mathrm{g}$, showed low $\mathrm{PuF}_{6}$ retention. Results of the sorption studies suggest the existence of complexes between the sorbents and $\mathrm{PuF}_{6}$ similar to those formed with $\mathrm{UF}_{6}$ and were generally in agreement with results reported previously. However, the high retention of $\mathrm{PuF}_{6}$ at $400^{\circ} \mathrm{C}$ also indicates that these complexes may not be easily reversible.

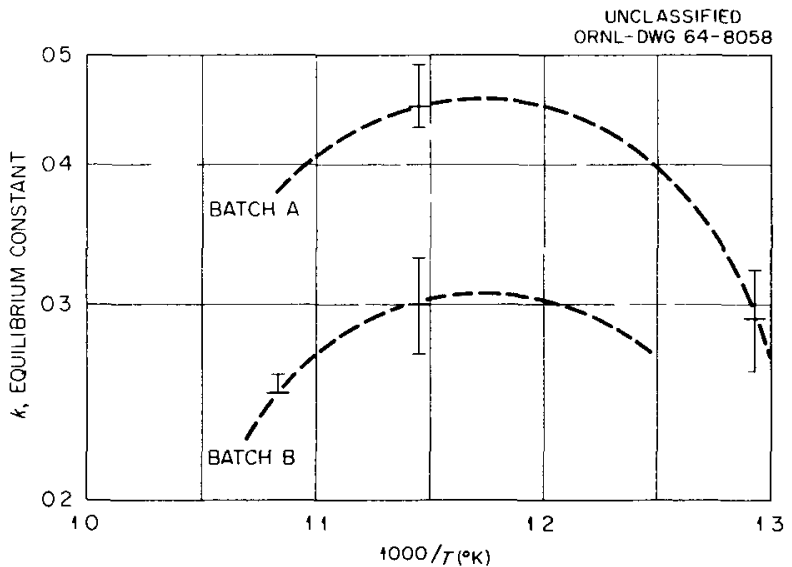

Fig. 2.17. Effect of Temperature on PuF 6 Volatilization from Two Nominally Identical Batches of 31-2445 Mole \% LiF-NaF-ZrF 4 . 


\section{Conclusions}

The volatilization of $\mathrm{PuF}_{6}$ from molten fluoride salts has been found to be controlled by an equilibrium existing between the gas and salt phases. Although the equilibrium constant may be varied to some extent by changes in salt composition, temperature, pressure, and salt purity, the effective half-time in a batch fluorination process would be approximately 3 to $4 \mathrm{hr}$ when using a linear velocity of fluorine gas of about $1 \mathrm{fpm}$ (or a mass velocity of $6.3 \mathrm{lb} \mathrm{ft}^{-2} \mathrm{hr}^{-1}$ ) at the surface of the salt. Sparging for a period of eight or more half-times would be required for adequate recovery (more than 99\%). Thus, a more efficient gas-salt contacting unit is required (see Sect. 2.8). Both volatilization and sorption tests showed that plutonium recovery from low-enrichment fuels by the moltensalt volatility process is chemically feasible.

Further laboratory work on the plutonium probblem will consist in devising process flowsheets for specific fuels, extending the studies of sorption beds, and developing a method for recovery of the sorbed plutonium.

\subsection{FLUORINATION WITH GAS PHASE CONTINUOUS}

An investigation of the fluorination of $\mathrm{UF}_{4}$ from falling droplets of molten salt that contain the uranium was made to determine the feasibility of using a fluorination tower into which the molten salt is either sprayed as a mist or injected as numerous fine streams. All results indicate the feasibility of using a spray or falling-drop process to fluorinate and volatılize uranıum and probably plutonıum from molten fluorıde salts.

Use of a gas-phase-continuous contactor of this type presents a possible method of achieving a more rapıd volatilization of plutonium as well as uranium. Also, the rate of corrosion of the contactor should be less than that when a fluorinator is operated batchwise with the salt phase continuous. A spray fluorination tower operated with countercurrent gas flow would be compatible with the operation of a continuous process, and it would also result in a product stream of more constant composition than that from batch fluorination.

The tests were made by dropping pulverized, classified salt from a powder-feeding device through a fluorination column held at a temperature above the melting point of the salt. The falling particles of salt were melted in a preheater section of the column before entering the fluorination zone.

\section{Progress and Status}

Successful uranıum volatılization tests have been made with molten salt droplets ranging from 53 to $3200 \mu$ in diameter, fluorination temperatures ranged from 550 to $670^{\circ} \mathrm{C}$. The salt employed was 47.5-47.5-5 mole \% NaF- $\mathrm{ZrF}_{4}-\mathrm{UF}_{4}$, which had a liquidus temperature of about $530^{\circ} \mathrm{C}$. The results generally indicate that a uranium volatilization of greater than $99 \%$ is achievable w1th droplets less than $150 \mu$ in diameter falling approximately 4.5 $\mathrm{ft}$ in 3 sec. The data have been used to denve an equation showing the relationship between uranium removal and particle size, temperature, and length of the fluorination column. This work will be extended to a study of uranium removal from other salt compositions and to the quick and complete volatılization and recovery of plutonium.

\section{Experimental Work}

Apparatus and Operation. - The falling-drop fluorination equipment (Fig. 2.18) consisted mainly of (1) a powder feeder, (2) the column, which was divided into a preheater section, a fluorination section, and an unheated section containing the salt receiver cup, (3) the fluorine$\mathrm{UF}_{6}$ trap, and (4) the electrical resistance heaters for the column. The column in which the first studies were made was about 1 in. in internal diameter, it was later replaced with a column that was about $3 \mathrm{in}$. in internal diameter.

The salt was prepared by grinding and sieving 47.5-47.5-5 mole \% $\mathrm{NaF}-\mathrm{ZrF}_{4}-\mathrm{UF}_{4}$. It was introduced into the column through the powder feeder, first falling through the 14-in.-long preheater section, where the particles melted to form droplets. These then fell through the 56-1n.-long fluorination section and into the unheated bottom section of the column, where they froze and were collected in the stamless steel salt receiver. In most runs, this cup was filled with a liquid fluorocarbon $\left(\mathrm{C}_{8} \mathrm{~F}_{16}\right)$ to prevent $\mathrm{UF}_{6}$ from being sorbed by the $\mathrm{NaF}$ in the frozen salt droplets. 


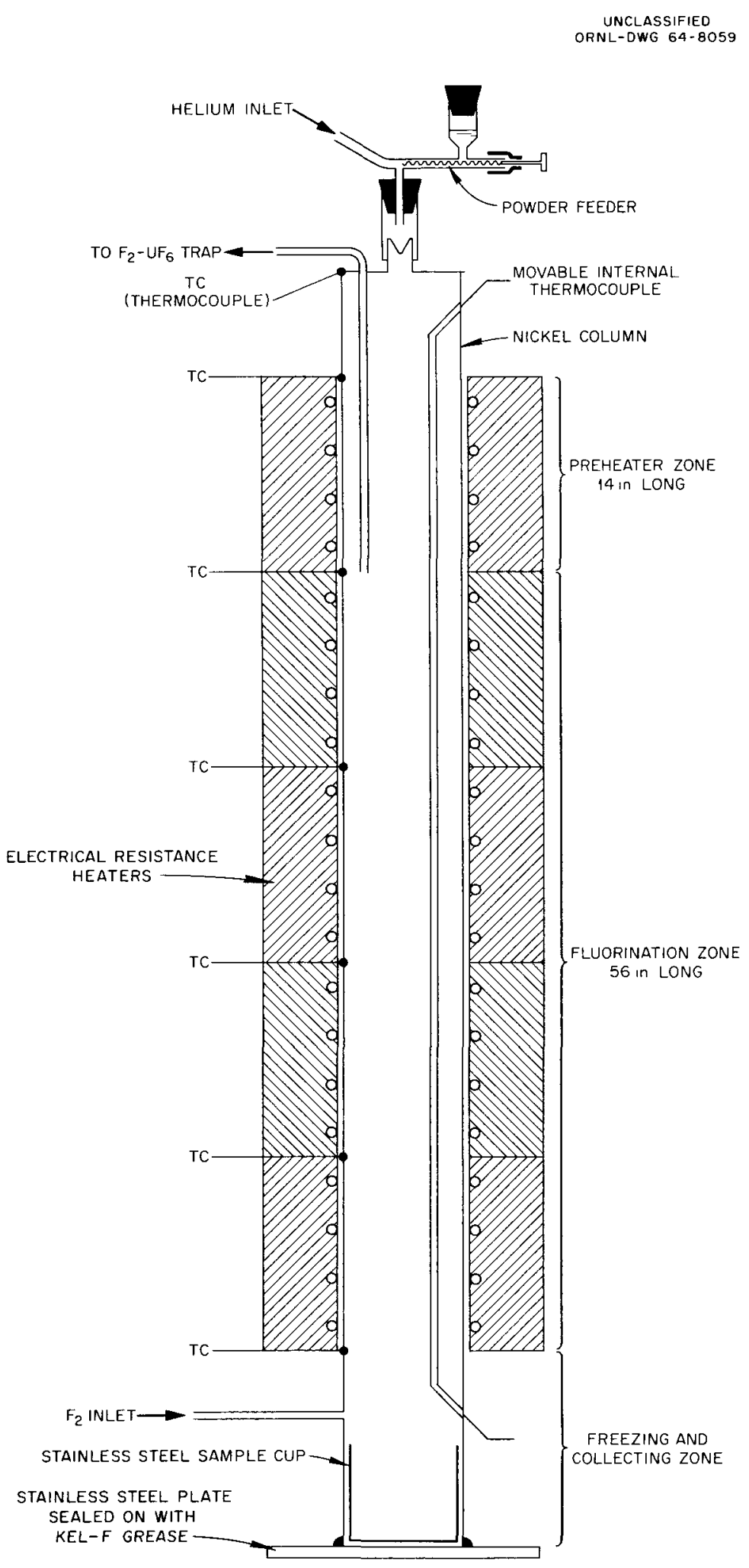

Fig. 2.18. Falling-Drop Fluorinator. 
The collected particles of salt were then sieved, sampled, and analyzed.

Results. - Representative results obtained with the present 3-1n.-OD fluorination column are given in Table 2.8. These data and those for the earlier 1-1n.-OD column are plotted in $F_{1}$. 2.19 as $\log \left[\left(1 / \mathrm{C}_{\mathrm{u}}\right) /-\left(1 / \mathrm{C}_{\mathrm{ou}}\right)\right] D^{2} / t$ vs $1 / T$, from the equation:

$$
\frac{1}{\mathrm{C}_{\mathrm{u}}}-\frac{1}{\mathrm{C}_{\mathrm{ou}}}=k \mathrm{e}^{-\alpha / T}\left(t / D^{2}\right)
$$

yrelding

$k=1.79 \times 10^{29}$ and

$$
a=4.42 \times 10^{4} \text { (arbitrary constants). }
$$

Here,

$$
\begin{aligned}
& D=\text { droplet diameter, } \mu, \\
& T=\text { fluorination temperature, }{ }^{\circ} \mathrm{K},
\end{aligned}
$$

$$
\begin{aligned}
t= & \text { fluorination time, sec, } \\
\mathrm{C}_{\mathrm{ou}}= & \text { original uranium concentration, wt frac- } \\
& \text { tion, and } \\
\mathrm{C}_{\mathrm{u}}= & \text { final uranium concentration, wt fraction. }
\end{aligned}
$$

Fluorination times were calculated by the standard method, using drag coefficients, and, to a good approximation, they are inversely proportional to the square of the diameter for the sizes of drops used (except the 3000- $\mu$-diam drops). ${ }^{34}$

Of special interest in $F_{1 g} .2 .19$ is the adequate $f_{11}$ of the data to the equation over a very wide range of droplet diameters ( 58 to $3200 \mu$ ), although

\begin{tabular}{|c|c|c|c|c|c|c|}
\hline & \multicolumn{6}{|c|}{ Run No. } \\
\hline & $4 \mathrm{~B}$ & $14 \mathrm{~B}^{a}$ & $16 \mathrm{~B}$ & $17 \mathrm{~B}$ & $18 \mathrm{~B}$ & $10 \mathrm{~B}$ \\
\hline Initial range of powder diameters, $\mu$ & $63-88$ & $63-88$ & $125-149$ & $125-149$ & $149-177$ & 3200 \\
\hline Inıtıal uranium concentration, wt fraction & 0.077 & 0.094 & 0.0961 & 0.086 & 0.0837 & 0.080 \\
\hline Average fluorination temp, ${ }^{\circ} \mathrm{C}$ & 622 & 574 & 572 & 566 & 572 & 582 \\
\hline Length of fluorinating section, in. & 56 & 56 & 56 & 56 & 56 & 56 \\
\hline Preheater temp, ${ }^{\circ} \mathrm{C}$ & 664 & 623 & 619 & 640 & 648 & 636 \\
\hline \multicolumn{7}{|c|}{ Amount of Uranium Removed (\%) } \\
\hline \multicolumn{7}{|l|}{ Sample-diameter range, $\mu$} \\
\hline$<53$ & & 98.94 & & & & \\
\hline $53-63$ & 99.56 & 99.17 & & & & \\
\hline $63-88$ & 99.93 & 99.42 & & & & \\
\hline $88-105$ & 99.89 & 99.40 & & & & \\
\hline $105-125$ & 99.89 & 99.44 & 99.93 & 99.95 & & \\
\hline $125-149$ & 99.70 & 98.62 & 99.69 & 99.72 & 99.74 & \\
\hline $149-177$ & 97.70 & & & 98.97 & 99.19 & \\
\hline $177-210$ & & & 97.01 & 98.92 & 97.42 & \\
\hline$>210$ & & & & & 95.53 & \\
\hline 3200 & & & & & & 7.2 \\
\hline
\end{tabular}
there is considerable scatter in the data. From this we conclude that the correlation equation can be used to predict uranium removals at conditions other than those investigated.

\footnotetext{
${ }^{34}$ J. H. Perry (ed.), Chemical Engineering Handbook, pp. 1018-20, McGraw-H111, New York, 1950.
}

Table 2.8. Results of Falling-Drop Fluorinations in the 3-in.-OD Fluorinator

$L$

Fluorination time calculated from $t$ (sec) $=\frac{L}{1.246 \times 10^{-3} D^{2}}$, where $D_{1 \mathrm{~s}}$ the particle diameter $(\mu)$, and $L$ is the length (in.) of the fluorinating section.

${ }^{a}$ Sample-collection cup contained no fluorocarbon. 
In Fig. 2.20, all the data obtained with the 3-in.OD fluorinator (excepting the $3200-\mu-$ diam drops) is plotted as percentage removal of uranium vs droplet diameter. At the temperature of these runs (about $570^{\circ} \mathrm{C}$ ), the best removals (better than 99.9\%) were for droplet diameters between 70 and $140 \mu$, with the collected droplets being protected from back sorption of UF ${ }_{6}$. Fluorination times for these sizes ranged from 2.3 to $9.2 \mathrm{sec}$. Droplets with diameters of less than $70 \mu$ are not desirable because they sorb some $\mathrm{UF}_{6}$ before they can be collected. This lowers the maximum uranium removal to about $99.4 \%$. Loss through drifting to the wall is also a problem with the material of smaller particle size (less than $70 \mu$ in diameter).

Preheater temperature seemed to affect the removal of uranium from droplets larger than $150 \mu$ in diameter; this fact suggests that these larger particles are not completely melted in passing through the preheater zone at $620^{\circ} \mathrm{C}$.

A probable mechanism, and the one on which the correlating equation is based, is the simultaneous

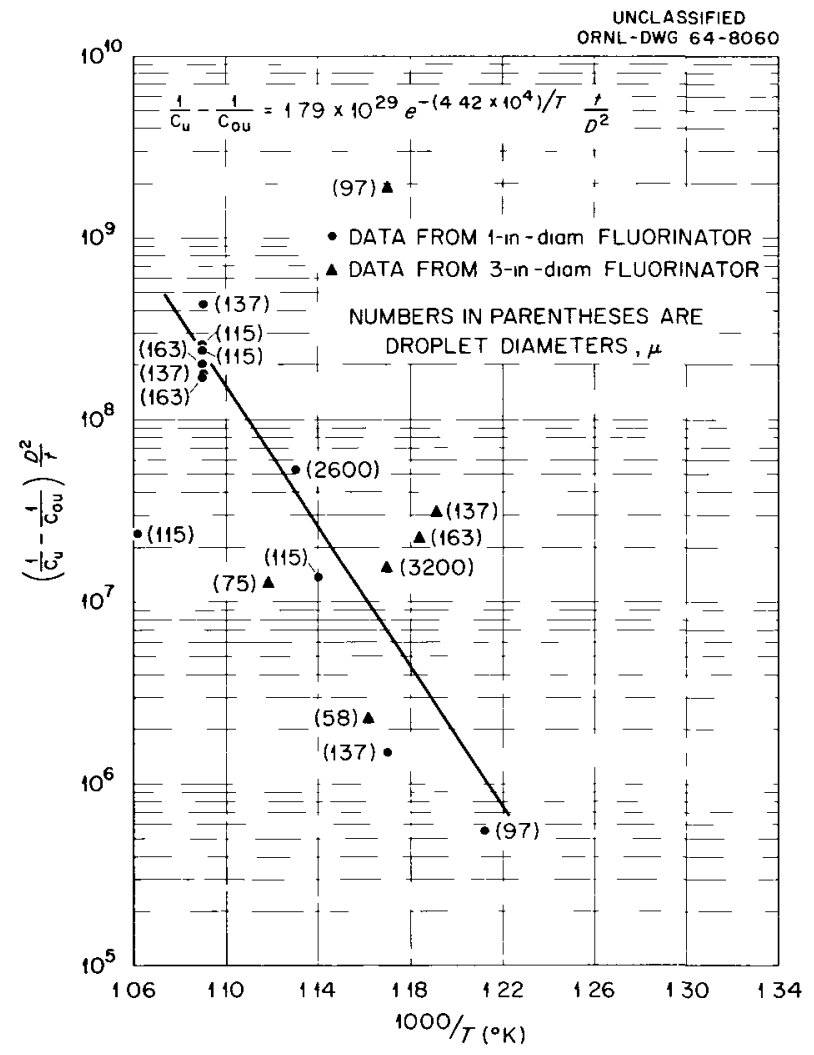

Fig. 2.19. Test of Correlation Equation for FallingDrop-Fluorinator Data.

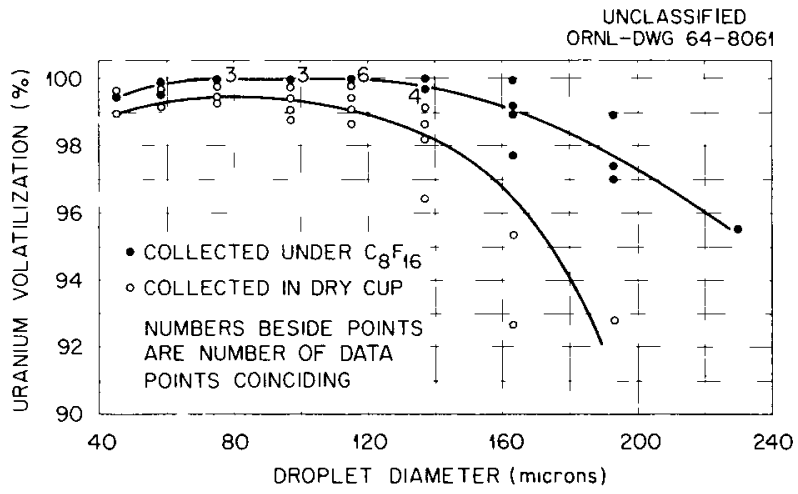

Fig. 2.20. Variation of Quantity of Uranium Volafilized with Droplet Diameter for Fluorination at $570^{\circ} \mathrm{C}$.

diffusion of fluorine and $\mathrm{UF}_{4}$ to a reaction zone inside the drop, with subsequent diffusion of $\mathrm{UF}_{6}$ out of the drop. Supporting this mechanism is the negative pressure surge observed when powder is initially dropped into the fluorinator, indicating that the fluorine is taken up prior to evolution of the UF 6 .

Conclusions. - The falling-drop method of fluorinating and volatilizing uranium from fluoride salts shows promise of being a useful process method. Particularly encouraging are the very high rates of removal for uranium, which suggest that this method may also be useful for plutonium volatilization. More than $99.9 \%$ of the uranium can be removed from $125-\mu$-diam drops in about $3 \mathrm{sec}$ at $550^{\circ} \mathrm{C}$. This rate is about a thousand times greater than that possible when a molten pool of salt is used. The large increase in rate with uranium suggests that a similar increase may be obtained with plutonium. This is important since the rate of plutonium volatilization from fused salts is undesirably low. The high gas-to-salt volume ratio, inherent in a spray column, would be particularly advantageous for plutonium volatilization in view of the equilibrium involved (see Sect. 2.7).

The importance of keeping the droplets molten is shown by the successful use of factors based on diffusional mechanisms in developing the correlating equation. The scatter in the results is attributed to uranium volatilizations usually greater than $99 \%$. In future work, operating variations will be made in order to obtain less complete uranium volatilization. Tests will also be made with other salt compositions containing both plutonium and uranium. 


\subsection{MEASUREMENT OF URANIUM HEXAFLUORIDE CONCENTRATIONS IN STREAMS OF OTHER GASES}

Three types of gas analyzers are being tested in an attempt to provide a reliable, accurate means for determining concentrations of $\mathrm{UF}_{6}$ as well as other volatile fluorides for the evaluation of both large- and small-scale equipment for almost all steps of the molten-salt fluoridevolatility process. Most of the work has involved the determination of the $\mathrm{UF}_{6}$ concentration in a stream containing various combinations of fluorine, oxygen, and nitrogen. A discussion follows of work with a gas chromatograph, an infrared analyzer, and a Constriction Response Analyzer (CRA).

The three types have not been used in equivalent systems and therefore cannot be directly compared. Based on present knowledge, the gas chromatograph gives greater precision than the others, the infrared analyzer shows the shortest response time, and the CRA is the most suitable for a continuous in-line monitor.

\section{Gas Chromatography}

The use of gas chromatography for the analysis of gas streams containing volatile fluorides has been limited primanly by the absence of satisfactory column materials and to the absence of gas-sampling valves that will withstand the corrosiveness of the fluorides. However, the development of a satisfactory column packing material at the Oak Ridge Gaseous Diffusion Plant (ORGDP) has increased interest in this type of gas analyzer for fluoride mixtures. A gas chromatograph has the particular advantage that analysis for one or more components of a multicomponent gas stream is possible, most analyzers can be used only for binary or pseudobinary gas mixtures.

The past application of gas chromatography was limited to laboratory-type analyses and not extended to the analysis of a process gas stream every 5 or $10 \mathrm{~min}$, this limitation was dictated by the absence of a reliable, automatic, gas-sampling valve. In the laboratory, the time required for sampling and analysis is very often not nearly as critical as it is when the transitory behavior of process equipment is being followed by periodic analyses. Accordingly, recent work has been con- centrated on the development of a reliable gassampling valve and on finding conditions that allow analyses to be made in 5 or $10 \mathrm{~min}$.

A multiport, piston-type gas-sampling valve was made at ORNL from nickel and Teflon, and it has been operating for about a year on streams containing volatıle fluorides such as $\mathrm{UF}_{6}, \mathrm{ClF}_{3}$, and $\mathrm{HF}$ in $\mathrm{F}_{2}$ or $\mathrm{N}_{2}$. No difficulties with the valve have been observed. It has been used with a dual-column gas chromatograph ( $F$ and $M$ Scientific Corp., model 720) that was modified so that all parts contacting the sample are of either nıckel or Teflon. The column packing is Kel-F molding powder coated with Kel-F No. 10 o1l. A thermal conductivity cell with a nickel filament is the detector.

The analysis of $\mathrm{UF}_{6}$ in nitrogen or fluorine was accomplished on a 4-min schedule, while the analysis of more complex samples took more time. For the analysis of a $\mathrm{UF}_{6}-\mathrm{N}_{2}$ stream, a linear relation was observed between the instrument reading and the $U_{F}$ concentration in the range of 1 to 65 mole $\% \mathrm{UF}_{6}{ }_{6}$ with a $5 \cdot \mathrm{cm}^{3}$ sample loop and in the range of 0.2 to 20 mole $\%$ with a $15-\mathrm{cm}^{3}$ sample loop. The limit of detection is about 0.01 mole $\% \mathrm{UF}_{6}$ with the larger sample loop.

\section{Infrared Absorption}

A Beckman IR-15A nondispersive type of infrared analyzer was modified and tested for the determination of the $\mathrm{UF}_{6}$ concentration in streams containing nitrogen or fluorine, or both. The instrument as presently operated can measure $\mathrm{UF}_{6}$ concentrations between $0.5 \%$ and $25 \%$ with an accuracy of $\pm 0.2 \%$. The response time is nearly instantaneous. Initially, it had a rather severe zero drift, equivalent to $6 \%$ of full scale per hr, apparently due to an increase in transparency of the window material on exposure to $\mathrm{UF}_{6^{*}}$. This $\mathrm{drift}$ was slowed to $0.4 \%$ of full scale per hr by preconditioning the apparatus with dry nitrogen for $24 \mathrm{hr}$.

\section{Constriction Response Analyzer}

Th1s analyzer was developed at ORGDP for continuously monitoring process streams containing $\mathrm{UF}_{6}{ }^{35}$ A small side stream $(0.2$ to 0.3 liter/

\footnotetext{
${ }^{35}$ C. W. Weber and W. S. Pappas, "A Constriction Response Analyzer and Its Application to Continuous Uranium Hexafluoride Determination," to be submitted for publication in Analytical Chemistry.
} 
min) is withdrawn from the process stream and passed first through an onfice and then through a capillary restriction. The pressure drop across the capillary restriction and the pressure ahead of the orifice are held constant, the entire system is held at constant temperature. Under these conditions, the pressure drop across the orifice, $\Delta P$, is proportional to the molecular weight of the gas divided by the square of the viscosity. The high molecular weight of $\mathrm{UF}_{6}$ relative to either fluorine or nitrogen, the usual major components of the stream, makes possible the detection of low concentrations of $\mathrm{UF}_{6}$.

In our application, fluorine, oxygen, and nitrogen have been the major diluent gases, and, by the nature of the process, the relative concentrations of these three gases vary. The instrument is quite sensitive to the small differences in density and viscosity of these gases (as shown by the scale readings for the pure gases, Fig. 2.21), therefore, the carrier-gas composition must be known before the $\mathrm{UF}_{6}$ concentration can be determined.
Batch fluorination of uranium oxide has been monitored with this instrument, and some gas samples have been taken for UF ${ }_{6}$ determination by chemical analysis. A plot of values indicated by the instrument as the run progressed is shown in $F_{1}$. 2.21, with chemically determined $U_{F}$ concentrations shown beside the scale readings observed at the time of sampling. In this particular case, the only oxygen in the stream was that produced by the reaction of the uranium oxide with fluorine, as the fluorination approaches completion, the oxygen content approaches zero. A small, known amount of nitrogen is present as an instrument purge, and the balance is fluorine. With this knowledge of the variation of the carriergas stream, we interpreted the leveling-out of the instrument readings as the end point of the reaction. From the low concentration found at the end point, we infer that the limit of detection of $\mathrm{UF}_{6}$ is less than $0.1 \%$, provided that the composition of the carrier gas is known.

- LOg-book record of remote chart reading at time shown, no 1 ORIFICE (0 007-in DIAM) IN USE

$\triangle$ SAME AS ABOVE, NUMBER 2 ORIFICE (O OI1-In DIAM) IN USE (REQUIRED FOR HIGH UF CONC TO KEEP READOUT ON SCALE)

PERCENTAGES SHOWN BESIDE POINTS ARE VOLUME PERCENT OF UF 6 IN GAS SAMPLE, CALCULATION BASED ON WET-CHEMICAL ANALYSIS

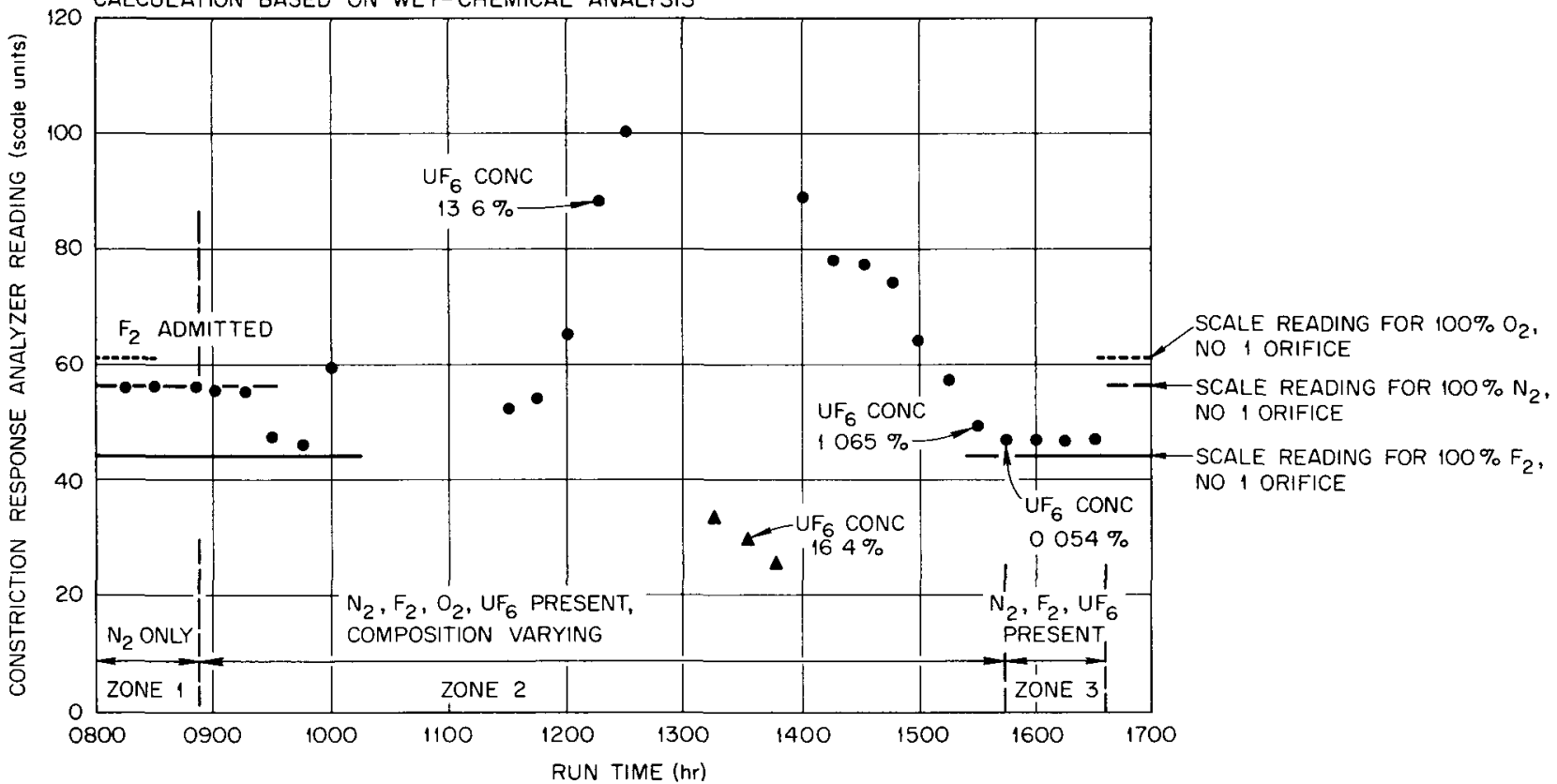

Fig. 2.21. Plot of Constriction-Response-Analyzer Scale Readings Against Run Time, Showing Variation of UF 6 Concentration in Product Stream with Time (Run CVF-16). 


\section{10 GENERAL CORROSION STUDIES}

Since corrosion of the hydrofluorination and fluorination vessels is a major concern in the molten-salt fluoride-volatility process, the problem is being studied extensively. At ORNL, studies are being made at both laboratory and engineering scales and in the Volatility Pilot Plant. Also, many laboratory-scale corrosion data are obtained from studies made at Battelle Memorial Institute (BMI) under a subcontract with ORNL.

Results of corrosion studies that are closely related to major topics in this chapter are reported under the appropriate section headings (see Sects. 2.1, 2.2, and 2.5). Only studies of a more general nature are reported in this section.

\section{Multifactor Experiment Conducted in an Attempt to Explain Variable Corrosion of INOR-8 Under Hydrofluorination Conditions}

A multifactor experiment was conducted at BMI to (1) determine the reasons for the extensive intergranular penetration of INOR-8 noted after its exposure to $52-37-11$ mole \% NaF-LiF- $Z_{\mathrm{rF}}$ and $H F,{ }^{36}$ and (2) to attempt to explain the variations in the degree of intergranular penetration found when various lots and forms of INOR-8 were exposed to ten cycles of hydrofluorination and fluorination in another laboratory-scale experiment. ${ }^{37}$ In the latter experiment, the current process for $Z_{\mathrm{r}-\mathrm{U}}$ alloy fuels was simulated as nearly as possible, with hydrofluorinations and fluorinations at 650 and $500^{\circ} \mathrm{C}$ respectively. Among the conclusions from the multifactor experiment are, for example, that the chief offender during hydrofluorination is a melt that is high in alkali-metal fluoride, that purification of the melt with $\mathrm{HF}$ and hydrogen is apparently unnecessary, and that the metallurgical properties of INOR-8 have little effect. Other evaluations are also included.

\footnotetext{
${ }^{36}$ P. D. Miller et al., Cortosion Resistance of NickelBase Alloys in a NaF-LIF- $\mathrm{ZrF}_{4}$ Salt Mixture Considered for EBR-1 Fuel Recovery, BMI-X-247 (July 31, 1963).

${ }^{37} \mathrm{P}$. D. Miller et al., The Corrosion of an INOR-8 Single-Vesisel Hydrofluorinator-Fluorinator, BMI-X-234 (May 27, 1963).
}

Some of the factors suspected of affecting the degree of attack during hydrofluorination were: (1) actual variations between heats of INOR-8; (2) the relatively high initial concentration of sulfur in the melts used in both experiments ( 83 to $184 \mathrm{ppm}$, compared with the usual value of less than $5 \mathrm{ppm}$ ); (3) the possibility that the intergranular penetration of INOR-8 when exposed to highly corrosive conditions, such as during the fluorination step of the standard process for $Z \mathrm{r}-\mathrm{U}$ alloys and during hydrofluorination in 52-37-11 mole $\% \mathrm{NaF}-\mathrm{LiF}-\mathrm{ZrF}_{4}$, is an extension of ordinary corrosion; and (4) variations in the grain size and the amount of second phase present in different INOR- 8 heats. INOR- 8 tubing consistently has a much smaller grain size than does plate, and both the plate with high amounts of second phase and the tubing seemed to be susceptible to intergranular attack. Suitable heat treatment and possibly the use of vacuum-melted INOR-8 were suggested $^{38}$ as possibilities for improving the performance of INOR-8.

Another aim of the experiment was to standardize the new procedure for simulating process conditions. This new procedure called for containing a complete charge of simulated fuel-element metal in a cup near the bottom of the test vessel. The bottom of the cup was perforated, and $\mathrm{HF}$ and molten salt circulated around the cylinders or bars of fuel metal (see third part of Sect. 2.1).

At the end of the report period, both the experimental work at BMI and their report had been completed. $^{39}$ After the exposures at BMI, selected specimens of INOR-8 were then sent here for examination by Metals and Ceramics Division personnel; this work has not been completed. We also plan to subject the numerical corrosion data to two independent types of statistical analysis, or factor screening; thus far, however, only preliminary contacts with Mathematics Division personnel have been made.

The design of the experiment called for the use of four separate test vessels, each $4 \mathrm{in.}$ in inner diameter. Two of the vessels contained 52-37-11 mole $\% \mathrm{NaF}-\mathrm{LiF}-\mathrm{ZrF}_{4}$. The salt in one of these

\footnotetext{
${ }^{38}$ Suggested by J. T. Venard and H. E. McCoy, Metals and Ceramics Division.

${ }^{39}$ P. D. Miller et al., The Effect of Heat Treatment and of Salt Composition on the Corrosion of INOR-8 and HyMu 80 During Hydrofluorination, BMI-X-288 (May 28, 1964).
} 
vessels had been purified in the Reactor Chemistry Division's molten-salt-production facility with $\mathrm{HF}$ and hydrogen, while the salt in the other vessel had not been purified. The other two vessels contaned purified and unpurified $\mathrm{NaF}$ $\mathrm{L}_{1} \mathrm{~F}-\mathrm{ZrF}_{4}$ (37.5-37.5-25 mole \%). Each of the four vessels contained specimens of INOR-8 sheet that were susceptible to intergranular attack, specimens that were not susceptible, an untested heat, vacuum-melted INOR-8, specimens of tubing, and specimens of HyMu 80 sheet - a total of six categories. The principal specimens of INOR-8 were subjected to four types of heat treatment the standard anneal of $2150^{\circ} \mathrm{F}$ for $1 \mathrm{hr}$ in argon followed by rapid cooling, ${ }^{40} 1 \mathrm{hr}$ at $2300^{\circ} \mathrm{F}$ and rapid cooling, $1 \mathrm{hr}$ at $2300^{\circ} \mathrm{F}$ and rapid cooling, followed by $100 \mathrm{hr}$ at $1600^{\circ} \mathrm{F}$, and no heat treatment. The second heat treatment was intended to provide as nearly a complete solutionanneal as possible without melting the alloy, while the third treatment was expected to reprecipitate any "tramp" elements, or to be equivalent to sensitization of austenitic stainless steels.

A comparison between corrosion during dissolution of reactor fuels and nondissolution was obtained by first dissolving metals in the melts $Z_{1 \text { rcaloy- } 2}$ in the melt containing 25 mole $\% \mathrm{ZrF}_{4}$ and type 347 stanless steel in the melt contaning 11 mole $\% \mathrm{ZrF}_{4}$. The second phase of each experiment consisted in determining the attack on a new set of corrosion coupons, here, the salt remaining at the end of the first (dissolution) phase of the test was used.

The experiments were conducted according to plan, except that one vessel falled at the beginning of the nondissolution phase. That portion of the experiment was repeated, then, the nondissolution phase was conducted in the normal manner. All tests were made at $650^{\circ} \mathrm{C}$, with $\mathrm{HF}$ flow rates of $10 \mathrm{~g} / \mathrm{hr}$, nominal. During the dissolution phases of the runs, utilization of $\mathrm{HF}$ was about $80 \%$ for $Z_{1 \text { rcaloy }-2}$ and about $10 \%$ for type 347 stainless steel.

The main conclusions with respect to the constructional materials for the hydrofluorinator vessel presented in the BMI report were as follows

\footnotetext{
${ }^{40}$ The specimens were cooled by rapidly transferring them from the hot zone of the annealing furnace to a water-cooled end section. The average cooling rate down to $500^{\circ} \mathrm{F}$ was approximately $200^{\circ} \mathrm{F} / \mathrm{min}$.
}

1. The study confirmed earlier results that indicated that salt compositions high in alkalimetal fluorides are more corrosive than those high in $\mathrm{ZrF}_{4}$. For example, INOR-8 was attacked at rates of $1 \mathrm{mil} /$ month, or less, in 37.5-37.5-25 mole \% NaF-LiF- $\mathrm{ZrF}_{4}$ while $Z_{1}$ rcaloy- 2 was being dissolved, and INOR- 8 was attacked at rates up to $150 \mathrm{~m} 1 \mathrm{~s} /$ month in 52-37-11 mole \% NaF-LiF- $\mathrm{ZrF}_{4}$ while stainless steel was being dissolved. Spec1mens of HyMu 80 (Alloy 79-4) were penetrated at similar rates, but, in general, INOR-8 was slightly more resistant to the systems studied than was HyMu 80.

2. The maximum corrosion occurred at interface areas, as is normal in these salt systems.

3. The differences in corrosion noted between dissolution and nondissolution portions of the runs were not significant in the 25 mole \% $\mathrm{ZrF}_{4}$ salt, in the 11 mole $\% \mathrm{ZrF}_{4}$ salt, however, the attack at the interface was more severe while metal was being dissolved.

4. The purification of initial melts with HF and hydrogen was not an important factor in corrosion. Interestingly, the sulfur content of one unpurified melt used in a dissolution (hydrofluorination) phase of the experiments was $331 \mathrm{ppm}$, yet the melt was no more corrosive than the other melts, purified and unpurified, in which the sulfur content was less than $5 \mathrm{ppm}$.

5. Differences in composition and heat treatment of INOR-8 had 1ittle effect on its corrosion. Thus, annealing an INOR- 8 vessel after welding is apparently unnecessary, at least from the standpoint of resistance to corrosion by molten fluorides and $\mathrm{HF}$.

6. Personnel at BMI concluded that the intergranular modifications are merely the start of carbide precipitation, which occurs when the metal is heated to about $1200^{\circ} \mathrm{F}$. They also feel that the metal in the region of intergranular modifications should not be considered unsound since the modifications were only observed after etching. Also, bending of these specimens over a small radius did not open up visible cracks in the grain boundaries. At ORNL, we prefer to reserve judgment on this point since the modifications occurred more frequently and more severely with the more corrosive melt. 


\section{Cathodic Protection Greatly Reduced Corrosion of INOR.8 by HF when Submerged in Molten Fluorides, but Attack at Melt-Gas Interface Only Slightly Reduced}

Cathodic and anodic protection procedures are widely used to reduce corrosion in a variety of aqueous systems. Since corrosion is a major problem in the hydrofluorinator, an experimental program was undertaken at BMI to determine the feasibility of using an impressed voltage to retard corrosion in molten-salt environments.

Corrosion experiments that were run under conditions where INOR- 8 specimens were made cathodic showed that submerged areas were well protected but that measurable attack occurred at the interface areas. However, the attack at the interface was significantly less than is normally encountered without impressed voltage.

In order to obtain the optimum current-voltage relationships for use in the cathodic protection experiments, the development of polarization curves for the materials of interest - INOR-8, Zircaloy, and graphite - was necessary. The polarization characteristics were obtained by the use of a potentiostat, with platinum as a reference electrode and graphite as an anode. Figure 2.22 shows the results for the salt composition 38-3626 mole \% NaF-LiF- $\mathrm{ZrF}_{4}$. All measurements were made with the system at $650^{\circ} \mathrm{C}$ and at an $\mathrm{HF}$

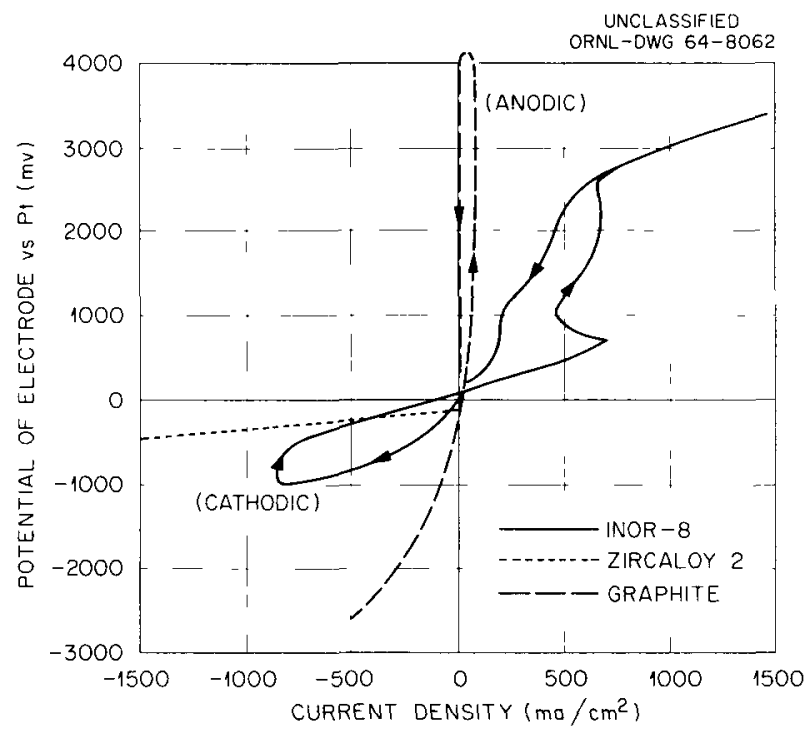

Fig. 2.22. Polarization Curves for Electrodes Under Hydrofluorinator Conditions. Salt composition: 38-3626 mole \% NaF-LiF- $\mathrm{ZrF}_{4}$. flow of about $5 \mathrm{~g} / \mathrm{hr}$. The arrows on the curves show the direction in which the impressed voltage was varied. The hysteresis noted is believed to be the result of some residual polarization.

As would be expected, the more resistant a material is to corrosion the steeper the slope of its polarization curve. For example, the curve for Zircaloy, which is the least resistant to the salt mixture of the materials tested, exhibited a gentle slope when compared with those for INOR-8 or graphite. Results not shown in the figure predict much less corrosion for INOR-8 under helium than under HF.

Similar measurements were made in the 52-37-11 mole $\% \mathrm{NaF}-\mathrm{LiF}-\mathrm{ZrF}_{4}$ mixture. Since this salt is more corrosive than the one containing 26 mole \% $\mathrm{Z}_{\mathrm{rF}}$, curves for INOR-8 and $Z$ ircaloy as cathodes in the melt with 11 mole $\% \mathrm{ZrF}_{4}$ had less slope than that of the curve for the other salt.

The results shown in the upper right quadrant of Fig. 2.22 indicated that the graphite could be polarized anodically but that the INOR- 8 could not be polarized. The cathodic curves in the lower left quadrant indicated that a potential of about 5 to $50 \mathrm{mv}$ (negative) for INOR-8 was sufficient to furnish protection. Keeping this voltage as low as possible was desirable for two reasons: (1) to minimize the excessive deposition of nickel on the INOR-8 cathode, particularly when the salt is high in metal content, and (2) to prevent polarization of the graphite anode.

Three experiments were conducted to determine whether INOR-8 could be cathodically protected. A $1 / 2$-in.-diam graphite rod was used as the anode in the first two. In the third, the INOR-8 specimen was placed between two graphite electrodes. The Hastelloy B container wall was used as the reference electrode in the control circuit of the potentiostat. A galvanostat or battery was used as the power source in the last two experiments. A specimen of INOR-8 electrically insulated with Teflon from the rest of the system was inserted in each experiment as a blank.

Operating conditions and corrosion results are shown in Table 2.9. In all cases the corrosion on the submerged portion of the cathodically protected coupon was about ten times less than that observed for the blank.

The interfacial area, which is normally attacked severely, was protected slightly by an impressed current of about $3.2 \mathrm{amp} / \mathrm{ft}^{2}$. At higher current densities of about 31 to $53 \mathrm{amp} / \mathrm{ft}^{2}$, the corrosion 
Table 2.9. Results of Cathodic Protection of INOR-8 in Presence of 52-37-11 Mole \% NaF-L,F-ZrF ${ }_{4}$ and $H F$ at $650^{\circ} \mathrm{C}$

Cathodic protection nearly eliminated attack on that part of INOR-8 specimen exposed to molten salt below the salt-gas interface. Attack at the interface was only slightly reduced when practical current densities were used.

Conditions: Time $=100 \mathrm{hr}$

HF flow rate $=\sim 5 \mathrm{~g} / \mathrm{hr}$

\begin{tabular}{|c|c|c|c|c|c|}
\hline \multirow{2}{*}{$\begin{array}{c}\text { Experiment } \\
\text { No. }\end{array}$} & \multirow{2}{*}{$\begin{array}{c}\text { Coupon } \\
\text { No. }\end{array}$} & \multirow{2}{*}{$\begin{array}{c}\text { Impressed } \\
\text { Potential } \\
\text { (mv) }\end{array}$} & \multirow{2}{*}{$\begin{array}{c}\text { Cathodic } \\
\text { Current } \\
\text { Density } \\
\left(\mathrm{amp} / \mathrm{ft}^{2}\right)\end{array}$} & \multicolumn{2}{|c|}{ Penetration (mils/month) } \\
\hline & & & & $\begin{array}{c}\text { Interface } \\
\text { (by micrometry) }\end{array}$ & $\begin{array}{c}\text { Below Interface } \\
\text { (by weighing) }^{a}\end{array}$ \\
\hline 1 & 3 & 0 & 0 & 93 & 19 \\
\hline 1 & 2 & $22-40$ & $31-53$ & 8 & $<2$ \\
\hline 2 & 1 & 0 & 0 & 194 & 24 \\
\hline 2 & 4 & 3 & 3.2 & 179 & $<2$ \\
\hline 3 & 5 & 0 & 0 & 148 & 18 \\
\hline 3 & 6 & 3 & 32 & 125 & $<2$ \\
\hline
\end{tabular}

${ }^{a}$ The cathodically protected coupons were weighed after all obvious nickel sponge was removed by abrasion. The amount of sponge was very large on coupon 2. Rate of attack on surface below interface was estimated after sharp attack at the interface had been accounted for.

was reduced by a factor of 10 . The graphite anodes were reduced in area to some extent at the interface regions.

Thus, cathodic protection should be useful in reducing corrosion of submerged areas in INOR-8 systems, but, at practical current densities (less than $10 \mathrm{amp} / \mathrm{ft}^{2}$ ), this method w1ll not satisfactorily protect the interfacial areas.

\section{Preliminary Results Show That Use of an Inert Gas with the HF May Inhibit Corrosion at the Melt-Gas Interface}

The appearance of the coupon from the cathodicprotection study run at high current density (see preceding section) suggested that hydrogen produced at the cathode reduced corrosion in certain areas. The lower rate of corrosion was postulated to be a result of a lower activity of the $\mathrm{HF}$ in the vapor phase, compared with its activity in the liquid. Some exploratory experiments were therefore made to test the hypothesis that the introduction of an inert gas just below the surface of the molten salt during hydrofluorination would reduce the rate of corrosion of INOR-8 at the interface without adversely affecting fuel dissolution rates.

Preliminary studies showed that the presence of an inert gas significantly reduced the penetration of INOR-8 at the salt-gas interface in 52-37-11 mole \% NaF- $\mathrm{L}_{1} \mathrm{~F}-\mathrm{Z}_{\mathrm{rF}}{ }_{4}$ salt at $650^{\circ} \mathrm{C}$. However, more experiments must be made before a final conclusion can be reached as to the practicability of diluting the $\mathrm{HF}$ above the molten salt with inert gas in order to control corrosion.

Five experiments were conducted with the 5237.11 mole \% NaF- $\mathrm{L}_{1} \mathrm{~F}-\mathrm{Z}_{\mathrm{rF}} \mathrm{F}_{4}$ salt that had been used in the electrochemical protection studies. This composition was selected because of 1 ts exceptionally high corrosivity.

Helium or argon was introduced below the surface of the liquid in amounts shown in the third column of Table 2.10. The HF was introduced near the bottom of the container at a rate of about $5 \mathrm{~g} / \mathrm{hr}$. Experiment 6 was run as a control in 
Table 2.10. Reduction of Corrosion of INOR-8 Under Hydrofluorinator Conditions After Addition of Inert Gas

Conditions: $52-37-11$ mole $\% \mathrm{NaF}-\mathrm{L}_{1} \mathrm{~F}-\mathrm{ZrF}_{4}$ from cathodic protection experiments, temperature $650^{\circ} \mathrm{C}, \mathrm{HF}$ at about $5 \mathrm{~g} / \mathrm{hr}$ introduced about $4 \mathrm{in}$. below surface of salt, container $4 \mathrm{in}$. in internal diameter and made of Hastelloy B, exposure times $100 \mathrm{hr}$ except for experiments 4 and 7 , which were 74 and $41 \mathrm{hr}$ respectively

\begin{tabular}{|c|c|c|c|c|}
\hline \multirow{2}{*}{$\begin{array}{l}\text { Experiment } \\
\text { No. }\end{array}$} & \multirow{2}{*}{$\begin{array}{l}\text { Coupon } \\
\text { No. }\end{array}$} & \multirow{2}{*}{$\begin{array}{c}\text { Amount of Inert Gas } \\
\text { Introduced }\end{array}$} & \multicolumn{2}{|c|}{ Penetration Rates (mils/month) } \\
\hline & & & $\begin{array}{l}\text { At Interface, } \\
\text { by Micrometry }\end{array}$ & $\begin{array}{c}\text { Submerged } \\
\text { Area, by Wt Loss }\end{array}$ \\
\hline 4 & 7 & $1.5 \mathrm{~g} / \mathrm{hr}$ of He under coupon 8 & 23 & 11 \\
\hline 4 & 8 & (HF introduced below coupon 7 ) & 15 & 12 \\
\hline $5^{a}$ & 9 & $1.5 \mathrm{~g} / \mathrm{hr}$ of $\mathrm{He}$ under the & $<6$ & $<4$ \\
\hline $5^{a}$ & 10 & surface near coupon 10 & $<2$ & $<3$ \\
\hline 6 & 11 & None (HF introduced below & 380 & 32 \\
\hline 6 & 12 & coupon 11) & 250 & 13 \\
\hline 7 & 13 & $20 \mathrm{~g} / \mathrm{hr}$ of argon under the & $<4$ & $<2.1$ \\
\hline 8 & 15 & $37 \mathrm{~g} / \mathrm{hr}$ of argon under the & 4 & $<0.7$ \\
\hline 8 & 16 & surface near coupon 15 & 7 & $<1.0$ \\
\hline
\end{tabular}

${ }^{a}$ Stainless steel was being dissolved during this experiment.

which only $\mathrm{HF}$ was introduced. All experiments were run for about $100 \mathrm{hr}$ unless noted otherwise in the table.

Note that wherever the inert-gas sparge was used, the corrosion was much less than that for the control experıment when only $\mathrm{HF}$ was present. For example, a maximum rate of $23 \mathrm{mils} /$ month was obtained in experiment 4, contrasted with $380 \mathrm{mils} /$ month in experiment 6 . Figure 2.23 shows the severe notching of control coupons 11 and 12 , compared with the mild attack on coupons 15 and 16 . The corrosion of the submerged areas was also reduced somewhat by the inert-gas sparge (see Table 2.10).

The results of experiment 5 showed that the dissolution of type 347 stainless steel was hardly affected by the inert-gas sparge. As might be expected, this experiment also resulted in slightly reduced corrosion of the INOR-8 coupons.

In previous studies using similar salt compositions without an inert-gas sparge, ${ }^{41}$ corrosion

\footnotetext{
${ }^{41}$ P. D. Miller et al. Cortosion Resistance of NickelBase Alloys in a NaF-LiF-ZrF Salt Mixture Considered for EBR-1 Fuel Recovery, ${ }^{4}$ BMI-X-247 (July 31, 1963).
}

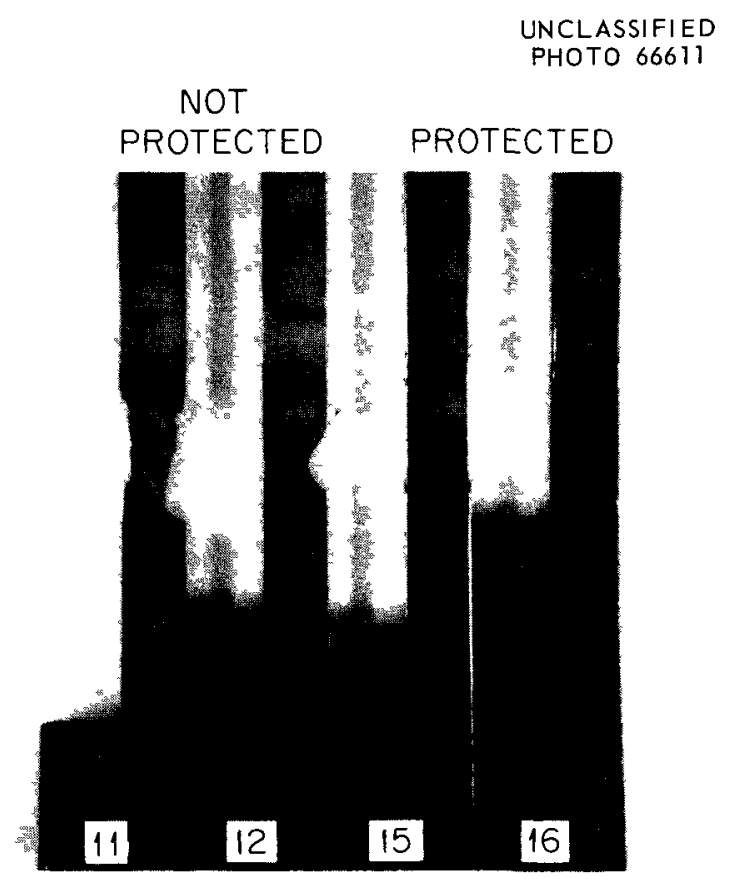

Fig. 2.23. Use of Argon with HF Practically Elımınates Severe Notching Usually Found at the Salt-Vapor Interface in 52-37-11 Mole \% NaF-L,F-ZrF $4^{\prime}$, with HF at $650^{\circ} \mathrm{C}$. 
rates at the interface were generally in excess of those found in this study. Thus, some further effectiveness from the inertagas sparge is indicated.

Program PLOTDATA Prepared for CDC.1604-A Digital Computer to Process Data and Plot Results from Battelle's Corrosion Studies

In support of the studies of corrosion being conducted at BMI, a program, PLOTDATA, was written in FORTRAN language for use with the CDC-1604-A computer. It performs the required calculations and prepares magnetic tapes for use in plotting both corrosion resuits and rates of dissolution of metal added to the test vessels to simulate plant conditions. The program has been revised several times and is now performing satisfactorily. We plan to further modify the program so that, as an option, the corrosion results can be printed in a format suitable for use in a statistical analysis.

The program prepares two printed output sheets, two bar charts of corrosion results, and one graph showing both quantity of metal dissolved on a cumulative basis and a calculated instantaneous rate of metal dissolution vs time. Values for metal dissolved are based on a storchiometric relation of the hydrogen evolved during a run to either zirconium, stainless steel, or aluminum. Values of dissolution rate are calculated for each measurement of evolved hydrogen by assuming that the metal specimens dissolved uniformly over their entire surface. For a given run, the metal is added as rods of the same shape and length. The cross section may be circular, square, or rectangular.

The program has been helpful in eliminating manual calculations at BMI and in enabling us to see the results of the experiment in both numerical and graphical form before the report describing the experiment is recelved.

\footnotetext{
${ }^{42}$ N. G. Hardie, A Mult -Variable Screening Procedure Adaptable to Electronic Computers for the Empirical Exploration of Response Surfaces (thesis), Georgia Institute of Technology (April 1963).
}

\section{Prelimınary Attempt Made to Correlate Hydrofluorination Corrosion Data by Using Factor-Screening Procedures}

In an attempt to better understand the significance of the overall collection of corrosion data that has been obtained at BMI on a laboratory scale, selected data points were submitted to the Georgia Tech Research Institute for processing by use of a multivariable screening procedure that appeared applicable. ${ }^{42.43}$ Quoting from reference 41 , "the method used is essentially the classification of data points by setting arbitrary class limits on each independent variable and thereby creating pseudolevels of that factor. The factors are treated in pairs as in factorial design, and the error sum of squares is compared for each parr. The relative magnitudes of these error sums of squares provide indications of the relative goodness of $f_{1 t}$ for each pair, and thereby assist the investigator in a preliminary screening of factors with which he need not be concerned. ... the candidate variables are ranked according to the variation in the response which is removed when the effects of each factor are removed. In addition, the organization and display in tabular form of the estumates of the mean and variance for each factorlevel combination of those factor combinations having a relatively small error sum of squares, provide the experimenter with an estimate of the general contour of the response surface over the observed range of paired factors."

The results of the one computer run that was made must be considered preliminary since some errors in the original submission of data have since been located. Also, the scarcity of points in one category caused that category to be overemphasized in the conclusions. Plans are to rewrite the program to make it suitable for use on the Laboratory's CDC-1604-A computer, to include the data that have been collected since the original submission, and to make further computer runs.

\footnotetext{
${ }^{43}$ H. M. Wadsworth and N. G. Hardie, "A Screening Procedure for the Empirical Exploration of Response Surfaces," paper presented at the American Statistical Association Meeting, Cleveland (Sept. 4, 1963).
} 


\section{Waste Treatment and Disposal}

The waste treatment and disposal development program was designed to develop a comprehensive waste management system for nuclear wastes, including their final disposal, and to estimate the cost of this operation. The effective, economic management of radioactive effluents is a prerequisite to the natural growth of a nuclear power industry.

Two methods are being developed for the conversion of high-level radioactive wastes (HLW) to solids, the Potcal (pot calcination) and Potglass (fixation of wastes in glassy solids) processes. ${ }^{1-5}$ The calcined or glassy solids are contained in 88-in.-long 5- to 24-in.-diam stainless steel "pots" (p1pes), which are designed to be closed by welding prior to shipment and ultimate disposal. Since there are no off-gases, future surveillance requirements during ultimate disposal should be negligible. Glassy solids, rather than porous calcines, are desirable because of their higher thermal conductivity and high degree of insolubility. These properties should result in an increase in economy and safety. A major remaining program objective is to determine costs of calcination and fixation in

\footnotetext{
${ }^{1}$ F. L. Culler et al., Chem. Technol. Div. Ann. Progr. Rept. May 31, 1963, ORNL-3452 (Sept. 13, 1963).

${ }^{2} \mathrm{~J}$. M. Holmes et al., "Pot-Calcination Process for Converting Highly Radioactive Wastes to Solids," Proceedings of Symposium on the Treatment and Storage of High-Level Radioactive Wastes, Held in Vienna Oct. 8-13, 1962, pp. 255-86, IAEA, Vienna.

${ }^{3}$ W. E. Clark and H. W. Godbee, "Fixation of Simulated Highly Radroactive Wastes in Glassy Solids," Proceedings of Symposium on the Treatment and Storage of High-Level Radroactive Wastes, Held in Vienna Oct. 8-13, 1962, pp. 411-39, IAEA, Vienna.

${ }^{4} \mathrm{C}$. W. Hancher et al., Engineering Studies on Pot Calcination for Ultimate Disposal of Nuclear Wastes from the TBP-25, Darex, and Purex Processes, ORNL3277 (Sept. 9, 1963).

${ }^{5}$ R. E. Blanco et al., Status of the ORNL Potcal and Potglass Processes for the Converston of Highly Radioactive Liquid Wastes to Solids, ORNL-TM-857 (May 8, 1964).
}

glassy solids and the interrelation of cost and safety.

Low-level radioactive wastes (LLW), such as cooling water, canal water, floor-drain water, and other very low-salt-content waters, are treated to remove radionuclides prior to their discharge to the environment. Two general treatment methods are being developed for this purpose: the scavenging-precipitation ion-exchange process ${ }^{1,6,7}$ and the scavenging-precipitation foam separation $1,8-10$ process. An improved scavenging-precipitation ionexchange process was successfully tested in a 600 -gph pilot plant, where ORNL process waste was decontaminated to a level less than $2.0 \%$ of the maximum permissible levels for human exposure. The improvements reduced the estimated treatment cost from $78 \phi$ to $66 \$$ per 1000 gal for a 750,000 gal/day plant. The scavenging-precipitation foam separation process will be tested in the pilot plant in June 1964. These processes have been developed as high-capacity, bulk-treatment operations to achreve the desirable economics inherent in this type of processing, compared with the costs of specialized treatment processes where batching operations, many analyses, and high labor requirements lead to high unit costs.

\footnotetext{
${ }^{6}$ R. E. Brooksbank et al., Low-Radioactivity-Level Waste Treatment. Part II. Pilot Plant Demonstration of the Removal of Activity from Low-Level Process Waste by a Scavenging-Precipitation Ion-Exchange Process, ORNL-3349 (May 20, 1963).

${ }^{7}$ R. R. Holcomb, Low Radioactivity-Level Waste Treatment. Part I. Laboratory Development of a Scavenging-Precipitation Ion-Exchange Process for Decontamination of Process Water Wastes, ORNL-3322 (July 10, 1963).

${ }^{8}$ Waste Treatment and Disposal Quart. Progr. Rept. November 1963-January 1964, ORNL-TM-803 (1n press).

${ }^{9}$ E. Schonfeld, Effects of Impurities on Calcrum Precipitation, to be published in the June issue of the Journal of American Water Works Association.

${ }^{10}$ Waste Treatment and Drsposal Quart. Progr. Rept. May 1963-October 1963, ORNL-TM-757.
} 
Intermediate-level radioactive wastes (ILW), such as residues from processing LLW, evaporator concentrates, and concentrates from the second and third solvent extraction cycles from processing nuclear fuels and other high-salt-content wastes, can be processed by incorporation in asphalt or concrete prior to burial in a controlled area. Work on incorporation in asphalt is promising (low leach rate, high volume reduction, easily shipped) and is continuing. ${ }^{8}$

Economic and safety analyses on the HLW management systems show that the cost of conversion of wastes to solids and their storage in ultimate disposal sites, such as a salt mine, will be well within economic limits. ${ }^{11,12}$ These studies, con-

$11 \mathrm{~J}$. J. Perona et al., "Economic Evaluation of Tank Storage and Pot Calcination of Power-Reactor FuelReprocessing Wastes," Proceedings of Symposium on the Treatment and Storage of High-Level Radioactive Wastes, Held in Vienna Oct. 8-13, 1962, pp. 309-35, IAEA, Vienna.

${ }^{12} \mathrm{~J}$. J. Perona et al., Comparative Costs for Final Disposal of Radioactive Solids in Concrete Vaults, Grante, and Salt Formation, ORNL-TM-664 (Oct. 23, 1963). ducted jointly with the Health Physics Division, will be extended to other waste-solidification systems in the future to provide the AEC with a sound basis for national and international comparison of alternative systems and to serve as a guide for the direction of the experimental work.

\subsection{SOLIDIFICATION OF HIGH-LEVEL RADIOACTIVE WASTE}

The primary concept of the pot process is that an evaporator and a solidification unit should be used together in a loop (Fig. 3.1). Advantages of the loop include (1) reduced evaporation load on the pot, (2) retention of all solids (and sulfate) in the loop, (3) retention of entrained solids from the pot in the evaporator, (4) low entrainment (high decontamination) from evaporator to overhead vapor, and (5) controlled (low) acidity in the evaporator to reduce ruthenium volatility. The raw waste is fed to an evaporator (both a continuous and a batch evaporator have been developed for this purpose),

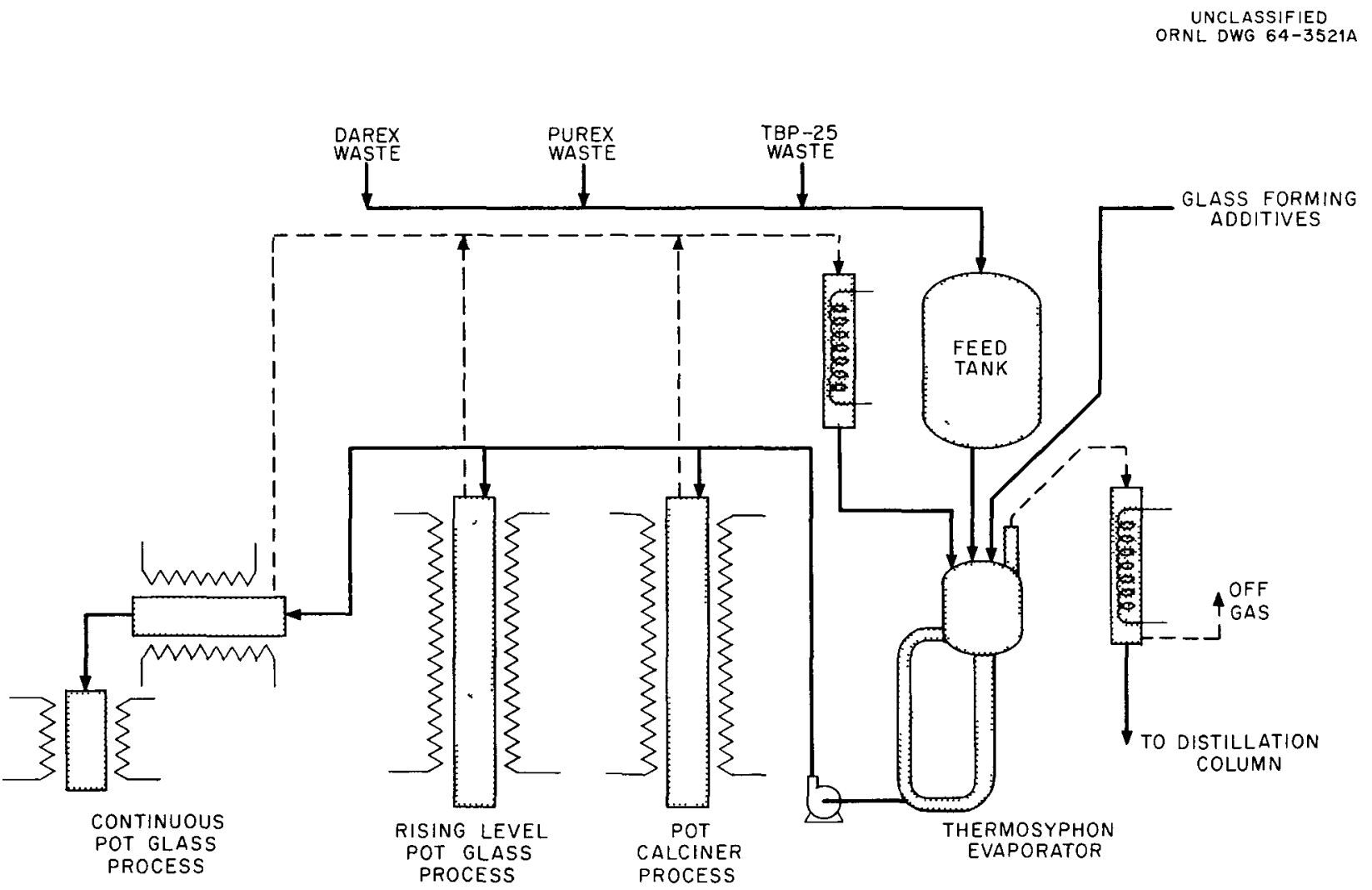

Fig. 3.1. Pot Processes for Converting High-Level Radioactive Wastes to Solids. 
where it is concentrated as much as possible without precipitating solids. The concentrated waste is then pumped to the pot, and the overhead vapors from the pot are condensed and returned to the evaporator. A deentrainer is provided for the evaporator overhead prior to condensation. The evaporator condensate is fed to a distillation column for recovery of nitric acid, off-gas scrubbing, and decontamination of the waste water to be discharged to the environment. Some of the water is recycled to the evaporator. Little net production of off-gas occurs since the nitrogen oxides are readsorbed in the off-gas system. The evaporation and total processing rate is limited by the capacity of the solidification unit.

\section{Progress and Status}

The pot calcination (Potcal) development program has been successfully completed using 4- and 8. in.-diam pots with resistance furnaces and the three major (simulated) wastes, Purex, TBP-25 (aluminum), and Darex (stainless steel). A 16-in.. diam unit is now being tested for determining processing rate as a function of diameter and for perfecting the use of induction heating. The development of the RL-Potglass (rising level) and Con-Potglass (continuous) processes is continuing. A complete mechanical mockup unit for the Potcal process was constructed and successfully tested to demonstrate its functional reliability in remote radioactive operations. ${ }^{1}$ This design, suitable for both the Potcal and RL-Potglass processes, will be used to test these processes in the Hanford Waste Solidification demonstration prototype pilot plant; highly radioactive wastes and induction heating units will be used. A major objective of the Potglass program is the development of formulations for glassy solids that have low corrosion rates in stainless steel equipment, thus eliminating the need for a platinum liner in a continuous melter. Glasses with higher corrosion rates can be tolerated in the RL-Potglass system where pots are used only once.

\section{Engineering Studies}

Potcal Process. - In the Potcal processes, the concentrated aqueous waste is fed to the pot continuously, and the aqueous level in the pot is controlled by a proportional thermocouple probe. Solids build up on the walls radially until the pot is filled. The aqueous feed is then stopped, and the solids are heated to $900^{\circ} \mathrm{C}$. The pot calcination process has been successfully demonstrated with Purex, TBP-25, and Darex wastes in 88-in.-high pots ${ }^{2,4,5,8}$ having 6 - to 8 -in. diameters.

Typical waste compositions tested are listed in Table 3.1. Considerable variation occurs in Purex waste, and, consequently, three compositions were tested to establish the versatility of the process: Purex $1 \mathrm{WW}$, where the $2 \mathrm{Na} / \mathrm{SO}_{4}$ mole ratio is less than 1; FTW-65 (formaldehyde-treated waste, expected in 1965), where the $2 \mathrm{Na} / \mathrm{SO}_{4}$ ratio is 1 ; and future waste, where the $2 \mathrm{Na} / \mathrm{SO}_{4}$ ratio is more than 1. The latter also represents neutralized waste that would be reacidified with sulfuric acid prior to calcination to bring the ratio to 1 or less. In the Potcal standard operating procedure, $\mathrm{Ca}\left(\mathrm{NO}_{3}\right)_{2}$ is added to the pot continuously to maintain approximately a $10 \%$ stoichiometric excess of $\mathrm{Ca}^{2+}+\mathrm{Na}^{+}$over the concentration of $\mathrm{SO}_{4}{ }^{2-}$. This ensures that sulfate will not be volatilized. The maintenance of a stoichiometric excess of sulfate to sodium also reduces cesium volatility.

8-In.-Diam Pots. - Two Potcal tests (R-77 and R-78) were made in 8-in.-diam pots with reacidified Purex wastes (Tables 3.1 and 3.2). Foaming was excessive, and the average feed rate dropped to about 19 liters $/ \mathrm{hr}$, with a maximum of 72 and 132 liters/hr for tests $\mathrm{R}-77$ and $\mathrm{R}-78$ respectively. A normal feed rate is about 28 liters/hr for Purex 1 WW waste (Table 3.1). The product densities $\left(1.3 \mathrm{~g} / \mathrm{cm}^{3}\right)$ and residual nitrate content $(0.04$ to 0.07 wt \%) were satisfactory. Corrosion was negligible.

16-In.-Diam Pot. - A new 16-in.-diam pot system was constructed in order to evaluate the effect of scaleup on the economics of the pot processes and also to determine the feasibility of induction heating. All previous work had been done with resistance furnaces.

In the new system, waste is fed from a 1400 -liter tank (at $75^{\circ} \mathrm{C}$ ) through a feed loop to a 16-in.-diam, 6-ft-high pot, i.e., $6 \mathrm{ft}$ of active length (Figs. 3.2 and 3.3). The pots are made from $\frac{1}{2}$-in.-thick stainless steel (type 347) and are equipped with 12 Chromel-Alumel thermocouples spaced at 12-in. intervals down the center ${ }^{6}$ and sides $^{6}$ for controlling the furnace. A liquid-level thermocouple, developed here, ${ }^{8}$ is used to sense the liquid level in the pot and control the magnetic flowmeter-feedvalve system. 
Table 3.1. Compositions of High-Level Radioactive Waste

Compositions of high-sulfate Purex 1WW, FTW-65, TBP-25 (aluminum), and Darex

(stainless steel) wastes are given in Refs. 1 and 5

\begin{tabular}{cccc}
\hline $\begin{array}{c}\text { Constituent } \\
\text { (g-moles per 11ter of waste) }\end{array}$ & $\begin{array}{c}\text { Purex } \\
\text { FTW-65 X3 } \\
\text { (27 gal per ton of U) }\end{array}$ & $\begin{array}{c}\text { Future Acid } \\
\text { (or Reacidified) } \\
\text { Purex }\end{array}$ & $\begin{array}{c}\text { Non-Sulfate } \\
\text { Purex }\end{array}$ \\
\hline $\mathrm{H}^{+}$ & 1.5 & 0.5 & 0.5 \\
$\mathrm{Na}^{+}$ & 0.9 & 1.2 & 0.6 \\
$\mathrm{Al}^{3+}$ & 0.15 & $d$ & 0.2 \\
$\mathrm{Fe}^{3+}$ & 0.30 & 0.1 & 0.05 \\
$\mathrm{Cr}^{3+}$ & 0.06 & 0.01 & 0.006 \\
$\mathrm{Ni}^{2+}$ & 0.03 & 0.02 & 0.006 \\
$\mathrm{Hg}^{2+}$ & $0.0105^{e}$ & 0.005 & $d$ \\
$\mathrm{Ru}^{+}$ & 0.006 & $d$ & $d$ \\
$\mathrm{SO}_{4}{ }^{2-}$ & 0.45 & $0.2(0.6)$ & $d$ \\
$\mathrm{PO}_{4}{ }^{3-}$ & 0.015 & $d$ & 0.02 \\
$\mathrm{SiO}_{3}{ }^{2-}$ & 0.03 & $d$ & $d$ \\
$\mathrm{~F}^{-}$ & 0.0015 & 0.0005 & $d$ \\
$\mathrm{NO}_{3}{ }^{-(f)}$ & $\sim 3.1$ & $\sim 1.6$ & \\
\hline
\end{tabular}

\footnotetext{
${ }^{a}$ The FTW-65 X3 represents the highest concentration of this waste type that can be conveniently simulated by direct makeup from laboratory reagents without heating.

${ }^{b}$ Also corresponds to neutralized waste prior to reacidification (1.e., $2 \mathrm{Na} / \mathrm{SO}_{4}=3$ ), $\mathrm{SO}_{4}=0.6$ after reacidifica tion.

${ }^{c}$ Estimated from consideration of various Savannah River plant flowsheet wastes.

${ }^{d}$ Content not specified.

e Maxımum.

${ }^{f}$ Enough $\mathrm{NO}_{3}{ }^{-}$to balance in each waste.
}

Purex FTW-65 X3 waste (Table 3.1) was used in the first test. Calcium nitrate was added continuously to the pot $\left[0.05\right.$ mole of $\mathrm{Ca}\left(\mathrm{NO}_{3}\right)_{2}$ per 1iter of waste]. About 2234 liters of waste were processed in $94 \mathrm{hr}$ (average rate about 24 liters/hr). This confirms the rate predicted by the radialdeposition model ${ }^{8}$ ( 2600 liters in $140 \mathrm{hr}$ ). At the 95th hr, a recurring short circuit developed between the pot and furnace, and the run was terminated. The pot was wedged firmly in the fumace and required considerable force for its removal. A 4-in.wide hole had formed in the pot, extending from the bottom upward for $6 \mathrm{ft}$. The maximum temperature recorded with the external thermocouples was $1095^{\circ} \mathrm{C}$, whereas the bottom center showed that more than $1200^{\circ} \mathrm{C}$ had been reached there (the thermocouple was assumed to have falled). Several possible mechanisms which may account for this nonhomogeneous heating effect are being studied. Visually, the hole appears to be the result of melting the metal wall and excessive corrosion caused by the high temperature.

RL-Potglass Process. - In the RL-Potglass process $^{8}$ the concentrated aqueous feed, containing glass-forming additives, is fed directly into the pot, the liquid is vaporized, and the solid residue is melted to a glassy solid. The additives can be added directly to the evaporator or continuously to the feed line entering the pot. With proper glass formulation, the operating temperature should be 
Table 3.2. Summary of Engineering.Scale Tests of the Potcal and Potglass Processes

Potcal and RL-Potglass in 8-1n.-diam 88-1n.-high or 16-1n.-diam 72-1n.-h1gh pots

Con-Potglass in 8-1n.-diam 40-1n.-long horizontal melter

\begin{tabular}{|c|c|c|c|c|c|c|c|}
\hline Test No. & Process & Waste Type & $\begin{array}{c}\text { Average } \\
\text { Feed Rate } \\
(\text { (11ters } / \mathrm{hr})\end{array}$ & $\begin{array}{c}\text { Bulk } \\
\text { Density } \\
\left(\mathrm{g} / \mathrm{cm}^{3}\right)\end{array}$ & $\begin{array}{c}\text { Volume } \\
\text { Reduction }\end{array}$ & $\begin{array}{l}\text { Calcination } \\
\text { or Melt } \\
\text { Hold Time } \\
\text { (hr) }\end{array}$ & $\begin{array}{c}\text { Nitrate in } \\
\text { Solids } \\
\text { (wt \%) }\end{array}$ \\
\hline $\mathrm{R} \cdot 77$ & $\begin{array}{c}\text { Potcal } \\
(8-1 \text {. diam })\end{array}$ & Reacidified Purex & 19 & 1.26 & 12.1 & 25 & 0.01 \\
\hline $\mathrm{R}-78$ & $\begin{array}{c}\text { Potca1 } \\
(8-1 \text {. diam })\end{array}$ & Reacidified Purex & 19 & 1.36 & 15.1 & & 0.01 \\
\hline $\mathrm{R} \cdot 83^{b}$ & $\begin{array}{c}\text { Potcal } \\
(16-1 n . \text { diam })\end{array}$ & FTW-65 Purex & 24 & 1.3 & 10.6 & & $c$ \\
\hline $\mathrm{R}-76^{b}$ & RL-Potglass & $\mathrm{TBP}-25^{d}$ & 4.8 & c & & 7 & c \\
\hline $\mathrm{R}-79,80$ & RL-Potglass & TBP $-25^{d}$ & 6 & 1.9 & 8.2 & 2 & 0.05 \\
\hline $\mathrm{R}-81$ & RL-Potglass & $\mathrm{TBP}-25^{d}$ & 7 & 2.2 & 8.0 & 12 & 0.04 \\
\hline $\mathrm{R}-82$ & RL-Potglass & FTW-65 $\times 3^{e}$ & 8 & 2.4 & 11.0 & 18 & 0.01 \\
\hline $\mathrm{C}-2$ & Con-Potglass & $\mathrm{TBP}-25^{d}$ & $10^{d}$ & 2.6 & 10.6 & None & $\mathrm{c}$ \\
\hline$C-4$ & Con-Potglass & FTW-65 $\times 3^{d}$ & $5-7^{c}$ & 2.8 & 12.5 & None & c \\
\hline
\end{tabular}

\footnotetext{
${ }^{a}$ Time for calcination or to complete melting after termination of 1 iquid feed.

${ }^{b}$ Not completed.

${ }^{c}$ Limited by present furnace capacity.

${ }^{d}$ Composition, in mole \%: $\mathrm{AI}_{2} \mathrm{O}_{3}, 25.0 ; \mathrm{PbO}, 15.9 ; \mathrm{Na}_{2} \mathrm{O}, 18.6, \mathrm{P}_{2} \mathrm{O}_{5}, 40.5 ; \mathrm{mp}, 900^{\circ} \mathrm{C}$ (see No. 1 in Table 3.6 of ORNL-3452).

${ }^{e}$ See FTW-1, Table 3.3 .
}

$900^{\circ} \mathrm{C}$ or lower. As the level rises, three phases are present: liquid glass at the bottom, a small solid interface, and a small aqueous supernatant pool (Fig. 3.4). The overhead vapors are condensed and returned to the evaporator, thus preserving the advantages of the loop concept (Fig. 3.1). The Potcal equipment can be used for the rising-level process. However, provision should be made to flush the off-gas lines to remove dusts.

Two tests were made with a TBP-25 fixation formulation (see footnote $d$ in Table 3.2) and one with an FTW-65 X3 formulation (FTW-1, Table 3.3), in 8-1n.-diam by 88-1n.-high pots (Tables 3.2 and 3.3). The average feed rates were low, 5 to 8 liters/hr, which is characteristic of this system because of its limited area for heat transfer. The wall temperatures for the TBP-25 runs were about $1000^{\circ} \mathrm{C}$ (undesirably high) to make the melt sufficiently fluid for practical operation. The pot and thermocouple walls showed a pitting attack up to a depth of $150 \mathrm{mils}$. The wall temperature for the FTW-65 X3 run was 900 to $950^{\circ} \mathrm{C}$. Corrosion at the top of the pot showed pitting up to $120 \mathrm{mils}$, with the average estimated as 80 to $100 \mathrm{mils}$. This is considered acceptable in "single-use" pots where the allowance has been arbitrarily set at $150 \mathrm{mils}$ out of a total wall thickness of $320 \mathrm{mils}$. However, these operating temperatures are higher than desirable for use with type 304 stainless steel. Lower corrosion rates are expected as the development program proceeds and glasses with lower softening points and decreased inherent corrosivities are developed. 


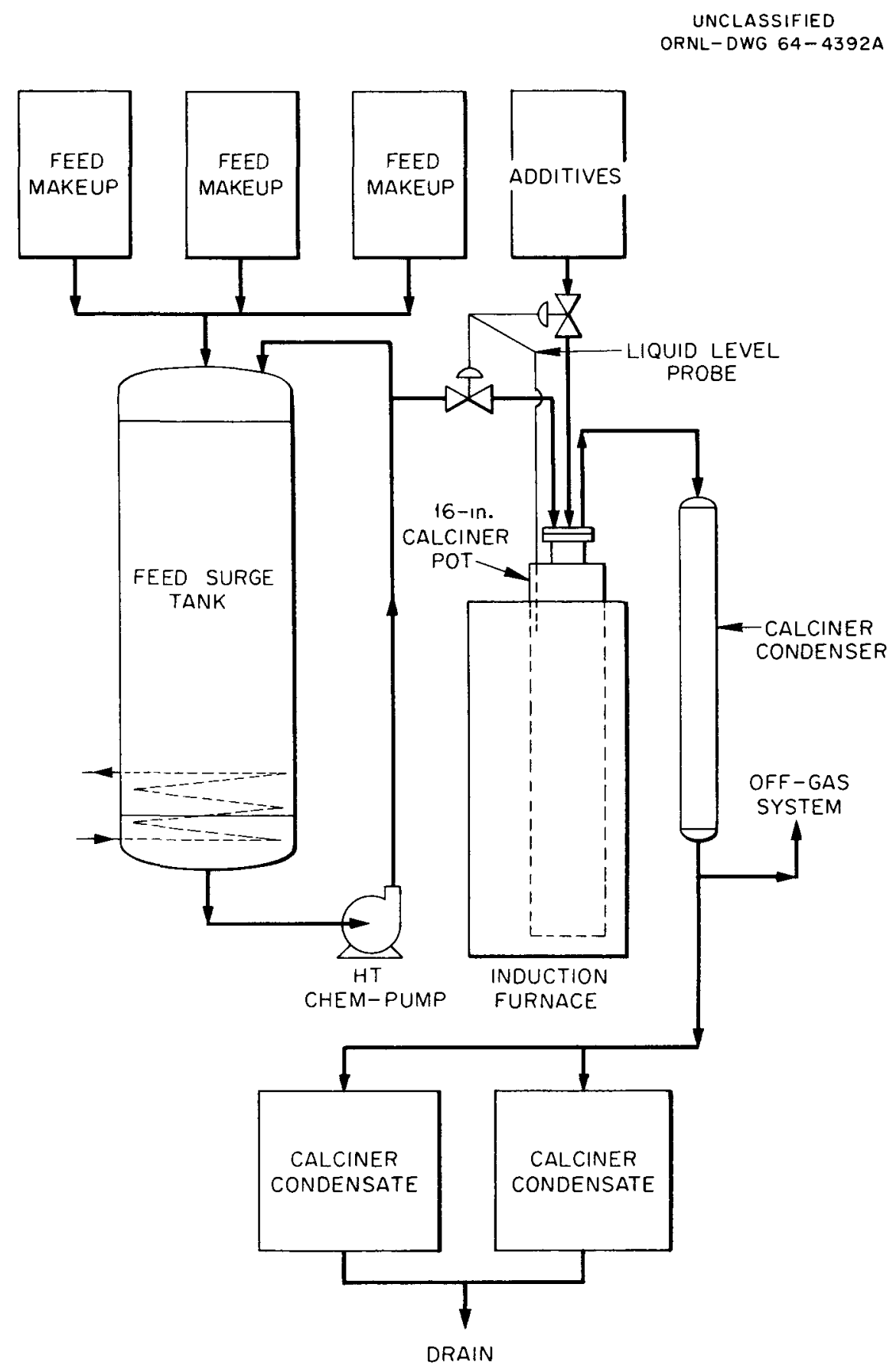

Fig. 3.2. System for Evaluation of the Potcal Process in 16-in.-diam, 72-in.-High Pot, Heated by Induction. 


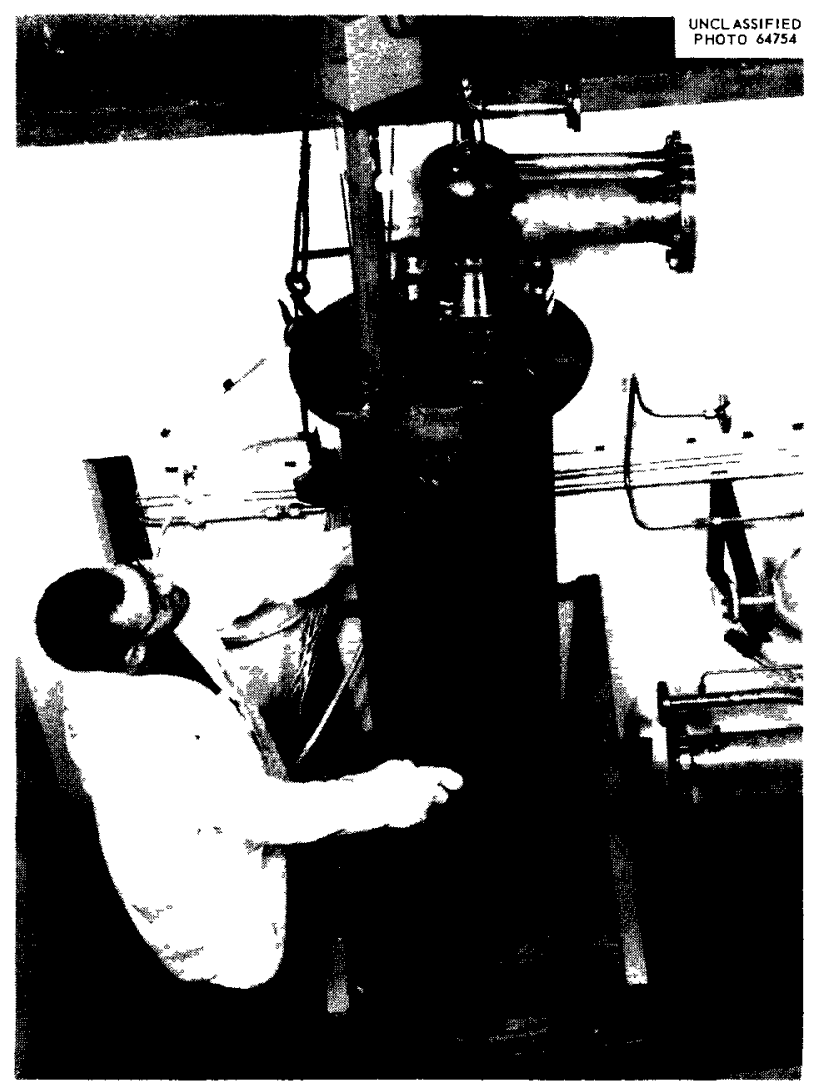

Fig. 3.3. Removal of 16-in.-diam, 72-in.-High Pot from Induction Furnace.

The RL-Potglass process is similar to a risinglevel process now being developed in the United Kingdom. ${ }^{13}$ In their program, principal emphasis has been placed on silicate glasses, with considerable work on phosphate glasses. This system depends on small off-gas lines (rapid gas flows) and a filter system to control the dusting problem. Our system relies on large off-gas lines, provided with flushing facilities, and recycle to the evaporator in the loop concept to control the dusting problem.

Con-Potglass Process. - The objective of this program ${ }^{5,8,10}$ is to develop a continuous melter that would (1) apply in the loop concept, (2) have a faster processing rate than the RL-Potglass proc-

\footnotetext{
${ }^{13} \mathrm{M}$. N. Ellot et al., "Fixation of Radioactive Waste in Glass. Part III. The Removal of Ruthenium and Dust from Nitric-Acid Vapours," Proceedings of Symposium on the Treatment and Storage of High-Level Radioactive Wastes, Held in Vienna Oct. 8-13, 1962, pp. 489-506, IAEA, Vienna.
}

ess, and (3) produce glass in a pot suitable for ultimate disposal. Since the rising-level processing rate is limited by the small heat transfer area at the solid-liquid interfaces, an obvious method for increasing the rate was to increase this contact area by the use of a horizontal melter. The length of the melter can be as long as that required to achieve the desired rate, with an appropriate increase in diameter to increase the total heat transfer area. The feed, containing glass-forming additives, is added directly to the melt as in the rising-level process.

The initial test unit, $8 \mathrm{in}$. in diameter and $40 \mathrm{in}$. long, is constructed of type $304 \mathrm{~L}$ stainless steel, with 350-mil-thick walls (Figs. $3.5 a$ and $b$ ). The

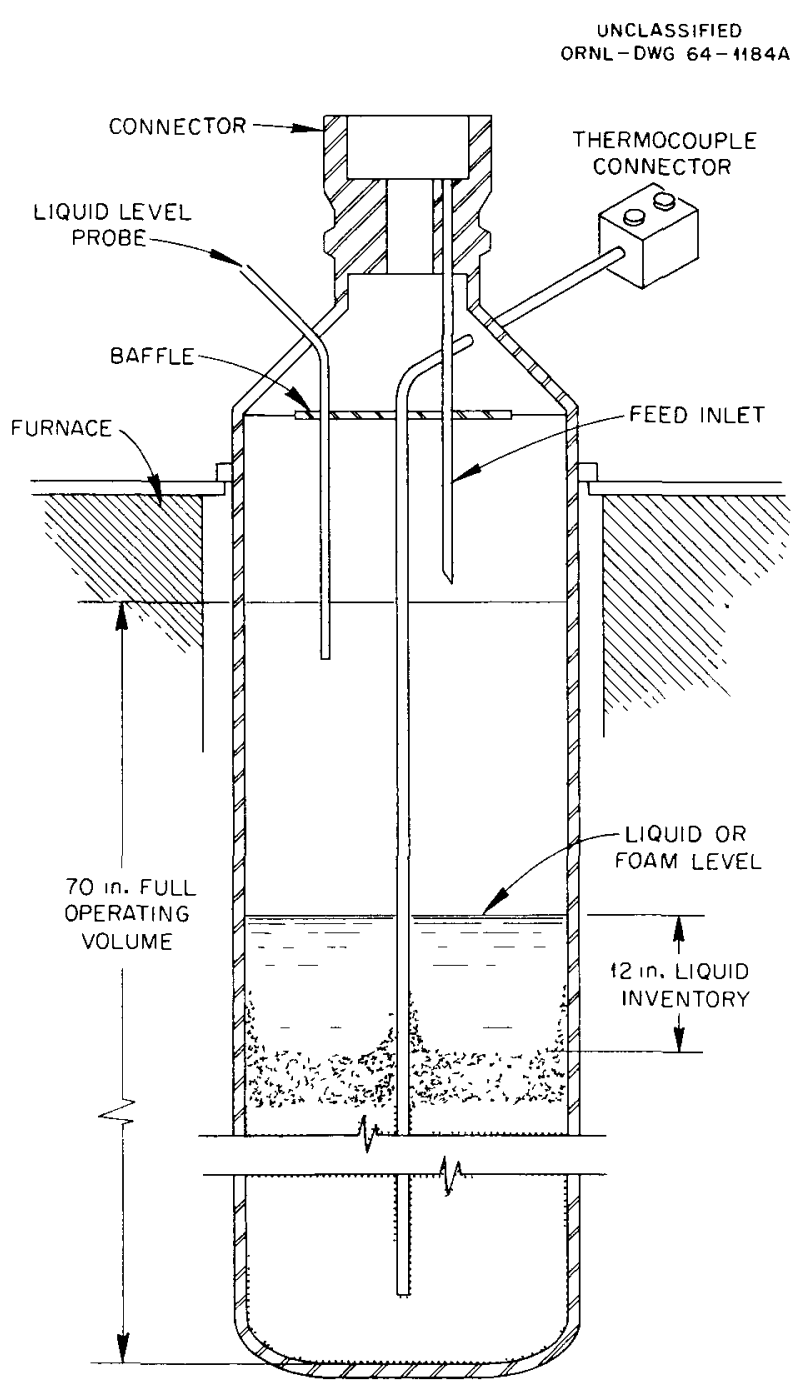

Fig. 3.4. Phase Positions in the RL-Potglass Process. 
operating temperature is $1000^{\circ} \mathrm{C}$. The feed enters through four water-cooled feed inlets at rates up to 20 liters/hr, with an average rate of 5 to 10 liters/hr. The rate is limited by the present furnace capacity [1.e., to the rate at which a wall temperature of $1000^{\circ} \mathrm{C}$ can be maintained (Table 3.2)]. The initial problems of dusting and off-gas line plugging were satisfactorily controlled by the use of an updraft condenser and by recycle of the condensate to the evaporator. The molten glass

Table 3.3. Compositions of Some Typical Solid Products from Fixation of Purex Wastes

\begin{tabular}{|c|c|c|c|c|}
\hline & \multicolumn{2}{|c|}{ F'TW-65 Waste X3 } & \multirow{2}{*}{$\begin{array}{c}1 W W \\
\text { Waste } \\
1 W W-1\end{array}$} & \multirow{2}{*}{$\begin{array}{c}\text { Non-Sulfate } \\
\text { Purex }\end{array}$} \\
\hline & FTW-1 & FTW-3 & & \\
\hline \multicolumn{5}{|c|}{ Addit1"es, g-moles per liter of waste } \\
\hline $\mathrm{H}_{3} \mathrm{PO}_{4}$ or $\mathrm{H}_{3} \mathrm{PO}_{3}$ & 1.02 & 2.27 & 2.27 & $0.75-1.5$ \\
\hline $\mathrm{Al}\left(\mathrm{NO}_{3}\right)_{3}$ & 0.5 & 1.0 & 1.0 & \\
\hline $\mathrm{L} 1 \mathrm{OH}$ & 1.14 & 2.53 & 2.53 & \\
\hline $\mathrm{NaOH}$ & & 1.4 & 1.4 & \\
\hline $\begin{array}{l}\mathrm{Ca}\left(\mathrm{NO}_{3}\right)_{2} \text { or } \mathrm{Ca}(\mathrm{OH})_{2} \\
\mathrm{Fe}\left(\mathrm{NO}_{3}\right)_{3}\end{array}$ & 0.2 & 0.16 & 0.16 & \\
\hline $\begin{array}{l}\mathrm{Pb}\left(\mathrm{NO}_{3}\right)_{2} \\
\mathrm{Na}_{2} \mathrm{~B}_{4} \mathrm{O}_{7}\end{array}$ & & & & $0.2-0.3$ \\
\hline $\begin{array}{l}\text { Waste oxides, wt \% (theo- } \\
\text { retical) }\end{array}$ & 44.5 & 25.8 & 32.2 & $16.9-26.5$ \\
\hline \multicolumn{5}{|c|}{ Composition, mole \% (theoretical) } \\
\hline $\begin{array}{l}\mathrm{A}_{2} \mathrm{O}_{3} \\
\mathrm{CaO}\end{array}$ & $\begin{array}{r}11.8 \\
7.2\end{array}$ & 11.7 & 10.4 & $6.7-9.8$ \\
\hline $\mathrm{Na}_{2} \mathrm{O}$ & 16.3 & 23.4 & 18.9 & $20.1-29.4$ \\
\hline $\mathrm{L}_{2}{ }_{2} \mathrm{O}$ & 20.6 & 25.7 & 23.9 & \\
\hline $\mathrm{Fe}_{2} \mathrm{O}_{3}$ & 5.4 & 4.7 & 6.2 & $1.7-2.5$ \\
\hline $\mathrm{Cr}_{2} \mathrm{O}_{3}$ & 1.1 & 0.6 & 0.1 & $0.2-0.6$ \\
\hline $\mathrm{N} 1 \mathrm{O}$ & 1.1 & 0.6 & 0.1 & $0.4-0.6$ \\
\hline $\mathrm{RuO}_{2}$ & 0.2 & 0.1 & 0.04 & \\
\hline $\mathrm{SO}_{3}$ & 16.3 & 9.1 & 18.9 & $37.8-54.5$ \\
\hline $\mathrm{P}_{2} \mathrm{O}_{5}$ & 18.4 & 23.2 & 21.5 & $37.8-54.5$ \\
\hline $\mathrm{SiO}_{2}$ & 1.1 & 0.6 & & \\
\hline $\mathrm{F}^{-}$ & 0.5 & 0.3 & & \\
\hline $\mathrm{PbO}$ & & & & $14.3-20.1$ \\
\hline \multicolumn{5}{|l|}{$\mathrm{B}_{2} \mathrm{O}_{3}$} \\
\hline Approx. melting temp., ${ }^{\circ} \mathrm{C}$ & 750 & 825 & 750 & $500-700$ \\
\hline Approx. pouring temp., ${ }^{\circ} \mathrm{C}$ & $900-1000$ & 900 & 800 & $600-800$ \\
\hline $\operatorname{Rat}_{10}^{a}$ & 1.22 & 1.49 & 1.06 & \\
\hline $\begin{array}{l}\text { Percent } \mathrm{SO}_{3} \text { lost }(100 \mathrm{~min} \\
\text { at temperature })\end{array}$ & $5.3(900), 0.7^{b}$ & $5.2(925)$ & $6.2(900)$ & \\
\hline Description & $\begin{array}{l}\text { Brown rock, insoluble, } \\
\text { noncorrosive at } 900^{\circ} \mathrm{C}\end{array}$ & $\begin{array}{l}\text { Brown rock, in- } \\
\text { soluble }\end{array}$ & $\begin{array}{l}\text { Hard brown rock, } \\
\text { insoluble }\end{array}$ & $\begin{array}{l}\text { Green glass, in- } \\
\text { soluble }\end{array}$ \\
\hline
\end{tabular}

$\frac{\text { Chemical equivalents }\left(\mathrm{Na}^{+}+\mathrm{C}_{1}{ }^{+}+\mathrm{Ca}^{2+},\right.}{\text { Chemical equivalents }\left(\mathrm{SO}_{4}{ }^{2-}+\mathrm{PO}_{3}{ }^{-}+\mathrm{BO}_{3}{ }^{-}+\mathrm{S}_{10} \mathrm{O}^{2-}+\mathrm{F}^{-}\right)}$

${ }^{b}$ Loss in semiengineering test. 


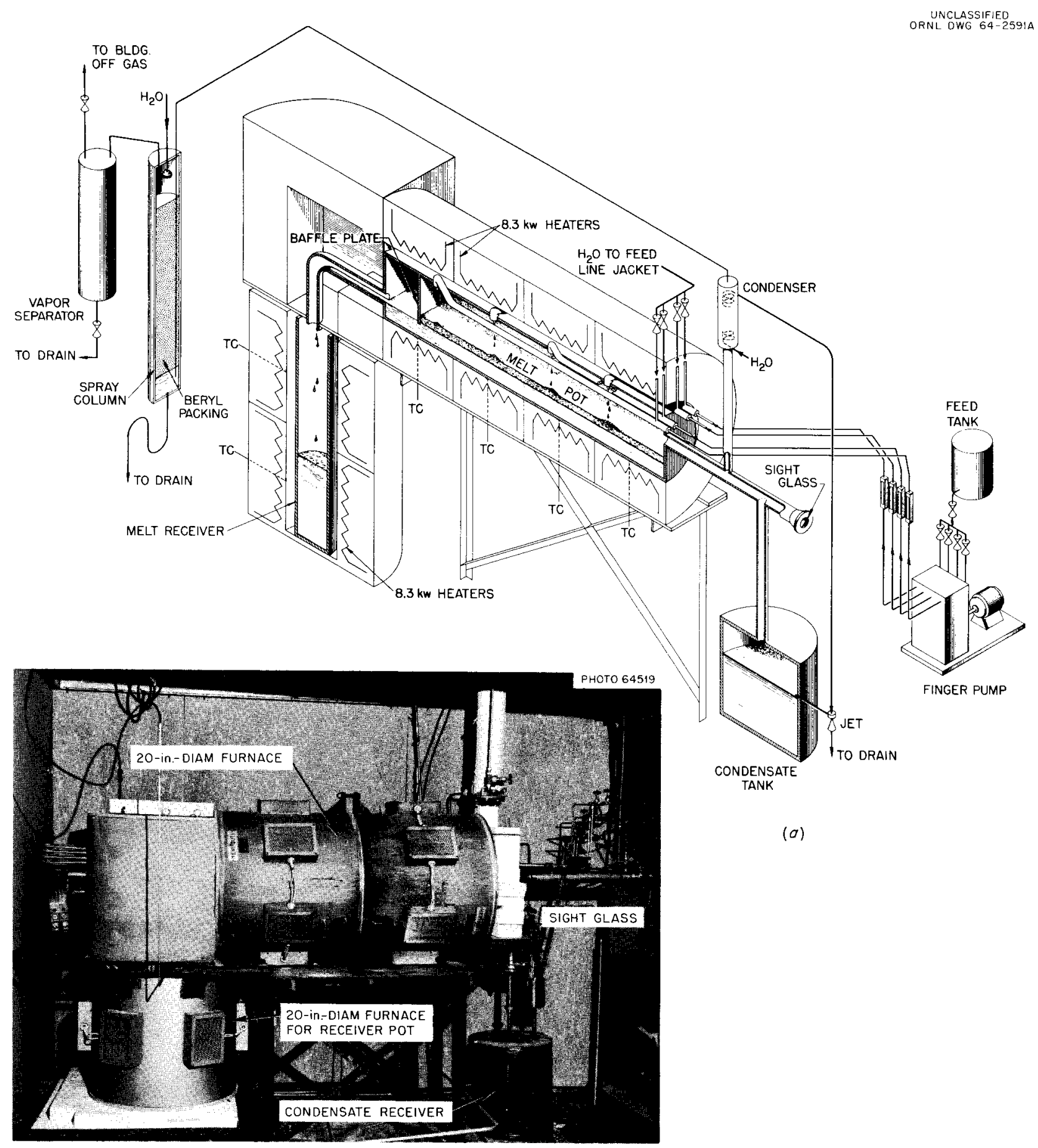

(b)

Fig. 3.5. Continuous Melter ( $8 \mathrm{in.}$ in Diameter and $40 \mathrm{in.}$ Long) for Converting High-Level Radioactive Wastes to Glassy Solids. 
flows under a baffle, through a $3 / 4$-in.-diam pipe, and into a receiver pot. A freeze valve was successfully tested on an earlier model ${ }^{10}$ (as in Fig. 3.6 , but without agitator). In this case a freeze trap (250-m1 volume) was located inside the resistance furnace. Cooling and melt freezing (700 to $800^{\circ} \mathrm{C}$ ) were accomplished by flowing air or steam through an exterior cooling coil for about $10 \mathrm{~min}$. The freeze-trap discharge line $(3 / 4$-in.-diam 13 -in.long stainless steel pipe) was heated by autoresistance, $400 \mathrm{amp}$ at $6 \mathrm{v}$.

A third model of a continuous melter was constructed which uses an agitator to improve heat transfer (Fig. 3.6). The bearings are made of hightemperature Graphalloy, externally cooled and protected from the contents of the melter by Inconelasbestos packing. Excessive friction developed in the packing during initial tests, so the shaft and packing gland are being redesigned to extend the packing gland to the outside of the furnace in order to permit the use of low-temperature lowfriction packings.

The receiver pot is made of type 304L stainless steel and is similar to those used in the Potcal process. It is located in a furnace so that the melt can be slowly cooled and annealed. Mildsteel pots could be used if they prove safe enough for use as interim storage and shipping containers,

The principal emphasis, at present, is on the development of an engineering unit that meets the above objectives. The current "best" mix formulations are used for Purex and TBP-25 wastes. Corrosion rates were lower than those obtained in the rising-level process. The longest run was $120 \mathrm{hr}$, using the TBP-25 glass formulation before failure of the melter discharge line. The ultimate objective is to develop a melter system that uses conventional materials of construction and produces glasses that have low melting points and low corrosivities. If such glasses cannot be developed, the melter must have a platinum liner.

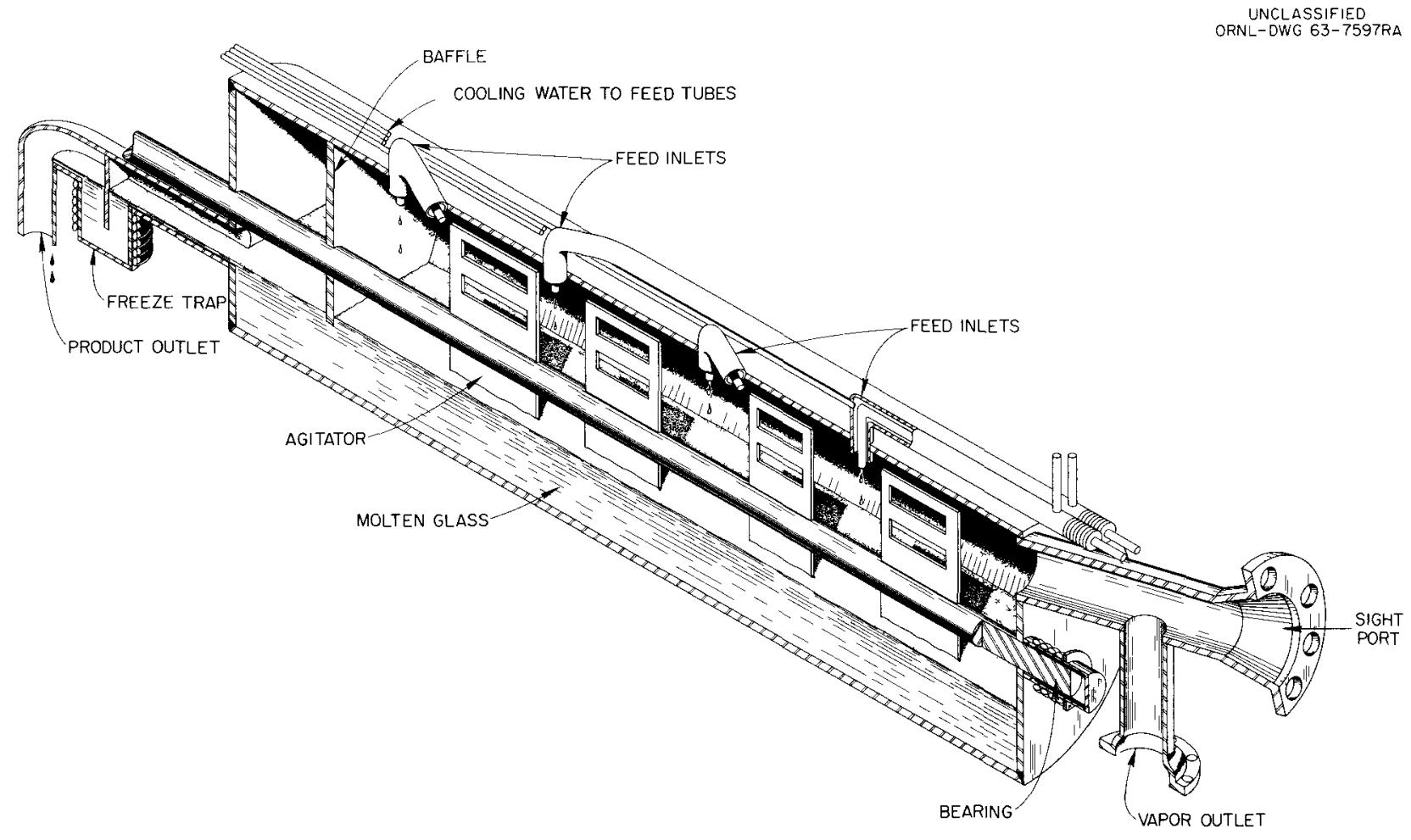

Fig. 3.6. Continuous Melter with Agitator for Converting High-Level Radioactive Wastes to Solids. This melter is also $8 \mathrm{in.} \mathrm{in} \mathrm{diameter} \mathrm{and} 40 \mathrm{in.}$ long. 
Continuous melters are also being developed at Brookhaven National Laboratory (BNL) and at the Hanford Laboratory. ${ }^{14-16}$ In the BNL system the concentrated waste is mixed with phosphoric acid and fed to a denitrator-evaporator prior to enternng the continuous melter. In the Hanford system the concentrated feed, containing glass-forming add1tives, is spray calcined, and the calcined powder is fed to a continuous melter. Both systems require relatively small melters. In the ORNL system the concentrated feed, containing glass-forming addtives, is fed directly into the continuous melter. As a result of this process simplification, a larger melter is required, which may or may not be a disadvantage.

Evaluation of Waste-Evaporator Pumps. - Pumps for circulating the waste in the evaporator loop and feeding the pot were tested for $1150 \mathrm{hr}$ in a pump-test loop, 1.0 and $3.0 \mathrm{M}$ nitric acid and simulated Purex waste were used. The model CFT Chempump (CFT-1-1/2-3/4S) and the model GA Chempump (GA-1-1/2K-751-1S) performed 1deally. The model CFT Chempump will probably be more reliable than the model GA for use in the Hanford Hot Pilot Plant because of the provisions for removing heat from the motor and the better prov1sions for keeping the solids in the process stream from entering the bearıngs. [The model CFT Chempump has been superseded by the Chempump model GAT $(1-1 / 2 \times 3 / 4 S)$.] These two pumps operated at a rate of 8 to $10 \mathrm{gpm}$ at a discharge pressure of 20 to 25 psi, pumping a liquid within 2 or $3^{\circ} \mathrm{C}$ of its boiling point with little trouble due to cavitation. The wear on these pumps during the initial 1000-hr test period was negligible. The bearing wear ranged from a maximum of 0.0015 to a minımum of $0.0003 \mathrm{in}$. , and the shaft wear was about $0.0002 \mathrm{in}$.

The Allis-Chalmers pump (C-10BS) operated satisfactorily for $650 \mathrm{hr}$, but farled to complete $1000 \mathrm{hr}$ of testing. However, it was more given to cavitation and was noisy due to impeller imbalance. During the day preceding the 650th hr of operation,

\footnotetext{
${ }^{14}$ L. P. Hatch et al., Chem. Technol. Group, Chem. and Chem. Eng. Div., BNL, Monthly Reports for Perlod 1963-1964.

${ }^{15}$ A. M. Platt et al., Progress Report - Research and Development Activities, Solidification of Radioactrve Wastes, HW-81829 (Apr. 15, 1964).

${ }^{16}$ E. R Irish, Quart. Progr. Rept. Research and Development Activities, Fixation of Radroactive Residues, October-December 1963, HW-80526 (January 1964).
}

the pump made scraping noises and eventually wore out the hydraulic balance plate, causing the shaft to freeze in the front bearing. When the pump was disass embled, the bearings were found to be excessively worn, and the front shaft was grooved and bent.

After the 1000 -hr test with solutions was completed, the two Chempumps were tested with a concentrated Purex waste in which enough chemicals had been added to form a heavy slurry with the following composition

$\begin{array}{ll}\text { Molarity } & \text { Constituent } \\ 0.3 & \mathrm{Fe}\left(\mathrm{NO}_{3}\right)_{3} \\ 0.45 & \mathrm{Na}_{2} \mathrm{SO}_{4} \\ 0.1 & \mathrm{Na}_{2} \mathrm{~S}_{3} \\ 0.07 & \mathrm{HNO}_{3}\end{array}$

Both pumps falled after $150 \mathrm{hr}$ because the slurry worked into the rotor housing (because of low purge rates) and severely eroded the front bearngs and rotor shell. This slurry was probably excessively erosive and is not necessarily representative of actual waste, the Chempump is expected to operate satisfactorily on actual waste.

The pumps, equipment, and procedures used to test these pumps are described in detall elsewhere. ${ }^{17}$

\section{Pilot-Plant Desıgn}

Cooperation with Hanford on the design of the Hanford Waste Solidification Demonstration Prototype included (1) design of the pot calciner and associated off-gas equipment, (2) heat transfer studies for pot cooling, and (3) preparation of a proposed operating plan for the pot process, including objectives, run schedule, and sampling schedule.

The present furnace design for the pot calcination demonstration uses inductive heating of a susceptor that surrounds the calcination pot. Power to the furnace produces a net transfer of about $80 \mathrm{kw}$ to the pot at a pot-wall temperature of $900^{\circ} \mathrm{C}$. Heat will be transferred from the susceptor operating at 1000 to $1100^{\circ} \mathrm{C}$ to the pot wall $\left(900^{\circ} \mathrm{C}\right)$ by

${ }^{17} \mathrm{C}$. W. Hancher and E. J. Frederick, Waste Processing Pump Test Loop Progress Report, July 1, 1963, ORNL-TM-648 (Aug. 7, 1963). 
radiation. The water-cooled induction coils surrounding the susceptor must be protected by a layer of insulation to prevent high heat loss. Without insulation, the heat losses are estimated to be close to the maximum power input, so it is doubtful if a $900^{\circ} \mathrm{C}$ pot-wall temperature could be achieved. An optimal insulation thickness would permit rapid cooling of the pot upon completion of calcination, yet maintain heat losses during calcination at a reasonable level.

Transient-state cooling-rate calculations for pots filled with solids initially at $900^{\circ} \mathrm{C}$ were performed at Hanford, using average heat transfer coefficients between the pot and the coolant as determined by steady-state calculations. The transient-state cal- culations determined the center-line temperature of the solids as a function of time for various pot-wall heat transfer coefficients. Figures 3.7 and 3.8 show the maximum center-line temperatures as a function of pot-wall heat transfer coefficients for pot diameters of 8,12 , and 16 in. The calcine (Fig. 3.7) was assumed to have a thermal conductivity of $0.2 \mathrm{Btu} \mathrm{hr}^{-1} \mathrm{ft}^{-1}\left({ }^{\circ} \mathrm{F}\right)^{-1}$, while the glassy solids (Fig. 3.8) were assumed to have a conduc-

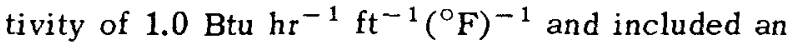
allowance in the specific heat term for the heat of crystallization. Since the pot-wall heat transfer coefficients were based on the pot-wall area, these curves could be used for other types of furnaces as long as the coolant temperature is in the vicinity of $100^{\circ} \mathrm{F}$.

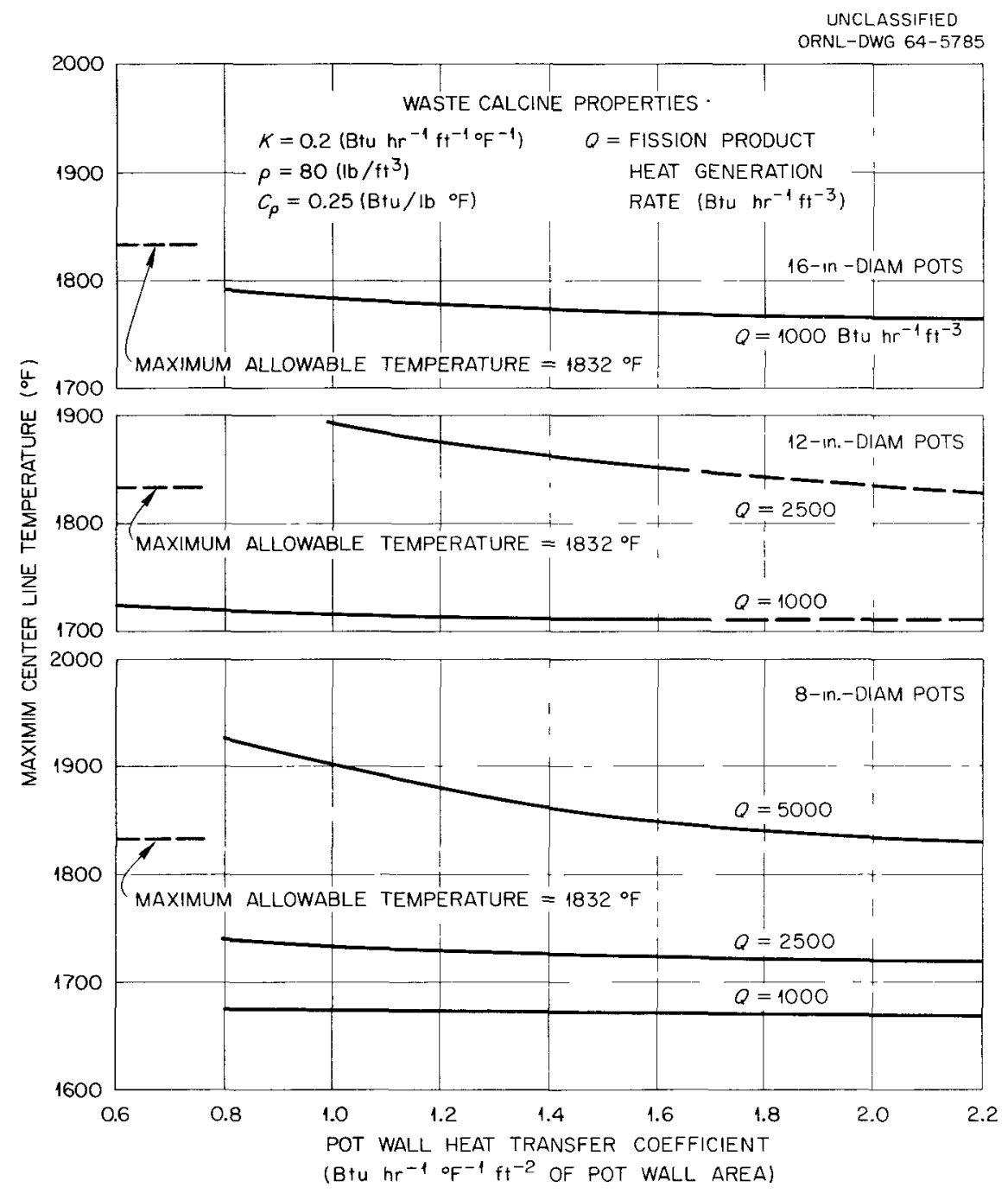

Fig. 3.7. Maximum Center-Line Temperatures for Calcine During Cooling Cycle. 


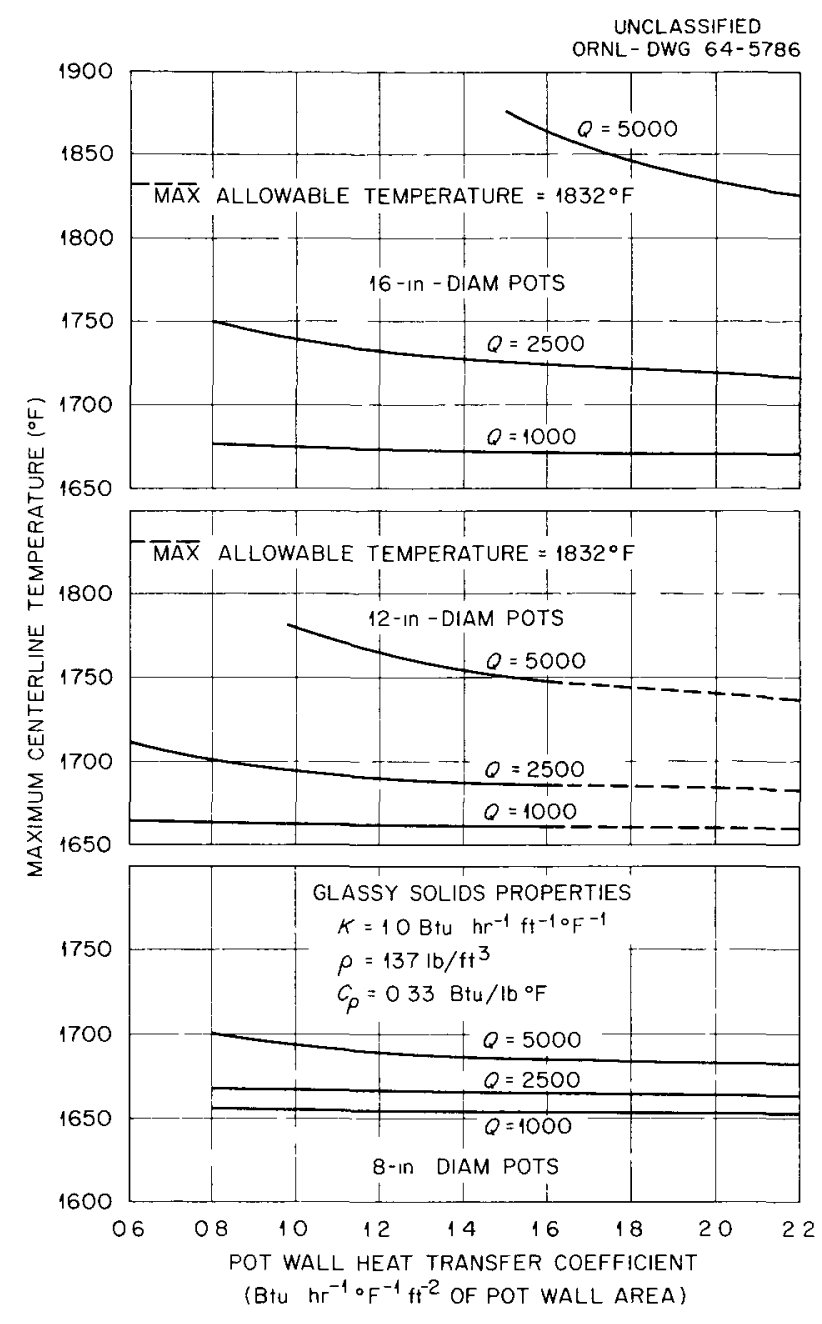

Fig. 3.8. Maximum Center-Line Temperatures for Glassy Solids During Cooling Cycle.

Table 3.4 gives the results of the heat transfer rate calculations for different conditions, which include 1.5- and 0.75-in. thicknesses of "Fiberfrax" insulation (made by the Carborundum Company), the addition of a susceptor, and the use of cooling a1r in addition to the coil-cooling effect. This table also gives the maximum pot center-line temperature for calcines and glassy solids for an internal heat generation rate of $5000 \mathrm{Btu} \mathrm{hr}^{-1} \mathrm{ft}^{-3}$.

It is apparent from Fig. 3.7 that calcine internal heat generation rates should be limited to 5000 Btu $\mathrm{hr}^{-1} \mathrm{ft}^{-3}$ for 8-in.-diam pots and $2500 \mathrm{Btu}$ $\mathrm{hr}^{-1} \mathrm{ft}^{-3}$ for 12-in.-diam pots. This limitation is based on a maximum allowable calcine temperature of $1832^{\circ} \mathrm{F}\left(1000^{\circ} \mathrm{C}\right)$. Cooling air between the pot and insulation will also be required to achieve a pot-wall coefficient of at least $2.0 \mathrm{Btu} \mathrm{hr}^{-1}\left({ }^{\circ} \mathrm{F}\right)^{-1}$ $\mathrm{ft}^{-2}$ of pot-wall area. Figure 3.8 shows that glassy solids having heat generation rates of $5000 \mathrm{Btu}$ $\mathrm{hr}^{-1} \mathrm{ft}^{-3}$ can be cooled easily in 8- or 12-in. pots, even at low pot-wall coefficients.

A schedule of 20 test runs was proposed for demonstration of the Potcal process in the Waste Calcination Demonstration Pilot Plant at Hanford. The proposed schedule included 11 runs with FTW-65 waste, 7 with the Potcal process and 4 with the RL-Potglass process. Five runs with Redox waste (aluminum) were also proposed to simulate TBP-25 (aluminum) waste. It was recommended that a special sulfate-free Purex waste be prepared that could be adjusted with iron, chromium, and nickel nitrates to simulate the Darex waste. Heat transfer and off-gas decontamination problems would be studied by using three levels of radioactivity. Tests at low levels of radioactivity would be followed by medium-level tests that would produce solids with a heat generation rate of approximately $1000 \mathrm{Btu} \mathrm{hr}^{-1} \mathrm{ft}^{-3}$. High-radioactivity tests would produce solids with a heat rating of $5000 \mathrm{Btu} \mathrm{hr}^{-1}$ $\mathrm{ft}^{-3}$. Hanford has proposed even higher-level tests in which cerium is added to normal Purex wastes. In this case 6-in.-diam pots will probably be used for calcination.

Mechanical Equipment. -- The mechanical equipment developed for the Potcal process and tested at Lockheed Nuclear Products Facility-Georgia Nuclear Laboratory ${ }^{18}$ was modified to reflect the change in operating philosophy between the Idaho Chemical Processing Plant and Hanford. The filling station and associated operations were enclosed in a secondary containment hood to minimize the contamination potential to the cell. The calciner-pot screw cap and pot lift head are prealigned in a jig located in the cold makeup area. The assembly is brought into the cell and lowered partially into the furnace by the in-cell crane. A torque wrench is used to remove the cap, which is retained in position by the pot lift head resting on the top hood assembly. The pot is then lowered the remaining distance into the furnace. The air-driven dolly that moved the pot between stations was replaced by a manually operated dolly. Raising and

\footnotetext{
${ }^{18}$ E. W. Miller, Mechanical Development and Evaluation of the ORNL Pot Calciner, ER-6297 (July 1963).
} 
Table 3.4. Maximum Center-Line Temperatures for Cooling of 8-in.-diam Pots in an Induction Furnace

\begin{tabular}{|c|c|c|c|}
\hline Conditions & $\begin{array}{c}\text { Average Heat } \\
\text { Transfer Coefficient } \\
\text { Outside of } \text { Pot }^{a}\end{array}$ & $\begin{array}{c}\text { Maximum Pot } \\
\text { Center-Line Temperature } \\
\text { of Calcine }{ }^{b}\left({ }^{\circ} \mathrm{F}\right)\end{array}$ & $\begin{array}{c}\text { Maximum Pot } \\
\text { Center-Lıne Temperature } \\
\text { of Glassy Solids }{ }^{c}\left({ }^{\circ} \mathrm{F}\right)\end{array}$ \\
\hline 1.5-1n. insulation ${ }^{d}$ and susceptor & 0.83 & 1922 & 1697 \\
\hline 0.75-1n. insulation ${ }^{d}$ and susceptor & 1.49 & 1853 & 1685 \\
\hline $0.75-1 n$. insulation; ${ }^{d}$ no susceptor & 1.70 & 1844 & 1684 \\
\hline $\begin{array}{l}\text { 1.5-1n. insulation }{ }^{d} \text { and susceptor: } \\
155 \mathrm{cfm} \text { cooling air }\end{array}$ & 2.13 & 1831 & 1682 \\
\hline $\begin{array}{l}0.75-1 \mathrm{n} . \text { insulation and susceptor; } \\
155 \mathrm{cfm} \text { cooling air }\end{array}$ & 2.44 & 1825 & 1682 \\
\hline 1.5-1n. insulation; no susceptor & 0.87 & 1918 & 1698 \\
\hline
\end{tabular}

${ }^{a} \mathrm{Btu} \mathrm{hr^{-1 }}\left({ }^{\circ} \mathrm{F}\right)^{-1}$ per square foot of area on pot calciner wall.

${ }^{b} Q=5000 \mathrm{Btu} \mathrm{hr}{ }^{-1} \mathrm{ft}^{-3} ; K=0.2 \mathrm{Btu} \mathrm{hr}^{-1} \mathrm{ft}^{-1}\left({ }^{\circ} \mathrm{F}\right)^{-1}$.

${ }^{c} Q=5000 \mathrm{Btu} \mathrm{hr}^{-1} \mathrm{ft}^{-3} ; K=1.0 \mathrm{Btu} \mathrm{hr}^{-1} \mathrm{ft}^{-1}\left({ }^{\circ} \mathrm{F}\right)^{-1}$.

${ }^{d}$ Fiberfrax insulation, product of the Carborundum Company.

lowerng of the pot at the fill station will be done with the in-cell crane instead of by air-operated Duff-Norton jacks. An impact wrench will replace the "through-the-wall" clamp closure operation. After calcination the pot will be moved back to the initial position, the cap will be inserted, and the enclosed assembly will be removed to exther the welding station or to storage. The pot lift head will be removed for reuse.

The equipment and operating policies will be cold tested in a mockup at Hanford and modified, if necessary, before installation in the Waste Calcination Prototype.

\section{Laboratory Studies}

Laboratory studies included the development of suitable glasses (glass in this report includes both true glasses and rocklike crystallıne solids) for the incorporation of Purex wastes ${ }^{19}$ [work on TBP-25 (aluminum) and Darex wastes reported previously], ${ }^{20}$ removal of mercury from wastes, ${ }^{21}$ semiengineering-scale (4-1n.-diam by 24-1n.) development of the RL-Potglass process, ${ }^{22}$ use of conductivity probes for monitonng solution levels, ${ }^{22}$ and corrosion tests.

Glass Formulation. - Objectives of the glassformulation development program are to
1. produce a glass that corrodes stanless steel only slightly,

2. hold fission products and sulfate in the solid product and eliminate side streams,

3. achieve a large volume reduction and a high concentration of waste oxides in the glass;

4. produce a solid product that is stable under storage conditions, mechanically strong, insoluble, and a good heat conductor;

5. develop universal matrix glasses which can be used with a wide variety of waste compositions;

6. operate safely and economically.

\footnotetext{
${ }^{19}$ W. E. Clark, H. W. Godbee, and C. L. Fitzgerald, Laboratory Development of Processes for Fixation of High-Level Radroactive Wastes in Glassy Solids. (3) Wastes from the Purex Solvent Extraction Process, ORNL-3640 (in preparation).

${ }^{20}$ W. E. Clark and H. W. Godbee, Laboratory Development of Processes for Fixation of High-Level Radioactive Wastes in Glassy Solids: Wastes Containing (1) Aluminum Nitrate and (2) the Nitrates of Constituents of Stanless Steel, ORNL-3612 (in press).

${ }^{21}$ W. E. Clark and C. L. Fitzgerald, Proposed Methods for the Removal of Mercury from Radioactive Waste Solutions, ORNL-TM-827 (Mar. 31, 1964).

${ }^{22} \mathrm{H}$. W. Godbee and W. E. Clark, Conversion of Simulated High-Level Radioactive Waste Solutions to Glassy Solids in a Pot by a Rising Liquid Level Method: The RL-Potglass Process, ORNL-3629 (in press).
} 
Phosphate was chosen as the primary glass former because (1) its salts are more easily handled in acid solution than silicates; (2) it usually has lower melting points than silicates and has less tendency toward puffiness during meltdown than borates; (3) it appears to be more compatible with sulfate than either silicate or borate; and (4) it is formed by the oxidation of phosphite. The use of phosphite (or hypophosphite) may be desirable for retention of ruthenium in the solid product.

It will not be possible to maximize all these criteria. So, it will be necessary to relax some of them in order to meet the more important objectives. A prime objective is to produce glasses that are not very corrosive toward stainless steels during the production of the glassy solids. Hence it may be necessary to accept crystalline solids rather than true glasses - and somewhat higher solubilities. This is particularly true of Purex wastes containing sulfate. The production of a true glass may not be a reasonable criterion in any event, since most glasses will tend to devitrify at the high temperatures expected to be generated internally by decay of large amounts of fission products.

The general effect produced by the retention of large amounts of sulfate in the product is to make formation of a true glass difficult (if not impossible) and to increase the difficulty of producing homogeneous solid products. In general, true glasses are less soluble than crystalline materials of similar composition, probably because of their smaller surface areas for specified shapes and volumes (i.e., smaller roughness factors). The effect of waste oxide concentration in a given glass is not known, as yet. However, the marked differences in leach rates for similar compositions of solid products indicate that vitrification is more important than waste oxide content in determining leach rate (Fig. 3.9).

A new series of solid compositions was developed for the fixation of sulfate-containing Purex waste; lithium was substituted for sodium as a fluxing additive. Since sodium is normally a major constituent of Purex waste (Table 3.1), the addition of lithium produces a solid with both of these alkali metals as major constituents. As a general rule, the melts prepared by lithium addition have softening temperatures as low as or lower than the corresponding sodium melts, are more fluid at a given temperature, suffer no greater sulfate loss, are somewhat less soluble, and are generally more satisfactory both from the operational standpoint and from the nature of the final product. One of the compositions selected for semiengineeringscale fixation tests of the RL-Potglass process contained $44.5 \%$ waste oxides and lost less than $1 \%$ of its $\mathrm{SO}_{3}$ (Table 3.3). The dissolution rate of this ceramic product in water was about $10^{-4} \mathrm{~g}$ $\mathrm{cm}^{-2}$ day $^{-1}$ after about a month. This is comparable to the solubility of another glassy product, which lost about $15 \%$ of its $\mathrm{SO}_{3}$ during fixation and therefore should have been more insoluble (Fig. 3.9).

A large number of experimental melts were prepared $^{8,10}$ by the addition of lithium, phosphate,

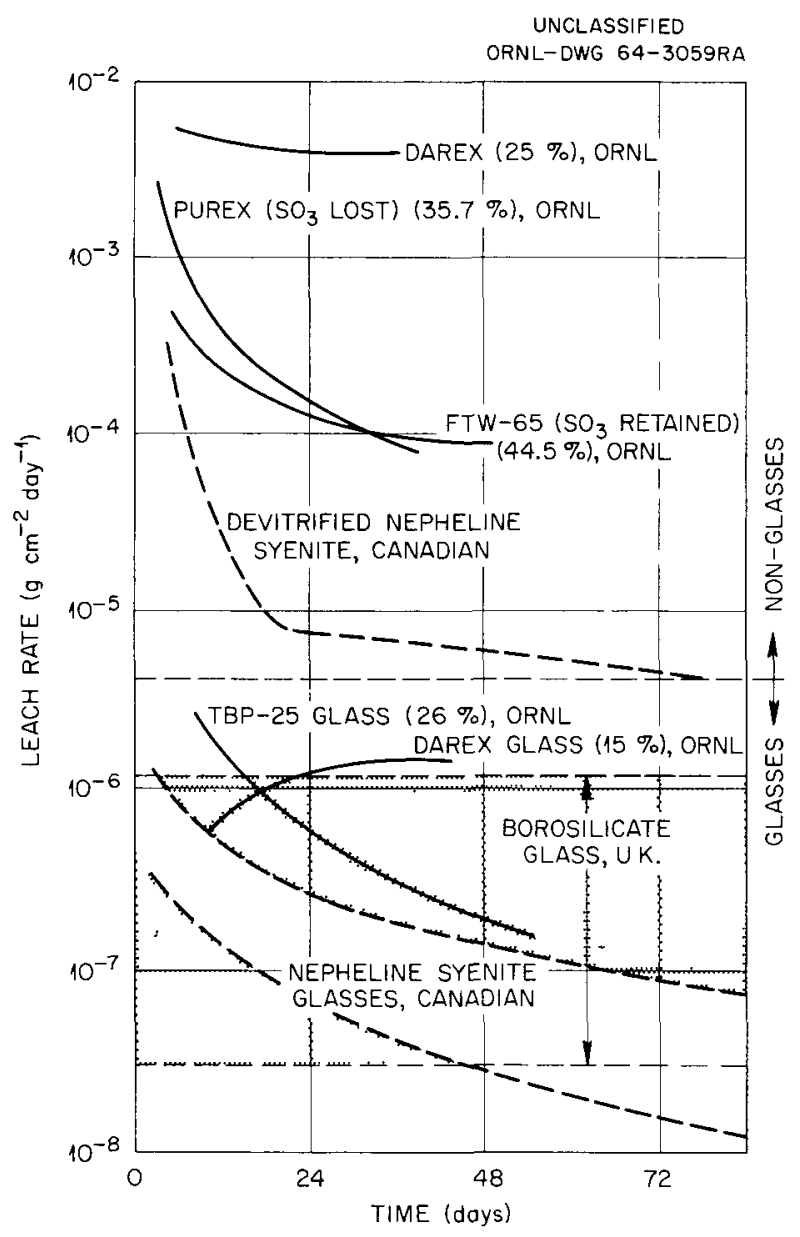

Fig. 3.9. Comparative Leach Rates of Glasses and Non-Glasses. Numbers indicate percent waste oxide content. ORNL leach rates were based on ${ }^{137} \mathrm{Cs}$, UK rates on uranium, Canadian rates on gross fission products. 
alumınum, and sometimes calcium, magnesıum, borate, and/or silicate to the FTW- 65 waste solution. Since correlation of composition with properties becomes extremely difficult when the number of major var1ables becomes as large (s1x or seven) as in the present case, computer coding will be used for correlating the data. Typical better compositions are presented in Table 3.3. Solid products FTW- 3 and $1 W W-1$ were formed by the addition of the same additives to both FTW- 65 and Purex IWW waste solution. Such universal additive formulations will doubtless be of value in handling variable compositions within a given waste type, but they cannot be expected to yreld volume reductions as high, or physical properties as desirable, as can be obtaned by use of a formulation especially selected for a given waste composition.

A few scope studies were armed at the development of solids for the fixation of Purex waste that contains no sulfate. The phase studies of Takahash ${ }^{23}$ were used as a guide. Addition of $\mathrm{PbO}$ to the sodium alumınum phosphate system was effective in producing low-melting glasses (Table 3.3), though their properties (especially corrosion) require further evaluation.

Waste that consists primanly of sodium nitrate with little or no nonvolatile anion is not amenable to fixation by pot calcination, ${ }^{24}$ because gross displacement of solids takes place on heating. The addition of sulfuric acid is undesirable since the resulting melt, which consists principally of $\mathrm{Na}_{2} \mathrm{SO}_{4}, 1 \mathrm{~s}$ soluble. The addition of aluminum to counteract the excess of alkali oxides over nonvolatile acid oxides prevented the displacement of solids and the volatilization of cesium. When the following ratio was maintained,

$$
\frac{\text { Chemical equivalents }\left(\mathrm{Na}^{+}+\mathrm{Cs}^{+}\right)}{\text {Chemical equivalents }\left(\mathrm{SO}_{4}{ }^{2-}+\mathrm{AlO}_{2}{ }^{-}\right)} \geqq 1 \text {, }
$$

the amount of ${ }^{137} \mathrm{Cs}$ in the off-gas system was no greater than that expected from entrainment (Table 3.5). Addition of excess alumina [added to the solution before calcination as $\left.\mathrm{Al}\left(\mathrm{NO}_{3}\right)_{3} \cdot 9 \mathrm{H}_{2} \mathrm{O}\right]$ did not increase the volatilization of either alkalı or

\footnotetext{
${ }^{23}$ K. Takahash1, "Advances in Glass Technology," VI Intern. Congress on Glass, Washington, D.C., July $8-14,1962$, pp. 366-77, Plenum, New York, 1962.

${ }^{24} \mathrm{~J} . \mathrm{K}$. Green and J. E Brown, Unclassified Research and Development Programs Executed for the Division of Reactor Development and the Division of Research, HW-78035 (May 1963).
}

acıd oxides. Aluminum appears, therefore, to act as a truly amphoteric oxide in the calcine. The use of alumina is also compatible with the formation of phosphate glass from this waste type.

Development of the RL- and Con-Potglass Processes. - The development of the RL-Potglass process was completed on a semiengineering scale. ${ }^{22}$ Experiments were performed in pots $4 \mathrm{in}$. in diameter and $24 \mathrm{in}$. high. A final five runs were made with FTW-65 glass formulations (Table 3.6). Feed rates were 35 to $\sim 42 \mathrm{ml} / \mathrm{min}$. One of these, in which a borophosphate melt was employed, was very corrosive, and the $f_{1 x a t i o n}$ pot was perforated. Use of an improved melt allowed the successful completion of three runs, with negligible corrosion. However, when the method of operation was changed to provide sparging by nitrogen (in the hope that the agitation would make higher feed rates possible), the pot was perforated again. The corrosion was attributed to the hydrolysis of sulfates when the aqueous phase was mixed with the molten salt. Sparging is not recommended. The thermal conductivity of the solid produced in these experiments was higher over the entire temperature range from 200 to $870^{\circ} \mathrm{C}$ (about 400 to $1600^{\circ} \mathrm{F}$ ) than that of any fixation solid measured thus far (Fig. 3.10). Volatilization of ruthenium (20.7 to $37.1 \%)$ and iron (3.1 to $14.9 \%$ ) was excessive. Although higher than desirable, these volatilities are acceptable since the condensed off-gas is recycled to the evaporator in the loop system. Comparison of the iron with the phosphate $(\leqq 0.4 \%)$ in the off-gas implies that iron, as well as ruthenium, is being volatilized rather than being simply entrained.

It was concluded that the RL-Potglass process was satisfactory in terms of flow rate, product quality, and corrosion, and that larger-scale eng1neering tests should proceed (see "Engineering Studies," this chapter).

A few initial tests were made with a small contınuous melter, that 1s, with a 4-1n.-diam pot with a configuration similar to that shown in Fig. 3.4. The melt depth is maintained at about $1 \mathrm{in}$. by a fixed overflow outlet in the center of the bottom. The overflow outlet and a center heating rod are not shown in Fig. 3.4. The FTW-1 mix (Table 3.3) was not fluid enough at $900^{\circ} \mathrm{C}$ for use in this melter. Addition of more lithium and phosphate, reducing the waste oxide content from $44.5 \%$ to $39.6 \%$ (FTW-2, Table 3.3), produced a melt which was easily handled. Feed rates of 2 to 5 liters $/ \mathrm{hr}$ were obtained. 
Table 3.5. Suppression of the Volatility of Sodium, Cesium, and Sulfate During Calcination of Sulfate-Deficient Purex Waste ${ }^{a}$ in the Presence of Aluminum

\begin{tabular}{|c|c|c|c|c|c|}
\hline & \multicolumn{5}{|c|}{ Experiment } \\
\hline & & 1 & 2 & 3 & 4 \\
\hline \multirow{2}{*}{$\begin{aligned} \mathrm{Al}\left(\mathrm{NO}_{3}\right)_{3} \text { added, } \mathrm{g} \text {-moles } / 1 \text { ter of waste } \\
\text { Mole ratios: } \mathrm{Al} / \mathrm{NaNO}_{3}{ }^{b} \\
\\
\mathrm{~A} 1 / \text { total } \mathrm{Na}+{ }^{137} \mathrm{Cs}\end{aligned}$} & & 0 & 0.34 & 0.675 & 1.0 \\
\hline & & 0 & 0.225 & 0.45 & 0.566 \\
\hline \multicolumn{6}{|c|}{ Volatility and Entrainment ( $\%$ of Total) } \\
\hline \multicolumn{6}{|l|}{${ }^{137} \mathrm{Cs}^{+}$} \\
\hline \multicolumn{2}{|l|}{$\begin{array}{l}\text { Total in off-gas line, condenser, }{ }^{c} \text { and } \\
\text { condensate receiver }\end{array}$} & & 0.01 & 0.012 & 0.006 \\
\hline \multicolumn{6}{|l|}{$\mathrm{Na}^{+}$} \\
\hline In off-gas line and condenser & & 0.25 & 0.13 & 0.005 & Negligible \\
\hline \multirow[t]{2}{*}{ In condensate receiver } & & 0.15 & 0.12 & 0.004 & 0.018 \\
\hline & Tota1 & 0.45 & 0.25 & 0.009 & 0.018 \\
\hline \multicolumn{6}{|l|}{$\mathrm{SO}_{4}^{2-}$} \\
\hline In off-gas line and condenser & & 0.29 & 0.12 & $<0.003$ & Negirgible \\
\hline \multirow[t]{2}{*}{ In condensate receiver } & & 0.17 & 0.10 & 0.004 & 0.014 \\
\hline & Total & 0.46 & 0.22 & $<0.007$ & 0.014 \\
\hline Observations & \multicolumn{2}{|c|}{$\begin{array}{l}\text { Gross displacement of solids } \\
\text { took place from inner cup } \\
\text { to cooler parts of } 1 \text { gnition } \\
\text { tube; some white solid in } \\
\text { exit tube from condensate } \\
\text { receiver }\end{array}$} & $\begin{array}{l}\text { No gross dis placement of } \\
\text { solids; some white } \\
\text { solids in off-gas sys- } \\
\text { tem }\end{array}$ & $\begin{array}{l}\text { No gross displacement of } \\
\text { solids; solids slightly } \\
\text { visible in the off-gas } \\
\text { system }\end{array}$ & $\begin{array}{l}\text { No solids } \\
\text { visible } \\
\text { in off- } \\
\text { gas sys- } \\
\text { tem }\end{array}$ \\
\hline
\end{tabular}

${ }^{a}$ Future acid Purex waste. Composition (g-moles/11ter): $\mathrm{H}^{+}, 0.5 ; \mathrm{Na}^{+}, 1.2 ; \mathrm{Fe}^{3+}, 0.1 ; \mathrm{SO}_{4}{ }^{2-}, 0.2 ; \mathrm{NO}_{3}{ }^{-}, \sim 1.6$ (to balance).

${ }^{b}$ More precisely, Al/moles Na minus $\left(2 \times\right.$ moles $\left.\mathrm{SO}_{4}{ }^{2-}\right)$.

${ }^{\mathrm{c}}$ Cesium and sodium volatilities measured in separate experiments. 
Table 3.6. Semiengineering-Scale Tests of the RL-Potglass Process

Pots $4 \mathrm{kn}$. in diameter by $24 \mathrm{in.} \mathrm{high}$

Waste composition Run A (see FTW-4, Table 3.3)

Run B (see FTW-1, Table 3.3)

\begin{tabular}{|c|c|c|c|c|c|}
\hline & \multicolumn{5}{|c|}{ Run No. } \\
\hline & A & $\mathrm{B}$ & $\mathrm{C}$ & $\mathrm{D}^{a}$ & $E^{b}$ \\
\hline \multicolumn{6}{|l|}{$\begin{array}{l}\text { Volatility and entrainment, } \% \text { of } \\
\text { total present }\end{array}$} \\
\hline $\mathrm{SO}_{4}{ }^{2-}$ & 40.3 & 6.1 & 1.1 & 0.5 & 22.5 \\
\hline $\mathrm{Ru}$ & 26.64 & 20.7 & 37.1 & 29.7 & 22.3 \\
\hline $\mathrm{Fe}$ & 5.76 & 6.4 & 14.9 & 6.8 & 3.1 \\
\hline $\mathrm{PO}_{4}^{3-}$ & 0.23 & 0.4 & 0.4 & 0.4 & 0.18 \\
\hline Average feed rate, $\mathrm{m} 1 / \mathrm{m} 1 \mathrm{n}$ & 35.5 & 36.9 & 41.8 & 38.0 & 38.4 \\
\hline $\begin{array}{l}\text { Apparent volume reduction, volume } \\
\text { solid/volume unconcentrated } \\
\text { waste }\end{array}$ & & $\sim 36$ & $\sim 36$ & $\sim 36$ & $\sim 36$ \\
\hline Corrosion & Excessive & Negative & Negative & Negative & Excessive \\
\hline
\end{tabular}

${ }^{a} 0.1 \mathrm{MH}_{3} \mathrm{PO}_{3}$ was added just before startup to compare ruthenum volatility with that from an aged solution.

${ }^{b}$ Operated with a sparge of $\mathrm{N}_{2}$ at the bottom of the fixation pot.

The use of electrical resistance as a monitor of the level of solution, calcine, and melt in the pot was investigated and found to be potentially useful. The prototype probe consisted of a number of Nichrome wires enclosed in quartz tubes, each of which was open to the interior of the pot at a different level (Fig. 3.11). Readings from probes of this type were compared and correlated with thermocouple readings during two semiengineeringscale fixation experiments. Though the technique is feasible, it may not warrant adoption since in any event it is desirable to monitor internal pot temperatures with thermocouples. Also, it has proved feasible to locate the rising level in radioactive fixations, at least approximately, by means of radiation monitors. ${ }^{25}$

Mercury Removal. - Mercury is present in some types of Purex waste and in all TBP-25 (aluminum)

${ }^{25} \mathrm{R}$. T. Allemann et al., Hot Cell Studies of the Solidification of Hanford High-Level Wastes by Radiant Heat Spray and Pot Calcination, HW-SA-2877 (March 1963), presented at the AIChE Symposium on HighLevel Radıoactıve Wastes, Buffalo, N.Y., May 1963. wastes. Since mercury forms no compounds that are thermally stable at temperatures used for the solidification of wastes $\left(400\right.$ to $\left.900^{\circ} \mathrm{C}\right)$, its presence in the off-gas system is a potential problem. The selective condensation of mercury was not successful. ${ }^{4}$ Hence, a system has been developed that removes mercury in a simple column prior to the solidification step. ${ }^{21}$ The column contains a more active metal, such as copper or aluminum, which displaces the mercury (Fig. 3.12). The mercury is converted to an amalgam surtable for ultimate disposal in pots. The small amount of active metal added to the waste does not affect the waste solidification and increases the waste bulk only slightly.

A batch operation is possible in which the column is discarded upon exhaustion, or a continuous process in which the metal is added through the top of the column as it is needed. The amalgam formed would be removed at the bottom of the column. A vibrated column filled with copper shot appears best for FTW-65 Purex wastes and, in principle, for all waste solutions with an acidity 


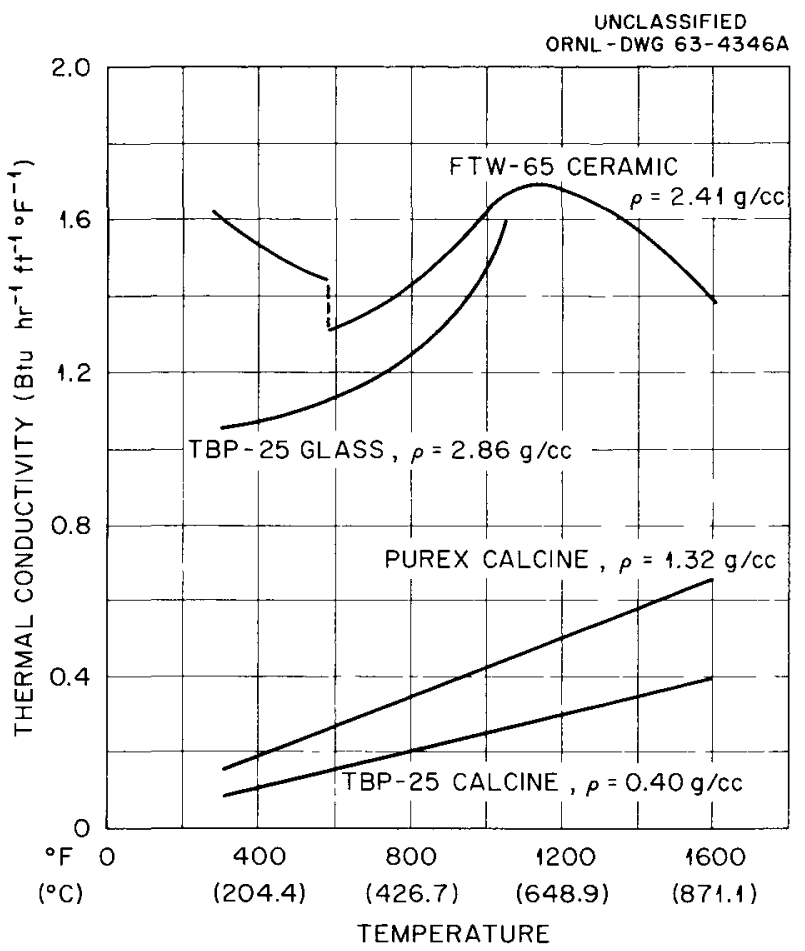

Fig. 3.10. Comparative Thermal Conductivities of Calcines and "Glasses" from Fixation of TBP.25 and Purex Waste Types.

lower than about $1.0 \mathrm{M}$. Aluminum may be used for column packing with Purex waste solutions containing up to $1.5 \mathrm{M}$ free acid, but lower acidities are required for TBP-25 (aluminum) wastes. Anodic polarization of the copper prolonged the effective life of the column, but it is questionable whether the increase warrants the added complexity of design.

More than $99 \%$ of the mercury was removed from 400 column volumes of FTW-65 (Purex) waste solution by passage through a stainless steel column packed with copper shot and vibrated to settle the amalgam and to prevent plugging and channeling in the bed. A nonagitated column with a small anodic current imposed removed more than $99.9 \%$ of the mercury from more than 800 bed volumes of FTW- 65 waste. About $0.05 \mathrm{M} \mathrm{Cu}^{2+}$ was added to the waste in each case. More than $99 \%$ of the mercury was removed from TBP-25 (1.26 M $\mathrm{HNO}_{3}$ ) waste by a copper-packed column, but the copper concentration in the effluent was excessively high, about $0.5 \mathrm{M}$, as a result of the high acidity. The number of equivalents of copper dis- solved per equivalent of mercury removed ranged from about 16 to about 25. The composition of the copper amalgam formed was not determined, but the product was a thixotropic liquid that flowed through a glass stopcock at the bottom of the column. This indicates a probable copper content of $6 \mathrm{wt} \%$ or less. Zinc, lead, tin, cadmium, and iron were all attacked too rapidly for satisfactory operation.

Corrosion. - Corrosion limitations differ for the three pot processes. In the Potcal and RL-Potglass processes, the pot is used only once. Hence, a higher corrosion rate can be tolerated than in the case of the Con-Potglass process. Corrosion has been negligible for the Potcal process with the three major waste types, but corrosion in the glass systems has been undesirably high. A total penetration of up to 150 mils has been selected as a

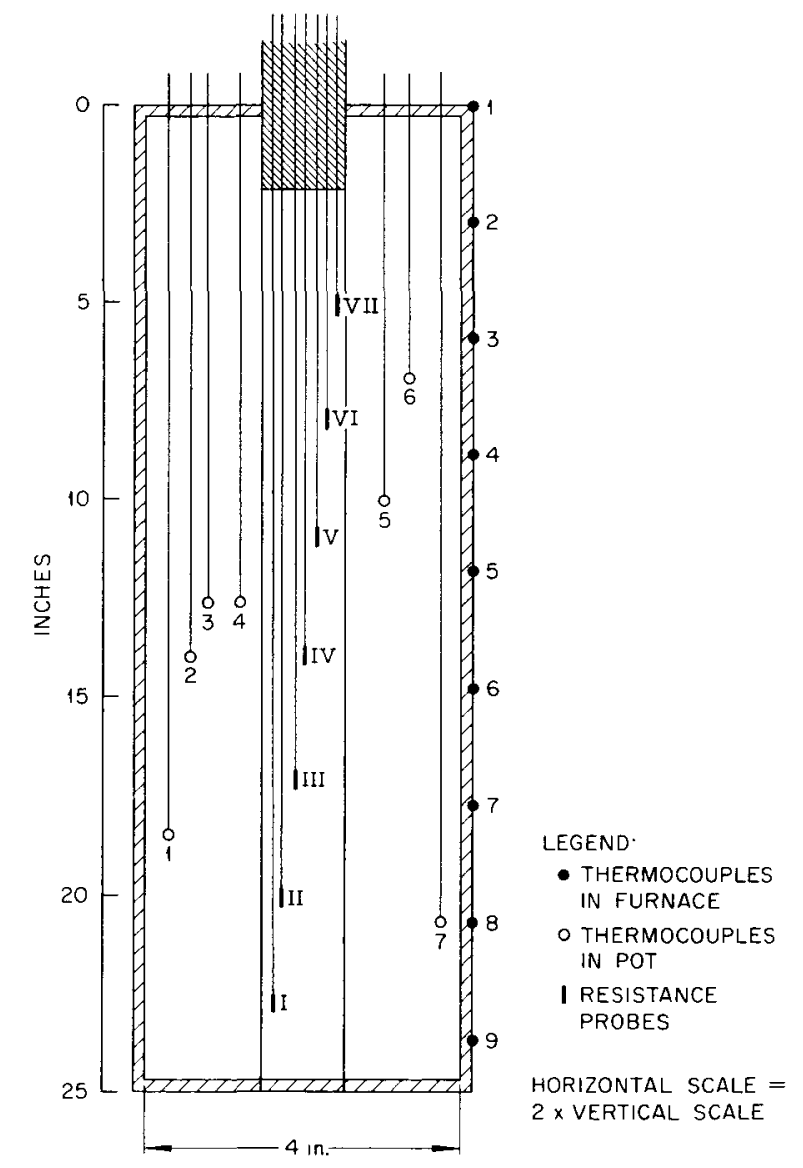

Fig. 3.11. Arrangement of Electrical Resistance Probes Used for Determining Levels of Solution, Calcine, and Melt in a Rising-Liquid-Level Fixation Pot. 


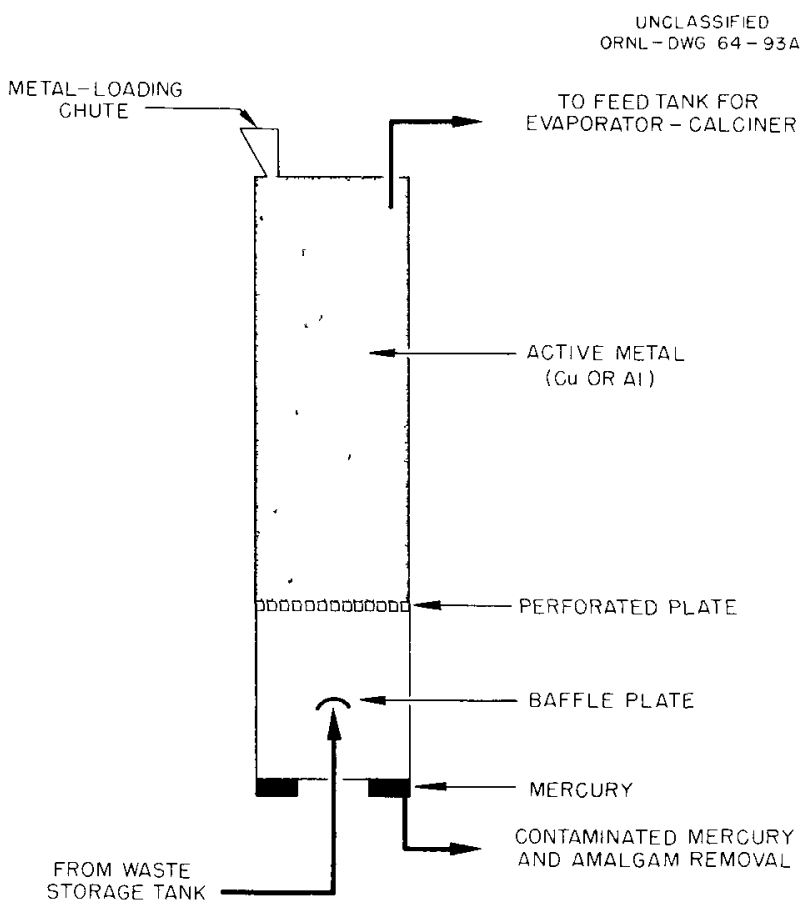

Fig. 3.12. Schematic Diagram of Proposed Column for Continuous Removal of Mercury from Acid Waste Solutions.

suitable limit for use with the standard single-use pots with a wall thickness of 320 mils, although lower rates are desirable. A much lower rate is required for the continuous melter. If a glass mix with a suitably low corrosion rate cannot be developed for use in a replaceable stainless steel continuous melter, a platinum-lined melter will be required. The economics for scheduled replacement of stainless steel melters would be different at each installation.

Exposure of type 304L stainless steel and titanium $45 \mathrm{~A}$ in waste evaporator solutions both with and without glass-making additives confirmed predictions that the stainless steel will eventually undergo intergranular attack and that the corrosion rate of the titanium will be negligible. Overall rates for type $304 \mathrm{~L}$ stainless steel varied from $0.1 \mathrm{mil} /$ month in the boiling, unconcentrated FTW65 Purex waste to $1.4 \mathrm{mils} /$ month in concentrated $1 W W$ Purex waste. The corrosion rate of titanium was negligible ( $\leqq 0.04 \mathrm{mil} / \mathrm{month})$ in all cases. Coupling the stainless steel test specimens to titanium had no noticeable effect on the corrosion of the titanium.
Stainless steel (type 304L) is a satisfactory material of construction for the pots. Successful fixations have been carried out in type $304 \mathrm{~L}$ stainless steel in 4-in.-diam by 24-in.-high and 8-in.diam by 88 -in.-high pots at maximum operating temperatures of 950 to $1000^{\circ} \mathrm{C}$ with FTW-65 and TBP-25 wastes. Maximum penetration in the latter case (for about $120 \mathrm{hr}$ of exposure) was about 120 mils, but no actual failure of the container occurred. Small-scale corrosion tests in the laboratory indicated penetrations of as much as 63 mils for $24 \mathrm{hr}$ in FTW-65 waste plus fixation additives at $1050^{\circ} \mathrm{C}$. Both large- and small-scale continuous melters failed within a few hours after beginning operation at about $1000^{\circ} \mathrm{C}$ when glass formulation FTW-1 (Table 3.3) was used.

The conclusions that can be drawn from the corrosion data are: (1) Corrosion increases rapidly with increase in temperature above about $900^{\circ} \mathrm{C}$, and operating temperatures as high as 1000 to $1050^{\circ} \mathrm{C}$ can be tolerated with stable melts for limited periods of time in equipment that will be used only once. (2) The corrosion rate at a given temperature decreases drastically when all the volatile material (particularly water) has been driven off.

Exposure of type $304 \mathrm{~L}$ stainless steel in $\mathrm{NaCl}$ with varying amounts of impurities added (e.g., $\mathrm{H}_{2} \mathrm{O}$, CaSO ${ }_{4}$, and $\mathrm{MgCl}_{2}$ ) indicated a maximum rate of about $0.03 \mathrm{mil} / \mathrm{month}$ for $3600 \mathrm{hr}$ (five months) exposure at $300^{\circ} \mathrm{C}$. It appears that the moisture in the environment will govern the corrosion rate and that corrosion should, therefore, almost completely stop after the first month's storage in a salt mine, provided that the temperature of the pot wall does not exceed about $300^{\circ} \mathrm{C}$ and that water cannot reach the storage containers.

\subsection{TREATMENT OF LOW-LEVEL RADIOACTIVE WASTE}

Low-level radioactive wastes (LLW) consist of waters with low solids and radioactivity contents. They are customarily treated to remove activity before discharge to streams. The objective of the ORNL program is to develop, evaluate, and determine the cost of alternative processes for decontaminating LLW to less than the maximum permissible levels, $\mathrm{MPC}_{\mathrm{w}}$, permitted for water for occupational exposure (168 $\mathrm{hr} /$ week) in order to avoid the spread of radioactivity. The retained 
solids and radioactivity can be combined with high-level wastes for ultımate disposal or, more economically, incorporated in concrete or asphalt and buried in restricted areas. Two processes are being developed, the scavenging-precipitation ionexchange process and the scavenging-precipitation foam-separation process. The precipitation steps were originally intended for clarification (including radiocollo1ds) and reduction of the hardness (calcium and magnesium ions) content to increase the efficiency of the resin or detergent used in the second step. Recent tests show, however, that recycle of the radioactive contaminants to the precipitation step and removal of all radioactivity from the systems in the sludge precipitate is economically attractive for the 1on exchange system but probably is not feasible for the foam system.

Previous pilot-plant tests showed that the scavenging-precipitation ion-exchange process can be used to decontaminate LLW at ORNL to less than $2 \%$ of the $\mathrm{MPC}_{\mathrm{w}}$ for about $78 \notin$ per 1000 gal. Process 1mprovements were tested and shown to reduce the estimated cost to about $66 \phi$ per $1000 \mathrm{gal}$ without loss in decontamination efficiency. Improvements included an alumina column to remove phosphates, which had caused erratic hardness removal, and recycle of the resin regenerant along with added Grundite clay to the precipitation system. Thus, all radioactivity is removed in the precipitated sludge, and the need for a regenerant evaporator and tanks to store the concentrated regenerant is eliminated. Anıon exchange resins were not very selective for ruthenium and cobalt removal.

Small-scale tests of the scavenging-precipitation foam-separation process showed that it was particularly effective for strontium removal and that LLW at ORNL can be decreased to about $2 \%$ of the $\mathrm{MPC}_{\mathrm{w}}$ for strontium. Cesium was not removed effectively unless Grundite clay was added. Overall decontamination factors for cesium and other activities were lower than for strontium but are probably adequate for most installations in the nuclear industry. More accurate decontamination factors and cost estımates will be obtained in projected pilot-plant tests.

\section{Scavenging-Precipitation lon-Exchange Process}

Laboratory Studies. - Several modifications to the scavenging-precipitation ion-exchange proc- ess $^{6.7}$ were evaluated. The proposed process (Fig. 3.13) consists in

1. the use of an activated alumina column to remove phosphates from untreated raw waste,

2. the recycle of regenerant waste from the cation exchange column together with Grundite clay to the main waste stream,

3. The precipitation of hardness cations and scavenging of radionuclides (strontium, cesium, etc.) and clanification of the combined waste stream,

4. the removal of the remaining strontium and cesium by Duolite CS- 100 cation exchange resin,

5. the possible removal of the remaining ruthenium and cobalt by anion exchange.

After 1500 to 2000 bed volumes of waste pass through 1 volume of CS-100 resin, the resin bed is eluted with $0.5 M \mathrm{HNO}_{3}$, washed with water, and reconditioned with $0.1 \mathrm{M} \mathrm{NaOH}$. Grundite clay is added to this regenerant solution to sorb cesium and fractions of the other radionuclides. The resultant slurry is metered (recycled) into the untreated low-level waste, where the clay and sorbed activities are retained in the settled sludge in the clarifier. Important features of the modified process are discussed below.

Alumina Sorption. - The efficiency of activity removal by the scavenging-precipitation ion-exchange process is lowered when phosphates are present in low-level waste. Their sequestering action results in the incomplete precipitation of hardness cations, and, as a consequence, the resin capacity is used to sorb hardness cations (calcium, magnesium, etc.) instead of radionuclides. Hardness precipitation was satisfactory at a phosphate concentration of $1 \mathrm{ppm}$ but not at $2 \mathrm{ppm}$ in micropilot-plant tests. ${ }^{7}$ The upper $11 \mathrm{mit}$ for phosphate concentration has not been determined as yet. Phosphate can be removed by sorption on activated alumina. ${ }^{1,8,10}$ In micro-p1lot-plant and pilot-plant tests (see below), using alumina columns that removed more than $50 \%$ of the phosphate, hardness precipitation was entirely satisfactory at phosphate concentrations up to 0.8 and $0.7 \mathrm{ppm}$, respectively, at the end of the tests. Laboratory experiments show that approximately 15,000 bed volumes of raw waste, containing 1 to $3 \mathrm{ppm}$ of phosphate, can be processed upflow through a fluidized bed of chromatographic-grade alumına (ALCOA F-20 grade, -80 to 200 mesh), with a sorption efficiency of 


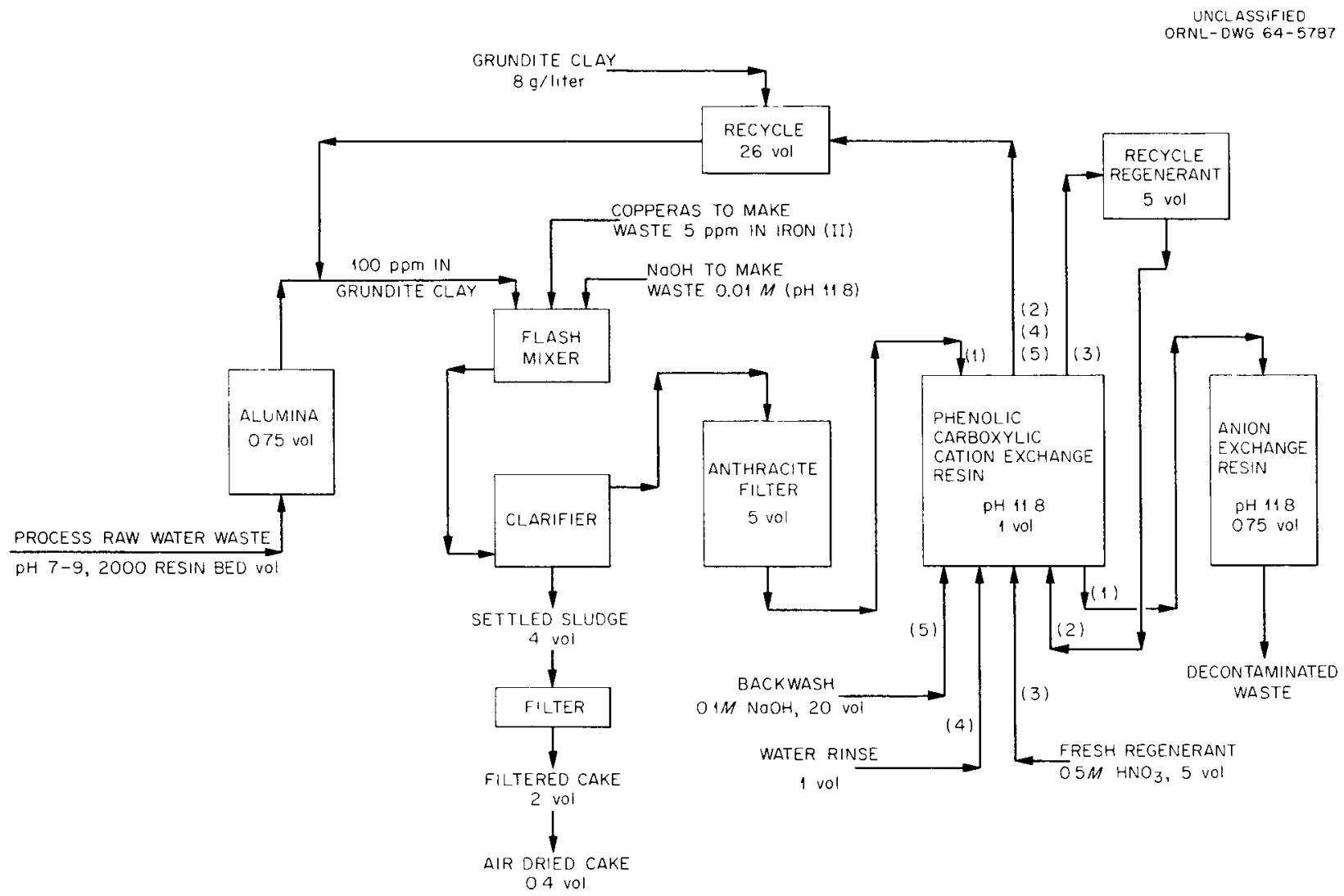

Fig. 3.13. Flowsheet Used in the Micro Pilot Plant Tests of the Modified Scavenging-Precipitation lon-Exchange Process Includes the Addition of an Alumina Column, an Anion Column, and a Grundite.Clay Recycle System.

$50 \%$ or more. This is a volume comparable to that from five to seven runs of the scavenging-precipitation ion-exchange process, when the bed-volume ratio of alumina to CS-100 resin is 0.75 to 1 (Fig. 3.13). A less expensive form of alumina is now being tested.

The efficiency of sorption of phosphate on alumina increased when the phosphate concentration was greater than $1 \mathrm{ppm}$. Up to $80 \%$ of the phosphate was sorbed from waste containing $3.6 \mathrm{ppm}$ of phosphate. No loss in efficiency was noted by increasing the liquid linear flow rate through the column from $12 \mathrm{~cm} / \mathrm{min}$ to $22 \mathrm{~cm} / \mathrm{min}$, equivalent to residence times of 4 and $2 \mathrm{~min}$. Regeneration of exhausted alumina restored its capacity and its efficiency. After treating with six volumes each of $1 \mathrm{M} \mathrm{NaOH}$ for phosphate removal and $1 \mathrm{MHNO}_{3}$ for fission product removal, another 13,000 bed volumes of waste were processed before the phos- phate sorption efficiency dipped below $50 \%$. Studies are being continued to determine minimum regenerant requirements.

The capacity of the alumina for phosphate, as determined by analysis of the regenerants, is estimated to be at least 0.4 meq per $\mathrm{ml}$ of $\mathrm{Al}_{2} \mathrm{O}_{3}$ (which is equivalent to the removal of $1 \mathrm{ppm}$ of phosphate from 13,000 volumes of waste per volume of alumina). This is numerically equivalent to 60 meq of $\mathrm{Al}^{3+}$ per meq of $\mathrm{PO}_{4}{ }^{3-}(1 \mathrm{ml}$ of dry $\mathrm{Al}_{2} \mathrm{O}_{3}=1 \mathrm{ml}$ of wet $\mathrm{Al}_{2} \mathrm{O}_{3}=0.8 \mathrm{~g}$ of $\mathrm{Al}_{2} \mathrm{O}_{3}$ ). The stated equivalence ratio indicates that phosphate sorption on alumina is a surface-dependent phenomenon. Moreover, the observed slow rate of phosphate removal from alumina by $1 M \mathrm{NaOH}$ corroborates the work of Sinha and Choudhury, ${ }^{26}$

\footnotetext{
${ }^{26}$ P. R. Sinha and A. K. Choudhury, J. Indian Chem. Soc. 31, 211 (1954).
} 
in which they suggest that phosphate sorption is a chemical reaction between phosphate and the surface alumina to form insoluble aluminum phosphate.

Alumina has a limited but unknown capacity for ${ }^{137} \mathrm{Cs},{ }^{60} \mathrm{Co}$, and ${ }^{106} \mathrm{Ru}$. For a waste containing 5 to 80 dis $\min ^{-1} \mathrm{ml}^{-1}$ of ${ }^{137} \mathrm{Cs}, 1$ to 5 of ${ }^{60} \mathrm{Co}$, and 1 to 6 of ${ }^{106} \mathrm{Ru}$, at least 1,2 , and $10 \%$, respectively, of these activities were sorbed from 20,000 alumina bed volumes of waste and were recovered during the regeneration step.

Grundite-Clay Recycle. - The object of using the Grundite-clay recycle is to consolidate all the radioactivity into a solid form and thus eliminate further processing of the CS-100 resin regenerant liquid. In pilot-plant tests, more than $50 \%$ of the strontium but only about $10 \%$ of the cesium is scavenged prior to cation exchange. ${ }^{6}$ Batch experiments show, however, that Grundite clay, a cheap commercial product $(68.5 \notin$ per $100 \mathrm{lb})$, has an optimum capacity for cesium in a narrow range around $\mathrm{pH} 11.8$ - the $\mathrm{pH}$ prescribed for the original process. Clay at concentrations of as little as $1 \mathrm{~g}$ per liter of regenerant waste removes more than $50 \%$ of the cesium, while $2 \mathrm{~g} /$ liter removes more than $80 \%$. Cesium sorption is independent of particle size but is about $3 \%$ greater if clay is added to the waste prior to $\mathrm{pH}$ adjustment to 11.8 (Fig. 3.14).

A number of micro-pilot-plant runs were made in order to demonstrate the Grundite-clay recycle modification together with the use of alumina to reduce phosphate concentration. The decontamination factor of 7 for cesium, shown in Table 3.7, illustrates the efficiency of Grundite for sorbing this element in the precipitation step. Without clay, less than $10 \%$ of the cesium processed was found in the sludge of the clarifier; with clay, more than $80 \%$. Also, with clay, overall decontamination factors across the clarifier and cation exchanger for cobalt and ruthenium appear to be improved, although the accuracy of the values at such low activity levels is doubtful. The values for ${ }^{60} \mathrm{Co}$ and ${ }^{105} \mathrm{Ru}$ were increased from 2 to 3 , while that for ${ }^{90} \mathrm{Sr}$ increased from 3000 to 6000 . The factor for waste volume reduction (to air-dried cake) was increased by about 1.6 (from 3400 to 5500 ), see Table 3.8. (See below for discussion of these effects on cost.)

Anion Exchange. - Two strong-base anion exchange resins, Illco TAD-1 and Dowex $21 \mathrm{~K}$, were included in the micro-pilot-plant runs to evaluate them for removal of ruthenium and cobalt remain- ing in the waste after cation exchange processing. These resins were selected because they had the most favorable decontamination factor for ruthenium (about 5) out of a group of 15 organic and inorganic sorbents that had been tested in a batch equilibrium experiment with treated ILW at $\mathrm{pH} 11.8$.

Both resins, preequilibrated to $\mathrm{pH} 11.8$ with caustic, showed relatively poor selectivity for ruthenium. In two runs, in which 2000 column volumes of waste were treated with Illco TAD-1 resin (equivalent to Dowex 1), average decontamination factors for ruthenium were 2 and 4 . The wastes had previously been treated by cation exchange and contained 0.97 and $1.7 \mathrm{dis} \min ^{-1} \mathrm{ml}^{-1}$ respectively. If it is assumed that more than one form of ruthenium escaped removal in the precipitation and cation exchange steps, the data could be interpreted in terms of the resin having effectively removed one or more forms of ruthenium. Alternatively, it could be that the resin performed well for relatively few bed volumes (compared with 2000 for the cation resin).

The average decontamination factors obtained in two runs with Dowex $21 \mathrm{~K}$ were poorer (about 1.3 and 1.2) for effluent processed from the cation exchanger, with average ruthenium activities of 0.4 and $27 \mathrm{dis} \min ^{-1} \mathrm{ml}^{-1}$ respectively. The waste processed in the latter run was composed of LLW spiked with treated ILW, which contains more ruthenium.

Clarification of Raw Waste. - Two methods are being considered for coagulating suspended solids in untreated, neutral LLW prior to its decontamination by ion exchange. The first includes the addition of $\mathrm{Al}_{2}\left(\mathrm{SO}_{4}\right)_{3}$. For waste that approximates tap water $(\mathrm{pH}$ of 7 to 8 , an initial total hardness of $125 \mathrm{ppm}$, and a specific conductance of 250 micromhos $/ \mathrm{cm}$ ), jar tests show that the aluminum sulfate treatment is optimum (1) when the waste is made 10 to $20 \mathrm{ppm}$ in $\mathrm{Al}_{2}\left(\mathrm{SO}_{4}\right)_{3}$, (2) when the mixture is flash-mixed for $5 \mathrm{~min}$, and (3) when the mixture is finally coagulated for $30 \mathrm{~min}$. Both the specific conductance and the total hardness of the clarified waste remain the same, but its $\mathrm{pH}$ is lowered from 7.5 to 7.0 .

The other method involves adding copperas and lime, which not only clarifies the waste but also partially precipitates hardness cations and thus reduces the load on the subsequent ion exchange step. The optimal conditions for coagulation are obtained by first making the waste $5 \mathrm{ppm}$ in copperas and flash mixing for $2 \mathrm{~min}$, then making 


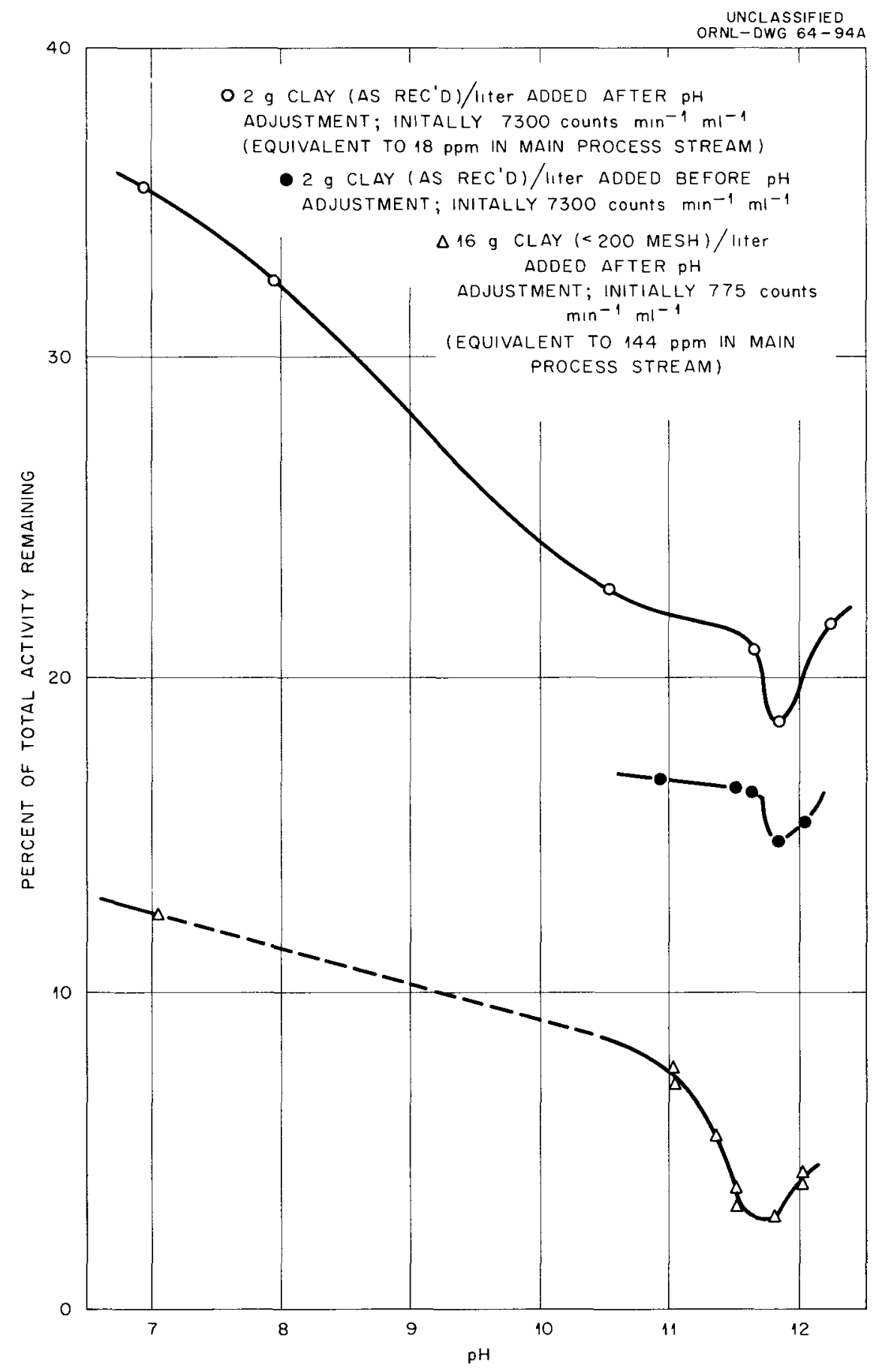

Fig. 3.14. Cesium Sorption on Grundite Clay. Sorption is optimum in a narrow range around $\mathrm{pH} 11.8$ and is more efficient when clay is added prior to $\mathrm{pH}$ adjustment. 
Table 3.7. Enhanced Effects of Grundite-Clay Recycle on Decontamination Factors in Micro-Pilot-Plant Tests of the Scavenging-Precipitation lon-Exchange Process on ORNL Low-Level Waste ${ }^{a}$

\begin{tabular}{|c|c|c|c|c|c|c|}
\hline & \multicolumn{6}{|c|}{ Decontamination Factors } \\
\hline & Gross $\gamma$ & $\begin{array}{c}\text { Total } \\
\text { Rare Earths }\end{array}$ & ${ }^{137} \mathrm{Cs}$ & ${ }^{90} \mathrm{Sr}$ & ${ }^{60} \mathrm{Co}$ & ${ }^{106} \mathrm{Ru}$ \\
\hline \multicolumn{7}{|l|}{ No Grundite-clay recycle ${ }^{b}$} \\
\hline Clarifier and cation exchanger & 3 & $>380^{\circ}$ & $>110^{c, d}$ & 3000 & 2 & 2 \\
\hline \multicolumn{7}{|l|}{ With Grundite-clay recycle ${ }^{b}$} \\
\hline Clarifier and cation exchanger & 10 & $>120^{c}$ & 630 & 6000 & 3 & 3 \\
\hline Clarıfier & 5 & 6 & 7 & 5 & 3 & 3 \\
\hline Cation exchanger & 2 & $>20^{\mathrm{c}}$ & 90 & 1200 & 1 & 1 \\
\hline
\end{tabular}

${ }^{a} 11001$ iters/run, equivalent to about 2000 bed volumes of Duolite CS-100 cation exchange resin.

${ }^{b}$ Average activity of fission products in stream to clarifier.

\begin{tabular}{|c|c|c|}
\hline & $\begin{array}{c}\text { No Recycle } \\
\text { (Run 7) }\end{array}$ & $\begin{array}{c}\text { With Recycle } \\
\text { (Run 8) }\end{array}$ \\
\hline Gross beta, counts $\mathrm{min}^{-1} \mathrm{ml}^{-1}$ & 86 & 35 \\
\hline Gross gamma, counts $\mathrm{mm}^{-1} \mathrm{~m}^{-1}$ & 3 & 18 \\
\hline TRE, counts $\mathrm{min}^{-1} \mathrm{ml}^{-1}$ & 42 & 17 \\
\hline${ }^{136} \mathrm{Cs}, \mathrm{d} 1 \mathrm{~s} \mathrm{~min}^{-1} \mathrm{~m}^{-1}$ & 6 & 81 \\
\hline${ }^{90} \mathrm{Sr}, \mathrm{d} 1 \mathrm{~s} \mathrm{~min}^{-1} \mathrm{ml}^{-1}$ & 93 & 62 \\
\hline${ }^{60} \mathrm{Co}, \mathrm{d} 1 \mathrm{~s} \mathrm{~min}^{-1} \mathrm{ml}^{-1}$ & 3 & 5 \\
\hline${ }^{106} \mathrm{Ru}, \mathrm{d}_{1 \mathrm{~s}} \mathrm{~m}^{-1} \mathrm{~m}^{-1}$ & 2 & 1 \\
\hline
\end{tabular}

Recycle consisted of $0.25 \mathrm{lb}$ of Grundite clay slurried into 10 liters of regenerant waste from a CS-100 column, previously loaded with cesium and strontium. The effective clay concentration after entering the main waste stream was about $100 \mathrm{ppm}$.

${ }^{c}$ Cesium and total rare earths reduced to limit of detection. Decontamination factors of 100 to 1000 have been obtained for rare earths both with and without Grundite clay added.

${ }^{d}$ Individual cesium decontamination factors for the clarif ier and cation exchanger were not obtainable. A material balance, however, showed that, without Grundite clay, $<10 \%$ cesium activity was in the sludge, while, with Grundite clay, $>80 \%$ cesium activity was in the sludge.

the waste $70 \mathrm{ppm}$ in lime and flash mixing for 3 $\mathrm{min}$, and, finally, by coagulating for $30 \mathrm{~min}$. The $\mathrm{pH}$ of the clarified solution increases from 7.9-8.5 to $10.0-10.4$, and up to $40 \%$ of the waste hardness 1s removed when $0.75 \mathrm{ppm}$ of phosphate is present. Nearly $70 \%$ of the hardness is removed if no phosphate is present. After copperas is added, the specific conductance is minimum when the amount of lime is optimum, thus, the measurement is potentrally useful as a simple method for continuously controlling lime addition (Fig. 3.15). The figure also shows that for tap water, the specific conductance decreases directly to a minımum, while, for waste water, it increases before proceeding downward. This initial increase is probably due to phosphates in the waste, which caused calcium supersaturation prior to the precipitation of the hardness cations. The work on clarification under neutral conditions is preliminary, and no conclusions can be drawn regarding the most efficient method.

Pilot-Plant Tests. - The low-level-waste pilot plant was revised as follows:

1. A 4-ft-diam agitated clarifier was installed for use with both the scavenging-precipitation ionexchange and the scavenging-precipitation foam-separation processes.

2. A fluidized bed of activated alumina was installed to remove phosphate from the waste water in order to prevent phosphate interference with the precipitation of calcium. 
Table 3.8. Effect of Grundite-Clay Recycle on Waste Volume Reduction in the Scavenging-Precipitation Ion-Exchange Process

\begin{tabular}{lcc}
\hline & $\begin{array}{c}\text { Without } \\
\text { Recycle }\end{array}$ & $\begin{array}{c}\text { With } \\
\text { Recycle }\end{array}$ \\
\hline Feed, bed volumes & 2000 & 2000 \\
Waste, bed volumes & & \\
CS-100 liquid regenerant & & \\
Recycle regenerant & 5 & 5 \\
Discard regenerant & 5 & None \\
Wash and backwash & 21 & None \\
Settled sludge & 3.1 & 3.7 \\
Filtered sludge cake & 1.5 & 1.9 \\
Air-dried sludge cake & 0.32 & 0.37 \\
Volume reduction factor & & \\
Filtered cake + concentrated & $1120^{a}$ & $1050^{a}$ \\
liquid & & \\
Air-dried cake + concentrated & $3400^{a}$ & $5500^{a}$ \\
liquid & & \\
\hline
\end{tabular}

${ }^{a}$ Volume reduction factors without recycle include CS. 100 liquid regenerant waste which was reduced in volume by evaporation to the maximum practical degree. Volume reduction factors with recycle are for solid waste only.

3. Provision was made to recycle the ion exchange regenerant, with Grundite clay as additive, to the raw waste feed.

Three demonstration runs were made with the revised equipment. Also a preliminary test was made of a process in which waste water is merely filtered through a deep-bed anthracite filter before the calcium and magnesium hardness ions and radionuclides are removed by weak-acid (IRC-50) and strong-acid (Dowex 50) resin beds in sequence. Previous pilot-plant tests have been reported. ${ }^{6.27}$

Flowsheet for the Scavenging-Precipitation IonExchange Process Tests. - Three runs were made according to the following flowsheet (similar to the one shown in Fig. 3.13 but with a small anion resin column): Low-level waste (at $10 \mathrm{gpm}$ ) was

${ }^{27}$ R. E. Brooksbank, L. J. King, and J. T. Roberts, Pilot Plant Demonstration of the Removal of Radioactivity from Low-Level Process Waste Water by a Scavenging-Precipitation Ion-Exchange Process, presented at Symposium on Radionuclide Exchange on Soils, Minerals, and Resins, Amer. Chem. Soc., Philadelphia, Pa., April 10, 1964. fed to a 2-ft-diam alumina column containing about $4.4 \mathrm{ft}^{3}$ of Alcoa F20, 80- to 200-mesh activated alumina. The alumina column throughput rate was $191 \mathrm{gal} \mathrm{hr}^{-1} \mathrm{ft}^{-2}$, which fluidized the bed to about 2.4 times its packed volume and allowed the liquid about $4 \mathrm{~min}$ of residence time in the expanded bed. In recycle runs, the resin-column eluate from the previous run was returned to the waste water feed stream along with Grundite clay. The clay was added (as a slurry) to sorb cesium and other activities at a rate of about $0.7 \mathrm{lb}$ per $1000 \mathrm{gal}$ of waste. The eluate recycle and Grundite were both added to the process waste stream between the alumina column and the flash mixer. The alumina column effluent went to the flash mixer (residence time, $18 \mathrm{sec}$ ), where it was mixed with a $10 \mathrm{M} \mathrm{NaOH}$ solution and a solution
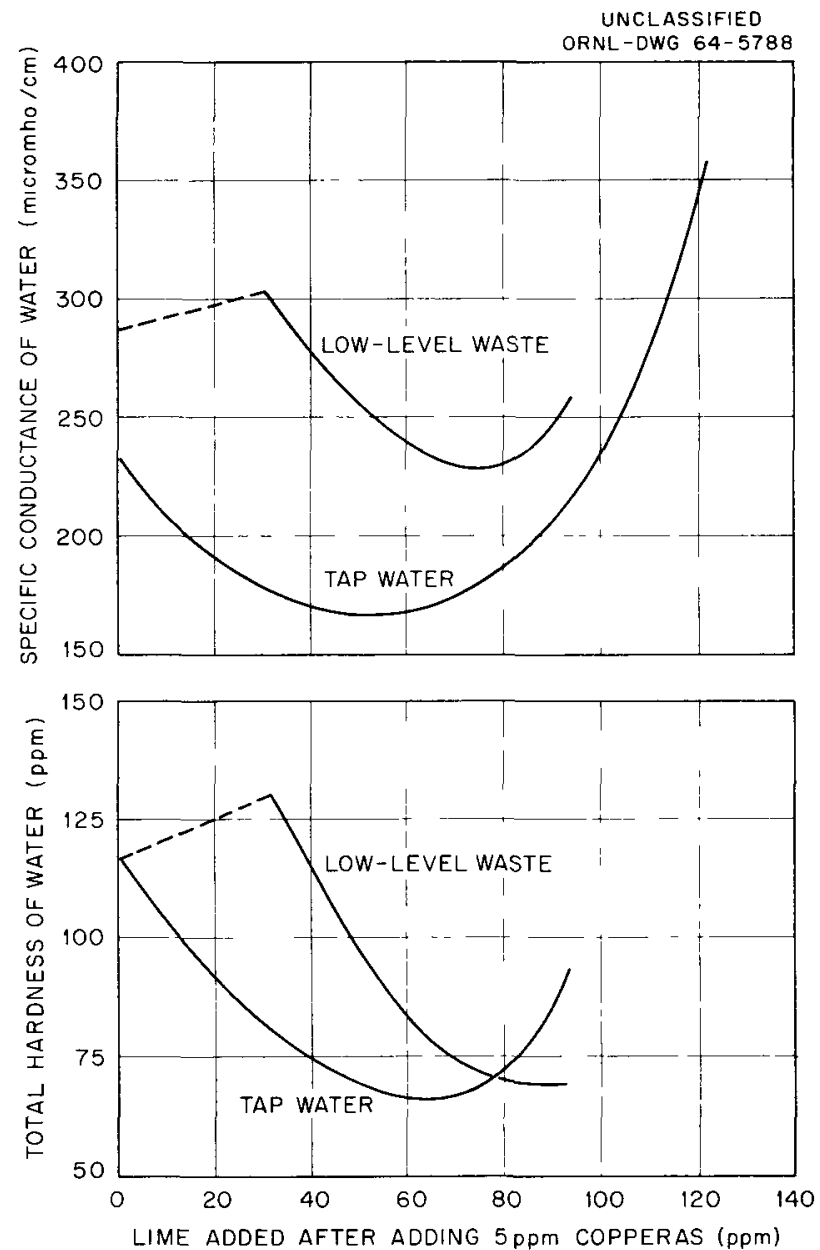

Fig. 3.15. Specific Conductance Is Minimum at the Point of Maximum Precipitation of Total Hardness. 
of copperas (24 g/liter) to make a solution that was $0.01 M$ in $\mathrm{NaOH}$ and contained $5 \mathrm{ppm}$ of $\mathrm{Fe}^{2+}$. That mixture went to the flocculator, where it was agitated at $1 \mathrm{rpm}$ during a $15-\mathrm{min}$ residence time, then to the bottom of the clarifier, and passed up through a sludge blanket 4 or $5 \mathrm{ft}$ deep. The clarifier agitator was operated at $0.5 \mathrm{rpm}$. Residence time in the clarifier was 53 min, and the throughput rate was $48 \mathrm{gal} \mathrm{hr}^{-1} \mathrm{ft}^{-2}$. Sludge from the bottom of the clarifier was recycled to the flash mixer at $1.9 \mathrm{liters} / \mathrm{min}$. Sludge from the sludge blanket was removed at the rate required to maintain the sludge level at the top sludge-collection dam, and representative fractions were sent to the sludge filter.

The clarifier effluent was passed through the deep-bed anthracite filter and fed to the ion exchange column ( 8 in. in diameter), which contained $4.4 \mathrm{ft}^{3}$ of sodium-form Duolite CS-100 resin. The resin column was loaded with 2000 bed volumes $(66,000 \mathrm{gal})$ of clarified waste, then removed from the process stream and eluted with $0.5 M \mathrm{HNO}_{3}$. The first 5 bed volumes of acid (165 gal), containing most of the fission products, was held for recycle during the next loading cycle. The second 5 bed volumes of acid would normally be held for the next elution. The 20 bed volumes of $0.1 \mathrm{M} \mathrm{NaOH}$ that was used to return the resin to the sodium form was added to the recycle acid, and the mixture was neutralized before being recycled.

A small $(60-\mathrm{ml})$ column of anion resin (Illco TAD-1) was used in run HR-18 following the cation exchange column (Table 3.9).

Removal of Phosphate and Hardness Ions. About 500,000 gallons of waste water containing 0.5 to $2.0 \mathrm{ppm}$ of phosphate was treated in the alumina column. The phosphate concentration was reduced to 0.1 to $0.7 \mathrm{ppm}$. The phosphate-removal efficiency was more than $50 \%$ for the first 325,000 gal of waste $(10,000$ alumina packed-bed volumes). The reduction in phosphate concentration undoubtedly contributed to the efficient precipitation of hardness in the next step. Over a 32-day period, hardness was reduced to an average of $7 \mathrm{ppm}$ (as $\mathrm{CaCO}_{3}$ ) in the clarifier effluent and to $4 \mathrm{ppm}$ in the filtered effluent. These values are lower than the values (12 to $22 \mathrm{ppm}$ ) obtained in tests on nonradioactive, clean tap water at the same throughput rates (48 gal $/ \mathrm{ft}^{2}$ ) (see below). Factors which may have contributed to this improved performance are (1) the presence in the waste of solids that provide sites for precipitation, (2) the control of phosphate concentration by the alumina column, (3) the presence of Grundite clay in the sludge blanket, and (4) the age and/or history of the sludge blanket.

Removal of Radioactivity. - In all three runs, the treated waste contained less than $2 \%$ of the $\mathrm{MPC}_{\mathrm{w}}$ for continuous occupational (168-hr) exposure for strontium and less than $0.005 \%$ of the $\mathrm{MPC}_{\mathrm{w}}$ for cesium (Table 3.9). Overall decontamination factors were 1225,1772 , and 1407 for strontium and 720,623 , and 2106 for cesium respectively. This is equivalent to 99.92 to $99.94 \%$ strontium removal and to 99.84 to $99.95 \%$ cesium removal. Recycling resin-column eluate and adding Grundite clay before flash mixing resulted in an increase in cesium retention in the sludge from $29 \%$ to over $60 \%$ and possibly resulted in a slight reduction (from $80 \%$ to $72 \%$ ) in the amount of strontium retained. Except for the gross beta activity in run HR-18, more than $50 \%$ of all types of radioactivity fed to the system was retained in the sludge. The low removal of gross beta activity in run HR-18 is attributed to short-lived isotopes known to have been present in the waste.

The third run, HR-19, was continued beyond 2000 bed volumes (the nominal capacity used in cost estimations) to 6250 bed volumes, with no Grundite eluate recycle after 2000 bed volumes. At that time, the hardness content of the resin column effluent had not increased. Gross beta, gross gamma, and total rare earth activities were $1.3,3$, and 0.33 counts $\min ^{-1} \mathrm{ml}^{-1}$, respectively, and the ${ }^{90} \mathrm{Sr},{ }^{137} \mathrm{Cs},{ }^{106} \mathrm{Ru},{ }^{95} \mathrm{Zr}-\mathrm{Nb}$, and ${ }^{60} \mathrm{Co}$ activities were $0.02,3.2,0.13,0.5$, and 2.3 dis $\min ^{-1} \mathrm{ml}^{-1}$ respectively. This is $0.05,1$, $0.7,0.06$, and $0.2 \%$ of the $\mathrm{MPC}_{\mathrm{w}}$ for total rare earths (as ${ }^{91} \mathrm{Y}$ ), ${ }^{90} \mathrm{Sr},{ }^{137} \mathrm{Cs},{ }^{106} \mathrm{Ru}$, and ${ }^{60} \mathrm{Co}$ respectively. Radiation scans of the resin column indicate that the cesium broke through the resin column at about 2600 bed volumes.

In the three runs, the decontamination factors for rare earths were 383,705 , and 657 , averaging 581. The factors for ruthenium were $2.2,2.1$, and 3.5 , averaging 2.6 ; they are of doubtful accuracy because of the low levels of radioactivity. The factors for ${ }^{95} \mathrm{Zr}-\mathrm{Nb}$ and ${ }^{60} \mathrm{Co}$ are similarly low. The use of a small anion exchange resin column after the cation resin column increased the overall decontamination factor for ruthenium and cobalt 
Table 3.9. Radiochemical Data from Scavenging-Precipitation Ion-Exchange Runs to Demonstrate the Use of an Alumina Column for Phosphate Control and the Recycle of Resin Column Eluate and the Addition of Grundite Clay

to Elıminate the Need for Evaporation and Storage of Resin Column Eluate

\begin{tabular}{|c|c|c|c|c|c|c|c|c|}
\hline Run & Gross Beta & Gross Gamma & Total Rare Earths & ${ }^{89-90} \mathrm{Sr}$ & ${ }^{137} \mathrm{Cs}$ & ${ }^{106} \mathrm{Ru}$ & ${ }^{95} \mathrm{Zr}-\mathrm{Nb}$ & ${ }^{60} \mathrm{Co}$ \\
\hline \multicolumn{9}{|l|}{ HR-17 } \\
\hline $\begin{array}{l}\text { Feed (2000 res } 1 \mathrm{n} \text { bed volumes), } \\
\text { dis } \mathrm{m}_{1} \mathrm{~m}^{-1} \mathrm{~m} 1^{-1}\end{array}$ & $29^{a}$ & $7^{a}$ & $11.5^{a}$ & 49 & 7.2 & 0.45 & 2.7 & 1.4 \\
\hline \multicolumn{9}{|l|}{ Recycled eluate, ${ }^{b}$ dis $\mathrm{min}^{-1} \mathrm{~m}^{-1}$} \\
\hline DF of scavenging-precipitation & 4.3 & 2.3 & 7.2 & 4.9 & 1.41 & & & \\
\hline DF of 1 on exchange & 2.6 & $\sim 3$ & $\sim 53.3$ & $\sim 250$ & $>510$ & & & \\
\hline DF overall & 11.2 & $\sim 7$ & $\sim 383.3$ & $\sim 1225$ & $>720$ & & & \\
\hline Percent of $\mathrm{MPC}_{\mathrm{w}}$ in effluent & & & $0.004^{\mathrm{c}}$ & 1.8 & 0.002 & 0.1 & & 0.07 \\
\hline \multicolumn{9}{|l|}{ HR -18} \\
\hline $\begin{array}{l}\text { Feed (2000 resin bed volumes), } \\
\text { dis } \min ^{-1} \mathrm{~m}^{-1}\end{array}$ & $42^{a}$ & $5^{a}$ & $12^{a}$ & 42 & 5.9 & 0.42 & 1.4 & 1.7 \\
\hline Recycled eluate, ${ }^{b} \mathrm{~d} 1 \mathrm{~s} \mathrm{~min}^{-1} \mathrm{ml}^{-1}$ & $5.12^{a}$ & $1.25^{a}$ & $2.09^{a}$ & 11.16 & 6.56 & 0.01 & & 2.67 \\
\hline DF of scavenging-precipitation & 1.8 & 2.08 & 4.27 & 3.54 & 2.71 & 1.9 & & 6.2 \\
\hline DF of ion exchange & 1.18 & 6 & 165 & 500 & 230 & 1.2 & & 1.2 \\
\hline $\begin{array}{l}\text { Percent of } \mathrm{MPC}_{\mathrm{w}} \text { in effluent } \\
\text { (DF using anion exchange, } 300 \text { bed volumes) }\end{array}$ & & & $0.003^{c}$ & 1.4 & 0.005 & $\begin{array}{c}0.09 \\
(5)^{d}\end{array}$ & & $\begin{array}{c}0.05 \\
(1.6)^{e}\end{array}$ \\
\hline (DF overall using anion exchange) & & & & & & $(14)^{d}$ & & $(11)^{e}$ \\
\hline \multicolumn{9}{|l|}{ HR-19 } \\
\hline $\begin{array}{l}\text { Feed (2000 res in bed volumes), } \\
\text { dis } \mathrm{mm}^{-1} \mathrm{ml}^{-1}\end{array}$ & $18.6^{a}$ & $3^{a}$ & $8^{a}$ & 29 & 4.6 & 0.4 & 0.9 & 1.3 \\
\hline Recycled eluate, $^{b}$ dis $\mathrm{min}^{-1} \mathrm{~m}^{-1}$ & $10.68^{a}$ & $1.13^{a}$ & $5.14^{a}$ & 13.2 & 5.93 & 0.008 & 0.01 & 0.08 \\
\hline DF of scavenging-precipitation & 4.35 & 2.1 & 5.3 & 3.8 & 2.5 & & & \\
\hline DF of ton exchange & 5.0 & 6.7 & 125 & 367 & 840 & & & \\
\hline DF overall & 22.5 & 13.8 & 657 & 1407 & 2106 & & & \\
\hline Percent of $\mathrm{MPC}_{\mathrm{w}}$ in effluent & & & $0.003^{c}$ & 1.4 & 0.001 & 0.05 & & 0.05 \\
\hline
\end{tabular}

${ }^{a}$ Counts $\mathrm{min}^{-1} \mathrm{~m}^{-1}$

${ }^{b}$ Calculated from eluate analysis - no recycle during HR-17.

${ }^{c} \mathrm{MPC}_{\mathrm{w}}$ for ${ }^{91} \mathrm{Y}$.

${ }^{d}$ Anion exchange $\mathrm{DF}=1.5$ at 1500 bed volumes.

${ }^{e}$ Anion exchange $\mathrm{DF}=1.0$ at 1500 bed volumes. 
to about 14 and 11 in treating 300 bed volumes of waste. For plants requiring ruthenium decontamination factors higher than about 2.5, the extra cost of the anion exchange system would be justified. On an absolute basis, the decontamination factor for ruthenium can be about 100 times lower than that of strontium since the $\mathrm{MPC}_{\mathrm{w}}$ for ruthenium is approximately that much higher and since the fission yield in curies is about the same.

It was concluded that the process as tested without the anion exchange column was satisfactory for treating wastes similar to ORNL lowlevel wastes since all treated effluents contained less than $2 \%$ of the MPC for drinking water.

Agitated-Clarifier Tests. - A 7-ft-diam nonagitated sludge-blanket clarifier was used in a previous pilot-plant demonstration ${ }^{6,7.27}$ of the removal of radioactivity from low-level process wastes by the scavenging-precipitation ionexchange process. In that clarifier, the influent stream occasionally channeled up through the sludge blanket, causing a sharp increase in the total hardness of the clarifier effluent that resulted in reductions of the on-stream lifetimes of the anthracite polishing filter and the cationexchange resin column. Such a breakthrough of total hardness in the scavenging-precipitation foamseparation column would upset the foam column. Laboratory experiments concerning the head-end treatment of low-level wastes prior to foam separation ${ }^{28}$ indicated that an agitated sludge-blanket clarifier operated at flow rates up to $60 \mathrm{gal} \mathrm{hr}^{-1}$ $\mathrm{ft}^{-2}$ yielded effluents containing less than $5 \mathrm{ppm}$ (as $\mathrm{CaCO}_{3}$ ) total hardness. An agitated clarifier that has a throughput rate of $48 \mathrm{gal} \mathrm{hr}^{-1} \mathrm{ft}^{-2}$ at the pilot-plant feed rate of $10 \mathrm{gpm}$ was installed and tested with tap water feed to which copperas and caustic were added to make the final solution 5 to $10 \mathrm{ppm}$ in $\mathrm{Fe}^{2+}$ and $0.01 N$ in $\mathrm{NaOH}$ (Fig. 3.16, Table 3.10). The clarifier effluent total hardness was higher in the pilot-plant tests, but paralleled laboratory results. At 47 to 48 gal $\mathrm{hr}^{-1} \mathrm{ft}^{-2}$, the pilot-plant clarifier effluent and the laboratory clarifier effluent contained 12 to 16 and 4 to $10 \mathrm{ppm}$ of total hardness respectively. The pilot plant clarifier effluent contained 6 to

\footnotetext{
${ }^{28}$ E. Schonfeld and W. Davis, Jr., Softening and Decontaminating Waste Water by Caustic-Carbonate Precipitants and Filtration in a Slowly.Stired SludgeBlanket Clarifier: Laboratory Development and SemrPlot-Plant Testing, ORNL-TM-835 (Jan. 15, 1964).
}

$10 \mathrm{ppm}$ of total hardness at $24 \mathrm{gal} \mathrm{hr}^{-1} \mathrm{ft}^{-2}$, and the laboratory effluent contained 1.5 to 2.5 $\mathrm{ppm}$ at $20 \mathrm{gal} \mathrm{hr}^{-1} \mathrm{ft}^{-2}$. An additional sludge dam was then installed in the pilot-plant clarifier to allow sludge removal from the top of the sludge blanket in order to provide for good sludgeblanket-level control. Also, four baffles were installed in the bottom cone section of the clarifier. These modifications did not affect the results appreciably (Table 3.10 ).

A study of the effect of agitation on effluent hardness revealed that at a throughput rate of $24 \mathrm{gal} \mathrm{hr}^{-1} \mathrm{ft}^{-2}$, optimal agitation was achieved at $1 \mathrm{rpm}$, with only the lower paddle being used. Increasing or decreasing the agitator speed resulted in high effluent hardness. Agitating with only the lower paddle was beneficial at the 48 gal $\mathrm{hr}^{-1} \mathrm{ft}^{-2}$ throughput rate, and reducing the agitator speed from $1.0 \mathrm{rpm}$ to $0.5 \mathrm{rpm}$ improved hardness removal. Equipment limitations prevented lowering the agitator speed below $0.5 \mathrm{rpm}$ (Table 3.10).

The head-end treatment proposed for the scavenging-precipitation foam-separation process (5 to $10 \mathrm{ppm} \mathrm{Fe}^{3+}, 0.005 M \mathrm{NaOH}$, and $0.005 M$ $\mathrm{Na}_{2} \mathrm{CO}_{3}$ ) was also tested with tap water feed at 5 and at $2.5 \mathrm{gpm}$. The clarifier effluent contained 2 to $3 \mathrm{ppm}$ of total hardness (as $\mathrm{CaCO}_{3}$ ), in good agreement with laboratory tests (Table 3.9). The agitated clarifier operated smoothly, and there was no channeling of liquid through the sludge blanket.

Fixed-Bed Ion Exchange Process. - The fixedbed ion exchange process proposed by Higgins ${ }^{1.29}$ involves the sorption of cationic species of ra. dionuclides (the majority of the radioactivity) and the cations associated with the bicarbonatehardness constituents of the process water on a bed of weak-acid cation exchange resin and a bed of strong-acid cation exchange resin arranged in series. Regeneration of the resin beds by the split-regeneration method results in high regenerant utilization and leaves concentrated waste in the form of neutral salts.

One preliminary test was made in the pilot plant to demonstrate the operability of the equipment and to familiarize the operators with it. Low-level radioactive process waste water was pumped from the ORNL equalization basin through a deep-bed anthracite filter, a $4.4-\mathrm{ft}^{3}$ bed of weak-acid resin

${ }^{29}$ I. R. Higgins, personal communication, January 1963 . 
(IRC-50), and a $4.4-\mathrm{ft}^{3}$ bed of strong-acid resin (Dowex 50W-X8). Column loading was continued until the total hardness $\left(\right.$ as $\mathrm{CaCO}_{3}$ ) of the system effluent was $50 \%$ of the total hardness of the feed. The resin columns were then regenerated with fresh nitric acid. After 1000 bed volumes (the flowsheet quantity) of process waste was pumped through the resin column and just before cesium breakthrough from the strong-acid resin (Dowex 50) column, average decontamination factors for gross beta, gross gamma, cesium, strontium, cobalt, and total rare earths were $25,1.4,35,2766,1.0$, and 134 respectively. Plant effluent, which was strongly tinted green, contained $0.05,1.4,1.5$, 0.09 , and $0.25 \%$ of the $168-\mathrm{hr} M \mathrm{MPC}_{\mathrm{w}}$ for ${ }^{137} \mathrm{Cs}$, ${ }^{90} \mathrm{Sr},{ }^{103-106} \mathrm{Ru},{ }^{95} \mathrm{Zr}-\mathrm{Nb}$, and ${ }^{60} \mathrm{Co}$ res pectively.

The process effluent during this test contained less than the maximum permissible concentration of all radionuclides. However, the effluent did contain algae (it was strongly tinted green), and

Table 3.10. Performance Tests with Tap Water in Agitated Clarifier in Low-Level Radioactive Waste Pilot Plant

Tap water feed contaned 100 to $120 \mathrm{ppm}$ total hardness (as eq. of $\mathrm{CaCO}_{3}$ ) and had pH of 7.2 to 7.8

Copperas, caustic, soda ash, and recycle sludge added to flash mixer

Speed of agitator in flocculator, $1 \mathrm{rpm}$

\begin{tabular}{|c|c|c|c|c|c|c|}
\hline $\begin{array}{c}\text { Tap Water } \\
\text { Feed Rate } \\
\text { (gpm) }\end{array}$ & $\begin{array}{l}\text { Agitated Clarifier } \\
\text { Throughput Rate } \\
\left(\text { gal hr }{ }^{-1} \mathrm{ft}^{-2} \text { ) }\right.\end{array}$ & $\begin{array}{c}\text { Clarif ier } \\
\text { Agitator Speed } \\
\text { (rpm) }\end{array}$ & $\begin{array}{l}\text { Copperas } \\
\text { Concentration } \\
\left(\mathrm{ppm} \mathrm{Fe}^{2+}\right)\end{array}$ & $\begin{array}{c}\text { Sludge } \\
\text { Recycle Rate } \\
\text { (11ters } / \mathrm{m} 1 \mathrm{n})\end{array}$ & $\begin{array}{c}\text { Clarifier } \\
\text { Effluent } \mathrm{pH}\end{array}$ & $\begin{array}{c}\text { Average Clarıfier } \\
\text { Effluent } \\
\text { Total Hardness } \\
\text { (ppm eq. to } \mathrm{CaCO}_{3} \text { ) }\end{array}$ \\
\hline
\end{tabular}

Scavenging-Precipitation Ion Exchange; Caustic Added to Make Solution $0.01 M$ in $\mathrm{NaOH}$

\begin{tabular}{lllllll}
\multicolumn{7}{l}{ Sludge Removed from Lower Dam; Upper Dam and Baffles Not Installed } \\
10 & 48 & 1 & 5 & 1.9 & 11.3 & $12-15$ \\
10 & 48 & 1 & 10 & 1.9 & 12.1 & $12-16$ \\
7.5 & 36 & 1 & 5 & 1.4 & $11.8-12$ & $7-10$ \\
5 & 24 & 1 & 5 & 0.9 & 12.0 & $\sim 10$ \\
5 & 24 & 1 & 10 & 0.9 & $11.5-11.8$ & $6-8$
\end{tabular}

10

10

5

5

$10 \quad 48$

524

524

524

524

524

$10 \quad 48$

Sludge Removed from Upper Dam; Baffles Installed in Conical Bottom

\begin{tabular}{|c|c|c|c|c|c|}
\hline 48 & 1 & 5 & 1.9 & $11.8-12.0$ & $14-17$ \\
\hline 48 & 1 & 10 & 1.9 & 12.1 & $19-22$ \\
\hline 24 & 1 & 5 & 0.9 & $12-12.2$ & $8-9$ \\
\hline 24 & 1 & 10 & 0.9 & $11.9-12.0$ & $6-7$ \\
\hline
\end{tabular}

Upper Agitator Paddle Removed

$\begin{array}{rlrrrr}48 & 1 & 5 & 1.9 & 11.9-12.0 & 13.8 \\ 24 & 1 & 5 & 0.9 & 11.9-12.2 & 4.1 \\ 24 & 0.5 & 5 & 0.9 & 12.0-12.2 & 4.2 \\ 24 & 1.5 & 5 & 0.9 & 12.0-12.1 & 4.4 \\ 24 & 2 & 5 & 0.9 & 12.0-12.1 & 6.7 \\ 48 & 3 & 5 & 0.9 & 12.0-12.1 & 8.3 \\ & 0.5 & 5 & 1.9 & & 11.8\end{array}$

Scavenging-Precipitation Foam Separation; Caustic and Soda Ash Added to Make Solution $0.005 \mathrm{M}$ in $\mathrm{NaOH}$ and $0.005 \mathrm{M}$ in $\mathrm{Na}_{2} \mathrm{CO}_{3}$

Upper Agitator Paddle Removed

$\begin{array}{lllllll}5 & 24 & 0.5 & 10 & 0.9 & 11.2-11.3 & 2.7 \\ 2.5 & 12 & 0.5 & 10 & 0.5 & 11.2-11.3 & 2.3 \\ 5 & 24 & 0.5 & 10 & 0.9 & 11.2-11.5 & 1.5\end{array}$


UNCLASSIFIED ORNL-LR-DWG 7B656A

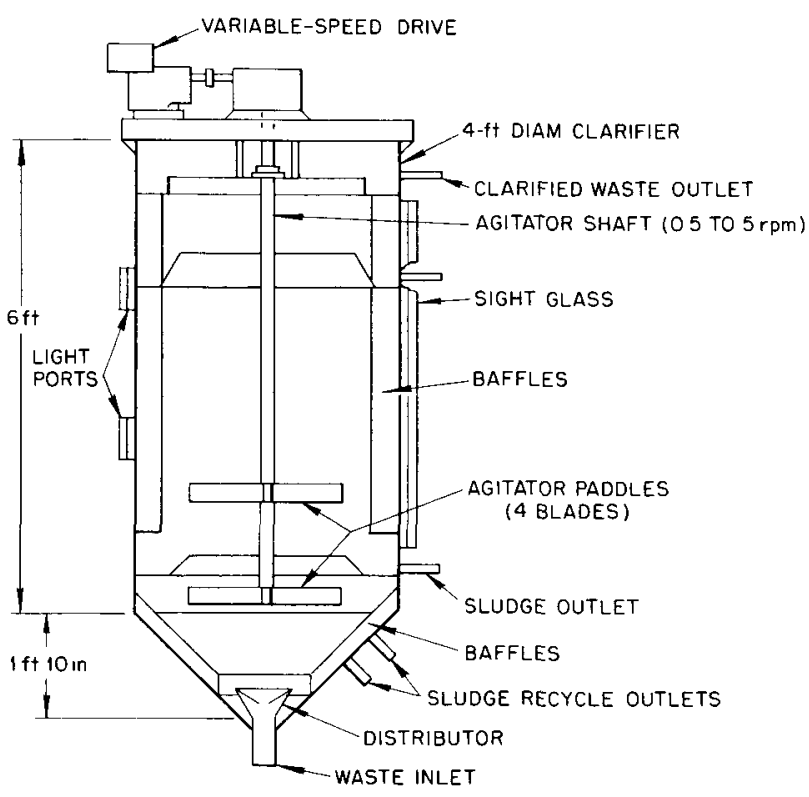

Fig. 3.16. Modified Clarifier.

radioactivity is known to concentrate in algae that accumulate in the ORNL storage canals. It is felt, therefore, that a clarification pretreatment, such as a scavenging-precipitation, will be required for this process.

Cost Estimates for the Improved ScavengingPrecipitation Ion-Exchange Process. - A cursory cost estimate was prepared in accordance with the initial results from the current pilot-plant program. A detailed estimate will be made at the end of the program when all the data are available. Costs of $71.6,78.4,91.3$, and $131.6 \phi$ per 1000 gal were estimated for the original scavengingprecipitation phenolic-resin ion-exchange process for $2000,1500,1000$, and 500 bed volumes per resin cycle respectively. ${ }^{6}$ The number of bed volumes per cycle, based on obtaining minimum decontamination factors of 1000 for strontium and 100 for cesium, varied over this range in the original pilot-plant test ${ }^{6}$ as a result of fluctuations in the phosphate concentration in the waste. Excessively high phosphate concentrations occasionally caused insufficient hardness removal in the scavenging-precipitation-filtration head-end step and consequent premature breakthrough of radioactivity from the ion exchange column. Although the costs calculated for treatment of an average of 1500 resin bed volumes of waste per resin bed cycle were economically attractive, it is desirable to optimize the process. Phosphate should be consistently removed to a level of $1 \mathrm{ppm}$ or less to eliminate occasional early breakthrough of radioactivity when high phosphate concentrations occur and to make it economical to process waters that consistently have high concentrations of phosphate. If hardness removal is maximum, the number of bed volumes treated approaches 2600 before cesium breakthrough occurs and is limited by the sodium concentration. For waters in which strontium is the limiting radionuclide, more than 6000 bed volumes can be treated if hardness removal before ion exchange is efficient (see pilot-plant tests above).

Laboratory and pilot-plant tests showed that phosphate can be removed by sorption on activated alumina to a level of $1 \mathrm{ppm}$ or less. The added cost is estimated as $7 \phi$ per 1000 gal, based on $2 \phi$ in fixed costs, $1 \phi$ in chemical costs, and $4 \phi$ in waste-handling costs (same basis as in Ref. 6). This cost would apply, however, only to waters containing excessive amounts of phosphate. This method is much less expensive than one calling for the use of sodium carbonate. The total process cost, using carbonate addition, was estimated to be $\$ 1.02$ per 1000 gal, $^{6}$ partly due to increased chemical cost and partly due to the reduction of column capacity to 1000 bed volumes.

The use of the Grundite-clay regenerant recycle also has a clear cost advantage. In accordance with the previous estimate as a basis, ${ }^{6}$ the elimination of regenerant waste evaporation and tank storage of evaporator concentrate decreased the cost by $15 \phi$ for treating 2000 bed volumes, and $20 \notin$ for treating 1500 bed volumes. Cost increases were $3 \phi$ for sludge burial and $1 \phi$ for fixed and chemical costs, a total of $4 \phi$.

The net cost for the revised scavenging-precipitation ion-exchange process using alumina and the Grundite-regenerant recycle is $66 \phi$ per 1000 gal for treating about 2000 resin bed volumes of waste, with minimum DF's of 1000 and 100 for strontium and cesium respectively. This includes $34 \phi$ for fixed costs, $22 \phi$ for chemical costs, and $10 \phi$ for waste handling costs. If phosphate removal is not required, the total cost is about $60 \phi$ per 1000 gal. If strontium is limiting, instead of cesium, and if 6000 resin bed volumes are treated per cycle, the total cost is about $56 \phi$ per 1000 gal. 


\section{Scavenging-Precipitation Foam-Separation Process}

Laboratory Studies. - Two methods for decontaminatıng low-level radioactive process waste water by foam separation were examined: (1) The two-step process, in which most of the hardness (calcium and magnesium ions) is first precipitated in a sludge bed by making the water $0.005 \mathrm{M}$ each in sodium hydroxide and sodium carbonate in the presence of 2 to $9 \mathrm{ppm}$ of ferric ion scavenger. Further purification of the clarified effluent is then achreved by adding, as the sodium salt, 60 to $70 \mathrm{ppm}$ of dodecylbenzene sulfonate (DBS) surfactant in a countercurrent foam column. (2) The one-step process, in which caustic-sodium orthophosphate precipitant, ferric ion scavenger, surfactant, and a flotation agent (such as Armeen Z) are all added together. The slurry thus formed (containing strontium in a solid state) and the dissolved strontium are then removed as a combination of foam and froth.

Two-Step Process. - Most of the development work reported here deals with the two-step process (see $F_{1 g} .3 .23$ in ref. 1), in which overall strontium decontamination factors up to $10^{4}$ and $10^{2}$ were attained with tap water and waste water feeds, respectively, when the foam condensate was recycled. (These values were about two to four tımes higher when the foam condensate was not recycled.) Average DF's obtaned for other radionuclides in three $12-\mathrm{hr}$ waste water runs were: ${ }^{137} \mathrm{Cs}, 1.2$ to $1.9 ;{ }^{60} \mathrm{Co}, 5$ to $15 ;{ }^{106} \mathrm{Ru}, 3$ to 10 ; ${ }^{144} \mathrm{Ce}, \geqq_{10}^{2}$; and ${ }^{95} \mathrm{Zr}-\mathrm{Nb}, 2$ to 23 . None of these values is necessarily the maximum possible.
Radiochemical analyses were done by resolving the complex spectra obtained with a 256-channel gamma-ray spectrometer using the method of least squares. ${ }^{30}$

Densities of the sludge in a suspended-bed clarifier were measured for a bed 10 to $13 \mathrm{~cm}$ deep at a water flow rate of $20 \mathrm{gal} \mathrm{ft}^{-2} \mathrm{hr}^{-1}$. Calcium and magnesium concentrations decreased by a factor of 5 to 5.5 from the bottom to the top of the bed, while the concentration of ferric ion decreased by a factor of 3.5 . The concentrations of each of these elements in slurry samples taken at the bottom, middle, and top of the bed are summarized in Table 3.11.

Increasing the flow rate threefold (from 20 to 60 gal $\mathrm{ft}^{-2} \mathrm{hr}^{-1}$ ), when $0.01 M \mathrm{NaOH}$ (no carbonate) was used as the precipitant, decreased the bed density by a factor of 2 to 2.5 (Table 3.12).

Recycle of foam to the sludge-bed premixer produced no mechanical difficulties, but an increase in the entrainment of solids in the effluent was noted in waste water runs. This apparently reduced the efficiency of strontium removal in the foam column. Also, the surfactant, dodecyc1benzene sulfonate (DBS), accumulated in the solid phase of the sludge, probably as calcium and magnesium dodecyclbenzene sulfonates.

Phosphate, even in the few-parts-per-million range, interferes with the precipitation of calcium, ${ }^{9}$ which, in turn, adversely affects strontium removal by the foam column.

${ }^{30}$ E. Schonfeld, unpublished data.

Table 3.11. Distribution of Iron and Total-Hardness Cations in the Sludge Bed

Conditions: Flow rate, $20 \mathrm{gal} \mathrm{ft}^{-2} \mathrm{hr}^{-1}$

$0.005 M \mathrm{NaOH}-0.005 \mathrm{M} \mathrm{Na}{ }_{2} \mathrm{CO}_{3}$, except where noted

\begin{tabular}{|c|c|c|c|c|}
\hline Sample Point & $\begin{array}{c}\text { Total Hardness } \\
\left.\text { (as } \mathrm{CaCO}_{3}\right) \\
\text { (g/1iter) }\end{array}$ & $\begin{array}{c}\text { Calcium } \\
\left(\text { as } \mathrm{CaCO}_{3}\right) \\
\text { (g/1iter) }\end{array}$ & $\begin{array}{c}\text { Iron } \\
\text { (g/liter) }\end{array}$ & $\begin{array}{c}\mathrm{CaCO}_{3} \text { in Total Hardness } \\
(\%)\end{array}$ \\
\hline Bottom & 16.70 & 12.02 & 1.355 & 73 \\
\hline Middle & 11.34 & 6.66 & 0.845 & 59 \\
\hline Top ${ }^{a}$ & 3.35 & 2.19 & 0.390 & 65 \\
\hline
\end{tabular}

\footnotetext{
${ }^{a} 0.01 M \mathrm{NaOH}$, no carbonate.
} 
Table 3.12. Effect of Increasing the Flow Rate of the Feed on Density of the Sludge Bed

Precipitant: NaOH, sufficient to make the feed $0.01 M$

\begin{tabular}{ccccc}
\hline $\begin{array}{c}\text { Flow Rate of Feed to the } \\
\text { Sludge Bed } \\
\left(\mathrm{gal} \mathrm{ft}^{-2} \mathrm{hr}^{-1}\right)\end{array}$ & $\begin{array}{c}\text { Tota1 Hardness, } \\
\text { as } \mathrm{CaCO}_{3} \\
(\mathrm{~g} / 1 \mathrm{lter})\end{array}$ & $\begin{array}{c}\text { Calcium, as } \\
\mathrm{CaCO} \\
(\mathrm{g} / 1 \mathrm{lter})\end{array}$ & $\begin{array}{c}\text { Ferric Iron } \\
(\mathrm{g} / 1 \text { ter })\end{array}$ & $\begin{array}{c}\mathrm{CaCO}_{3} \text { in Total } \\
\text { Hardness } \\
(\%)\end{array}$ \\
\hline 20 & 3.35 & 2.19 & 0.39 & 63 \\
47 & 2.00 & 1.25 & 0.28 & 62.5 \\
60 & 1.40 & 0.88 & 0.20 & 62.5 \\
\hline
\end{tabular}

Phosphate can be temporarıly removed as a ferric phosphate if the ferric ion is added while the $\mathrm{pH}$ of the water is low (5 to 8 ), rather than when the $\mathrm{pH}$ is high, as would be the case after the addition of caustic-carbonate, which causes calcium to precipitate as the carbonate. At the high final $\mathrm{pH}$ (11.3), the ferric phosphate gradually redissolves and thus increases the amount of soluble phosphate ion avallable for inhibiting the precipitation of calcium. For this reason, in prolonged operation (several days) under high-phosphate conditions, no important gain is realized from separate iron addition. The final soluble phosphate concentration in the sludge column would slowly approach the same value it would have were the ferric ion and caustic-carbonate added simultaneously to a high-phosphate feed. The effect of separate iron addition was more pronounced for simulated waste (tap water containing $5 \mathrm{ppm}$ of phosphorus as sodium orthophosphate) than for actual waste water, which contained 1 to $5 \mathrm{ppm}$ of phosphorus as mixed ortho-, meta-, and polyphos phates. ${ }^{10}$

Also worth noting is a brief study that indicated that the algae in waste water tend to concentrate phosphates, which could then be readily removed by filtration in a sludge bed or by flotation in a foam column.

The addition of 0.3 to $0.6 \mathrm{lb}$ of Grundite clay per $1000 \mathrm{gal}$ of feed water removed about 85 to $90 \%$ of the cesium in the sludge bed but had little or no effect on the removal of strontium. Baking the clay for $20 \mathrm{~min}$ at $600^{\circ} \mathrm{C}$ almost doubled the sludge-bed DF for cesium - from about 7 or 8 to almost 15. Asbestos CMS (a refined asbestos product of Union Carbide Corp.) and purified mag- nesium ammonium phosphate powder were found to be 4.5 to 15 times less effective for sorbing cesium than untreated Grundite clay of even larger particle size ( $>50$ mesh).

Attempts to enhance cesium decontamination in the foam column by complexing it with surfactants having good foaming properties and active phenolic groups in basic solution failed in a single-stage column. RWA-100 (a monobutyl phenylphenol sodium sulfonate), hexachlorophene, dichlorophene, and each of these in combination with dodecylbenzene sulfonate (DBS) were tested. These were chosen because they had shown selective cesium-complexing ability at $\mathrm{pH} 12$ or higher in 1on exchange or solvent extraction systems containing high concentrations of sodium. They showed no selectivity in the foam-column studies.

The foam-column parameter, $V / L D$ (where $V$ and $L$ are the gas and liquid flow rates, respectively, in cubic centimeters per minute and $D$ is an average bubble diameter, in centimeters), which is proportional to the extraction factor, must exceed 150 if adequate strontium DF's (at least 100) are to be achieved in the foaming step. Correlation of this function with DF's for other radionuclides in process waste water has not been done to date. However, in runs with tap water that contained only ${ }^{137} \mathrm{Cs}$ tracer, $V / L D$ values in the range 250 to 350 were not sufficient for cesium extraction.

A semiquantitative comparison was made of the biodegradability of the branched-chain alkylbenzene sulfonates (ABS) present in (1) waste water from unknown commercial cleaning compounds, (2) Fab, and (3) Trepolate F-95. After 
two to three weeks, all the specimens had been degraded to an average extent of about $50 \%$.

One-Step Process. - Improvement of the onestep process yielded strontium DF's ${ }^{31}$ of 250 to 450. New flotation agents superior to Armeen $Z$ were also found. Costs for chemicals are too high for the one-step process to be competitive with other available decontamination methods. Further laboratory development work has been suspended.

Engineering Studies. - Engineering studies for the design and operation of separation columns using countercurrent flow of a stable foam and a liquid were completed. Specific problems for a low-level radioactive waste treatment pilot plant were investigated.

Feed Distributor. - A feed distributor, designed to give 37 feed streams on about a $3 \frac{3}{4}-1 n$. triangular spacing in a 24-1n.-diam column, gave uniform flows, low discharge velocities, and reduced channeling to the degree required for largediameter foam columns. Parallel, horizontal 3/81n.-OD tubes were spaced across the column, with 0.037-1n.-diam metering orifices and baffles to give a low discharge velocity.

The effects of dodecylbenzene sulfonate and $\mathrm{Na}^{+}$ concentrations on foam stability in a 24-1n.-diam column with a 48-1n. foam height were studied at various gas and liquid flow rates. The low-levelwaste foam column should have a stable foam when the liquid contains $25 \mathrm{ppm}$ of dodecylbenzene sulfonate; at $10 \mathrm{ppm}$, gross bubble growth occurred, and over three-fourths of the surface generated was lost.

Orifice Foam Breaker. - The idea of an orifice as a foam breaker was developed from consideration of the foam-breaking mechanism in a previously tested sonic cyclone and centrifugal foam breakers. Since sharp pressure changes and even pressure discontinuities are possible in an orifice, the performance of orifices as foam breakers was tested.

Experimental data was collected for four orifice diameters, using foam from extra-coarse-porosity, fritted-glass disk gas spargers. Foam generated from a 200- to 275-ppm Trepolate F-95 solution was drawn through the orifice by vacuum, with the top of the column vented to the atmosphere.

\footnotetext{
${ }^{31}$ E. Rubin, E. Schonfeld, and J. Weinstock, Removal of Metallic Ions by Foaming Agents and Suspensions: Laboratory and Engineering Studies, RAI-116 (December 1963).
}

The amount of uncondensed foam was measured by operating the orifice for 2 to $5 \mathrm{~min}$ and then venting the vacuum pot and discharging the liquid and foam into a graduate. The orifice diameter, the foam rate, the pressure drop across the orifice, the foam density, the distance from the orifice to the vacuum chamber wall, and the wall material were varied.

Foams were easily condensed by an orifice, with residual foam volumes being about a thousandth of those of the inlet volumes for welldrained foams. Pressure drops from atmospheric for the inlet foam to $1 / 2$ atm in the vacuum pot were adequate. The same pressure ratio would probably apply at other pressures (1.e., an upstream-todownstream pressure ratio of 2 is probably adequate). With the inlet foam at atmospheric pressure, condensation was less complete for a 30 - or 25-cm $\mathrm{Hg}$ pressure drop, compared w1th a pressure drop of 50 or $65 \mathrm{~cm}$ of $\mathrm{Hg}$, and became very poor for lower pressure drops.

Thus, condensation occurs as the bubbles pass through the orifice, and orifices smaller than the bubble and impingement of the bubbles on a surface are not necessary. The condensation of foam was about equally efficient for 0.015 - and $0.250-\mathrm{cm}-\mathrm{d}_{1}$ am orifices. The $0.015-\mathrm{cm}-\mathrm{d}_{1}$ am orifice was smaller than nearly all the bubbles, while the $0.250-\mathrm{cm}$-diam orifice was larger (mean bubble diameters of 0.05 to $0.08 \mathrm{~cm}$ ). For most tests, the stream from the orifices impinged on a Teflon sheet placed 2 to $3 \mathrm{in}$. from the orifice. The amount of uncondensed foam was slightly decreased by placing the orifice $24 \mathrm{in}$. from the Teflon sheet. The amount of uncondensed foam was slightly greater for a glass surface in place of the Teflon sheet. It appeared that the foam bubbles broke before they hit the surface and that the liquid striking the surface caused some formation of new foam bubbles, depending on the material and position of the surface.

Solution Flow. - The laminar flow of solution in the continuous liquid phase between stable foam bubbles was studied. The model used for the foam structure postulates that most of the flow of liquid through the foam is in the spaces enclosed by three bubbles (Plateau borders). The foamdrainage models in the literature did not adequately describe the Plateau borders and used empirical constants to describe the experimentally observed foam drainage. Equations and theoretical constants derived in this investigation show good agreement 
with experimental results for several foam-drainage situations. The equations fit new experimental results and data in the literature for the accumulation of solution below a stationary bed of foam. The density and drainage of foam were correlated for countercurrent, vertical flow of foam and liquid, and for continuous time steady-state discharge of foam flowing vertically or horizontally through drainage chambers. The principal variables were average foam bubble diameters of 0.3 to $1.5 \mathrm{~mm}$, average foam densities of 0.001 to $0.34 \mathrm{~g} / \mathrm{cm}^{3}$, the dimensions of the foam beds or drainage chambers, and superficial foam or liquid velocities of 0 to 1.0 and 0 to $0.35 \mathrm{~cm} / \mathrm{sec}$ respectively. These experimental results were obtained in 6-in.-ID foam columns and in a 24-in.-diam column operated with flows up to $80 \mathrm{liters} / \mathrm{min}$ for foam and 13 liters $/ \mathrm{min}$ for liquid.

A square, Lucite foam column was operated with a size ( $4 \times 4$ in.) and conditions to represent one liquid feed orifice unit of the low-level-waste pilot-plant column. Tests have shown that a stable flow regime may be expected. At a feed rate of $400 \mathrm{ml} / \mathrm{min}$ (equivalent to a pilot-plant rate of $5 \mathrm{gpm}$ ), channeling and flow inversions are observed, as would be expected from a predicted "flooding rate" of $2.8 \mathrm{gpm}$.

Pilot-Plant Design. - A foam-separation pilot plant has been designed and is currently being installed in the ORNL Low-Level-Waste Pilot Plant. The process will be tested using ORNL low-level waste, which is representative of similar wastes produced at most installations. A general flowsheet is shown in Fig. 3.17. The precipitation equipment used for the ion exchange process will also be used for the foam process (see Sect. 3.2, Pilot-Plant Tests). In this case, a carbonate precipitation $\left(0.005 \mathrm{M} \mathrm{Na}_{2} \mathrm{CO}_{3}, 5 \mathrm{ppm}\right.$ copperas) is used to remove hardness ions (calcium, magnesium, etc.), and Grundite clay ( $0.5 \mathrm{lb} / 1000 \mathrm{gal})$ is used to sorb cesium. After clarification and filtration through the anthracite filters, waste will be fed to the foam-separation columns shown in Fig. 3.17.

The process equipment includes a countercurrent foam column ( $2 \mathrm{ft}$ square and $14 \mathrm{ft}$ high) for decontamination of the waste, three recovery columns in series for the removal and recycle of surfactant from the waste effluent before discharge, and two types of foam-breaking equipment (orifices and a centrifugal foam breaker). The ait system for the generation of foam in the countercurrent and recovery columns includes a Nash vacuum pump, which maintains a closed circulation of air to prevent the release of contamination from the process. The only gas requiring cleanup will be the excess gas bled from the system through the water seal in order to control the system inventory. This will be discharged to the pilot-plant scrubber and the building-ventilation-system filters. Air for the distributors in the foam columns is supplied by the vacuum pump at a controlled volume and pressure. Excess air over that required by the distributors is bypassed to the air header and is then distributed to the foam section of the recovery columns, where it mixes with the air from the recovery column distributors. This arrangement provides more air for sweeping the foam out of the columns into the orifice foam breakers, and it also provides a constant air flow rate through the orifices. Consequently, changes in orifice size to compensate for changes in the air fed to the distributors will not be necessary. Air fed to the countercurrent column is separated from the foam in the centrifuge foam breaker and then fed to the air header, where it mixes with the bypass air stream.

Details of the foam columns are shown in Fig. 3.18. The countercurrent column is $2 \mathrm{ft}$ square and has about $8 \mathrm{ft}$ of countercurrent contacting height. Foam is generated by nine 3-in.-diam spinnerets immersed in a 24-in.-deep pool of water. Each spinneret has 4174 holes, $60 \mu$ in diameter, for distributing the air for foam generation. Liquid from the bottom of the column is fed continuously to the recovery columns, where the surfactant is stripped, and then recycled back to the bottom of the countercurrent column. The countercurrent column feed distributor consists of $\operatorname{six} 3 / 8$-in.-diam pipes with six orifices drilled along each pipe, making a total of 36 orifices. The orifice diameter is 0.052 in. A small baffle is provided below each orifice to prevent the jet of liquid from impinging directly on the foam. As the foam rises above the feed distributor, it enters a short vertical drying section and then a 6 -ft-long baffled horizontal drying section. These sections provide sufficient residence time for entrained liquid to drain from the foam, thus increasing the overall volume reduction for the system. Liquid drained from the horizontal drying section is redistributed in the column by a distributor positioned just below the main feed distributor. Foam leaving the drying section will be collapsed in the centrifugal foam breaker. 
Recovery of the surfactant is accomplished in a series of three 2-ft square foam columns adjacent to the countercurrent column. Each column is 44 in. high, with a 24-in.-deep liquid pool and a large foam outlet nozzle positioned just above the liquid level to prevent foam collapse before it leaves the column. The foam is collapsed while passing through orifices in these nozzles. Liquid introduced in the top column flows to the lower columns through sealed downcomers. The liquid from the bottom column is the decontaminated waste that has been stripped down to contain less than $5 \mathrm{ppm}$ of surfactant. Air distribution in each recovery column is accomplished with four Micro Metallic stainless steel spargers. The average mean pore-size opening in the spargers is $10 \mu$ (grade G). Foamate from all three recovery columns is recycled continuously to the countercurrent column.

The maximum design capacity of the system will be about $5 \mathrm{gpm}$ of ORNL low-level waste. The liquid pumps and the Nash vacuum pump have been sized to handle this feed rate, but lower throughput rates and a wide range of air-to-liquid ratios can also be studied in this equipment.

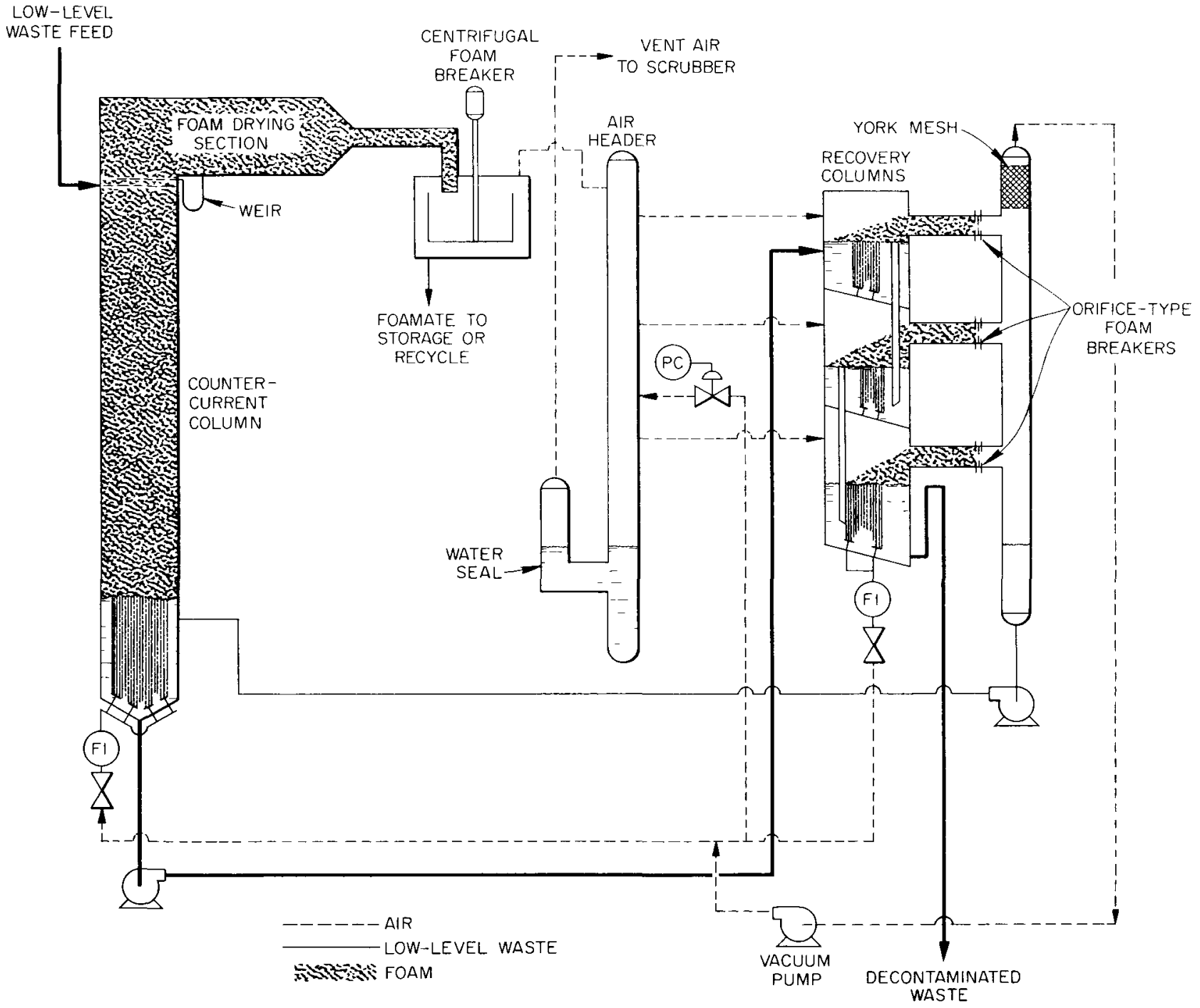

Fig. 3.17. Foam-Separation Pilot Plant. 
UNCLASSIFIED
ORNL DWG $64-578$

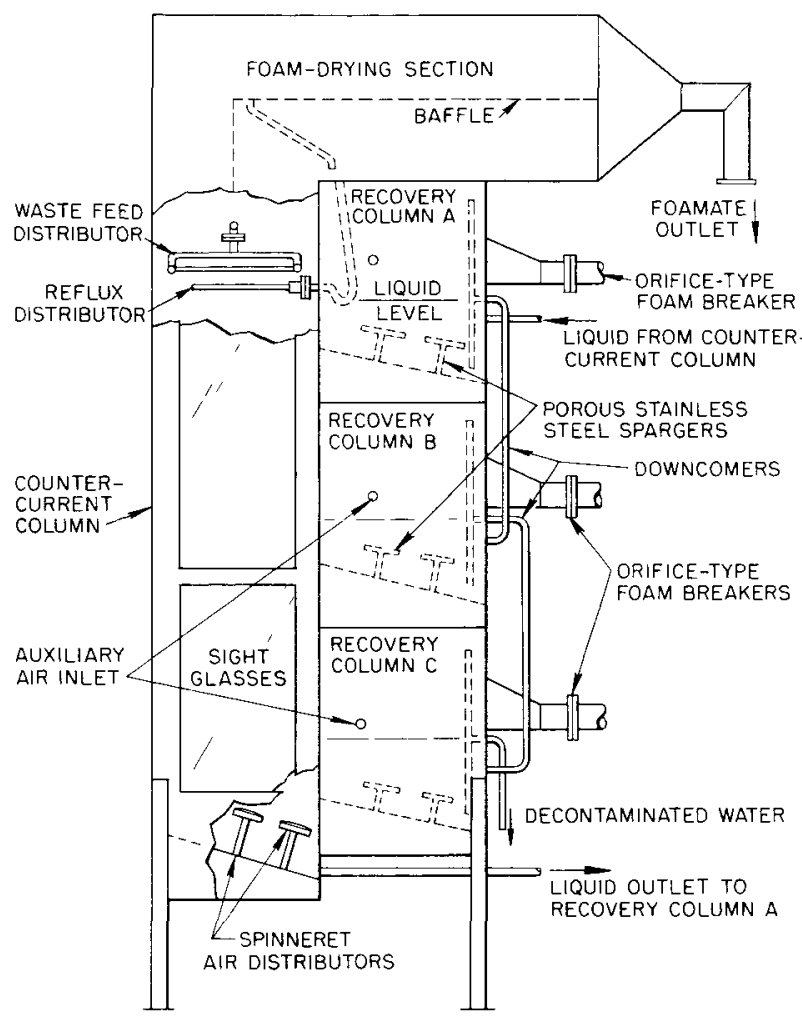

Fig. 3.18. Details of Foam Columns.

\subsection{DISPOSAL OF INTERMEDIATE-LEVEL RADIOACTIVE WASTE}

Simple, safe, and inexpensive methods are needed to store wastes whose radioactivity level is low enough that heat generation is not a problem but whose radioactivity level is high enough that they cannot be discharged to the environment. One method to reduce the volume and decrease the solubility of liquid concentrates and sludges is to eliminate the water and coat the dried solids with a cheap inert material. Incorporation of such wastes in asphalt or tar appears to be simple, inexpensive, relatively insensitive to the type of material being coated, and, within limits, independent of local geologic and hydrologic conditions. The product is easily shipped to a burial ground in a controlled area. Other methods, such as storage of concentrated solutions or storage of the solids from these solutions after various drying schemes, do not seem to offer the unique combination of advantages ascribed to asphalt.
Evaporator concentrates and sludges corresponding to miscellaneous wastes from an atomic center were incorporated in cement and emulsified asphalt. The waste slurries or solids are first mixed with the asphalt at room temperature. The temperature is then raised to $160^{\circ} \mathrm{C}$ to volatilize the water, leaving the solids encased in asphalt. In a plant facility the product would be transferred to a steel barrel before cooling. These studies showed that waste solutions or sludges are more easily incorporated (at lower temperatures and with less stirring) into emulsified asphalt than into asphalts such as those used at Mol, Belgium, ${ }^{32}$ which are almost rigid at room temperature. [ The asphalt paving emulsion used in our studies is defined in Federal Specification SS-A-674b (Emulsion Paving Asphalt) as type RS-2: a rapidsetting, high-viscosity, emulsified asphalt for surface treatment. The material used contained 35 wt \% water.] These studies also showed that volume reduction factors (volumes of waste solution per volume of product) were as high as 2 for products prepared from emulsified asphalt, while they were usually less than 1 for products prepared from Portland cement (Table 3.13). They also showed that the leach rates of ${ }^{137} \mathrm{Cs}$ and sodium were about 100 times greater for the cement products than for the asphalt products (Table 3.13). The leach rate (in distilled water at $25^{\circ} \mathrm{C}$ ) of ${ }^{137} \mathrm{Cs}$ from an asphalt product containing $20 \mathrm{wt} \%$ solids from simulated ORNL waste evaporator bottoms (Table 3.13 ) was $5.5 \times 10^{-5} \mathrm{~g} \mathrm{~cm}^{-2}$ day $^{-1}$ at the end of two weeks, while the rate from a product containing $62 \mathrm{wt} \%$ solids was $7.3 \times 10^{-4}$ at the end of two weeks. Experiments thus far indicate that the leach rate is affected more by the percentage of solids and by the species being leached ( $\mathrm{Cs}$ and $\mathrm{Na}>\mathrm{Ru}$ and $\mathrm{Sr}$ ) than by the type of leach test (i.e., flowing water vs stagnant water). The term "leach rate" rather than "dissolution rate" is used since the asphalt matrix does not dissolve. Leach rates were calculated by using the expression:

$$
\frac{\text { Activity leached } / \mathrm{cm}^{2} / \text { day }}{\text { Activity } / \mathrm{g} \text { of product }}=\mathrm{g} \mathrm{cm}^{-2} \text { day }^{-1} \text {, }
$$

\footnotetext{
${ }^{32} \mathrm{P}$. Dejonghe et al., Insolubilization of Radioactive Concentrates by A sphalt Coating; Final Report No. 2, 1st Part, Concerning Proposal 167, April 1, 1961, to March 31, 1963, EURAEC-695.
} 
fraction of activity leached per unit area per unit time for $1 \mathrm{~g}$ of product.

Possible disadvantages of an asphalt matrix may be its low melting temperature and stability toward radiation. Workers here ${ }^{33}$ concluded that,

${ }^{33}$ C. D. Wats on, A. J. Horberg, and G. A. West, Ind. Eng. Chem. 50, 87A-90A (1958).

Table 3.13. Incorporation of Intermediate-Level

Radioactive Waste Solution ${ }^{a}$ in Cement and Asphalt

\begin{tabular}{lcc} 
& Cement & Asphalt \\
\hline Volume reduction factor & 0.6 & 2.0 \\
Wt \% solids from waste solution & 24 & 62 \\
Leach rate after ten weeks, $^{b}$ & & \\
$\mathrm{~g} \mathrm{~cm}^{-2}$ day $^{-1}$ & & \\
$\mathrm{Na}$ & $4 \times 10^{-2}$ & $3 \times 10^{-4}$ \\
${ }^{137} \mathrm{Cs}$ & $3 \times 10^{-2}$ & $2 \times 10^{-4}$ \\
${ }^{106} \mathrm{Ru}$ & $\mathrm{c}$ & $6 \times 10^{-7}$ \\
${ }^{85} \mathrm{Sr}$ & $3 \times 10^{-3}$ & $d$ \\
${ }^{\text {Density, } \mathrm{g} / \mathrm{cm}^{3}}$ & 1.6 & 1.5 \\
\hline
\end{tabular}

${ }^{a}$ Molar composition: $6.61 \mathrm{Na}^{+}, 0.19 \mathrm{NH}_{4}{ }^{+}, 0.22 \mathrm{Al}^{3+}$, $0.35 \mathrm{SO}_{4}{ }^{2-}, 0.056 \mathrm{Cl}^{-}, 2.06 \mathrm{OH}^{-}$, and $4.64 \mathrm{NO}_{3}{ }^{-}$.

${ }^{b}$ Calculated according to the expression:

$$
\frac{\text { Activity leached } / \mathrm{cm}^{2} / \text { day }}{\text { Activity } / \mathrm{g} \text { of product }}=\mathrm{g} \mathrm{cm}^{-2} \mathrm{day}^{-1} \text {. }
$$

${ }^{c}$ No test made with ${ }^{106} \mathrm{Ru}$ in cement.

${ }^{d}$ None detectable after ten weeks of leaching. in general, asphalts and tars can be used sucm cessfully in radiation environments as long as the total exposure does not exceed about $10^{9}$ rads. Experiments at $\mathrm{Mol}^{32}$ showed that a dose of $10^{8}$ rads had little or no effect on the leach rate of materials incorporated in asphalt. Conservative calculations (Table 3.14) show that these doses will not be exceeded for most intermediate- and low-level wastes encountered in practice.

\subsection{ENGINEERING, ECONOMICS, AND SAFETY EVALUATIONS}

This study, undertaken in cooperation with the ORNL Health Physics Division, has as its objective the evaluation of the economics and safety associated with the management of radioactive waste. All steps between final processing and ultimate disposal are being considered, and it is expected that an optimal combination of operations will be defined for different methods of disposal and that the most promising areas for experimental study will be indicated.

\section{Progress and Status}

Principal emphasis has been placed so far on the economics of a series of operations believed to represent an acceptably safe scheme for the management of highly radioactive liquid wastes.

Table 3.14. Absorbed Dose ${ }^{a}$ of Asphaltic Products ${ }^{b}$ Incorporating Radioactive Solids

from Wastes of Intermediate Radioactivity Level

\begin{tabular}{|c|c|c|c|c|}
\hline Elapsed time, yr & 1 & 10 & 100 & 1000 \\
\hline \multicolumn{5}{|c|}{${ }^{137} \mathrm{Cs},{ }^{c}$ curies/gal of waste } \\
\hline 0.1 & $2.6 \times 10^{5}$ & $2.3 \times 10^{6}$ & $1.1 \times 10^{7}$ & $1.3 \times 10^{7}$ \\
\hline 5 & $1.3 \times 10^{7}$ & $1.2 \times 10^{8}$ & $5.5 \times 10^{8}$ & $6.2 \times 10^{8}$ \\
\hline \multicolumn{5}{|c|}{${ }^{106} \mathrm{Ru},{ }^{d}$ curies/gal of waste } \\
\hline 0.1 & $3.1 \times 10^{5}$ & $6.2 \times 10^{5}$ & $6.2 \times 10^{5}$ & $6.2 \times 10^{5}$ \\
\hline 5 & $1.6 \times 10^{6}$ & $3.1 \times 10^{6}$ & $3.1 \times 10^{6}$ & $3.1 \times 10^{6}$ \\
\hline
\end{tabular}

${ }^{a}$ Assuming infinite homogeneous medium.

${ }^{b}$ Asphaltic product represents a volume reduction of 2 from the waste and has a density of $1.5 \mathrm{~g} / \mathrm{cm}^{3}$.

${ }^{c}$ Energy of disintegration, $0.8 \mathrm{Mev}$, decay constant, $2.1 \times 10^{-2} \mathrm{yr}^{-1}$.

${ }^{d}$ Energy of disintegration, $1.3 \mathrm{Mev}$, decay constant, $6.9 \times 10^{-1} \mathrm{yr}^{-1}$. 
Estımated costs have been reported previously ${ }^{1} 34$ for interim storage of the wastes as liquids, conversion to solids by pot calcination, interim storage of solids, and shipment of solids. Also, the effects of fission product removal on waste management costs were estımated. ${ }^{1}$ A study of the costs for final disposal of solidified wastes in salt mines is currently nearing completion.

During the past year, studies were made of the comparative costs of the permanent storage of solidified waste in concrete vaults, granite formations, and salt mines, ${ }^{12}$ and of the implications arising from the presence of fission product tritium in fuel processing wastes. ${ }^{8}$

\section{Comparative Costs for Disposal in Vaults, Granite, and Salt}

Although cavities mined in salt formations are believed to offer the best possibilities for the permanent disposal of solidified wastes, the use of salt mines implies the probable need for shipping the wastes from a processing plant possibly many miles distant. Suitable deposits of granite or shale might be more accessible to a plant, and it is concervable that high-integrity concrete vaults could be constructed at the plant site for permanent containment. Lacking a formal safety analysis, a qualitative observation can be made that disposal in granite would, at best, be no safer than in salt and that concrete vaults would be less safe because of the limited durability of the concrete and the closeness of the waste to the biosphere. Therefore, the costs for mining space in granite must be as low as for salt, and for vaults, lower than for salt, for these alternative methods to be competitive. As can be seen below, this was not found to be the case. Costs for storage in concrete vaults were five to seven times greater than those for storage in salt, and costs for storage in granite were twice those for salt.

A basic assumption is that, after the waste has been placed in storage, all accesses to the storage area are sealed to provide the maximum containment and isolation from the environment. Under these circumstances, dissipation of the radioactive decay heat will occur only by conduction through the surrounding solid medium. Better heat transfer to permit more efficient

\footnotetext{
${ }^{34}$ F. L. Culler et al., Chem. Technol. Div. Ann. Progr. Rept. June 30, 1962, ORNL-3314 (Sept. 14, 1962).
}

utilization of storage space could be achieved by circulating air through the storage area and discharging it back into the atmosphere after appropriate cleaning and monitoring. However, this would represent a less-safe situation in that it would provide a direct route for the escape of the fission products into the environment in the event of sabotage or natural disaster.

Having avallable as a point of reference the more detalled analysis of the cost factors in the disposal of calcined wastes in salt mines, ${ }^{2,35}$ only a rather perfunctory analysis is needed to show the relative costs for disposal into vaults and granite. The procedure consisted in calculating the relative costs for storage space and then estimating space requirements as determined by heat transfer considerations. Handling procedures and operating costs were assumed to be identical to those used for disposal in salt.

As in previous cost studies in this series, a 6 metric ton/day plant was assumed, processing 1500 metric tons/year of thorium converter fuel at a burnup of $10,000 \mathrm{Mwd} /$ metric ton and 270 metric tons/year of thonum converter fuel at a burnup of $20,000 \mathrm{Mwd} / \mathrm{metric}$ ton. This hypothetical plant would process the fuel from a $15,000 \mathrm{Mw}$ (electrical) nuclear economy, which may be in existence by 1975. Ac1d Purex and reacidified Thorex wastes packaged in cylinders 6 to $24 \mathrm{in}$. in diameter were chosen for this study since they possessed the highest and lowest heat generation rates per unit volume respectively.

The concept of the concrete vault assumed the construction of concrete rooms completely buried, with just sufficient earth cover to provide the necessary shielding. Based on a preliminary design of such a vault, equipped with a stainless steel liner and an anr-cooling system, Watson et al. ${ }^{36}$ estimated a cost of $\$ 10.70$ per cubic foot of storage space. The gross resemblance to the vaults provided for storage of liquid wastes is striking, in that all are underground structures of reinforced concrete, are of about the same size and proportions, and have leaktight metal linings. The cost per unit of storage space for tanks ranges from $\$ 6$ to $\$ 22.50 / \mathrm{ft}^{3}$ at Hanford, Savannah River,

${ }^{35}$ R. E. Blanco and E. G. Struxness, Waste Treatment and Disposal Progress Report for February and March 1962, ORNL-TM-252, pp. 39-43 (Sept. 10, 1962).

${ }^{36}$ L. C. Wats on et al., Method of Storage of Solids Containing Fission Products, CRCE-736 (June 30, 1958). 
and the Idaho Chemical Processing Plant. ${ }^{37}$ After deductions for cooling systems and metal linings, space in these underground concrete structures costs about $\$ 3$ to $\$ 4 / \mathrm{ft}^{3}$. In the present study, the use of both ordinary and high-temperature concrete was considered, and the cost of space was taken to be $\$ 3$ and $\$ 4.30 / \mathrm{ft}^{3}$ respectively. Salt is mined for about $\$ 2 /$ ton, which means that the cost for space in salt formations is about $15 \phi / \mathrm{ft}^{3}$.

The spacing between cylinders of waste in a storage system is controlled by the necessity to dissipate the heat generated by radioactive decay without reaching temperatures that are injurious to the storage system. These limiting temperatures were taken to be $1650^{\circ} \mathrm{F}$ for the waste, 400 to $500^{\circ} \mathrm{F}$ for ordinary concrete, and $1000^{\circ} \mathrm{F}$ for special high-temperature concretes. Space requirements for acid Purex and reacidified Thorex wastes situated in racks in concrete vaults were computed as functions of age at burial, assuming for heat transfer estımates the case of a sem1infinite slab, initially at constant temperature, with a constant heat flux into one surface and heat loss from the other by convection. The greatest savings in space requirements for vaults, compared with those for salt, occurred for the storage of wastes aged 10 to 30 years, over this range of ages, the requirements differed by constant factors.

Hence, the comparison of costs was carried out only for 30-year-old wastes, the storage area requirements for which varied from $1.8 \mathrm{ft}^{2}$ for 6-1n.-diam cylinders of reacidified Thorex waste in high-temperature concrete to $1300 \mathrm{ft}^{2}$ for 24-1n.diam cylinders of acid Purex in salt.

The costs of storage space per cylinder in concrete vaults and in salt mines were obtained from the area requirements and space costs, assuming a floor-to-celling height of $15 \mathrm{ft}$ (Table 3.15). The costs for storage space in high-temperature concrete were 20 to $50 \%$ less than those for ordinary concrete, but the cost of space in vaults was at least eight times higher for both acid Purex and reacidified Thorex waste than the cost of space in salt formations. In calculating the total costs of storage in salt, 60 to $85 \%$ was for salt removal, and, since the other costs (e.g., for handling equipment and labor for storing the cans) would be about the same for all storage

\footnotetext{
${ }^{37}$ E. Dound, Design of Underground Storage Tanks for Radioactive Wastes, HW-57282 (March 1959).
}

Table 3.15. Cost of Space in Salt Formations and Concrete Vaults for Cylinders of Waste Aged 30 Years

\begin{tabular}{|c|c|c|}
\hline \multirow{2}{*}{$\begin{array}{c}\text { Diameter of the } \\
\text { Cylinders } \\
\text { (1n.) }\end{array}$} & \multicolumn{2}{|c|}{ Cost of Space (\$/cylinder) } \\
\hline & Acid Purex & Reacidified Thorex \\
\hline \multicolumn{3}{|c|}{ Salt Formations } \\
\hline 6 & 180 & 15 \\
\hline 12 & 740 & 59 \\
\hline 24 & 2920 & 230 \\
\hline \multicolumn{3}{|c|}{ Vault, $500^{\circ} \mathrm{F}$ Limit } \\
\hline 6 & 2300 & 185 \\
\hline 12 & 9100 & 720 \\
\hline 24 & 36,500 & 2850 \\
\hline \multicolumn{3}{|c|}{ Vault, $1000^{\circ} \mathrm{F}$ Limit } \\
\hline 6 & 1470 & 120 \\
\hline 12 & 5800 & 460 \\
\hline 24 & 21,900 & 1850 \\
\hline
\end{tabular}

systems, the relative total costs would probably differ by factors of 5 to 7 .

Excavation costs in hard rock (granite or metamorphosed basalt) have been reported to range from $\$ 9$ to $\$ 15 / \mathrm{yd}^{3}$ at a number of recent Government projects. ${ }^{38}$ By comparison, excavation costs in salt are about $\$ 4 / \mathrm{yd}^{3}(\$ 2 /$ ton). This difference exists because heavier equipment is required to mine hard rock, drilling is more difficult and slower, and costs of explosives are higher. Since the thermal properties of salt are within about $10 \%$ of those of granite, the space requirements in either medium would be about the same. Furthermore, the ratios of rock volume mined for storage space to that left as supporting pillars would also be comparable. Assuming all other costs (amounting to 15 to $40 \%$ of the total costs) to be the same also, storage in granite would cost about twice as much as storage in salt.

${ }^{38}$ P. L. Russell, U.S. Department of Inter1or, Bureau of Mines, personal communication to R. L. Bradshaw, ORNL, May 16, 1963. 


\section{Management of Tritium in Fuel.Processing Wastes}

Tritium, 12.3-year ${ }^{3} \mathrm{H}$, is produced in the fission of ${ }^{235} \mathrm{U}$, with a yreld ${ }^{39}$ of about $0.01 \%$, and 1 t merits special consideration from the standpoint of its management in wastes from fuel processing because it is unresponsive to separation and concentration by conventional procedures for treating waste. In fuel processing about $25 \%$ of the tritium appears in the dissolver off-gas and is released through the stack. Nearly all the remander appears as tritiated water in the evaporator condensates and is safely released to the ground water at the sites of existing United States processing plants.

The extent to which present practices can be applied to the future management of tritium-bearing wastes from recovery of power reactor fuels is unclear. Based on recent predictions ${ }^{40}$ of nuclear power growth in the U.S., the annual production of tritium may be expected to rise from about 15,000 curies in 1968 to about 6 million in the year 2000 . The accumulated production, allowing for natural decay, should rise from 15,000 curies to about 30 million in 2000.

If this tritium could be uniformly dispersed throughout the environment, the resulting increase in background would be of little significance. In the actual case, however, a fuel processing plant will have only its immediate environs available for dispersion, and the capacity of those environs will depend on the rate that tritium is released as well as on the many environmental factors that pertain to that particular site. The rate of tritium release will be determined by the irradiation history of the fuel and 1 ts rate of processing by the plant. While the earliest plants may be sized, because of low processing requirements, to handle only a ton or so of fuel a day, there will be a strong economic incentive to increase the capacities of individual plants as the nuclear power industry grows and to situate them less remotely.

Three possibilities other than those in current use at U.S. production sites for the disposal of tritium-bearing wastes are (1) dilution and release directly to surface waters, (2) distillation into the plant off-gas system and release up the

\footnotetext{
${ }^{39}$ E. L. Albenesius and R. S. Ondrejcin, Nucleonics 14, 100 (September 1960).

${ }^{40}$ Civilian Nuclear Power, Appendices to a Report to the President - 1962, USAEC, Washington 25, D.C.
}

stack, and (3) recycle of evaporator tritium to build up in the concentrated high-level waste stream, which is subsequently stored for decay. It is probable that none will offer the best answer for all future situations but that all three may eventually be utilized to the fullest practical extent.

The quantity of tritium that can be released to surface waters can be computed within the limitations that (1) the concentration shall not exceed $1 / 10$ the maximum permissible concentration in water $\left(\mathrm{MPC}_{\mathrm{w}}\right)$ for continuous occupational exposure, or $3 \times 10^{-3} \mu \mathrm{c} / \mathrm{cm}^{3}$, at the boundary of the controlled zone, and (2) the concentration shall subsequently not exceed the ICRP-recommended level for the general population of $1 / 30$ the $\mathrm{MPC}_{\mathrm{w}}$, or $1 \times 10^{-3} \mu \mathrm{c} / \mathrm{cm}^{3}$. If the controlled zone borders a stream of any significant size, the first of these restrictions is controlling.

A ton of fuel 1rradiated to $16,000 \mathrm{Mwd}$ at a specific power of $16 \mathrm{Mw}$ contains about 200 curies of tritium, which would require about 18 million gallons of dilution capacity for 1 t to be released from the controlled zone at $1 / 10$ the MPC. The total aqueous effluent from a plant operating with a Purex process flowsheet may be as much as $10^{6}$ gal per ton of fuel processed, but this is far short of the requirements for tritium dilution. The most practical means of achieving the on-site dilution requirement would be to have avallable for this purpose a creek or small river flowing through the controlled area. To meet the specification for use by the general population, this stream would have to flow into a larger body of water to achieve additional dilution by a factor of 3 or more.

It is desirable that a plant be situated adjacent to a large, preferably navigable river for other and possibly more important reasons than tritium disposal, but it is much less obvious that acceptable sites should be limited to those which, in addition, encompass a stream of the size useful for dilution. It is concluded, therefore, that with restrictions as presently interpreted, the alternative of release to surface waters is of very limited applicability as a general case.

Distillation into the plant off-gas may provide an acceptable means of releasing tritium and other fission product contaminants in the evaporator condensates. It $1 \mathrm{~s}$ estimated that about 1200 curies of tritium per day could be released from a 100-m-high stack under very unfavorable atmospheric conditions (mean wind speed of $3 \mathrm{mph}$ and 
extremely unstable conditions) without exceeding $1 / 10$ the maximum permissible concentration in air $\left(\mathrm{MPC}_{2}\right)$ for continuous occupational exposure of $2 \times 10^{-7}$ curies $/ \mathrm{cm}^{3}$ at any point near the ground. This allowable rate of release would permit a continuous fuel processing rate equivalent to $96,000 \mathrm{Mw}$ (thermal), which is the predicted size of the nuclear power economy in about 1985. A single plant of this capacity may not be in existence until an even later date.

A second aspect of the problem, however, is the deposition on the ground of tritiated water following its release. While it is believed that atmospheric concentration is probably the more important factor in determining allowable tritium releases, additional work will be required to establish ground tolerances and the mechanisms for estimating deposition rates following stack releases under different climatic conditions.

Finally, in determining the practicality of this method of tritium disposal, consideration must be given to the limitations set for the release of the other fission products which may also be present in the evaporator condensates. If ${ }^{90} \mathrm{Sr}$ is taken as the controlling nuclide, a decontamination factor of $10^{8}$ to $10^{9}$ between the feed and condensates of the evaporator would be required. This is achievable with present equipment but may require multiple-effect evaporation.

One means of limiting the release of tritium to the environment would be to recycle the principal tritium-bearing streams within the processing plant, causing the tritium inventory in these streams to increase until the tritium discharged for tank storage with the concentrated high-level wastes is equivalent to that entering with the irradiated fuel. A hydrogen balance across the HA and HS columns of a two-cycle Purex process flowsheet ${ }^{41}$ indicates that about $7 \%$ of the tritium in the feed would follow the organic product stream, while $93 \%$ would remain with the aqueous raffinate. The raffinate is subsequently evaporated to $1 / 30$ of $i$ ts original volume and stored. At this point, it contains about $3 \%$ of the tritium in the feed, and the evaporator condensate contains about $90 \%$. If all the aqueous process streams were recycled except the concentrated raffinate, the concentrations of tritium in all streams would increase until they were about 33 times greater than their initial values, and, at this point, the tritium in the high-level waste being bled from the process would equal that in the feed. If tritium concentrations of these magnitudes were undesirable in the final product streams, it could be reduced or eliminated by evaporating liquids to dryness and dehydrating salts, followed by new solution makeup with uncontaminated water.

While a total recycle of aqueous streams is technically possible, in practice it might be a rather complex and expensive proposition. In the proposed situation, other fission products, especially ruthenium, would build up in various streams. Presently uncontaminated process makeup areas would become radiation zones requiring safety precautions and limited personnel access.

Possibly the most important aspect in determining the feasibility of recycling condensates, which average in volume about 10,000 gal per ton of fuel processed, would be the demonstration of how effectively the organic content of these streams could be controlled. The so-called organic "cruds," composed principally of butyl phosphates and hydrocarbons, are steam-stripped during evaporation and would require removal from the condensates before recycling if operating difficulties were to be avoided. Suitable techniques have not as yet been demonstrated.

\footnotetext{
${ }^{41}$ E. R. Irish, Description of Purex Plant Process, HW-60116 (May 19, 1959).
} 


\section{Transuranium Element Processing}

The Transuranium Processing Plant (TRU) and the High Flux Isotope Reactor (HFIR) are being built here in order to provide gram quantities of many of the transuranium elements and milligram quantities of some of the transcalifornium iso topes. These materials will be used for research purposes in laboratories throughout the country.

Long-term irradiation of a $10-\mathrm{kg}$ batch of ${ }^{239} \mathrm{Pu}$ in a Savannah River production reactor has produced about $400 \mathrm{~g}$ of ${ }^{242} \mathrm{Pu}$ and a $200 \mathrm{~g}$ mixture of ${ }^{243} \mathrm{Am}$ and ${ }^{244} \mathrm{Cm}$. These materials were recovered at the Savannah River Laboratory (SRL) and then sent here. After fabrication into target rods, they will be further irradiated for 12 to 18 months in the HFIR, and the transcurium elements will be recovered as products. The curium isotopes then will be returned to the reactor for additional irradiation.

Chemical processes are being developed and equipment is being designed in order to make target rods, dissolve and recover transuranium elements from the irradiated targets, and then prepare and ship the recovered products to customers. This report summarizes the development of the chemical separations processes, methods for preparing actinide oxides suitable for incorporation into HFIR targets, the design and development of the equipment to do these processes, and progress in construction of the Transuranium Processing Plant. Development of the procedures for making the targets, under the direction of the Metals and Ceramics Division, and corrosion studies being done in the Reactor Chemistry Division are not reported here.

The Curium Recovery Facility (CRF) is under construction and will be used to test transuranium process chemistry at full-scale radioactivity levels, to recover multigram quantities of ${ }^{243} \mathrm{Am}$ and ${ }^{244} \mathrm{Cm}$ for incorporation into HFIR targets, and to purify gram quantities of ${ }^{242} \mathrm{Cm}$ and ${ }^{244} \mathrm{Cm}$ for use in thermoelectric converters (Chap. 5).
This facility is being installed in cells 3 and 4 of the High Level Chemical Development Facility, Building 4507. At present, the cell-3 complex is still under construction, while the cell-4 complex, which contains the solvent extraction equipment, is complete. Equipment calibration and leak testing have been completed; cold runs of chemical flowsheets are being made; and necessary equipment modifications are in progress.

\subsection{DEVELOPMENT OF CHEMICAL PROCESSES}

A summary flowsheet for HFIR target preparation and processing is shown in Fig. 4.1. Ten kilograms of $\mathrm{Pu}-\mathrm{Al}$ have been irradiated in a Savannah River production reactor to greater than $99.9 \%$ burnup of ${ }^{239} \mathrm{Pu}$. About $400 \mathrm{~g}$ of residual plutonium, primarily the mass-242 isotope, was recovered and purified at SRL. In addition, about $100 \mathrm{~g}$ of ${ }^{243} \mathrm{Am}$ and $100 \mathrm{~g}$ of ${ }^{244} \mathrm{Cm}$, along with 10,000 curies of rare-earth fission products in nitric acid, were recovered from the raffinate of the plutonium-recovery process at SRL. This material is stored in an underground tank at the Curium Recovery Facility and will be processed there for recovery of americium and curium. The americium, curium, and rare earths will be concentrated and converted to a chloride system by the Clanex (Co-Lanthanide-Actinide-Nitrate Extraction) process, in which americium, curium, and rare earths are extracted into a tertiary amine from neutral nitrate solution and are stripped into dilute hydrochloric acid. The product can then be adjusted to $11 M$ LiCl-0.1 $M \mathrm{HCl}$ for isolation of actinides from lanthanides by the Tramex process. The purified ${ }^{242} \mathrm{Pu},{ }^{243} \mathrm{Am}$, and ${ }^{244} \mathrm{Cm}$ will be converted to dense oxide in the particle-size range 20 to $200 \mu$, fabricated into targets by the Metals and Ceramics Division, and irradiated in the HFIR for 12 to 18 months. 


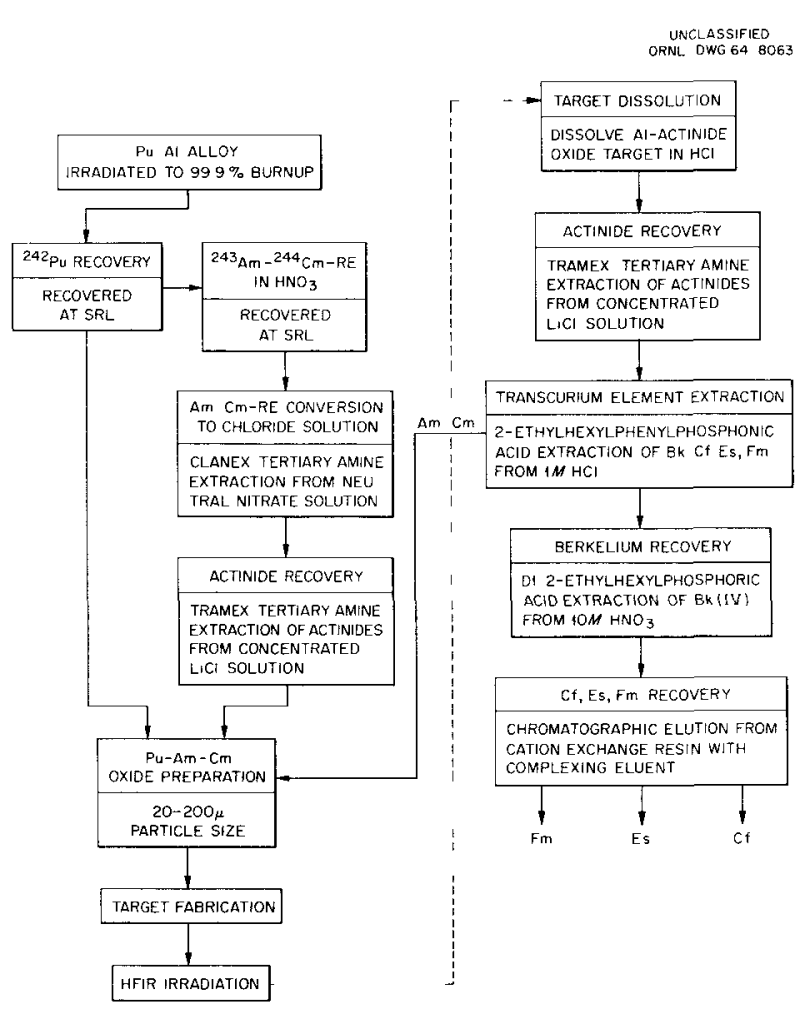

Fig. 4.1. Summary Flowsheet for HFIR Target Preparation and Processing.

The main-line HFIR target processing method (Fig. 4.1) consists of target dissolution in hydrochloric acid; actinide separation from fission products and aluminum by the Tramex process; transcurium element separation from americium and curium by phosphonate extraction from dilute hydrochloric acid; berkelium separation from californium, einsteinium, and fermium by dialkyl phosphate extraction of $\mathrm{Bk}(\mathrm{IV})$ from concentrated nitric acid; and californium, einsteinium, and fermium isolation by chromatographic elution from a cation exchange resin.

During the past year, no additional laboratory development work was performed on the Clanex process or the transcurium element extraction (which were reported last year); however, these processes will be tested at full-scale radioactivity levels in the Curium Recovery Facility. Additional laboratory development work is planned for the berkelium recovery process as soon as sufficient amounts of berkelium become available. Investigations were continued on developing, testing, and improving the Tramex process. In addition, bidentate compounds were investigated as extractants for trivalent actinide and lanthanide elements from plutonium acidwaste processing solutions; methods for the preparation of actinide oxides suitable for HFIR targets were studied; and tests were continued to find suitable techniques for intra-actinide separations by ion exchange.

\section{Tramex Process Development}

Investigations continued on developing, testing, and improving the Tramex process for separating transplutonium elements from fission products, corrosion products, and aluminum. This process may be used for separating all known transplutonium elements as a group from the lanthanide fission products and many other ionic impurities.

The process conditions shown in Fig. 4.2 are essentially the same as those presented last year. ${ }^{1}$ The only difference is in the addition of methanol to the feed solution to prevent acid losses caused by radiolysis. Laboratory tests indicate that as little as 2 vol \% methanol will effectively stabilize for two weeks Tramex feed containing $10 \mathrm{w}$ of alpha activity per liter.

Additional Tramex development work included the following: partial purification of Alamine 336, investigation of the stability of Alamine $336 \cdot \mathrm{HNO}_{2}$, determination of the solubility of $\mathrm{AlCl}_{3}$ in $\mathrm{LiCl}$ $\mathrm{HCl}$ mixtures, behavior studies of plutonium in

\footnotetext{
${ }^{1}$ F. L. Culler et al., Chem. Technol, Div. Ann. Ptogt. Rept. May 31, 1963, ORNL-3452, pp. 102-3.
}

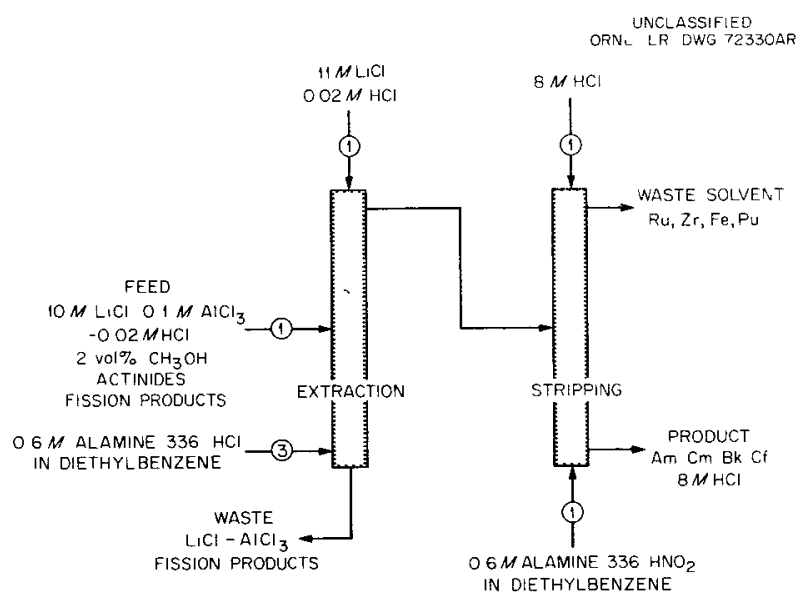

Fig. 4.2. Tramex Process Flowsheet. 
the Tramex process, and an evaluation of hazards resulting from the use of Alamine 336-diethylbenzene (DEB) in the Tramex process.

Test of the Tramex Process at High Power Density. - A series of five batch countercurrent solvent extraction tests were made of the Tramex flowsheet with ${ }^{242} \mathrm{Cm}$ at power densities varying from 5 to $10 \mathrm{w} /$ liter. $^{2}$ No adverse effect on solvent extraction due to the alpha radiation was noted. These runs were made in order to explore the effects of various operating conditions; consequently, no single run was made under conditions optimized for obtaining both high recovery of curium and high decontamination from fission products. However, the results indicate that the Tramex process is capable of meeting these goals. The best curium recovery observed (measured by raffinate losses) was $99.93 \%$. The best fission product decontamination factors were 400 for ${ }^{141} \mathrm{Ce}, 310$ for ${ }^{103} \mathrm{Ru}$, and $3 \times 10^{4}$ for ${ }^{95} \mathrm{Zr}-\mathrm{Nb}$.

Feed was prepared from four targets each of which contained 10 to $20 \mathrm{mg}$ of ${ }^{242} \mathrm{Cm}$ at the time of processing. The aluminum target matrix was dissolved in $2 \mathrm{M} \mathrm{HCl}$. Solvent extraction feed was prepared by adding $200 \mathrm{ml}$ of $11 \mathrm{M} \mathrm{LiCl}$ to the dissolver product and evaporating to a final temperature of $133^{\circ} \mathrm{C}$. This procedure produced acceptable feed, both in terms of salt concentrations $\left(10 \mathrm{M} \mathrm{LiCl}\right.$ and $\left.0.17 \mathrm{M} \mathrm{AlCl}_{3}\right)$ and acidity (probably less than $0.08 M \mathrm{HCl}$ ). The adjusted feed was contacted with $0.6 \mathrm{M}$ Alamine $336 \cdot \mathrm{HCl}$ in DEB in a semiautomatic batch, countercurrent solvent extraction apparatus. Volume ratios were $6,4.5$, and $9 \mathrm{ml}$ per cycle for feed, scrub, and solvent solutions respectively. The scrub solution was $10.8 \mathrm{M} \mathrm{LiCl}, 0.02 \mathrm{M} \mathrm{HCl}$. Curium was stripped from the solvent with 6 to $8 M \mathrm{HCl}$. Stripped product was washed with a fresh stream of solvent containing the nitrite and/or the chloride salt of Alamine 336 in diethylbenzene. Strip and wash volumes were each $6 \mathrm{ml}$ per cycle. Each of the five runs was made with six extraction, four scrubbing, two stripping, and eight washing stages. The main conclusions are as follows:

1. Curium at power density varying from 5 to 10 w/liter has no appreciable effect on the mechanical operation of the extraction process.

\footnotetext{
${ }^{2}$ W. D. Burch et al., Transuranium Quart. Progr. Rept. Aug. 31, 1963, ORNL-3558, pp. 8-18.
}

2. The acid concentration in the feed must be no more than a few hundredths molar, or curium will reflux in the extraction contactors. Refluxing occurred in runs $\mathrm{Cm}-2$ and $\mathrm{Cm}-6$; as a result, curium recovery was poor.

3. Cerium decontamination factors were poor in all runs. This was probably due to oxidation of cerium to the $\mathrm{Ce}^{4+}$ state at high radioactivity levels. This oxidation should be prevented by the presently planned addition of methanol to the feed solution.

4. Ruthenium decontamination factors were also poor, even though nitrate was added to the wash solvent to improve decontamination. It is probable that the nitrite decomposed before it was used; evidence from other tests indicates that freshly prepared Alamine $336 \cdot \mathrm{HNO}_{2}$ would have been effective.

5. Zirconium decontamination was excellent when the acid concentration in the strip was sufficiently high.

Control of Acidity in High-Radioactivity-Level Tramex Feed. - Separations by the Tramex process are greatly affected by small changes in acidity, and several methods were investigated for controlling acid losses caused by radiolysis. The exact mechanism of the loss is not understood, but it is probably due to chloride oxidation. Analysis of radiolytic gas from $10 \mathrm{M} \mathrm{LiCl}$ containing ${ }^{242} \mathrm{Cm}$ $\left(14 \mathrm{w} /\right.$ liter) gave $\mathrm{H}_{2}: \mathrm{O}_{2}: \mathrm{Cl}_{2}$ ratios of $7.3: 1.2: 1.0$, but a material balance of the gaseous products did not account for all the chloride lost by the radiolytic destruction of the hydrochloric acid. Similarly, an oxygen material balance did not account for sufficient oxygen when the radiolysis of water is assumed to produce $\mathrm{H}_{2}+\frac{1}{2} \mathrm{O}_{2}$. Evidence of chlorine and oxygen retention in the solution was noted in a test in which large quantities of gas were evoived from a basic solution when it was acidified. The gas consisted of nearly equal quantities of $\mathrm{Cl}_{2}$ and $\mathrm{O}_{2}$, but no $\mathrm{H}_{2}$.

Since acid loss appears to result from the oxidation of the chloride ions, the addition of reducing agents to high-radioactivity-level Tramex feed was investigated as a means of preventing the loss. Certain reducing agents were effective, and the results obtained by adding hydrazine monochloride, formaldehyde, and methanol are shown in Fig. 4.3. 


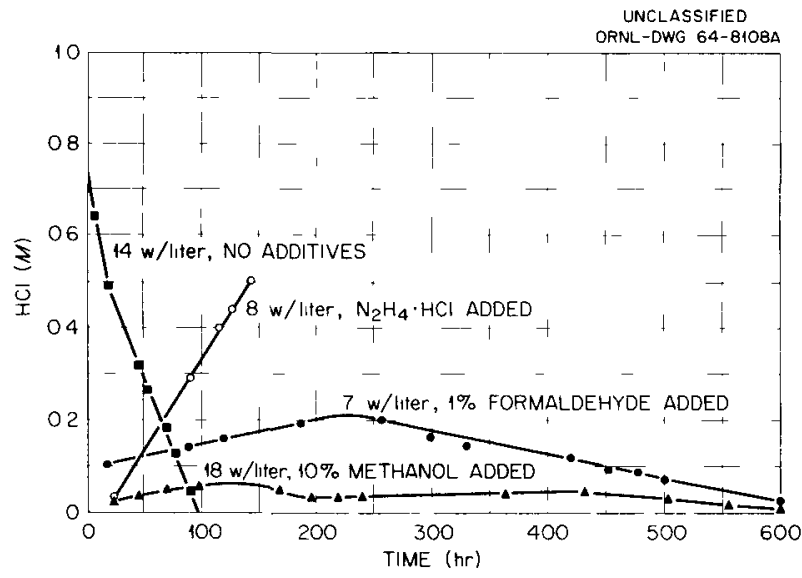

Fig. 4.3. Effect of Curium-242 Alpha Activity on Acid in $10 \mathrm{M} \mathrm{LiCl}$.

Both hydrazine monochloride and formaldehyde increased the acidity, while methanol was the most effective additive for maintaining the correct acidity. When 10 vol \% methanol was present in $10 \mathrm{M} \mathrm{LiCl}$ containing $18 \mathrm{w}$ of ${ }^{24} \mathrm{Cm}$ per liter, the solution was stable even after 24 days, and the acid concentration was 0.03 to $0.06 M$ during the entire 25 days. The accumulated radiation dose was greater than $10 \mathrm{kwhr} /$ liter. In additional studies, it was found that a $10 \mathrm{M} \mathrm{LiCl}-0.05 \mathrm{M}$ $\mathrm{HCl}$ solution containing $10 \mathrm{w}$ of alpha activity per liter can be stabilized for as long as two weeks by adding as little as $2 \mathrm{vol} \% \mathrm{CH}_{3} \mathrm{OH}$.

The Effect of Methanol on the Tramex Process. The use of methanol to inhibit acid loss by radiolysis appears to be completely satisfactory and does not produce any detrimental side effects in the extraction process. Phase separation is more rapid with methanol present, and its use in extraction tests caused no gross change in distribution coefficients, extraction kinetics, or fission product behavior.

Distribution coefficients were determined for americium and $\mathrm{HCl}$ between $0.6 M$ Alamine 336 . $\mathrm{HCl}-\mathrm{DEB}$ and feeds that consisted of $11 M \mathrm{LiCl}$ or $10 M \mathrm{LiCl}-0.15 \mathrm{M} \mathrm{AlCl}_{3}$ and 2, 5, or 10 vol \% $\mathrm{CH}_{3} \mathrm{OH}$. Free acid was varied from 0.02 to $0.30 \mathrm{M}$. No adverse effects due to the presence of as much as $10 \% \mathrm{CH}_{3} \mathrm{OH}$ were noted. Americium distribution coefficients were not changed by the addition of $2 \% \mathrm{CH}_{3} \mathrm{OH}$, but increases of about $25 \%$ were obtained by making the feed solution either 5 or 10 vol \% in $\mathrm{CH}_{3} \mathrm{OH}$. Hydrochloric acid distribution coefficients appear to be independent of feed acid concentrations below $0.15 \mathrm{M}$. Acid distribution coefficients for $11 \mathrm{M} \mathrm{LiCl}$ feed at low acidities were of the order of $5.0,4.4$, and 4.0 for 2,5 , and 10 vol \% methanol respectively. Scouting experiments indicated that europium behavior parallels that of americium.

The effect of methanol on curium distribution coefficients was investigated with a $10-\mathrm{w} /$ liter ${ }^{242} \mathrm{Cm}$ solution stabilized with 2 vol $\% \mathrm{CH}_{3} \mathrm{OH}$. The distribution coefficients remained almost constant over the eight-day period, and no detrimental effects were noted.

The effect of methanol addition on curium and fission product behavior was investigated in a mixer-settler run of the Tramex process at tracer activity levels. Zirconium and ruthenium remained quantitatively in the organic phase. The overall curium recovery was $99.9 \%$, and no fission products were detectable in the product, corresponding to a decontamination factor of better than 1000 . Curium and fission product behaviors were typical of tests made in which methanol was not used, and no hydraulic or kinetic problems were encountered.

Acid Adjustment in Tramex Feed by Adding Hydrogen Chloride Gas. - The equilibration of Tramex feed with hydrogen chloride gas was also investigated as a means of restoring acidity lost through radiolysis. Since high $\mathrm{HCl}$ concentrations resulted when pure $\mathrm{HCl}$ was equilibrated with feed solutions $\left(1.0 \mathrm{M} \mathrm{HCl}\right.$ and $0.4 \mathrm{M} \mathrm{HCl}$ at $\left.120^{\circ} \mathrm{C}\right)$, the effect of equilibrating Tramex feed with inert gas containing a reduced partial pressure of hydrogen chloride was studied.

Initial experiments established that the partial pressure of hydrogen chloride over $10 \mathrm{M} \mathrm{LiCl}-0.1$ $M \mathrm{HCl}$ at $23^{\circ} \mathrm{C}$ is only $0.45 \mathrm{~mm}$ of mercury. This means that the partial pressure of hydrogen chloride in the gas stream must be only $0.45 \mathrm{~mm}$ of mercury and that the gas flow necessary to replace acid losses in Tramex feed would be excessive at room temperature. However, by increasing the temperature of the feed, a larger partial pressure of hydrogen chloride can be used, and thus a smaller total gas flow is needed. Studies at elevated temperatures indicate that Tramex feed could be maintained at about $0.1 \mathrm{M} \mathrm{HCl}$ with gas at an $\mathrm{HCl}$ partial pressure of $20 \mathrm{~mm}$ mercury and a flow rate of 3 liters per minute per 50 liters of feed when the feed is maintained at $120^{\circ} \mathrm{C}$. However, the difficulties attendant with maintaining feed at this 
temperature are sufficiently severe to make this method of acid control much less attractive than controlling it by adding methanol.

Effect of Nitrate on Extraction in the Tramex Process. - The addition of small amounts of Alamine $336 \cdot \mathrm{HNO}_{3}$ to Alamine $336 \cdot \mathrm{HCl}-\mathrm{DEB}$ was investigated as a possible means of increasing actinide distribution coefficients and minimizing acid-loss problems. With higher distribution coefficients, it was thought that control of the acid concentrations of Tramex feed might be less critical, but unfortunately, this was not true.

Distribution coefficients were determined for americium, europium, and hydrochloric acid between (1) $11 M \mathrm{LiCl}$ containing 0.05 to $0.20 \mathrm{M} \mathrm{HCl}$ and (2) the mixed nitric and hydrochloric acid salts of $0.6 \mathrm{M}$ Alamine 336 in DEB. The concentration of Alamine $336 \cdot \mathrm{HNO}_{3}$ was vaned from 0.01 to $0.10 \mathrm{M}$. Americium and europium distribution coeff 1 icients were both increased by the addition of nitrate, however, separation factors between americium and europium were decreased because the increase in distribution coefficients for europium was greater than the increase in the distribution coefficients for americium. In addition, 1t was found that americium-europium separation factors were dependent on the concentration of free acid. Since separation factors are not affected by free-acid concentration in the all-chloride system, the mixed chlonde-nitrate system appears to be more sensitive to free acid than the allchloride system, even though the distribution coefficients are greater.

Purification of Alamine 336. - Alamme 336 is a mixture of octyl and decyl tertiary amines, containing small amounts of primary and secondary amines. Only the tertiary amine hydrochlorides extract actinides from concentrated lithium chloride solutions. Primary and secondary amines appear to reduce actinide distribution coefficients somewhat, and their presence needlessly increases the viscosity of the Tramex extractant. A method of purifying the amine based on partial neutralization of the amine hydrochloride salt to produce two solvent layers was used to fractionate a sample of Alamine 336 into a bottom layer containing 10 mole $\%$ of the amines (mostly primary and secondary) and a top layer of purıfied tertiary amıne. Each cut was dissolved in diethylbenzene to a concentration of $0.6 \mathrm{M}$ total amine hydrochloride, and americium distribution coefficients from $10 \mathrm{M}$ $\mathrm{L}_{1} \mathrm{Cl}-0.15 \mathrm{M} \mathrm{AlCl}_{3}$ at various concentrations of hydrochloric acıd were determined. The variation in distribution coefficients for treated and untreated Alamine $336 \cdot \mathrm{HCl}$ as a function of the concentration of hydrochloric acid in the organic phase is shown in Fig. 4.4. These results indicate that by simply neutralizing with hydrochloric acid and discarding $10 \%$ of the Alamine 336 , most of the primary and secondary amines can be removed, producing a purified Alamine 336 that gives distribution coefficients that are about $50 \%$ higher.

A similar evaluation, made with a more highly purified Alamine 336 that is now avalable from the manufacturer as the hydrochloride salt dissolved in diethylbenzene, resulted in americium distribution coefficients that are $20 \%$ higher than those for the original material.

Solubility of $\mathrm{AlCl}_{3}$ in $\mathrm{LiCl}-\mathrm{HCl}$ Mixtures. - As previously reported, ${ }^{3}$ the maximum solubility of aluminum chloride in $10 \mathrm{M} \mathrm{L} \mathrm{L}_{1} \mathrm{Cl}_{\text {is }} 0.2 \mathrm{M}$. At these salt concentrations hydrochloric acid in excess of $0.05 M$ will precipitate aluminum chloride. The

\footnotetext{
${ }^{3} \mathrm{D}$. E. Ferguson et al., Transurantum Quart. Progr.
} Rept. Nov. 30, 1962, ORNL-3408, pp. 21-22.

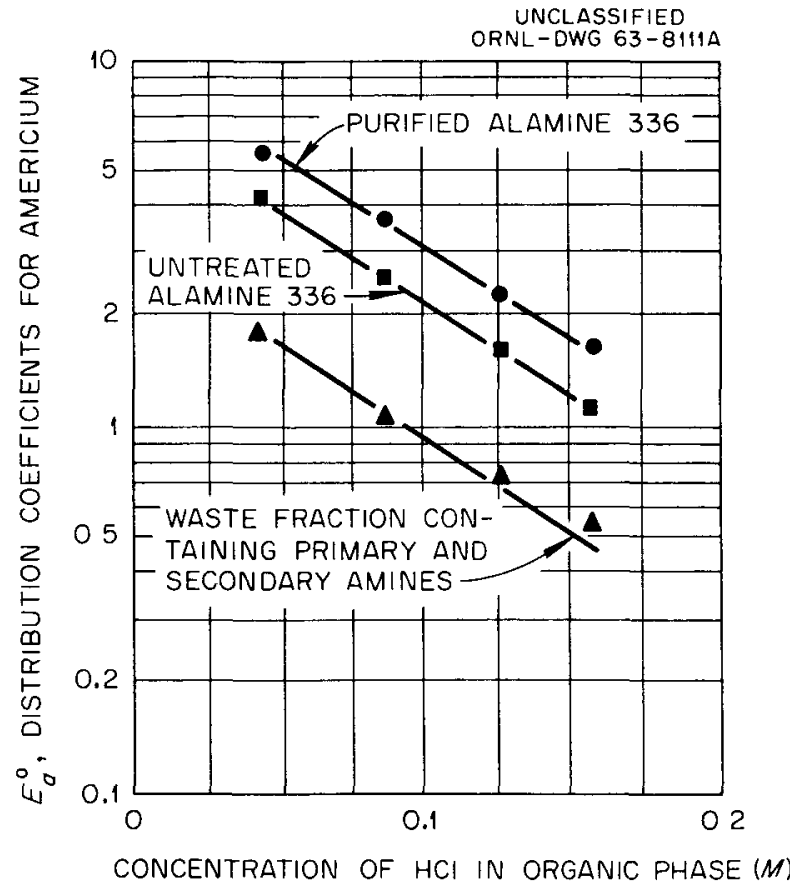

Fig. 4.4. Effect of Primary and Secondary Amine Removal from Alamine 336 on Americium Distribution Coefficients. 
solubility of aluminum chloride in $10 M \mathrm{LiCl}$ solution decreases as the acid concentration increases (Fig. 4.5). At acid concentrations of 0.45 and $0.90 \mathrm{M}$, the solubilities are 0.15 and 0.10 $M$ respectively.

Stability of Alamine 336. $\mathrm{HNO}_{2}$. - In the Tramex process $\mathrm{Ru}^{4+}$ extracts into the organic phase; however, after extraction it is slowly reduced by the amine solvent to the inextractable $\mathrm{Ru}^{3+}$ state. One proposed method of maintaining ruthenium in its extractable form during curium stripping operations is to incorporate Alamine $336 \cdot \mathrm{HNO}_{2}$ into the organic scrubbing section of the strip column. The preparation and stability of $0.6 M$ Alamine 336 . $\mathrm{HNO}_{2}-\mathrm{DEB}$ was therefore investigated.

Alamine $336 \cdot \mathrm{HNO}_{2}$ can be readily prepared by contacting $0.6 M$ Alamine $336 \cdot \mathrm{HCl}-\mathrm{DEB}$ with $1 M$ $\mathrm{KNO}_{2}$; however, this amine salt decomposes upon standing at room temperature. In $72 \mathrm{hr}$, about $50 \%$ of the nitrous acid is destroyed. When the amine

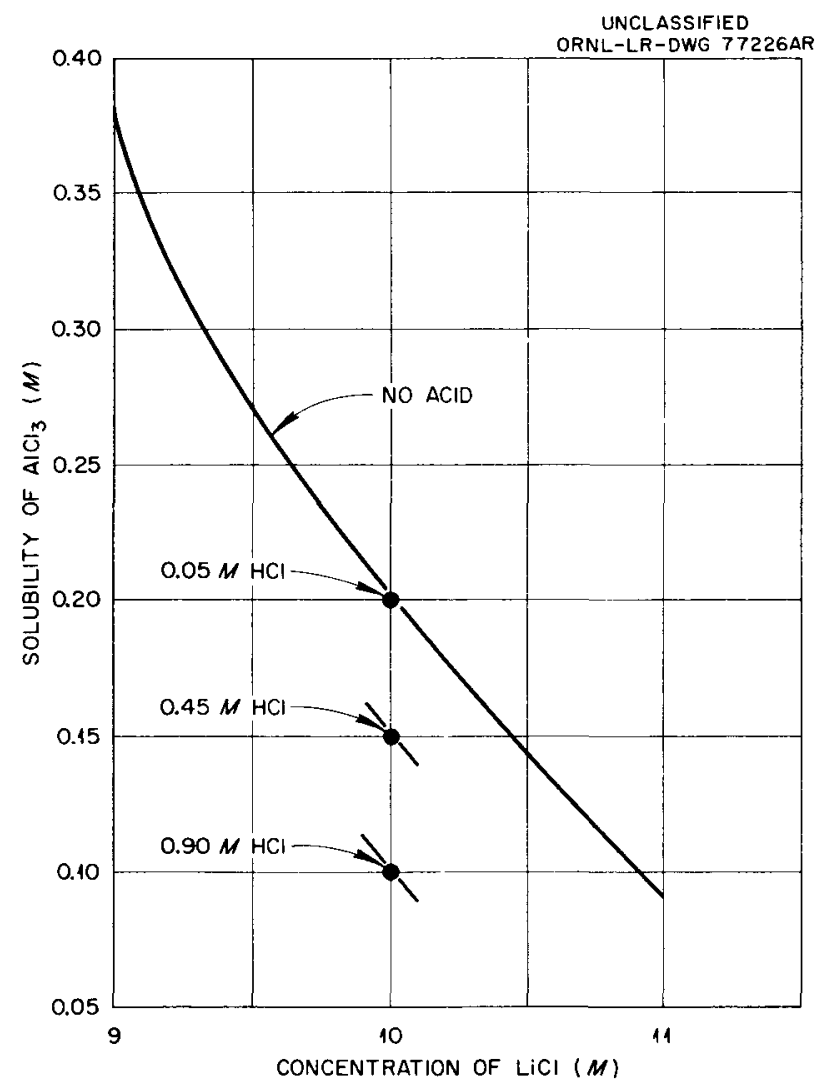

Fig. 4.5. Solubility of $\mathrm{AlCl}_{3}$ in Concentrated $\mathrm{LiCl}$ Solution Containing $\mathrm{HCl}$. salt was kept in contact with $8 \mathrm{M} \mathrm{HCl}$, only $20 \%$ of the nitrous acid remained after $72 \mathrm{hr}$. Contacting the amine salt with $8 \mathrm{M} \mathrm{HCl}$ at $60^{\circ} \mathrm{C}$ further increased the decomposition rate. At $60^{\circ} \mathrm{C}$ the concentration of nitrous acid was decreased from 0.6 to $0.1 M$ in $30 \mathrm{~min}$; the nitrous acid was totally destroyed in $4 \mathrm{hr}$. Because of this instability, Alamine $336 \cdot \mathrm{HNO}_{2}$ must be prepared immediately prior to use in order to be effective.

Plutonium Behovior in the Tramex Process. During HFIR target processing, it may become necessary, because of target failure before complete burnup, to process targets that still contain significant amounts of $\mathrm{PuO}_{2}$. In order to handle such targets by the method that will be used for totally burned targets, it will be necessary to dissolve residual $\mathrm{PuO}_{2}$ in hydrochloric acid. The dissolution of $\mathrm{PuO}_{2}$ in $\mathrm{HCl}$ and the behavior of plutonium in the Tramex process were therefore investigated.

Plutonium oxide that had been calcined at $800^{\circ} \mathrm{C}$ could be successfully dissolved only in $6 \mathrm{M} \mathrm{HCl}$ that was $0.02 M$ in $\mathrm{CuF}_{2}$. A $3-\mathrm{g} \mathrm{Al}^{-} \mathrm{PuO}_{2}$ cermet that contained $1 \mathrm{~g}$ of $\mathrm{PuO}_{2}$ was completely dissolved in $50 \mathrm{ml}$ of dissolver solution within $1 \mathrm{hr}$. Both copper and fluoride ions were required since, singly, neither one catalyzed the dissolution. Further investigation of this dissolver solution is necessary to determine whether the amount of fluoride required in the dissolution will be detrimental to the processing equipment, which is made of Zircaloy-2 and may be susceptible to attack.

Plutonium behavior in the Tramex process was investigated in a laboratory-scale mixer-settler run. Plutonium that had been dissolved in $6 \mathrm{M}$ $\mathrm{HCl}-0.02 M \mathrm{CuF}_{2}$ was adjusted to Tramex feed conditions ( $11 \mathrm{M} \mathrm{LiCl}-0.02 \mathrm{M} \mathrm{HCl}$ ) and extracted with $0.6 M$ Alamine $336 \cdot \mathrm{HCl}-\mathrm{DEB}$. Plutonium valence in the adjusted feed was $86 \% \mathrm{Pu}^{3+}$ and $14 \% \mathrm{Pu}^{4+}$. More than $99.9 \%$ of the plutonium was extracted; however, only $3 \%$ of the extracted plutonium could be stripped with $8 M \mathrm{MCl}-0.1 \mathrm{M}$ $\mathrm{NH}_{2} \mathrm{OH} \cdot \mathrm{HCl}$. When $1 \mathrm{M} \mathrm{HCl}$ was used as the strip solution, a plutonium recovery of $95 \%$ was obtained. All the plutonium valence in the production solution was trivalent, and plutonium losses incurred during stripping were due to the presence of some $\mathrm{Pu}^{4}$.

Tramex Safety. - Numerous small-scale laboratory tests have been made to determine the possibility of fires and explosions resulting from the use of Alamine $336-D E B$ in the Tramex process. Such 
hazards would exist if the solvent were heated in the presence of nitrate. This could occur either by the accidental carry-over of solvent with product currum, which will be converted from chloride to nitrate solutions (Chap. 5), or by recycle of nitrate feed that has been contacted with the extractant.

It was possible to initiate two types of undesirable reactions, however, at least two of the following extreme conditions were required. evaporation to dryness, introduction of a continuous spark in the vapor phase, and the presence of excessive amounts of solvent. By use of a continuous spark in the vapor phase, it was possible in some cases to ignite the vapors, this effect appeared to be simple combustion. The second type of reaction occurred only when the contents of the reaction flask had been distilled nearly to dryness. This reaction could be described as a mild explosion, characterized by a flash of light and a rapid increase in pot temperature. Only two sets of conditions produced an audible detonation, and in no case was the explosion sufficiently violent to rupture the glass reaction flask.

No indications of a fire or explosion could be produced by distilling a mixture of Alamine $336 \cdot \mathrm{HNO}_{3}-\mathrm{DEB}$ and concentrated $\mathrm{HNO}_{3}$ to dryness, however, a very mild explosion or flash occurred in this system when a continuous electric spark was introduced in the vapor phase during distillation. This reaction occurred only after the solution had been evaporated nearly to dryness $\left(147\right.$ to $\left.150^{\circ} \mathrm{C}\right)$.

The addition of $11 M \quad \mathrm{~L}_{1} \mathrm{Cl}$ was effective in reducing this explosion hazard. With the addition of $11 \mathrm{M} \mathrm{LiCl}$ (16 vol \%), mild flashes produced by continuous sparking did not occur until a pot temperature of $265^{\circ} \mathrm{C}$ was reached. The addition of $3 M \mathrm{AlCl}_{3}$ or $10 M \mathrm{LiCl}_{-} 0.01 \mathrm{M} \mathrm{AlCl}_{3}$ (16 vol \%) completely eliminated any reaction, even though the mixture was evaporated to pot temperatures as high as $375^{\circ} \mathrm{C}$. This indicates that $\mathrm{AlCl}_{3}$ is more effective than $\mathrm{L}_{1} \mathrm{Cl}$ for suppressing the reaction.

The addition of either $\mathrm{LiNO}_{3}$ or $\mathrm{Al}\left(\mathrm{NO}_{3}\right)_{3}$ definitely increases the risk of explosion when Alamine $336 \cdot \mathrm{HNO}_{3}-\mathrm{DEB}$ is distilled in the presence of $\mathrm{HNO}_{3}$. In the presence of $8 M \mathrm{LiNO}_{3}(16 \mathrm{vol} \%)$, an audible detonation occurred at $250^{\circ} \mathrm{C}$, with sufficient force to blow all fittings out of the reaction flask. This explosion occurred with or without a continuous spark in the vapor phase, but, when the spark was used, multiple vapor ignitions occurred, beginning at about $85^{\circ} \mathrm{C}$.
These vapor-phase ignitions were also promoted by $\mathrm{Al}\left(\mathrm{NO}_{3}\right)_{3}$, but there was no reaction upon heating to dryness in the absence of a spark.

These results indicate that it is probably safe to adjust Tramex feed to $10 M \mathrm{LiCl}$ by evaporation even if some solvent is present and that care should be taken to make certain that no solvent is present during conversion of the curium product from a chloride to nitrate (Sect. 5) or during heating of $\mathrm{LiNO}_{3}$ or $\mathrm{Al}\left(\mathrm{NO}_{3}\right)_{3}$ solutions.

Since methanol will be used in Tramex feed, the flammability of 2 to 10 vol \% methanol in $11 \mathrm{M}$ $\mathrm{L}_{1} \mathrm{Cl}$ was investigated. These mixtures were distilled to dryness as in the above tests. Methanol vapors could not be ignited with a continuous spark in the free space of the reaction flask, either with or without an air sparge. However, a spark at the condenser outlet did ignite the methanol vapor. The vapor was ignited twice for brief intervals ( 2 or $3 \mathrm{sec}$ ) when the pot temperature reached $133^{\circ} \mathrm{C}$.

\section{Bidentate Compounds as Extractants for Trivalent Actinide and Lanthanide Elements}

Following the recovery of ${ }^{242} \mathrm{Pu}$ from highly 1rradiated ${ }^{239} \mathrm{Pu}$, the ${ }^{243} \mathrm{Am}$ and ${ }^{244} \mathrm{Cm}$ must be recovered from the acıd ${ }^{242} \mathrm{Pu}$ raffinate. $\mathrm{B} 1$ dentate extractants were evaluated as a means of recovering americium, curıum, and rare earths from such solutions. Tetraamyl methylenediphosphonate [TA(MDP)] and dihexyl methylenediphosphonate [DH(MDP)] strongly extracted trivalent actinides and lanthanides from nitric acid solution, in contrast to monodentate extractants, which are generally effective only from nearly neutral salt solutions or very concentrated nitric acid solutions. Although separations between elements in these systems are such that effective intragroup separations cannot be made, these ex. tractants would be useful for the recovery of trivalent actınides and lanthanides from acıd waste solutions.

Extraction coefficients were obtained for Am, Cf, $\mathrm{Ce}$, and Eu between 10 vol \% TA(MDP)-DEB and nitric acid which varied in concentration from 0.2 to $3 \mathrm{M}$. Extraction coefficients decreased in the following manner $\mathrm{Ce}>\mathrm{Am}>\mathrm{Cf}>\mathrm{Eu}$. Separation factors between adjacent elements were 2 or less. With 10 vol \% TA(MDP), extraction coefficients are low, however, useful extractions can be obtained 
with higher concentrations of TA(MDP). The effect of nitric acid concentration on the extraction of americium and europium from $4 \mathrm{M} \mathrm{HNO}_{3}$ is shown in Fig. 4.6. The extraction coefficients of americium and europium are third-power dependent on the percentage of TA(MDP) in the range of 10 to $75 \mathrm{vol} \%$ (Fig. 4.7).

Extraction coefficients were also obtained for $\mathrm{Am}, \mathrm{Cf}, \mathrm{Ce}$, and Eu between 5 vol \% DH(MDP)-DEB and $\mathrm{HNO}_{3}$ (Fig. 4.8). Extraction coefficients are much larger in this system; they decrease with increasing acid concentration. Again, separation factors between adjacent elements are small. Concentrated DH(MDP) is very viscous, and high dilution is necessary to obtain good handling characteristics.

\section{Preparation of Oxides for HFIR Targets}

HFIR targets will be made from pressed pellets of aluminum powder and actinide oxide, and it is

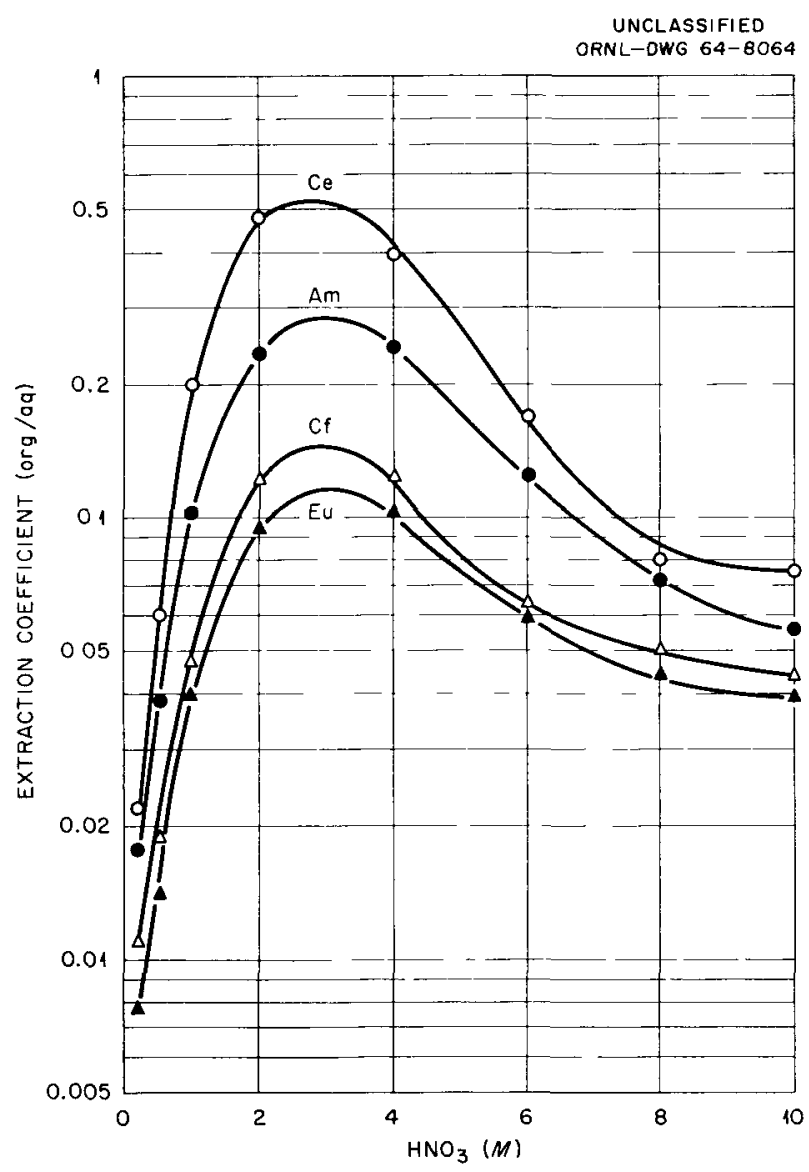

Fig. 4.6. Extraction of Am, Cf, $\mathrm{Ce}_{e}$, and $\mathrm{Eu}_{\mathrm{u}}$ by $10 \%$ Tetraamyl Methylenediphosphonate in Diethylbenzene from Nitric Acid Solutions.

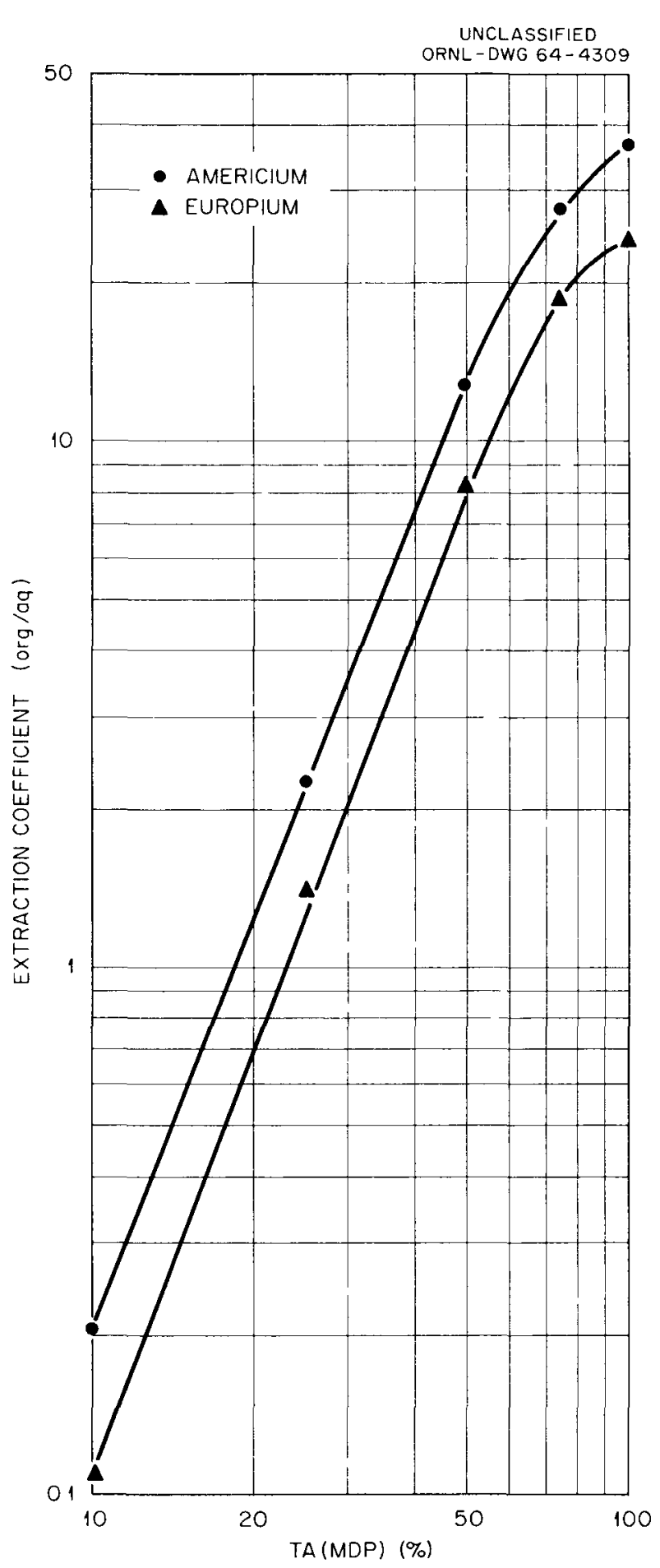

Fig. 4.7. Effect of Reagent Concentration on Americium and Europium Extraction by Tetraamyl Methylenediphosphonate form $4 \mathrm{MHNO}_{3}$. 


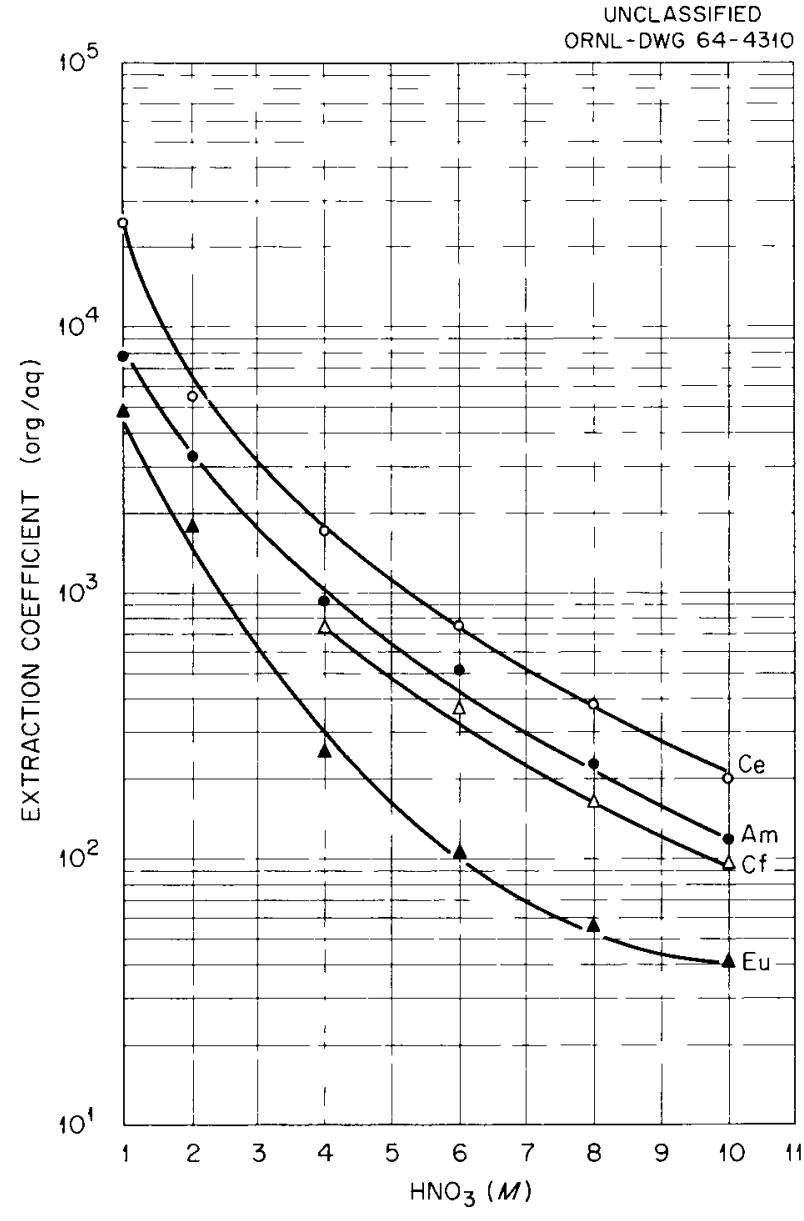

Fig. 4.8. Extraction of Am, Cf, Ce, and Eu by 5 vol \% (0.07 M) Dihexyl Methylenediphosphonate in Diethylbenzene from Nitric Acid Solutions.

essential that the aluminum phase be continuous in order to ensure satisfactory heat transfer during irradiation. When actinide oxide particles less than $10 \mu$ in diameter are mixed with -325 mesh aluminum powder and pressed into cermets, the oxide phase is continuous and the thermal conductivity of the pellet is low. But, with oxide particles ranging from 20 to $200 \mu$ in diameter, the aluminum phase will be continuous, and conductivity will be satisfactory for irradiation in high neutron fluxes.

A modified sol-gel process involving a hydroxide precipitation for preparing dense, coarse particles of $\mathrm{PuO}_{2}$ was reported last year ${ }^{4}$ and, during this

\footnotetext{
${ }^{4}$ F. L. Culler et al., Chem. Technol. DIv. Ann. Progr. Rept. May 31, 1963, ORNL-3452, pp. 114-15.
}

report period, the process was used to prepare two batches for inclusion in prototype target rods.

In the preparation of $\mathrm{PuO}_{2}$ by hydroxide precipitation, about $25 \%$ of the oxide was less than $20 \mu$ in diameter and could not be used. Recycle of this material is a problem since either dried hydroxide or high-fired oxide is difficult to dissolve even in boiling concentrated nitric acid containing $\mathrm{HF}$ catalyst. However, the preparation of $\mathrm{PuO}_{2}$ by a sol-gel method would simplify the recycle problem because the dried gel can be sized before firing at $1150^{\circ} \mathrm{C}$, and the fines generated by grinding the gel are readily dispersible in water. Preliminary indications are that a satisfactory sol-gel process for the preparation of dense $\mathrm{PuO}_{2}$ can be developed.

The hydroxide precipitation method was also successfully used to produce large-particle-size $\mathrm{AmO}_{2}$ powder. Brief attempts to produce americium sols were not successful; however, this effort is continuing. In addition to the investigation of oxide preparations, a method was developed to recover $\mathrm{PuO}_{2}$ from $\mathrm{HFIR}$ target rejects.

Preparation of $\mathrm{PuO}_{2}$. - Seventy-nine grams of dense, high-fired $\mathrm{PuO}_{2}$ containing $69.27 \mathrm{~g}$ of ${ }^{239} \mathrm{Pu}$ was prepared for use in prototype HFIR targets. The oxide was prepared by precipitating $\mathrm{Pu}\left(\mathrm{NO}_{3}\right)_{4}$ with $\mathrm{NH}_{4} \mathrm{OH}$, by washing and drying the precipitate, and then calcining at $1150^{\circ} \mathrm{C}$. The calcined oxide was ground with a mortar and pestle so it would pass through a 70 -mesh screen. Fines ( -325 mesh) generated during grinding were recycled. The particle size of the remaining oxide was as follows:

$\begin{array}{rr}\text { Screen Size } & \text { W } \% \\ -70+140 & 48.37 \\ -140+170 & 15.89 \\ -170+200 & 9.74 \\ -200+325 & 26.00\end{array}$

The above procedure was also used to prepare $90 \mathrm{~g}$ of oxide containıng $80 \mathrm{~g}$ of ${ }^{242} \mathrm{Pu}$. This latter oxide was incorporated into seven target elements, which were fabricated by the Metals and Ceramics Division. The completed targets are being irradiated in one of the SRL reactors to produce transplutonium elements and to gain additional irradiation experience with HFIR target elements.

The ${ }^{242} \mathrm{Pu}$ as received was a finely powdered oxide that had been calcined at about $600^{\circ} \mathrm{C}$. Total dissolution of this material was effected by 
refluxing for $6 \mathrm{hr}$ in $13 M \mathrm{HNO}_{3}-0.025 M \mathrm{HF}$. Following dissolution, plutonium valence was adjusted from (VI) to (IV) with nitric oxide, and the hydroxide was prepared. The calcined oxide was ground with a striking mortar and pestle so it would pass through a 70 -mesh screen. Fines (-325 mesh) generated during grinding will be recycled. With this grinding procedure, the following particle-size distribution was obtained:

$\begin{array}{rr}\text { Screen Size } & W+\% \\ -70+100 & 38.3 \\ -100+200 & 30.3 \\ -200+325 & 14.0 \\ -325 & 17.4\end{array}$

$\mathrm{PuO}_{2}$ Sol Preparation. - Apparent plutonium sols were prepared by digesting freshly precipitated and washed $\mathrm{Pu}(\mathrm{OH})_{4}$ at $60^{\circ} \mathrm{C}$ for $8 \mathrm{hr}$ at a $\mathrm{pH}$ of 1.5. The highest $\mathrm{pH}$ at which complete peptization occurred, regardless of digestion time or temperature, was 1.5. This pH may be a function of batch size and plutonium concentration, as well as of hydrogen ion concentration. Solids that were produced upon drying such sols at $120^{\circ} \mathrm{C}$ were readily dispersible in water; however, they were soft and friable and appeared to be quite porous. When this gel was redispersed in water, the $\mathrm{pH}$ of the sol was 1.5. Calcination of the gel produced a porous, friable $\mathrm{PuO}_{2}$ product that does not appear to be suitable for the preparation of HFIR targets. However, greatly improved product was obtained by heating the dried gel at $160^{\circ} \mathrm{C}$ for $2 \mathrm{hr}$, repeptizing in water, drying to the gel, and calcining. The $\mathrm{pH}$ of the sol formed by resuspending the original gel (after heating at $160^{\circ} \mathrm{C}$ for $2 \mathrm{hr}$ ) was 1.8. Calcination of this gel to the oxide at $1150^{\circ} \mathrm{C}$ produced a hard, glassy product with a density of $10.38 \mathrm{~g} / \mathrm{cc}( \pm 10 \%)$. Such material should be suitable for HFIR target preparation. Laboratory work is continuing in an effort to produce improved plutonium sols and to develop reliable sol-gel procedures.

$\mathrm{AmO}_{2}$ Preparation. - Americium dioxide of acceptable particle size was successfully prepared by the hydroxide precipitation method used to prepare $\mathrm{PuO}_{2}$. In this method, americium was precipitated from nitric acid solution with excess $\mathrm{NH}_{4} \mathrm{OH}$. The resultant precipitate was very fine, but it could be filtered with a medium glass frit. Following washing, the hydroxide was allowed to air dry for several days; small, hard particles formed during the drying process. After calcination at $600^{\circ} \mathrm{C}$ to the oxide, nearly all particles were between 20 and $200 \mu$ in diameter. In subsequent batches, larger particles were produced which would require grinding before incorporation into HFIR targets. The density of the calcined oxide was $10.0 \mathrm{~g} / \mathrm{cc}( \pm 10 \%)$. Attempts to suspend americium hydroxide as a sol by the procedures outlined for plutonium sol preparation were not successful; however, other possible methods of sol preparation are being investigated. Lanthanum will be used as a stand-in for americium.

Dissolution of Prototype HFIR Targets. - Four unirradiated prototype HFIR targets were processed for plutonium recovery, and about $60 \mathrm{~g}$ of plutonium was recovered. These targets consisted of a packed mixture of high-fired $\mathrm{PuO}_{2}$ and aluminum powder. The aluminum was readily dissolved in a solution $1.2 \mathrm{M}$ in $\mathrm{NaOH}$ and $1.5 \mathrm{M}$ in $\mathrm{NaNO}_{3}$. One liter of dissolver solution was used per mole of aluminum. Plutonium losses during aluminum dissolution averaged $0.7 \mathrm{mg} / \mathrm{liter}(0.005 \%)$. The $\mathrm{PuO}_{2}$ was washed with hot $2 \mathrm{MHNO}_{3}$ for additional decontamination from aluminum, and similar plutonium losses were incurred. The $\mathrm{PuO}_{2}$ was dissolved by refluxing for long times in concentrated nitric acid; during reflux, $2 M \mathrm{HF}$ was slowly added until a concentration of $0.01 M$ was reached. The plutonium product, concentrated to $24 \mathrm{~g}$ of plutonium per liter by evaporation, contained 0.02 $\mathrm{g}$ of aluminum per liter of solution.

The dissolution of aluminum in $2 \mathrm{M} \mathrm{HCl}$ was also tested; however, plutonium losses were increased from 0.005 to $0.1 \%$. Plutonium oxide could not be dissolved in either 6 or $12 \mathrm{M} \mathrm{HCl}$; less than $0.2 \%$ had dissolved after refluxing for more than $24 \mathrm{hr}$.

Dissolution in caustic appears to be useful for recovering plutonium from HFIR target rejects. It may not be necessary to dissolve and then re-form the plutonium oxide following aluminum dissolution if the oxide is thoroughly washed.

\section{Actinide Separations by lon Exchange}

An adequate solvent extraction process to separate transcalifornium isotopes or to separate americium from curium is not available; maximum separation factors of adjacent elements for the Tramex and phosphonate systems are less than 2.5. Chromatographic elution from cation resin 
with a-hydroxy1sobutyrate solution is still the most reliable method available for separating transcurium isotopes, and either this system or elution from anion exchange resin with $4.4 M$ $\mathrm{L}_{1} \mathrm{NO}_{3}$ can be used to separate americium from currum. In either process, scaleup to severalmilligram quantities will be difficult because of disturbance of the resin bed by gases formed by radiolysis of the solution.

Methods for controlling or preventing radiolyt1cally produced gas were investigated with americium-curium separations in which radioactivity levels as high as $150 \mathrm{w} /$ liter were provided by $242 \mathrm{Cm}$. Pressurized columns which employed spring-loaded resin beds controlled the effects of gassing by preventing separation of the resin bed, this allowed good separation of americium from curnum. It was also found that methanol was very effective in reducing radiolytic-gas formation in e1ther the a-hydroxyisobutyrate or the $\mathrm{L}_{1} \mathrm{NO}_{3}$ system, and the use of methanol may make it possible to separate einsteinium and fermium from gram quantities of californium.

As an aid in developing improved ion exchange separation methods, stability constants $\left(K_{s}\right)$ for various actinide complexes are being determined to evaluate ligands that are of potential interest. To date, stability constants for americium, curium, berkelıum, and calıfornıum have been determıned for diethylenetriaminepentaacetıc acid and for 1,2-diaminocyclohexyltetraacetic acid.

Separation of Curium from Americium at $\mathrm{H}_{1}$ gh Radioactivity Levels. - The separation of curium from americium by chromatographic elution from a spring-loaded cation exchange column with ammonium a-hydroxyısobutyrate at activity levels of $50 \mathrm{w} / 1_{1}$ ter was achieved. Two milligrams of ${ }^{242} \mathrm{Cm}$ and $4 \mathrm{mg}$ of ${ }^{241} \mathrm{Am}$ were loaded on a $20 \mathrm{ml}$ column of Dowex 1-X8 ( -400 mesh) resin at $80^{\circ} \mathrm{C}$. The curium and americium were eluted with $0.4 \mathrm{Ma}$ hydroxy1sobutyrate at $\mathrm{pH} 4.2$ at a flow rate of 0.3 $\mathrm{ml} \mathrm{cm}{ }^{-2} \mathrm{~min}^{-1}$. Gassing problems were controlled, and separation of the bed was prevented by spring loading the column of resin. Ninety percent of the curium and americium were recovered, with $10 \%$ cross contamination.

The separation of curium from americium was achieved by chromatographic elution from a springloaded anion exchange column with lithium nitrate, the radioactivity levels were equivalent to 100 w/1iter. The characteristic cherry-red glow from the radioactive elements separated into a white band and a red band. The white glow was assoc1ated with curium, while the red was presumably due to the excitation of americium. The separation factor was 1.87 , and results indicate that the separation of curium from americium could be achieved with about $1 \%$ cross contamination.

Since the addition of methanol to Tramex feeds was effective in greatly decreasing radiolytic-gas production, it was used in ion exchange separations of americium and curium. Americium and curium were loaded on $10 \mathrm{ml}$ of Dowex 1-8X (250 to 270 mesh) resin from $8 \mathrm{M} \mathrm{L}_{1} \mathrm{NO}_{3}-20 \mathrm{vol} \% \mathrm{CH}_{3} \mathrm{OH}$ at an activity level of $150 \mathrm{w} / 1$ iter. The methanol greatly inhibited but did not completely eliminate the gassing of the solution. Curium loaded on the column in a band at a radioactivity level equivalent to 500 to $1000 \mathrm{w} /$ liter. Although the resin became discolored within a few minutes, there was little gassing. Americium and curium were eluted with $3.6 M \mathrm{~L}_{1 N O}-20$ vol $\% \mathrm{CH}_{3} \mathrm{OH}$, giving one product containing $94 \%$ of the curium and $3 \%$ of the americium and another product containing $87 \%$ of the americium and $0.8 \%$ of the curium. Without methanol to inhibit radiolytic-gas formation, the column would have been inoperable because of large pockets of gas.

Methanol was also used to decrease the production of radiolytic gas during americium-curium separation by elution from cation resin with $0.5 M$ ammonium a-hydroxyisobutyrate-20 vol $\% \mathrm{CH}_{3} \mathrm{OH}$ at $\mathrm{pH} 4.1$. At radioactivity levels of 500 to $1000 \mathrm{w}$ per liter of resin, the column operated satisfactorily, with no disruption of the bands. One product contained $90 \%$ of the cursum and $1 \%$ of the americium, and the other contained $85 \%$ of the americium and $2 \%$ of the curium.

The use of methanol to inhibit radiolytic gas formation may make it possible to separate einsteinium and fermium from gram quantities of californium by chromatographic elution from cation exchange resin with a-hydroxyisobutyrate. This is of great importance since no other satisfactory method is available for this separation. The ${ }^{242} \mathrm{Cm}$ alpha activity levels in the above mentioned laboratory runs correspond to a ${ }^{252} \mathrm{Cf}$ loading equivalent to 1.5 to $2.0 \mathrm{~g}$ per liter of resin. However, larger-scale tests at the same activity levels are needed to prove the usefulness of this method.

Determination of Stability Constants for Ameriicium, Curium, Berkelium, and Californium Complexes. - Stability constants $\left(K_{s}\right)$ for various actinide complexes are being determined to evaluate 
ligands that are of potential interest in separation processes. These stability constants were determined by comparing (1) actinide distribution coefficients between cation exchange resin and aqueous solutions containing known quantities of the ligand and (2) distribution coefficients measured in the absence of a complexing ligand.

Americium, curium, berkelium, and californium stability constants were determined for diethylenetriaminepentaacetic acid (DTPA) and for 1,2diaminocyclohexyltetraacetic acid. The values obtained for DTPA and their relationship to lanthanide stability constants are shown in Fig. 4.9. The stability constant for americium is greater than that for any of the rare earths; however, actinide stability constants gradually decrease in the following manner: americium > curium $>$ berkelium $>$ californium. The stability constant for californium is only slightly greater than that for europium.

This study is of value in obtaining a better understanding of the Talspeak Process (Chap. 5). However, the strengths of the complexes formed do not completely explain the behavior of all actinides

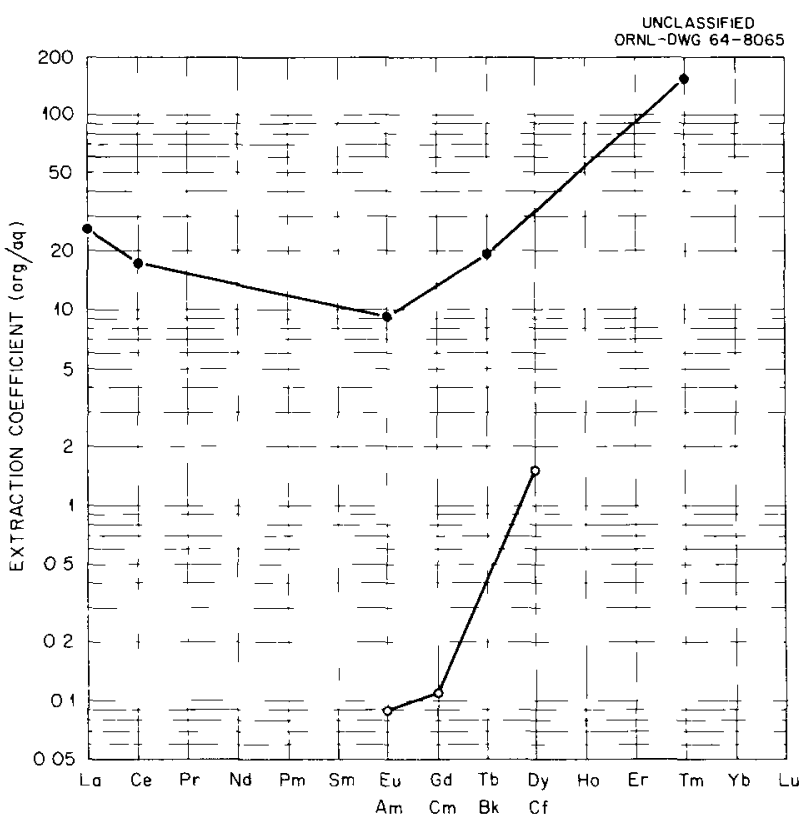

Fig. 4.10. Relative Extraction of the Actinides and Lanthanides by $0.1 M$ 2-EH( $\phi$ P)A-DEB from $1 M$ Glycolic Acid Containing $0.05 M$ DTPA at pH 3.0.

and lanthanides. When extraction is made into 2-ethylhexyl phenylphosphonic acid [2-EH( $\phi \mathrm{P}) \mathrm{A}]$ from dilute mineral acids, americium and curium extraction coefficients are between those of praseodymium and neodymium. However, the americium and curium complexes with DTPA are much stronger than the praseodymium and neodymium complexes (Fig. 4.9). In the presence of DTPA, americium and curium extraction into $0.1 \mathrm{M}$ $2-\mathrm{EH}(\phi \mathrm{P}) \mathrm{A}-\mathrm{DEB}$ is decreased sufficiently to make it possible to extract all lanthanides away from americium and curium (Fig. 4.10). Since the californium extraction coefficient into $2-\mathrm{EH}(\phi \mathrm{P}) \mathrm{A}$ from mineral acids without a complexing agent is about 40 times that for americium and curium, and since the californium-DTPA stability complex is weaker, the californium-europium separation factor is only 8 , compared with the americium-europium separation factor of more than 100 (Fig. 4.10).

Investigation of stability constants of the complexes will be continued both to aid in understanding Talspeak and to develop improved ion exchange separation methods for separating californium, einsteinium, and fermium.
Fig. 4.9. Stability Constants of Lanthanides and Actinides with Diethylenetriaminepentacetic Acid. 


\subsection{DEVELOPMENT OF PROCESS EQUIPMENT}

Experimental engineering studies are required in order to develop the equipment and procedures and to obtain information to permit the design of the chemical processing equipment. Maintenance and mechanical handling problems are being invest1gated in a full-scale mockup, complete with manipulators, cubicle floor pan and roof tank pit, and conveyor. Individual components, such as pulsed columns, pumps, disconnects, and ion exchange columns, are being tested, and design data are being obtained.

Tests of the equipment-rack handling system, including the transfer case and rack-guide system, have almost been completed, after some minor modifications, the system is functioning satisfactorily. The feasibility of handling a replaced alpha-seal window inside the cubicle with the transfer-case hoist and heavy-duty master-slave manıpulators was demonstrated. Several components, including the proposed sampling station, large-diameter disconnects for the waste and offgas header system, and an impact wrench for incell maintenance, were tested, modified as required, and made to function properly.

Satisfactory hydraulic operation of a pulsedcolumn set for the Tramex process was achieved, and adequate stage heights of $17 \mathrm{in}$. were measured for the scrub section. Tests of the phosphonate process for the separation of transuranium elements into an americium and curium fraction and a transcurium fraction showed that stage he1ghts of $8 \mathrm{in}$. for extraction and $14 \mathrm{in}$. for stripping could be achieved. Rare-earth tracers were used in these runs. A similar set of columns was built and placed in a glove box for use with actinide tracers. Operation of this set in the coming year will permit the measurement of extraction and stripping stage heights for the Tramex process and a complete demonstration of the phosphonate process with actinide tracers.

\section{Mockup Studies}

The suitability of design concepts for the process equipment is being determined by thorough experımental testing of full-scale apparatus. The testing of process equipment is nearly complete, as is the testing of handling and maintenance concepts in a full.scale cell mockup. Prototypes of most of the process equipment and maintenance apparatus will be tested in the cell mockup.

A single unit of the TRU sampler was mocked up and tested to check (1) the ease of part replacement, (2) the operation of the bottle-lift mechanism, and (3) the flow characteristics through the needle system. After minor change in the rear guide system of the lift mechanism and a reduction in orifice diameter, sampling tests with water and $10 M \mathrm{LiCl}$ solutions indicated that representative samples could be taken with a sampling time of 10 to $15 \mathrm{~min}$ and a pump frequency of $20 \mathrm{cpm}$.

The fabrication, assembly, and testing of the first six TRU pumps pinpointed the difficulties to be expected in the manufacture and operation of the remaining pumps. Problems encountered were (1) leaking check valves and (2) diaphragms that were sheared along the seal line. Check-valve leakage was considerably reduced by pressing a $1 / 4$-1n. hardened steel ball in the check-valve seat as an additional step in the assembly procedure. This consistently produces check valves that seal adequately. The shearing of the Zircaloy-2 diaphragm along the seal line is eliminated when the diaphragm is made of annealed stock. A test apparatus was operated to life-test both annealed and unannealed diaphragms, and diaphragm life in excess of $3 \times 10^{6}$ cycles was achieved for materials. An additional seal configuration in the form of a rectangular tongue $0.003 \mathrm{in}$. high and $0.015 \mathrm{in}$. wide was tested to see if this cheaper design could be effectively sealed. It sealed, but did not indent the diaphragm properly, therefore, we decided to use the original tongue-and-groove seal.

A $13 / 4-1 n .-O D$ disconnect was tested for use in the waste and off-gas headers in TRU. The test sample, constructed of stanless steel, leaked less than $2.5 \times 10^{-9}$ standard cc of helium per second after six make-and-break cycles.

A disconnect $\left(1 / 4^{-1 n}\right.$. size, with $3 / 8^{-1 n}$. tubing connections) was tested at a pressure of 25,000 psi for use in the lines to the hydraulic collapse unit in the target-fabrication cells. The disconnect, sealed at a torque of $20 \mathrm{lb}-\mathrm{ft}$ using the TRU disconnect clamp, was leaktıght against a pressure of 30,000 psi.

A right-angle drive unit for the electric impact wrench was tested for operation of the disconnect clamps. The torque output is reduced approximately $30 \%$ by the drive. A ratchet wrench (with a 
24 -in. handle) operated disconnect clamps successfully without overstressing the manipulators.

Test operation and adjustment of the equipmenttransfer case are nearing completion. The adjustments included the alignment and pinning of the door-guide plates, shimming of the door brackets, remachining galled surfaces in the hoist mechanism, the installation of a double-lead worm gear in the hoist drive section, the addition of positioning screws for the hoist drum, and adjustment of the transfer-case door-lock drives and cam plate. After proper door position was obtained, the door was watertight $\left(1 \frac{1}{2}\right.$ in. deep). Future plans call for a $1 / 32$-in.-high metal bead on the seal surfaces to give a better seal on the flat rubber gaskets. After the $1 / 16^{- \text {in. }}$-thick solid-rubber window gaskets were replaced with $\frac{1}{8}$-in.-thick sponge rubber, leakage was reduced to 0.8 liter of air per min at 0.3 in. of water pressure.

The equipment-transfer-case hoist functioned satisfactorily after the above changes were made. Equipment racks with a load of about $400 \mathrm{lb}$ were drawn into the transfer case and then reinstalled successfully on the tracks. The right equipment rack was removed and installed in the back-rack position and vice versa, demonstrating the feasibility of the transfer system. Some difficulty in starting the equipment rack into the transfer case was encountered. Redesigned guides with rollers and increased flare were installed. Tests and adjustments of the new guides should conclude the equipment-transfer-case work.

The new extended-reach, heavy-duty manipulators (Central Research Laboratory, model F) have performed very well and have required no maintenance to date. The locking feature proved very helpful in handling the equipment racks. This feature enables one operator, in a number of instances, to do the work of two.

Preliminary alpha-window-removal feasibility tests were completed. In this proposed scheme, the old alpha window is pushed into the cubicle as the replacement window is installed from the operating side. The old window frame is then disassembled in the cubicle and the window placed in a canvas bag prior to shattering it. This disassembly and breakage is required since the window is too large to go into the transfer case. A heavy steel plate weighing $300 \mathrm{lb}$ was handled with the transfer-case hoist and the cell manipulators. The plate was moved from its rest position with a small block and tackle (operated by the manipulators) to a new position for disassembly and then to another for bagging. Refinements were made in the design of the canvas bag and in the window-moving mechanism. The tests will be completed with a more-complete window mockup furnished by the window manufacturers.

The installation and removal of the hot disconnect well and the tube bundle by means of the building crane, extension cables, manipulators, and the equipment-transfer-case hoist were accomplished remotely, thus demonstrating the design feasibility. Only minor changes were needed to perfect the procedure.

Jumper lines which connected the hot disconnect well and the equipment racks were mocked up and tested for ease of installation and removal by means of master-slave manipulators. In a few instances it was necessary to remove the top disconnect clamp arm in order to clear the disconnect ferrule during assembly. However, this problem is minimized with the new disconnect clamp.

The feasibility of the service-line disconnect design concept was demonstrated by means of an alignment jig mockup installed on the backequipment track. The male disconnects with a short length of $\frac{1}{2}-$ in. tubing and a $90^{\circ}$ bend were clamped in a split manifold bolted to the equipment rack. The disconnects were then aligned in the jig. Perfect registration of the disconnects with the clamps on the side rack was made when the rack was moved from the jig to the side rack.

\section{Development of Pulsed Columns}

Small pulsed columns $\left(1 \frac{1}{2}\right.$ in. in diameter by $6 \mathrm{ft}$ high) are to be used in the TRU Facility. Development work was continued with pulsed columns $(3 / 4$ in. in diameter and $4 \mathrm{ft}$ high) to determine the best operating conditions for good efficiency and capacity.

For the rare-earth scrub section of the Tramex flowsheet, the best pulse conditions - a frequency of $40 \mathrm{cpm}$ and amplitude of $0.2 \mathrm{in.} \mathrm{-} \mathrm{gave} \mathrm{a} \mathrm{stage}$ height of $17 \mathrm{in}$. and a total capacity of $12 \mathrm{ml} / \mathrm{min}$ at $50^{\circ} \mathrm{C}$. Increasing the temperature to $70^{\circ} \mathrm{C}$ improved the efficiency and flow capacity slightly. Addition of FX-170, a fluorochemical surfactant, increased the flow capacity threefold but also increased the stage height by the same factor. It was necessary to increase the pulse frequency to 
$80 \mathrm{cpm}$ to obtain satisfactory efficiency, which also reduced the capacity; thus, there appears to be no advantage in adding the surfactant. Variation of aqueous flow rate (while maintaining constant organic flow) to give aqueous/organic ratios of $\frac{1}{3}, 1 / 2$, and $1 / 1$ caused no change in efficiency. Increasing the plate spacing from $1 / 4$ in. to $1 / 2$ in. increased the stage height by $50 \%$ without increasing the flow capacity significantly.

Very nearly complete removal of nitrate from $5 \mathrm{M}$ $\mathrm{HCl}-1 \mathrm{MHNO}_{3}$ was accomplished in one pulsed column by extraction of nitrate with $30 \%$ Alamine 336 in diethylbenzene. The nitrate content of the raffinate was $0.0005 \mathrm{MNO}_{3}$, which is equivalent to a stage height of $12 \mathrm{in.}$

The phosphonate process for the separation of transplutonium elements into an americium-curium fraction and a transcurium fraction was tested in the same $3 / 4$-in.-diam pulsed columns. Europium tracer (a stand-in for the transcurium elements) was extracted from $1.3 M \mathrm{HCl}$ by $1 M$ di-(2ethylhexy 1)phenylphosphonic acid in diethylbenzene and stripped with $3 \mathrm{M} \mathrm{HCl}$ at the following flow ratios: feed/organic/strip $=2 / 2 / 1$.

The total flow capacity was $35 \mathrm{ml} / \mathrm{min}$ at a pulse frequency of $40 \mathrm{cpm}$ and an amplitude of 0.2 in. at $25^{\circ} \mathrm{C}$. At the same operating conditions, the average stage height was 8 in. for extraction and $14 \mathrm{in.} \mathrm{for} \mathrm{stripping.} \mathrm{The} \mathrm{addition} \mathrm{of} \mathrm{air} \mathrm{at}$ $1 \mathrm{cc} / \mathrm{min}$ into the bottom of the column to simulate radiolytic-gas generation at a rate equivalent to a power density of $20 \mathrm{w} /$ liter caused some loss of pulse, which was compensated for by operating at a frequency of $60 \mathrm{cpm}$ where no significant loss of capacity or efficiency was observed.

\subsection{DESIGN AND FABRICATION OF PROCESS EQUIPMENT}

Chemical process equipment will be located in four cubicles and seven tank pits of the Transuranium Processing Plant. Equipment that requires access by the master-slave manipulators, either for operation or routine maintenance, will be mounted in the cubicles on one of three equipment racks. The tank pits, located below and behind the cubicle, will contain the process tanks and interconnecting process piping. Detailed design of this equipment is being done in the Engineering Department of the Oak Ridge Gaseous Diffusion Plant.
While some of the less unusual equipment is being procured commercially, the bulk will be built in the ORNL shops.

The design of most major equipment components, including seven of the ten equipment racks, the four process sampler stations, the process tanks, the interpit piping plug assemblies, and the cell waste and off-gas header system, has been completed, and fabrication or procurement is under way. Overall design progressed from about $20 \%$ complete at the beginning of the year to approximately $65 \%$ complete now. Cell piping, makeup area equipment, and cold-service piping comprise most of the remaining design effort. The design of process equipment is scheduled for completion by February 1965 and is on schedule.

In order to facilitate fabrication of the complex equipment required for the process, approval was requested and obtained from the $\mathrm{AEC}$ to make much of the critical and unusual equipment items in our shops. Equipment in this category requires an estimated 7000 man-days of shop work and includes the ten cubicle-equipment racks and all the in-cell process piping.

Fabrication of the equipment rack for the firstcycle solvent extraction system and one of the four sampler stations is completed. Fabrication of other components for which design has been completed is in progress. Procurement of the 28 tanks required for the process has been started. Following delivery of the basic tank vessels, scheduled for January 1965, the nozzles will be inserted through the vessel heads and mechanically rolled into the heads in our shops. Fabrication and procurement of all process equipment and piping, presently $15 \%$ complete, are scheduled for completion in August 1965.

\section{Equipment Design}

Design has been completed for most of the primary equipment components. Detailed process piping design is complete for cell 7 and cubicle 7 . Piping for the remainder of the cell bank and for the makeup and service area outside the cell bank is being designed.

Cubicle-Equipment Racks. - Cubicle equipment will be mounted on three removable racks, $3 \mathrm{ft}$ wide by $18 \mathrm{in}$. deep by $6 \mathrm{ft}$ high; two are located on the sides and one on the back of the four process cubicles. 
Equipment for the Tramex process will be on the left side rack in cubicle 7 and will consist of three pulsed columns, $1 \frac{1}{2}$ in. in diameter, with 5 -ft-long active sections. In addition to the columns, other components required for the operation of the solvent extraction system, including the feed-metering system, the pulsers, intercycle pumps, columns, pressure-pot control systems, and solution holdup tanks, will be mounted on the rack. The equipment rack pictured in Fig. 4.11 is undergoing cold testing. Equipment for the second cycle of solvent extraction, in which americium and curium is separated from the higher actinides, will be located on a similar rack in cubicle 6 .

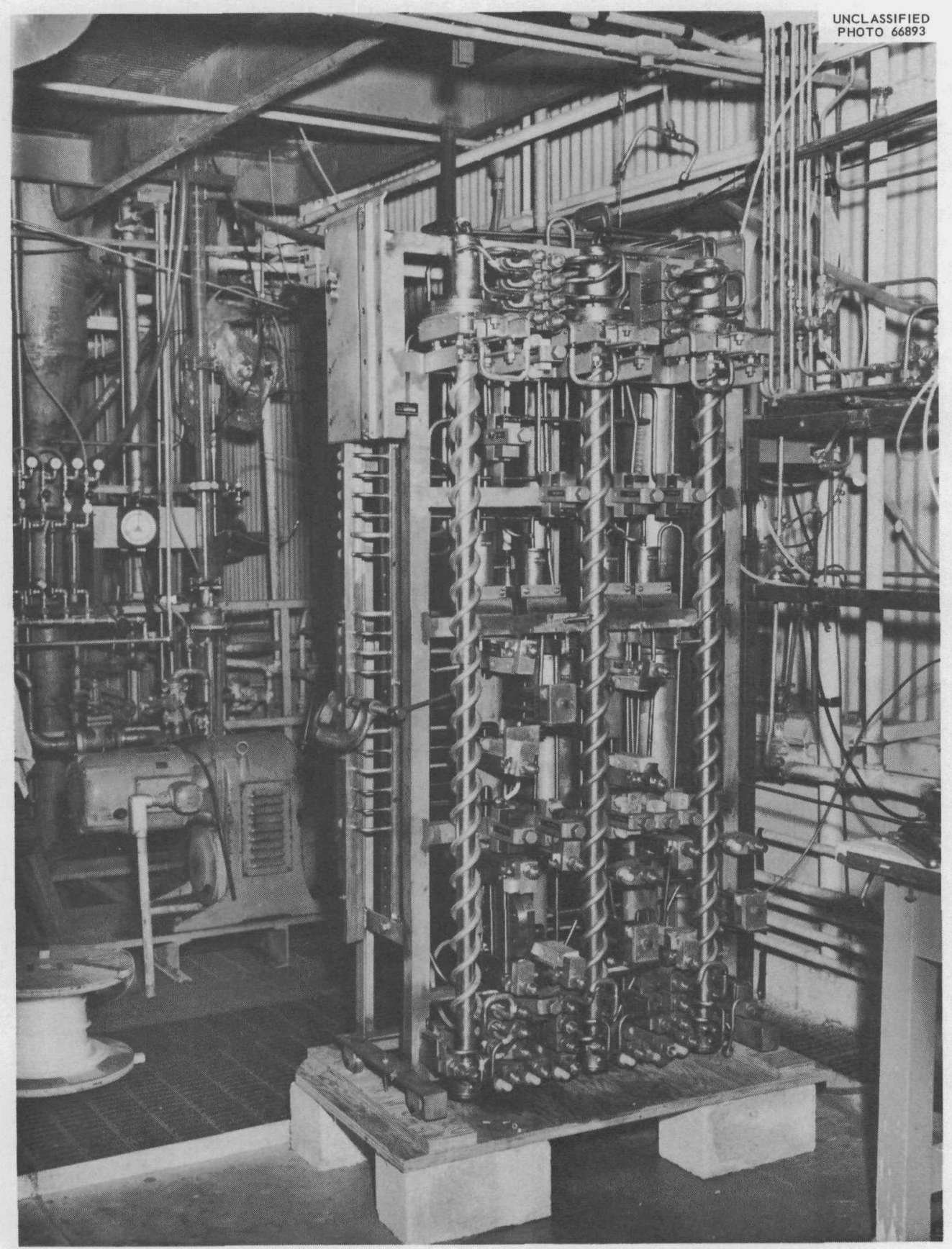

Fig. 4.11. First-Cycle Solvent Extraction Rack. Columns and all piping are of Zircaloy-2. 
The right side-rack in cubicle 6 will contain an ion exchange column with a 1.5-1iter resin capacity, associated feed pump, and resin handling and solution-distribution systems. This equipment will be used for miscellaneous recovery operations and plutonium recovery from short-term irradiations. A hydraulically operated piston at the top of the column retains and compresses the resin bed, making possible upflow loading and elution even in the presence of significant gas evolution.

Berkelium is separated from the higher actinides in a batch extraction system located on the right equipment rack in cubicle 6 . A nitric acid feed containing the mixed actinides is equilibrated with an organic extractant (30\% D2EPHA in decane) in a batch spray column. The berkelium is extracted into the organic and retained in the column. After the organic phase has been scrubbed with cold feed, the berkelium is stripped from the organic or purified product. Distribution coefficients would give separation factors better than $10^{7}$ in a single contact if complete phase separation were achieved, so the equipment was accordingly designed to minimize entrainment and solution holdup.

Each back equipment rack in the four process cubicles will house a 12 -unit sampler station ${ }^{5}$ for sampling the process tanks. Design of the stations is complete, and the first has been built. Distribution systems for the various actinide products and miscellaneous equipment will occupy the upper section of the back racks.

The two side racks in cubicle 4 will contain equipment for the separation of californium, einsteinium, and fermium, and for the preparation of actinide oxides for recycle back to the HFIR. Design is being held up pending flowsheet development work of this equipment. Cubicle 5 is free of equipment except for the sampler station. It will be used for special separations as the need arises.

Process Tanks. - The in-cell tanks for the process can be classified in three groups as: (1) feed and product evaporators, (2) product storage tanks, and (3) waste accumulation tanks. The tanks are about $4 \frac{1}{2} \mathrm{ft}$ high and range in volume from 20 to 150 liters. All nozzles terminate in TRU disconnects located $40 \mathrm{in}$. above the head of the tank. During maintenance operations, the tank

\footnotetext{
${ }^{5}$ F. L. Culler et al., Chem. Technol. Div. Ann. Progr. Rept. May 31, 1963, ORNL-3452, pp. 120-22.
}

pits will be flooded with water to a level just below the disconnects to provide shielding.

The evaporators consist of tantalum-lined, Hastelloy $\mathrm{C}$ vessels with flanged heads of $\frac{3}{8}$-in.thick tantalum plate. The evaporators and associated condensers are designed for boilup rates of 15 liters $/ \mathrm{hr}$.

The product storage and waste accumulation tanks (Fig. 4.12) will be of all-welded construction except for the tubing penetrations through the tank heads, where rolled joints will be used. The product storage tanks will be fabricated from Zircaloy-2, which is sufficiently resistant to corrosion to prevent the buildup of undesirable amounts of corrosion products or contaminants in the stored actinide products. The waste accumulation tanks will be made of Hastelloy $\mathrm{C}$, which

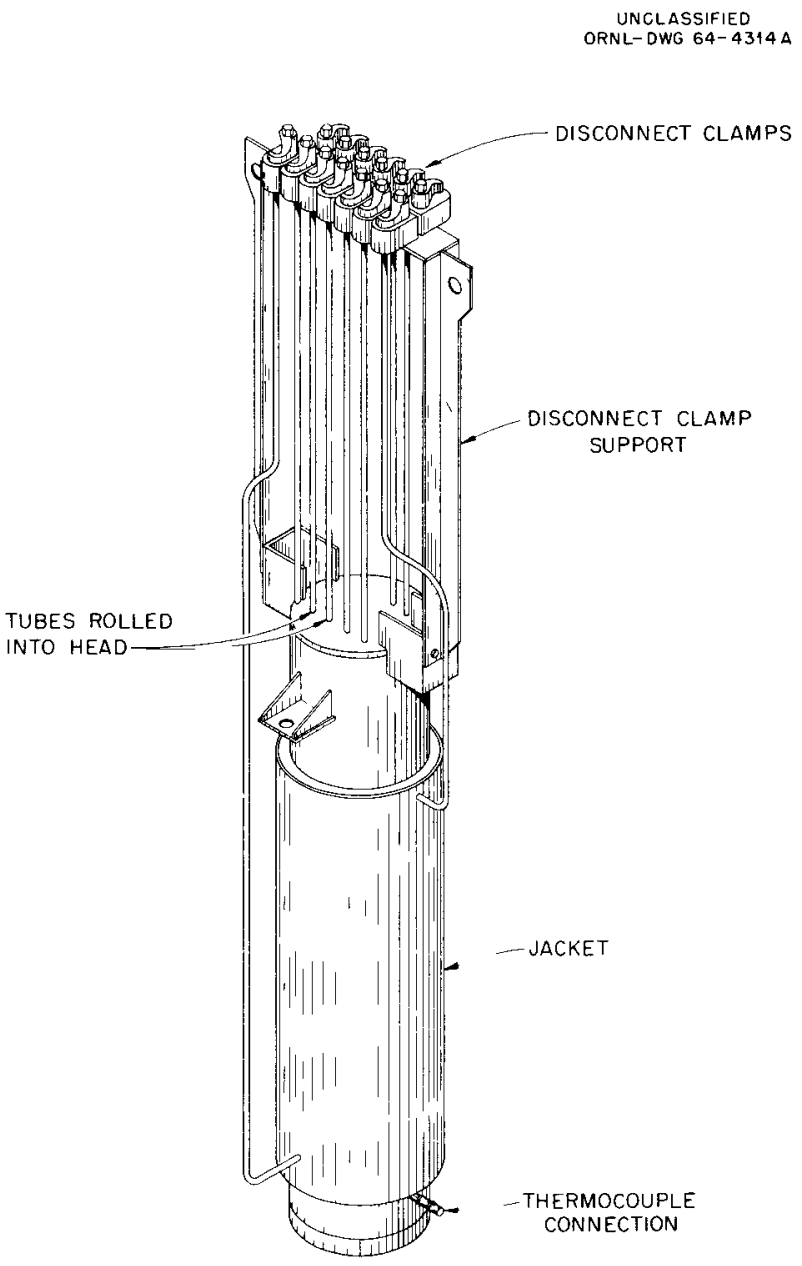

Fig. 4.12. Typical Design of TRU Process Tank for Product Storage and Waste Accumulation. 
has acceptable corrosion rates for this application. Nozzles for both types of tanks will be of Zircaloy-2.

The design of these vessels is complete, and procurement has just started.

In-Cell Process Piping. - Piping connections between equipment components in both cubicle and pit will be made by individual jumper lines; TRU disconnects will be used at either end. Interconnecting jumper lines between cubicles and pits are grouped in bundles.

Piping connections between cells will be routed through intercell piping plugs (Fig. 4.13) set into 1 - by 5 -ft openings in the cell partition walls. Jumper lines will run from disconnects mounted on these plugs to other locations in the pits. The plugs will seal to a metal frame permanently mounted in the opening. The waste header is installed in an opening in the removable plug, and the off-gas header is installed in a similar opening in the permanent frame above the piping plug. The waste header in any pit can be remotely replaced without disturbing the piping plugs. Individual sections of the off-gas header can be replaced only after disconnecting and moving sections in other cells.
Critical Path Scheduling. - Critical path scheduling is being used on the Transuranium project. For scheduling, the project is divided into two major segments: (1) design and construction of the building and (2) procurement of the equipment, including chemical process equipment, target fabrication equipment, and building mechanical equipment. The items in the second segment are the responsibility of ORNL.

In August 1963 the ORNL portion of the schedule, developed during the previous year, was revised and updated to reflect changes and progress in design. As a result of this updating, a significant increase in overall manpower requirements was evidenced (an increase from 8000 to 11,856 mandays). Since that time, about 2300 additional man-days have been added. At present, the design is $69 \%$ complete; the scheduled rate of expenditure of design manpower is shown in Fig. 4.14.

Each month, a detailed progress report itemizing the status of all design activities is prepared and transmitted to project personnel. This report, including progress curves for the three major design subgroups, a summary curve, and other pertinent information, is presented monthly to project management for review. The status of the

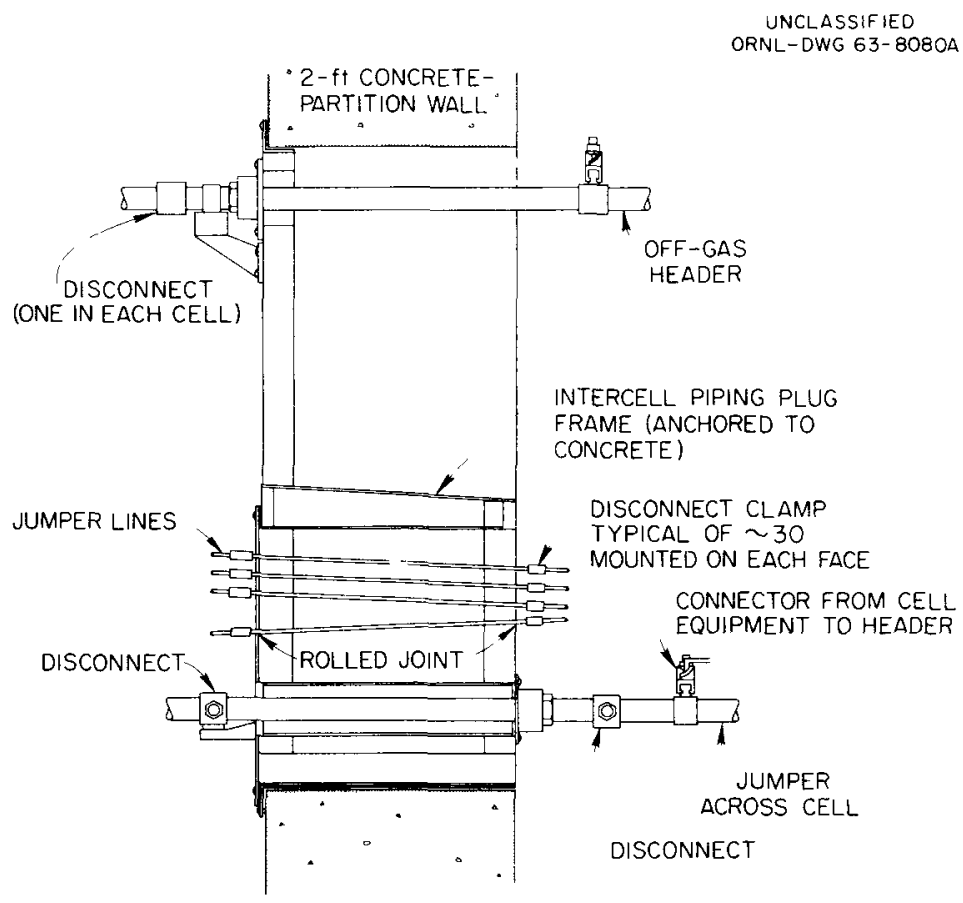

Fig. 4.13. Intercell Piping System, Elevation. 
three major design subgroups as of May 31, 1964, is as follows: chemical processing equipment (39\% of total design), $67 \%$ complete; mechanical equipment ( $23 \%$ of total design), $79 \%$ complete; and target fabrication equipment (38\% of total design), $67 \%$ complete.

In June 1963, a summary critical path schedule depicting the major components of the TRU construction program and their interrelationships was prepared (the March 1964 revision is shown as Fig. 4.15). This summary schedule is aimed at presenting only the important details affecting the schedule and is reported quarterly to the Atomic Energy Commission.

In July 1963, the development of a schedule for the fabrication of chemical processing equipment by the Plant and Equipment Division's fabrication department was agreed upon. In January 1964, such a schedule, involving approximately 7000 man-days of local shop effort, was generated. This work is now slated for completion in July 1965.

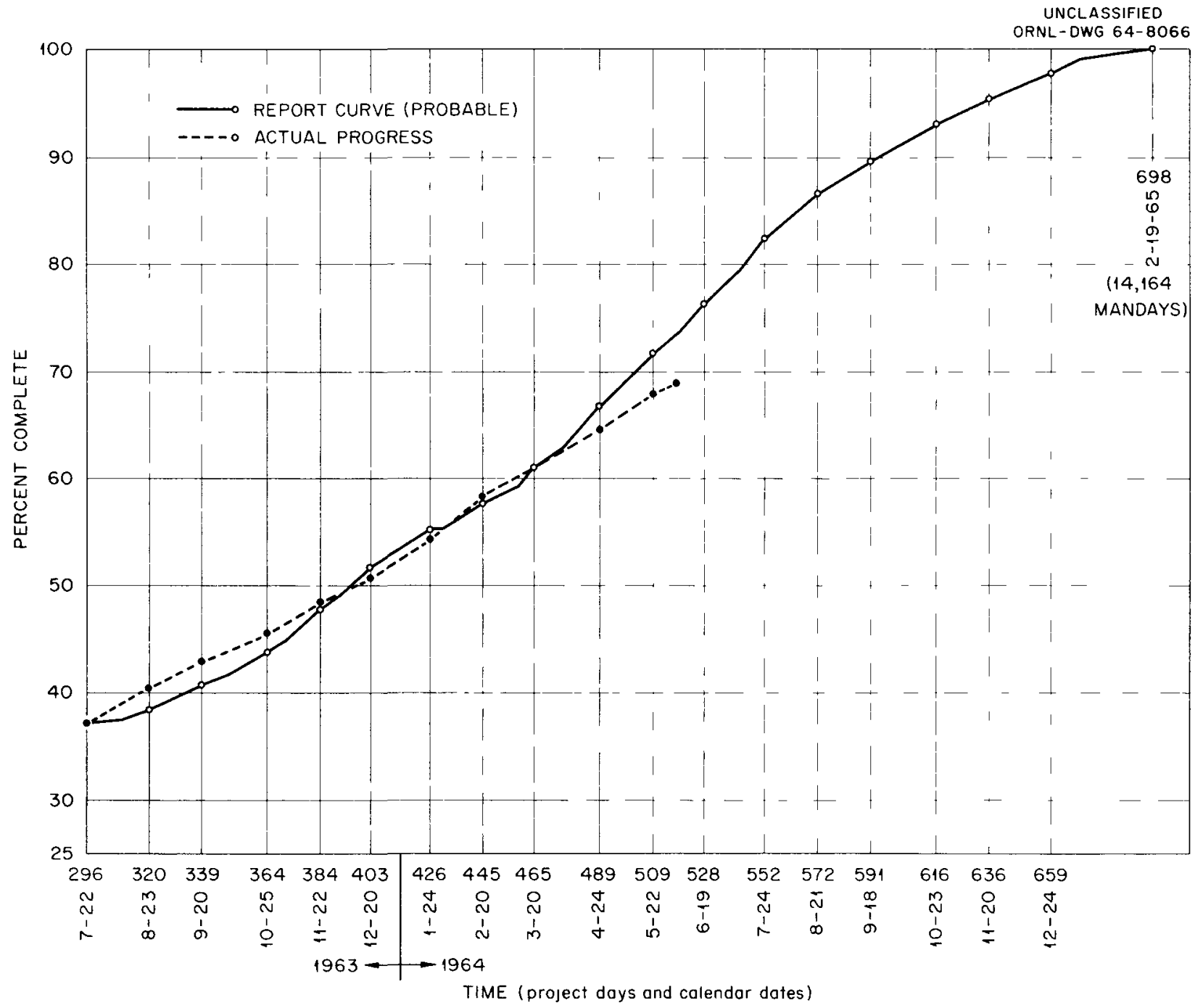

Fig. 4.14. Transuranium Processing Plant, Total Design-Progress Curve. 


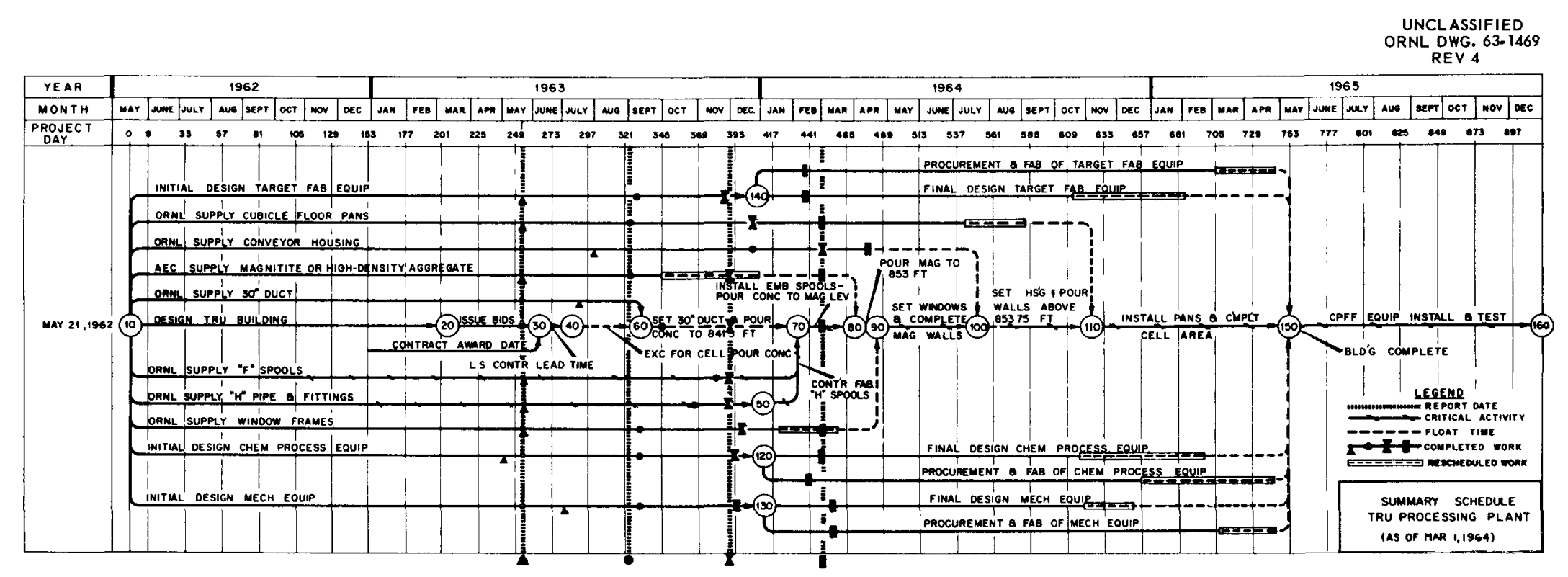

Fig. 4.15. Summary Schedule, TRU Processing Plant. 


\subsection{CONSTRUCTION OF THE TRANSURANIUM PROCESSING PLANT}

\section{Building Construction}

The construction contract for the Transuranium Processing Plant (TRU) was awarded to Blount Brothers Construction Company of Montgomery, Alabama, on June 14, 1963. The construction subsequently was started on July 1, 1963, with a scheduled completion date in early April of 1965. The construction, as of July 1, 1964, is approximately 50\% complete and progressing in accordance with the critical path schedule which the contractor has prepared for the Atomic Energy Commission.

The building is now completely enclosed and roofed in, except for the exterior doors. The concrete pits, which contain the cell ventilation and off-gas filter assemblies, the underground pipe tunnel, and the nine hot cells, have been poured to final first-floor elevation. High-density concrete has been successfully poured in the front cell wall, and the cell-viewing-window frames have been accurately positioned. The first application of Fiberglas-reinforced epoxy resin coating to the interior cell wall was completed. The first- and second-floor slabs have been poured, and the second-floor partition walls have been erected. All underground piping has been installed, as has the main heating and air conditioning unit.

The 50-ton building crane in the high bay area, with its 5-ton auxiliary hoist, was installed and is in temporary operating condition. The contractor has utilized it for placing concrete in the interior of the building and for placing the precast concrete shielding plugs that form the floor of the 11 mited-access area.

\section{Procurement of Government-Furnished Equipment}

The responsibility for the procurement of several specific, high-quality equipment 1 tems was removed from the contractor and accepted by us, prior to awarding the contract for the building construction. These items are to be furnished to the contractor for installation. To date, they have been avallable for the contractor's use as required by the contract specification, except for one or two items whose delayed delivery had no effect upon the contractor's schedule. The equipment and material items that have been supplied include all high-quality stainless steel pipe and pipe fittings, four prefabricated Hastelloy C piping assemblies, nine Hastelloy C sump assemblies for the cell floors, the stanless steel intercell conveyor housing, the ten cellviewing-window sleeves, stainless steel process valves, and certain special instruments. Still to be supplied are the Hastelloy $\mathrm{C}$ cell-cubicle floor pans and the filters for the bullding and cell ventilation and offegas systems, the procurement of which is on schedule.

\section{Development of High-Density Concrete}

Hydrous 1ron ore aggregate was to have been obtained from the Treasure Belt Mining Company in Montana for use as the principal ingredient in the high-density concrete shielding for the TRU Plant. After mining and delivery of about $20 \%$ of the required quantity, it became apparently impractical for Treasure Belt to fulf 111 the 1 contract, and they were subsequently declared in default. Therefore, it was necessary to develop a substitute material from which to make the high-density concrete.

The South Atlantic Division Laboratory of the Corps of Engineers, in Mar1etta, Georgia, assisted the AEC-ORO in developing a concrete-mix formula, ut1lizing ferrophosphorous and limonite aggregate. Subsequent testing by the Corps of Engineers, assisted by representatives of the AEC-ORO and ORNL, produced an acceptable $\operatorname{mix}$ for the shrelding requirements of the TRU Plant. These aggregate materials were then procured by AEC. ORO and delivered to the contractor. A second mix, utilizing the Montana hydrous iron aggregate, which had been purchased under the Treasure Belt contract, and the Alabama limonite, has also been developed in the same manner for some lesscritical shielding applications. 


\section{Curium Processing}

A joint program between the Isotopes Division and Chemical Technology Division has been established to produce curium heat sources for use in thermoelectric converters. It is the responsibility of the Chemical Technology Division to provide processing technology, facilities, and operations to isolate gram amounts of curium. Irradiated targets of ${ }^{241} \mathrm{AmO}_{2}$ in an aluminum matrix will be processed to separate ${ }^{242} \mathrm{Cm}$ from aluminum, fission products, and eventually from ${ }^{241} \mathrm{Am}$, although the first products will contain the residual ${ }^{241} \mathrm{Am}$ as well as ${ }^{242} \mathrm{Cm}$. A nitric acid solution of the product will be delivered to the Isotopes Division for subsequent fabrication of the thermoelectric heat sources. A number of process methods, facilities, and source materials are used for both the Curium Program and the closely related Transuranium Element Program.

The Curium Recovery Facility (CRF) was originally planned for testing transuranium element processes at high activity levels, but modifications have been made to increase capacity and to improve reliability so it can also be used to isolate multigram quantities of curium, free of fission products. A $10 \mathrm{~g}$ sample of ${ }^{244} \mathrm{Cm}$ for an experimental heat source will be isolated from a nitric acid concentrate containing about $100 \mathrm{~g}$ of ${ }^{243} \mathrm{Am}, 100 \mathrm{~g}$ of ${ }^{244} \mathrm{Cm}$, and 10,000 curies of rare-earth fission products which Savannah River Laboratory prepared as feed material for the Transuranium Element Program.

The Chemical Technology Division part of the Curium Program includes laboratory-scale development of the chemical processes, searching for altemative process methods which may be used in existing processing facilities, and design, construction, and operation of the CRF to test the processes and to isolate multigram amounts of ${ }^{242} \mathrm{Cm}$ and ${ }^{244} \mathrm{Cm}$.

\subsection{DEVELOPMENT OF THE PROCESS}

The proposed methods for isolating ${ }^{242} \mathrm{Cm}$ and ${ }^{244} \mathrm{Cm}$ differ slightly because of the difference in feed materials. Summary flowsheets are given in Fig. 5.1. Feed for ${ }^{24} \mathrm{Cm}$ isolation comes from the long-term irradiation of ${ }^{239} \mathrm{Pu}$ for the Transuranium Element Program. Savannah River has processed $10 \mathrm{~kg}$ of ${ }^{239} \mathrm{Pu}$ irradiated for the Transuranium Element Program and has supplied a nitric acid concentrate containing the ${ }^{243} \mathrm{Am}$, ${ }^{244} \mathrm{Cm}$, and all the rare-earth fission products. This solution will be converted from nitrate to chloride by the Clanex (Co-Lanthanide-ActinideNitrate Extraction) process in which americium, curium, and rare earths are extracted into Alamine $336 \cdot \mathrm{HNO}_{3}$-diethylbenzene (DEB) from neutral lithium nitrate solution and then stripped into dilute hydrochloric acid. This strip product is scrubbed with Alamine $336 \cdot \mathrm{HCl}-\mathrm{DEB}$ to remove the last traces of nitrate. The Tramex process will be used for decontamination and recovery of the ${ }^{243} \mathrm{Am}-{ }^{244} \mathrm{Cm}$. Americium and curium separation can be accomplished by several methods. Chromatographic elutions, either from cation exchange resin with $\alpha$-hydroxyisobutyrate or from anion exchange resin with $4 M \mathrm{LiNO}_{3}$, are effective separation methods. Another acceptable separation method is based upon precipitation of pentavalent americium as a double potassium carbonate while trivalent curium remains soluble.

For the ${ }^{242} \mathrm{Cm}$ isolation process, irradiated targets of ${ }^{241} \mathrm{AmO}_{2}$ in an aluminum matrix will be dissolved in $2 M \mathrm{HCl}$. Dissolver solution will be adjusted to prepare feed for the Tramex process by adding lithium chloride and evaporating to concentrate the solution and to distill off excess hydrochloric acid. Product from the Tramex process will be in $8 \mathrm{M} \mathrm{HCl}$. This must be converted 

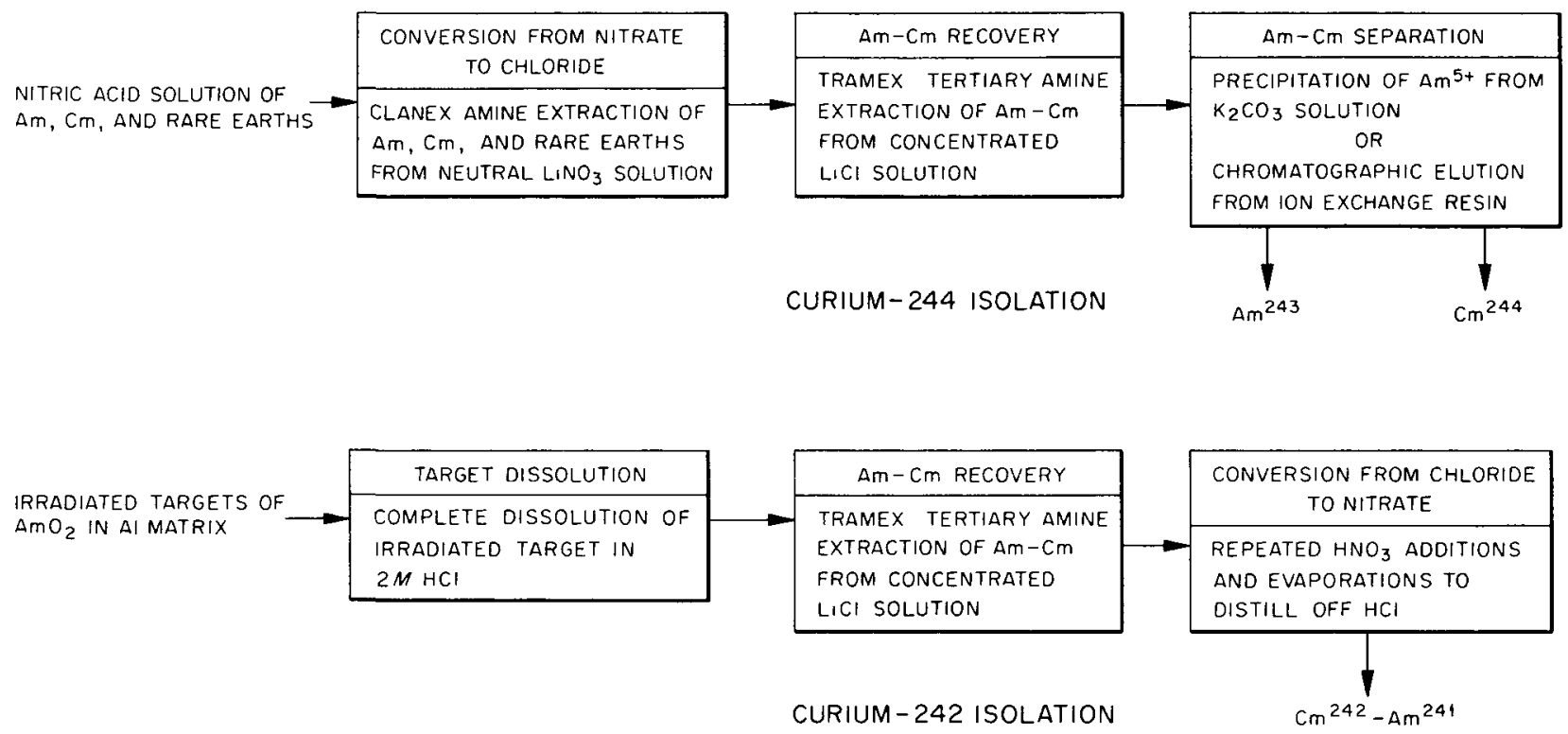

Fig. 5.1. Summary Flowsheets for Curium Processing.

to a nitric acid solution for subsequent processing to heat sources by the Isotopes Division. Laboratory demonstration has shown that repeated addition of nitric acid followed by evaporation is effective for this conversion. Two such additions and evaporations to produce concentrated nitric acid reduced the chloride concentration to only a few parts per million. The first samples of ${ }^{242} \mathrm{Cm}$ will not be separated from ${ }^{241} \mathrm{Am}$; however, either the ion exchange or precipitation methods can probably be used for this separation.

\section{Status of the Chemical Processes}

In general, satisfactory results for all the process steps have been obtained in laboratory-scale tests made at low radioactivity levels. The most critical steps have also been satisfactorily tested at full levels but with only a few milliliters of solution. Laboratory development to improve the processes will continue, but the next important step is to test the processes at full radioactivity level in the Curium Recovery Facility (CRF).

Clanex Process. - Conversion from nitrate to chloride by the Clanex process has been success- fully demonstrated in laboratory mixer-settler tests with simulated feed at low radioactivity levels. Americium, curium, and rare-earth recovery was better than 99.9\%; the product was $2 M$ in $\mathrm{HCl}$ and contained less than $0.01 \mathrm{MHNO}_{3}$, which is low enough not to interfere in the subsequent Tramex process.

Tramex Process. - As reported last year, Tramex tests made in laboratory-scale mixer-settlers gave americium losses of about $0.01 \%$ and fission product decontamination factors equal to or greater than $10^{4}$. No serious radiation-induced effects were noted in 1 - to $10-\mathrm{ml}$ batch extraction tests at activity levels up to the proposed processing level of $10 \mathrm{w} /$ liter. Loss of acid in Tramex feed by radiolysis has been satisfactorily controlled by making the feed solution 2 vol \% in methanol. The Tramex process is expected to operate satisfactorily at full radioactivity level in the CRF. However, two Tramex cycles may be required to routinely give satisfactory fission product decontamination factors of greater than $10^{4}$ or $10^{5}$.

Conversion of Tramex Product from Chloride to Nitrate Solution. - Conversion of Tramex product from $8 \mathrm{M} \mathrm{HCl}$ to a nitric acid solution by alternate additions of concentrated nitric acid 
and evaporations was successfully demonstrated in $1 / 10$-scale tantalum equipment with simulated Tramex product. Chloride concentration of the product was reduced to 1 or $2 \mathrm{ppm}$ after the second boiloff of the nitric acid; however, the final product was $15 M$ in $\mathrm{HNO}_{3}$, compared with the desired maximum concentration of $2 M$.

A modified Tramex process that produces chloride-free curium in $1 \mathrm{M} \mathrm{HNO}_{3}$ was demonstrated in a laboratory mixer-settler run at low radioactivity levels. The americium-curium product was free of chloride, zirconium, and rare-earth contaminants, but ruthenium decontamination was poor and must be improved.

Americium-Curium Separation. - The separation of americium and curium by precipitating pentavalent americium as $\mathrm{KAmO}_{2} \mathrm{CO}_{3}$ from potassium carbonate solutions in which the radioactivity level was 40 to $130 \mathrm{w} /$ liter has been demonstrated. The precipitated product contained 94 to $98 \%$ of the americium and carried from 2.0 to $3.8 \%$ of the curium. This procedure will probably be used in the CRF to separate ${ }^{241} \mathrm{Am}$ and ${ }^{242} \mathrm{Cm}$.

Americium and curium separation can also be made at high radioactivity levels by chromatographic elution from ion exchange resin if methanol is added to the solutions to suppress the formation of radiolytic gas. Elution with $4.4 \mathrm{M} \mathrm{LiNO}_{3}$ from anion exchange resin and elution with $0.5 M$ $\mathrm{NH}_{4} \alpha$-hydroxyisobutyrate at $\mathrm{pH} 4.1$ from cation exchange resin were both tested at radioactivity levels of 500 to $1000 \mathrm{w}$ per liter of resin. The americium products contained 85 to $90 \%$ of the americium along with 0.8 to $1.0 \%$ of the curium, and the curium products contained 90 to $95 \%$ of the curium along with 1 to $3 \%$ of the americium. For complete recovery, the eluate between these two product cuts must be recycled. Although these tests were made with small volumes of solutions and resin (10-m1 columns), scaleup appears to be feasible. Plans are to use ion exchange for separating ${ }^{243} \mathrm{Am}$ and ${ }^{244} \mathrm{Cm}$.

\section{Experimental Work}

Only part of the experimental work carried out during the past year is discussed here. Clanex, Tramex, and americium-curium separation by ion exchange are reported in Sect. 4.1 of this report. See also "Transuranium Element Processing" in the last annual. ${ }^{1}$
Conversion of Tramex Product from Chloride to Nitrate Solution. - When ${ }^{242} \mathrm{Cm}$ is purified by the Tramex process in the $\mathrm{CRF}$, the product will be contained in about 12 liters of $8 \mathrm{M} \mathrm{HCl}$. This must be converted to a nitric acid solution, preferably 4 liters of less than $2 \mathrm{MHNO}_{3}$, before shipment to the Isotopes Division since their process equipment is made of stainless steel. The proposed method of converting this to a nitrate solution is to evaporate to 4 liters, add 4 liters of concentrated nitric acid, and evaporate to 4 liters. This process is to be repeated two more times.

This conversion was tested at $1 / 10$ scale in tantalum equipment with simulated feed containing mixed rare earths as substitutes for americium and curium.

Chloride concentration of the product was reduced to 1 or $2 \mathrm{ppm}$ after the second boiloff of the nitric acid. The final product was approximately $15 \mathrm{M}$ in $\mathrm{HNO}_{3}$ and contained $0.5 \mathrm{~g}$ of rare earths per liter. Noncondensable acid reaction products (probably nitrosyl chloride) were readily scrubbed from the off-gas with dilute caustic. From all three boildowns, a total of 5.5 equivalents of acid per liter of product were collected in the caustic trap.

Some ruthenium decontamination can be obtained if $\mathrm{RuO}_{4}$ is volatilized during this conversion. However, ruthenium added as the trichloride did not volatilize even from boiling concentrated nitric acid during the final stages of conversion. Sodium bismuthate in concentrated nitric acid, or ozone bubbled through concentrated nitric acid containing sodium nitrite, effectively oxidized ruthe nium to the volatile $\mathrm{RuO}_{4}$ when the solutions were boiled.

Ruthenium decontamination factors of 70 to 100 were obtained with $\mathrm{NaBiO}_{3}$ concentrations as low as $0.004 M$, and a ruthenium decontamination factor of 5 was obtained with ozone in the presence of $0.02 \mathrm{M} \mathrm{NaNO}_{2}$.

There is considerable doubt that the nitric acid concentration can be reduced to $2 M$ by this method. In order to do so, the product must be evaporated to a small volume and then diluted. This means that the ${ }^{242} \mathrm{Cm}$ will be concentrated to several hundred watts per liter, and large entrainment losses during evaporation probably will occur.

\footnotetext{
${ }^{1}$ F. L. Culler et al., Chem. Technol. Div. Ann. Progr. Rept. May 31, 1963, ORNL-3452, pp. 96-115.
} 
If this conversion method is used, precautions must be taken so that Tramex solvent will not be present in the curium product, since Alamine $336-D E B$ in nitric acid is a potential hazard (see Sect. 4.1).

Modified Tramex Process to Produce ChlorideFree Curium. - Since a potential hazard would exist if residual organic solvent were present when curium product is converted from the chloride form to the nitrate by successive boildowns of the hydrochloric acid solution, and because a sufficiently low nitric acid concentration cannot be readily obtained by repeated boildowns (Sect. 5.3), a modified Tramex flowsheet was developed to produce chloride-free curium in $1 \mathrm{M} \mathrm{HNO}_{3}$.

The flowsheet for the modified Tramex process is shown in Fig. 5.2. In the process, americium and curium are extracted into $0.6 \mathrm{M}$ Alamine $336 \cdot \mathrm{HCl}-\mathrm{DEB}$ from $11 M \mathrm{LiCl}$ feed as before; however, Alamine $336 \cdot \mathrm{HCl}$ containing the extracted americium and curium is then converted from the chloride to the nitrate salt by contacting it with $8 M \mathrm{LiNO}_{3}$ in a conversion contactor.
The aqueous phase from this conversion is scrubbed with $0.6 \mathrm{M}$ Alamine $336 \cdot \mathrm{HNO}_{3}-\mathrm{DEB}$ to reduce americium and curium losses. Solvent from the conversion contactor is then stripped with $1 M$ $\mathrm{HNO}_{3}$, and the stripped product is scrubbed with $0.5 M$ di-(2-ethylhexyl)phosphoric acid-Amsco mixture to remove $z$ irconium.

In a laboratory-scale mixer-settler demonstration of this process, $99 \%$ of the curium and almost all the ruthenium and zirconium were extracted in the first contactor. In the conversion contactor, about $1 \%$ of the curium, about $20 \%$ of the ruthenium, and most of the zirconium were transferred to the aqueous raffinate. Product from the strip contactor contained $98 \%$ of the curium, about $30 \%$ of the ruthenium, and no detectable amounts of zirconium or chloride. In order for this process to be acceptable, ruthenium decontamination must be improved. No definite plans have been made to install the third contactor in the CRF so that this modified Tramex process can be used.

Precipitation of $\mathrm{KAmO}_{2} \mathrm{CO}_{3}$ to Separate Americium-Curium. - Precipitation of $\mathrm{KAmO}_{2} \mathrm{CO}_{3}$ from

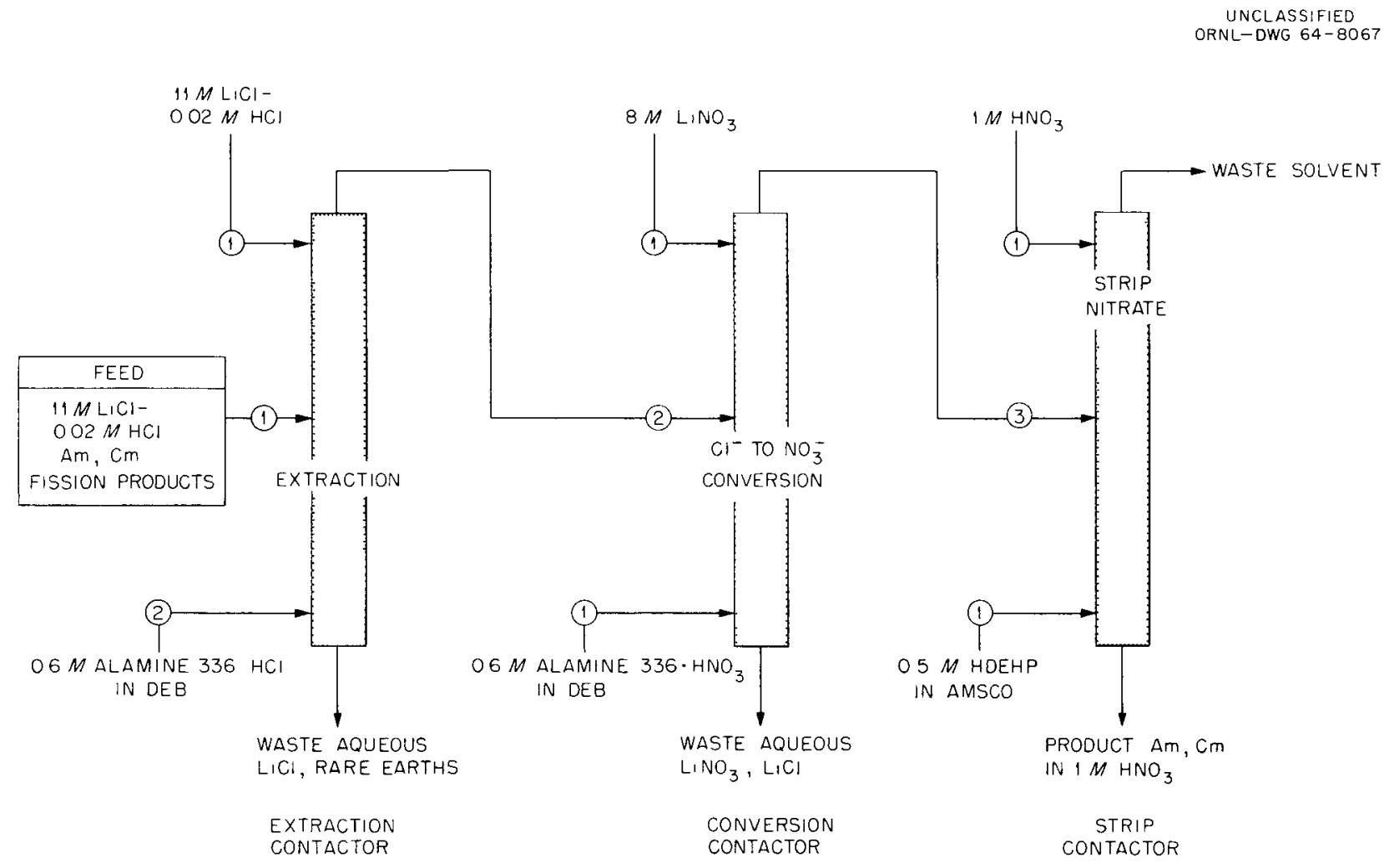

Fig. 5.2. Flowsheet of Modified Tramex Process to Produce Nitrate Product. 
$\mathrm{K}_{2} \mathrm{CO}_{3}$ solutions was investigated at alphaactivity levels of 40 to $130 \mathrm{w} / 1$ iter. It was found that americium can be satisfactorily oxidized at these activity levels. The precipitate contained 94 to $98 \%$ of the americium and carried from 2.0 to $3.8 \%$ of the curium (Table 5.1 ). Oxidation of americium with $\mathrm{NaOCl}$ proceeded rapidly at elevated temperature, and most of the americium precipitated within $15 \mathrm{~min}$. Americium can also be oxidized to the pentavalent state with persulfate at temperatures of 80 to $90^{\circ} \mathrm{C}$. A trace of silver was added to a1d the oxidation, however, it does not seem to be required. In the presence of potassium, americium oxidation does not proceed beyond the $5+$ state, but, in sodium carbonate solutions, some americium is oxidized to the soluble $6^{t}$ state. Curium in the filtrate precipitated after about $10 \mathrm{hr}$, presumably as a result of the high radioactivity level. The precipitated curium appeared to be the hydroxide since it was readily soluble in dilute acid, although the possibility of oxalate from the dimerization of the $\mathrm{CO}_{2}{ }^{-}$radical to form $\mathrm{C}_{2} \mathrm{O}_{4}{ }^{2-}$ may have been involved.

Although these tests were made with only about $5 \mathrm{ml}$ of solution, scale-up should be feasible. Large-scale tests w11 be made in the CRF.

\section{Conclusions}

All tests to date indicate that the proposed process methods are capable of producing pure
${ }^{243} \mathrm{Am},{ }^{244} \mathrm{Cm}$, and ${ }^{242} \mathrm{Cm}$. Final determination of their adequacy cannot be made until actual processing in the CRF is carried out at full radioactivity level.

Fission product decontamination factors equal to or greater than $10^{4}$ have been demonstrated in laboratory mixer-settler tests for the Tramex process. Tests at full levels of radioactivity in the CRF are needed to deternine if one cycle is sufficient or if two extraction cycles are necessary to routinely give decontamination factors of greater than the $10^{4}$ or $10^{5}$ required.

Conversion of Tramex product from $8 \mathrm{M} \mathrm{HCl}$ to nitric acid solution by alternate additions of concentrated nitric acid and evaporations yields a product low in chloride concentration but higher in nitric acid than desired. This method is also potentially hazardous if Tramex solvent is present. The Tramex process can be modified to give chloride-free product in dilute nitric acid, however, for the conditions tested, ruthenium decontamination was poor. Additional development is needed to $f_{1 n d}$ conditions for better decontamination.

Precipitation and ton exchange methods have both been satisfactory for separating americium and curium at radioactivity levels greater than $100 \mathrm{w} /$ liter. Although these tests were made with only a few milliliters of solution, scale-up to the liter scale should be feasible. Tests with larger volumes will be made in the CRF when gram quantities of ${ }^{242} \mathrm{Cm}$ are processed.

Table 5.1. Americium-Curium Separation by $\mathrm{KAmO}_{2} \mathrm{CO}_{3}$ Precipitation

Tests made with about $5 \mathrm{ml}$ of solution

\begin{tabular}{|c|c|c|c|c|c|}
\hline Conditions & $\begin{array}{l}\text { Initial } \\
241 \mathrm{Am} \\
\text { (g/1iter) }\end{array}$ & $\begin{array}{c}\text { Initial } \\
242 \mathrm{Cm} \\
\text { (g/liter) }\end{array}$ & $\begin{array}{c}\text { Americium } \\
\text { Precipitated } \\
(\%)\end{array}$ & $\begin{array}{c}\text { Curıum } \\
\text { Carried } \\
(\%)\end{array}$ & $\begin{array}{c}\text { Initial Feed } \\
\text { Activity Leve } 1 \\
\text { (w/11ter) }\end{array}$ \\
\hline $3 \mathrm{M} \mathrm{K}_{2} \mathrm{CO}_{3}-0.1 \mathrm{M} \mathrm{NaOCl}$ at $95^{\circ} \mathrm{C}$ for $1 \mathrm{hr}$ & 6.2 & 0.61 & 94 & 3.8 & 65 \\
\hline $3 \mathrm{M} \mathrm{K}_{2} \mathrm{CO}_{3}-0.1 M \mathrm{NaOCl}$ at $70^{\circ} \mathrm{C}$ for $2 \mathrm{hr}$ & 2.8 & 0.36 & 96 & 2.6 & 45 \\
\hline $4 M \mathrm{~K}_{2} \mathrm{CO}_{3}-0.05 M \mathrm{~K}_{2} \mathrm{~S}_{2} \mathrm{O}_{8}$ at $90^{\circ} \mathrm{C}$ for $1 \mathrm{hr}$ & 1.3 & 0.31 & 98 & 2.0 & 40 \\
\hline $\begin{array}{l}4 M \mathrm{~K}_{2} \mathrm{CO}_{3}-0.05 \mathrm{M} \mathrm{K}_{2} \mathrm{~S}_{2} \mathrm{O}_{8}+\text { trace of } \mathrm{Ag} \\
\text { at } 90^{\circ} \mathrm{C} \text { for } 3 \mathrm{hr}\end{array}$ & 5.2 & 1.05 & 96 & 3.1 & 130 \\
\hline
\end{tabular}




\subsection{DEVELOPMENT OF ALTERNATIVE PROCESSES: SEPARATION OF LANTHANIDES AND ACTINIDES}

\section{Talspeak Process}

A continuing study of the comparative chemistry of the lanthanides and trivalent actinides has produced a new method of separating the two groups. This is called the Talspeak process, from "Trivalent Actinide-Lanthanide Separation by Phosphorus-reagent Extraction from Aqueous Complexes." The lanthanides and yttrium are preferentially extracted by an aromatic hydrocarbon solution of di(2-ethylhexyl)phosphoric acid (HDEHP) from an aqueous carboxylic acid solution containing diethylenetriaminepentaacetic acid. The actinides may then be recovered by oxalate precipitation or by extraction under different conditions. The method has been successfully tested at tracer levels of radioactivity to separate americium and curium from fission product rare earths produced by the irradiation of ${ }^{241} \mathrm{Am}$. A detailed report of a study of the method has been prepared. ${ }^{2}$

Data from comparative experiments on extraction of several lanthanides and trivalent actinides have permitted the selection of extractants, diluents, carboxylic acids, an aminopolycarboxylic acid, $\mathrm{pH}$ values, and relative flow rates for tentative process flowsheets. Batch countercurrent tests of flowsheets have been made at tracer level and, in some cases, with macro concentrations of lanthanides. Continuous countercurrent tests also have been successful in separating americium and curium from fission product lanthanides at tracer levels of radioactivity. Studies of extraction kinetics have helped to determine the preferred extraction conditions. Results of other tests have shown that the separation properties of the system are resistant to the effects of irradiation and that stainless steel is a satisfactory material for process equipment.

Future work will include more detailed studies of the extraction behavior of individual lanthanides

\footnotetext{
${ }^{2}$ Boyd Weaver and F. A. Kappelmann, Talspeak, A New Method of Separating Americium and Curium from the Lanthantdes by Extraction from an Aqueous Solution of an Aminopolyacetic Acrd Complex with a Monoacidic Phosphate or Phosphonate, ORNL-3559 (to be issued).
}

and actinides, including those not yet studied, the behavior of impurities, kinetics of extraction, adaptation of the method to specific applications, development of special techniques such as extraction chromatography, and testing of flowsheets with aqueous feeds of compositions expected in practice.

Group Separation. - Comparative experiments included extractions by $0.3 M$ HDEHP in diis opropylbenzene (DIPB) of ${ }^{140} \mathrm{La},{ }^{144} \mathrm{Ce},{ }^{142} \mathrm{Pr}$, ${ }^{147} \mathrm{Nd},{ }^{147} \mathrm{Pm},{ }^{153} \mathrm{Sm},{ }^{152} \mathrm{Eu}$, and ${ }^{241} \mathrm{Am}$ from $1 M$ lactic acid containing from zero concentration to at least $0.05 M$ sodium diethylenetriaminepentaacetate (Na DTPA) (Fig. 5.3). These isotopes and ${ }^{91} \mathrm{Y}$, ${ }^{170}{ }^{5} \mathrm{Tm},{ }^{242} \mathrm{Cm}$, and ${ }^{252} \mathrm{Cf}$ were compared in extractions from $1 M$ lactic acid- $0.05 M \mathrm{Na}$ DTPA. Extraction of neodymium, the least-extractable lanthanide, from this aqueous solution was about 10 times that of californium and 50 times that of americium. Curium extraction was slightly greater than americium extraction. Relative extractabilities of elements of the two groups are shown in

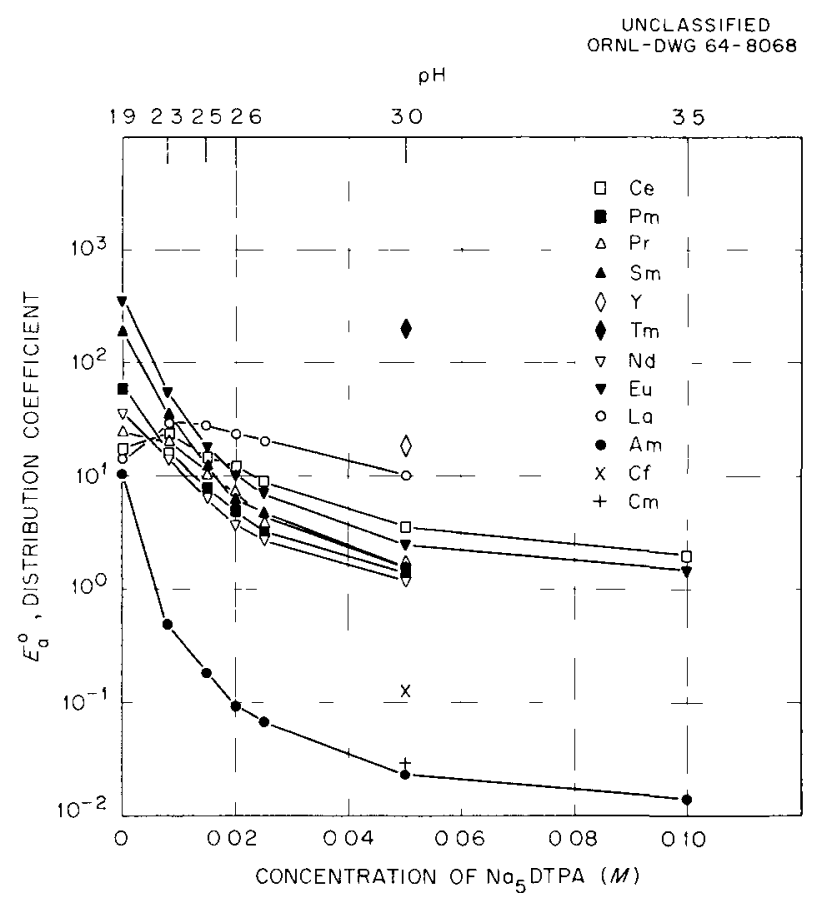

Fig. 5.3. Trivalent Actinides Are Less Extractable than Lanthanides from Solutions Containing Diethylenetriaminepentaacetic Acid. Organic phase: $0.3 M$ HDEHP in DIPB. Aqueous phase: $1 M$ lactic acid with variable concentration of $\mathrm{Na}_{5} \mathrm{DTPA}$. 
Fig. 5.4. The group-separation step in the tentative flowsheet shown in Fig. 5.5 is based on the use of an aqueous solution of about the same composition. This combination of solvent and aqueous-phase compositions appeared the most favorable of several studied for the separation of the lanthanides from californium.

Most of the tests were made with only ${ }^{144} \mathrm{Ce}$, ${ }^{152} \mathrm{Eu}$, and ${ }^{241} \mathrm{Am}$. With HDEHP, the maximum separation factor obtained between europium and americium was 100 . The same separation factor between these elements was also obtained by extraction with 2-ethylhexyl phenylphosphonate (HEH[ФP]) in DIPB, but the separation between europium and califomium was only about half that obtained with HDEHP. Aliphatic diluents gave considerably higher distribution coefficients than aromatic diluents, but the europium-americium separation factor was less than half as high with $n$-dodecane as with DIPB.

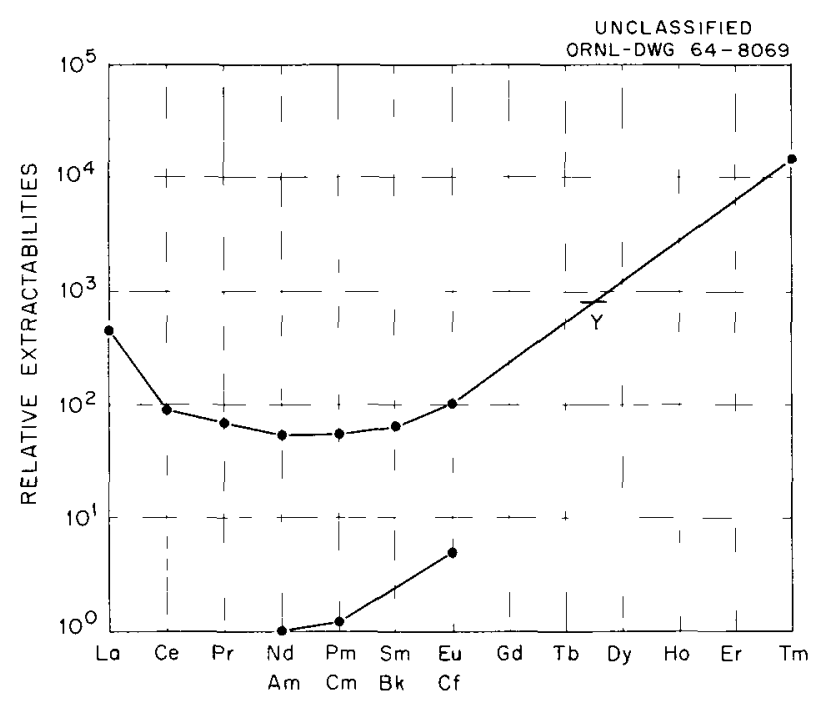

Fig. 5.4. Comparison of Extractabilities of Lanthanide and Actinide Groups. Organic phase: HDEHP in DIPB. Aqueous phase: $1 \mathrm{M}$ lactic acid, $0.05 \mathrm{M}$ $\mathrm{Na}_{5}$ DTPA.

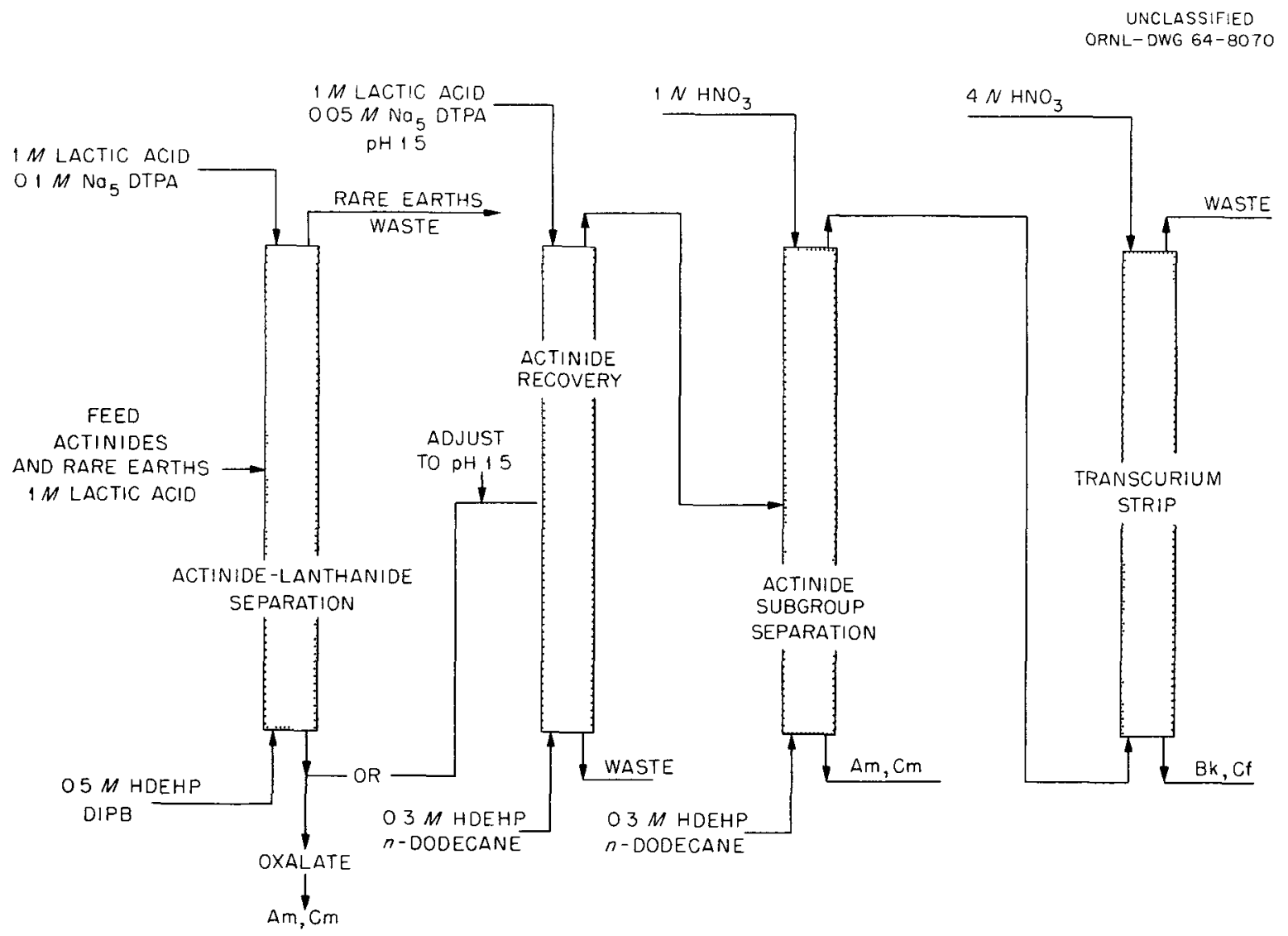

Fig. 5.5. Suggested Flowsheet for Purification of Trivalent Actinides. 
Carboxylic acıds were used as buffers, and as solubilizers of the aminopolyacetic acid complexing agents, in the aqueous phases. Lactic acid appeared to give somewhat better phase separation than did other carboxylic acids. However, extraction results were similar with glycolic and citric acids. Citric acid should be preferable with large concentrations of lanthanides because of its higher buffering power. This remains to be tested. The low solubility of lanthanide tartrates limits the use of tartaric acid.

Diethylenetriaminepentaacetic acid was used as the pentasodium salt, with the concentration of this salt and the carboxylic acid controlling the $\mathrm{pH}$ of the aqueous phase. A composition of $1 M$ lactic acid and $0.05 M \mathrm{Na}$ DTPA has a $\mathrm{pH}$ of 3.0. Nitrilotriacetic (NTA), hydroxyethylethylenediaminetriacetic (HEDTA), and triethylenetetraminehexaacetıc (TTHA) acids gave smaller separation factors than DTPA. Ethylenediaminetetraacetic acid (EDTA) and diamınocyclohexanetetraacetic acid (DCTA) were too insoluble in the desired $\mathrm{pH}$ range.

Recovery and Separation of the Actinides. After extraction of the lanthanides, the trivalent actinides may be recovered from the carboxylic acid solutions by oxalate precipitation. However, since this precipitation may not give adequate purification in some cases, studies were made of solvent extraction methods. Extraction with $0.3 \mathrm{M}$ HDEHP in $n$-dodecane after adjustment of the $\mathrm{pH}$ to 1.5 gave effective and rapid recovery, while extraction at higher $\mathrm{pH}$ was slow and gave lower distribution coefficients. Americium and curium may be stripped from this extractant with $1 N$ $\mathrm{HNO}_{3} \cdot$ Since the transcurium elements are much more extractable than curium from mineral acids, ${ }^{3}$ it should be possible to separate the actinides into two subgroups at this point, that is, the heaviest elements would be stripped subsequently by a more concentrated acid. This separation, represented by the third column in the tentative flowsheet (F1g. 5.5), has not yet been tested.

Applications and Advantages. - This process is an alternative to the Tramex and phosphonate processes (see Sect. 4.1) presently intended for use in processing HFIR targets. A study is also being made of the feasibility of using the group

\footnotetext{
${ }^{3}$ D. F. Peppard, G. W. Mason, and W. J. Driscoll., Inorg. Nuc1. Chem. 12, 144 (1959)
}

separation method for purifying the ${ }^{244} \mathrm{Cm}$ to be produced at Savannah River. Only the first groupseparation cycle should be necessary for this application. Some of the proposed feeds at Savannah River may contain relatively large concentrations of lanthanides. The effect of this variable on the Talspeak process is being evaluated.

The absence of chloride or any other highly corrosive constituent allows the use of stanless steel as a construction material for process equipment. Tests of stanless steel in various carboxylic acid and mixed solutions gave corrosion rates less than $1 \mathrm{~m} 1$ /year.

Extractions are not sensitive to the effects of irradiation, a considerable decomposition of the amınopolyacetic acid causes only a small change in distribution coefficients. In tests with curium alpha irradiation, there was an insignificant effect on extraction from irradiation up to $100 \mathrm{whr} / \mathrm{h}$ ter, which is more than would be encountered in practice. The presence of nitrate 1 on up to 1 equivalent/liter had no significant effect on extractions.

Effective separations were made between amer1cium and lanthanides at tracer level by the technique of extraction chromatography, in which the mixed elements were first deposited from an aqueous solution on columns contaning HDEHP on various support materials (such as microporous polyethylene, Saran powder, and diatomaceous silica) and then eluted separately by an aqueous complexing solution and nitric acid.

Conclusions. - The Talspeak process is a simple and effective method for separating the transplutonium elements, particularly americium and curium, from the lanthanides. It should be adaptable to the purification of ${ }^{242} \mathrm{Cm}$ produced by irradiation of ${ }^{241} \mathrm{Am}$ and to the purification of ${ }^{244} \mathrm{Cm}$ produced at Savannah River. Additional laboratory investigation is required to determine the behavior of metal ionic impurities and fission products other than the rare earths. Continuous countercurrent extraction tests at high activity levels are needed to make certain that there are no deleterious radiation effects and to determine the maximum decontamination factors for the process. If necessary, auxiliary extraction cycles can be developed to increase the removal of contaminants other than lanthanides. The versatılity of the Talspeak process can be increased by developing the proposed cycle for separating the actinides into two subgroups (Fig. 5.5). 
The adaptability of the process to techniques of extraction chromatography should make it especially useful in analytical and other small-scale applications.

\section{Other Extraction Systems}

Cerium, europium, and americium were compared in experiments with several new combinations of extractants and aqueous solutions including: primary amines vs sulfate solutions, quaternary ammoniums vs carboxylic acids, methylenediphosphonates vs carboxylic acids, naphthenic acids vs carboxylic acids, and aqueous-insoluble carboxylic acids vs nitrates or soluble carboxylic acids. Whenever there was significant extraction, there was no separation between the lanthanide and actinide groups.

\subsection{THE CURIUM RECOVERY FACILITY}

The Curium Recovery Facility (CRF) is being installed in the High Level Chemical Development Facility, Building 4507, for testing transuranium process chemistry at high radioactivity levels, recovering multigram amounts of ${ }^{243} \mathrm{Am}$ and ${ }^{244} \mathrm{Cm}$ for use in research, and purifying gram amounts of ${ }^{242} \mathrm{Cm}$ and ${ }^{244} \mathrm{Cm}$ for use in thermoelectric converters. Process equipment is provided for irradiated target dissolution, feed adjustment, a single extraction cycle, and product conversion from chloride to nitrate solution. Space has also been provided for temporary equipment to separate americium and curium by either ion exchange or precipitation. Materials of construction were selected for their corrosion resistance to both chlorides and nitrates. Process-tank capacities are from 30 to 150 liters, and the feed rate through the mixer-settlers is about 1 liter $/ \mathrm{hr}$. This corresponds to a maximum ${ }^{242} \mathrm{Cm}$ processing rate of $2 \mathrm{~g} /$ day. In practice, the facility will be operated on a campaign basis to isolate curium as it is required.

\section{Status of the Facility}

Construction of the CRF will be completed by July 1964. Most of the equipment has already been calibrated and tested for leaks. Cold runs of chemical flowsheets are in progress, and necessary equipment modifications are being made as required. A concentrate in nitric acid containing about $100 \mathrm{~g}$ of ${ }^{243} \mathrm{Am}, 100 \mathrm{~g}$ of ${ }^{244} \mathrm{Cm}$, and several kilograms of rare-earth fission products is stored in an underground tank at the facility. Operations to recover multigram quantities of ${ }^{243} \mathrm{Am}$ and ${ }^{244} \mathrm{Cm}$ from this concentrate will begin early next fiscal year.

\section{Description of the Facility}

The layout of the CRF is shown in the cutaway sketch, Fig. 5.6. Process equipment on removable racks is located in the cell so that it can be easily viewed from the operating area. Master-slave manipulators can be used to disconnect the racks for removal to the maintenance box on the roof of the cell. Process tanks are located just below the window level in the cells, and storage tanks are located below lead shielding in the cell floor. Most operations will be carried out from the front of the cell. The chemical makeup area for solvent, scrub, and other nonradioactive solutions is on the second level in back of the cell. Glove-box enclosures for sample and equipment removal are located on top of the cell. Also located on the top over cell 3 (not shown in Fig. 5.6) is a load-out station for removing product solution of ${ }^{242} \mathrm{Cm}$, and a slug chute for introducing irradiated targets into cell 3. Just outside Building 4507 is an underground tank in which the feed $\left({ }^{243} \mathrm{Am},{ }^{244} \mathrm{Cm}\right.$, and rare earths) is stored.

Cell 4. - The arrangement of equipment in cell 4 has been discussed previously. ${ }^{4}$ Most of the principal process equipment represented schematically in Fig. 5.7 is located in that cell. Only the dissolver and scrubber are installed in cell 3. Equipment for feed preparation consists of a dissolver, a feed adjustment evaporator, and a filter. Equipment for a single extraction cycle is provided. The solvent contactors are two mixersettler banks, each with 16 stages; catch tanks are provided for each of the exit streams. The product catch tank is an evaporator that can be used for converting Tramex product from a chloride solution to a nitrate solution. There are a number of interconnecting lines not shown on this diagram

\footnotetext{
${ }^{4}$ F. L. Culler et al., Chem. Technol. Div. Ann. Progr. Rept. May 31, 1963, ORNL-3452, pp. 138-43.
} 


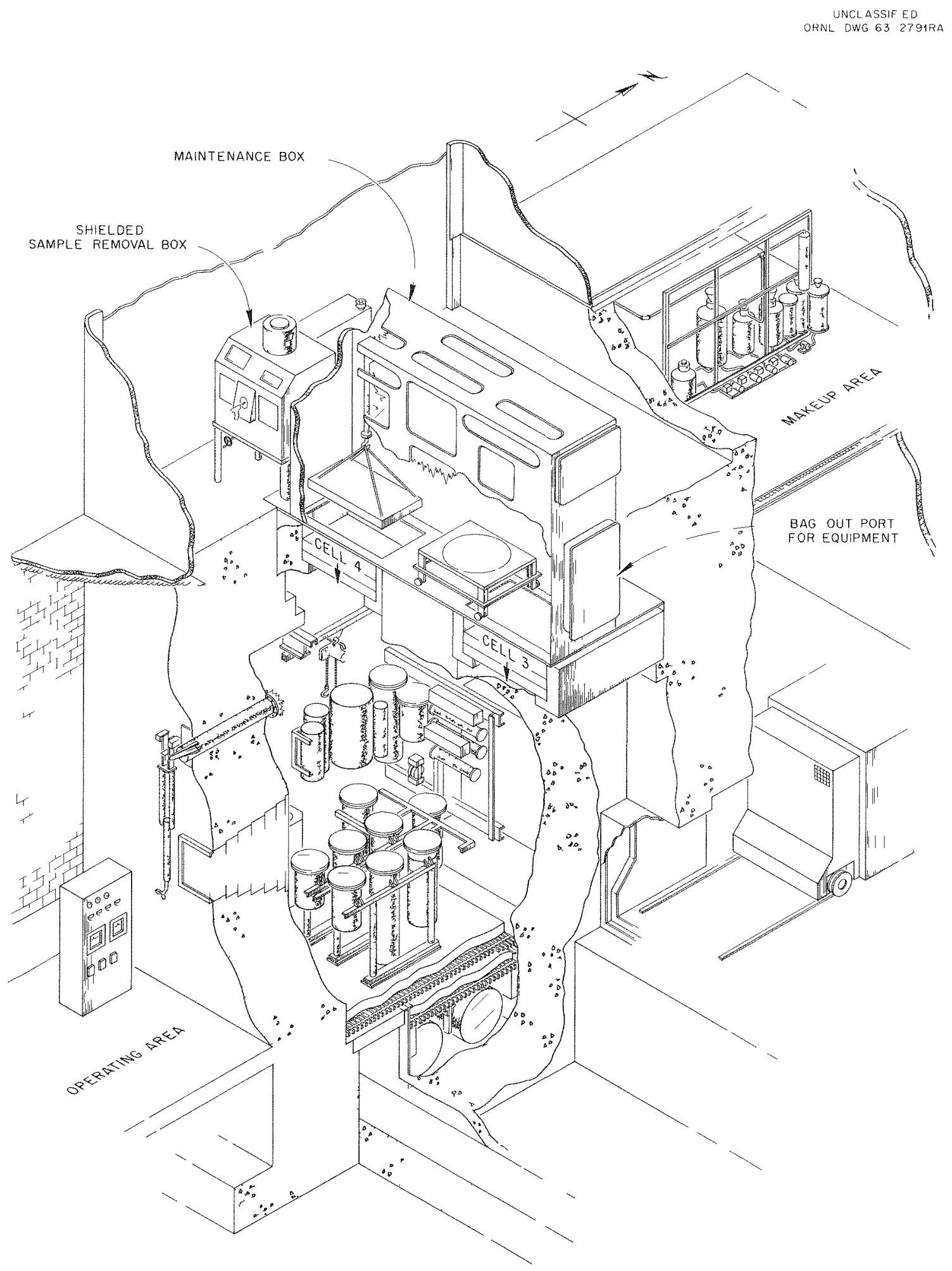

Fig. 5.6. Curium Recovery Facility - Cell 4 and Other Areas. 


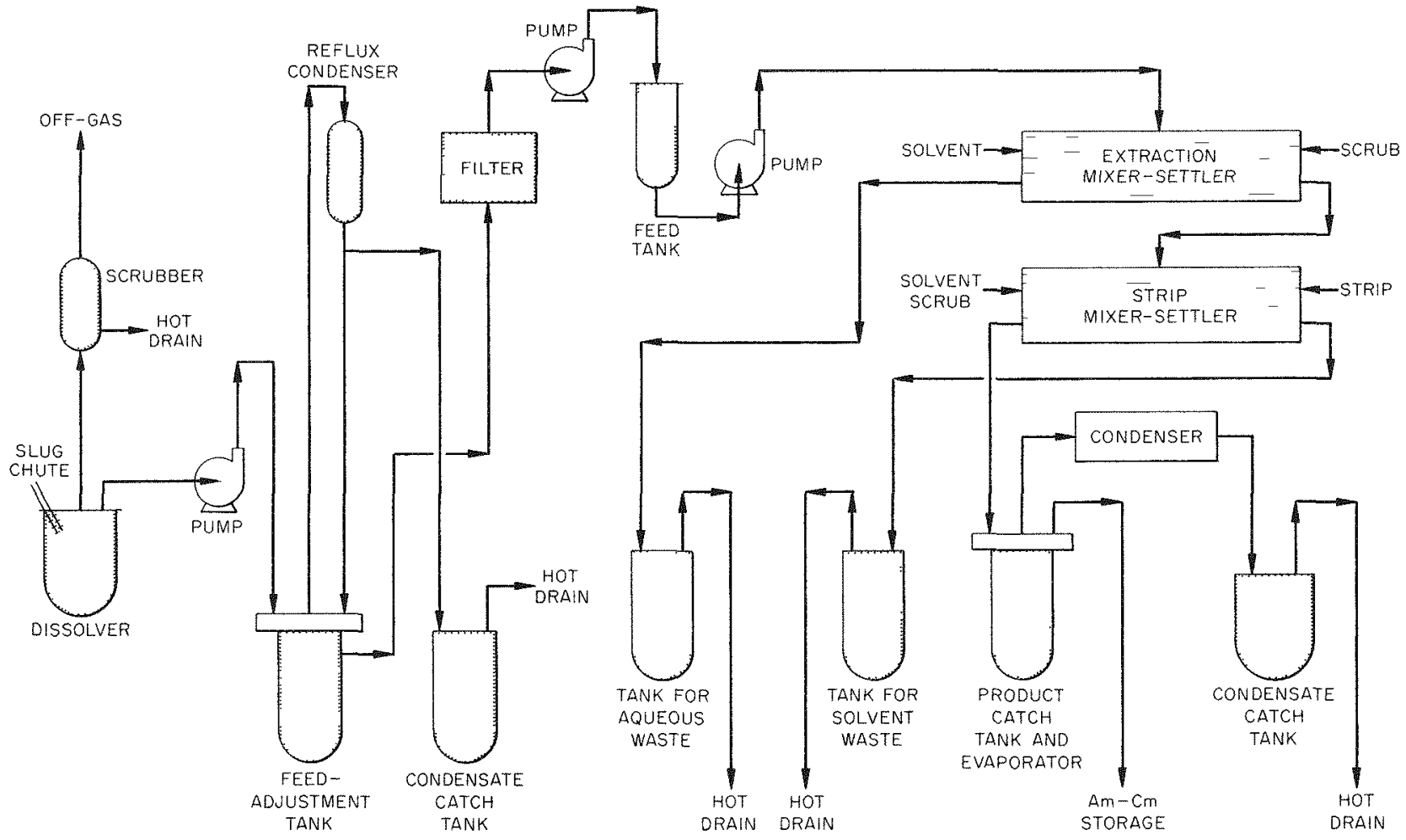

Fig. 5.7. Principal Process Equipment in the Curium Recovery Facility.

which are necessary so that solutions can be recycled if two extraction cycles are needed. For example, when ${ }^{244} \mathrm{Cm}$ is isolated, this equipment will be used first for the Clanex process to convert from nitrate solutions to chloride solutions by amine extraction. The equipment will be cleaned, and the same equipment will be used in the Tramex process to purify the americium and curium. Figure 5.8 is a photograph of the installed equipment taken through the viewing window from the operating area. All processing equipment in the cell is designed for remote manipulation and maintenance. The equipment is piped with jumper lines having remote disconnects at both ends. Tanks are located in the bottom of the cell, and other process equipment is mounted on removable equipment racks. Figure 5.9 shows the mixer-settler equipment rack. Note the two mixer-settler banks and all the transfer lines which terminate at disconnects that can be operated with an impact wrench held by the master-slave manipulator.
The arrangement of the tanks with removable jumpers to facilitate remote removal of the cell tanks is illustrated in a photograph (Fig. 5.10) taken through the opening in the cell roof. These particular tanks are located directly in front of the mixer-settler rack.

Cell 3. - A Zircaloy-2 dissolver and auxiliary equipment are being installed in cell 3 . This cell will also serve as a "hot" laboratory for laboratory-scale work in support of the operations in cell 4. Equipment for the separation of gram quantities of americium from curium and equipment for other product purification steps will be placed in the cell as needed.

The equipment flowsheet for the dissolver system is shown in Fig. 5.11, and the plan layout of cell 3 is shown in Fig. 5.12. Equipment boxes housing temporary equipment for americium-curium separation or for experimental work will be located in the work table area (Fig. 5.12). These boxes will enter and leave the cell via the maintenance 


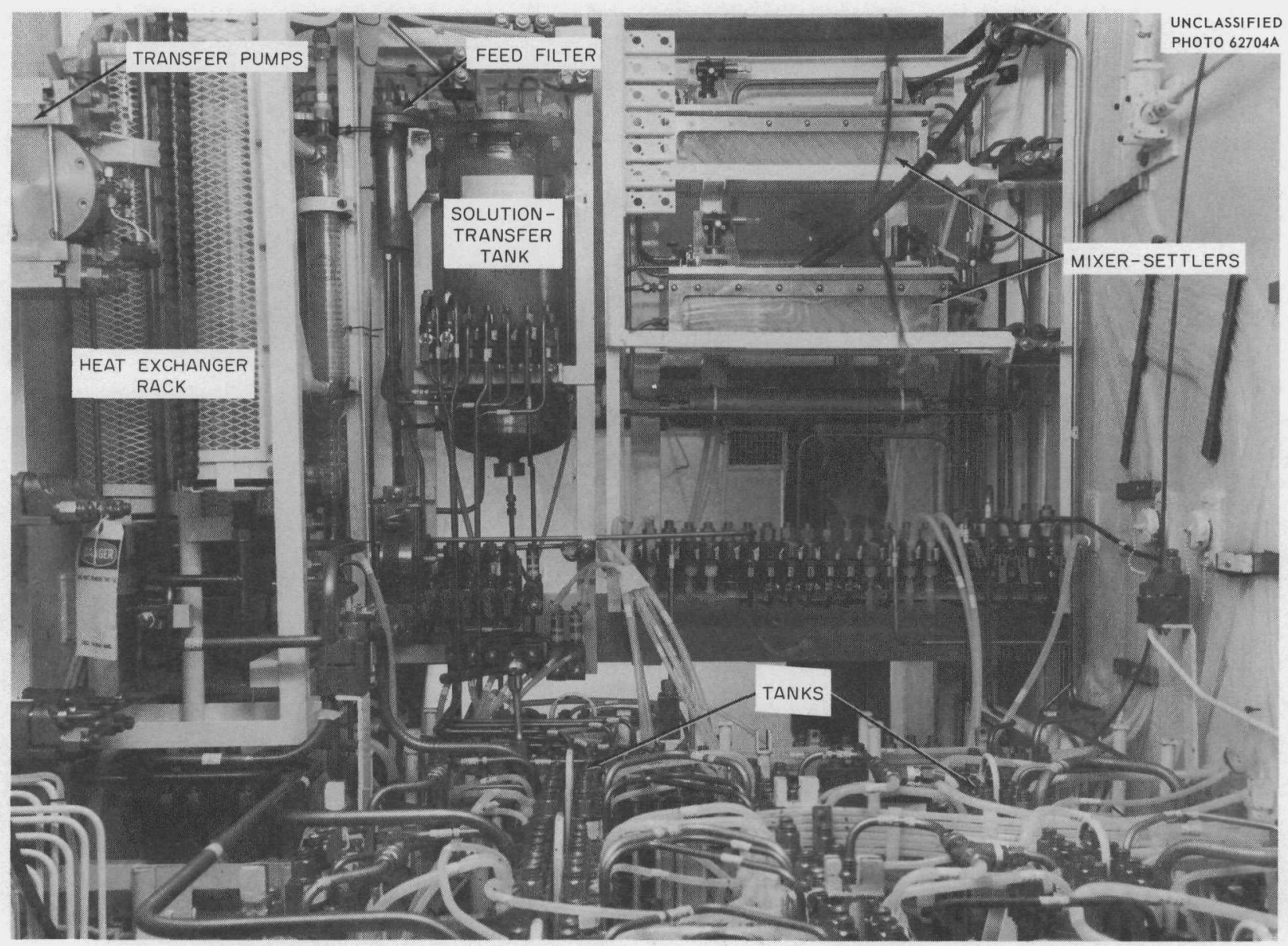

Fig. 5.8. Cell 4, View from the Operating Area.

box on the cell roof (Fig. 5.6). Cell 3 is now being prepared and will be completed and ready for operation by the end of this fiscal year.

Carriers. - A carrier for transferring irradiated ${ }^{241} \mathrm{Am}$ targets into cell 3 for dissolution has been designed and built. It is shielded by lead shot and paraffin.

A water-shielded carrier for transferring recovered ${ }^{242} \mathrm{Cm}$ from Building 4507 to the Isotopes Division was built, and a glove box arrangement for the transfer of this solution into the carrier was installed above cell 3 .

\section{Facility Testing and Modification}

During cold testing, repairs and changes were made to the equipment as required. Most were minor. However, it was necessary to replace unsatisfactory polyethylene welds and disconnects, replace tantalum-plated process tanks with glasslined vessels, eliminate air locks associated with equipment piping, replace the Homolite mixersettlers with Zircaloy-2 units, and repair the master-slave manipulators.

Polyethylene disconnects, lines adjacent to heated vessels, bends, and welded joints proved unreliable and were replaced with metal tubing and disconnects. Polyethylene disconnects could not be made to seal satisfactorily. Tubing that had been bent or welded was apparently degraded and began to crack in a few weeks. Metal disconnects have been completely satisfactory, even after numerous makes and breaks. Tantalum piping has presented almost no problems, and no difficulties have been encountered with Hastelloy C piping. 


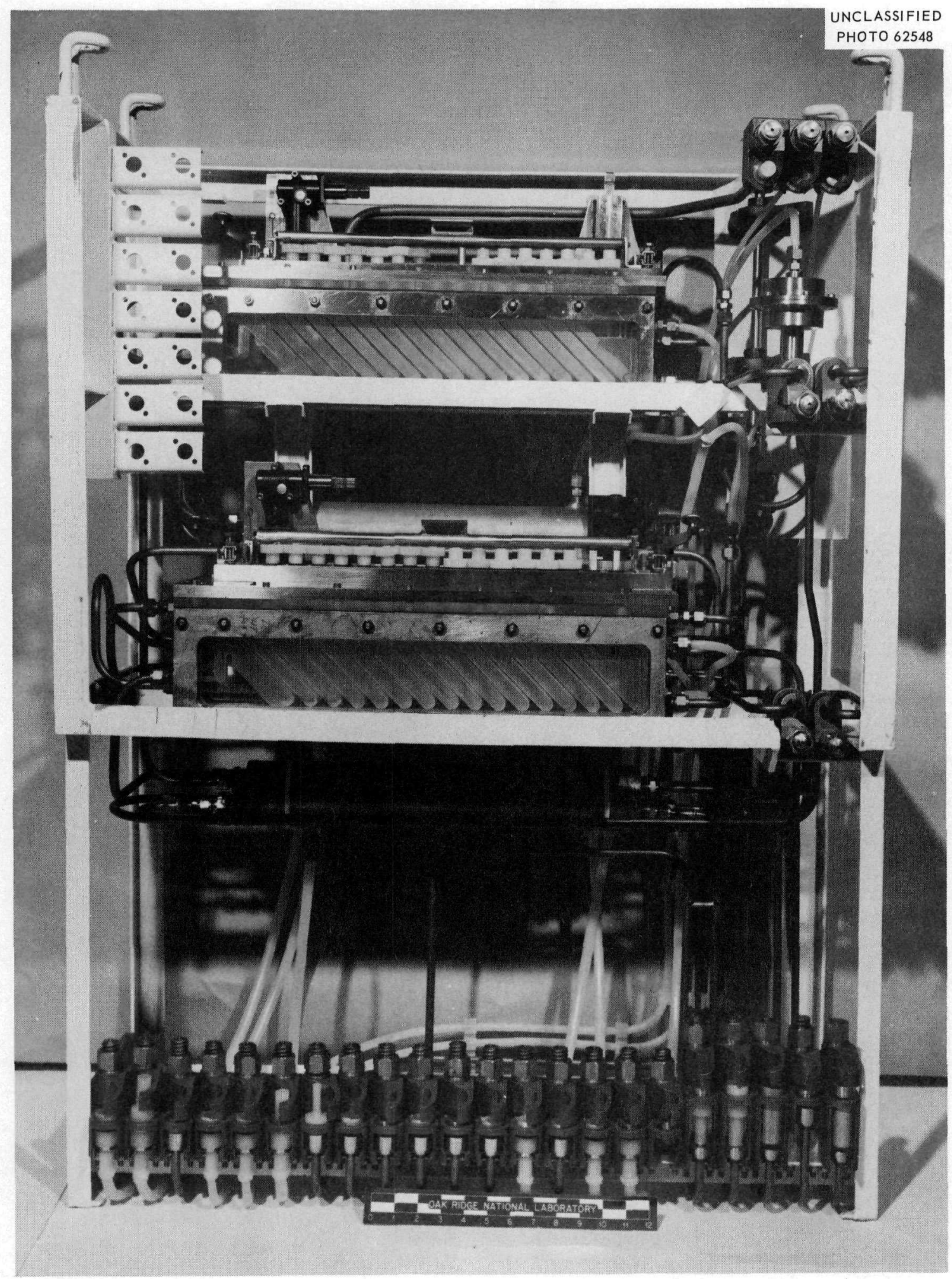

Fig. 5.9. Photograph of Mixer-Settler Solvent Extraction Rack. 


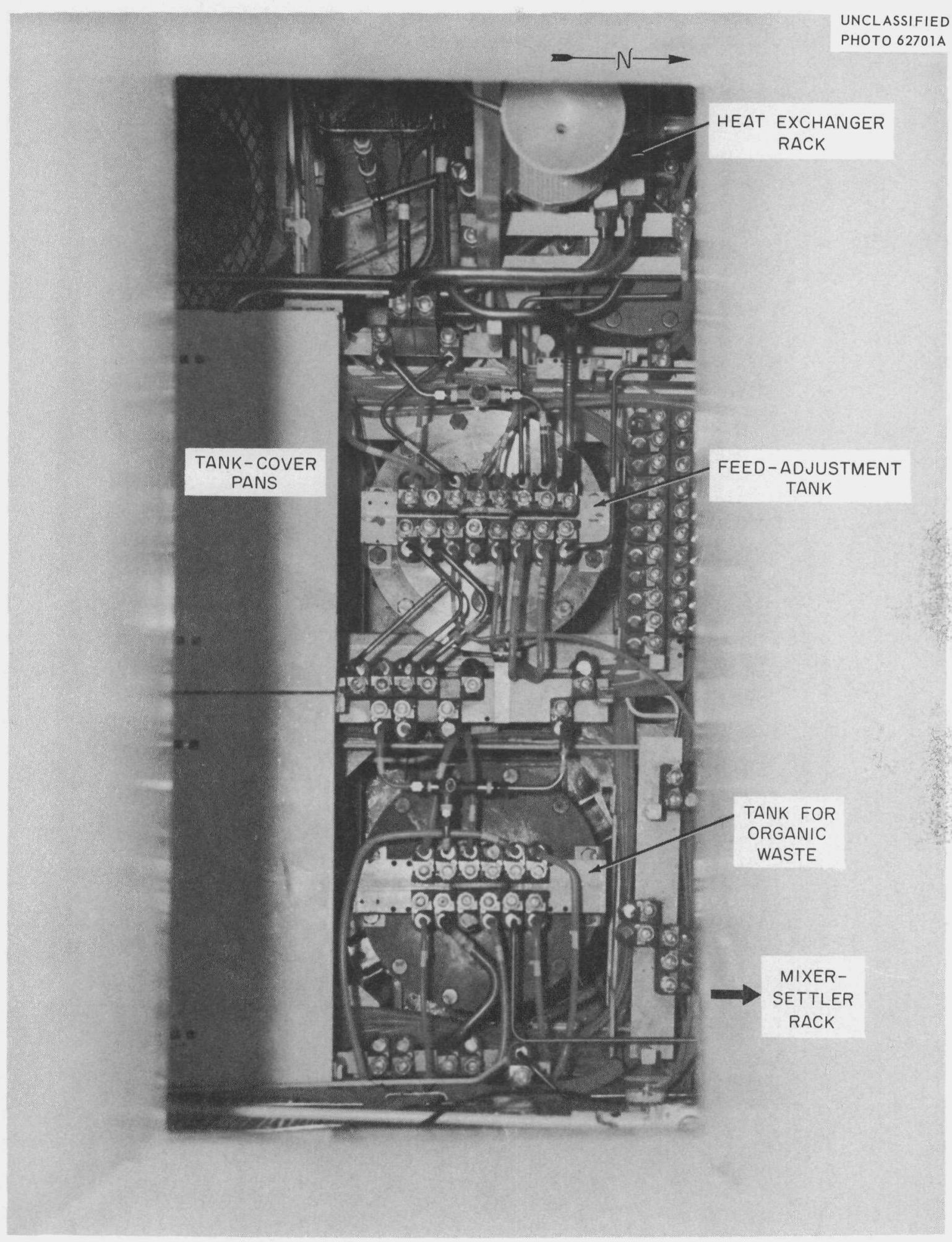

Fig. 5.10. Part of Cell 4, View Looking Down from Maintenance Box. 


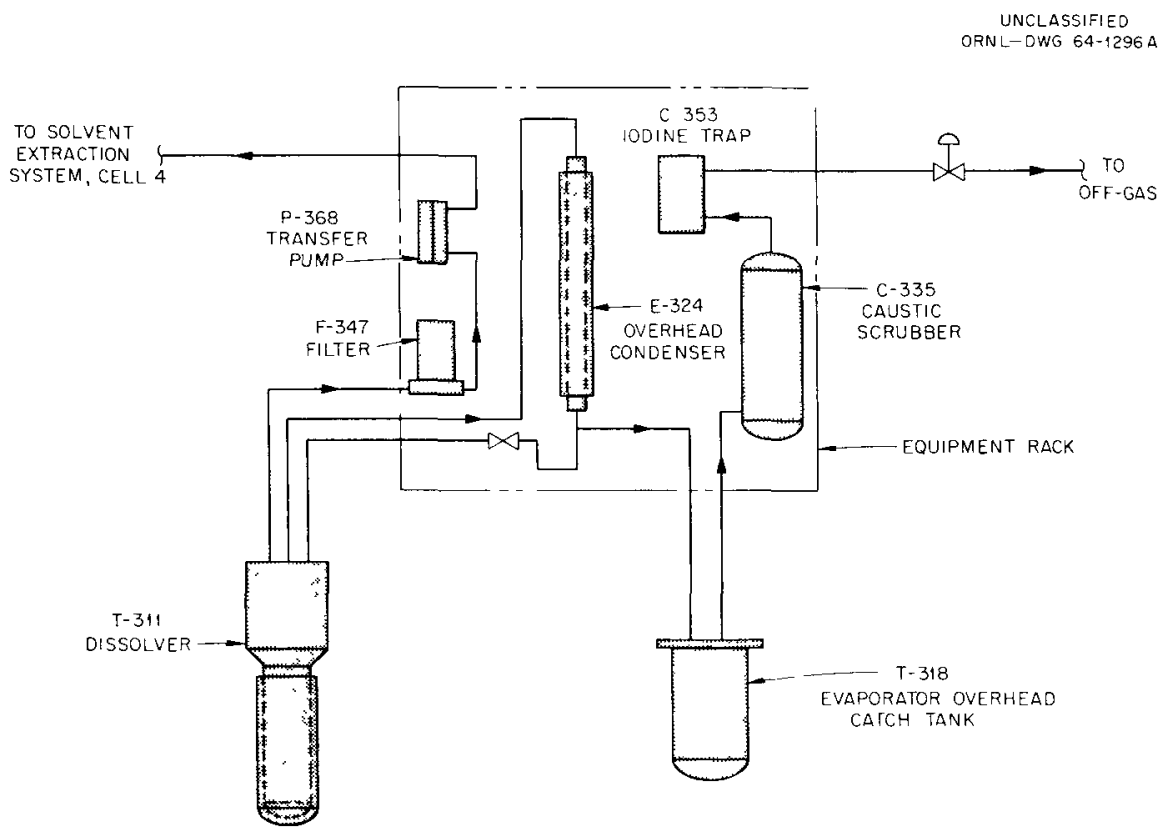

Fig. 5.11. Cell 3, Dissolver Equipment Flowsheet.

All the tantalum-plated tanks installed in cell 4 developed holes in the plating when tested with hot hydrochloric acid. The exact mechanism causing the plating failure has not been established, but indications are that impurities deposited on and within the plating formed weak spots or voids. These tanks have been temporarily replaced with glass-lined tanks, until tantalumlined ones can be procured.

Gravity-flow lines from the makeup area to the cell have consistently developed air locks. These lines are being equipped with spring-loaded check valves made of corrosion-resistant materials so that the lines will run full and not siphon. With this arrangement, flow rates can be satisfactorily regulated by calibrated pumps.

The Homolite mixer-settlers cracked and were repaired several times. There also appears to be corrosion and/or erosion of the Homolite, and it is possible that dissolved Homolite contributes to the emulsion problems encountered during process flowsheet tests. Zircaloy-2 units equipped with pure fused-silica windows are being made and will replace the Homolite mixer-settlers. The new units will be completed and mounted on a new equipment rack this fiscal year.

The AMF heavy-duty extended-reach manipulators have seen only limited service, but they do not appear to be adequate since considerable downtime has been required for repairs.

\section{Process Demonstrations}

Flowsheet and equipment tests have been completed on simulated target dissolutions, Tramex and Clanex feed adjustments, and conversion of product from hydrochloric acid to nitric acid solutions.

Cold testing of chemical processes that call for mixer-settlers has been hampered by severe emulsion problems encountered with Tramex reagents. The emulsions are now believed to have been caused, at least in part, by a molybdenum impurity in the lithium chloride solution. Dissolved Homolite from the mixer-settlers also appears to cause emulsions. Following the elimination of this problem, process demonstrations involving extraction and stripping will be completed.

Target Dissolution. - Curium-242 will be produced from the irradiation of targets consisting of ${ }^{241} \mathrm{Am}$ oxide in powdered aluminum. The targets are contained in aluminum cans, $1 / 2$ in. in diameter and 8 in. long. Each target will contain about $1.2 \mathrm{~g}$ of ${ }^{242} \mathrm{Cm}$ after irradiation, and two targets 


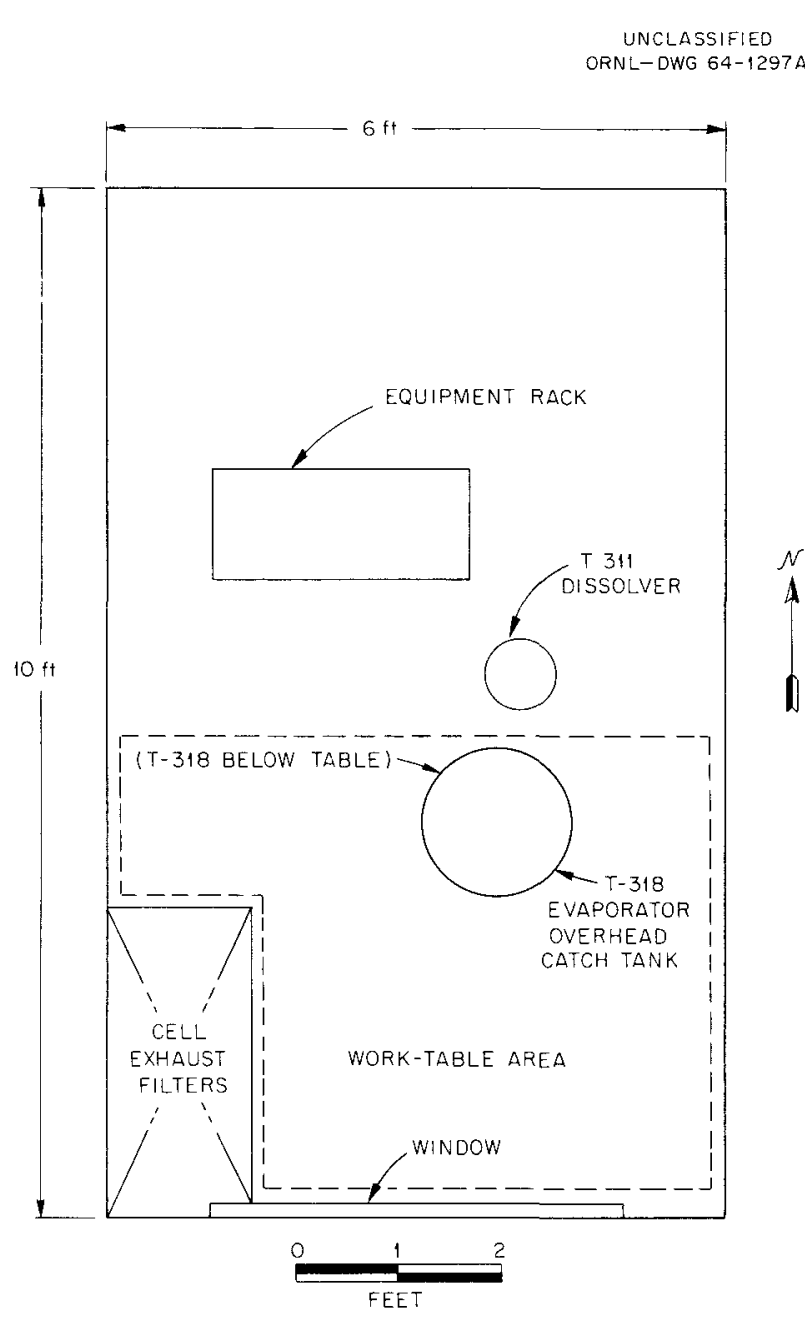

Fig. 5.12. Plan Layout of Cell 3.

will be used for each batch of Tramex feed. Two tests of the dissolution of the targets have been made with $1 / 2$-in. aluminum rods as dummy targets. While dissolving the aluminum in $2 \mathrm{M} \mathrm{HCl}$ at $37^{\circ} \mathrm{C}$, an air flow of 60 liters $/ \mathrm{min}$ was sufficient to dilute evolved hydrogen to less than 2 vol \%. No difficulty was experienced in controlling the reaction; in fact, the dissolution rate became too slow for practical purposes as the surface area and acid concentration decreased. This can be remedied by increasing the temperature as the dissolution progresses.

Tramex Feed Adjustment. - Tramex feed will be prepared from the dissolver solution, which will contain americium, curium, and rare earths in dilute hydrochloric acid. Excess $\mathrm{HCl}$ may be removed by adding a measured amount of $\mathrm{LiCl}$ solution, followed by evaporation to the desired salt strength. This feed adjustment (without aluminum) has been performed eight times with satisfactory results. An empirical relationship between final temperature and $\mathrm{LiCl}$ concentration which is accurate to about $1 \%$ has been obtained.

In addition to regulating salt strength, acid must be removed to a satisfactory degree. The concentration of $\mathrm{HCl}$ in the final solutions has varied from less than 0.01 to $0.06 M$, depending on starting conditions, rate of evaporation, and final temperature. This is within the desired range of acid concentration for Tramex feed. No additional work is planned for pure $\mathrm{LiCl}$ solution, but similar studies for $\mathrm{LiCl}$ solutions containing $\mathrm{AlCl}_{3}$ are in progress.

Clanex Feed Adjustment. - The Clanex process will be used when a nitrate feed containing nonvolatile salts is to be converted to a chloride system. This is accomplished by extracting both actinides and lanthanides into Alamine $336 \cdot \mathrm{HNO}_{3}$ from a neutral nitrate feed, stripping the actinides and lanthanides into dilute hydrochloric acid solution, and scrubbing the strip product with Alamine $336 \cdot \mathrm{HCl}$. The final product can then be adjusted to $11 \mathrm{M} \mathrm{LiCl}$ for isolation of actinides from lanthanides by the Tramex process.

Synthetic Clanex feed was successfully prepared. In this test, $\mathrm{Al}\left(\mathrm{NO}_{3}\right)_{3}-\mathrm{HNO}_{3}$ feed was concentrated by evaporation, and $\mathrm{HNO}_{3}$ was neutralized with dibasic aluminum nitrate to form a feed $7 N$ in nitrate with almost no free acid.

Conversion of Tramex Product from a Chloride to a Nitrate Solution. - In a simulated curiumproduct boildown and chloride-to-nitrate conversion (but with no curium present), the chloride concentration was reduced to $30 \mathrm{ppm}$, and the final product was $4.1 \mathrm{M}$ in $\mathrm{HNO}_{3}$. In this procedure 24 liters of $8 \mathrm{M} \mathrm{HCl}$ were continuously evaporated at a rate of 1 liter $/ \mathrm{hr}$ to a final volume of 12 liters. The $\mathrm{HCl}$ concentration of this solution was $6.3 \mathrm{M}$. To remove chloride, 3 liters of $15.8 \mathrm{M}$ $\mathrm{HNO}_{3}$ was added, and the solution was evaporated to a volume of 12 liters. This procedure was repeated three times, after which the solution contained $0.05 \mathrm{M} \mathrm{HCl}$ and $11.4 \mathrm{MHNO}_{3}$. In an attempt to reduce the $\mathrm{HNO}_{3}$ concentration, the solution was diluted with 3 liters of demineralized water and evaporated to 12 liters. After repeating 
this procedure eight times, the chloride concentration was reduced to $320 \mathrm{ppm}$ and the nitric acid concentration to $7.2 \mathrm{M}$. Final concentrations of chloride (30 ppm) and $\mathrm{HNO}_{3}(4.1 N)$ were obtained by evaporating the solution to a volume of 4 liters and then diluting to 12 . In order to reduce the nitric acid concentration to $2 M$, which has been requested by the Isotopes Division, it would be necessary to evaporate the solution to a volume that would concentrate ${ }^{242} \mathrm{Cm}$ to power densities of several hundred watts per liter before diluting to $2 \mathrm{MHNO}_{3}$. It is probable that at these conditions excessive curium losses will result through entrainment.

\section{Transfer and Storage of ${ }^{243} \mathrm{Am}-{ }^{244} \mathrm{Cm}_{\mathrm{m}}$ Concentrate}

About $100 \mathrm{~g}$ of ${ }^{243} \mathrm{Am}, 100 \mathrm{~g}$ of ${ }^{244} \mathrm{Cm}$, and 10,000 curies of rare-earth fission products in a nitric acid solution have been transferred from the Savannah River Laboratory to the underground storage tank at the CRF. This americium and curium was produced by the long-term irradiation of $10 \mathrm{~kg}$ of ${ }^{239} \mathrm{Pu}$ and will be recovered and purified for the Transuranium Element Program.

Heat, generated by ${ }^{243} \mathrm{Am}$ and ${ }^{244} \mathrm{Cm}$ alpha activity, is dissipated through the tank wall into a continuous stream of cooling water in the pit surrounding the tank. Radiolytically produced hydrogen is diluted to a safe concentration by normal instrument air flow. The storage tank is equipped to provide alarms if the tank temperature gets too high or if the cooling water level in the pit gets too low.

\section{Conclusions}

Construction and testing have not been completed, but the CRF should be ready for operation at full radioactivity level early in FY 1965 . The completed facility will be capable of using the Clanex and Tramex processes to isolate gram quantities of ${ }^{243} \mathrm{Am},{ }^{244} \mathrm{Cm}$, and ${ }^{242} \mathrm{Cm}$.

Cold testing of equipment installed in the CRF has shown that welds and bends in polyethylene tubing develop leaks and cannot be relied upon for long-term service. Although tantalum-plated tanks should be satisfactory in hydrochloric acid, all those installed failed because of defects in the plating and were temporarily replaced with glass-lined tanks. For the Tramex and Clanex processes, Homolite does not appear to be a satisfactory material of construction because of breakage, corrosion, and erosion.

In order to make the CRF into a reliable production facility, it is recommended that a second extraction cycle be added and that permanent equipment be installed for americium-curium separation. A better estimate of the need for these and other modifications can be made after some operating experience has been obtained, and the changes will not be started before the last part of the 1965 fiscal year. 


\section{Development of the Thorium Fuel Cycle}

\section{I THE KILOROD FACILITY}

During the past year, the Kilorod Program, a joint effort with the Metals and Ceramics Division, was successfully completed. Approximately 900 fuel rods, each containing $890 \mathrm{~g}$ of oxide (3 wt $\%{ }^{23} \mathrm{UO}_{2}-97$ wt $\% \quad \mathrm{ThO}_{2}$ ) and 200 rods, each containing $310 \mathrm{~g}$ of the same mixed oxide, were made. The mixed oxide in these rods, which are to be used for reactor parametric studies at Brookhaven National Laboratory, were made in the Kilorod Facility by the sol-gel process. The fuel was then vibratorily packed in tubes, and the rods were completed in the facility. The facility was designed to produce about ten rods a day; after the customary startup problems, it operated at or above the design production rate.

The process steps in the Kilorod Program consisted of (1) ${ }^{23} \mathrm{U}$ purification by solvent extraction, (2) $\mathrm{ThO}_{2}$ preparation by stream denitration of thorium nitrate, (3) preparation of mixed $\mathrm{ThO}_{2}$ $\mathrm{UO}_{2}$ by the sol-gel process, (4) sizing and loading the oxides into Zircaloy tubes by vibratory compaction, and (5) welding and inspecting the finished rods. The sizing, loading, welding, and inspecting operations were primarily the responsibility of the Metals and Ceramics Division and are not reported here.

Evaluation of the data collected during the Kilorod Program is in progress, and the facility is being cleaned prior to placing it in standby.

\section{Purification of Uranium-233 by Solvent Extraction}

Neutron irradiation of ${ }^{232} \mathrm{Th}$ to produce ${ }^{233} \mathrm{U}$ also produces ${ }^{232} \mathrm{U}$. The decay products of ${ }^{232} \mathrm{U}$ include energetic gamma emitters which seriously influence plant design and fuel-handling procedures. Purification of the uranium by solvent extraction can remove many of the daughters and thus facilitate fuel handling. The solvent extraction process and equipment were described in last year's annual report.

To date, about $50 \mathrm{~kg}$ of ${ }^{233} \mathrm{U}$ has been purified $37 \mathrm{~kg}$ for the Kilorod Program and $13 \mathrm{~kg}$ for other AEC-sponsored projects. A summary of the product quality obtained is presented in Table 6.1, together with the specifications set for the Kilorod Program. As can be seen, the product met specifications in all instances.

The gross-gamma decontamination factors presented in the table are those obtained from the gamma activity of the concentrated product. A more complete study of the gamma activity of the product is presented in Fig. 6.1. Here gamma activity, expressed as counts per min per $\mathrm{mg}$ of ${ }^{2}{ }^{3} \mathrm{U}$, is plotted vs time after purification. The initial drop in activity is due to the decay of the ${ }^{212} \mathrm{~Pb}$, which was not completely removed. After this initial decay, the activity increases as the longlived daughters grow in. Also presented for comparison of general behavior is a curve prepared from laboratory data and adjusted to fit the scale of gamma activity in the Kilorod Program. The data indicate that more complete removal of the short-lived daughters was achieved in the laboratory than was achieved in the Kilorod Program. However, after a few days, the growth curves were comparable.

In summary, the solvent extraction process for purifying ${ }^{233} \mathrm{U}$ produced material that met all specifications set for the Kilorod Program.

\section{Preparation of Thoria by Steam Denitration of Thorium Nitrate}

The denitration of thorium nitrate to prepare $\mathrm{ThO}_{2}$ suitable for preparing sol for use in the sol-gel process was carried out as an unshielded 
operation in an area apart from the Kilorod Facility. The denitrator was built before the start of the Kilorod Program but was built large enough to meet the requirements of that program. ThO was produced in $13.5-\mathrm{kg}$ batches. To smooth out possible batch-to-batch variations in the denitrated product, $70 \mathrm{~kg}$ of the product was charged to a powder blender. Following blending, the thoria powder was carefully weighed into $10-\mathrm{kg}$ (equivalent to about $8500 \mathrm{~g}$ of thorium metal) portions for charging to the blending operation in the sol-gel cubicle in the Kilorod Facility.

The denitrator was operated from early January to mid-November 1963 without a significant mechanical failure, that is, one causing loss of operating time. On this date, a simultaneous failure of the building steam supply and a safety pressure switch caused the steam superheater to burn out. More than enough $\mathrm{ThO}_{2}$ had been accumulated by this time to complete the Kilorod Program, so operation of the denitrator was discontinued.

During the above period, 99 batches of $\mathrm{ThO}_{2}$ were prepared. Five batches were rejected, two as a result of the superheater failure. The other three were rejected because of known operator error during preparation. The 94 acceptable batches amounted to $1272 \mathrm{~kg}$ of thoria. An additional $111 \mathrm{~kg}$ was prepared for use in related programs. Test dispersions and analytical results showed that all of this material $(1383 \mathrm{~kg})$ met requirements. Process control was excellent through- out the period. Denitrator product was within expected limits, which is shown by the thorium values of the $\mathrm{ThO}_{2}$ and by the range in $\mathrm{N} / \mathrm{Th}$ atom ratio (see Table 6.2).

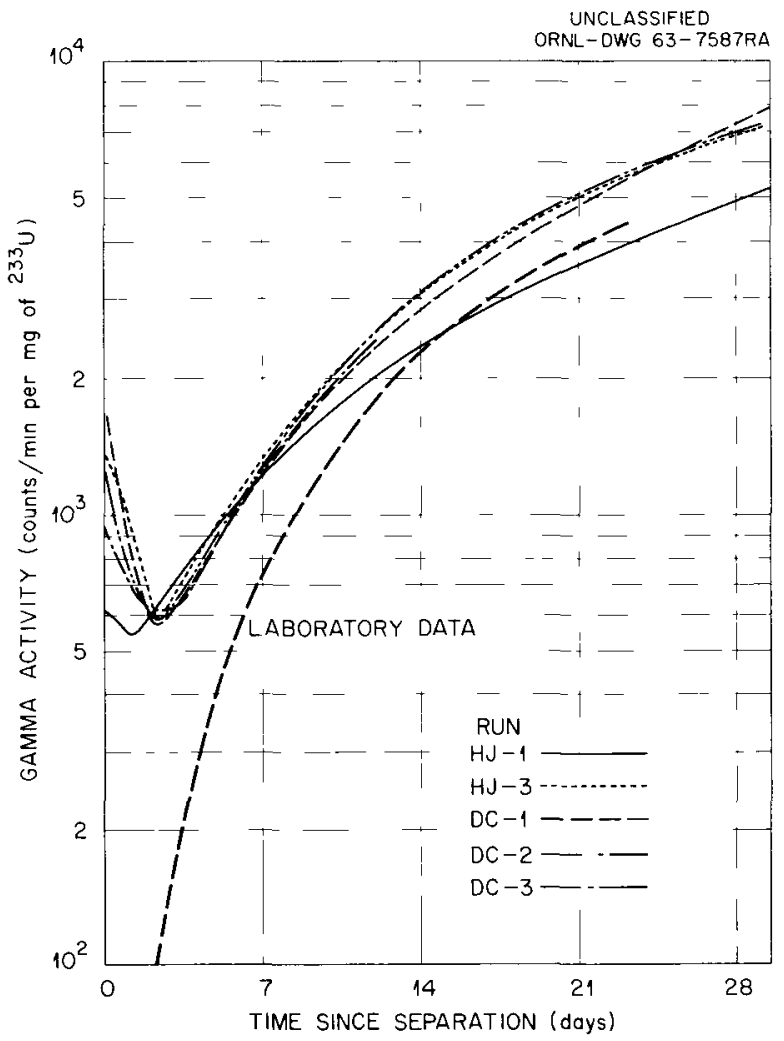

Fig. 6.1. Growth of Gamma Radioactivity in Purified Uranium-233.

Table 6.1. Kilorod Program: Operating Results for Solvent Extraction System ${ }^{a}$

\begin{tabular}{|c|c|c|c|}
\hline \multirow[b]{2}{*}{ Property Measured } & \multirow[b]{2}{*}{ Specification } & \multicolumn{2}{|c|}{ Results } \\
\hline & & Average & Range of Values \\
\hline${ }^{233} \mathrm{U}$ recovered, $\%$ & $>99.0$ & 99.8 & $99.6-99.9$ \\
\hline Product loss, \% & & 0.2 & $0.1-0.4$ \\
\hline \multicolumn{4}{|l|}{${ }^{23}{ }^{\mathrm{U}}$ decontamination: } \\
\hline Gross gamma, DF & $>100$ & 258 & $150-416$ \\
\hline Thorium, DF & $10^{3}$ & $3.5 \times 10^{3}$ & $2-6 \times 10^{3}$ \\
\hline Material balance, $\%$ & 99.0 & 99.3 & $99.0-99.7$ \\
\hline
\end{tabular}

${ }^{a} \mathrm{~A}$ total of $49.6 \mathrm{~kg}$ of ${ }^{233} \mathrm{U}$ processed in nine runs $(4-8 \mathrm{~kg} / \mathrm{run})$. 


\section{Preparation of Mixed $\mathrm{ThO}_{2}-\mathrm{UO}_{2}$ by the Sol-Gel Method}

After the denitration of thorium nitrate to prepare $\mathrm{ThO}_{2}$ suitable for preparing sol, the sol-gel method consists of blending uranyl nitrate solution with the thoria sol, adjusting the nitrate content and $\mathrm{pH}$, drying to form a gel, and then calcination-reduction to produce the final mixed oxide, which is sized to the desired range for vibratory compaction into fuel tubes (Fig. 6.2). In the Kilorod Facility each of these steps is performed as a batch operation. Since the blending, drying, and calcining are performed in the presence of high levels of alpha activity, the equipment for these operations is housed in a sealed carbon-steel cubicle, about $9 \mathrm{ft}$ long by $7 \mathrm{ft}$ wide by $7 \mathrm{ft}$ high, having eight windows, ten glove ports, and three transfer ports. This cubicle is located on the third floor of the Kilorod Facility

Table 6.2 Product Quality-Control Data for Denitrator Operation

\begin{tabular}{ccccc}
$\begin{array}{c}\text { Identification } \\
\text { of } \\
\text { Materials }\end{array}$ & $\begin{array}{c}\mathrm{ThO}_{2} \\
\text { Prepared } \\
(\mathrm{kg})\end{array}$ & $\begin{array}{c}\text { Percent } \\
\mathrm{Th} \\
\text { (ranges) }\end{array}$ & $\begin{array}{c}\text { Percent } \\
\mathrm{NO}_{3} \\
\text { (ranges) }\end{array}$ & $\begin{array}{c}\mathrm{N} / \mathrm{Th} \\
\text { Atom Ratio } \\
\text { (ranges) }\end{array}$ \\
\hline $\begin{array}{c}\text { Rotary denitrator batches } \\
1-12^{a}\end{array}$ & 165.5 & $85.3-86.4$ & $0.5-1.3$ & $0.02-0.06$ \\
$\begin{array}{c}\text { Blended batches } \\
\mathrm{BB}-1-\mathrm{BB}-17^{b}\end{array}$ & $1,120.7$ & $84.6-86.2$ & $0.58-1.06$ & $0.026-0.045$ \\
\hline
\end{tabular}

\footnotetext{
${ }^{a}$ This represents the first 12 denitrator batches which were analyzed individually in order to amass process-control data on the denitrator.

${ }^{b}$ The BB designation represents a batch obtained by mixing approximately five rotary denitrator batches in a batch blender to obtain $70 \mathrm{~kg}$ of thoroughly blended powder.
}

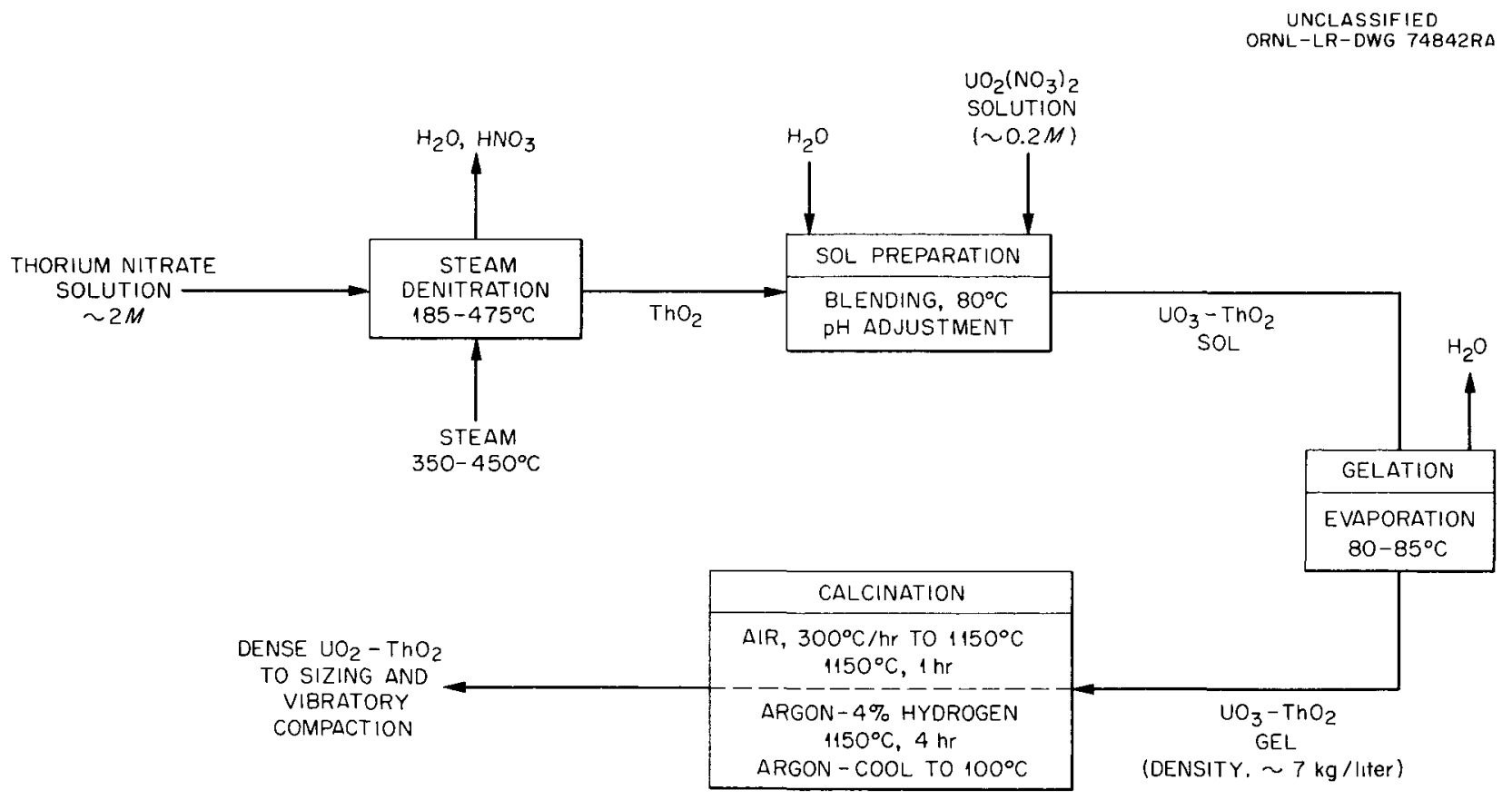

Fig. 6.2. Flowsheet for the Sol-Gel Process. 
(see Fig. 6.3). Biological shielding is provided on the sides by $8 \mathrm{in}$. of barytes concrete or $4 \frac{1}{2}$ in. of steel and on the floor by a $4 \frac{1}{2}$-in.-thick steel slab. The top and back of the sol-gel cubicle abut 4-ft-thick concrete slabs. Means are provided in the cubicle whereby vulnerable mechanical parts may be maintained without entering the operating cubicle.

In the criticality-safe (slab-shaped) blend tank (Fig. 6.4) the thoria is blended with a precisely measured quantity of ${ }^{23} \mathrm{U}$, introduced as uranyl nitrate solution. The quantities of thorium and uranium used are such that the $U / T h$ ratio, defined as $\left({ }^{233} \mathrm{U} \times 100\right) /\left({ }^{23} \mathrm{U}+\mathrm{Th}\right)$, meets the metal ratio specification. ${ }^{1}$ At the end of the blending

${ }^{1} \mathrm{U} / \mathrm{Th}$ specification: $\left({ }^{233} \mathrm{U} \times 100\right) /\left({ }^{233} \mathrm{U}+\mathrm{Th}\right)=$ $3.00 \pm 0.05$, or, if within $3.00 \pm 0.1$, powders may be blended to yield a mixture within the \pm 0.05 range. step, the batch is pumped to a tray dryer (Fig. 6.5). Here, the sol is dried to a gel in about $30 \mathrm{hr}$ and is then transferred from the trays to aluminum oxide crucibles. The crucibles of gel are placed in the calciner, and the temperature is raised to $1150^{\circ} \mathrm{C}$ while purging with air (Fig. 6.6). When $1150^{\circ} \mathrm{C}$ is reached, the gas purge is changed to $96 \% \mathrm{Ar}-4 \%$ $\mathrm{H}_{2}$. This purge is maintained in the furnace, held at $1150^{\circ} \mathrm{C}$, for $4 \mathrm{hr}$. The calciner is then turned off and allowed to cool to $350^{\circ} \mathrm{C}$. An argon atmosphere is maintained during the cooling portion of the cycle. The cooled oxide product (at a temperature less than $350^{\circ} \mathrm{C}$ ) is removed from the calciner and placed under an argon atmosphere until its temperature falls below $100^{\circ} \mathrm{C}$. The batch is then weighed and transferred to the rod-fabrication operation.

Construction of the sol-gel unit of the Kilorod Facility was completed, and testing of individual

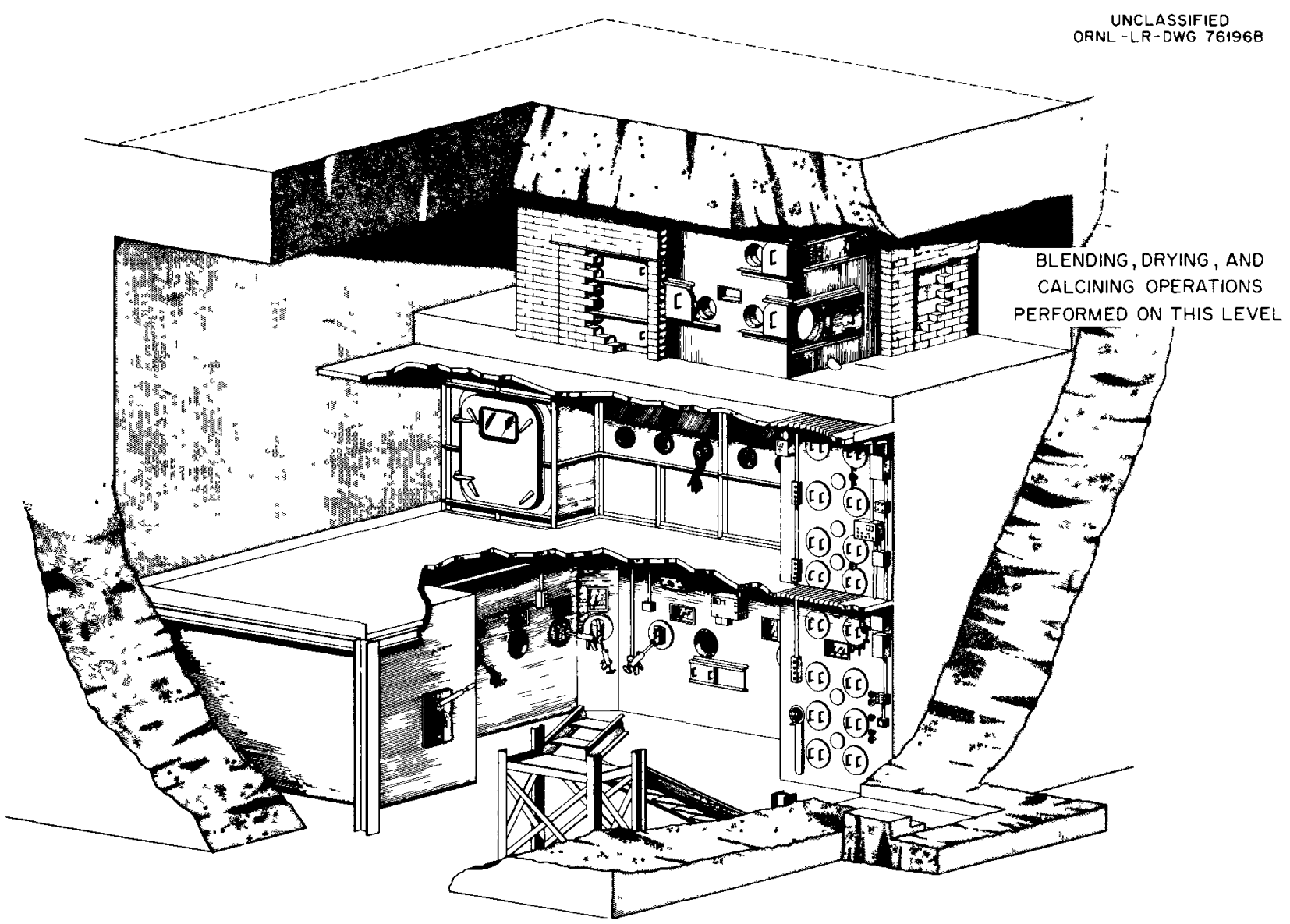

Fig. 6.3. Kilorod Solids-Preparation and Rod-Fabrication Facility. 


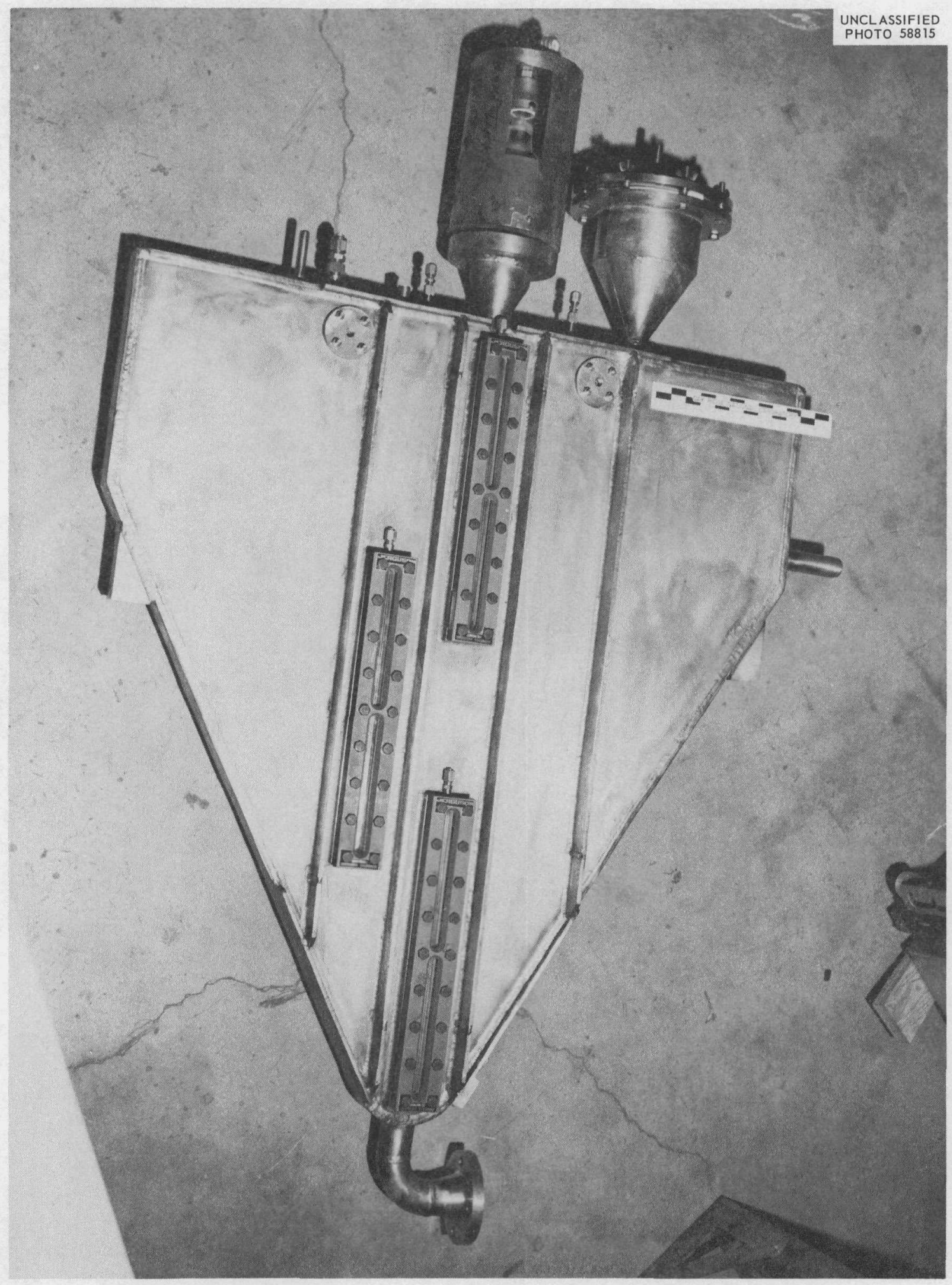

Fig. 6.4. Critically Safe Slab Blend Tank. Thoria powder is blended with ${ }^{233} \mathrm{UO}_{2}\left(\mathrm{NO}_{3}\right)_{2}$ solution, forming a sol. 


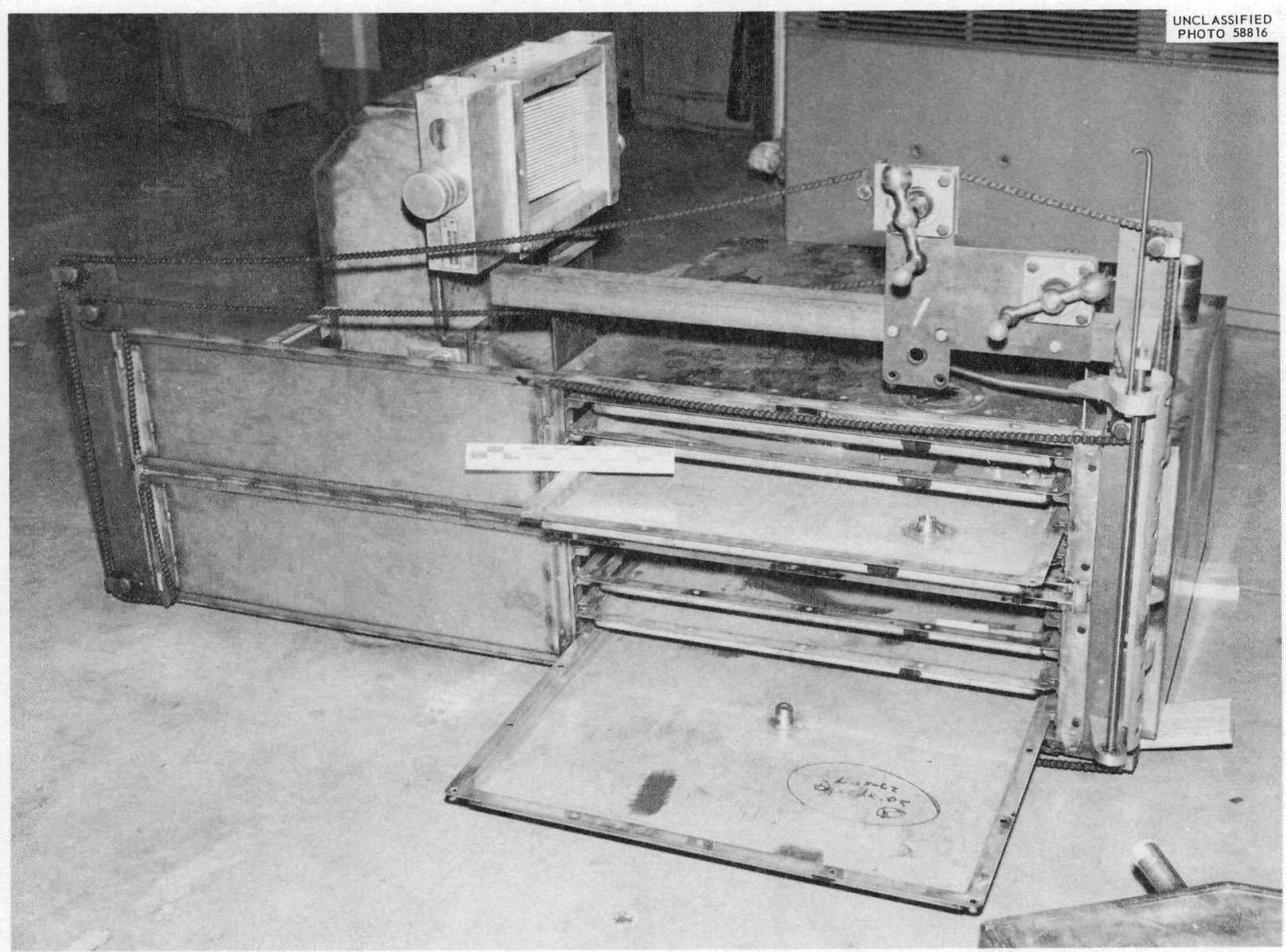

Fig. 6.5. Tray Dryer. In this equipment, the sol is dried to a gel.

equipment pieces started March 1, 1963. Equipment shakedown and cold testing of individual operations was completed May 3. A sustained five-day operating demonstration was then conducted from May 13-17, using depleted uranium as a stand-in for ${ }^{23}{ }^{3} \mathrm{U}$. This demonstration showed that the plant was operable as an integrated unit, that design production rates could be maintained, and that expected product-quality standards could be met.

Following cold testing, the plant was cleaned thoroughly, and final equipment adjustments were made. The facility was ready for operation with radioactive material on June 5, 1963.

A hundred sol-gel batches were prepared and calcined in the sol-gel operations. During the entire program only one batch was prepared which did not meet the $U / T h$ ratio specification. This batch $(\mathrm{U} / \mathrm{Th}$ ratio $=3.12)$ was used, however, with the permission of Brookhaven National Laboratory. Thus, all the sol-gel product was acceptable for rod fabrication. The total calcined product transferred to the rod fabrication operation was $988.8 \mathrm{~kg}$ (see Table 6.3). The total ${ }^{23}{ }^{3} \mathrm{U}$ consumed in the process was $26.5 \mathrm{~kg}$, while 860.2 $\mathrm{kg}$ of thorium was used. These quantities were processed in seven operating campaigns.

Product quality control (Table 6.4) met or exceeded all specifications. Even though the U/Th ratio specification of $3.00 \pm 0.05$ was established, an overall campaign ratio of $3.00 \pm 0.03$ appeared attainable from preliminary work. This narrower and better control range was obtained in all campaigns following the first. An improperly designed uranyl nitrate feed solution tank was the source of the trouble in the first campaign. The tank, 


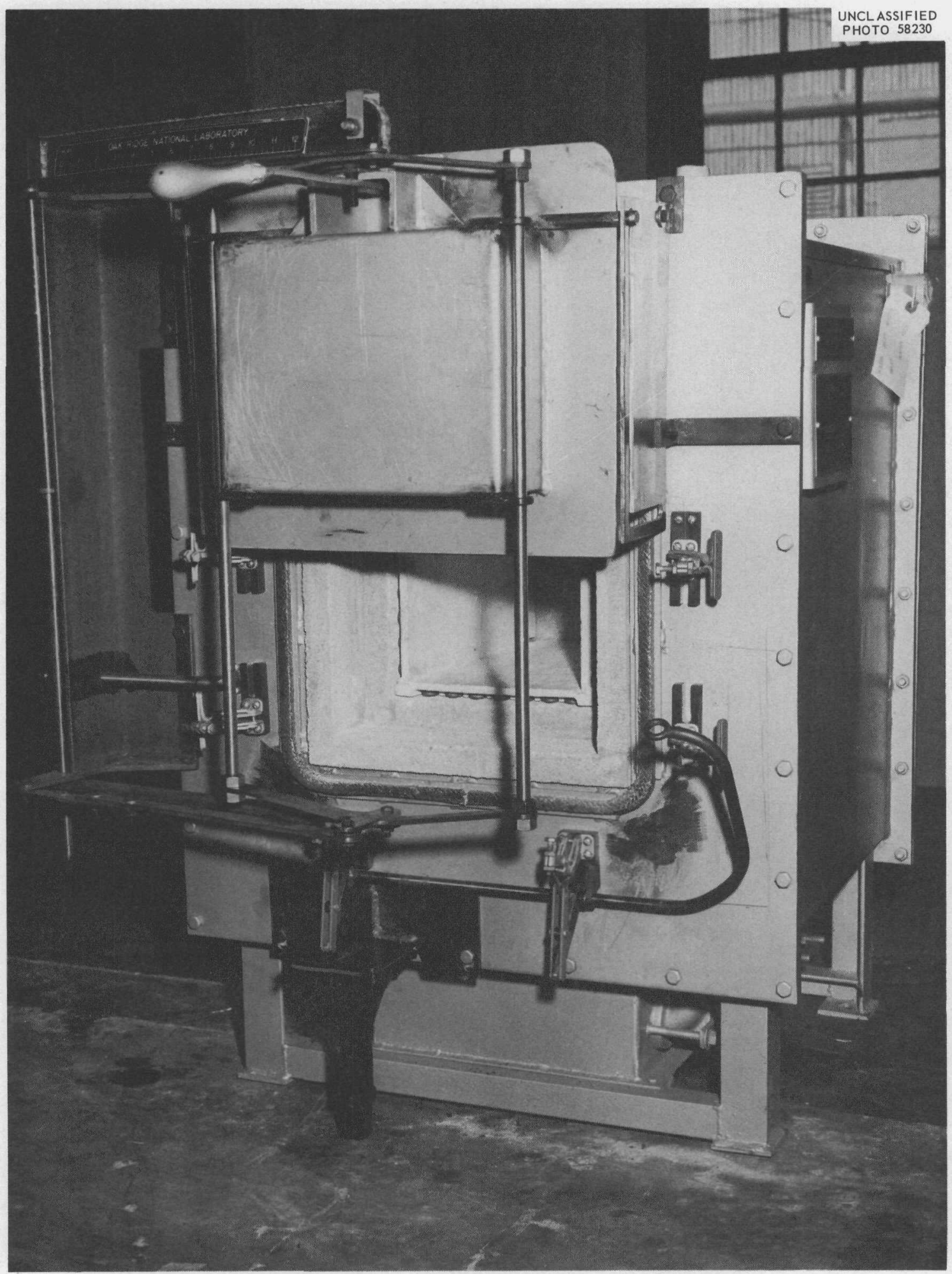

Fig. 6.6. Calcination-Reduction Furnace. Gel fragments are calcined to dense oxide, and the ${ }^{233} \mathrm{UO}_{3}-\mathrm{ThO}_{2}$ is converted to ${ }^{233} \mathrm{UO}_{2}-\mathrm{ThO}_{2}$. 
which was 18 in. in diameter and packed with borated-glass Raschig rings for criticality control, could not be agitated properly. Further, since a current of instrument a1r passed through the tank at all times, the concentration of the feed solution was constantly increasing because of the evaporation of water. After campaign 1, the tank was replaced with a geometrically safe [5 in. in diameter (IPS) and $13 \mathrm{ft}$ long], vertically mounted, unpacked storage tank. Excellent control was experienced thereafter.
In routine operation of the calciner, the quantity of gases released by the calcined product was not expected to exceed $0.05 \mathrm{std} \mathrm{cm}^{3} / \mathrm{g}$. Of 97 batches made under routine conditions, only three exceeded this value, and the highest of these was only 0.057 . Average gas-release values for any given campaign, or for the whole program, were considerably lower, as shown in Table 6.4. The gas-release values for the crushed oxide entering the fuel rods did not exceed the expected maximum in any case.

Table 6.3 Quantities of Uranium-233 and Thorium Charged, and Product

Removed from the Sol-Gel Operation

\begin{tabular}{|c|c|c|c|c|}
\hline $\begin{array}{c}\text { Campargn } \\
\text { No. }\end{array}$ & $\begin{array}{c}{ }^{233} \mathrm{U} \\
\text { Input } \\
\text { (g) }\end{array}$ & $\begin{array}{c}\text { Th } \\
\text { Input } \\
(\mathrm{kg})\end{array}$ & $\begin{array}{c}{ }^{23} \mathrm{UO}_{2}+\mathrm{ThO}_{2} \\
\text { Output } \\
(\mathrm{kg})\end{array}$ & 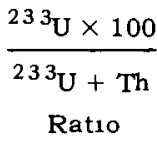 \\
\hline 1 & 3,196 & 104.7 & 118.6 & 2.96 \\
\hline 2 & 4,255 & 137.2 & 160.9 & 3.01 \\
\hline 3 & 3,166 & 102.5 & 118.5 & 3.00 \\
\hline 4 & 3,450 & 110.7 & 128.7 & 3.02 \\
\hline 5 & 6,056 & 195.5 & 226.8 & 3.00 \\
\hline 6 & 4,521 & 145.2 & 166.7 & 3.02 \\
\hline 7 & 1,874 & 59.9 & 68.6 & 3.03 \\
\hline Total & 26,518 & 855.7 & 988.8 & 3.01 \\
\hline
\end{tabular}

Table 6.4. Kilorod Program: Operating Summory of Sol-Gel Demonstration

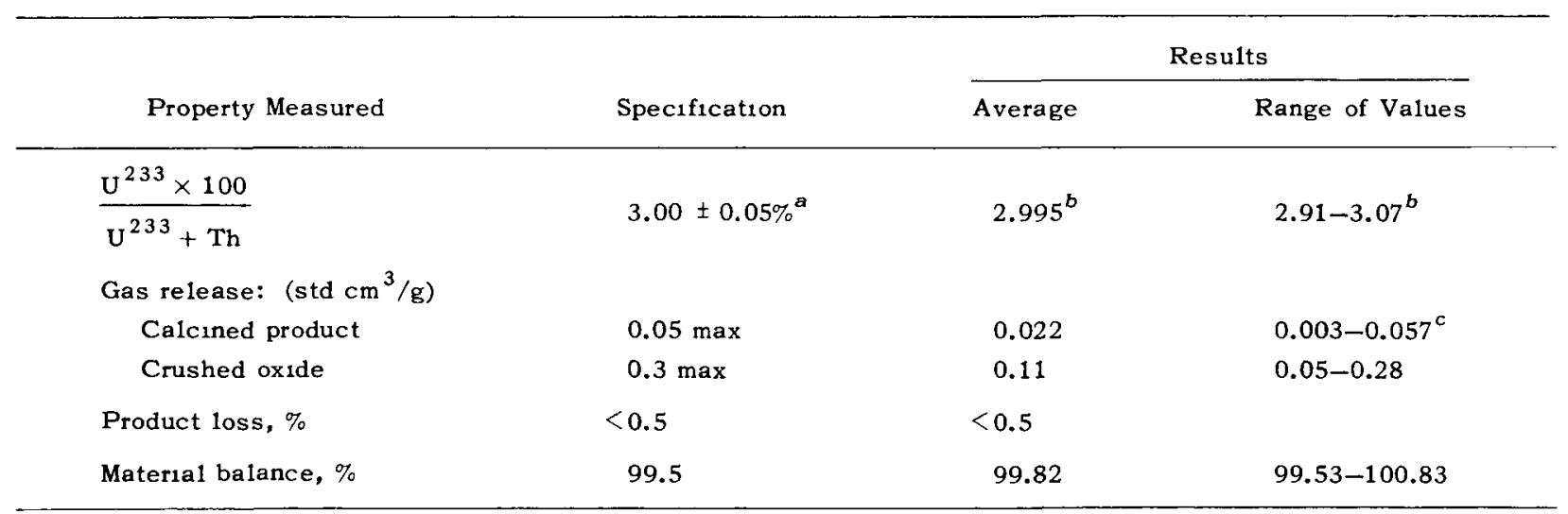

\footnotetext{
${ }^{a}$ Powders falling within a ratio of $3.00 \pm 0.10$ may be blended to obtain desired ratio of $3.00 \pm 0.05$.

${ }^{b}$ The average and the maximum and minimum analytical values reported for the metal ratio in all sol batches (campargns 2-7).

${ }^{c}$ Three batches exceeded $0.05 \mathrm{std}^{3} / \mathrm{g}$.
} 
Product loss (not recoverable) was nearly all limited to analytical losses and insignificant powder losses inside the cubicle These were too small to be measured and are estımated at $0.5 \%$ Material balances confirm this estimate and are within accepted analytical errors in all cases.

\section{Maintenance Experience}

Records were kept on maintenance for all equpment throughout the program. The solvent extraction system processed all the ${ }^{233} \mathrm{U}$ required without a single fallure. The major breakdown involved in the denitration operation occurred when a superheater falled. Minor maintenance within the solgel cubicle was limited to replacement of $\mathrm{pH}$ electrodes, thermocouples, and crucible supports in the calciner. None of these affected the onstream time of the process

The prime indicator of equipment reliability is the plant on-stream time and the number of major breakdowns that required cubicle entry. Percentage on-stream time was $90 \%$, limited only by major repairs. Four major repairs were made within the sol-gel cubicle. These included the replacement of three burned-out calciner elements and repair of three malfunctioning control valves. During the cold-testing phase of sol-gel process development, element replacement was predicted to be necessary after 20 batches of oxide were fired. Kilorod experience was somewhat better and ind1cated that a minımum of 33 batches could be fired with each element.

\section{Radiation Exposure Experience}

One of the primary objectives of the Kilorod Facility was to gain radiation data in the handling of ${ }^{233} \mathrm{U}$ on a plant scale. This information is expected to contribute design information for future facilities. Personnel radiation-exposure data compiled during the work indicate that rad $_{1-}$ ation levels to which workers were exposed were well below the maximum permissible exposure levels for workers in the field.

Table 65 presents a breakdown of the distr1bution of dosages recelved by the operators as a function of work activity. During the sol-gel operations, blending of $\mathrm{ThO}_{2}$ with the uranyl nitrate solution was responsible for $36 \%$ of the total exposure, and loading the evaporator was responsible for $17 \%$. During rod fabrication, the major contributors appeared to be vibratory compaction (19\%), welding (15\%), and blending of the sized oxides $(14 \%)$.

Table 6.5. Radiation Received by Personnel in the Kilorod Program as a Function of Task

\begin{tabular}{|c|c|c|c|}
\hline Operational Task & Exposure (\% of total) & Operational Task & Exposure (\% of tota1) \\
\hline Sol-Gel Phose & & Rod-Fabrication Phase & \\
\hline Blending & 35.7 & Jaw crushing & 8.3 \\
\hline Loading evaporator & 16.7 & Ball milling & 4.3 \\
\hline Unloading evaporator & 11.9 & Blending & 13.6 \\
\hline Loading furnace & 11.9 & Compacting & 18.6 \\
\hline Unloading furnace & 11.9 & Scanning & 3.8 \\
\hline \multirow[t]{6}{*}{ Dumping oxide } & 11.9 & Welding & 15.4 \\
\hline & 100.0 & Cleanıng & 5.3 \\
\hline & & Leak test, weighing & 5.9 \\
\hline & & Loading & 9.7 \\
\hline & & Supervision & 15.1 \\
\hline & & & 100.0 \\
\hline
\end{tabular}


Table 6.6. Kilorod Program: Summary of Personnel Radiation Exposure

\begin{tabular}{|c|c|c|c|c|}
\hline \multirow[t]{2}{*}{ Operational Phase } & \multirow{2}{*}{ Daily Throughput } & \multirow{2}{*}{$\begin{array}{c}\text { Time Since Purification } \\
\text { (range in days) }\end{array}$} & \multicolumn{2}{|c|}{$\begin{array}{c}\text { Average Weekly }{ }^{a} \\
\text { Personnel Exposure (millirems) }\end{array}$} \\
\hline & & & Hands and Arms & Total Body \\
\hline Solvent extraction & & & 0 & 0 \\
\hline Sol-ge1 & $10 \mathrm{~kg}$ & $7-50$ & 57 & 18 \\
\hline Rod fabrication & 10 rods & $13-51$ & 104 & 17 \\
\hline
\end{tabular}

Table 6.6 presents a radiation exposure summary obtanned over campangns 4-7. Note that ${ }^{233} U$ was processed over periods as long as 50 days after extraction. An actual increase in radioactivity of about $30 \%$ was noted in the in-process materials during these campaigns, but this is not of significance in comparison with overall dosages. During sol-gel operations the individual hand and forearm exposures averaged 57 millirems/ man-week. Total body doses averaged $18 \mathrm{mill}$ rems/man-week. The workers who fabricated rods accumulated an average of 104 millirems per man-week to the hands and 17 millirems per manweek to the body.

A single $10-\mathrm{kg}$ batch was processed through the Kilorod Facility equipment to simulate the handling of a ${ }^{232} \mathrm{U}$ concentration of $800 \mathrm{ppm}, 14$ days after purification by solvent extraction. A solution of ${ }^{233} \mathrm{UO}_{2}\left(\mathrm{NO}_{3}\right)_{2}$ purified six years previously was used for "spiking" the regular feed solution. The daughters from the ${ }^{232} \mathrm{U}$ present in this solution gave sufficient radioactivity to produce the desired radiation level. Table 6.7 compares exposures experienced in the Kilorod Program operation with those experienced while processing the simulated higher ${ }^{23}{ }^{3} \mathrm{U}$ content. An increase of 2 to 4 times the levels experienced in the Kilorod Program is noted. A word of caution must be added concerning spiked runs. At the end of the program, the general background within the processing cubicles frequently fell within the range of 15 to $30 \mathrm{mr} / \mathrm{hr}$. It is this background level that is reflected in the data from spiked runs rather than a level typical of a run with $800 \mathrm{ppm}{ }^{23}{ }^{2} \mathrm{U}$. It was not feasible to make more than one spiked run, so the back-
Table 6.7. Comparis on of Radiation Exposures as a Function of ${ }^{232} \mathrm{U}$ Content

Conditions: Data under column labeled "37 ppm ${ }^{232} \mathrm{U}$ " are average for kilorod program

Data under column labeled " 800 ppm $232 \mathrm{U}$ " represent values for a single run and do not reflect longoterm buildup of background

Doses in both cases were distributed between two operators for sol-gel work and among four operators for rod fabrication

\begin{tabular}{|c|c|c|c|c|}
\hline \multirow{3}{*}{$\begin{array}{l}\text { Operational } \\
\text { Phase }\end{array}$} & \multicolumn{4}{|c|}{$\begin{array}{l}\text { Personnel Exposure Data } \\
\text { (millirems/man-week) }\end{array}$} \\
\hline & \multicolumn{2}{|c|}{$37 \mathrm{ppm}{ }^{232} \mathrm{U}$} & \multirow{2}{*}{$\frac{800 \text { ppm }}{\text { Hands }}$} & \multirow{2}{*}{$\frac{{ }^{232} \mathrm{U}}{\text { Body }}$} \\
\hline & Hands & Body & & \\
\hline Sol-gel & 57 & 18 & 203 & 48 \\
\hline Rod fabrication & 104 & 17 & 198 & 55 \\
\hline
\end{tabular}

ground which might be found after a period of operating at the $800-p p m$ level is not known. Further, the data given were taken from dosimeters clipped to the wrist, and are not necessarily the dose to the hands, which were closer to the materal handled. The background level would undoubtedly be higher than the range of 15 to 30 $\mathrm{mr} / \mathrm{hr}$, and proper allowances must be made for both of these factors when using the figures obtained during the spiked run. 


\section{Conclusions}

1. The Kilorod demonstration shows that the sol-gel process is a practical production process.

2. Specifications requiring high purity of product and rigid analytical control can be met.

3. Loss of valuable process materials can be limited to extremely low values.

4. Radiation exposures to operators can be held well below permissible levels at a ${ }^{232} \mathrm{U}$ concentration of $38 \mathrm{ppm}$.

5. A ${ }^{232} \mathrm{U}$ concentration of $500 \mathrm{ppm}$ can be handled safely in the existing facility providing the feed is purified weekly.

6. Uranium-233 for use in the sol-gel process can be purified satisfactorly by a solvent extraction process using di-sec-butyl phenylphosphonate

\subsection{DEVELOPMENT OF THE SOL-GEL PROCESS}

Scoutıng experiments show that a small, controlled amount of porosity can be "built into" uranium-thorium oxide particles. This may increase their rate of dissolution and expedite fuel processing. In the present stage of development, the porosity is not uniformly distributed, and further development is needed.

Three different methods are under study for generating porosity in thoria and thoria-urania prepared by sol-gel techniques. In the first method, a low-density, $1200^{\circ} \mathrm{C}$-fired $\mathrm{ThO}_{2}$ powder is added to the sol in the blending step. The $\mathrm{ThO}_{2}$ powder maintains its low density throughout subsequent process steps, resulting in a low-density calcıned product. In laboratory-scale exper1ments it was shown that the bulk porosity of the sol-gel preparation was increased in proportion to the ratio of porous powder to total solids in the sol. However, the porosity of the product obtained by this method is not uniformly distributed. The nonuniformity is attributed to the high settling rate of the sintered $\mathrm{ThO}_{2}$ that is added to the sol. Even though the sol is concentrated to a viscous mass which is stirred constantly while being evaporated, settling out of the powder occurs. Work done to date has been only preliminary, and much more work remains to be done in this area.

\subsection{APPLICATION OF THE SOL-GEL PROCESS TO THE PREPARATION OF $\mathrm{THC}_{2}-\mathrm{UC}_{2}$}

The sol-gel process provides the basis for a new process for producing spheres of uraniumthorium carbide suitable for use as fissile-fertile fuel material. In common with other sol-gel processes, this new process also has the advantages over conventional processes of simplicity and of improved control over particle size and shape. Preliminary studies of this process were reported in last year's annual progress report. ${ }^{2}$ The process consists of the four steps outlined in Fig. 6.7. An oxide sol, containing from 0 to 10 metalat \% uranium, 1 s prepared by the basic sol-gel method (see Fig. 62 , Sect. 61 ), sufficient highsurface-area carbon 15 blended with the oxide sol to produce an oxide-carbon sol that can be completely converted to the desired carbide, the oxide-carbon sol is formed and set to gel spheres by dispersion in an organic liquid capable of extracting water from the sol, and the gel spheres are converted to carbide spheres by air drying and then firing at $1750^{\circ} \mathrm{C}$ in vacuum or in a stream of argon at 2000 to $2300^{\circ} \mathrm{C}$. The process has been tested on a laboratory scale. Good conversions (better than 99\%) to carbide were obtained, and the control of microsphere size and integrity was good.

While the process has been demonstrated to be feasible on a laboratory scale, some problems

\footnotetext{
${ }^{2}$ Chem Technol Div Ann Progr Rept. May 31, 1963, ORNL-3452.
}

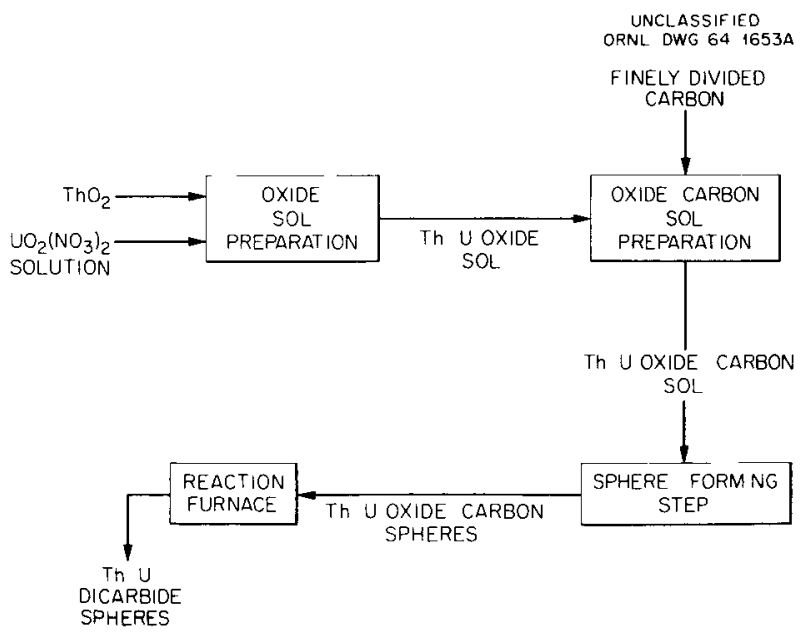

Fıg. 6.7. Sol-Gel Process for Preparing Carbides. 
remain unsolved. Particle densities ranged from 65 to $90 \%$ of the theoretical density of the crystals of the compounds. It is desirable to produce particles of controlled density up to the theoretically attainable density. Only preliminary work has been done on the control of the monocarbide/dicarbide ratio. Further study is needed in order to find the optimum form of carbon to use, and to find a method that will ensure uniformity and control of sol and finished-product properties from batch to batch.

The oxide-carbon sols used in the most successful preparation so far were prepared by blending fine particles of commercial channel black (Table 6.8) with uranium-thorium oxide sols. The requirements for carbon appear to be those indicated by Eq. (2) below. In addition, from 0.3 to 0.4 moles of carbon per mole of oxide are needed for reduction of nitrate ion and other oxidizing agents present in the thoria-carbon sol. Thus, for the usual $2 M$ oxide sol, the added carbon required for dicarbide conversion gives a solids concentration of 10.6 moles/liter, or about $630 \mathrm{~g}$ of solids per liter of sol. The electron micrograph (Fig. 6.8) shows what appear to be single crystals and small agglomerates of $\mathrm{ThO}_{2}$ coated with uniform halos of the carbon used. This suggests that very intimate contact is achieved.

The channel black carbons had particle sizes of about 110 to $140 \mathrm{~A}$, specific surface areas for nitrogen adsorption of 400 to $1100 \mathrm{~m}^{2} / \mathrm{g}$, and 5 to $16 \%$ of a volatile component which contained more than $50 \%$ by weight of oxygen (Table 6.8). Stable aquasols of these lyophilic carbons can be prepared with the aid of dispersing agents by shearing them in water or alkaline solutions. The carbon surfaces apparently carry two kinds of sites because they are electrophoretically negative at a $\mathrm{pH}$ higher than 3 and positive at lower $\mathrm{pH}$ 's. Conductimetric titration with sodium hydroxide gave a value of 1 to 5 micromoles of acidic sites per square meter. The diphenylguanidine adsorption index (Table 6.8) gives a convenient measure of the available acid (i.e., carboxylic acid) groups on the carbon surface.

Stable sols containing as high as 20 mole \% $\mathrm{U}$ have been prepared. The total uranium capacity of the system is unknown. The high solids content of the sols enhances the non-Newtonian flow properties of the oxide-carbon sols and increases their yield stress and apparent viscosity. The effect is increased by using carbons having larger areas. In order to avoid plugging the jets in the sphere-forming step, carbons having somewhat less than the highest surface area were chosen (e.g., Cabot Supercarbovar).

Studies of flow properties in oxide-carbon sols containing carbons of extremely high surface area are being conducted at Southwest Research Institute under a subcontract.

Table 6.8. Properties of Carbons Used for Preparation of Oxide-Carbon Sols

\begin{tabular}{|c|c|c|c|c|c|}
\hline Channel Black & $\begin{array}{c}\text { Particle Size } \\
\text { (A) }\end{array}$ & $\begin{array}{c}\text { Nitrogen } \\
\text { Surface Area } \\
\left(\mathrm{m}^{2} / \mathrm{g}\right)\end{array}$ & $\begin{array}{c}\text { Volatile } \\
\text { Matter Content } \\
\text { (\% by wt })\end{array}$ & $\begin{array}{c}\mathrm{pH}, 5 \mathrm{M} \text { Slurry } \\
\quad \text { in } \mathrm{H}_{2} \mathrm{O}\end{array}$ & $\begin{array}{c}\text { DPG Ads orption } \\
\text { Inde } x^{b}\end{array}$ \\
\hline Neo Spectra Mark $I^{\mathcal{C}}$ & 110 & 1100 & 16.2 & 3.0 & 100 \\
\hline Neo Spectra Mark II ${ }^{c}$ & 130 & 870 & 14.7 & 3.3 & 98 \\
\hline Black Pearls $46^{d}$ & 120 & 800 & 14.0 & 3.0 & 75 \\
\hline Supercarbovar $^{d}$ & 140 & 400 & 5.0 & 5.0 & 20 \\
\hline
\end{tabular}

\footnotetext{
${ }^{a}$ Loss in weight at $1000^{\circ} \mathrm{C}$ in argon.

${ }^{b}$ Diphenylguanidine chemisorption in arbitrary units; an indicator of readily available acid groups on the carbon surface.

${ }^{\mathrm{c} C o l u m b i a n}$ Carbon Company, New York, data sheet.

${ }^{d}$ Cabot Corporation, Boston, data sheet.
} 


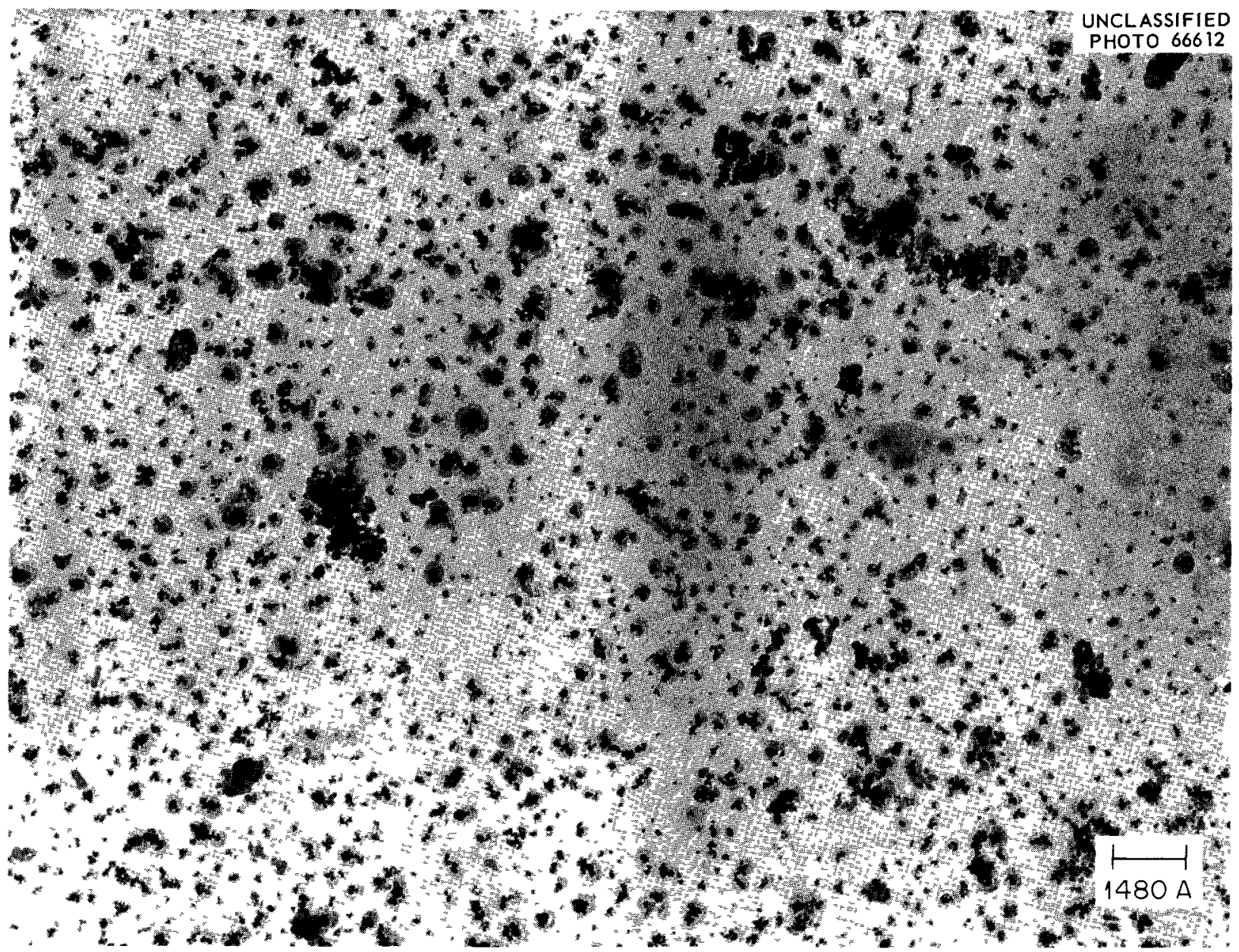

Fig. 6.8. Electron Micrograph of Dried Thoria-Carbon Sol. The dark spots are ThO ${ }_{2}$. The gray halos are thought to be due to carbon. $68,000 \mathrm{X}$.

\section{Gelation: Formation of Microspheres}

Oxide-carbon sols form gels which undergo fragmentation upon drying in a tray, just as the oxide sols do. However, since microspheres are the preferred shape for carbides, the present discussion is limited to the formation of oxidecarbon microspheres. In contrast to forming spheres from oxide sols, no surface-active agent is needed to adjust the interfacial surface tension between the oxide-carbon sols and the organic forming medium. However, a secondary alcohol (2-octanol) is added to the 2-ethylhexanol to suppress a slight tendency of the organic drying solvent to extract carbon with the water. The gel spheres (Fig. 6.9) are strong enough to be calcined directly to carbides.

\section{Calcining: Conversion of Oxide-Carbon Gels to Carbides}

The oxide-carbon gel spheres are converted to carbides by heating them to about $1800^{\circ} \mathrm{C}$ in a vacuum or in flowing argon. Reduction to the carbides appears to proceed by reactions (1) and (2) below:

$$
\begin{aligned}
& \mathrm{ThO}_{2}+3 \mathrm{C} \rightarrow \mathrm{ThC}+2 \mathrm{CO}_{(g)}, \\
& \mathrm{ThO}_{2}+4 \mathrm{C} \rightarrow \mathrm{ThC}_{2}+2 \mathrm{CO}_{(g)} .
\end{aligned}
$$

While it may be possible to prepare pure monocarbide by this method, the production of monocarbide uncontaminated by dicarbide or oxide has 


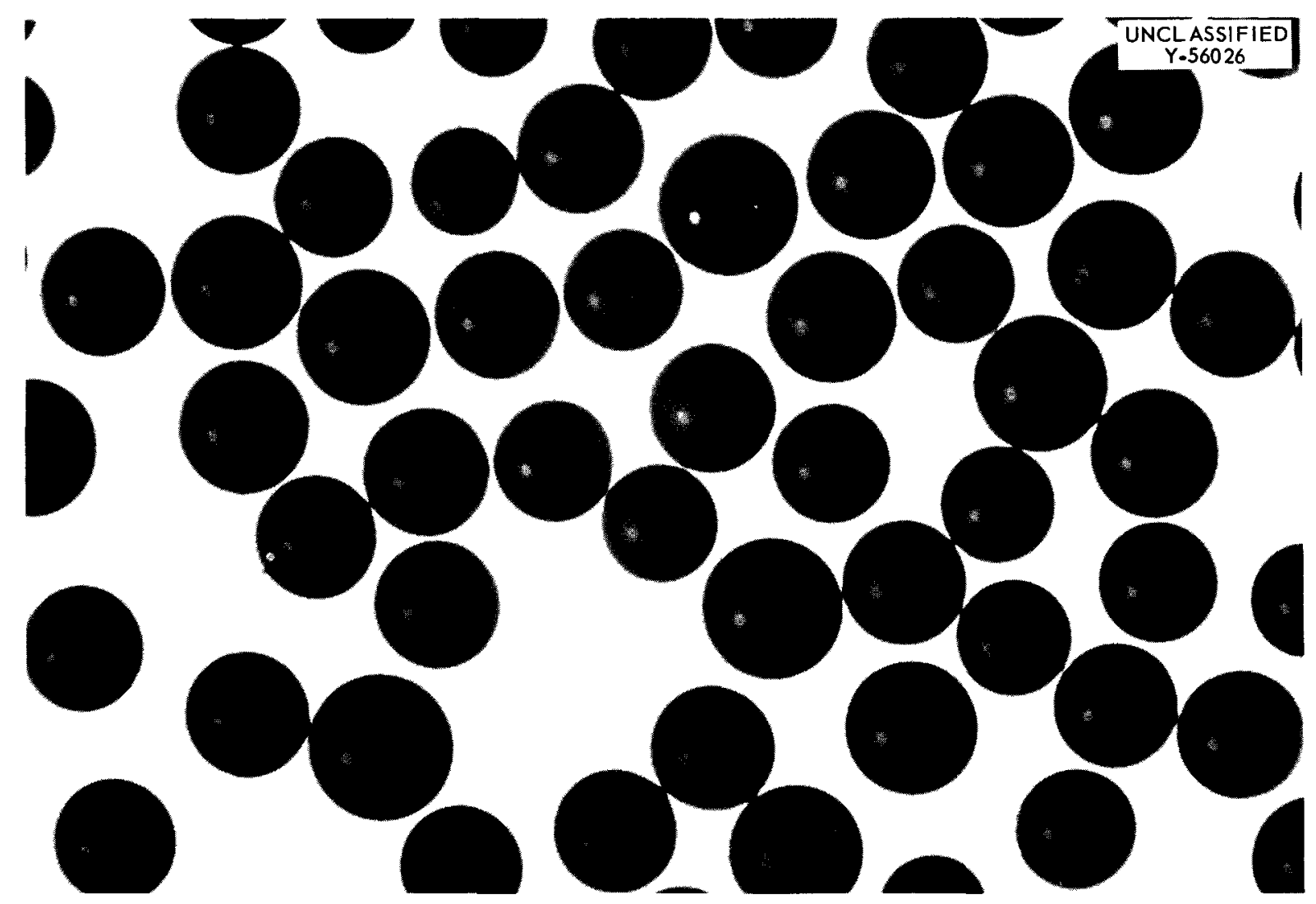

Fig. 6.9. Spheres of Urania-Thoria-Carbon Gel. The spheres are formed by dispersing the sol in an immiscible solvent, such as 2-ethylhexanol.

not as yet been demonstrated. In two experiments, with an initial $\mathrm{C} / \mathrm{Th}$ atom ratio of 3.4 , thorium monocarbide was obtained; however, traces of oxide and a large fraction of dicarbide were found by $\mathrm{x}$-ray diffraction.

Since all the reactants and products in Eqs. (1) and (2) except carbon monoxide are solids, equilibrium may be described by a curve of $\mathrm{CO}$ pressure vs temperature (Fig. 6.10). ${ }^{2}$ Reasonably complete conversions should be obtained between 1450 and $1800^{\circ} \mathrm{C}$ if the partial pressure of $\mathrm{CO}$ is kept below its equilibrium value by evacuation or by a sweep of argon.

The rates of conversion of the oxide-carbon gels to dicarbide were investigated from 1445 to $1750^{\circ} \mathrm{C}$, with $\mathrm{C} /(\mathrm{U}+\mathrm{Th})$ ratios of 4.3 to 6.8 , and $U /(U+T h)$ ratios of 0 to 0.05 . In each experiment, the sample was vacuum-outgassed by raising the temperature slowly to $1200^{\circ} \mathrm{C}$ and holding it there until the gas evolution was negligible. The sample was then heated to the desired reaction temperature, and the volume of gas

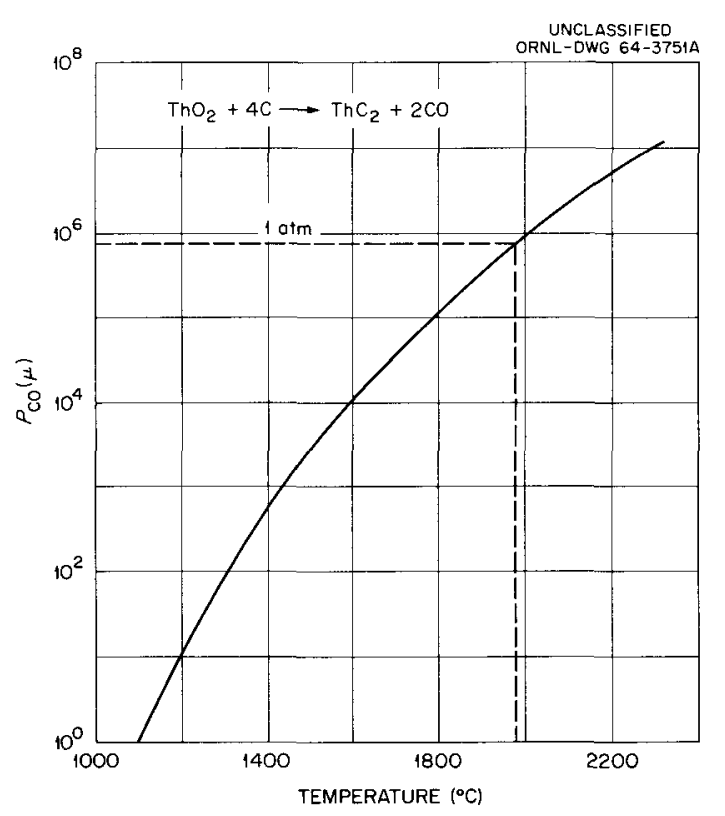

Fig. 6.10. Equilibrium Partial Pressure of Carbon Monoxide over Thoria-Carbon Mixtures. 
evolved was measured. Figure 6.11 is an Arrhenuus plot of data taken for temperatures between 1718 and $2023^{\circ} \mathrm{K}$. All points represent rate constants obtained by using carbon in excess of that required for forming dicarbide. The reaction was of an apparent first order with respect to the fraction of oxide that remained. The activation energy was about $112 \mathrm{kcal}$ per mole of $\mathrm{ThC}_{2}$. The reaction rates were independent of $\mathrm{U} /(\mathrm{U}+\mathrm{Th})$ and $\mathrm{C} /(\mathrm{U}+\mathrm{Th})$ atom ratios in the range studied and appeared to vary only with temperature and pressure.

\section{Properties of Uranium-Thorium Dicarbide}

A thorough evaluation of the carbide spheres has not been made. The properties thought to be important and some values for three preparations are shown in Table 69 . Densities have varied

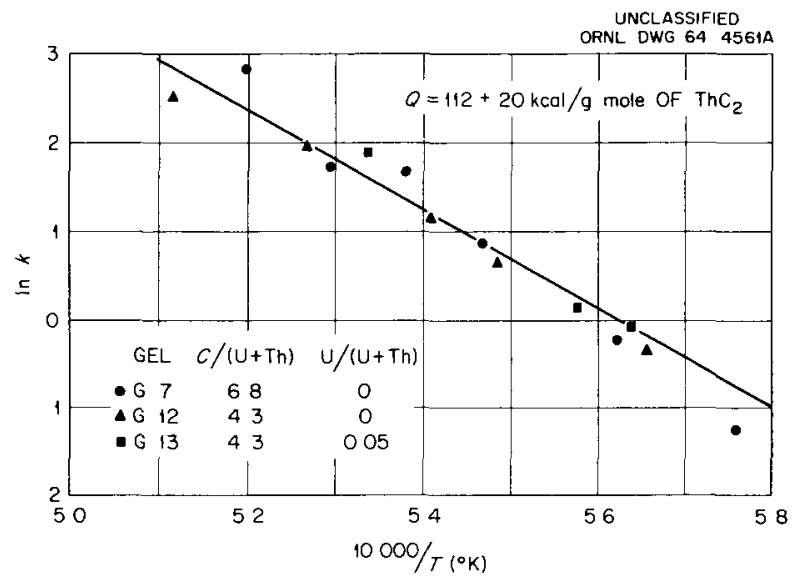

Fıg. 6.11. Temperature Dependence of Reaction-Rate Constant in Dicarbide Formation.

Table 6.9. Properties of Uranium-Thorium Dicarbides

Firing conditions: For irregular particles, $1500^{\circ} \mathrm{C}$ in vacuum, for microspheres, 1750 to $1950^{\circ} \mathrm{C}$ in flowing argon

Properties

Irregular Particles

from Run CNS-2
Microspheres from Run:

$\mathrm{SC} \quad \mathrm{BP}-46$

\section{Uranium-Thorium Oxide-Carbon}

$\mathrm{U} / \mathrm{Th}$ atom ratio in the $\mathrm{s}$ ol stage

Surface area $\left(\mathrm{N}_{2}\right.$ adsorption) of carbon used, $\mathrm{m}^{2} / \mathrm{g}$

Particle density of unfired sample, calculated

from tap density, $\mathrm{g} / \mathrm{cm}^{3}$

Particle density of unfired sample, from mercury porosity, $\mathrm{g} / \mathrm{cm}^{3}$
0.0330

0.0339

980

400

800

2.22

2.26

2.24

Uranium-Thorium Dicarbide Microspheres

Density, particle (mercury porosity), $\mathrm{g} / \mathrm{cm}^{3}$

8.53

89.0

0.2

0.16

6.21

7.58

Density, \% of theoretica ${ }^{a}$

Porosity, $\frac{\text { total pore volume }}{\text { particle volume }}$

Porosity, in closed voids

$\mathrm{U} / \mathrm{Th}$ atom ratio

0.53

99.0
65.7

0.342

0.168

0.033

1.64

$97.4^{b}$
79.7

1.74

$92.3^{b}$

${ }^{a_{\text {T }}}$ Theoretical density for $\mathrm{ThC}_{2} 1 \mathrm{~s} 9.6 \mathrm{~g} / \mathrm{cm}^{3}$.

${ }^{b}$ Samples may have reoxidized on handling. 


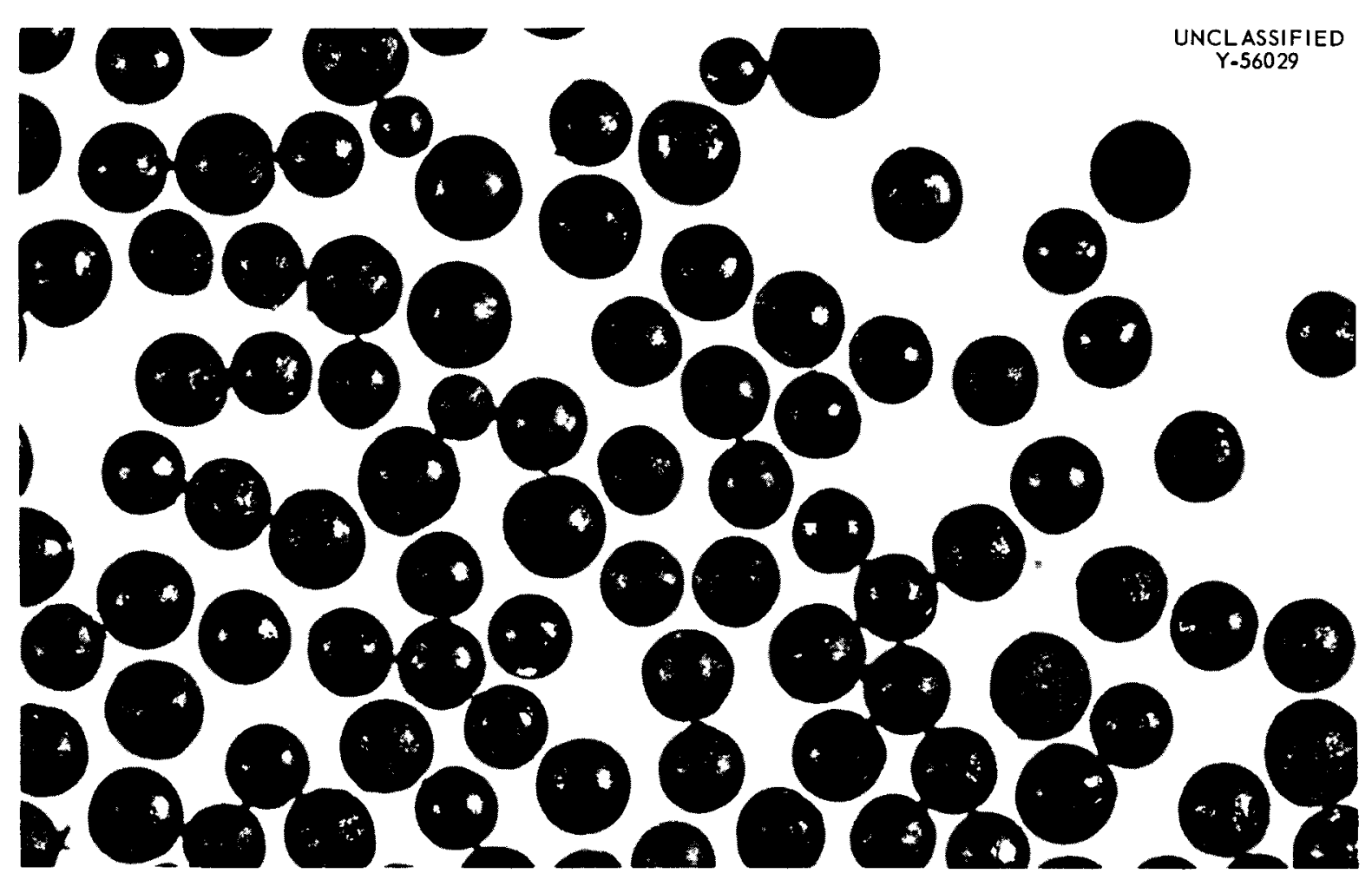

Fig. 6.12. Uronium-Thorium Dicarbide Microspheres Formed by the Sol-Gel Process.

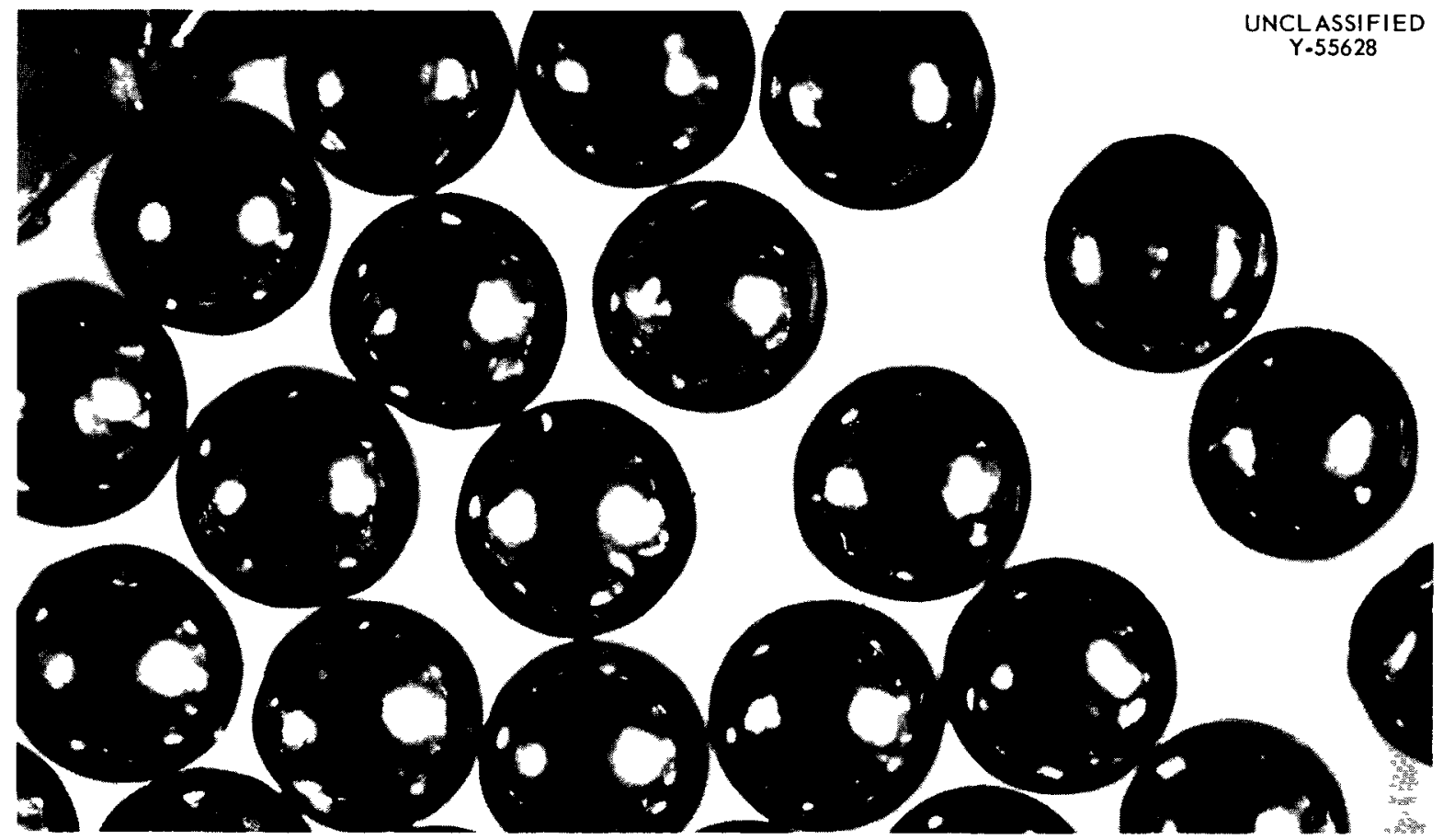

Fig. 6.13. Spheres of Uranium-Thorium Carbide, Coated with Pyrolytic Carbon. 
from 50 to $90 \%$ of the theoretically attainable value, and porosities have ranged from 0.065 to 0.34. Approximately $50 \%$ of the pores are isolated from the surface. The uranium was uniformly distributed in the sol and remained so throughout the process. The presence of 25 to $30 \%$ excess carbon did not appear to improve the percentage of conversion of oxide to dicarbide, but may have increased the porosity and decreased the density of the product. The fractional conversion to dicarbide is based on oxide appearing in the product and is in doubt because it is not known whether the source of $\mathrm{ThO}_{2}$ is unconverted oxide or oxide formed by the hydrolysis of the extremely active carbide on exposure to air. A calcined product typical of the later preparations is shown in Fig. 6.12. Surfaces of freshly prepared spheres are lustrous and look like metal. The carbide spheres can be readily coated with pyrolytic carbon to give microspheres like those shown in Fig. 6.13.

\subsection{PRODUCTION OF MICROSPHERES}

Coated oxide and carbide fuel microspheres will be used in gas-cooled reactors such as the Peach Bottom (High-Temperature Gas Reactor), Target, Dragon, and AVR. The sol-gel process has recently been adapted to the preparation of such microspheres. The microsphere-forming process promises to provide an easy, relatively inexpensive way to make microspheres of a variety of fuel materials in any size across a range from less than $50 \mu$ to $2000 \mu$. The microspheres are formed by dispersing the appropriate sol at room temperature in an organic liquid with which it is almost completely immiscible. The spherical droplets of sol that form are set to gels as the organic liquid extracts water from them. After drying, the gel spheres are calcined to oxide or carbide.

The sphere-forming technique has been developed in the laboratory to a scale of about $100-\mathrm{g}$ batches, and engineering scale-up studies are being conducted. Particle diameters can be closely controlled between 50 and $1000 \mu$, and they can be made smaller or larger with somewhat less control over size distribution. All the simplicity and ease of control of the basic sol-gel process (see Sects. 6.1 and 6.2) are also characteristic of the sol-gel microsphere adaptation. Yields of thorium oxide and uranium-thorium oxide spheres have been demonstrated in some runs to be greater than $95 \%$.
In early development work, microspheres were prepared by dispersing sols in carbon tetrachloride containing about 15 vol \% isopropyl alcohol in a beaker at room temperature; a controlledspeed stirrer was used. The method was successful in preparing spheres, but good control over gel-particle sizes was not achieved. In the second development, the droplets of sol were introduced from a hypodermic needle into the organic solvent and allowed to fall freely through an upflow of solvent in a column. This produced uniform-sized gel spheres; however, the lowest practical limit in diameter of the needle-orifice through which the sol could be successfully forced was about 0.006 in. This imposed a lower limit on sphere diameter of $500 \mu$. Sols having nonNewtonian flow behavior tended to solidify in smaller orifices and plug them. In the third technique, the one used at present, the sol and the organic dispersing solvent are pumped through different channels in the same nozzle. The organic solvent flows from an annulus around the tube from which the sol flows. On emerging, the sol stream "necks down" to a fine jet. The solvent flowing from the annulus and moving at a higher velocity distends the sol jet until it finally breaks up into sections about four times the length of the jet diameter. The sol sections, being immiscible with the solvent, contract to form spheres. Good size control can be achieved by this mechanism, which depends largely on the relative velocities of the two concentric streams.

Thorium oxide and uranium-thorium oxide sols for use in sphere-forming studies are prepared as described in Sect. 6.2, with two important qualifications. The sols are made as concentrated as possible, being limited by their apparent viscosity and yield point. At present, the concentration limits are about 5 moles of $\mathrm{ThO}_{2}$ or 3 moles of $5 \% \mathrm{U}$-thorium oxide per liter. As the uranium content is increased, the maximum allowable solids concentration is decreased. For sols containing 4 moles or more of carbon per mole of metal, as in carbide microsphere preparation, the limiting $(\mathrm{U}+\mathrm{Th})$ concentration in the sol is about $2 M$ (see Sect. 6.3).

About 20 organic solvents were screened in order to obtain several satisfactory ones for forming and drying microspheres in the column. The criteria for selection were: production of gel microspheres having good sphericity and no surface defects or cracks, and with low internal 
vordage, good dispersing-solvent flow behavior in the column, low solubility of dispersing solvent in the sols, but several percent solubility of water in the organic solvent, a low-bolling azeotropic mixture of organic solvent with water, and good thermal stability In general, the long-chain alcohols are the most satisfactory solvents with respect to sphere-forming properties. The alcohols 2-ethyl-1-hexanol and 2-methyl-1-pentanol were superior to the others tried. Esters were unstable when distilled. Halogenated solvents were avorded because of the health hazard and because of possible contamination of the product with halogens.

Surfactants were used in forming spheres from the oxide sols to prevent coalescence, clustering, and adhesion of spheres to walls. Although some types of cationic surfactants (1.e., fatty amines) worked well with $\mathrm{ThO}_{2}$, the nonionic types were generally more satisfactory. Of these, the ether alcohols, polyols, secondary alcohols, and tertiary alcohols performed best. Esters hydrolyzed when distilled with water and nitric acid which came from the sol during gelation. The sol-solvent interfacial tension was 4 to 15 dynes/cm for combinations of solvent and surfactant that formed spheres most satisfactorily. The surfactant was not needed for sols containing carbon. The lyophilic carbon had surface-active properties when used with alcohols and adjusted the interfacial tension to a value of 10 to 15 dynes/cm There was a tendency for the alcohols to extract a small amount of carbon from the sol, but this was prevented by adding about $10 \%$ by volume of 2 -octanol or 3 heptanol to the alcohol.

The engineering feasibility of producing spherical particles of thoria, thoria-urania, and thoriaurania-carbon with diameters of 100 to $1000 \mu$ was demonstrated in a fluidizing column in which 2-ethylhexanol was used as the forming and drying solvent. Briefly, the following is done: after an appropriate sol is prepared, it is dispersed into droplets at the top of a tapered glass column and allowed to settle until the droplets reach their fluidizing velocity. Coalescence of the droplets and wetting of the glass column are prevented by a suitable surface-active agent in the organic phase. As water is extracted from the sol droplets by the organic medium, a partial gelling or setting of the droplets occurs, this allows the spheroids to be removed intact from the bottom of the column after a holdup time of 10 to $30 \mathrm{~min}$. The gelled particles are dried at about $100^{\circ} \mathrm{C}$ to remove the excess drying solvent and to reduce the water content of the gel to approximately $5 \mathrm{wt} \%$. On firing to $1150^{\circ} \mathrm{C}$, the thoria and thoria-urania spheroids have densities close to the theoretical crystal density and exhibit very high crushing strengths.

An agitated vessel containing 2-ethylhexanol and a surfactant seemed to be more efficient than a tapered column for making spheres in the size range of 10 to $100 \mu$, but size control was poorer. The stirred system studied consisted of a 4-11ter baffled beaker and a turbine mixer with four vert1cal blades. Sol is poured into the drying agent at mixer speeds of 800 to $1600 \mathrm{rpm}$. The degree of agitation not only controls the particle-size distribution but also is the only mechanism for suspending the droplets while water is being extracted into the organic. For this reason the diameter of the gelled particles produced in a stirred-batch system must be less than 100 to $150 \mu$ to prevent settling out.

Controlled drameters were formed in the tapered column system by discharging the sol through a small orifice or through a two-fluid nozzle. For oxide-sol molarities of 2 to 5 , the respective droplet diameters must be 2.7 to 20 times greater than the desired diameter after calcining. The falling-drop mechanism predicts that the droplet diameter $D$ should be related to the orifice diameter $d$, the interfacial tension $\gamma$, the density difference $\Delta \rho$, and the acceleration of gravity $g$, by the following equation:

$$
D=\left(\frac{6 d \gamma}{\Delta \rho g}\right)^{1 / 3}
$$

A $4.9 M$ thoria sol was fed at a flow rate of 02 $\mathrm{cm}^{3} / \mathrm{min}$ through an onfice 6 mils in diameter immersed in 2-ethylhexanol containing 01 vol \% Paraplex G-62 (surfactant). The diameter of the calcined thorsa spheres prepared by this procedure 1s about $540 \mu$ (Fig. 6 14) The measured interfacial tension between the sol and organic phases was 15.4 dynes $/ \mathrm{cm}$, and the density difference was $1.33 \mathrm{~g} / \mathrm{cm}^{3}$. From Eq. (1) the predicted diameter of the drop is $1030 \mu$, which would shrink to about $520 \mu$ after calcination. The experimental agreement with Eq. (1) is within $4 \%$.

With the falling-drop mechanism and a fixed $\gamma$ and $\Delta \rho$, the orifice diameter must be reduced eightfold to reduce the diameter of the drop $50 \%$. In order to eliminate the undesirably small orifice 


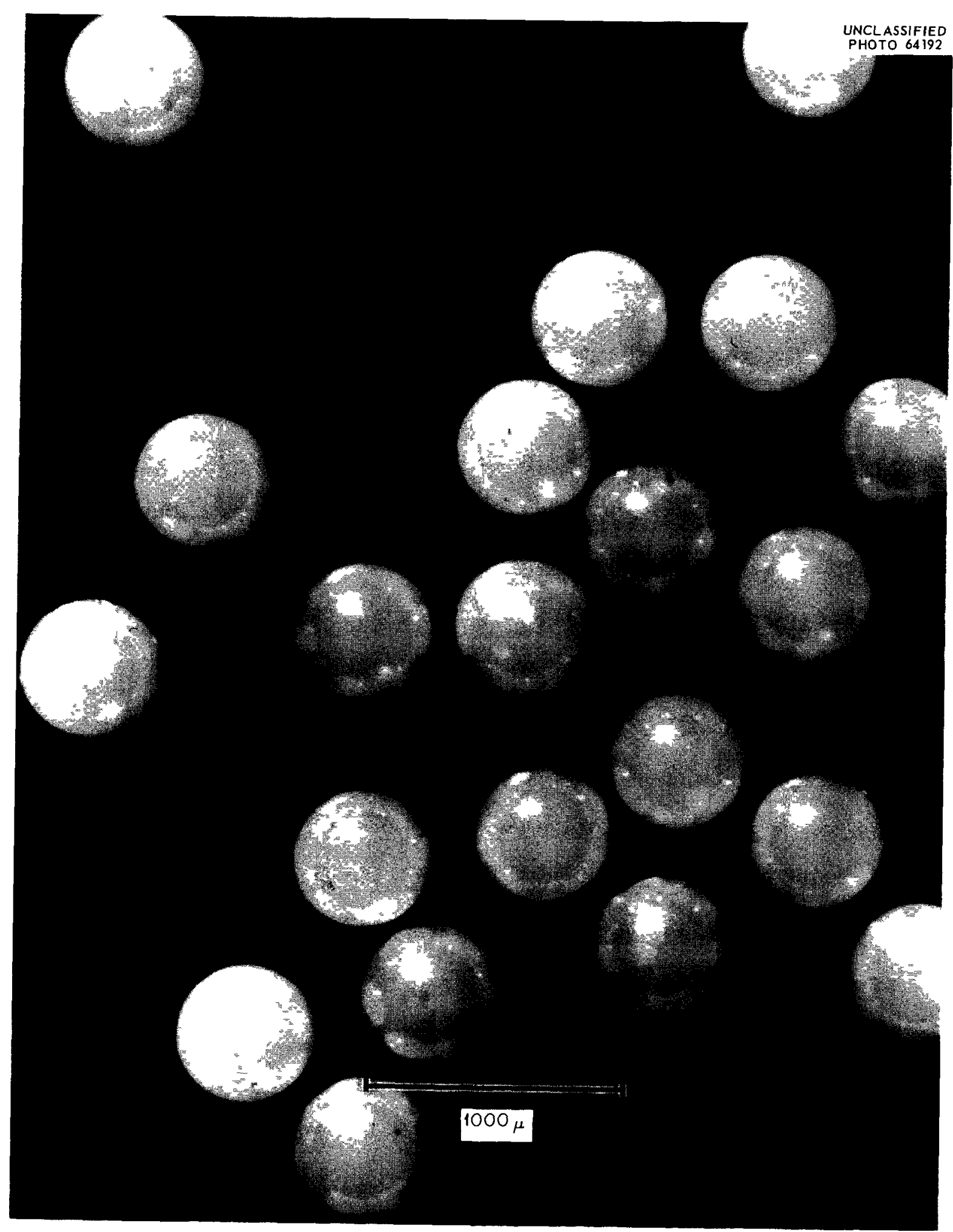

Fig. 6.14. Thoria Spheres Formed in a Fluidized Column of 2-Ethylhexanol and Paraplex G-62 and Calcined to $1150^{\circ} \mathrm{C}$. 
sizes required for drop formation by free fall through the drying agent, a two-fluid nozzle was used to form droplets. The sol is introduced in the center of a flowing organic stream of 2-ethylhexanol, which acts as a driving fluid, as described above. The continuous flow of sol is accelerated to the velocity of the coaxially flowing solvent and then breaks up to give sol droplets with a diameter about two times greater than the minimum diameter of the sol stream. A nozzle length of 6 to $10 \mathrm{in}$. is required for droplet formation before discharging into the tapered column. With this mechanism, the sol droplet diameter $D$ can be related to sol flow rate $t$, the drive-fluid flow rate $F$, and the cross-sectional area for drivefluid flow $A$, by the following equation:

$$
D=2.3 \sqrt{\frac{f A}{F}} .
$$

A $2.5 M$ thoria sol was fed through a No. 20 hypodermic needle into the center of a $3 / 16^{-i n}$.-ID plastic tube containing a flowing stream of 2-ethylhexanol with 0.4 vol \% Ethomeen S-15, a surfactant. At respective sol and organic flow rates of 1.2 and $290 \mathrm{~cm}^{3} / \mathrm{min}$, about $75 \mathrm{~g}$ of thoria spheres were formed, with the following size distribution after calcination to $1150^{\circ} \mathrm{C}: 1.4 \%$, larger than $250 \mu$; $38.6 \%, 210$ to $250 \mu ; 49.7 \%, 150$ to $210 \mu$; and $10.3 \%$, smaller than $150 \mu$. Equation (2) predicts a sol droplet diameter of $630 \mu$, which would shrink to $254 \mu$ after calcination. The Reynolds number of the organic flow in the plastic tube was 150 , and, consequently, the maximum drivefluid velocity was twice the average organic velocity $F / A$. When this correction is applied to Eq. (2), the predicted droplet diameter is $445 \mu$, which would shrink to $180 \mu$ after calcination and be within the experimentally determined size range. In order to form uniformly sized droplets with a two-fluid nozzle, the drive-fluid flow must be laminar, and therefore the sol should be injected in such a manner as to minimize disturbances.

As mentioned above, in order to keep the sol droplets from sticking to each other and wetting the glass column wall while water is being extracted, a surfactant is dissolved in the organic phase. A surfactant concentration of 0.1 to 0.4 vol \% in the organic liquid seems to be sufficient.
Thoria spheres in the size range of 50 to 250 $\mu$ after calcination to $1150^{\circ} \mathrm{C}$ were produced in an agitated vessel containing Span 80 (Atlas) dissolved in a 20 vol \% isopropanol- $\mathrm{CCl}_{4}$ solution; however, in a fluidized column this organic system produced pear-shaped particles. With Span 80 and 2-ethylhexanol in a stirred beaker, thoria spheres larger than 100 to $150 \mu$ could not be produced. This difference in behavior is mainly due to the difference in solvent densities (the density of 20 vol \% isopropanol- $\mathrm{CCl}_{4}$ is 1.42 $\mathrm{g} / \mathrm{cm}^{3}$; the density of 2-ethylhexanol is 0.834 $\mathrm{g} / \mathrm{cm}^{3}$ ) which manifests itself in the bouyancy of the solvents. In a fluidized column, however, Span 80 in 2-ethylhexanol appears to be a satisfactory mixture for producing thoria-gel spheroids 100 to $300 \mu$ in diameter. For thoria gel sizes larger than $300 \mu$, the Span 80 apparently lowers the interfacial tension enough to allow the fluid forces to distort the droplet into ellipsoidal shapes. Paraplex G-62 (a Rohm and Haas Co. plasticizer used in polyvinyl chloride tubing) in 2-ethylhexanol was used in a fluidized column to produce thoria gel particles in the size range of 500 to $1000 \mu$ with almost no droplet coalescence. However, attempts to make smaller thoria spheroids resulted in the deposition of the gelled particles on the glass column walls; this appeared to be due to a surface-charge effect. The Paraplex G-62 was known to be a weak surfactant for this system since the G-62 addition did not alter the interfacial tension between the aqueous sol and 2ethylhexanol, which was 15.4 dynes $/ \mathrm{cm}$.

Of several surfactants recommended for the 2-ethylhexanol system, ${ }^{3}$ the following showed some promise: Hodag $40 \mathrm{R}$, Sarkosyl O (Geigy), and Ethomeen S-15 (Armour). Hodag $40 \mathrm{R}$ is a high-molecular-weight ester and was very similar in behavior to Paraplex G-62 in 2-ethylhexanol. Sarkosyl $O$ was the best surfactant tested for preventing droplet coalescence and particle agglomeration in all size ranges; however, thoria was extracted from the sol droplets into the organic phase. Sarkosyl $\mathrm{O}$ has two possible active sites an amide and carboxylic acid radicals. From earlier experience, oleic acid dissolved in $\mathrm{CCl}_{4}{ }^{+}$ isopropanol was satisfactory for forming thoriagel spheroids except for the extraction of thoria into the organic liquid. In order to eliminate the

\footnotetext{
${ }^{3}$ Chem. Technol. Div. Ann. Progr. Rept. June 30,
} 1962, ORNL-3314. 
effect of the carboxylic acid radical, an amide (Ethomid 0-15) was tried as a surfactant in 2ethylhexanol, but it did not prevent coalescence of the droplets.

Ethomeen S-15 (a tertiary amine) at concentrations of 0.2 to 0.4 vol $\%$ in 2-ethylhexanol appeared to be the most promising system for producing thoria spheres of any size up to $1000 \mu$ in diameter. This mixture prevented droplet coalescence and particle agglomeration, and there was no evidence of thoria extraction into the organic phase. A possible explanation for the apparent success of Ethomeen S-15 is that this tertiary amine in the organic phase causes the free nitric acid in the aqueous sol phase $(\mathrm{pH}=3.2)$ to concentrate at the interior droplet surface, producing a gelled film of oxide. A solid surface film on the droplets should be sufficient to prevent coalescence of the sol.

A thoria-8 wt \% urania sol, prepared by dispersing steam-denitrated thoria with 0.06 mole of $\mathrm{HNO}_{3}$ (instead of the usual 0.077 mole) per mole of thoria, behaved differently from the previously tested thoria sols. In the 2-ethylhexanol and Ethomeen S-15 system, the thoria-urania sol $(\mathrm{pH}=3.4)$ presented a serious particle-agglomeration problem. As the sol droplets lost water and partially gelled, they appeared to stick together on collision. This problem was solved by returning to the Span 80 and 2-ethylhexanol system. With this particular thoria-urania sol, no distortion of the droplets was encountered for gel sizes up to $1000 \mu$. The results suggest that many of the problems encountered with different organic systems could be controlled by slight alterations of the aqueous sol.

Four different tapered glass columns were used in the microsphere studies. The smallest column system held only $200 \mathrm{ml}$ of organic solution. It was used for testing various surfactants. The glass column is 15 in. long and is tapered from $1 / 4$ in. at the bottom to $1 \mathrm{in}$. (inner diameters) at the top; the included angle of taper is $3^{\circ}$. A second column system held 6 liters. It was used primarily for testing the feasibility of a two-fluid nozzle for making sol droplets. Here, the glass column is 24 in. long and is tapered from 1 in. at the bottom to $3 \mathrm{in.}$ at the top (inner diameters). The tapered angle of $5^{\circ}$ creates an uncontrollable flow separation at the column wall, thus causing the sol droplets and gelled spheroids to be in continuous motion up and down the column. The entrance section for the drying liquid is at the bottom of this column and is a 3-in.-to-1-in. glass reducer which adds to the flow-instability problem. With the random vertical mixing of sol droplets and gelled spheres, the probability of droplet coalescence and agglomeration is increased; also, the operation of the column must be on a semibatch basis. A flow-distributor plate ( 37 holes, with a diameter of $3 / 32$ in.) containing $32 \%$ free area was inserted below the tapered column at the 1-in.-ID section; however, the column flow pattern was not significantly improved.

The most satisfactory column, based on operational criteria, had a volume of 2 liters; it was used for testing the formation of sol droplets from orifices of different sizes. It produced 30 - to $40-\mathrm{g}$ batches of thoria and carbon-thoria-urania spheroids. This glass column has a converging, tapered entrance section, $12 \mathrm{in.}$ long, decreasing from $1 \frac{1}{2}$ in. to $\frac{1}{2}$ in. in inner diameter. The fluidizing or diverging section of the column increases from $1 / 2$ to $1 \frac{1}{8}$ in. in inner diameter in a 24 -in. length (included angle of taper is $1 \frac{1}{2}{ }^{\circ}$ ). Even at a Reynolds number of 400 (based on the $1 / 2$-in.diam cross section and the properties of the organic liquid), the first few sol droplets produced in the column indicated flow separation at the wall; however, as the number of droplets increased, a bed of droplets was formed, thus lessening the flow instabilities. Within $20 \mathrm{~min}$, at a sol flow rate of 15 to $20 \mathrm{~cm}^{3} / \mathrm{hr}$, two distinct beds were formed. A layer containing fluidized sol droplets (not yet gelled) was separated about an inch above a second bed of fluidized gelled particles. The Stokes terminal velocity for a gelled particle is 1.3 to 1.4 times greater than for a newly formed sol droplet ( $5 M$ thoria sol). This two-layer phenomenon, which would permit the continuous operation of a column system, persisted throughout several runs, in which a uniform sol-droplet size was achieved.

A fourth column system had a volume of 12 liters; it was installed (Fig. 6.15) to study the effect of scaleup on the flow patterns of the organic liquid and to produce $200 \mathrm{~g}$ batches of thoria and thoriaurania spheres. A two-fluid nozzle was used to form the sol droplets, and the flow of the sol was metered by a variable-speed, continuous infusionwithdrawal pump. A considerable amount of vertical mixing of the sol droplets and gelled spheres was encountered in this column, due to its configuration, and, in order to keep the droplets 


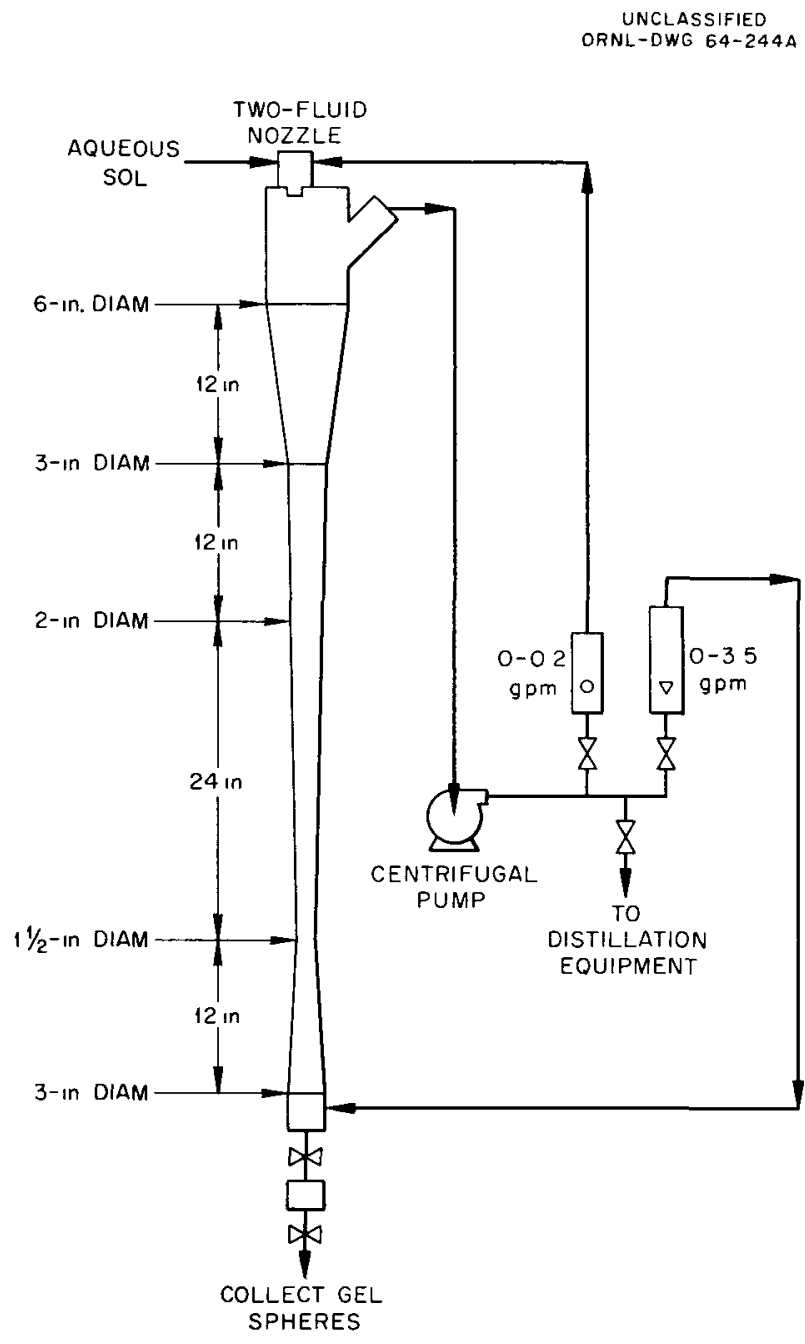

Fig. 6.15. Schematic Flow Diagram of Equipment for Producing Gel Spheres from Aqueous Sol.

fluidized, it was necessary to restrict the minimumflow area by inserting a rod in the center of the column. Several different rods, some straight and some tapered, were tried in the center of the column to form an annulus for the organic flow. The majority of runs made in this column were with a $1 / 4$-in. annular spacing at the minimum-columnflow area. Although vertical mixing was not entirely eliminated, the annular flow pattern was superior to flow in the bare column.

The 2-ethylhexanol, which extracts water from the sol droplets, becomes saturated when the water content is $2.55 \mathrm{wt} \%$. Continuous singlestage distillation is a useful way to remove the water and regenerate the organic dispersing solvent. A sidestream of 2-ethylhexanol is taken from the sphere-forming column system and preheated with dried organic; it is then fed into a still where it is partially vaporized. Most of the water is vaporized, and the compositions of the liquid and vapor streams leaving the still are controlled by the temperature of the still. If the sphere-forming system is operated with 2-ethylhexanol containing 1 wt \% water and the still is operated at $145^{\circ} \mathrm{C}, 10 \%$ of the feed to the still is vaporized, and the liquid product contains 0.5 wt $\%$ water. The vapor phase contains 5.5 wt \% water and separates into two saturated phases after condensation. The water saturated with 2-ethylhexanol ( $0.1 \mathrm{wt} \%)$ is discarded, and the organic saturated with water is returned to the still. All the sphere-forming runs to date were batchwise and were terminated when the waterin-alcohol concentration reached 1.5 to $2.0 \mathrm{wt} \%$. A still, 5 liters in volume, was constructed to provide temperature-vs-composition data and is being used to regenerate the 2-ethylhexanol used in these development studies.

Several samples of thoria and thoria-uraniacarbon spheroids were made for testing and coating with pyrolytic carbon. About $1300 \mathrm{~g}$ of calcined thoria spheres in the size range of 150 to $250 \mu$ were prepared for coating tests. For expediency, about $700 \mathrm{~g}$ of these spheres were made in $60 \mathrm{~g}$ batches with an agitated vessel containing $20 \mathrm{vol} \%$ isopropanol- $\mathrm{CCl}_{4}$ and 0.1 vol \% Span 80. The equipment consisted of a 4-liter beaker and a turbine-type mixer. Table 6.10 shows the size yield from run MB-39, at different mixer speeds for a $4.6 M$ thoria sol. The remaining $600 \mathrm{~g}$ of thoria spheres in the $150-$ to $250-\mu$ range were prepared in a fluidizing column containing 2-ethylhexanol and 0.4 vol \% Ethomeen S-15. About $150 \mathrm{~g}$ of thoria-urania-carbon spheres were prepared for testing various carbon-sol preparations. These gelled spheroids were made in a fluidizing column of 2-ethylhexanol containing Paraplex G-62 as a surfactant.

About $2250 \mathrm{~g}$ of thoria- $8 \mathrm{wt} \%$ highly enriched urania microspheres were prepared in the 12-1iter column. The sol droplets were formed with a twofluid nozzle and suspended in 2-ethylhexanol containing 0.2 vol \% Span 80 . The sol droplets required a holdup time of 15 to $20 \mathrm{~min}$ in the column to become gelled. After gelation, the microspheres were removed from the column and air 
dried at about $100^{\circ} \mathrm{C}$. The mercury-displacement density of the gelled spheres was $4.5 \mathrm{~g} / \mathrm{cm}^{3}$, and the average crushing strength of 25 gelled particles was $363 \mathrm{~g}$. The dried gel spheres were then heated to $1150^{\circ} \mathrm{C}$ at the following rates: $100^{\circ} \mathrm{C} / \mathrm{hr}$ from 25 to $500^{\circ} \mathrm{C}$ and $300^{\circ} \mathrm{C} / \mathrm{hr}$ from 500 to $1150^{\circ} \mathrm{C}$. After calcination at $1150^{\circ} \mathrm{C}$ the microspheres had the following size distribution: $14 \%$, greater than $420 \mu, 28 \%, 297$ to $420 \mu ; 56 \%, 150$ to $297 \mu$, and $2 \%$, less than $150 \mu$. Properties of the calcined microspheres are presented in Tables 6.11 and 612.
From Table 6.11 we conclude that the sol-gel oxide microsphere process is capable of producing exceptionally dense, strong, high-quality spheres. The presence of carbon is probably due to the surfactant ("Span-80", an ester) used in forming. The firing in air eliminated much of the carbon, which indicates that it was largely on the surface. Analyses were not made for ionic impurities since the impurities in the original thorium nitrate and uranyl nitrate were known to be negligible.

The total gas volumes evolved from the arrfired sample at temperatures up to $1200^{\circ} \mathrm{C}$ in

Table 6.10. Thoria Size Yield After Calcination at $1150^{\circ} \mathrm{C}$ for Different Mixer Speeds

\begin{tabular}{ccccccc}
\hline $\begin{array}{c}\text { M1xer Speed } \\
(\mathrm{rpm})\end{array}$ & $\begin{array}{c}>250 \mu \\
(\mathrm{g})\end{array}$ & $\begin{array}{c}210-250 \mu \\
(\mathrm{g})\end{array}$ & $\begin{array}{c}150-210 \mu \\
(\mathrm{g})\end{array}$ & $\begin{array}{c}<150 \mu \\
(\mathrm{g})\end{array}$ & $\begin{array}{c}\text { Total } \\
(\mathrm{g})\end{array}$ & $\begin{array}{c}150-250 \mu \\
(\% \mathrm{y} \text { eld })\end{array}$ \\
\hline 330 & 14.3 & 12.6 & 14.6 & 19.3 & 60.8 & 45 \\
350 & 28.6 & 41.8 & 50.1 & 62.5 & 183.0 & 50 \\
370 & 0.8 & 12.9 & 21.3 & 25.9 & 60.9 & 56 \\
\hline
\end{tabular}

Table 6.11 Properties of Sol-Gel Uranium-Thorıum Oxide Microspheres

Nominal composition: 8 at. \% highly enriched uranium-thorium oxide

\begin{tabular}{|c|c|c|}
\hline Property & $\begin{array}{c}\text { Alr Fired, } \\
1150^{\circ} \mathrm{C}\end{array}$ & $\begin{array}{c}4 \% \mathrm{H}_{2}-\mathrm{Ar} \text { Fired, } \\
1150^{\circ} \mathrm{C}\end{array}$ \\
\hline Density, $\mathrm{g} / \mathrm{cm}^{3}$, tap & 6.2 & 6.1 \\
\hline By helium pycnometry & 10.0 & 9.98 \\
\hline By toluene pycnometry & 10.0 & \\
\hline By mercury pycnometry & 9.99 & To be reported \\
\hline \multicolumn{3}{|l|}{ Porosity, fraction of sphere volume, ${ }^{a}$} \\
\hline Accessible to surface & 0.001 & To be reported \\
\hline Closed & 0.004 & 0.006 \\
\hline Surface area, $\mathrm{m}^{2} / \mathrm{g}$ ( $\mathrm{Kr}$ adsorption method) & 0.004 & 0.003 \\
\hline Roughness factor ${ }^{b}$ & 1.3 & 1.76 \\
\hline Crushing load, ${ }^{c} \mathrm{~kg}$ & $>5.71$ & \\
\hline $\mathrm{U} /(\mathrm{U}+\mathrm{Th})$, atom ratio & 0.0803 & 0.0799 \\
\hline $\mathrm{O} / \mathrm{U}$, atom ratıo & 2.52 & 2.005 \\
\hline Carbon, ppm & 80 & 410 \\
\hline
\end{tabular}

${ }^{a}$ From mercury porosimetry data at 8000 psi.

${ }^{b}$ Ratio, surface area by BET (Kr) to surface area calculated from weighted average sphere diameters. Probable er. ror, about $25 \%$.

${ }^{C}$ Average load required to crush a single sphere taken over 25 samples $>5710$ g (11mitung capacity of apparatus). 
Table 6.12 Gases Evolved from Sol-Gel Microspheres

Heated in static vacuum to various temperatures unt1l equilibrium pressures are obtained. Sample, $8 \%$ enriched $\mathrm{U}$, Th oxide, fired in $4 \% \mathrm{H}_{2}-\mathrm{Ar}$ at $1150^{\circ} \mathrm{C}$ for $4 \mathrm{hr}$, cooled in argon (see Table 6.11)

\begin{tabular}{|c|c|c|c|c|c|}
\hline \multirow{2}{*}{ Gas } & \multicolumn{4}{|c|}{ Volumes of Various Gases at Temperature, $\mathrm{cm}^{3} / \mathrm{g}$} & \\
\hline & $500^{\circ} \mathrm{C}$ & $800^{\circ} \mathrm{C}$ & $1200^{\circ} \mathrm{C}$ & Total & \\
\hline Total & 0.007 & 0.004 & 0.006 & 0.017 & \\
\hline $\mathrm{H}_{2}$ & 0 & 0 & 0.00198 & 0.00198 & \\
\hline $\mathrm{H}_{2} \mathrm{O}$ & 0.00525 & 0.00125 & 0.00024 & 0.00674 & \\
\hline $\mathrm{HC}^{\mathrm{a}}$ & 0.00008 & 0 & 0 & 0.00008 & \\
\hline $\mathrm{N}_{2}+\mathrm{CO}^{b}$ & 0.00028 & 0.00028 & 0.00294 & 0.00350 & 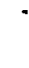 \\
\hline $\mathrm{O}_{2}$ & 0.00003 & 0.00008 & 0.00006 & 0.00017 & \\
\hline Argon & 0.00008 & 0.00004 & 0.00006 & 0.00018 & \\
\hline $\mathrm{CO}_{2}$ & 0.00137 & 0.00240 & 0.00078 & 0.00455 & \\
\hline
\end{tabular}

${ }^{a}$ Total hydrocarbons.

${ }^{b}$ Approximately $90 \% \mathrm{~N}_{2}$ at temperatures up to $500^{\circ} \mathrm{C}$, and $90 \% \mathrm{CO}$ above $500^{\circ} \mathrm{C}$.

vacuum were high, $0.645 \mathrm{cc} / \mathrm{g}$, the gas was $90 \%$ free $\mathrm{O}_{2}$, with the remainder being largely $\mathrm{CO}_{2}$ and $\mathrm{H}_{2} \mathrm{O}$. The sample which was fired in air to $1150^{\circ} \mathrm{C}$, then fired in $4 \% \mathrm{H}_{2}-\mathrm{Ar}$ and cooled in argon had much less gas $(0.017 \mathrm{cc} / \mathrm{g})$. Water, $\mathrm{CO}_{2}, \mathrm{CO}$, and $\mathrm{H}_{2}$ were major components of the small amount of gas present.

Future work will be directed toward the scaleup of a two-fluid nozzle and toward fluidizing column concepts. The development, design, fabrication, and test operation of a $35-\mathrm{kg} /$ day system for the production of microspheres is scheduled during the next year.

\section{Southwest Research Institute (SRI) Subcontract No. 2326}

Studies are in progress at SRI, San Antonıo, Texas, to apply their techniques to the encapsulation of sol drops that can then be gelled and dried to microspheres. The sol and an organic polymer solution are fed to two concentric or1fices to form droplets of sol with a shell of organic polymer solution. The polymer solution shell is solidified by chemical reaction, drying, or solvent extraction. The sol core may then be gelled by removal of water by its diffusion out of the sol through the shell or by the diffusion of gelling agent through the shell into the sol. The polymer coating may be removed completely during calcination or may be formulated to leave a desitable carbon coating.

Most of the tests have been with shells of methacrylate, cellulose acetate butyrate, or polyvinylpyrrolidone polymer solutions. The sol encapsulation techniques have been improved unt1l the formation of irregular shapes, the slow hardening of the polymer shell, and clustering in the hardening bath are not serious problems. However, the capsules usually collapse, break, or become misshapen due to shrinkage of the sol during gelation. Procedures intended to keep the organic shell pliable or plasticized during the gelation have not yet been successful.

The gelation of sol drops without encapsulation was tested by exposing the drops to alkanolamines and polyamines. Smooth spheres of $270-\mu$ average size were prepared by washing the drops gelled in diethylenetriamine repeatedly in acetone, washing in toluene, and then alr drying. Other washing or drying conditions gave cracked, clustered, or misshapen particles. 


\section{Separations Chemistry Research}

New separations methods and reagents are being developed, particularly for use in radiochemical processing. The current emphasis is principally on solvent extraction technology. Those solvents that were developed in the former ORNL raw materials program have proved to be extensively useful. Additional extractants have been discovered more recently in the continuing evaluation of new reagents. In addition to solvent extraction applications, some of these reagents or analogous compounds should be useful in other separations methods, for example, in extraction chromatography and resinous ion exchange. The present program includes (1) descriptive chemical studies pertinent to existing and potential separations, (2) development of selected separations into specific complete processes, and (3) fundamental chemical studies to increase knowledge of the reaction mechanisms and better define their potential applications.

\subsection{STUDIES IN DESCRIPTIVE CHEMISTRY}

Descriptive chemical studies pertinent to existing and potential separations methods form a central part of the Separations Chemistry Research Program. They include systematic study of the controlling variables and of the responses of various metal ions in particular separations, study of susceptibility of reagents to chemical and radiation damage and means of minimizing such damage, and a continuing search for useful new reagents.

\section{Extraction of Metal Nitrates by Amines}

A detailed study of the amine extraction characteristics of the principal fission products in nitrate solutions has been completed with the study of niobium. $^{2}$ Extractions increased with increasing

\footnotetext{
${ }^{1}$ Work done by the Department of Nuclear Engineering, MIT, under subcontract.
}

nitric acid concentration throughout the range 2 to $12 M$ and were higher with primary amine than with the other amine classes (Fig. 7.1). The extraction coefficients varied in nearly direct proportion to the amine concentration. They were not affected by varying the aqueous niobium concentration from $10^{-9}$ to $10^{-7} M$. Of the different amine classes, the tertiary amine is at present of most interest for potential use in fuel reprocessing. Its extractions of several other fission products from nitric acid solutions ${ }^{3}$ are compared with niobium extraction in

\footnotetext{
${ }^{2}$ Takashi Watanabe and E. A. Mason, The Solvent Extraction of Niobium by Alkyl Amines from Nitrate Systems, MITNE-32 (Subcontract No. 1327) (in press).

${ }^{3}$ V. C. A. Vaughen and E. A. Mason, Equilibrium EXtraction Characteristics of Alkyl Amines and Nuclear Fuels Metals in Nitrate Systems, TID-12665 (Subcontract No. 1327) (Oct. 1, 1960).
}

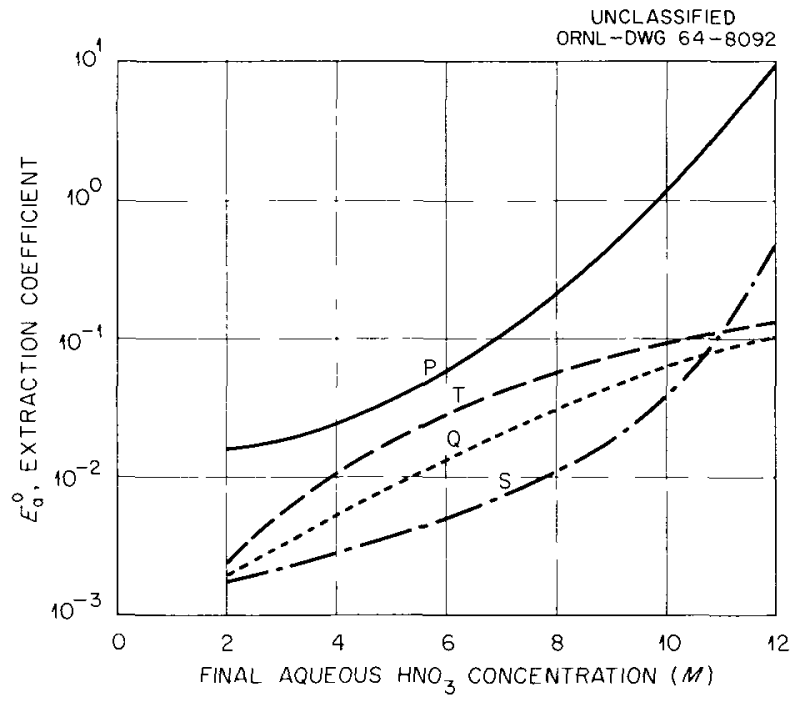

Fig. 7.1. Extraction of Niobium Nitrate by Amines in Toluene. Twenty-minute extraction from fresh aqueous solutions. Amines (each $0.3 \mathrm{M}$, in tolvene): $\mathrm{P}$, Primene JMT; S, ditridecylamine; $T$, trilaurylomine; $Q$, Aliquat 336. 
Fig. 7.2. Niobium is the most extractable at nitric acid concentrations above $6 \mathrm{M}$, and nitrosylruthenium the most extractable below $6 M$, each reaching a maximum extraction coefficient of about 0.1 with $0.3 M$ trilaurylamine (TLA) in toluene. It should be noted that, while ${ }^{95} \mathrm{Zr}-{ }^{95} \mathrm{Nb}$ extractions are often lumped together for analytical expediency or necessity, the TLA extraction coefficients of the daughter niobium range one to two orders of magnitude higher than those of the parent zirconium.

Equilibration was rapid in niobium extractions from $\leqq 4 M \mathrm{HNO}_{3}$ but was increasingly slow at higher nitric acid concentrations, especially with the primary amine. The apparent extraction coefficient from $12 \mathrm{M} \mathrm{HNO}_{3}$ with the primary amine increased from 1 at $1 \mathrm{~min}$ to 8 at $20 \mathrm{~min}$ and to 80 at $100 \mathrm{~min}$. However, the extraction coefficients with the primary amine below $8 \mathrm{MHNO}_{3}$ and those with the other amines at all acidities had reached constant values at $20 \mathrm{~min}$ (Fig. 7.1). These extractions, together with extractions after timed aging of specific aqueous solutions and at varying phase ratios, indicated that there is slow equilibration among niobium species in the aqueous nitric acid solutions. There appear to be at least two extractable species and at least one inextractable species. The results suggest tentatively that the most extractable species is a tetranitrate complex.

In a briefer survey of the extraction of other elements by trilaurylamine nitrate, ${ }^{4}$ the extraction coefficients of $\mathrm{Hg}(\mathrm{II}), \mathrm{Se}(\mathrm{IV})$, and $\mathrm{Sb}$ (III) varied only slightly with varying nitric acid concentration from 0.1 to $10 \mathrm{M}$. The extraction coefficients with $0.1 \mathrm{M}$ TLA in toluene were in the range 0.4 to 0.7 for mercury, 0.001 to 0.003 for selenium, and $10^{-4}$ to $10^{-3}$ for antimony. They varied in direct proportion to the amine concentration for selenium, and for mercury from 0.1 to $1 M \mathrm{HNO}_{3}$, but in proportion to about the $1 / 4$ power of amine concentration for mercury from 5 to $10 M \mathrm{HNO}_{3}$.

Trilaurylamine nitrate extracts excess nitric acid in considerable amounts, which often must be accurately known. Usually the excess acid is titrated (e.g., refs. 2 and 3 ), but titrations failed in the presence of extracted ruthenium. Conductivity of the organic phase proved to be a useful measure of the excess nitric acid (Fig. 7.3) and in preliminary tests appeared not to be affected by ruthenium. ${ }^{4}$

\footnotetext{
${ }^{4}$ P. J. Lloyd and E. A. Mason, Equilibrium Extraction Characteristics of Alkyl Amines and Nuclear Fuels Metals in Nitrate Systems, MITNE-43 (Subcontract No. 1327) (Dec. 2, 1963).
}

The apparent stoichiometry of the uranyl-trilaurylamine-nitrate extract complex varies with loading, that is to say, with the ratio of uranyl ion to total amine. A new extraction model has been proposed $^{4.5}$ to account for this on the basis that it is

${ }^{5}$ P. J. Lloyd and E. A. Mason, The Mechanism of Extraction of Hexavalent Uranium by Trilaurylamine Nitrate, Abstract No. 32,14D, 146th American Chemical Society Meeting; Denver, January 1964.

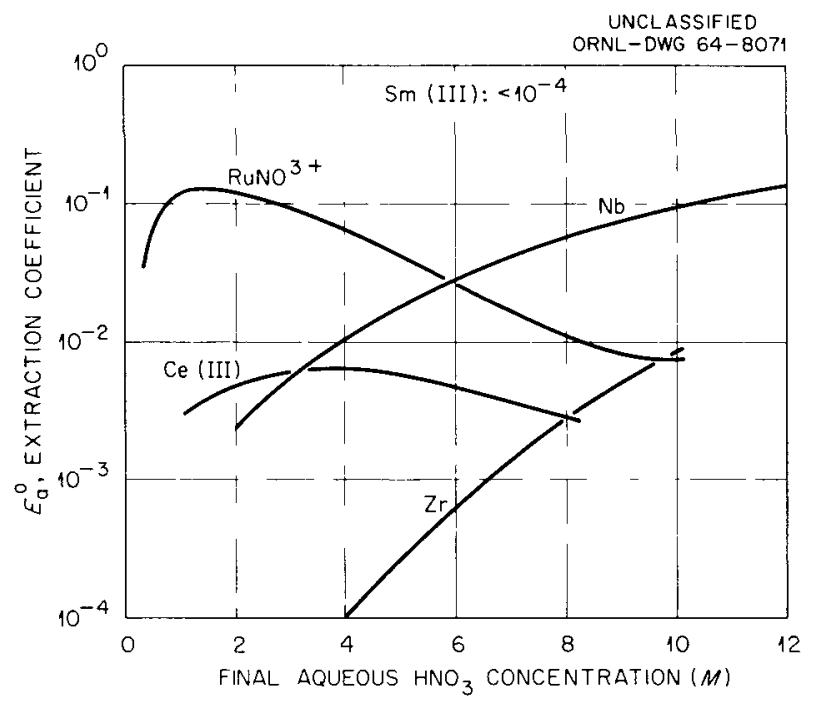

Fig. 7.2. Comporison of Fission Product Extractions from Nitric Acid Solutions by Trilaurylomine. $0.3 \mathrm{M}$ TLA, in toluene.

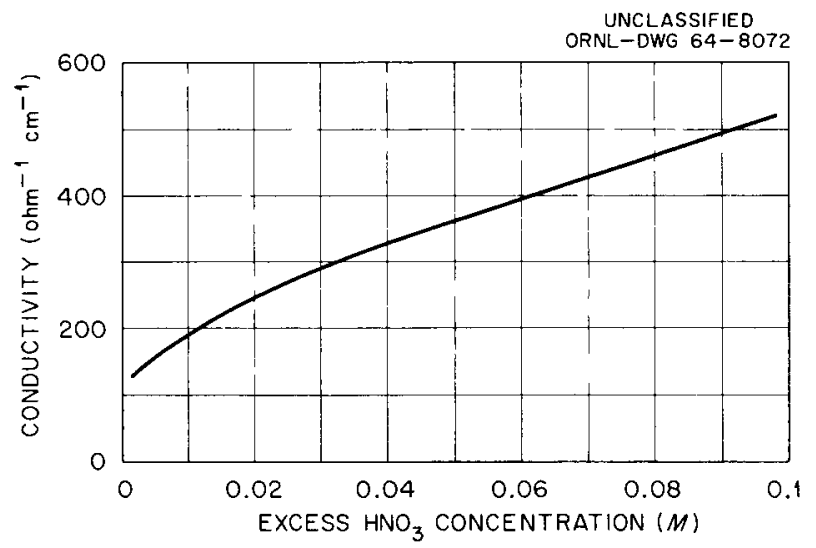

Fig. 7.3. Organic-Phase Conductivity as a Measure of Excess Nitric Acid Extracted by Trilaurylamine. $0.26 \mathrm{M}$ TLA, in toluene; conductivity of $25^{\circ} \mathrm{C}, 1000 \mathrm{cps}$, cell constant $0.100 \mathrm{~cm}^{-1}$. 
due to independent extraction by amıne nitrate monomers and dimers.

$$
\begin{aligned}
2 \mathrm{R}_{3} \mathrm{NHNO}_{3} \rightleftharpoons & \left(\mathrm{R}_{3} \mathrm{NHNO}_{3}\right)_{2} \quad K_{1} \approx 125 \text { (ref. 6), } \\
2 \mathrm{R}_{3} \mathrm{NHNO}_{3}+ & \mathrm{UO}_{2}\left(\mathrm{NO}_{3}\right)_{2} \rightleftharpoons \\
& \left(\mathrm{R}_{3} \mathrm{NHNO}_{3}\right)_{2} \mathrm{UO}_{2}\left(\mathrm{NO}_{3}\right)_{2} \quad K_{2} \approx 50, \\
2\left(\mathrm{R}_{3} \mathrm{NHNO}_{3}\right)_{2}+\mathrm{UO}_{2}\left(\mathrm{NO}_{3}\right)_{2} \rightleftharpoons & \\
{\left[\left(\mathrm{R}_{3} \mathrm{NHNO}_{3}\right)_{2}\right]_{2} \mathrm{UO}_{2}\left(\mathrm{NO}_{3}\right)_{2} } & K_{3}-200 .
\end{aligned}
$$

This model gave good correlation of uranyl extractions with up to $0.3 \mathrm{M}$ TLA in toluene vs aqueous solutions with ion product $\left[\mathrm{H}^{+}\right]\left[\mathrm{NO}_{3}^{-}\right]$through the range 0.01 to 3 .

${ }^{6} K_{1} \approx 125$ was derived from the data of $E$. Högfeldt, Royal Institute of Technology, Stockholm, Sweden (to be published).

\section{Extraction of Metal Chlorides by Amines}

In view of the increasing utilization of amine extractants, a systematic survey is being made of the extraction behavior of most representative metals from a variety of aqueous systems.

Data are shown in Fig. 7.4 for the extraction of technetium, silver, cadmium, and palladium from $\mathrm{HCl}$ and from $\mathrm{L}_{1} \mathrm{Cl}-0.2 M \mathrm{HCl}$ over the range 0.5 to $10 M$ total chloride. Extractions of about 20 other metals were reported previously. ${ }^{7}$ In all cases the solvents were $0.1 M$ solutions of representatıve primary, secondary, tertıary, and quaternary amines in diethylbenzene. All four of the

${ }^{7}$ Chem. Technol. Div. Ann. Progr. Rept. June 30, 1962, ORNL-3314, p. 104, also Chem. Technol. Div. Ann. Progr. Rept. May 31, 1963, ORNL-3452, p. 170.
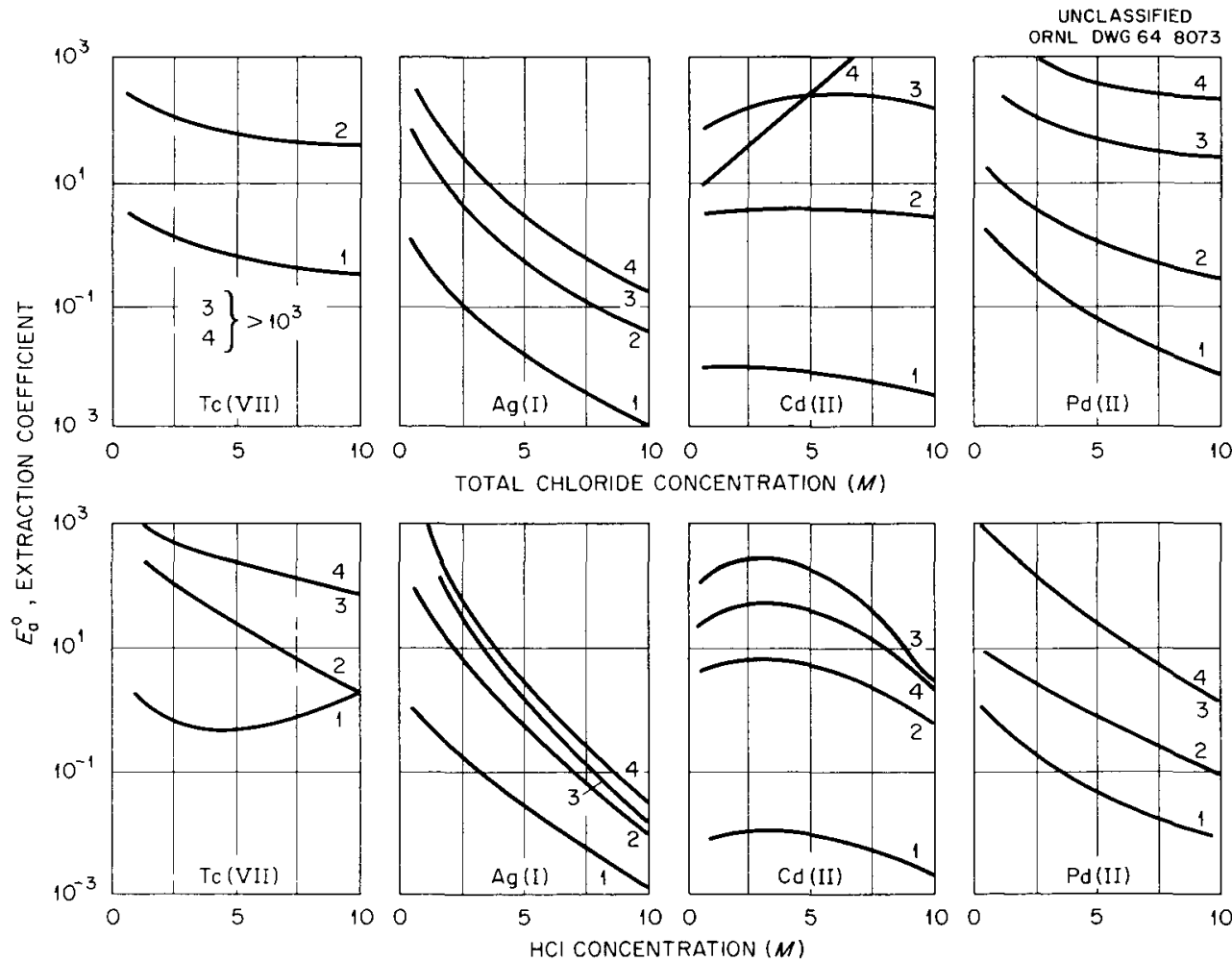

Fig. 7.4. Extraction of Metal Chlorides with Amines. Organic phase: $0.1 M$ solutions of (1) Primene JM (RR'R" $\mathrm{CNH}_{2}, 18$ to 24 carbon atoms), (2) Amberlite LA-1 (RR'R' CNHC ${ }_{12} \mathrm{H}_{23}, 24$ to 27 carbon atoms), (3) Alamıne $336\left(\mathrm{R}_{3} \mathrm{~N}, \mathrm{R}=\right.$ n-octyl-n-decyl mixture), and (4) Aliquat $336\left[\mathrm{R}_{3}\left(\mathrm{CH}_{3}\right) \mathrm{N}^{+}, \mathrm{R}=\right.$ n-octyl-n-decyl mixture $]$ in diethylbenzene (with Aliquat 336, 3 vol \% tridecanol was added to the solvent phase to prevent third-phase formation). Amınes were in chloride form. Aqueous phase: $0.01 \mathrm{M}$ metal ion in $\mathrm{L}, \mathrm{Cl}-0.2 \mathrm{M} \mathrm{HCl}$ (top graphs) or $\mathrm{HCl}$ solutions $(0.5$ to $10 \mathrm{M} \mathrm{Cl})$. For technetium and silver, tracer only was used. Contact: $10 \mathrm{~min}$ at $1 / 1$ phase ratıo. 
metals were extracted effectively under some conditions. With few exceptions, the extraction coefficients decreased with increasing chlonde concentration and were slightly higher from the salt solution than from hydrochloric acid. In most cases, the extraction power of the amines for the various metals varied in the order Aliquat 336 (quaternary amıne) $\geqq$ Alamıne 336 (tertiary amıne) > Amberlite LA-1 (secondary amıne) > Primene JM (primary amıne).

\section{Performance of Degraded Diluents}

In radiochemical processing by solvent extraction, deterioration of the solvent phase can cause unsatisfactory operation. The amount of degradation varies with the materials used and with the extent of their exposure to radiation and reactive chemicals during the processing of the aqueous feed. Studies of several aspects of extractant and diluent degradation have been made at ORNL, and a summary of prior work has been published. ${ }^{8}$ This year, studies have continued on the stabilities of aliphatic and aromatic diluents, especially the latter.

Of the aliphatic diluents, normal paraffins in the $\mathrm{C}_{12}$ range are most desirable. Also, their eventual avallability in quantity at low price seems assured because of their growing use in the biodegradable- detergent industry. In the interim, however, there is interest in treating present commercial diluents to make them more resistant to nitration. A sulfuric acid treatment method used to improve the stability of Amsco 125-82 was described previously. ${ }^{8.9}$ Recently, two additional commercial diluents were treated by this method, and their stabilities toward nitric acid degradation were also improved. The diluents, Soltrol 170 (Phillips Petroleum Company) and Peneteck White O1l (Pennsylvania Refining Company), are described as follows:

$\begin{array}{lcl} & \text { Soltrol } 170 & \text { Peneteck } \\ \text { Type } & \sim 100 \% \text { 1soparaffin } & \text { White o11 } \\ \text { Sp. gr }, 60 / 60^{\circ} \mathrm{F} & 0.77 & 0.80 \\ \text { Flash point, }{ }^{\circ} \mathrm{F} & 185 & 265 \\ \quad \text { (closed cup) } & & \end{array}$

Both diluents degraded severely when the as-recelved solvents were made $1 M$ in TBP and boiled with $2 \mathrm{M} \mathrm{HNO}_{3}$ (Table 7.1) and degradation was markedly less severe after sulfuric acid treatment. However, their degradation was still measurably

\footnotetext{
${ }^{8}$ C. A. Blake, W. Davis, and J. M. Schm1tt, Nucl. Sc 1 Eng. 17, 626-37 (1963).

${ }^{9}$ Chem. Technol. Div Ann. Progr. Rept May 31, 1963, ORNL-3452, p. 174.
}

Table 7.1. Treatment of Aliphatic Diluents with Sulfuric Acid

Relative degradation of $1 M$ TBP-diluent measured by ${ }^{95} \mathrm{Zr}-\mathrm{Nb}$ extraction ${ }^{a}$ (gamma counts $\mathrm{sec}^{-1} \mathrm{~m}^{-1}$ )

\begin{tabular}{|c|c|c|c|c|c|}
\hline \multirow[t]{2}{*}{ Diluent } & \multirow{2}{*}{$\begin{array}{c}\text { Blank } \\
\text { Extraction Before } \\
\text { Degradation }\end{array}$} & \multicolumn{2}{|c|}{$\begin{array}{l}\text { Degraded }{ }^{b} \text { Without }_{1} \\
\mathrm{H}_{2} \mathrm{SO}_{4} \text { Treatment } \\
\end{array}$} & \multicolumn{2}{|c|}{$\begin{array}{c}\text { Degraded }{ }^{b} \text { After } \\
\mathrm{H}_{2} \mathrm{SO}_{4} \text { Treatment }\end{array}$} \\
\hline & & $4 \mathrm{hr}$ & $24 \mathrm{hr}$ & $4 \mathrm{hr}$ & $24 \mathrm{hr}$ \\
\hline Soltrol 170 & 200 & 3600 & 6000 & 200 & 700 \\
\hline Peneteck & 200 & 4000 & $>6000$ & 350 & \\
\hline Amsco $125-82$ & 100 & 4000 & $>6000$ & $<100$ & 400 \\
\hline$n$-Dodecane & 100 & 125 & 450 & & \\
\hline
\end{tabular}

${ }^{a}$ Extraction from $2 \mathrm{MHN}_{3}$, initial ${ }^{95} \mathrm{Zr}-\mathrm{Nb}=10^{4}$ gamma counts $\mathrm{sec}^{-1} \mathrm{ml}^{-1}$, equal volumes, 10-min contact at room temperature. Organic phase treated prior to extraction as follows: wash twice with equal volumes of $0.2 M$ $\mathrm{Na}_{2} \mathrm{CO}_{3}(10 \mathrm{~min}$ each contact), contact $30 \mathrm{~min}$ with solid calcium hydroxide, about $50 \mathrm{~g}$ of the solid per liter of organic phase, and separate from solid (calcium test) (ref. 8).

${ }^{b}$ Equal volumes $1 M$ TBP-diluent and $2 \mathrm{MHNO}_{3}$, bolled under total reflux.

${ }^{\mathrm{c}}$ Heated while stirring diluent with equal volumes of $96 \% \mathrm{H}_{2} \mathrm{SO}_{4}$ at $50^{\circ} \mathrm{C}$ for $1.5 \mathrm{hr}$. 
greater than that of $n$-dodecane or of treated Amsco 125-82, probably because of different initial contents of readily degradable components. It seems safe to predict that sulfuric acid treatment can similarly stabilize various other commercial diluents, excepting any that might contain readily degradable species as major components.

Aromatic diluents were shown previously ${ }^{8,9}$ to have advantages over aliphatics in certain solvent extraction applications. For example, their use with TBP improved radiation stability, uranium extraction, uranium/fission product separation, and solubility of extracted metal salts. Commercial diethylbenzene, a mixture of isomers, has been used successfully in the recovery of ${ }^{233} \mathrm{U}$ from gross amounts of thorium in nitrate solutions with di-sec-buty1 phenylphosphonate (Sect. 6.1). [It also is being tested as a diluent for tertiary amines in the recovery of transuranium elements from chloride solution (Sect. 4.1).] Stability studies during this year emphasized the nitration properties of diethylbenzene (DEB) isomers and their mixtures. The DEB's or their $1 M$ TBP solutions were subjected to degradation by mixing with $2 \mathrm{M} \mathrm{HNO}_{3}$ in the presence or in the absence of ${ }^{60} \mathrm{Co}$ gamma ionizing radiation. The temperature during irradiations was $50^{\circ} \mathrm{C}$. Treatments in the absence of radiation were at 50 and about $100^{\circ} \mathrm{C}$.

The extent of degradation was tested in three ways: (1) measurement of the increase of ${ }^{95} \mathrm{Zr}-\mathrm{Nb}$ or ${ }^{18}{ }^{1} \mathrm{Hf}$ extraction by degradation products; (2) analysis of nitrogen uptake; and (3) gas chromatographic analysis, sometimes in conjunction with vacuum distillation, to determine the loss of $\mathrm{DEB}$ and to provide spectra of the volatile degradation products.

Fission product ${ }^{95} \mathrm{Zr}-\mathrm{Nb}$ extractions reported last year showed that the meta-DEB was most stable of the three isomers. Gas chromatography and nitrogen analyses (Fig. 7.5) have confirmed the stability of the meta-DEB and also its superiority over ortho- and para-DEB but with less difference than was indicated by the tracer extractions. The explanation appears to be that one or more contaminants often but not always present in DEB give rise to most of the zirconium-extracting nitro degradation product. Samples presumably free of such contaminant appeared resistant to the degradation. The particular batches of meta-DEB and para-DEB represented in Fig. 7.5, and also one particular batch of commercial DEB (18\% ortho, $48 \%$ meta, $29 \%$ para, $5 \%$ low boiling), showed about the same resistance to nitrative degradation (within a factor of 2 at a 4 -hr reflux) as did $n$-dodecane. Thus the problem in obtaining maximum stability of DEB is not separation of the isomers, as previously suggested, but identification and elimination of certain impurities. Work on the identification is in progress, using a special gas-chromatographcolumn packing developed for high resolution of the DEB isomers. ${ }^{10}$

As with aliphatic diluents, ${ }^{8}$ irradiation while mixing DEB with $2 \mathrm{M} \mathrm{HNO}_{3}$ accelerates degradation but gives the same type and distribution of products as are obtained simply by heating the DEB with $2 \mathrm{M} \mathrm{HNO}_{3}$ (Fig. 7.6). (Spectra for only meta-DEB tests are shown; those for ortho- and para-DEB tests are similar.) Ketone, but little or no nitrogen or carboxylic acid, was found in a

\footnotetext{
${ }^{10}$ C. A. Blake, Anal. Chem. 35, 1759-60 (1963).
}

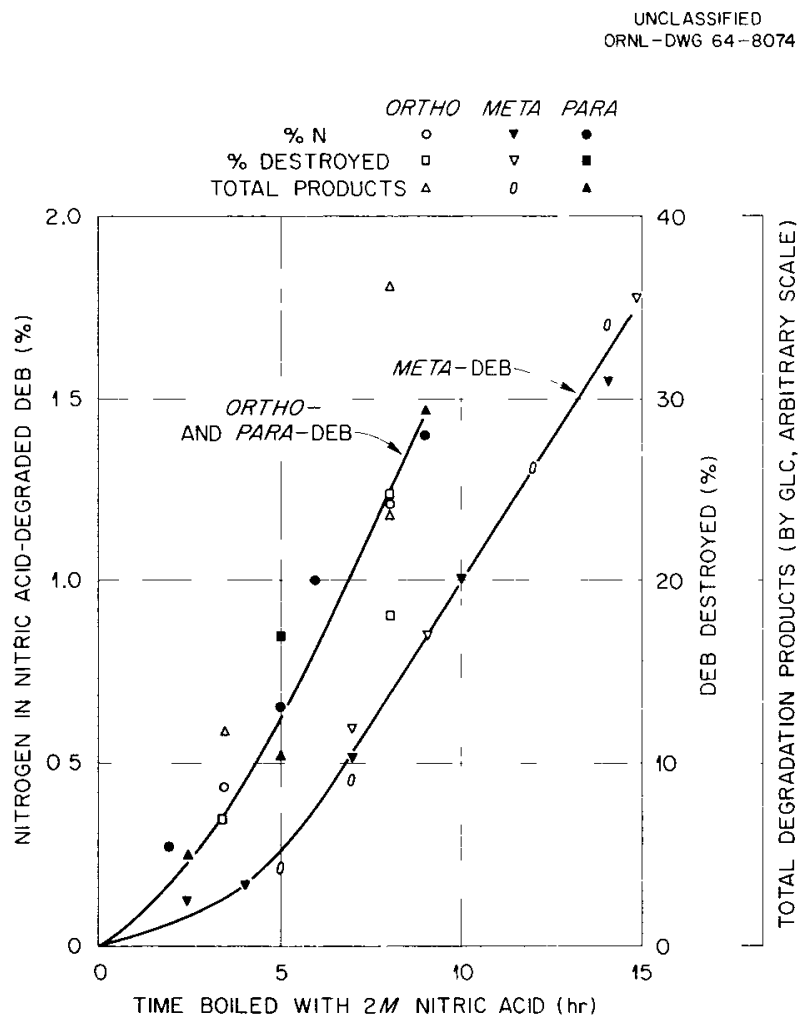

Fig. 7.5. Degradation of Diethylbenzene (DEB) Isomers by Nitric Acid. (Percent DEB destroyed - by comparison of DEB peak areas before and after degradation - see Fig. 7.6. Total degradation products growth in degradation product peak area with degradation - see Fig. 7.6.) 


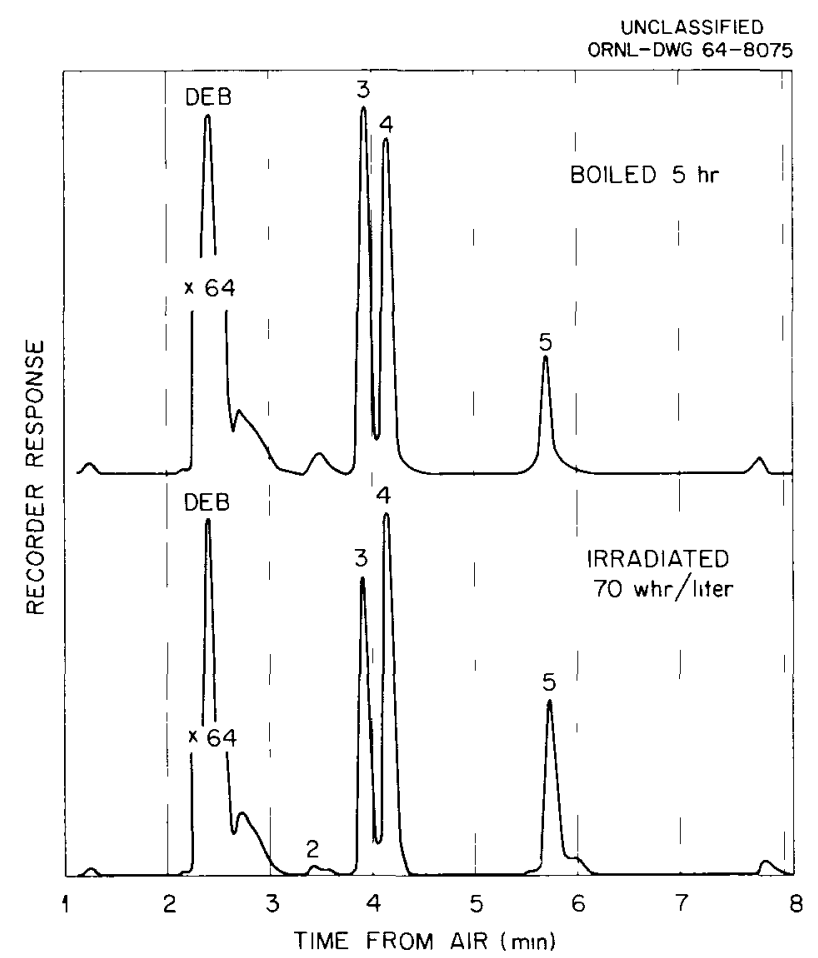

Fig. 7.6. Chromatographs Comparing meta-Diethylbenzene (DEB) Degradation by $2 M$ Nitric Acid With and Without Irradiation. (Chromatograph of meta-DEB before degradation gave single DEB peak.) (Aerograph Auto-Prep, model A-700, $1 / 4$-in.-diam, 20-ft-long copper column, $20 \%$ SE-30 on Chromosorb W-HMDS. Helium flow at $50 \mathrm{psi}$ and $65 \mathrm{ml} / \mathrm{min}$. Sample $=11 \lambda$, temperature programmed from 140 to $240^{\circ} \mathrm{C}$.)

vacuum distillation fraction $\left(70\right.$ to $90^{\circ} \mathrm{C}, 0.05 \mathrm{~mm}$ $\mathrm{Hg}$ ) including components of peaks 1 to 4 in Fig. 7.6, while high nitrogen content was found in a second fraction ( 90 to $130^{\circ} \mathrm{C}, 0.5 \mathrm{~mm} \mathrm{Hg}$ ) including components of peaks 5 and 6 . Material from peak 4 has been identified as ethylacetophenone. The nitrogen-rich distillation fraction has not been resolved, and it may contain components that are not found by gas chromatography because they are decomposed at the highest column temperatures (up to $250^{\circ} \mathrm{C}$ ).

As with aliphatic diluents, the presence of TBP (other conditions constant) increases the rate of DEB degradation by a factor between 2 and 3 , probably because of $\mathrm{HNO}_{3}$ and $\mathrm{HNO}_{2}$ extracted by the TBP.

In all the DEB degradation tests, ${ }^{18}{ }^{1} \mathrm{Hf}$ extraction correlated fairly well with nitrogen content of the degraded solvent (TBP was always present at $1 M$ during the extraction tests, whether or not present during degradation). The trend was $E_{\mathrm{a}}^{\circ}(\mathrm{Hf}) \propto[\mathrm{N}]^{2}$ over the range $[\mathrm{N}]=0.01$ to $0.2 \%$, with $E_{\mathrm{a}}^{\mathrm{o}}(\mathrm{Hf})=0.1$ at $0.2 \% \mathrm{~N}$.

\section{Sorption by Immobilized Extroctants}

In extraction chromatography a water-insoluble extractant, immobilized on a support to form a quasi-solid and packed in a column, is used for separations of extractable materials by the usual chromatographic techniques. It can offer advantages over liquid-liquid extraction in at least two kinds of circumstances: (1) when many stages but not high capacity and throughput are needed and (2) when some physical limitation such as limited solubility of the extractant in suitable diluents interferes with simple liquid-liquid equilibration. In the latter case, and even for scoping tests in the former case, the column may be used on loading instead of chromatographic basis, or the quasisolid may be slurried with the aqueous feed solution.

The following tests showed some of the advantages expected from sorption by immobilized extractants; but they also showed some difficulties that may represent general limitations in the technique.

Uranyl Sorption by Phosphine Oxide. - Trialkylphosphine oxides, especially $n$-octyl (TOPO) and $n$-decyl (TDPO), are well known as strong and versatile extractants. ${ }^{11,12}$ However, their potential usefulness in processing is impaired by limited solubility in hydrocarbon diluents. It was previously demonstrated ${ }^{13}$ that solid TDPO could sorb uranyl nitrate from aqueous solution to reach the expected loading limit of $\mathrm{U}: \mathrm{TDPO}=1: 2$. (The TDPO, initially crystalline, became gummy, fluid, and hard as uranyl sorption progressed.) Recently,

\footnotetext{
${ }^{11}$ C. A. Blake, K. B. Brown, and C. F. Coleman, Solvent Extraction of Uranium (and Vanadium) from Acid Liquors with Trialkylphosphine Oxides, ORNL-1964 (Nov. 4, 1955).

${ }^{12} \mathrm{~J}$. C. White and W. J. Ross, Separations by Solvent Extraction with Tri-n-octylphosphine Oxide, NAS-NS. 3102 (Feb. 8, 1961).

${ }^{13}$ C. A. Blake, K. B. Brown, and C. F. Coleman, Solvent Extraction of Uranium (and Vanadium) from Acrd Liquors with Trialkylphosphine Oxides, ORNL-1964, p. 87 (Nov. 4, 1955).
} 
corresponding tests were made with TOPO supported on granules of microporous polyethylene, ${ }^{14}$ sorbing uranyl nitrate and uranyl sulfate from aqueous solutions. The sorbent was prepared by slurrying 30- to 40-mesh granules in an ether solution of TOPO ( $1 \mathrm{~g}$ of TOPO per gram of polyethylene) and evaporating the ether. Physical perform. ance was good. The sorbent floated on the aqueous solution, was easily filtered, and showed no change (except in color) during uranium sorption or elution, in contrast to the behavior of the unsupported TDPO. The extent of uranyl sorption, however, was low (Fig. 7.7), with not more than $50 \%$ of the expected loading capacity utilized, in contrast to the high loading of the solid TDPO. Subsequent elution of the sorbed uranium from the supported TOPO was also inefficient. Only 50\% was eluted in either test by two successive 5 -min contacts with $0.2 \mathrm{M}$ sodium carbonate solution, $50 \mathrm{ml}$ per 2 grams of TOPO-2 grams of ethylene, in contrast to ready elution from the solid TDPO. ${ }^{13}$ The reN.Y.

${ }^{14}$ Supplied by Winsten Laboratories, Westbury, L.I.,

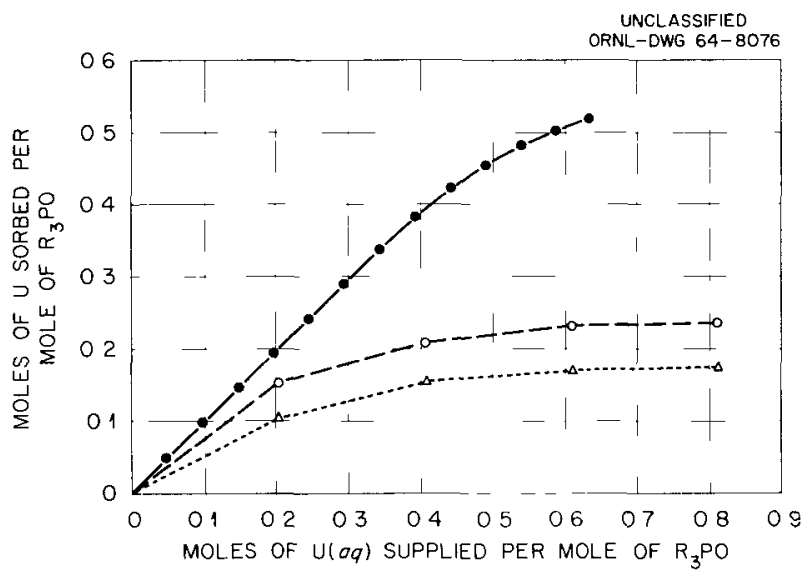

Fig. 7.7. Sorption of Uranyl by Solid Tri-n-decylphosphine Oxide, and by Tri-n-octylphosphine Oxide Supported on Microporous Polyethylene.

- $2.35 \mathrm{~g}$ TDPO, 30 min contact with successive 50 . $\mathrm{ml}$ batches of $0.0042 \mathrm{MUO} \mathrm{UO}_{2}\left(\mathrm{NO}_{3}\right)_{2}$.

$O 2 \mathrm{~g}$ TOPO on $2 \mathrm{~g}$ polyethylene, 5-min contact with successive $50-\mathrm{ml}$ batches of $0.021 \mathrm{MUO}_{2}\left(\mathrm{NO}_{3}\right)_{2}$.

$\triangle 2 \mathrm{~g}$ TOPO on $2 \mathrm{~g}$ polyethylene, 5-min contact with successive batches of $0.021 \mathrm{MUO}_{2} \mathrm{SO}_{4}$ in $0.5 \mathrm{M}$ $\mathrm{Na}_{2} \mathrm{SO}_{4}, \mathrm{pH} \mathrm{l}$. sults suggest that a large portion of the TOPO was in positions of hindered accessibility, some perhaps completely inaccessible, to the sorbable uranium.

Americium-Lanthanide Separations. - A chromatographic separation was previously reported, show. ing well-separated peaks of europium and americium in elution with successive 13 and $11 M$ chloride solutions from a column of tertiary amine chloride supported on polystyrene-divinylbenzene beads. ${ }^{15}$ In recent tests, well-separated peaks of americium and cerium were obtained in elution from a column of di(2-ethylhexyl)phosphoric acid (HDEHP) in diisopropylbenzene (DIPB) supported on microporous polyethylene (Fig. 7.8). The first eluting solution contained $1 \mathrm{M}$ glycine nitrate and $0.05 \mathrm{M}$ pentasodium diethylenetriaminepentaacetate $\left(\mathrm{Na}_{5} \mathrm{DTPA}\right)$, corresponding to a typical feed solution used in the Talspeak separation process (Sect. 5.2). The second eluting solution was $1 M$ nitric acid. The column packing consisted of $5 \mathrm{ml}$ of $0.3 M$ HDEHP in DIPB supported in $5 \mathrm{~g}$ of 30 - to 40 -mesh microporous polyethylene beads. ${ }^{14}$

${ }^{15}$ Chem. Technol. Div. Ann. Progr. Rept. June 30, 1962, ORNL-3314, p. 110.

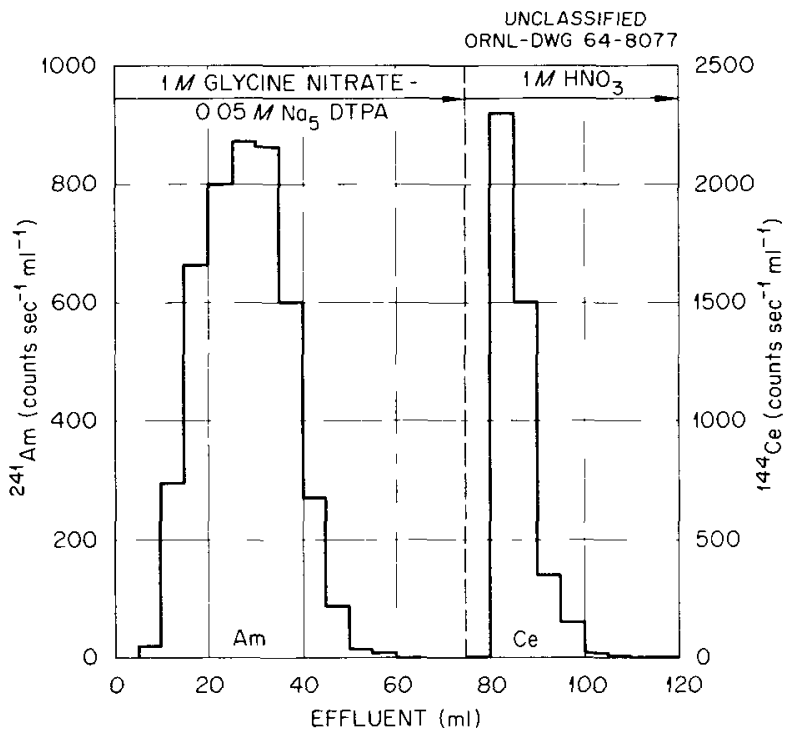

Fig. 7.8. Extraction-Chromatographic Separation of Americium from Cerium. Column approximately $20 \mathrm{~cm}$ long and $1 \mathrm{~cm}^{2}$ in cross section, containing $5 \mathrm{ml} 0.3 \mathrm{M}$ HDEHP in DIPB supported in $5 \mathrm{~g} 30-40$ mesh microporous polyethylene. Loading solution $(10 \mathrm{ml})$, same as firsteluting solution plus americium and cerium tracers. Elution rate, opprox $1 \mathrm{~m} ! / \mathrm{m} ı \mathrm{n}$. 
Similar tests with the same extractant supported on Saran powder, silane-treated silica gel, and silane-treated diatomaceous silica gave similar, compact, well-separated peaks for americium and europium. (The americium-europium separation is more difficult than the americium-cerium separatıon.) However, closer examination of these columns shows that, in spite of the rapid completion of elution apparently shown by the elution rates, around 1 or $2 \%$ of the americium is still held up in the column and is eluted only very slowly by the complexing eluant. The practical significance of such holdup will presumably differ in different specific applications. Current tests are aimed toward determining the cause and the possible control of the holdup.

\section{New Extraction Reagents}

A continued search for new separations reagents, particularly solvent extraction reagents, has included a series of $\mathrm{N}$-alkyl amides, phosphorus esters, phosphoramides, carboxylic acids (see Sect. 8.3), and substituted phenols.

N-Alkyl Amides. - A previous progress report in this series ${ }^{16}$ compared uranium and thorium extraction abilities of $14 \mathrm{~N}, \mathrm{~N}$-dialkyl amides with those of tri-n-butyl phosphate (TBP) and $\mathrm{d}_{1}-$ (sec-butyl) phenylphosphonate (DSBPP). ${ }^{17}$ Briefly, these data indicated that thorium and uranium can be recovered separately or simultaneously by choosing the appropriate amide structure and aqueous nitric acid concentration. None of the amides (mostly commercial N,N-dimethyl amıdes of fatty acıds) gave uranium extraction coefficients as high as those obtained with TBP or DSBPP at the same concentration in the solvent. However, all the amides tested indicated uranium-thorium separations that were at least as good as those obtained with TBP. The largest effect of structure on extraction properties was encountered when the $\alpha$-carbon atom of the carboxylic acid fraction was completely substituted, as in 2,2-dımethylundecano1c (neotridecanoic) acid. Under comparable conditions, the thonum extraction coefficient with $\mathrm{N}, \mathrm{N}$-dimethylneotridecanamide was $10^{3}$ to $10^{4}$ times lower than

\footnotetext{
${ }^{16}$ Chem. Technol. Div. Ann. Progr. Rept. May 31, 1963, ORNL 3452, p. 178.

${ }^{17}$ C. A. Blake, Jr., et al., Comparison of Dialkyl Phenylphosphonates with TBP in Nitrate Systems, ORNL-3374 (Jan. 8, 1963).
}

that with TBP. The uranium coefficient, however, was also depressed excessively, by 10 to 40 times.

Recently, with assistance from W. H. Baldwin of the ORNL Chemistry Division, a series of 2-ethylheyanamides was prepared from several amines, including the cyclic imine morpholine. The monoethyl substitution on the $a$-carbon atom has an effect on extraction properties similar to, but less drastic than, that of the dimethyl substitution cited above, so that with changing $\mathrm{N}$-alkyls a range of extractabilities is obtained (Fig. 7.9) which fits between that of the $\mathrm{N}, \mathrm{N}$-dimethylneotridecanamide and those of the $\mathrm{N}, \mathrm{N}$-dimethyl fatty amides described previously. ${ }^{16}$ Indicated separation factors, uranium over thorium (F1g. 7.10), decreased rapidly with increasing aqueous nitric acid, but up to $5 \mathrm{M}$ $\mathrm{HNO}_{3}$ all the amides gave higher uranıum/thorium separation factors than did TBP. Highest separations were achieved with the $n$-propyl, $n$-butyl, and morpholine derivatives, which at $3 \mathrm{M} \mathrm{HNO}_{3}$ gave uranium/thorium separation factors 7 to 10 times as high as those with DSBPP and 80 to 100 times as high as those with TBP. Extraction of nitric acid by the 2-ethylhexanamides was about the same as that by TBP. Each mole of amide extracted 1 mole of $\mathrm{HNO}_{3}$ when the equilibrium aqueous phase was 6 to $7 \mathrm{MHNO}_{3}$, the same occurs with TBP when the final concentration of $\mathrm{HNO}_{3}$ in the aqueous layer is about $8 \mathrm{M}$. Ruthenium and $z_{1}$ rconium extractions were lower with the amides than with TBP to about the same extent as the uranium extractions, so that uranium/zirconsum and uranıum/ruthenıum separation factors were similar to those with TBP. Extractions of americium and europium were very low from nitric acid, even with undiluted amides. Coefficients were higher from salted solutions ( $6 M \mathrm{~L}_{1} \mathrm{NO}_{3}-0.1 M \mathrm{HNO}_{3}$ ), but extractions were slow, and separation factors between the two elements were less than 2.

The work reported here was nearly finıshed when it was found that T. H. Siddall of the Savannah River Laboratories had previously examined amides as extractants, particularly with reference to selective extraction of uranium, neptunium, and plutonium from fission products. ${ }^{18,19}$ Three of the 23 amide structures examined by Siddall (N,Ndibutylacetamide, N,N-diethyldecanamide, and N,Ndibutyl-2-ethylhexanamide) were also among those

\footnotetext{
${ }^{18}$ T. H. Siddall III, J. Phys. Chem. 64, 1863 (1960).

${ }^{19}$ T. H. Siddall III, Applications of Amides as Extractants, DP-541 (January 1961).
} 


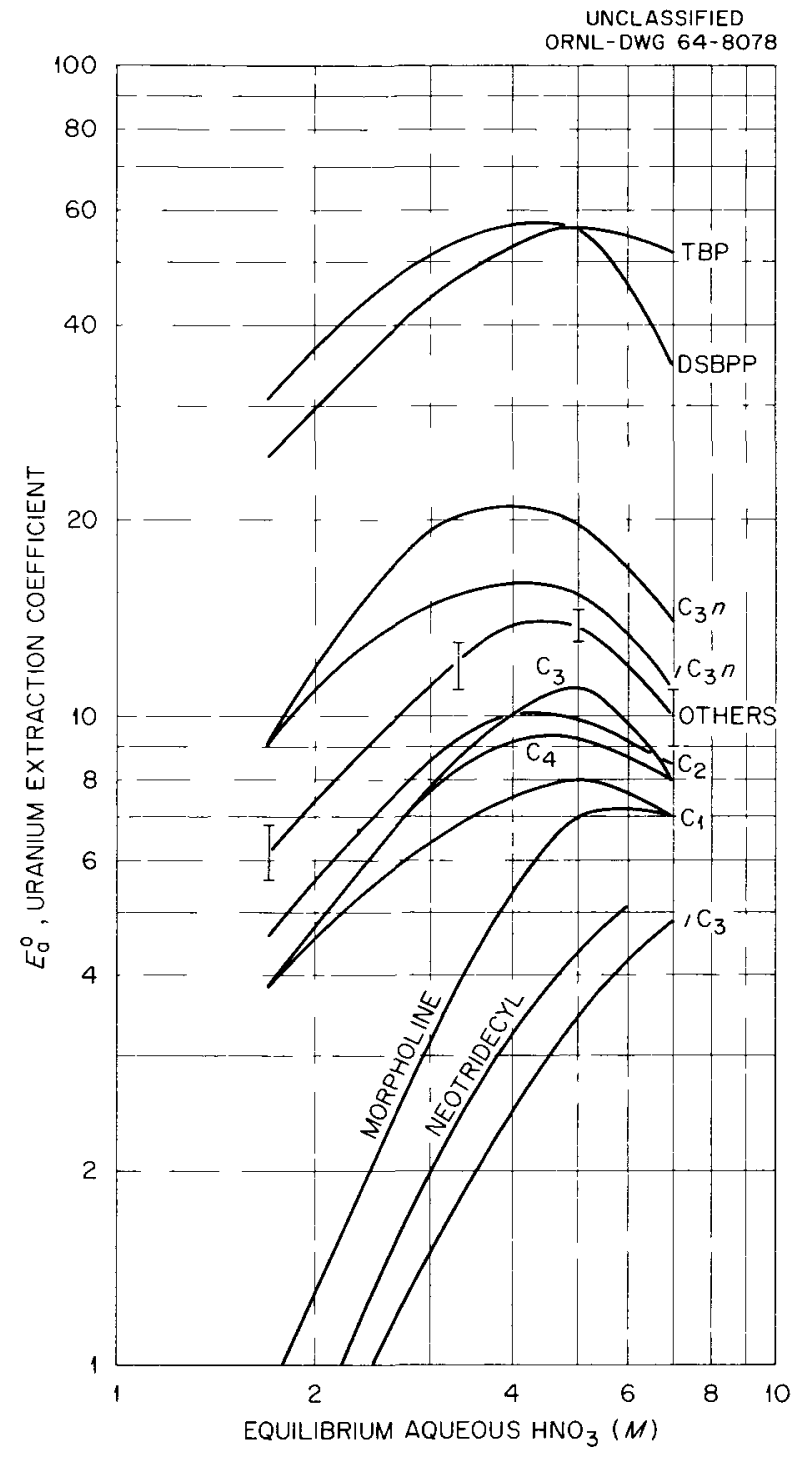

Fig. 7.9. Uranium Extraction with $1.0 \mathrm{M}$ Solutions of Amides in Diethylbenzene. Inıtıal aqueous phase: $0.004 M U(V \mid)$. Contact: Equal volumes, organic and aqueous phases, $10 \mathrm{~min}$ at room temperature.

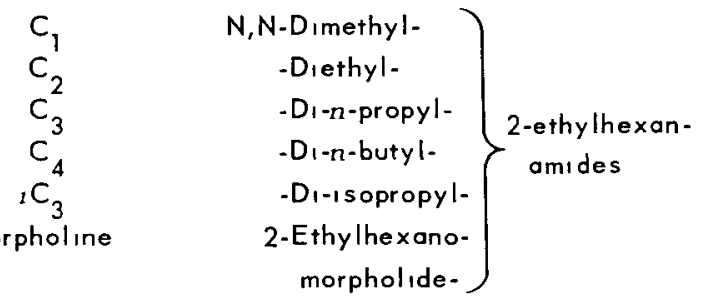

$\left.\begin{array}{cc}\mathrm{C}_{3}{ }^{n} & \text { N,N-Di-n-propyl- } \\ { }_{1} \mathrm{C}_{3}{ }^{n} & \text {-Di-Isopropyl- }\end{array}\right\}$ n-octonamides

"Others" N,N-Dimethyl amides described previously 16

Neotridecyl N,N-Dimethylneotridecanamide

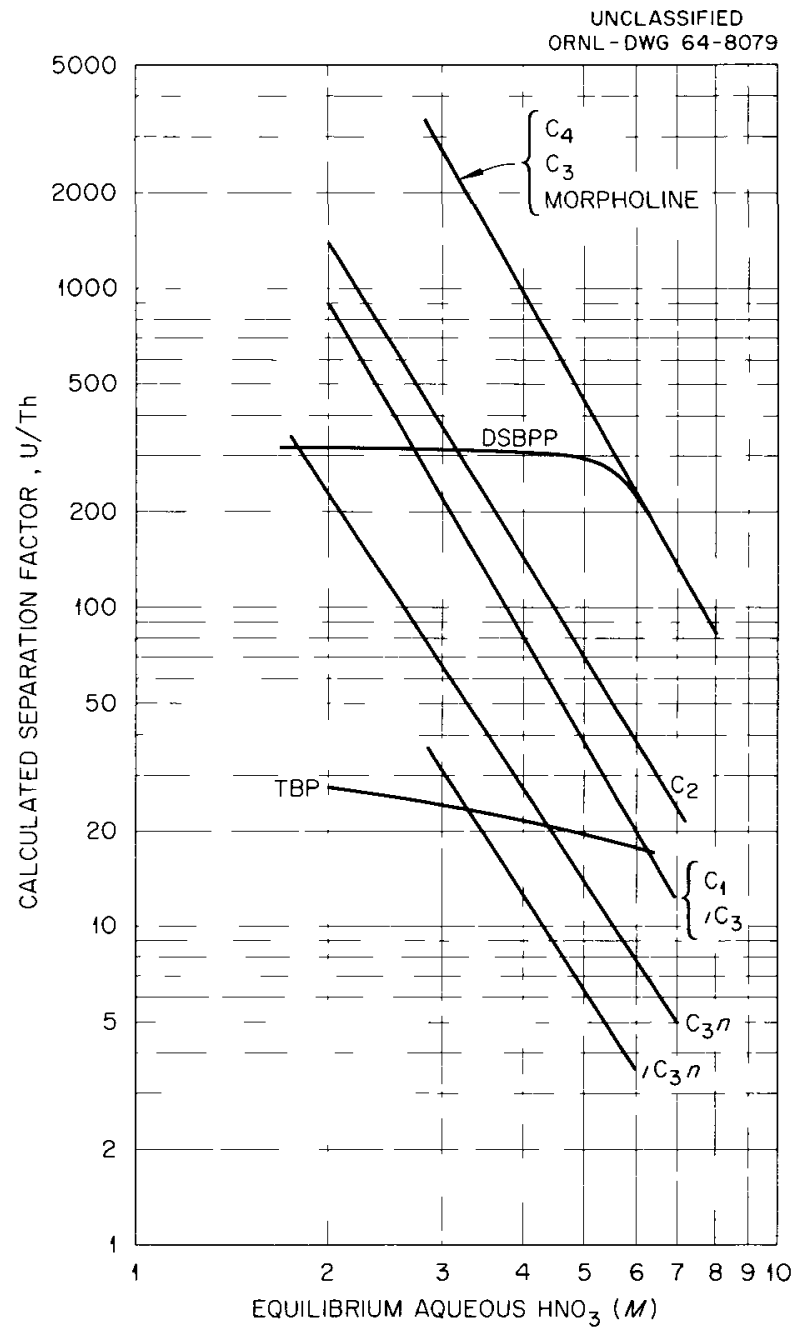

Fig. 7.10. U/Th Separation Factors with $1.0 \mathrm{M}$ Solutions of Amides in Diethylbenzene. Initial aqueous phases: $0.004 M U(V I)$ or Th. Contact: Equal volumes, aqueous and organic phases, $10 \mathrm{~m}$ in at room temperature.

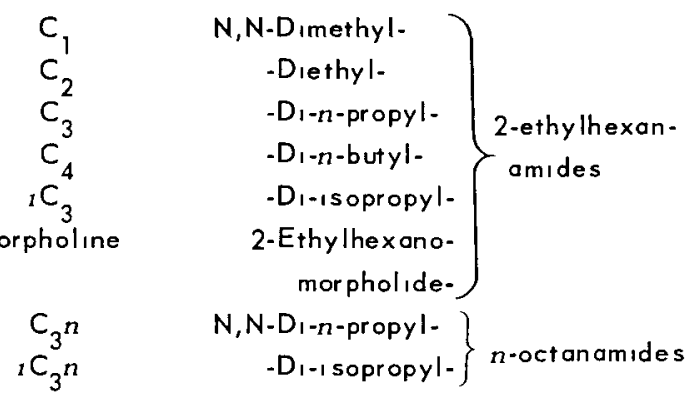


tested at ORNL, and allowing for differences in reagent sources, concentration, diluents, and test conditions, the uranium and thorium extraction coefficients are in agreement. There were no other duplications in the remaining compounds in the two test series, but each encompassed enough similarity in structure to lead to similar conclusions about structural effects on extraction, separation, solubility, and stability properties.

Phosphate Esters and Phosphoramides. - About 50 neutral organophosphorus compounds (esters and phosphoramides) were examined as extractants for cerium, europium, and americium. Some were strong extractants from the highly salted $6 \mathrm{MLiNO}_{3}$ tracer solutions, and these are listed in Table 7.2. Where the coefficients were too high for accurate measurement, extractions were repeated from $2 \mathrm{MHNO}_{3}$. None of the reagents tested (including those of lower extraction ability not shown on the table) gave separations of europium from americium by factors greater than 3 .

D1-(sec-butyl) phenylphosphonate, a reagent very effective in separating uranium and thorium by solvent extraction (ref. 17, see also Sect. 6.1), must be used in a predominantly (more than $75 \%$ ) aromatic diluent to ensure the organic-phase solubility of the extracted uranium. A similar compound, but with a methyl group replacing one of

Table 7.2. Extraction of ${ }^{144} \mathrm{Ce},{ }^{152} \mathrm{Eu}$, and ${ }^{241}$ Am with Neutral Organophosphorus Compounds

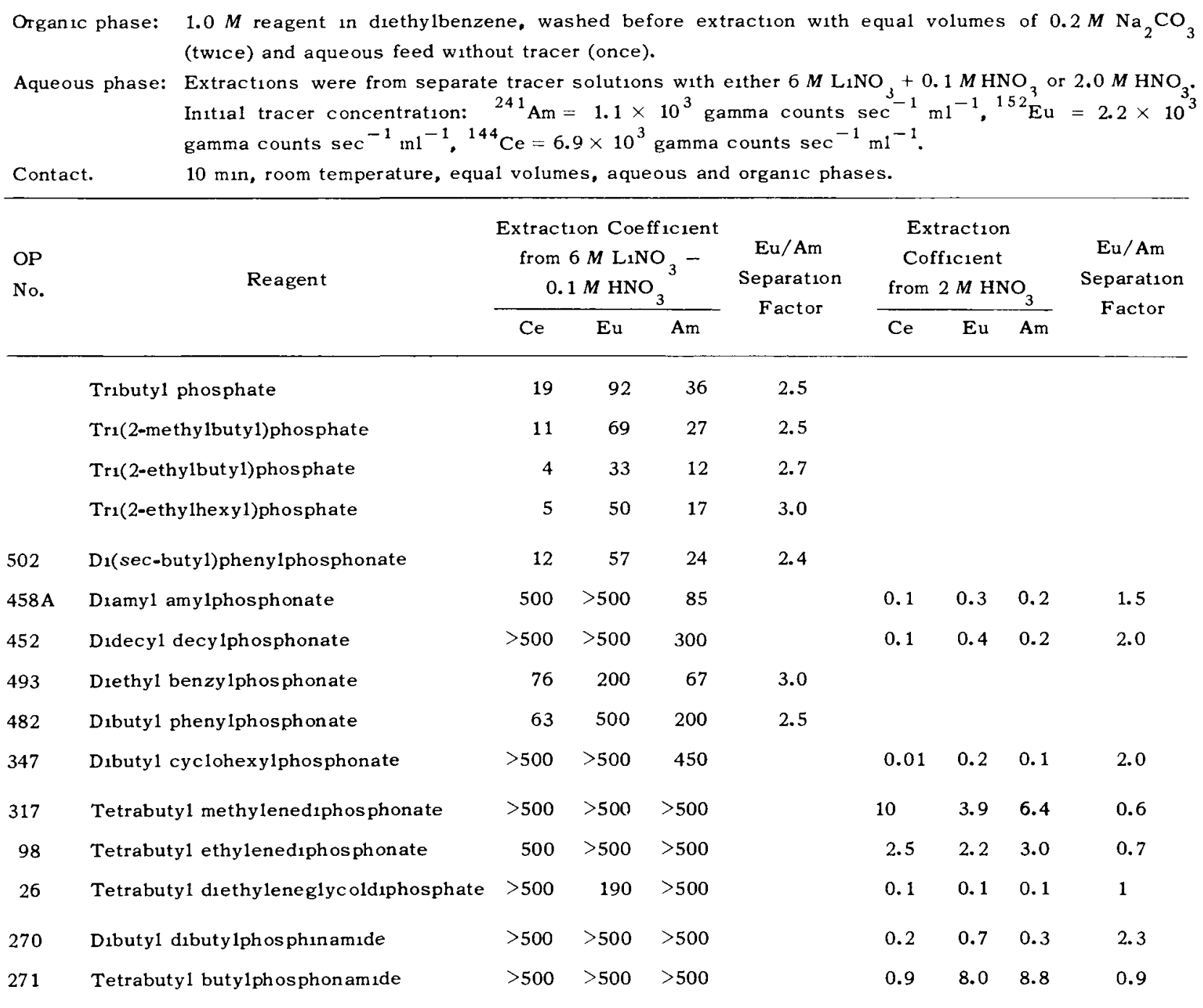


the hydrogens on the benzene ring, permitted the use of a diluent that was $25 \%$ aromatic and $75 \%$ aliphatic. Uranium extraction and separation from thorium were unaffected by the change in reagent structure.

Tests w1th the cage-structure phosphate ester, 4-octyl-1-phospha-2,6,7-trioxabicyclo [2.2.2]octane1 oxide<smiles>CCC12COP(=O)(OC1)O2</smiles>

were reported previously ${ }^{16}$ as showing high extraction power for thorium and high selectivity for thorium over uranium. Tests with a second and larger sample of the same material now prove that the high extraction power was caused by the presence of 5 to $10 \%$ acidic impurity in the product. A two-phase titration of the reagent-diethylbenzene mixture in $70 \%$ ethanol with aqueous $\mathrm{NaOH}$ showed the presence of both strong ( $\mathrm{pH}$ about 6.0) and weak ( $\mathrm{pH}$ about 9.5) acıd functions. No attempt was made to purify the reagent, but some extrac- tion tests were made at high uranium and thorium concentrations (equilibrium aqueous phase concentrations of 50 to $100 \mathrm{~g}$ of metal ion per liter) where extraction by the impurity was small compared with the extraction by the actual reagent. These tests showed that both uranium and thorium extractions from $2 \mathrm{MHNO}_{3}$ by the cage compound were low, estımated $E_{\mathrm{a}}^{\mathrm{O}} \mathrm{U} \leqq 0.5$ and $E_{\mathrm{a}}^{\mathrm{o}} \mathrm{Th} \leqq 0.1$ with $1 M$ cage phosphate vs $E_{\mathrm{a}}^{\mathrm{o}} \mathrm{U}=2$, and $E_{\mathrm{a}}^{\mathrm{o}} \mathrm{Th}=$ 1.1 with $1 M$ TBP, both in diethylbenzene.

Substituted Phenols. - Seven new phenols were obtained with structures chosen to test certain variations from the previously established good extractants, BAMBP and Santophen-1. Of these (Table 7.3), only 4-chloro-2-( $\alpha$-methylbenzyl)phenol showed both high cesium extraction and favorable physical performances. This compound is equivalent to Santophen-1 with an $a$-methyl added, which decreased sodium extraction and/or phenol loss to the aqueous phase and increased cesium extraction, at least in proportion to the increased final $\mathrm{pH}$. Its 1somer 4-chloro-2-( $\beta$-phenylethyl)phenol had limited solubility in dissopropylbenzene and extracted very little cesium. Two low polymers of

Table 7.3. Cesium Extraction by Substituted Phenols. Effects of Reagent Structure

5-min contact at $1: 1$ phase rat to

Diluent was disopropylbenzene except as noted

\begin{tabular}{|c|c|c|c|c|c|}
\hline \multirow{2}{*}{ Pheno1 } & \multirow{2}{*}{$M$} & \multicolumn{2}{|c|}{$0.01 M \mathrm{NaOH}$ Initral ${ }^{a}$} & \multicolumn{2}{|c|}{$0.1 M \mathrm{NaOH}$ Initial ${ }^{a}$} \\
\hline & & Final $\mathrm{pH}$ & $E_{\mathrm{a}}^{\circ}(\mathrm{Cs})$ & Final $\mathrm{pH}$ & $E_{\mathrm{a}}^{\mathrm{o}}(\mathrm{Cs})$ \\
\hline \multicolumn{6}{|l|}{ BAMBP: $4 \cdot$ sec-buty 1-2-(a-methy1- } \\
\hline benzy1)phenol & 1 & 11.5 & 1.8 & 12.8 & 20 \\
\hline 4-sec-butyl-2-benzylphenol & $0.5^{b}$ & $5.8(\mathrm{ppt})$ & 0.08 & $12.6(\mathrm{ppt})$ & 0.5 \\
\hline $4-(1,1,3,3-$ tetramethy 1 but y1 $) 2$-benzylphenol & $1^{c}$ & 11.8 & 0.5 & 12.9 & 1.2 \\
\hline $2,6-b_{1}$ s (a-methylbenzy 1 )-phenol & 1 & 11.7 & $<0.01$ & 12.9 & 0.05 \\
\hline Santophen-1: 4-ch1oro-2-benzylphenol & 1 & 10.2 & 0.6 & 11.7 & 15 \\
\hline 4-chloro-2-(a-methylbenzy1)phenol & 1 & 11.0 & 1.8 & 12.1 & 30 \\
\hline 4-ch 1oro-2-( $\beta$-phenylethy 1$)$ phenol & 0.5 & 11.2 & $<0.01$ & 12.4 & 0.02 \\
\hline Dimer of 4 -chloro-2-(a-hydroxyethy1)phenol & 0.5 & $9.6(\mathrm{ppt})$ & 0.6 & $11.7(\mathrm{ppt})$ & 100 \\
\hline Tetramer of 4-chloro-2-(a-hydroxyethy1)phenol & $<0.2$ & $8.9(p p t)$ & $>100$ & $10.3(\mathrm{ppt})$ & 100 \\
\hline
\end{tabular}

${ }^{a}$ Containing $10^{-4} M \mathrm{Cs}+{ }^{134} \mathrm{Cs}$ tracer, initial $\mathrm{pH} 11.9(0.01 \mathrm{M})$ and $12.9(0.01 \mathrm{M})$.

${ }^{b}$ Diluent DIPB $+3 \%$ tridecanol, corresponding $E_{a}^{o}(\mathrm{Cs})$ with BAMBP -0.3 and 1.6.

${ }^{c}$ Diluent xylene, corresponding $E_{a}^{\circ}(\mathrm{Cs})$ with BAMBP -0.7 and 7 . 
a closely related monomer, 4-chloro-2-( $\alpha$-hydroxyethyl)phenol, although of limited solubility and showing poor phase separation, gave very high cesium extraction coefficients. Further compounds of this nature will be sought for comparison. All those structures related to BAMBP (equivalent to omission of its $a$-methyl, to replacement of its $p$-sec-butyl with a p-tert-octyl, and to replacement of its $p$-sec-butyl with a second $o$-a-methylbenzyl) extracted less cesium than did BAMBP. Several miscellaneous phenolic compounds (bis-cresols and diphenyl ether derivatives) were insufficiently soluble in hydrocarbons for testing.

Commercial BAMBP was rectified in a Podbielniak column at $6 \mathrm{~mm}$ and $186^{\circ} \mathrm{C}$ for use in physicochemical studies. The nominal purity of the commercial BAMBP is $98+\%$, and the average neutral equivalent (by tetrabutylammonium hydroxide titration in pyridine) is consistent with that. Gas chromatography indicates several percent of slightly more volatile and slightly less volatile components in the starting material, decreased but not completely eliminated in the distillate. Cesium extraction coefficients were the same with starting material and distillate. These results indicate that the commercial BAMBP is of good quality but probably does contain some homologs or other compounds closely resembling BAMBP in chemical nature.

\subsection{DEVELOPMENT OF SEPARATIONS PROCESSES}

Processes are developed for specific separation and recovery applications, both where no practicable process yet exists and where existing processes are less than satisfactory. New processes are ordinarily devised on the basis of potential methods discovered in the descriptive studies (Sect. 7.1) and by extending the applications of previously developed processes. Where warranted, development is carried to the point that largescale performance can be predicted.

\section{Cesium Recovery from Ores}

The phenol extraction (Phenex) process, which was developed for recovering fission product cesium from reactor fuel processing wastes (Sect. 8.1 ), has continued to be successfully applied to the recovery of cesium from ores. The process provides a simple, continuous, and inexpensive method for preparing high-purity cesium compounds. Most of the studies were made with 4-sec-butyl2-( $\alpha$-methylbenzyl)phenol (BAMBP), and principal emphasis was on recovering cesium from pollucite ore, which is the most important source of cesium. Recent studies included further development of the alkaline-roast-water-leach method for dissolving cesium from pollucite ore and successful demonstrations of the solvent extraction process in bench-scale continuous runs.

Dissolution of Cesium from Pollucite Ore. Batch tests, aimed at optimizing the roast-leach process, showed that the $\mathrm{Na}_{2} \mathrm{CO}_{3}: \mathrm{NaCl}$ ratio in the flux and the roasting temperature and time can all be decreased below those used previously, ${ }^{20}$ without lowering cesium recoveries. Decreasing the $\mathrm{Na}_{2} \mathrm{CO}_{3}: \mathrm{NaCl}$ ratio has the advantages of decreasing the cost of the flux and also lowering the loss of the phenol extractant to the aqueous phase (because of the lower aqueous $\mathrm{pH}$; see below) in the subsequent extraction operation. Optimum recovery (better than 97\%) was obtained with a $\mathrm{Na}_{2} \mathrm{CO}_{3}: \mathrm{NaCl}$ weight ratio of about 0.5 (Fig. 7.11). With this flux composition, the roast temperature was not critical in the range 640 to $850^{\circ} \mathrm{C}$. In all these tests, the roast time was 2 $\mathrm{hr}$, and $25 \mathrm{ml}$ of water per gram of ore was used for leaching the calcine. In other tests, equivalent results were obtained with roast times as short as $0.5 \mathrm{hr}$ and with much smaller volumes of water in the leaching step.

Stripping of Cesium. - Since the substituted phenols are very weak acids and extract cesium only at high $\mathrm{pH}$ levels, they are easily stripped with dilute acid. Only a slight excess of acid over that equivalent to the extracted cesium need be supplied for complete stripping. The mineral acids, as well as organic acids, are useful stripping agents; therefore, the preparation of a wide variety of cesium compounds is possible. Also, by appropriate choice of acid concentration, the cesium can be concentrated by a large factor in the stripping cycle to give a concentrated product solution.

With $1 N$ acetic or oxalic acids, more than $95 \%$ of the cesium was stripped from $1 M$ BAMBP in kerosene (loaded with $18 \mathrm{~g}$ of cesium per liter)

\footnotetext{
${ }^{20}$ Chem. Technol. Div. Ann. Progr. Rept. May 31, 1963, ORNL-3452, p. 176.
} 


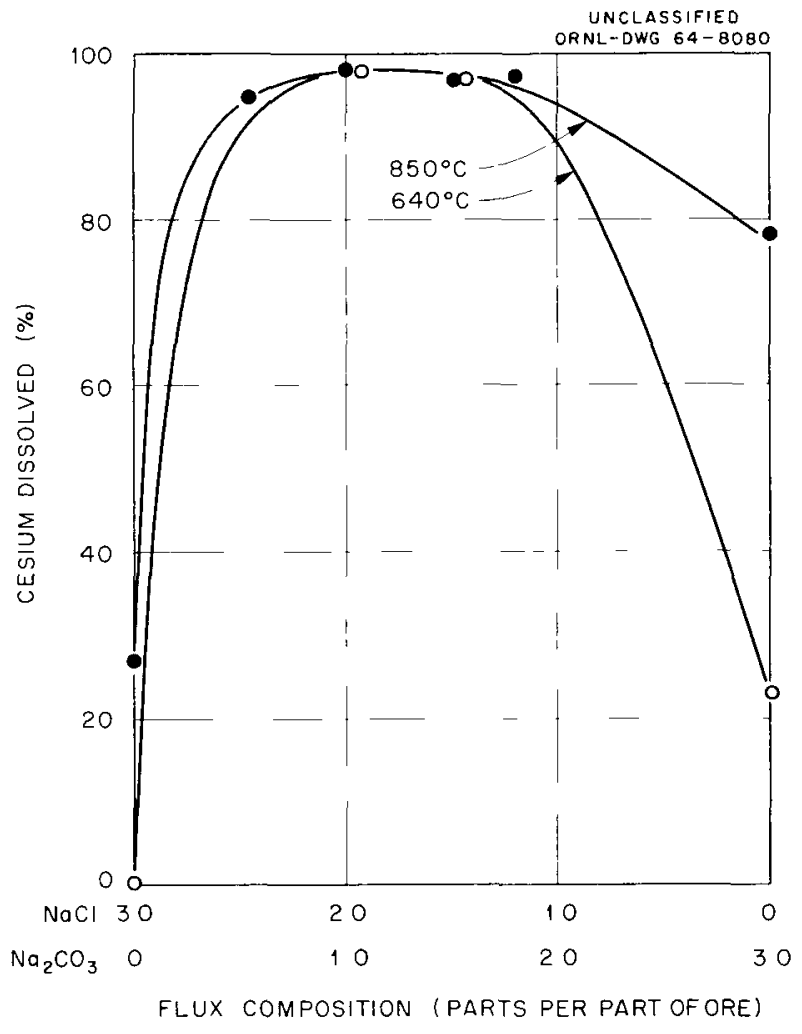

Fig. 7.11. Effect of Flux Composition and Roast Temperature on Cesium Dissolution. Procedure: -200 mesh pollucite ore roasted 2 hr with 3 times its weight of flux; leached with water.

in a single batch contact at an organic to aqueous ratio of 6:1. Highly effective stripping was also obtained with water plus carbon dioxide (carbonic acid) to give a cesium carbonate product.

Loss of BAMBP to the Aqueous Phase. - The distribution loss of BAMBP to the aqueous phase increases with increasing aqueous $\mathrm{pH}$ and decreasing sodium concentration (Fig. 7.12). With a solution of $1 M$ BAMBP in $n$-octane, and $\mathrm{NaCl}-\mathrm{NaOH}$ solutions $0.9 M$ in $\mathrm{Na}^{+}$, the concentrations of BAMBP in the aqueous phase were 0.03 and 0.38 $\mathrm{g} /$ liter at $\mathrm{pH}$ 's of 11.5 and 12.5 respectively. With $3.1 \mathrm{M} \mathrm{Na}^{+}$in the aqueous phase and these same $\mathrm{pH}$ 's, BAMBP concentrations in the aqueous were 0.007 and $0.08 \mathrm{~g} /$ liter respectively. These results indicate that, under expected flowsheet conditions $\left(3 \mathrm{M} \mathrm{Na}^{+}\right.$in raffinate at $\mathrm{pH}$ about 12.5$)$, the distribution loss of BAMBP should be lower than $0.1 \mathrm{~g}$ per liter of raffinate.
Continuous Runs. - The chemical and operational feasibilities of the process were confirmed in two continuous bench-scale mixer-settler runs with $1 M$ BAMBP in kerosene. In the first of these runs, more than $98 \%$ of the cesium was recovered from a pollucite ore leach liquor $(9.8 \mathrm{~g}$ of cesium per liter, $\mathrm{pH} 13.1$ ), prepared by the $\mathrm{Na}_{2} \mathrm{CO}_{3}-$ $\mathrm{NaCl}$ roast-water-leach method, using four extraction and three water-scrub stages. The extract was stripped with $4 \mathrm{M} \mathrm{HCl}$ to give a cesium chloride product solution containing $375 \mathrm{~g}$ of cesium per liter. Other constituents of the product solution, in grams per liter, were: $0.059 \mathrm{Rb}, 0.002 \mathrm{~K}$, $0.014 \mathrm{Na}$, less than $0.0005 \mathrm{Li}$, less than $0.002 \mathrm{Si}$, less than $0.005 \mathrm{Al}$, and $0.015 \mathrm{Fe}$.

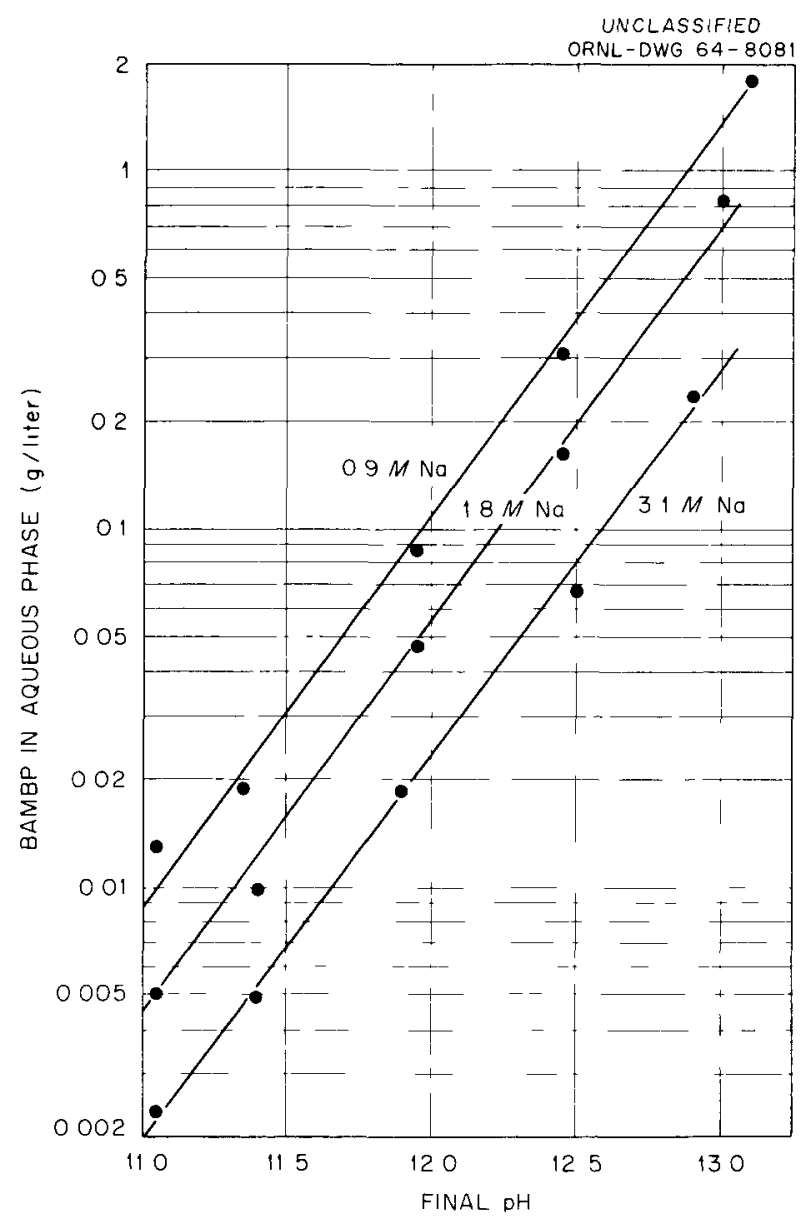

Fig. 7.12. Distribution Loss of BAMBP to the Aque ous Phase. Organic Phase: $1 M$ BAMBP in n-octane. Aque ous phase: $\mathrm{NaCl}-\mathrm{NaOH}$ solutions $0.9,1.8$, or $3.1 \mathrm{M}$ in total sodium. 
Flowsheet conditions for a second run, in which the carbonate stripping method was demonstrated, are shown in Fig. 7.13. The feed liquor for this run was prepared by roasting pollucite ore for $1 \mathrm{hr}$ at $750^{\circ} \mathrm{C}$ with 2 parts of $\mathrm{NaCl}$ and 1 part of $\mathrm{Na}_{2} \mathrm{CO}_{3}$ per part of ore and leaching with water. This treatment dissolved $97.5 \%$ of the cesium. More than $99 \%$ of the cesium was recovered in four stages of extraction and five stages of scrubbing with $0.01 M$ tartaric acid. Cesium was stripped from the extract in two carbonate (carbon dioxide plus water) stripping stages backed up by a single $\mathrm{HCl}$ stripping stage. Cesium stripping in the carbonate system was 90 to $95 \%$ complete, with the residual cesium being stripped quantitatively in the $\mathrm{HCl}$ system. Consumption of carbon dioxide and $\mathrm{HCl}$ were about 0.22 and $0.015 \mathrm{lb}$, respectively, per pound of cesium. In process practice, the cesium chloride product solution would probably be recycled to the extraction step. A white cesium carbonate product containing less than $0.008 \%$ combined alkali-metal impurities, and negligible amounts of other impurities, was obtained by evaporating the carbonate strip solution (about $160 \mathrm{~g}$ of cesium per liter) to dryness. Decontamination factors (feed liquor to strip product) for cesium were $3.6 \times 10^{2}$ from $\mathrm{Rb}$, better than $4 \times 10^{4}$ from K, $5 \times 10^{5}$ from Na, better than
$9.6 \times 10^{3}$ from $\mathrm{Li}, 5 \times 10^{2}$ from $\mathrm{Fe}$, more than $2.6 \times 10^{2}$ from $\mathrm{Al}$, and better than $3.7 \times 10^{4}$ from $\mathrm{Si}$.

Total reagent costs for the process, assuming use of the carbonate stripping method, are estimated at about $32 \$$ per pound of cesium recovered. About $65 \%$ of this cost is for the roasting chemicals and $25 \%$ is for loss of BAMBP.

\section{Beryllium Recovery from Ores}

A tentative solvent extraction process using primary amines has been outlined for recovering beryllium from sulfuric acid digests of low-grade beryllium ores. The increasing demand for beryllium (for high-temperature metal alloys, atomic reactor use, etc.) and the scarcity of high-grade ores has increased the need for processes capable of treating the low-grade domestic ores.

Effect of Amine and Diluent Choice. - Of the amines tested for their ability to extract beryllium from sulfate solutions, only the primary amines were useful, and Amine 21F81 [1-(3-ethylpentyl)-4-ethyloctylamine] was much more effective than other primary amines. For example, in extractions at $\mathrm{pH} 2.5$ with $0.3 \mathrm{M}$ solutions of various amines in Solvesso 100 (a high-boiling, aromatic,

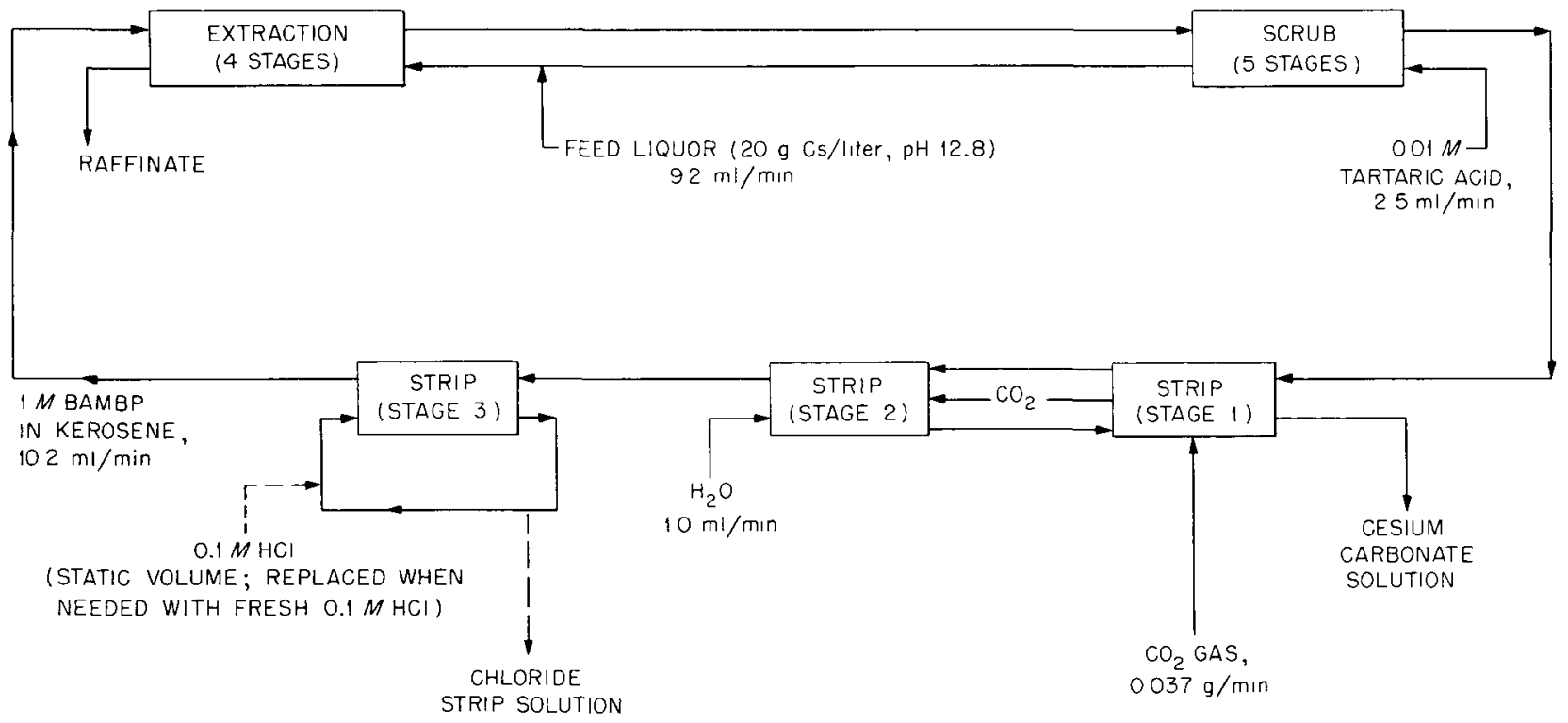

Fig. 7.13. Flowsheet Conditions for Continuous Cesium Recovery Run. Organic phase: $1 M$ BAMBP in kerosene. 
petroleum product), the extraction coefficients were $10,3.0,2.7$, and 0.5 , respectively, for Amine 21F 81, 1-nonyldecylamme, 1-heptyloctylamine, and Primene JM (Table 7.4). Adding a long-chain alcohol or tri-n-butyl phosphate (TBP) to Amine 21F81-Solvesso 100 depressed beryllium extractions. Beryllium extraction coefficients with this amine were slightly lower in kerosene or Amsco 125-82 diluents than in Solvesso 100. The highest coefficient, 21, was with carbon tetrachloride diluent.

Effect of pH and Confact Time. - In extractions with $0.3 M$ Amine $21 \mathrm{~F} 81$ in Solvesso 100 from 1.8 $M$ sulfate solution, the beryllium extraction coefficients were less than 1 at $\mathrm{a} \mathrm{pH}$ of 1 and increased with increasing $\mathrm{pH}$, reaching a maximum of about 17 in the $\mathrm{pH}$ range 3.5 to 4 ( $\mathrm{F}_{1}$ g. 7.14). In contrast to the very slow extractions of beryllium obtained with $\mathrm{d}_{1}$ (2-ethylhexyl)phosphoric acid (D EHPA), ${ }^{21,22}$ extractions with amines are rapid. Att a $\mathrm{pH}$ of 2 or below, extractions attained after contacts of $1 \mathrm{~min}$ were equivalent to those attained after $30 \mathrm{~m} ı \mathrm{n}$. At higher $\mathrm{pH}$ 's, more than $90 \%$ of the attanable extraction occurred within $1 \mathrm{~min}$, but there was a slow increase in the magnitude of the extraction coefficient up to contact times of $1 \mathrm{hr}$.

Effect of Other Extraction Variables. - Increasing the sulfate concentration from 0.2 to $2 M$ nearly doubled the beryllium extraction coefficients with Amine $21 \mathrm{~F} 81$. Also, increasing the temperature in the range 15 to $50^{\circ} \mathrm{C}$ increased the coeff 1 cients slightly. On the other hand, adding small concentrations of fluoride to the liquor drastically reduced extractions. In most systems, the beryllium

\footnotetext{
$21_{\text {Laird Crocker et al., Recovery of Beryllium from }}$ Spor Mountain, Utah Ore by Solvent Extraction and Caustic Stripping, U.S. Bureau of Mines Report RI6173 (1963).

${ }^{22}$ R. A. Wells, D. A. Everest, and A. A. North, Nuct Sc1. Eng. 17, 259-67 (October 1963).
}

Table 7.4. Effect of Amine and Diluent Choice on Beryllium Extraction

Organic phase: $\quad 0.3 M$ primary amine in indicated diluent (organic solutions were preequilibrated with $0.5 \mathrm{M} \mathrm{SO}_{4}{ }^{2-}$ solution, $\mathrm{pH} 2.5$, to minimize $\mathrm{pH}$ change during extraction).

Aqueous phase: $0.02 \mathrm{MBe},{ }^{7} \mathrm{Be}$ tracer, $1.8 \mathrm{M} \mathrm{SO}_{4}{ }^{2-}, \mathrm{pH} 2.5$.

Contact: $\quad 10 \mathrm{~min}$ at phase ratio of 1.1 .

\begin{tabular}{llc}
\hline \multicolumn{1}{c}{ Amine } & \multicolumn{1}{c}{ Diluent } & $\begin{array}{c}\text { Beryllium Extraction } \\
\text { Coefficient, } E_{a}^{\circ}\end{array}$ \\
\hline 1-Heptyloctylamine & Solvesso 100 & 2.7 \\
1-Nonyldecylamine & Solvesso 100 & 3.0 \\
Primene JM & Solvesso 100 & 0.5 \\
Amine 21F81 & Solvesso 100 & 10 \\
& Solvesso 100+5\% TDA ${ }^{a}$ & 4.7 \\
& Solvesso 100+5\% TBP & 6.5 \\
& Benzene & 9.8 \\
& Amsco 125-82 & 7.4 \\
& Kerosene & 8.6 \\
& Carbon tetrachloride & 0.3 \\
& Hexane & \\
\hline
\end{tabular}




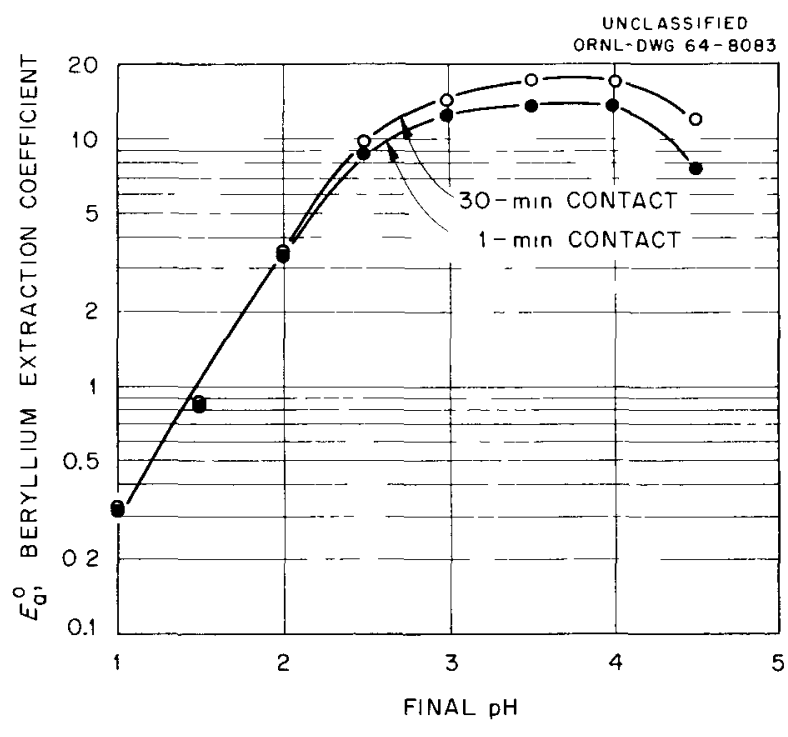

Fig. 7.14. Effect of $\mathrm{pH}$ and Contact Time on Beryllium Extraction with $0.3 M$ Amine 21F81. Aqueous phase: $0.02 M \mathrm{Be}, 1.8 \mathrm{M} \mathrm{SO}_{4}$. Phase ratio: $1 / 1$.

extraction coefficient was proportional to about the 0.7 power of the amine concentration.

Extractions from Synthetic Liquors. - All the extraction tests described above were from "pure" solutions, containing no metal contaminants except sodium. In extractions from synthetic leach liquors, beryllium extraction coefficients were much lower, due primarily to interference from aluminum. Although the aluminum extraction coefficients are low, its concentration in beryllium liquors is ordinarily sufficiently high to provide significant competition for the extractant. Ferric iron is extracted strongly, but its interference is prevented by reducing it to the ferrous state prior to extraction. Although fluoride interferes with beryllium extraction from "pure" solutions, its presence in leach liquors is desirable since it complexes aluminum in the aqueous phase and decreases the competition from aluminum. In tests with $0.3 \mathrm{M}$ Amine $21 \mathrm{~F} 81$ in Solvesso 100 and a synthetic leach liquor, beryllium extraction coefficients were 1.2 to 1.5 in the $\mathrm{pH}$ range 2 to 3 :
Final pH

1.5

2.0

2.5

3.0
Beryllium Extraction

Coefficient, $E_{a}^{\circ}$
The coefficients in this $\mathrm{pH}$ range, although low, are adequate for process use. The above tests were made at a phase ratio of $1: 1$ with a solution containing (in grams per liter) $0.5 \mathrm{Be}, 5 \mathrm{Al}, 0.5$ $\mathrm{Fe}(\mathrm{II}), 2.5 \mathrm{~F}$, and $96 \mathrm{SO}_{4}$.

In other tests with this synthetic liquor it was shown that most of the extracted aluminum can be displaced from the solvent by loading it to near saturation with beryllium. The maximum beryllium loading obtained from this solution with $0.3 \mathrm{M}$ Amine $21 \mathrm{~F} 81$ was about $0.4 \mathrm{~g} /$ liter. The separation from aluminum can be further increased by scrubbing the extract with dilute sulfuric acid.

Beryllium Stripping. - Although a number of reagents (including chloride or nitrate salt solutions, alkaline reagents, etc.) strip beryllium effectively, 0.5 to $1 \mathrm{M} \mathrm{H}_{2} \mathrm{SO}_{4}$ has been tentatively selected as the preferred stripping solution.

Batch Countercurrent Tests. - In batch countercurrent demonstrations of the process with $0.3 \mathrm{M}$ Amine $21 \mathrm{~F} 81$ in Solvesso $100,92 \%$ of the beryllium was recovered from a synthetic leach liquor $(\mathrm{pH}$ 2.9 , analysis given above) in six extraction and four scrub stages; the organic/aqueous feed/scrub ratio was $10 / 7.6 / 2.5$. Beryllium extraction coefficients ranged from 0.9 in the feed stage to 1.6 in the last extraction stage. Beryllium was stripped from the scrubbed extract with $1 \mathrm{M} \mathrm{H}_{2} \mathrm{SO}_{4}$, precipitated with $\mathrm{NH}_{4} \mathrm{OH}$, and the precipitate was reslurried with dilute caustic $(\mathrm{pH} 12.5)$ to increase the separation from aluminum. The product contained about $0.3 \% \mathrm{Al}$, based on the beryllium content.

Another demonstration run was made with an actual leach liquor supplied through the courtesy of the Salt Lake City Station of the U.S. Bureau of Mines. The liquor was prepared by sulfuric acid leaching of Spor Mountain, Utah, ore and contained (in grams per liter): $0.65 \mathrm{Be}, 4.0 \mathrm{~A} 1,2.3 \mathrm{Fe}, 16 \mathrm{~F}$, and $110 \mathrm{SO}_{4}$. Coefficients for extraction of beryllium from this liquor were appreciably lower than from the synthetic liquor, possibly due to its higher fluoride content and the presence of certain additional contaminants, for example, calcium. However, effective recovery of beryllium was obtained by operating at a higher organic/aqueous flow ratio. The recovery was about $96 \%$ complete in six extraction and two scrub stages with organic/ aqueous feed/scrub ratios of 20/5/3. Analyses of the product are not complete. 


\section{Thorium Recovery from Granitic Rocks}

As described previously, granitic rocks are being evaluated as a future source for large tonnages of thorium which eventually will be needed for power reactor systems. After tests of a large variety of granitic rocks from different locations, ${ }^{23-26}$ principal interest has centered on the Conway granite formations in New Hampshire. These granite formations are especially attractive, due to their relatively high thorium content and good response to process treatment.

Drill-Core Samples of Conway Granite. - In the past year, the three holes that were drilled in the Conway granite formations in 1962 were extended from their original depths of 500 to $600 \mathrm{ft}$ to 1000 to $1050 \mathrm{ft}$ (as part of the U.S. Upper Mantle Project). Investigators at Rice University (under subcontract to ORNL) have completed gamma-ray spectrometric analyses of two of the deeper cores. These data are shown in Table 7.5 along with data reported previously ${ }^{25}$ for the more-shallow core samples. The thorium concentration in the Kanca core decreased slowly with depth over the first $400 \mathrm{ft}$ (average thorium content $=48 \mathrm{ppm}$ ) and then increased as the depth was extended from 500 to $1010 \mathrm{ft}$ (average thorium content $=62 \mathrm{ppm}$ ). For the Mad River core, the concentration varied only in the range of 63 to $73 \mathrm{ppm}$ (averaging 67 $\mathrm{ppm}$ ) for rock from the first $500 \mathrm{ft}$ and from 900 to $1050 \mathrm{ft}$. The middle sections of the core $(500$ to $900 \mathrm{ft}$ ) showed significantly lower thorium concentrations (average thorium content - $55 \mathrm{ppm}$ ). The average thorium concentrations for the total cores were 56 and $63 \mathrm{ppm}$ for the Kanca and Mad River cores, respectively, which is in good agreement with the average concentration of $56 \pm 6 \mathrm{ppm}$ for the entire formation, ${ }^{24}$ calculated on the basis of surface samples.

Processing of Conway Granite. - In acid leaching tests (6-hr leach with $2 \mathrm{~N} \mathrm{H}_{2} \mathrm{SO}_{4}$ at room temperature and $60 \%$ pulp density) of drill-core samples, the average thorium recovery from Kanca

${ }^{23}$ Chem. Technol. Div. Ann. Progr. Rept. May 31, 1961, ORNL-3153, p. 102.

${ }^{24}$ Chem. Technol. Div. Ann. Progr. Rept. June 30, 1962, ORNL-3314, p. 182.

${ }^{25}$ Chem. Technol. Div. Ann. Progr. Rept. May 31, 1963, ORNL-3452, p. 196.

${ }^{26} \mathrm{H}$. Brown and L. T. Silver, Proc. Intern. Conf. Peaceful Uses At. Enerǵy, Geneva, 1955 8, 129 (1956). core samples taken at depths of 700 to $1000 \mathrm{ft}$ was about $70 \%$, or about the same as was obtained previously $^{25}$ from rock taken at 0 to $600 \mathrm{ft}$. The process amenability of Mad River core samples taken at the 700 - to $800-\mathrm{ft}$ level was relatively poor, thorium recoveries being only about $45 \%$ complete. By comparison, recoveries were about $67 \%$ complete from rock taken at 0 to $500 \mathrm{ft}$ or at $1000 \mathrm{ft}$.

Table 7.5. Thorium and Uranium Content of Drill.Core Samples

\begin{tabular}{|c|c|c|}
\hline \multirow{2}{*}{$\begin{array}{l}\text { Depth } \\
(\mathrm{ft})\end{array}$} & \multicolumn{2}{|c|}{ Average Concentration ${ }^{a}(\mathrm{ppm})$} \\
\hline & Thorıum & Uranium \\
\hline \multicolumn{3}{|c|}{ Kanca Core } \\
\hline $0-100$ & 52 & $15^{b}$ \\
\hline $100-200$ & 49 & $16^{b}$ \\
\hline $200-300$ & 48 & $16^{b}$ \\
\hline $300-400$ & 44 & $15^{b}$ \\
\hline $400-500$ & 53 & $19^{b}$ \\
\hline $500-600$ & 64 & $20^{b}$ \\
\hline $600-700$ & 60 & 17 \\
\hline $700-800$ & 60 & 16 \\
\hline $800-900$ & 66 & 19 \\
\hline $900-1010$ & 69 & 20 \\
\hline \multicolumn{3}{|c|}{ Mad River Core } \\
\hline $0-100$ & 66 & $16^{b}$ \\
\hline $100-200$ & 67 & $17^{b}$ \\
\hline $200-300$ & 73 & $17^{b}$ \\
\hline $300-400$ & 63 & $18^{b}$ \\
\hline $400-500$ & 66 & $21^{b}$ \\
\hline $500-600$ & 59 & 15 \\
\hline $600-700$ & 53 & 17 \\
\hline $700-800$ & 55 & 16 \\
\hline $800-900$ & 54 & 18 \\
\hline $900-1000$ & 64 & 19 \\
\hline $1000-1050$ & 73 & 19 \\
\hline
\end{tabular}

\footnotetext{
${ }^{a}$ Gammawspectrometric analyses at Rice University.
}

${ }^{b}$ Chemical analyses at ORNL. 
Grinding of Conway granite to -20 mesh is adequate for effective leaching of thorium. Thorium recoveries from a Redstone-quarry sample were nearly the same (84 to $86 \%$ ) from -20 -mesh as from -200-mesh material (Table 7.6). For grinds coarser than -20 mesh, recoveries dropped off slowly with increase in particle size but were still good (78\%) even from - 4-mesh material.

Reserves of Thorium and Uranium. - Based on the surface and drill-core data, the reserves of thorium in the outer $1000 \mathrm{ft}$ of the main Conway formations are estimated at 35 million tons. Although less information is available on the uranium content of these formations, it apparently is equal to a fourth to a third of the thorium content, or 8 to 12 million tons. About two-thirds of these thorium and uranium reserves, or about 24 and 5 to 8 million tons, respectively, are recoverable by ordinary processing techniques.

\section{Biochemical Separations}

A new program has been initiated, in cooperation with the Biology Division, to recover and separate the transfer ribonucleic acids ( $t$-RNA's) from Escherichia coli bacteria. The transfer ribonucleic acids are intermediates in the synthesis of proteins from $\alpha$-amino acids. The $E$. coli bacteria were chosen as a source because they can be

Table 7.6. Effect of Fineness of $G$ rind on Thorium Recovery from Conway Granite

Leaching procedure: Ore leached with $2 \mathrm{~N} \mathrm{H}_{2} \mathrm{SO}_{4}$ (130 lb of $\mathrm{H}_{2} \mathrm{SO}_{4}$ per ton of ore) for 6 hr at $25^{\circ} \mathrm{C}$

Grind Size of Ore

Thorium Recovery (\%) grown easily and there is much information available concerning them.

In order to form viable proteins, amino acids must be joined, through the formation of peptide bonds, in a highly specific sequence. About 18 amino acids are utilized in the formation of proteins. The information controlling this synthesis is contained in the nucleic acids and is believed to be expressed in their chemical composition. The deoxyribonucleic acid (DNA) in the cell nucleus directs the formation of other ribonucleic acids (RNA's) in the cytoplasm. One species of these, the $t$-RNA's, combine with the amino acids and transport them to the ribosome, the site of protein synthesis. There is at least one type of $t$-RNA for each amino acid, and possibly more than one in some cases, thus giving a total of 25 to $40 \mathrm{t}$-RNA's, differing only slightly in chemical and physical properties. The information directing the function of the nucleic acids is thought to be "coded" by the sequence of organic bases (adenine, guanine, cytosine, uracil, and "rare" bases in $t$-RNA) attached to the RNA chains. Each $t$-RNA thus must have two coded "sites," one which recognizes the proper amino acid and the other which interacts at the ribosome to give the correct amino acid sequence. It is postulated that the specific $t$-RNA's are identical, regardless of the source, thus implying a universal code. However, pure $t$-RNA's have not been obtained in significant quantities.

It is the object of this program to develop methods for obtaining a purified mixture of the $t$-RNA from $E$. coli and for subsequently fractionating this into the individual $t$-RNA species. Multigram quantities are needed for the determination of the base sequence by chemical analysis, for physical-chemical investigations of the molecular weight and secondary structure by techniques such as Debye light scattering, and to make available samples of the specific $t$-RNA's for biochemical and biological experiments. Successful completion of even a portion of this program would provide a definitive test of the base-sequence concept of information coding and of the universality of the code.

The following sequence of operation has been developed for the recovery of $t$-RNA:

1. The bacteria are "broken" in a mixture (unstable emulsion) of $88 \%$ phenol and aqueous buffer. Nucleic acids dissolve in the aqueous 
phase, while most of the other cell constituents dissolve in the phenol or are insoluble.

2. The nucleic acid mixture obtained from the separated aqueous phase is fractionated in an aqueous sodium acetate-isopropanol mixture to selectively precipitate most of the DNA.

3. The resulting RNA mixture is loaded on a DEAE-cellulose column, and the $t$-RNA is recovered by elution with $0.65 \mathrm{M} \mathrm{NaCl}$.

4. Finally, the bound amino acids are discharged by a basic digestion, and the resulting purified $t$-RNA is stored as an aqueous solution.

The overall recovery and purity of two $t$-RNA products prepared here and one obtained from a commercial source are shown in Table 7.7. Purity was determined by ${ }^{14} \mathrm{C}$ amino acid incorporation. Considerable variation in product purity and in overall recovery was experienced. It is evident that additional knowledge of the effect of process variables, starting with the bacteria growth step and involving all chemical recovery steps, would be desirable.

Preliminary experiments are under way to design a liquid ion exchange system, applicable to reversephase column chromatography techniques, for the separation of the specific $t$-RNA's. Quaternary ammonium compounds in oxygenated diluents such as alcohols, ethers, and acetates are being screened. Extraction of $t$-RNA into organic phases such as $0.1 M$ dimethyldilaurylammonium chloride in amyl acetate from $0.33 \mathrm{M} \mathrm{NaCl}$ solutions and subsequent stripping of the $t$-RNA into $0.40 \mathrm{M}$ $\mathrm{NaCl}$ has been demonstrated. Chromatography experiments are under way to investigate the partition of specific $t$-RNA's.

Table 7.7. Recovery and Purity of Transfer Ribonucleic Acid

\begin{tabular}{lccc}
\hline & $1-90$ & $1-131$ & Commercial \\
\hline $\begin{array}{l}\text { Recovery, milligrams of } t_{-} \\
\text {RNA per gram of bacteria }\end{array}$ & 1.85 & 0.85 & \\
Leu cine incorporation $^{a}$ & 106 & 58 & 56 \\
Isoleucine incorporation $^{a}$ & 62 & 31 & 28 \\
Valine incorporation $^{a}$ & 65 & 49 & 51 \\
\hline
\end{tabular}

\footnotetext{
${ }^{a}$ Micromicromoles of amino acid incorporated per optical-density unit of the $t$-RNA.
}

\subsection{FUNDAMENTAL STUDIES ON THE EQUILIBRIA AND KINETICS OF SOLVENT EXTRACTION}

This program encompasses a group of fundamental investigations aimed at increasing the understanding of both the equilibria and the mechanisms of separations systems, and in such a way as to improve, extend, or define the limits of their process, analytical, and physicochemical uses. Current studies are concentrated almost entirely on solvent extraction systems - emphasizing amines, dialkylphosphoric acids, and synergistic combinations - together with some utilization of solvent extraction in studying the physical chemistry of aqueous solutions.

\section{Extraction of Alkaline Earths and Alkali Metals by $\mathrm{Di}(2$-ethylhexyl)phosphoric Acid}

The experimental investigation of the extraction of sodium and strontium by di(2-ethylhexyl)phosphoric acid (HDEHP or HA) and by mixtures of this acid with its sodium salt (HDEHP + $\mathrm{NaDEHP}$ or HA $+\mathrm{NaA}$ ) in benzene is complete, and its interpretation is nearly complete. The reagent and hydrogen-ion dependences in two aqueous systems, $0.5 \mathrm{M}$ and $4.00 \mathrm{M} \mathrm{NaNO}{ }_{3}$, are summarized in Fig. 7.15. The reactions for sodium and strontium extraction when nearly all the extractant is in the acid form (HA), producing the extract species $\mathrm{NaA} \cdot 3 \mathrm{HA}$ and $\mathrm{SrA}_{2} \cdot 4 \mathrm{HA}$, were reported previously. ${ }^{27}$ The generalized equation:

$$
\begin{aligned}
\mathrm{M}^{+\nu}+n / y(a \mathrm{HA} \cdot b \mathrm{NaA})_{y} \rightleftharpoons & \mathrm{MA}_{\nu}(n-\nu) \\
& (\alpha \mathrm{HA} \cdot \beta \mathrm{NaA})+1 \mathrm{H}^{+}+j \mathrm{Na}^{+}, \\
a+b= & 1, \alpha+\beta=1, i+j=\nu,
\end{aligned}
$$

has been found useful in extending the interpretation of both sodium and strontium extraction to systems containing various proportions of the salt NaA. The parameters $i, j$, and $n$ have been sought as a function of $b$, the proportion of salt in the extractant $(\mathrm{NaA} / \Sigma \mathrm{A})$. The value of $y$ as a function of $b$ has been measured separately. ${ }^{28}$

\footnotetext{
${ }^{27}$ Chem. Technol. Div. Ann. Progr. Rept. May 31 , 1963, ORNL-3452, p. 182; also W. J. McDowell and C. F. Coleman, J. Inorg. Nucl. Chem. 25, 234 (1963).

${ }^{28}$ A. L. Myers, W. J. McDowe11, and C. F. Coleman, J. Inorg. Nucl. Chem. (in press).
} 


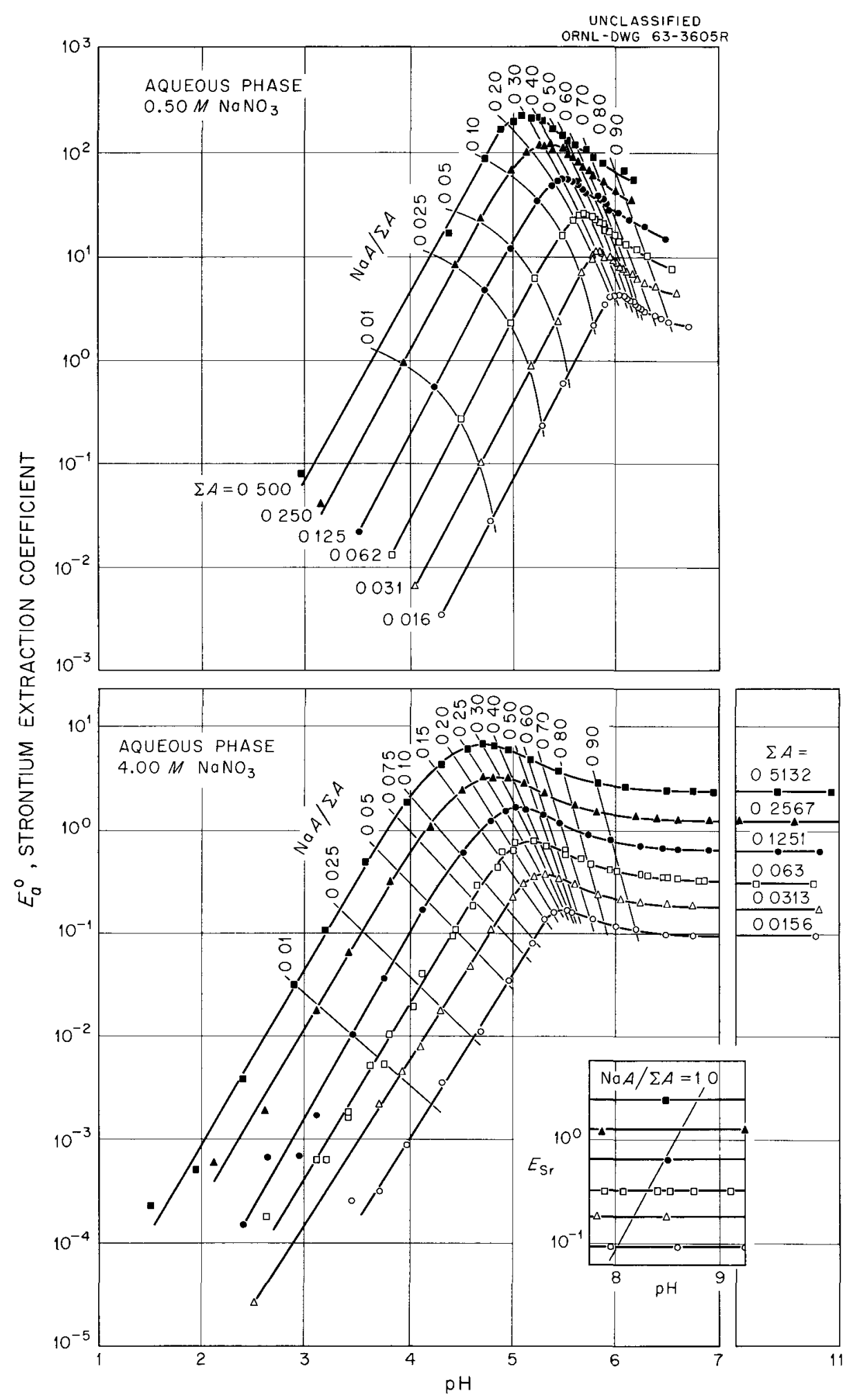

Fig. 7.15. Extraction of Strontium from Sodium Nitrate Solutions by NaDEHP-HDEHP in Benzene. Heavy lines:

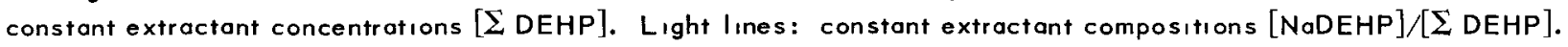


Alternative evaluations of $i$ and $j$ for strontium extraction are compared in Fig. 7.16. The dashed lines show the values to be expected if $\mathrm{SrA}_{2} \cdot 4 \mathrm{HA}$ were the only extract species produced throughout the range from acid-form to salt-form extractant; $i$ would be positive at extractant compositions $b$ $<1 / 3$, and then would become negative at $b>1 / 3$ since hydrogen ion would have to be extracted along with strontium to form $\operatorname{SrA}$.4HA. The experimental values of $i$ follow closely along this line at extractant compositions up to $b=0.4$ or 0.5 , then level off, showing that one or more new strontium species not containing hydrogen have become important in the extract. The values of $j$ conform to those of $i$, although with large uncertainties due to the geometric magnification of errors in individual graphical analyses.

Using the experimental values of $i$ shown in Fig. 7.16 for strontium extraction, and the value of $i=1$ for sodium extraction, allowed graphical determination of $n / y$ from the slope of $E_{M}\left[\mathrm{H}^{+}\right]^{i}$

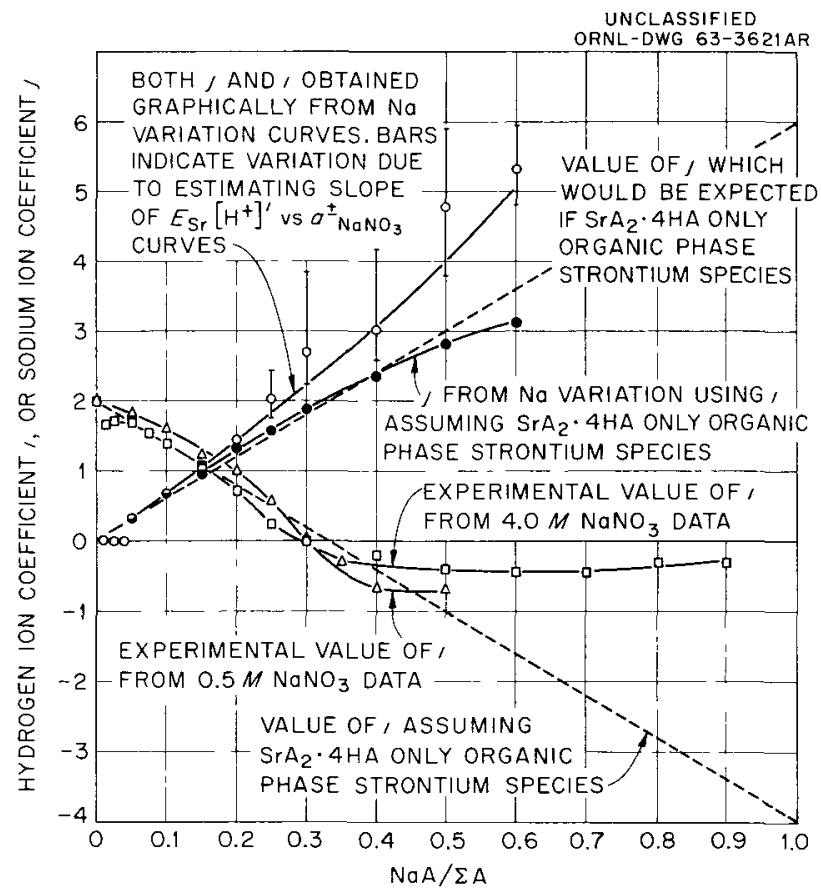

Fig. 7.16. Sodium and Hydrogen Concentration Dependence in Strontium Extraction by DEHP. Hydrogen ion coefficient $i$ and sodium ion coefficient $j$ as defined in Eq. (1), evaluated graphically from extraction curves at various aqueous sodium nitrate concentrations (e.g., Fig. 7.15); 0.125 $M$ DEHP in benzene.

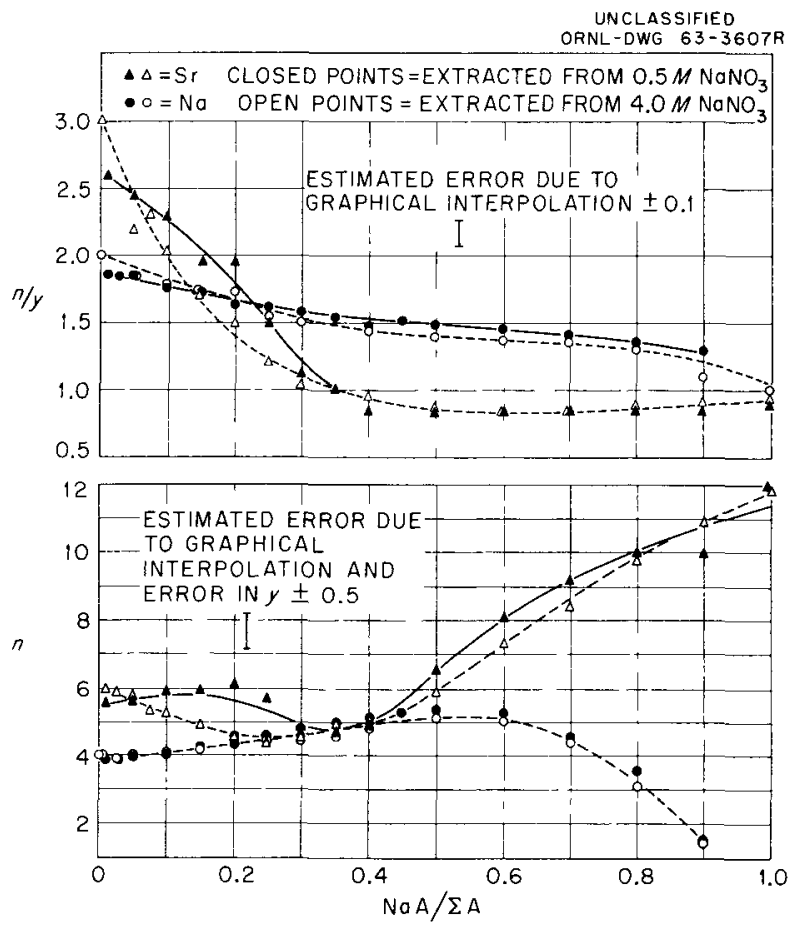

Fig. 7.17. Extractant Concentration Dependences for Sodium and Strontium Extraction by DEHP in Benzene. Extractant coefficient $n / y$ and combining ratio $n$ as defined in Eq. (1).

vs $\Sigma A$ at various constant $b$ values (Fig. 7.17). Applying the value of $y$ (average degree of total phosphate polymerization) in the case of strontium and the value of ay (average degree of acid polymerization) in the case of sodium allowed the calculation of their respective $n$ values, shown in Fig. 7.17. Within experimental variation the value of $n$ for sodium follows the expected trend (i.e., 4 at extractant compositions up to $\mathrm{NaA} / \Sigma \mathrm{A}=0.25$ and then decreasing to a limit of 1 ) over the entire extractant composition range. For strontium, the value of $n$ is in the range 5 to 6 , in agreement with the value of 6 indicated by acid-form reagent dependence studies, up to $\mathrm{NaA} / \Sigma \mathrm{A}=0.5$. The increase in $n$ for strontium extraction at $\mathrm{NaA} / \Sigma \mathrm{A}$ $>0.5$ probably means that the extracted strontium is associating with $\mathrm{NaA}$, either as a specific compound analogous to $\mathrm{SrA} \cdot 4 \mathrm{HA}$ or (more likely) by incorporation into $\mathrm{NaDEHP}$ aggregates.

The foregoing correlations required that hydrogenion concentrations in the aqueous solutions be obtainable from $\mathrm{pH}$ measurements. Experimental 
demonstration was previously reported ${ }^{29}$ of proportionality between the hydrogen-ion concentration and the apparent $\mathrm{pH}$ as measured by glass electrode in $4 M \mathrm{NaNO}_{3}$ solution, "pH" $+0.6=$ $-\log \left[\mathrm{H}^{+}\right]$, in the $\mathrm{pH}$ ranges $<4$ and $>7$, but residual volume errors were magnified too much in the intermediate region 4 to 7 for the direct measurements to be significant. The same proportionality has now been demonstrated through this intermediate region by direct comparison of the potential of the glass electrode with that of a quinhydrone electrode. The potential of the quinhydrone electrode is known to reflect the hydrogen-ion activity accurately at $\mathrm{pH}$ levels up to about 8 (ref. 30). The experimental comparison showed glass-electrode $\mathrm{pH}$ closely proportional to that of the quinhydrone electrode from $\mathrm{pH} 3$ to $\mathrm{pH} 8$ in the $4 M \mathrm{NaNO}_{3}$, hence proportional to $-\log a_{H_{+}}$and (since the activity coefficient should be nearly constant in this $\mathrm{pH}$ region at such high ionic strength) to $-\log \left[\mathrm{H}^{+}\right]$. Since these results overlapped the previous direct measurements, the same proportionality constant was also demonstrated, " $\mathrm{pH} "+0.6=-\log \left[\mathrm{H}^{+}\right]$.

The relative extractabilities of $\mathrm{Mg}, \mathrm{Ca}, \mathrm{Sr}$, and Ba by HDEHP were measured by simultaneous extraction from aqueous nitrate-hydroxide solutions initially containing each of the alkaline-earth ions at a concentration of $0.1 \mathrm{M}$. The amount of hydroxide initially present controlled the total amount of metal ion extracted by controlling the amount of hydrogen ion removed from the extractant in exchange and was adjusted to give from 10 to $100 \%$ metal-hydrogen exchange. The results with $0.1 M$ HDEHP in benzene are shown in Fig. 7.18 as ratios of the magnesium, calcium, and strontium extraction coefficients to that of barium, $E_{\mathrm{M}} / E_{\mathrm{Ba}}=\left[\mathrm{M}^{2+}\right]_{\text {org }}\left[\mathrm{Ba}^{2+}\right]_{a q} /\left[\mathrm{M}^{2+}\right]_{a q}\left[\mathrm{Ba}^{2+}\right]_{\text {org }}$. The differences in extractability are greatest at low loading: $\mathrm{Ca}>\mathrm{Mg}>\mathrm{Sr}>\mathrm{Ba}$. (This order is the opposite of the order for cation exchange with the usual resins. Alkali-ion selectivity by HDEHP, $\mathrm{Li}>\mathrm{Na}>(\mathrm{K}, \mathrm{Cs})$, is also opposite to the order shown by usual resinous cation exchangers. ${ }^{31}$ ) At higher loading, the order of strontium and barium

\footnotetext{
${ }^{29}$ Chem. Technol. Div. Ann. Progr. Rept. June 30, 1962, ORNL-3314, p. 112.

${ }^{30}$ S. Glasstone, Textbook of Physical Chemistry, 2d ed., p. 995, Van Nostrand, New York, 1946.

${ }^{31}$ Chem. Techno1. Div. Ann. Progr. Rept. June 30, 1962, ORNL-3314, p. 114.
}

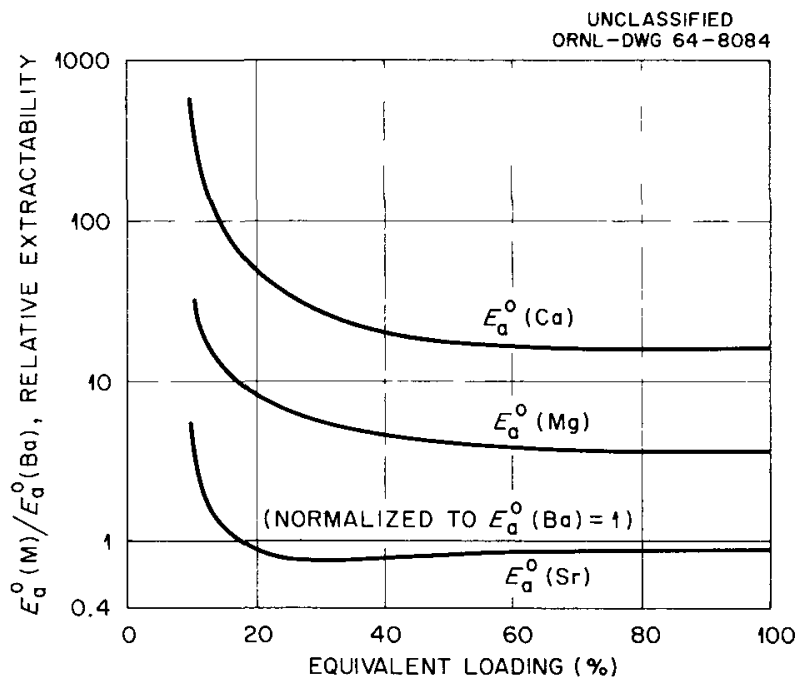

Fig. 7.18. Extraction of Alkaline Earths by $0.1 \mathrm{M}$ Di(2-ethylhexyl)phosphoric Acid in Benzene. Extraction coefficients of $\mathrm{Mg}, \mathrm{Ca}_{0}$, and $\mathrm{S}_{r}$ relative to extraction coefficient of $\mathrm{Ba}$ normalized to 1 , in extraction from 0.8 $N\left(\mathrm{NO}_{3}^{-}+\mathrm{OH}^{-}\right)$solutions, vs equivalent percent loading $=200\left[\Sigma \mathrm{MA}_{2}\right] /\left([\mathrm{HA}]+2\left[\Sigma \mathrm{MA}_{2}\right]\right)$.

was reversed. Results were similar at lower HDEHP concentrations, except that at $0.05 M$ the greatest differences in extractability appeared nearer to $15 \%$ than to $10 \%$ loading, and at $0.01 \mathrm{M}$, between 15 and $20 \%$ loading.

\section{Use of Dielectric Measurements in the Study of Interactions Between Extraction Components}

In the study of the synergistic extraction of strontium by the mixed extractants acid or sodium di(2-ethylhexyl)phosphate (HDEHP or NaDEHP) plus tri-n-butyl phosphate (TBP), the equilibria indicate some competition between the formation of the mixed strontium complex and the association of the HDEHP or NaDEHP with TBP. Either of the latter would be expected to interfere with the extraction of strontium. Baker and Baes ${ }^{32}$ found molecular-compound formation in mixed solutions of HDEHP and tri-n-octylphosphine oxide (TOPO) by means of infrared absorption. By analogy, TBP might be expected to form a similar, though

\footnotetext{
${ }^{32}$ H. T. Baker and C. F. Baes, Jr., J. Inorg. Nucl. Chem. 24, 1277-86 (1962).
} 
probably somewhat weaker, compound. They were not able to determine this interaction, however, because the expected peak from the intermolecular compound (about $1250 \mathrm{~cm}^{-1}$ ) occurred at the same place as the sum of the peaks (1230 and 1270 $\mathrm{cm}^{-1}$ ) of the two separate phosphate species.

The existence or absence of intermolecular bonding of TBP with HDEHP, TOPO with HDEHP, and TBP with the complex sodium salt NaDEHP-3HDEHP has been examined qualitatively by measurement of the dielectric constant of $n$-octane solutions of these mixtures, at constant total reagent concentration, as a function of varying composition. In addition, the molar polarizations of several phosphate species in $n$-octane have been determined.

For dilute solutions of polar solvents where the mole fraction and polarizability of the solvent remain almost unchanged from that of pure solvent, the dielectric constant of the solution may be written:

$$
\epsilon_{1 s}=\epsilon_{s}+\alpha_{1} x_{1}
$$

where $\epsilon_{\mathrm{s}}$ is the dielectric constant of the solvent, and $\alpha_{1}$ and $x_{1}$ are the polarizability and mole fraction of a given solute. When two such dilute solutions are mixed, the dielectric constant of the mixture is

$$
\begin{aligned}
\epsilon_{m}=\epsilon_{s}+\alpha_{1 m} x_{1}+\alpha_{2 m} x_{2} & \\
=\epsilon_{s}+\alpha_{1 m}\left(x_{1}+x_{2}\right) & +\left[x_{1}\left(\alpha_{2 m}-\alpha_{1 m}\right)\right. \\
& \left.+x_{2}\left(\alpha_{2 m}-\alpha_{1 m}\right)\right] \frac{x_{2}}{x_{1}+x_{2}} .
\end{aligned}
$$

Here, $\alpha_{1 m}$ and $\alpha_{2 m}$ are the polarizabilities of the two solutes in the mixture. They should be the same as $a_{1}$ and $a_{2}$ when there is no interaction between the solutes, so that a plot of $\epsilon_{m}$ vs $x_{2} /\left(x_{1}+x_{2}\right)$ should be linear. When there is intermolecular bonding, $\alpha_{1 \mathrm{~m}}$ and $\alpha_{2 \mathrm{~m}}$ will $\mathrm{d}_{1}$ ffer from $\alpha_{1}$ and $\alpha_{2}$, and it is unlikely that they would happen to vary so as to produce a fortuitous linear relation between $\epsilon_{m}$ and $x_{2} /\left(x_{1}+x_{2}\right)$ for all compositions. Hence, when there is intermolecular bonding, the plot of $\epsilon_{m}$ vs $x_{2} /\left(x_{1}+x_{2}\right)$ should be curved. Such plots (Fig. 7.19) show curvatures for the HDEHP-TOPO mixtures, as already expected from the work cited, and for the NaDEHP.3HDEHP-

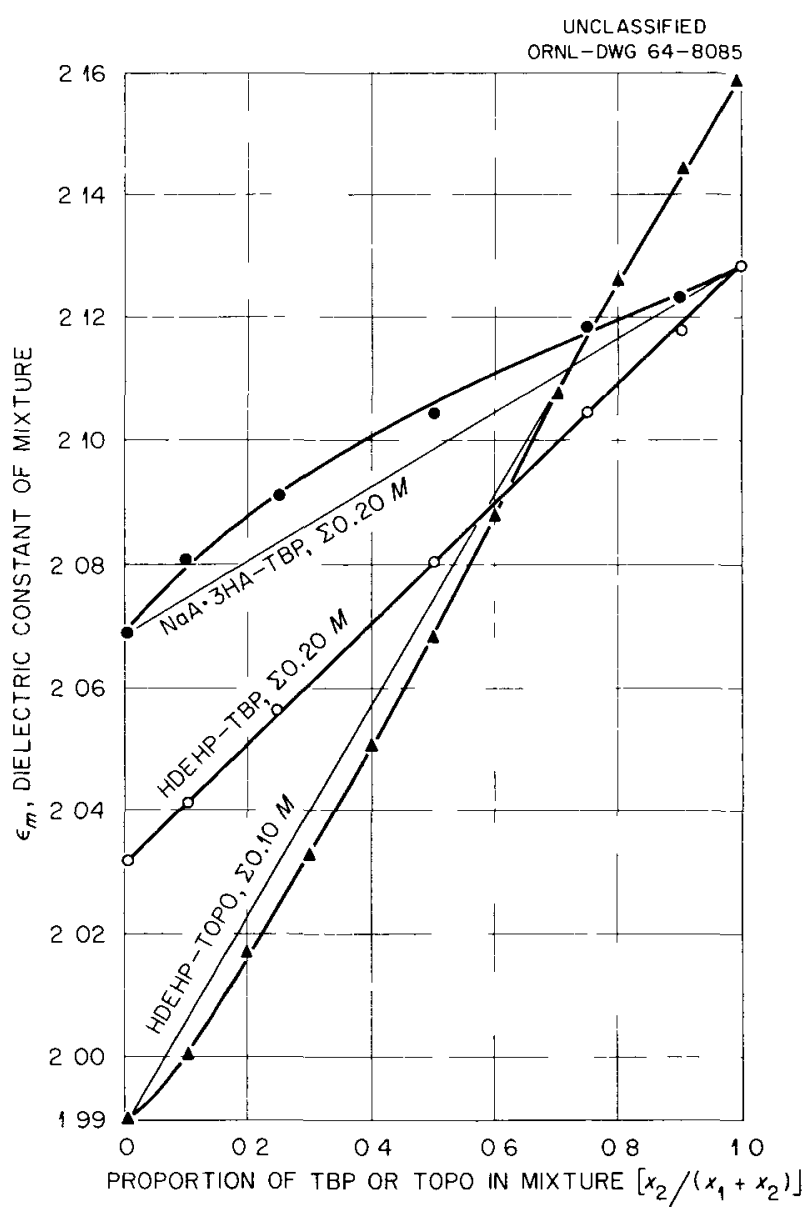

Fig. 7.19. Dielectric Constants of Phosphate Extractant Species Mixtures in n-Octane.

TBP mixtures, but not for the HDEHP-TBP mixtures, indicating little or no intermolecular association between HDEHP and TBP in the n-octane solutions. The results shown have been further corroborated by linear variation of $\epsilon_{\text {vs }}$ [HDEHP] at constant [TBP] and of $\epsilon_{m}$ vs $[\mathrm{TBP}]$ at constant [HDEHP].

In addition to the measurements at constant total phosphorus concentration, the dielectric constants of TBP, TOPO, (HDEHP), NaDEHP.3HDEHP, and $\operatorname{Sr}(\mathrm{DEHP})_{2}$ solutions in $n$-octane were determined over a range of concentrations. There were no discontinuities or inflections. Plots of $\epsilon$ vs concentration were linear except for very small deviations at the highest concentrations, 0.5 to $1.0 \mathrm{M}$, such as are generally attributed to increased solute dipole interaction. Molar polarizations were 
calculated by the method of Guggenheim. Values compared at 0.10 mole of the stated dipole per liter are as follows:

$\begin{array}{cccccc}\text { Dipole: } & \text { TBP } & \text { TOPO } & \text { (HDEHP) } & \text { NaDEHP.3HDEHP } & \operatorname{Sr}_{2}(\mathrm{DEHP})_{2} \\ \frac{\text { Debye units }}{\text { Formula weight }} & 28 & 4.5 & 2.7 & 4.4 & 12.8 \\ \frac{\text { Debye units }}{\text { Moles of phosphorus }} & 28 & 4.5 & 1.3 & 1.1 & 6.4\end{array}$

The high value for $\operatorname{Sr}(\mathrm{DEHP})_{2}$ probably results from polymerization of that salt in the hydrocarbon solution.

\section{Extraction of Alkali Metals by Substituted Phenols}

The high extraction power and selectivity of substituted phenols for cesium (see Phenex process, Sects. 7.2 and 8.1 ) prompted a detailed investigation of the extraction equilibria. The extractant 4-sec-butyl-2-( $\alpha$-methylbenzyl)-phenol (BAMBP) was chosen for detailed study because it shows high cesium extraction power, good physical performance, and low loss to aqueous solutions. ${ }^{33}$ Various diluents were used, particularly $n$-octane and (for infrared and nuclear-magnetic-resonance studies) carbon tetrachloride.

Cesium extraction from aqueous cesium hydroxide solutions at concentrations up to about $2 \mathrm{M}$ (left side of Fig. 7.20) increases with increasing hydroxide concentration and approaches asymptotically a Cs:BAMBP mole ratio of $1: 4$ in the organic phase. At low loading (mole ratio Cs:BAMBP around 0.01 or less), the cesium extraction coefficient is inversely proportional to the hydrogenion concentration in the aqueous phase as represented by the $\mathrm{pH}$, and directly proportional to the cube of the BAMBP concentration (Fig. 7.21). The proportionality of $E$ to $1 /\left[\mathrm{H}^{+}\right]$also holds at higher loading, up at least to Cs:BAMBP $\approx 0.1$ (Fig. 7.22), provided that the observed extraction coefficients are corrected for the decreased concentration of free BAMBP on the basis of 4

\footnotetext{
${ }^{33}$ Chem. Technol. Div. Ann. Progr. Rept. May 31, 1963, ORNL-3452, p. 189.
}

BAMBP molecules bound by each extracted cesium ion, as suggested by the limiting loading ratio.

The foregoing relations suggest that the cesium extraction curve as shown in Fig. 7.20 should be approximated by an equation of the form $E \propto$ $C_{a q}\left[C_{R}-4 C_{o r g}\right]^{3}$ or $C_{o r g}=k C_{a q}{ }^{2}\left[C_{R}-4 C_{o r g}\right]^{3}$, $C_{a q}=\left\{C_{o r g} / k\left[C_{R}-4 C_{o r g}\right]^{3}\right\}^{1 / 2}$, where $E$ is the cesium extraction coefficient, and $C_{a q}, C_{o r g}$, and $C_{R}$ are the concentrations of aqueous-phase cesium, organic-phase cesium, and total BAMBP. This equation matches fairly closely the cesium extraction curves of $\mathrm{Fig}$. 7.20 over the range of $\mathrm{C}_{a q}$ from about $1 \mathrm{M}$ to below $0.1 \mathrm{M}$, with the proportionality constant $k$ being 80 for BAMBP in octane diluent and 15 for carbon tetrachloride diluent. The agreement gives some corroboration of the third-power extractant concentration dependence at high loading, whereas the direct measurements were limited to loadings of less than 0.01 $M$ Cs.

A third- instead of fourth-power dependence on BAMBP concentration, when 4 BAMBP molecules appear to be bound per cesium ion, suggests that the BAMBP is partially polymerized in solution. Several different methods (infrared spectroscopy, nuclear magnetic resonance, and osmotic coefficient determinations, all discussed later in this

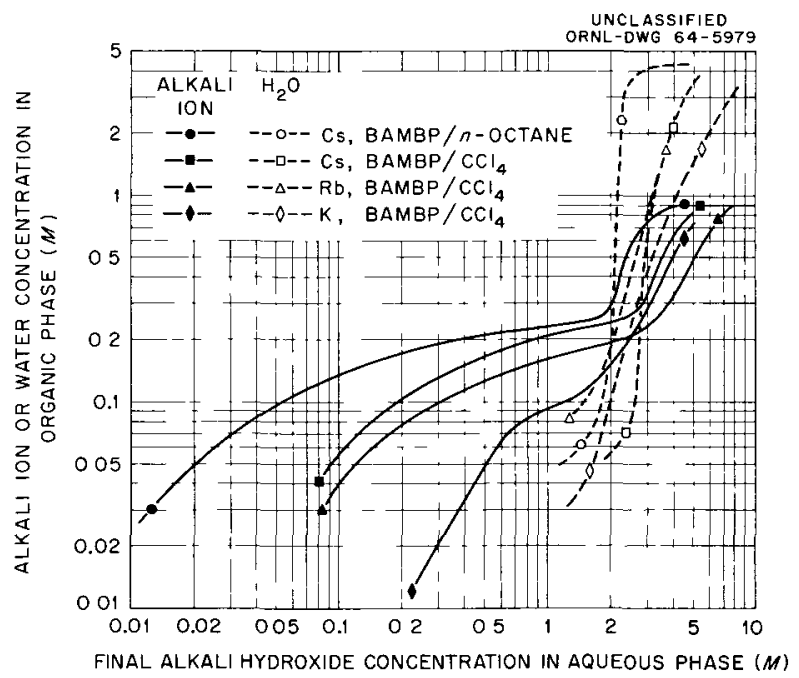

Fig. 7.20. Effect of Aqueous Alkali-Metal Hydroxide Concentration on Alkali and Water Extraction by BAMBP. BAMBP concentration $1.1 M$ in n-octane and $1.0 M$ in $\mathrm{CCl}_{4}$, except when diluted by water extraction, for example, approaching about $0.9 M$ as the extracted water concentration approaches $4 M$. 


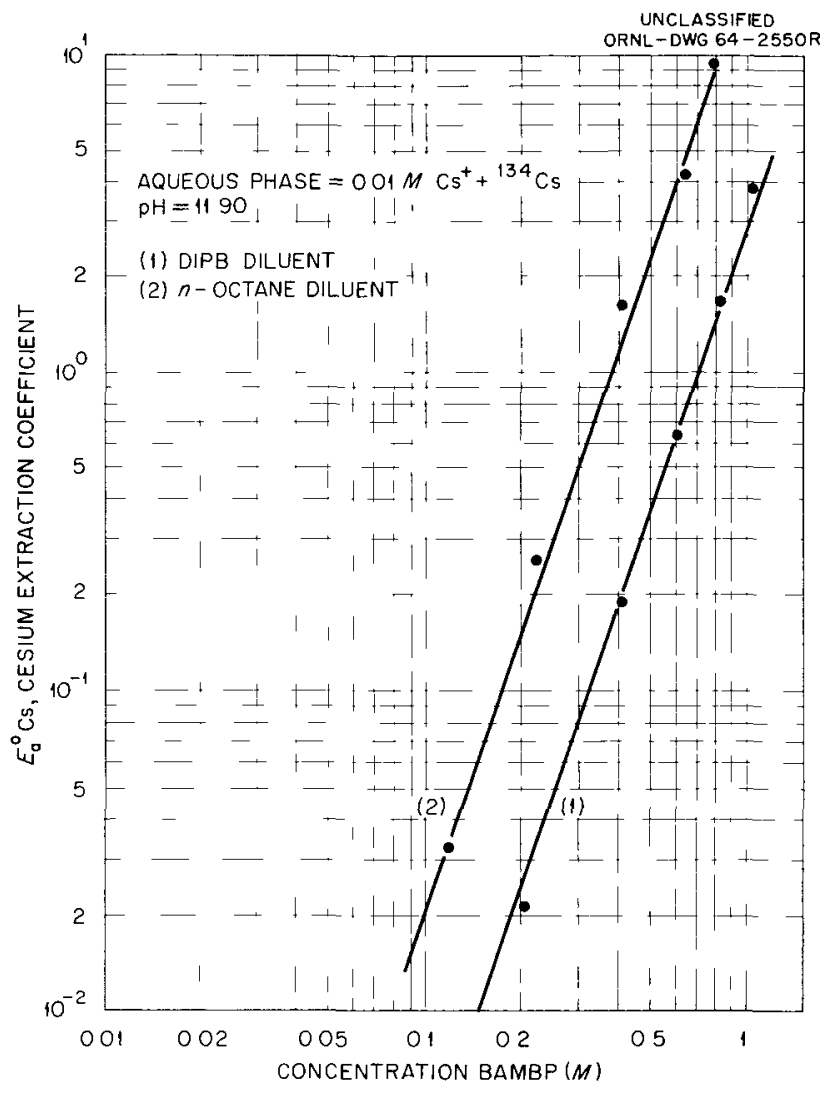

Fig. 7.21. Dependence of Cesium Extraction on BAMBP Concentration. (DIPB $=d_{1-1}$ sopropylbenzene.) Final $\mathrm{pH}$ 's varied from 10.9 to 11.9 ; the abserved extraction coefficients were normalized to $\mathrm{pH} 11.90$ on bosis of $\log E \propto \mathrm{pH}$.

section) agree qualitatively in indicating some polymerization, but it cannot yet be correlated quantitatively with the extractions. Osmotic measurements showed that the average polymerization number for BAMBP in wet hexane varies approximately linearly with the BAMBP concentration, from 1 at low concentration to 3 near $1 \mathrm{M}$. This should lead to a changing power dependence of extraction on BAMBP concentration instead of the constant dependence found, unless the stoichiometry of the extract species changes with BAMBP concentration at low loading. At high loading, the average degree of polymerization may be affected by the presence of cesium and phenolate 1ons.

When the aqueous cesium hydroxide concentration is increased above about $2 M$, the extraction response changes abruptly, as shown at the right side of Fig. 7.20. The Cs:BAMBP mole ratio increases from 1:4 toward 1:1, and at the same time the concentration of extracted water increases from a few hundredths molar to about $4 M$. In this region of the extraction system the other alkali ions are extracted to about the same extent as cesium and are similarly accompanied by large amounts of water. The simplest explanation for the overall extraction curve appears to be as follows: Below about $2 M$ alkali metal hydroxide, each alkali metal ion is extracted by exchange for the proton of 1 phenol molecule, producing a phenolate ion, and also associates with several more phenol molecules in replacement of its hydration in the aqueous phase. At higher concentrations of alkali hydroxide, the phenol is more readily ionized, more of it is converted to alkali phenolate, and there are insufficient phenol molecules to replace the waters of hydration, which

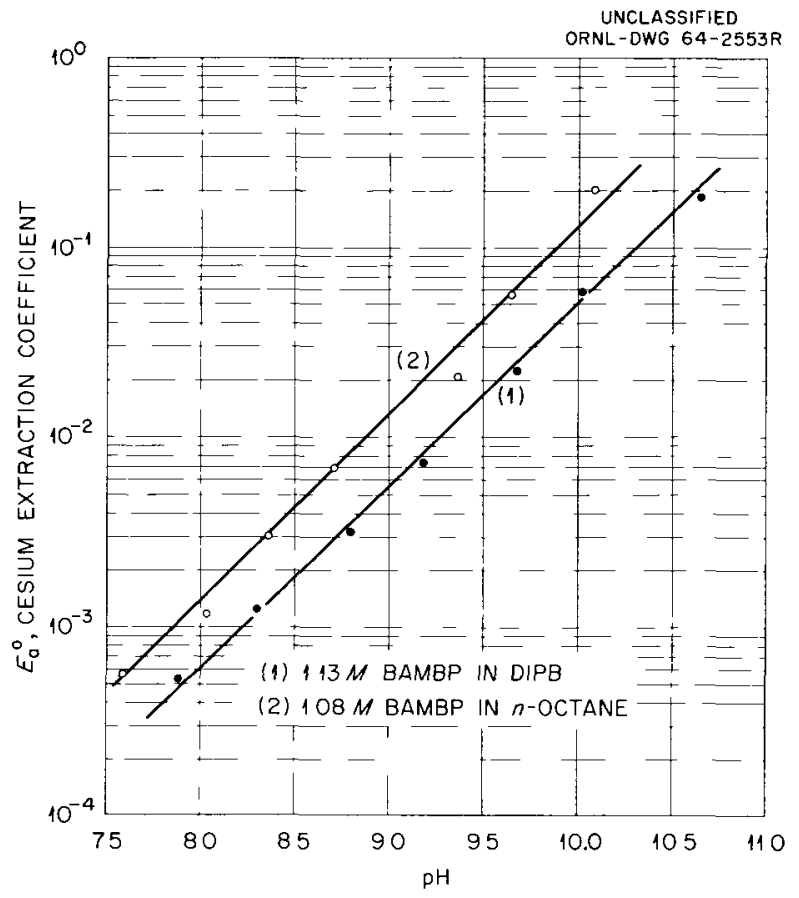

Fig. 7.22. $\mathrm{pH}$ Dependence of Cesium Extraction with BAMBP. Loading effects eliminated by colculating free BAMBP on basis of 4 BAMBP's bound per Cs, and correcting the observed extraction coefficients to 1.13 or $1.08 M$ on basis of third-power reagent concentration dependence. Aqueous phase initially $1 M$ in $\mathrm{CsNO}_{3}$ (plus trocer) and $0.1 \mathrm{M}$ in $\mathrm{No}\left(\mathrm{OH}, \mathrm{NO}_{3}\right)$. 
then accompany the alkali-metal ions into the organic phase.

\section{Investigation of Phenol-Alkali-Metal Extraction Species by Nuclear Magnetic Resonance and Infrared Spectroscopy}

Both infrared absorption and nuclear magnetic resonance (NMR) reflect the nature of bonds formed in the organic phase and accordingly give some information about intermolecular aggregation of the substituted phenol extractant and about the changes accompanying extraction of alkali ions and water.

Infrared spectra of 4-sec-butyl-2-( $\alpha$-methylbenzy1)phenol (BAMBP) and its solutions in carbon tetrachloride at 28 to $30^{\circ} \mathrm{C}$ (Fig. 7.23) show three regions of absorption by the phenolic $\mathrm{OH}$ bond: a sharp band at $3612 \mathrm{~cm}^{-1}$, ascribed to unassociated (monomeric) phenol; a broader band near 3540 $\mathrm{cm}^{-1}$, ascribed to dimerized phenol; and the region around 3400 to $3500 \mathrm{~cm}^{-1}$, ascribed to phenol polymerized into larger aggregates by hydrogen bonding. The spectra indicate that the BAMBP contains only a trace of monomer when undiluted (about $4 M$ ), is almost entirely monomeric below $0.05 \mathrm{M}$, and (with estimated correction for overlapping of bands) is about $30 \%$ monomeric at $1 M$. The NMR of the phenolic proton also undergoes a shift with concentration, from which a dimerization constant can be estimated for the concentration range in which only monomer and dimer are important. The value obtained for BAMBP in carbon tetrachloride at $34^{\circ} \mathrm{C}$ is $K_{\text {dimer }}=$ $2.0 \pm 0.3$, which indicates about the same proportion of monomeric BAMBP as does the infrared absorption, at concentrations up to nearly $1 M$.

On extraction of cesium (but not water) from cesium hydroxide solutions less concentrated than $2 \mathrm{M}$, as shown in Fig. 7.20, the monomer and dimer absorptions decrease, and the polymer absorption increases. When water is extracted, from cesium hydroxide solutions more concentrated than $2 \mathrm{M}$, the polymer absorption increases markedly. The NMR's of several identifiable protons in the BAMBP molecule show appreciable changes of intensity and fine structure on extraction of cesium, and that of the phenolic proton is shifted markedly. As the ratio of cesium to BAMBP increases, approaching $1: 4$, the phenolic proton line is broadened and shifts downfield, as shown in Fig. 7.24. This shift is reversed when water extraction starts, and the hydroxyl proton resonance spectrum then approaches that of water. The shifts in the presence of the other alkalimetal ions were similar but relatively a little smaller, $\mathrm{Cs}>\mathrm{Rb}>\mathrm{K}(>\mathrm{Na})$, and reached the reversal due to water extraction at lower loadings. Although interpretation of these results is not complete, they indicate that inter-phenol hydrogen bonds are stronger in the presence than in the absence of alkali-metal ion - strongest when the ion is cesium. This in turn suggests intermolecular bonding among the phenols involved with an extracted alkali-metal ion, instead of simple association of each individually with that ion.

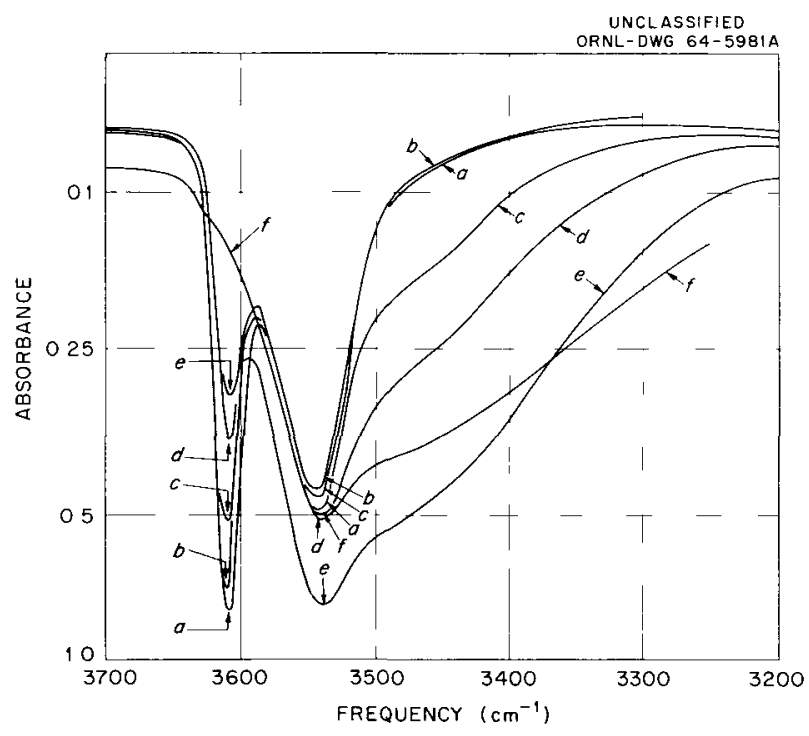

Fig. 7.23. Infrared Absorption by Phenolic - $\mathrm{OH}$ of 4-sec-Butyl-2-( $(\alpha$-methylbenzyl)phenol (BAMBP). Band at $3612 \mathrm{~cm}^{-1}$, monomeric phenol; $\sim 3540 \mathrm{~cm}^{-1}$, dimerized phenol; 3400 to $3500 \mathrm{~cm}^{-1}$, polymerized phenol. Diluent, $\mathrm{CCl}_{4}$; cell temperature, $31 \pm 2{ }^{\circ} \mathrm{C}$.

\begin{tabular}{cccc} 
Curve & $\begin{array}{c}\text { Concentration } \\
(M)\end{array}$ & $\begin{array}{c}\text { Path Length } \\
(\mathrm{mm})\end{array}$ & Product \\
\hline$a$ & 0.0482 & 1.200 & 0.0578 \\
$b$ & 0.0963 & 0.600 & 0.0578 \\
$c$ & 0.3825 & 0.150 & 0.0574 \\
$d$ & 0.963 & 0.060 & 0.0578 \\
$e$ & 1.926 & 0.030 & 0.0578 \\
$f$ & 3.95 & $(0.0133$ & $(0.0525$ \\
& (undilut- & corrected & corrected \\
& ed) & to 0.0146$)$ & to 0.0578$)$
\end{tabular}




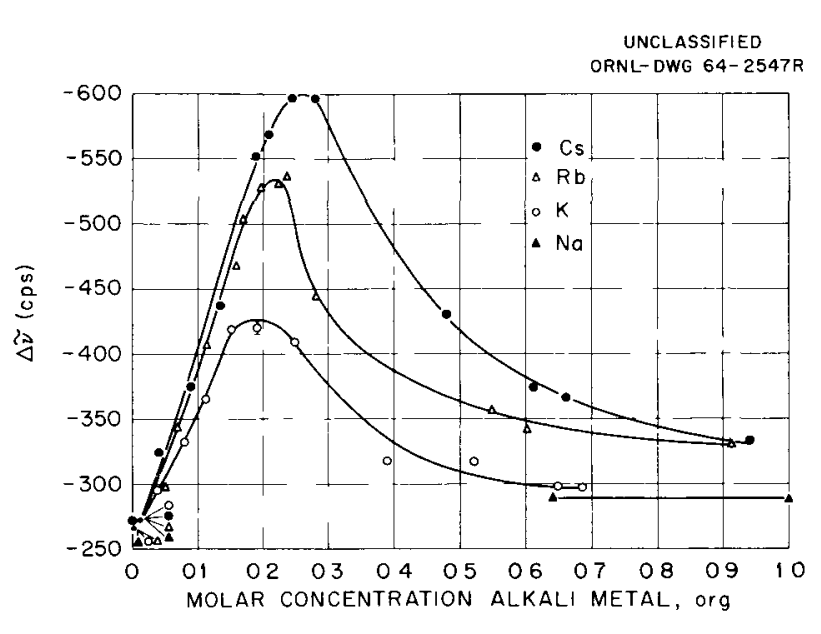

Fig. 7.24. Downfield Shift of Nuclear Magnetic Resonance Line of Phenolic Proton as a Function of Extracted Alkali-Metal lon Concentration. $1 M$ 4-secButyl-2-( $\alpha$-methylbenzyl)phenol (BAMBP) in carbon tetrachloride, $34^{\circ} \mathrm{C}$. For the corresponding extraction equilibria, see Fig. 7.20.

\section{Kinetics of the Transfer of Sulfate During Extraction by Amines}

Evidence of the participation of both neutral complex transfer and complex anion transfer in the amine extraction of uranyl sulfate was previously reported, based on kinetics of tagged sulfate transfer from organic to aqueous and on interfacial tension measurements that showed the interface to be saturated with undissociated amine sulfate adsorbed in preference to the uranyl-aminesulfate complex. ${ }^{34}$ Those results have been confirmed and extended by kinetic measurements with a wider range of aqueous sulfate concentrations, with the tracer $\left({ }^{35} \mathrm{~S}\right)$ sulfate initially in the aqueous instead of the organic phase, and with the tracer sulfate initially present in various organic-phase species. As before, tracer transfer was measured with uranium absent, with uranium being extracted from the aqueous phase, and with uranium already at equilibrium distribution.

Transfer of tagged sulfate from the organic to the aqueous was slower during uranium extraction

\footnotetext{
${ }^{34}$ W. J. McDowell and C. F. Coleman, Interface Mechanism for Uranium Extraction by Amine Sulfate, Abstract No. 62, 25K, 144th American Chemical Society Meeting, Los Angeles, April 1963.
}

than with uranium absent at very low sulfate concentrations, became about equal at $0.025 \mathrm{M}$ $\mathrm{SO}_{4}{ }^{2-}$, and was faster during uranium extraction than with uranium absent at higher sulfate concentrations, up to $1 M$. Transfer of tagged sulfate in the opposite direction, aqueous to organic, was examined at sulfate concentrations from 0.025 to $1 M$, and in each case the equilibration of tracer was more rapid during uranium extraction. Since the number of microcuries of ${ }^{35} \mathrm{~S}$ and the amount of uranium transferred was known, it was possible to calculate the number of sulfate ions transferred per uranium atom from these figures and the known ${ }^{35} \mathrm{~S} / \Sigma \mathrm{SO}_{4}$ ratio. The values obtained were as follows:

$\begin{array}{lllll}\text { Aque ous sulfate, } M & 0.025 & 0.05 & 0.50 & 1.00 \\ \text { SO }_{4} / U \text { in average } & 1.24 & 1.64 & 2.7 & 2.0 \\ \text { species transferred } & & & & \end{array}$

The results of tracer transfer in both directions corroborate the previous conclusions that the predominating species, either neutral complex or complex anion, is the species principally transferred. In more detail, they indicate a slight preference for transfer of the anion; that is to say, from a sulfate solution where $\mathrm{UO}_{2} \mathrm{SO}_{4}$ and $\mathrm{UO}_{2}\left(\mathrm{SO}_{4}\right)_{2}{ }^{2-}$ concentrations are nearly equal, a little more of the $\mathrm{UO}_{2}\left(\mathrm{SO}_{4}\right)^{2-}$ than of the $\mathrm{UO}_{2} \mathrm{SO}_{4}$ is transferred.

A mathematical model was developed for the self-diffusion transfer of ${ }^{35} \mathrm{~S}$ aqueous to organic and organic to aqueous in the particular apparatus used. If $x=\left[{ }^{35} \mathrm{~S}\right]_{o r g}$ and $y=\left[{ }^{35} \mathrm{~S}\right]_{a q}$, we write

$$
-\frac{d x}{d t}=k_{1} x-k_{2} y,
$$

where $k_{1}$ is the rate constant for ${ }^{35} \mathrm{~S}$ transfer or $g \rightarrow a q$, and $k_{2}$ for the transfer $a q \rightarrow$ org. Substitution of $\left(x_{0}-x\right)$ for $y$, integration, and evaluation of the integration constant at $t=0$ yield:

$$
x=x_{0} e^{-\left(k_{1}+k_{2}\right) t}+\frac{k_{2} x_{0}}{\left(k_{1}+k_{2}\right)}\left(1-e^{-\left(k_{1}+k_{2}\right) t}\right) .
$$

With the aid of the IBM 7090 computer, the data were shown to give a good fit to this first-order model. 


\section{Kinetics of the Extraction of Iron by Di(2-ethylhexyl)phosphoric Acid}

While equilibration is usefully rapid in the extraction of many metal ions by di(2-ethylhexyl)phosphoric acid (HDEHP), some metal ions such as $\mathrm{Fe}(\mathrm{III})$ and aluminum show very slow equilibration. A kinetic study has been started to find the reasons for and mechanisms of the slow extractions. Besides its importance in the fundamental study of solvent extraction, an understanding of the slow extraction should aid in safeguarding against difficulties in extraction processes and should provide a basis for devising separations to exploit rate differences.

The first system being examined is the extraction of $\mathrm{Fe}$ (III) $\left[{ }^{59} \mathrm{Fe}\right.$ tracer plus stable iron $(0.002 M)$ as carrier] from acid perchlorate solutions by HDEHP solutions in $n$-octane. The equilibria in this system have been previously reported. ${ }^{35}$ Over the range of conditions so far examined, the extraction rate is first order with respect to the aqueous iron concentration. The rate constant, $k_{a}=-d \log [\mathrm{Fe}] / d t$, varies inversely with close to the first power of perchloric acid concentration (ionic strength constant at $2 \mathrm{M} \mathrm{HClO}_{4}+\mathrm{NaClO}_{4}$ ) in extraction with a limited, quiescent interface between slowly stirred phases and with total dispersion by rapid stirring in a baffled cell. The rate constant varies directly with the HDEHP concentration, but in changing degree: $k_{a} \propto[\text { HDEHP] }]^{1.4}$ above and $k_{a} \propto$ [HDEHP] $]^{0.3^{a}}$ below about $0.4 M$ HDEHP. The equilibrium data cited above suggest that the change in power dependence on the extractant concentration may be due to a shift in predominance between extract species.

With the present extraction equipment, there is a gap between the highest aqueous acidity usable with the quiescent interface (constant interfacial area) and the lowest aqueous acidity usable with dispersion (interfacial area varying with mixing rate). Both types will be modified so as to obtain an overlap, which should aid in distinguishing between controlling resistance at the interface or in the adjacent liquid layers.

\footnotetext{
${ }^{35}$ C. F. Baes, Jr., and H. T. Baker, J. Phys. Chem. 64, 89-94 (1960).
}

\section{Determination of the Activity Coefficients of Aqueous Acids by Amine Extraction}

Many different studies of acid extraction by amines have shown that under certain conditions the anion to amine ratio in the organic phase varies with the aqueous acidity. With sulfuric acid at least (equilibrated with amine sulfatebisulfate), the anion to amine ratio has been shown to depend only on the aqueous sulfuric acid activity, whether the aqueous solutions contain the acid alone or the acid mixed with its salts. This suggests that the activity of an acid, in aqueous solution together with any number of nonextractable solutes, should be obtainable by matching against a separate solution of the acid alone, through the medium of an amine solution. A relatively brief examination of this possibility gave encouraging results in some tests. For example, $0.5241 \mathrm{~m} \mathrm{HCl}-1.578 \mathrm{~m} \mathrm{NaCl}$ mixture matched $1.025 \mathrm{~m} \mathrm{HCl}, \gamma_{ \pm}=0.794$, compared with 0.800 from the literature, and $0.8836 \mathrm{~m} \mathrm{HCl}-$ $2.834 \mathrm{~m} \mathrm{NaCl}$ mixture matched $2.248 \mathrm{~m} \mathrm{HCl}, y_{ \pm}=$ 1.336, compared with 1.316 from the literature, when aqueous acid and aqueous mixture were stirred in the separate legs of an H-cell in simultaneous contact with a $0.25 \mathrm{M}$ solution of tri-noctylamine in benzene filling the crossbar of the H-cell. Other tests showed that under some conditions the measurement fails because of excessively slow or insensitive equilibration. Extraction isotherms of the acids, as illustrated for $\mathrm{HCl}$ in Fig. 7.25, show that some parts of the curves are very flat (insensitive). Different amine-diluent combinations give favorably sloping extraction curves at different acidities, so that from compilations of such curves it should be possible to choose a suitable amine solution for any acidity.

Extractants other than amines can also extract acids from aqueous solutions, and parallel tests were made with tri- $n$-butyl phosphate (TBP) and several ethers, alcohols, and amides. However, the TBP failed to give satisfactory equilibration in $\mathrm{H}$-cell tests because excessively rapid transfer of water through the TBP phase between the two aqueous phases prevented the acid concentrations from reaching equilibrium. Acid transfer rates were excessively slow with the other reagents tested. 


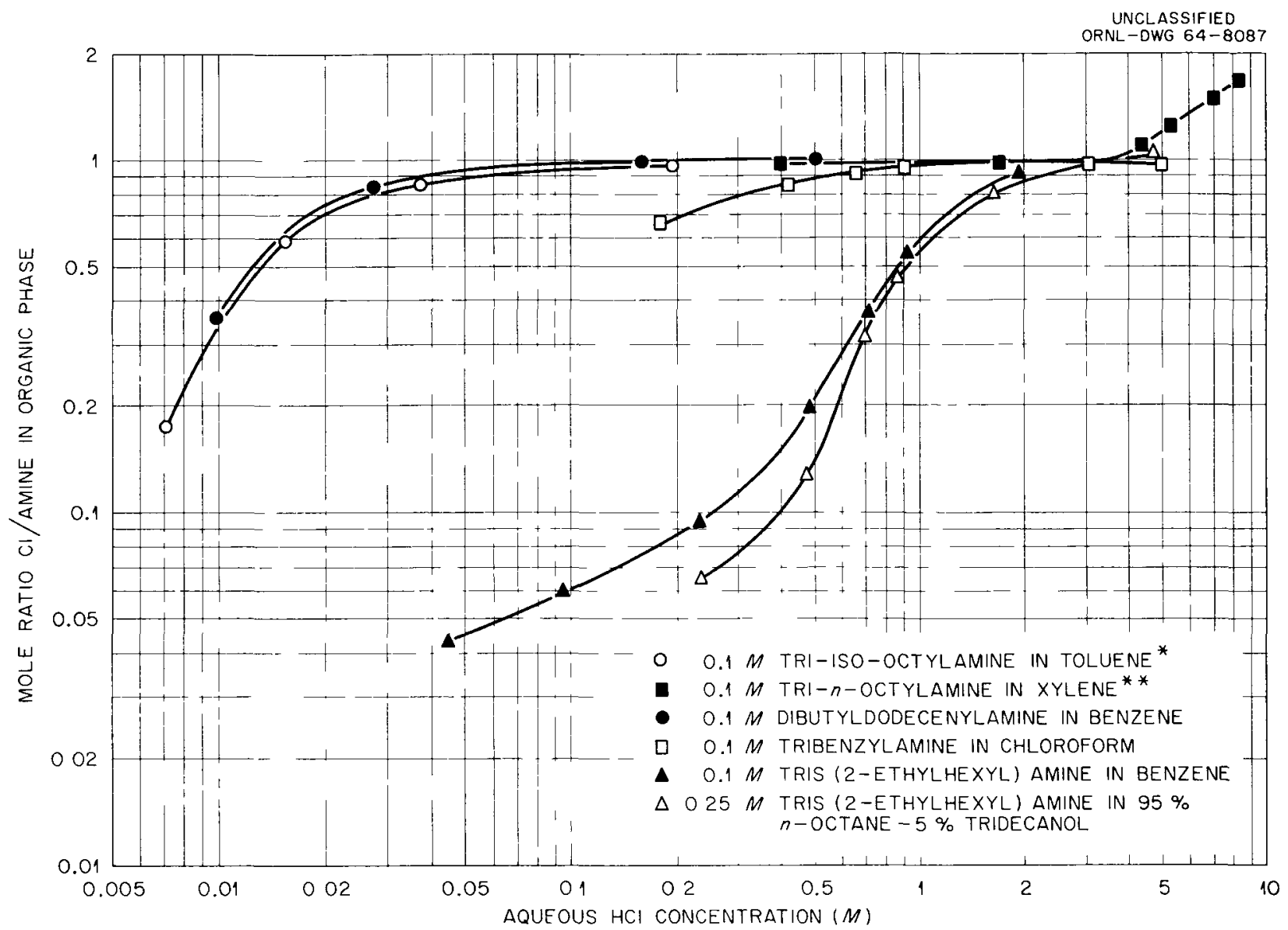

Fig. 7.25. Equilibrium Curves for Hydrochloric Acid Extraction by Tertiary Amines. The single asterisk refers to J. C. Peak, "The Equilibrium Between Chloride, Nitrate, and Sulfate Salts of Tri-iso-octyl Amine," Thesis, Mas. sachusetts Institute of Technology, January 1959. The double asterisk refers to U. Bertocel and G. Rolandi, J. Inorg. Nucl. Chem. 23, 323-32 (1961).

\section{Activity Coefficients of the Solvent Phases}

In addition to direct testing of solutions of extractants, to determine their activity coefficients or degrees of aggregation, the differential vaporpressure measurements previously described ${ }^{36}$ are being used to determine activity coefficients and osmotic coefficients of organic solutions of compounds that are useful as isopiestic reference solutes. These are being determined both in anhydrous systems and in water-saturated systems, the latter being more closely related to the solvent extraction systems of ultimate interest. The first reference solute so "calibrated" was triphenylmethane, which is useful but limited to dilute solutions by its low solubility. ${ }^{37}$ Azobenzene is somewhat more soluble and so far appears to be a generally useful reference solute. In a search through other feasible compounds with low vapor pressures, bibenzyl was the most soluble in both benzene and hexane (Table 7.8) and was chosen for next examination.

\footnotetext{
${ }^{36}$ Chem. Technol. Div. Ann. Progr. Rept. Aug. 31, 1960, ORNL-2993, p. 173; also A. L. Myers, W. J. McDowell, and C. F. Coleman, J. Inorg. Nucl. Chem. (in press).
}

\footnotetext{
${ }^{37}$ Chem. Technol. Div. Ann. Progr. Rept. May 31, 1963, ORNL-3452, p. 186.
} 
Table 7.8. Solubilities of Compounds Considered for Use as Isopiestic Reference Solutes

\begin{tabular}{|c|c|c|c|}
\hline \multirow[t]{2}{*}{ Compound } & \multirow{2}{*}{$\begin{array}{c}\text { Vapor Pressure } \\
\text { at } 25^{\circ} \mathrm{C} \\
(\mu)\end{array}$} & \multicolumn{2}{|c|}{$\begin{array}{l}\text { Solubility at } \\
20^{\circ} \mathrm{C}(\mathrm{m}) \text { in: }\end{array}$} \\
\hline & & Benzene & $n-H e x$ ane \\
\hline Triphenylme thane & $<1$ & 0.4 & 0.4 \\
\hline Azobenzene & $<1$ & 2.9 & 1.0 \\
\hline Bibenzyl & 40 & 10.0 & 2.8 \\
\hline Biphenyl & 9 & 6.7 & 1.3 \\
\hline Phenanthrene & $<1$ & 2.8 & 0.6 \\
\hline \multicolumn{4}{|l|}{$\mathrm{Bi}(p$-bromopheny 1$)$} \\
\hline \multicolumn{4}{|l|}{ Hexachlorobenzene } \\
\hline \multicolumn{4}{|l|}{ Diazoaminobenzene } \\
\hline Benzoin & & $<0.3$ & $<0.1$ \\
\hline$p$-Terphenyl & & & \\
\hline Dotriacontane & & & \\
\hline
\end{tabular}

Osmotic coefficients of dry benzene solutions of triphenylmethane and azobenzene, and water-saturated $n$-hexane solutions of azobenzene and bibenzyl, are summarized in Fig. 7,26. The latter are still tentative (although the nearly constant values for both at about 0.8 between 0.5 and $1 \mathrm{~m}$ seem to be consistent) because the measurements so far made below $0.5 \mathrm{~m}$ have not appeared consistent, and the reasons have not yet been resolved.

The sensitivity and precision of the differential vapor-pressure apparatus is being improved by use of capacitance between two plates to locate the mercury surface in one arm of the differential manometer. One plate floats on the mercury surface, while the position of the other is adjusted by means of a high-precision micrometer head to reproduce a standard capacitance, and hence a standard spacing, between the plates. The $\mathrm{mi}$ crometer head $^{38}$ has a least count of $0.5 \mu$ by vernier, and average measurements of the mercury position were reproducible to within $1 \mu$ in mockup tests. This is to be compared with a least count of $10 \mu$ (estimate to $1 \mu$ ) and reproducibility of average measurements within about $2 \mu$ with the present measuring system, in which the position of a needle is adjusted by means of a modified machinist's micrometer while contact of the needle

\footnotetext{
${ }^{38}$ Boeckler non-rotating spindle micrometer head, model 4-MBR, Arizona Tool and Die Co., Tucson, Ariz.
}

point with the mercury surface is observed through a 20x binocular microscope.

Average polymerization numbers of 4-sec-butyl2-( $\alpha$-methylbenzyl)phenol (BAMBP) were determined in several diluents, for use in the study of BAMBP extraction equilibria (Sect. 7.3). The method used was isopiestic balancing against solutions of azobenzene. Three series of solutions in $n$-hexane were tested (Fig. 7.27): solutions dried with magnesium perchlorate; solutions equilibrated in the presence of saturated nitrate solution, water activity $=0.5$; and solutions equilibrated in the presence of saturated barium chloride solution, water activity $=0.9$ (communication through vapor phase only). The osmotic behavior of azobenzene found at 0.5 to $1 \mathrm{~m}$ concentrations in wet hexane (above) was provisionally assumed to be valid for the other conditions included in Fig. 7.27. The results show the average polymerization increasing in nearly direct proportion to the BAMBP concentration to about the trimer at $1 M$ BAMBP and slightly lower when water was eliminated. A few tests in n-octane gave similar results, but the BAMBP appeared essentially monomeric at a concentration of about $1 M$ in chloroform.

Although the state of aggregation of amine sulfate in general and of tri-n-octylamine sulfate in particular has been extensively studied in various organic diluents, there are still some unresolved questions. On one hand, mass-action analyses of equilibria involving tri-n-octylamine sulfates have suggested that they are polymeric, and, on the other hand, various physical measurements have indicated that the normal sulfate (TOAS) is not

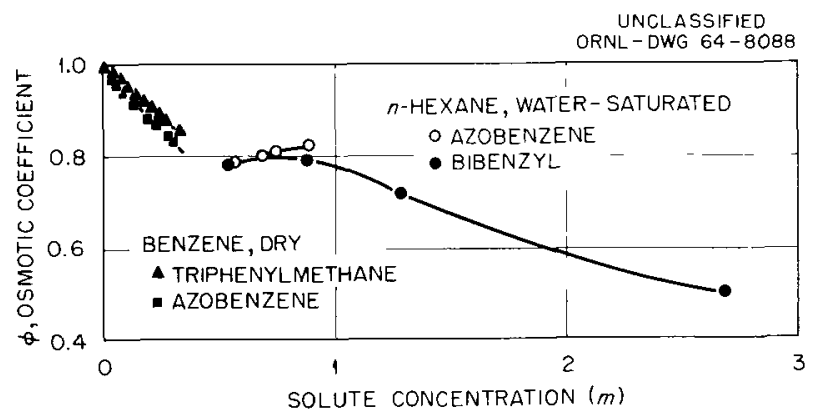

Fig. 7.26. Osmotic Coefficients at $20^{\circ} \mathrm{C}$ of Solutions of Compounds to Be Used as Isopiestic Reference Solutes. 


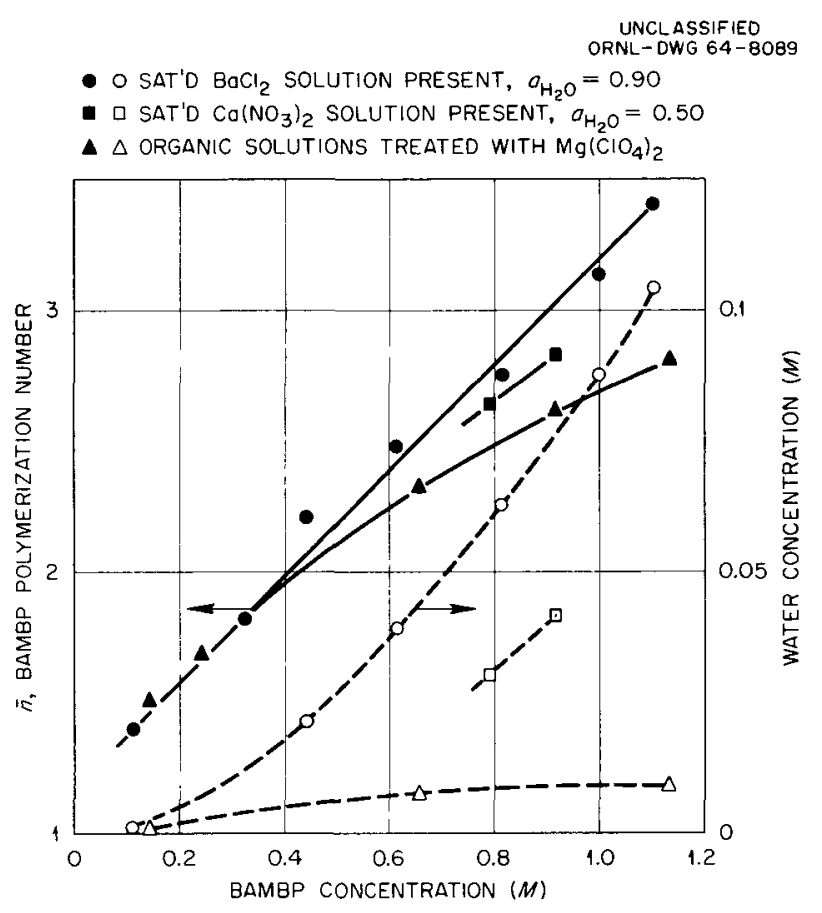

Fig. 7.27. Water Contents and Polymerization of BAMBP in $n$-Hexane Solutions. Isopiestic baloncing vs azobenzene solutions at $25^{\circ} \mathrm{C}$. Solid lines and black symbols, overage polymerization number, $\bar{n}$; dashed lines and open symbols, organic-phose water concentrations determined by Karl Fischer titration.

polymerized at all and that the bisulfate (TOAHS) is only slightly polymerized, $\vec{n} \approx 2$ to 4 . However, the conditions of the physical measurements have not exactly matched those of the extraction equilibria, particularly with respect to the water content of the extractant phase and possibly with respect to sulfate-bisulfate ratios. The tests reported here have nearly closed those gaps for benzene solutions of TOA and its sulfates.

Figure 7.28 shows average polymerization numbers in dry benzene at $25^{\circ} \mathrm{C}$, determined by isopiestic balancing against triphenylmethane, as the sulfate content increases from 0 to $50 \%$ excess sulfuric acid. (The results are corrected for nonideality of the triphenylmethane, Fig. 7.26, and all nonideality of the TOA, TOAS, and TOAHS species is automatically included in their average polymerization numbers.) The free-base amine, the normal sulfate, and all mixtures between them are close to monomeric. Noticeable polymerization commences with the formation of bisulfate and increases in direct proportion to the bisulfate content, but only to $\bar{n} \approx 3.6$ for pure bisulfate. The polymerization increases more rapidly with the incorporation of excess sulfuric acid, to $\bar{n} \approx$ 12.5 at $50 \%$ excess, which (except for the absence of water) would correspond to equilibrium with about $10 M$ aqueous sulfuric acid.

At least in the range between free-base amine and bisulfate, the polymerization appears independent of amine concentration from 0.08 to $0.3 \mathrm{~m}$. In further tests, so far complete with the bisulfate only, polymerization was almost unaffected by the addition of water to the system (via vapor phase) at water activities up to 0.9 , which is approaching the water activity in typical amine sulfate extraction systems:

$\begin{array}{llllll}{ }_{{ }_{H}} \mathrm{O} & 0 & 0.33 & 0.50 & 0.75 & 0.90 \\ \bar{n}_{\text {TOAHS }} & 3.60 & 3.67 & 3.69 & 3.53 & 3.50\end{array}$

Water is a common, variable, and probably important component in the organic phases of amine extraction systems. Hence, as a part of the studies attempting to resolve apparent discrepancies in amine sulfate extraction systems, concentrations and activities of water in the amine-diluent

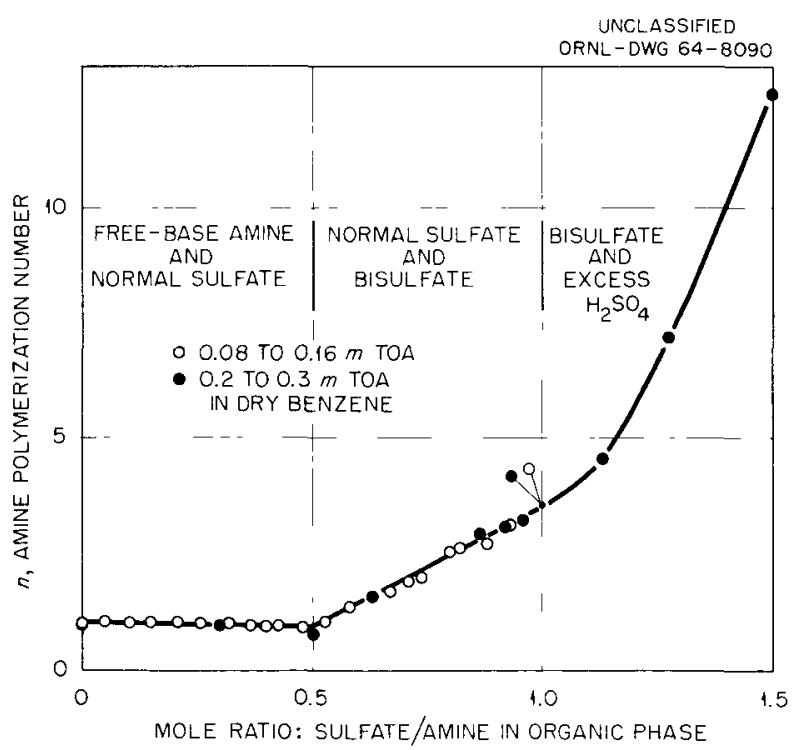

Fig. 7.28. Polymerization of Tri-n-octylamine Sulfates in Benzene. From isopiestic measurements vs triphenylmethane, $25^{\circ} \mathrm{C}$. 
phase are being measured as a function of sulfate to amine ratio. In some amine extraction systems the equilibria have been shown to be shifted by the effect of a large interfacial area produced by dispersion. ${ }^{39}$ In order to check the possibility that water might be involved in that behavior, or might be affected similarly, the water-distribution tests included liquid-liquid equilibrations through both dispersed and limited interfaces and vaporphase equilibration in an isopiestic system. So far, no clear-cut difference in water behavior with means of equilibration has been found.

The water activity in the aqueous phases was controlled by varying sodium sulfate concentration $\left(a_{\mathrm{H}_{2}} \mathrm{O}\right.$ from 0.86 to 1.00$)$ when the phases were to be in direct contact, and by using saturated aqueous solutions of appropriate salts $\left(a_{\mathrm{H}_{2} \mathrm{O}}\right.$ from 0.11 to 0.90 ) when they were not. Water concentration in the organic phase decreased with decreasing water activity in the aqueous phase, and also with increasing sulfate to amine ratio in the organic phase. Choosing pure water as the reference state for water in the organic phase as well as in the aqueous phase sets the equilibrium water activity in the organic phase equal to that in the aqueous phase. Of the various possible ways of expressing the organic-phase water concentration, its mole ratio to ionized amine gave the simplest and most uniform correlation of the corresponding activity coefficients (Fig. 7.29). This suggests that the water may be associated principally with the amine cation rather than with the sulfate or bisulfate anions or free-base amine. The activity coefficients decrease slightly with increasing water contents, and they increase with

${ }^{39}$ K. A. Allen and W. J. McDowe1l, J. Phys. Chem. 64, 877-80 (1960). increasing amine bisulfate fraction, especially at the low water activities. The abrupt drops at lowest water contents, $\left[\mathrm{H}_{2} \mathrm{O}\right] /\left[\mathrm{TOAH}^{+}\right]$less than $0.2, a_{\mathrm{H}_{2} \mathrm{O}}=0.11$, may result from limiting error in the corrections for water solubility in the diluent.

UNCLASSIFIED

MOLE RATIO SULFATE / TOA IN ORGANIC PHASE
O $020, \mathrm{SO}_{4}^{2-} / \mathrm{TOA}$
- 022
$\checkmark$ oso (NORMal sulfate)
0,060
- 065
- 094
$\triangle 098$
$\triangle 100$ (BISULFATE)

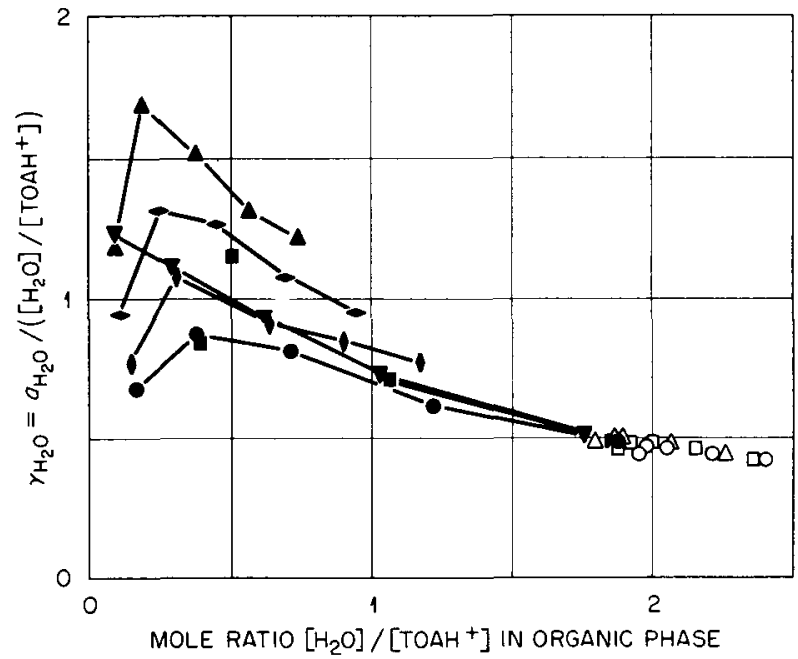

Fig. 7.29. Activity Coefficients of Water In Tri-noctylamine Sulfate Solutions. Water concentration expressed as mole ratio to ionized amine, corrected for water dissolved by diluent alone, reference state, pure water. TOA concentrations 0.1 to $0.2 \mathrm{M}$. Black symbols from isopiestic equilibrations with phenylcyclohexone diluent. Open symbols from liquid-liquid equilibration with benzene diluent. 


\section{Recovery of Fission Products by Solvent Extraction}

The objective of the fission-product-recovery program is to develop processes applicable to large-scale recovery and purification of fission products from reactor fuel processing wastes. The program includes basic chemical research, development of recovery methods, and development of engineering procedures to carry out these operations. Large quantities of certain fission product elements are being requested for industrial, space, and other applications, and there is evidence that the demand will increase. Also, aside from their utility for recovering useful fission products, the recovery methods developed are of interest for fractionating wastes to ease certain wastedisposal problems.

The principal effort in this program has been on the development of solvent extraction methods since this technique is a particularly versatile one and is readily adaptable to large-scale operations. Thus far, a solvent extraction process using di(2-ethylhexyl)phosphoric acid (D2EHPA) has been successfully developed for recovering ${ }^{90} \mathrm{Sr}$ and mixed rare earths. A modification of this process has been operated in plant scale at the Hanford Atomic Products Operation. New processes have also been developed in the laboratory for recovering cesium with substituted phenols and for recovering zirconium-niobium and possibly yttrium and ruthenium. The combination of these developments with previous studies on rare-earths separations and on the recovery of technetium, neptunium, and plutonium affords an integrated solvent extraction flowsheet for the recovery of all important fission products and other components from waste liquors. Current studies are aimed at consolidating, optimizing, and completing these developments and at devising new processes that will provide even more advantages in operations and cost.

\subsection{CESIUM}

Highly favorable results continued to be obtained in the development of the Phenex process $^{1,2}$ for recovering cesium from alkaline solutions by extracting with substituted phenols and stripping with dilute acid. Although several different substituted phenols have performed acceptably, nearly all recent test work was with 4-secbutyl-2-( $\alpha$-methylbenzyl)phenol (BAMBP), which has especially attractive extraction characteristics. The studies included (1) successful demonstration of the process in continuous tests, (2) evaluation of the chemical and radiation stability of BAMBP, and (3) evaluation of the synergistic reagent combination, BAMBP plus D2EHPA.

\section{Continuous Tests}

To confirm the chemical and operational feasibility of the process that had been outlined on the basis of batch tests, continuous cyclic runs were made in mixer-settlers with simulated Purex waste solution (tartrate-complexed and adjusted to $\mathrm{pH}$ 12.7). The solvent was $1 M$ BAMBP in Amsco 125-82. The extract was scrubbed with $0.002 M$ sodium tartrate and stripped with $0.1 \mathrm{M} \mathrm{HNO}_{3}$. With aqueous feed/organic/scrub/strip flow ratios of $10 / 5 / 1 / 0.25$, cesium recovery was better than $99 \%$, and overall cesium decontamination factors were 2000 from sodium and more than 6000 from

\footnotetext{
${ }^{1}$ Chem. Technol. Div. Ann. Progr. Rept. June 30, 1962, ORNL-3314, p. 120.

${ }^{2}$ Chem. Technol. Div. Ann. Progr. Rept. May 31, 1963, ORNL-3452, p. 189.
} 
1ron, chromium, and nickel. No change in performance was noted through $26 \mathrm{hr}$ of operation, equivalent to 23 complete cycles through the system.

\section{Stability of 4-sec-Butyl-2-( $a$-methylbenzyl)phenol}

The radiation and chemical stabilities of BAMBP are good within the range of expected flowsheet conditions. One-molar solutions of BAMBP in Amsco $125-82$ were exposed to ${ }^{60} \mathrm{Co}$ radiation for various periods of time (with absorbed doses up to $100 \mathrm{whr} /$ liter) while being intimately mixed either with tartrate-complexed simulated Purex $1 \mathrm{WW}$ (pH 12.5) or with $0.05 M \mathrm{HNO}_{3}$ strip solution. Comparative tests were also made in the absence of radiation. The solvent contacted with the radioactive acid strip solution and those contacted with the alkaline feed with and without radiation, showed a factor of 2 to 3 increase in cesium (and sodium) extraction power compared with that for untreated solvent, whereas the fourth solvent showed no change (Table 8.1). There were no significant changes in the titratable phenol content of any of the solvents nor in their selectivity for cesium over metal contaminants in the Purex 11quor. Also, phase-separation properties were not impaired by the treatments.

A similar increase in the cesium extraction power of $1 M$ BAMBP-Amsco 125-82 occurred on contact with $2 M \mathrm{NaOH}$ for extended periods. Solvent treated for one day extracted cesium with a coefficient twice that for untreated solvent, but there was no further change for up to 14 days contact. No significant differences in the treated and untreated solvents were discernible from infrared spectroscopy or nuclear magnetic resonance measurements.

BAMBP was readily nitrated by contact with $3 \mathrm{MHNO}_{3}$, but there was little or no reaction at

Table 8.1 Radiation Stability Tests with BAMBP

Solvent-treatment conditions: $1 M$ BAMBP in Amsco 125-82 contacted with (1) simulated Purex $1 \mathrm{WW}$ (tartrate-complexed, pH 12.7) or (2) $0.05 M$ $\mathrm{HNO}_{3}$ in ${ }^{60}$ Co source. Parallel tests were run without the radiation field. After treatment, all solvents were stripped with $0.05 \mathrm{M} \mathrm{HNO}_{3}$ and subjected to standard cesium extraction tests.

\begin{tabular}{|c|c|c|c|c|}
\hline \multicolumn{4}{|c|}{ Contacting Conditions } & \multirow{2}{*}{$\begin{array}{c}\text { Cesium } \\
\text { Extraction } \\
\text { Coefficient, }{ }^{a} E_{a}^{o}\end{array}$} \\
\hline Type of Contact & $\begin{array}{l}\text { Aqueous } \\
\text { Solution }\end{array}$ & $\begin{array}{l}\text { Contact } \\
\text { Time (hr) }\end{array}$ & $\begin{array}{c}\text { Calculated } \\
\text { Absorbed Dose } \\
\text { (whr/liter) }\end{array}$ & \\
\hline \multirow{4}{*}{$\begin{array}{l}\text { None } \\
{ }^{60} \text { Co Source }\end{array}$} & & None & None & $22,24,25$ \\
\hline & (1) & 5 & 10 & 33 \\
\hline & & 23 & 43 & 42 \\
\hline & & 52 & 98 & 62 \\
\hline \multirow[t]{3}{*}{ No radiation } & (1) & 5 & None & 23 \\
\hline & & 23 & & 44 \\
\hline & & 52 & & 50 \\
\hline \multirow[t]{3}{*}{${ }^{60}$ Co Source } & (2) & 5 & 7 & 35 \\
\hline & & 23 & 31 & 43 \\
\hline & & 52 & 71 & 52 \\
\hline \multirow[t]{3}{*}{ No radiation } & (2) & 5 & None & 23 \\
\hline & & 23 & & 26 \\
\hline & & 52 & & 24 \\
\hline
\end{tabular}

${ }^{a}$ Extraction at a phase ratio of $1 / 1$ from tartrate-complexed simulated $1 \mathrm{WW}$ waste $(0.001 \mathrm{MCa})$ at $\mathrm{pH} 12.7$. 
nitric acid concentrations of $1 M$ or below. In agreement with Hanford results, extensive degradation (with loss of cesium extraction power) occurred on contact with $1 \mathrm{M} \mathrm{HNO}_{3}$ that was $0.1 \mathrm{M}$ in nitrite. Degradation in the presence of nitrite was much slower at a $\mathrm{pH}$ of 1 and was negligible in contact with alkaline nitrite solutions.

\section{Synergistic Solvent Mixtures}

The synergistic solvent mixture, BAMBP plus D2EHPA, is being evaluated as an alternative to BAMBP alone for cesium recovery - following extraction of strontium and rare earths with D2EHPA. (A process for the coextraction of strontium, rare earths, and cesium at $\mathrm{pH} 4$ with D2EHPA-BAMBP has been developed at Hanford. ${ }^{3}$ ) The synergistic solvent extracts cesium effectively at much lower $\mathrm{pH}$ levels than the $\mathrm{pH}$ of $\sim 12$ required with $\mathrm{BAMBP}$ alone. Also, unless special precautions are taken, some accumulation of D2EHPA in the BAMBP solvent might occur by crossover from the strontium-rare-earths recovery cycle. A feed $\mathrm{pH}$ of $\sim 8$ rather than a lower $\mathrm{pH}$ (e.g., 4) was chosen since, in the former case, a much lower D2EHPA concentration is required for equivalent cesium extraction power, and the selectivity for cesium over metal contaminants is better.

In a batch countercurrent test, more than $99 \%$ of the cesium was recovered from tartrate-complexed simulated Purex $1 W W(\mathrm{pH} 8.4$ ) with $1 M$ BAMBP $0.04 M$ D2EHPA - Amsco 125-82 in four extraction and one scrub stages (Table 8.2). The cesium was stripped to the extent of $98.6 \%$ in three stages with $1 / 5$ volume of $0.2 \mathrm{M} \mathrm{HNO}_{3}$. Overall cesium decontamination factors were 750 from sodium, 150 from strontium, and 1300 from europium.

The savings in caustic for feed adjustment made possible by use of the synergistic solvent must be balanced against its inferior selectivity and poorer response to stripping by dilute acid, compared with the effectiveness of BAMBP alone. A more definitive comparison of the solvents with regard to their influence on overall processing costs would be required before a final choice could be made.

\footnotetext{
${ }^{3}$ L. A. Bray, Solvent Extraction Process for Recovery of Strontium, Rare Earths, and Cesium from Radioactive Waste Solutions, HW-SA-2982 (June 17, 1963).
}

Table 8.2 Batch Countercurrent Cesium Recovery with BAMBP.D2EHPA

Organic: $1 M$ BAMBP-0.04 $M$ D2EHPA-Ams co 125-82

Aqueous feed: Simulated Purex $1 \mathrm{WW}$ complexed with tartrate (2 moles per mole of $\mathrm{Fe}$ ), diluted threefold with caustic to $\mathrm{pH} 8.4$, traced with ${ }^{134} \mathrm{Cs}$

Scrub: $0.15 M \mathrm{HNO}_{3}-0.001 M$ tartaric acıd

Flow ratios: Aque ous feed/organ $1 \mathrm{c} / \mathrm{scrub}=10 / 5 / 1$

\begin{tabular}{llll}
\hline \multirow{2}{*}{ Stage } & \multicolumn{2}{c}{$\begin{array}{c}\text { Cesium Gamma Activity } \\
\text { (counts min }\end{array}$} & \multicolumn{1}{c}{$\begin{array}{c}\text { Cesium Extraction } \\
\text { Coefficient, } E_{a}^{\circ}\end{array}$} \\
\cline { 2 - 3 } & Organic & Aqueous & \\
\hline Scrub 1 & $7.0 \times 10^{4}$ & $8.4 \times 10^{2}$ & 83 \\
Aqueous feed & & $3.5 \times 10^{4}$ & \\
Extraction 1 & $7.1 \times 10^{4}$ & $4.8 \times 10^{3}$ & 16 \\
Extraction 2 & $1.0 \times 10^{4}$ & $6.8 \times 10^{2}$ & 15 \\
Extraction 3 & $1.6 \times 10^{3}$ & $\sim 1.8 \times 10^{2}$ & $\sim 9$ \\
Extraction 4 & $\sim 1.9 \times 10^{2}$ & $<10^{2}$ & \\
\hline
\end{tabular}

\subsection{STRONTIUM AND RARE EARTHS}

Further studies of the D2EHPA extraction process for recovering strontium and mixed rare earths from Purex wastes included (1) investigation of the factors affecting rare-earths extraction rates, (2) study of cerium oxidation followed by extraction with D2EHPA to obtain separation from other rare earths, and (3) study of strontium separation from calcium.

\section{Rate of Rare Earths Extraction}

The slow extraction ${ }^{4}$ of rare earths with D2EHPA from tartrate- or citrate-complexed liquors is due to slow readjustments to equilibrium in the aqueous phase after the system has been disturbed. This was demonstrated by batch contacting tartrate-complexed Purex $1 \mathrm{WW}(\mathrm{pH}$ 5) with $0.2 \mathrm{M}$ D2EHPA-0.1 $M$ NaD2EHP-0.15 $M$ TBP-Amsco $125-82$ for $1 \mathrm{~min}$ and aging the raffinate for various periods before contacting again with fresh solvent. The cerium extraction coefficient in the second 1 -min contact was 12 with $24 \mathrm{hr}$ between contacts,

\footnotetext{
${ }^{4}$ Chem. Technol. Div. Ann. Progr. Rept. May 31, 1963, ORNL-3452, p. 192.
} 
compared with only 0.5 with 5 min between contacts. Subsequent experiments, in which metal contaminants were added to a nitrate-tartratesulfate solution (one at a time) showed that iron, aluminum, and chromium, particularly the last, depressed rare-earth extraction rates (Fig. 8.1). The adverse effect of chromium on rare-earth extractions has also been observed by Hanford workers. ${ }^{5}$ Analyses of the solvent phases for contaminant metals showed that the amounts extracted were not large enough to represent significant competition for the D2EHPA extractant. With $0.003 \mathrm{M} \mathrm{Cr}$ in the aqueous phase, cerium extraction coefficients were $8.5,25$, and 120 for contact times of 1,10 , and $30 \mathrm{~min}$ respectively. By contrast, both cerium and europium coefficients were higher than 700 in 1-min extractions from pure sodium tartrate solutions or from this solution with $0.003 M \mathrm{Ni}$ added. The magnitude of the effect of each interfering metal was different for the different rare earths. Iron depressed extractions of europium and neodymium more than that

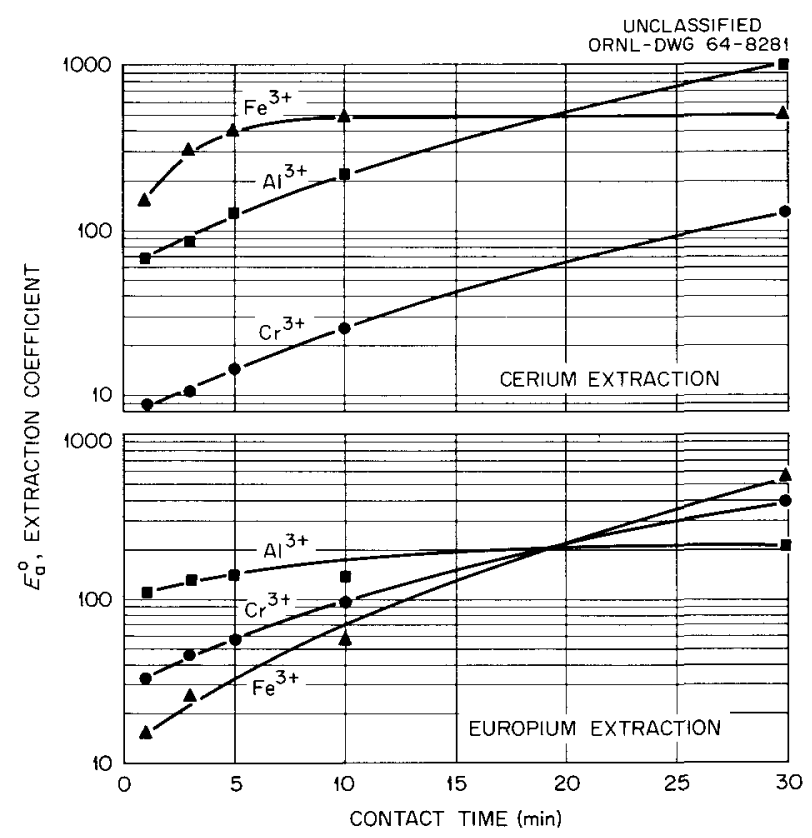

Fig. 8.1. Effect of Metal Contaminants on Extrac. tion Rates of Rare Earths. Organic phase: $0.2 \mathrm{M}$ D2EHPA-0.1 $\boldsymbol{M}$ NaD2EHP-0.15 $\boldsymbol{M}$ TBP-Amseo 125-82. Aqueous phase: $0.67 \mathrm{M} \mathrm{NO}_{3}{ }^{-}, 0.33 \mathrm{M} \mathrm{SO}_{4}{ }^{2-}$, $0.33 M$ tartrate, $0.0003 M \mathrm{Ce}$ (or Eu), and $0.17 M \mathrm{Fe}^{3+}$ or $0.03 \mathrm{M} \mathrm{Al}$ or $0.003 \mathrm{M} \mathrm{Cr}^{3+}$, at $\mathrm{pH}$ 6. Phase ratio: $1 / 1$. of cerium, while chromium depressed cerium extraction more than europium extraction. In other tests, increasing the chromium concentration in the feed from $0.003 M$ to $0.03 M$ decreased cerium extraction coefficients (3-min contacts) by a factor of 100 .

These and other results suggest that the aqueous phase contains unextractable metal-rareearth-tartrate complexes which dissociate slowly to extractable rare-earth species. The adverse effect of the offending metals can be partially overcome by increasing the amount of excess tartrate in the solution. For example, increasing the tartrate concentration in adjusted Purex $1 W W$ from $0.3 M$ to $0.4 M$ increased cerium coefficients from 19 to 40 , respectively, in $2-\mathrm{min}$ contacts and from 75 to 120 in $20 \%$ min contacts. Other variables, including the time of aging of the complexed feed and the extraction temperature are also of some importance in controlling the extraction rates of the rare earths.

\section{Cerium Oxidation and Extraction}

Cerium can be separated from the other rare earths by oxidizing, for example, with potassium permanganate, ${ }^{6}$ to $\mathrm{Ce}^{4+}$ and extracting with D2EHPA. Promising alternative oxidants studied recently include ammonium persulfate and ozone, the latter being attractive because it adds no extraneous ions to the system. In tests with $0.05 M \mathrm{Ce}\left(\mathrm{NO}_{3}\right)_{3}-\mathrm{HNO}_{3}$ feeds, the rate and extent of cerium oxidation with ozone increased with increase in temperature and with increase in nitric acid concentration in the range 2 to $10 \mathrm{M}$. With $6 \mathrm{MHNO}_{3}$, more than $95 \%$ of the cerium was oxidized (and subsequently recovered by extracting with $0.3 M$ D2EHPA-Amsco 125-82) by bubbling ozonized oxygen through a fine-porosity glass frit into a 6-in.-deep column of solution at $60^{\circ} \mathrm{C}$ for $1 \mathrm{hr}$. Analyses of the inlet and exit gas streams showed that about $3.6 \mathrm{lb}$ of ozone per pound of cerium were fed to the system over this period, with about $12 \%$ of the ozone being consumed. Contacting the phases in a four-stage countercurrent column considerably increased the ozone

\footnotetext{
${ }^{5}$ Personal communication with G. L. Richardson of Hanford, Feb. 1, 1963.

${ }^{6}$ T. A. Butler and E. E. Ketchen, Ind. Eng. Chem. 53, 651 (1961).
} 
utılization efficiency. With a solution residence tıme in the column of about $1 \mathrm{hr}$ at $60^{\circ} \mathrm{C}$, more than $90 \%$ of the cerium was oxidized on passing $0.7 \mathrm{lb}$ of ozone per pound of cerrum through the column. Approximately 25\% of this ozone was consumed.

Using silver-catalyzed ammonium persulfate as the oxidant, oxidation was very slow at room temperature but increased with increasing temperature, increasing oxidant and catalyst concentration, and decreasing acidity. Although cerium recoveries better than $90 \%$ were obtained under certain conditions by oxidizing the cerium prior to extraction with $03 M$ D2EHPA-Amsco 125-82, results were consistently better when the oxidant was added to the feed while contacting with the solvent phase. This was not due to the longer contact time in the latter case since the extraction of $\mathrm{Ce}^{4+}$ is rapid, With the latter procedure, more than $98 \%$ of the cerium was recovered in $30 \mathrm{~min}$ at $55^{\circ} \mathrm{C}$ from a mixed rare-earth feed containing $9 \mathrm{~g}$ of cerlum per 11 ter, the $\mathrm{HNO}_{3}$ concentration was $1.3 \mathrm{M}$. The persulfate/cerium ratio was $2.2 / 1$, and the silver concentration was $0.005 M$. With comparable conditions, but performing the extraction after 30 min of oxidation, cerium recovery was only $25 \%$.

\section{Separation of Strontium from Calcium}

Previous studies showed that calcium may be separated from strontium by selective extraction with D2EHPA from feeds complexed with acetate ${ }^{7}$ or by partitioning from the extractant with citrate ${ }^{8}$ solution. Although no provision was made originally for strontium-calcium separation in the threecycle process for the recovery of strontrum and mixed rare earths from Purex $1 W W$ feed, subsequent tests showed the feasibility of their separation by slight modification of second-cycle extraction conditions. In this cycle the rare earths are extracted with D2EHPA at a $\mathrm{pH}$ of about 2 to separate them from strontium, which remains in the aqueous raffinate. By making the feed $0.02 \mathrm{M}$ in citrate, to prevent the precipitation of rare earths,

\footnotetext{
${ }^{7}$ R. E. McHenry and J. C. Posey, Ind. Eng. Chem 53, 651 (1961).

${ }^{8}$ W. W. Schultz, G. L. Richardson, and J. E. Mendel, paper presented at the American Chemical Society Meeting, Washington, D.C., March 1962.
}

and operating at a $\mathrm{pH}$ of about 2.6 , most of the calcium can be made to extract with the rare earths (from which it can be readily separated in subsequent processing). This was demonstrated in a batch countercurrent test. With four extraction and three scrub stages, more than $98 \%$ of the calcium was coextracted with the rare earths, leaving more than $98 \%$ of the strontium in the raffinate

\subsection{RECOVERY OF STRONTIUM WITH CARBOXYLIC ACIDS}

A tentative process was outlined for recovering strontum from complexed Purex wastes by extraction with carboxylic acids and stripping with dilute acid. As reported previously, ${ }^{9}$ strontium extraction with these reagents is strongly dependent on $\mathrm{pH}$, reaching a maximum in the $\mathrm{pH}$ range 7.5 to 8.5 . Rare earths are also extracted appreciably, but the extraction rates are low and they limit the recoveries obtanable within reasonable times.

In a batch countercurrent demonstration of the process using $0.5 \mathrm{M}$ Sunaptic A (a commercial naphthenic ac1d mixture) in Amsco 125-82, more than $99.5 \%$ of the strontium was recovered in five extraction and two scrub $\left(0.3 M \mathrm{HNO}_{3}\right)$ stages. For $\mathrm{pH}$ control, the extractant fed to the system was about one-third in the sodium-salt form and two-thirds in the acid form. The feed was simulated Purex FTW (expected 1965 composition) waste, which was complexed with citrate and adjusted with caustic to $\mathrm{pH}$ 5.2. The $\mathrm{pH}$ in the extraction system was about 8 . Nearly $70 \%$ of the rare earths and nickel in the solution were extracted with the strontium. The strontium was quantitatively stripped from the extract with $1 / 4$ volume of $1 \mathrm{M} \mathrm{HNO}_{3}$. Overall decontamination factors for strontium were about 300 from iron, 100 from aluminum, 7000 from chromium, 300 from zirconium-niobium, 300 from ruthenium, and 10 from sodium

These results are not competitive with those given by the D2EHPA process for strontium (and rare-earths) recovery. However, the carboxylic acids used were not of optımum structure. New reagents are being obtained for testing.

\footnotetext{
${ }^{9}$ Chem. Technol. Div. Ann. Progr. Rept May 31, 1963. ORNL-3452 (supp1. 1), p. 16.
} 


\subsection{TECHNETIUM}

Previous studies ${ }^{10,11}$ showed that technetium is extracted from acid solution with tertiary amines and from acid, neutral, or basic solution with quaternary ammonium compounds. In recent tests with a quaternary extractant (Aliquat 336), technetium was effectively extracted from simulated Hanford tank waste supernatant ( $\mathrm{pH} 9$ to 13). Coefficients in the range of 70 to 130 were obtaned with $0.2 M$ Aliquat 336 in $95 \%$ dissopropylbenzene-6\% tridecanol diluent. Of many reagents tried, effective stripping was obtained only with $\geqq 2 \mathrm{M} \mathrm{HClO}_{4}$.

\subsection{ENGINEERING STUDIES}

The solvent extraction process for the recovery of cesium from adjusted Purex-type waste by use of a substituted phenol (BAMBP) as the extractant was tested in glass pulsed columns $(2$ in. in diameter and $24 \mathrm{ft}$ high) with adjusted simulated Purex $1 \mathrm{WW}$ as feed. The general operability of the pulsed columns was good, no emulsion and very little entrainment were observed. The flow capacity at flooding is shown in Table 8.3 for the extraction, scrub, and strip sections of the flowsheet. The flow capacity of a sieve plate $\left(\frac{1}{8}-1 n\right.$. holes, $23 \%$ free area) column operated with the aqueous phase continuous and at a pulse amplitude of $1 \mathrm{nn}$. was $960 \mathrm{gal} \mathrm{hr}^{-1} \mathrm{ft}^{-2}$ at a pulse frequency of $50 \mathrm{cpm}$, and 440 at $70 \mathrm{cpm}$ for the extraction section. For scrub the capacity was 430 and $260 \mathrm{gal} \mathrm{hr}^{-1} \mathrm{ft}^{-2}$ at 50 and $70 \mathrm{cpm}$ respectively. For strip, the capacity was 710 and $430 \mathrm{gal} \mathrm{hr}^{-1} \mathrm{ft}^{-2}$ respectively. The testing of nozzle plates $\left(\frac{1}{8}-1 \mathrm{n}\right.$. holes, $10 \%$ free area) operated with the organic phase contınuous showed a

\footnotetext{
${ }^{10}$ G. E. Boyd and Q. V. Larson, J. Phys. Chem 64, 988-96 (1960).

${ }^{11}$ C. F. Coleman, F. A. Kappelmann, and B. Weaver, Nuc1. Scr. Eng. 8, 507-14 (1960).
}

Table 8.3 Flow Capacity of Pulsed Columns for Recovery of Cesium by $1 M$ BAMBP in Amsco $125-82$

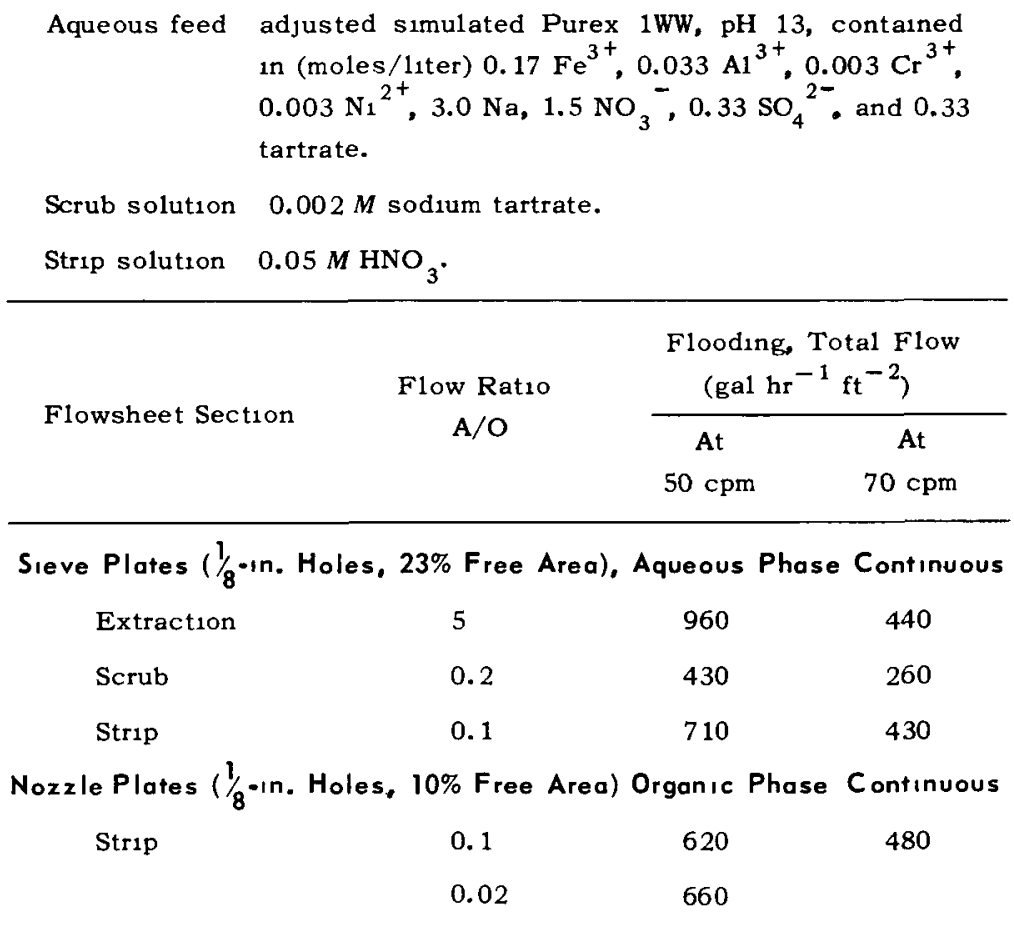


slightly lower flow capacity for the strip section. Increasing the organic/aqueous flow ratio from $10 / 1$ to $50 / 1$ had very little effect on flow capacity.

Batch phase-separation tests in a standard, baffled tank mixer ( 6 in. in diameter and 6 in. deep) were made in order to determine the feasibility of using mixer-settlers as contactors for the process. The mixing, even at the lowest power input required to produce a uniform dispersion, is more intense than that obtained in a pulsed column, and any tendency to form a stable emulsion is more likely in a mixer. Phase separation was satisfactory for systems that are typical for the extraction and strip sections of the process. The break time of the dispersion ranged from 60 to $150 \mathrm{sec}$ and was nearly independent of power input over the range of 2 to $140 \mathrm{hp}$ per $1000 \mathrm{gal}$ and mixing time from 2 to $5 \mathrm{~min}$. However, phase separation for the scrub section was erratic and in some cases extremely slow with the usual conditions set by the flowsheet. Increasing the tartrate concentration in the aqueous scrub solution from $0.002 M$ to $0.02 M$, or adding a nitrate salt to make the scrub solution about $0.5 \mathrm{M}$ in nitrate, greatly improved the phase separation. 


\section{Chemistry of Protactinium}

The purpose of this program is to study the chemistry of protactinium, with emphasis on systems potentially applicable to separations processes. Protactinium has an extreme tendency to hydrolyze, and present knowledge does not permit handling it reliably above trace concentrations in most chemical systems. Studies based largely on solvent extraction and ion exchange methods have been conducted in both sulfuric acid and hydrochloric acid solutions. However, the major effort during the past year was diverted from fundamental studies to the purification of about $40 \mathrm{~g}$ of ${ }^{231} \mathrm{~Pa}$ that was borrowed from England for use in preparing ${ }^{232} \mathrm{U}$. The ${ }^{23}{ }^{2} \mathrm{U}$ is being used for nuclear cross-section measurements as part of the Tripartite Nuclear Cross-Section Program.

\subsection{PROTACTINIUM RECOVERY}

Recovery of protactinium for return to England is complete. Approximately $39 \mathrm{~g}$ of ${ }^{231} \mathrm{~Pa}$ was recovered and has been shipped. Several potential processes, including both solvent extraction and ion exchange, were studied and partially developed, but the conventional process involving anion exchange from the hydrochloric acid-hydrofluoric acid system was used for the actual separation.

Following separation of the ${ }^{232} \mathrm{U}$, the protactinium was contained in about 8 liters of $\mathrm{HCl}-\mathrm{HF}$ solution, which was stored for over a year to permit decay of ${ }^{233} \mathrm{~Pa}$ and some fission products. Important contaminants included ${ }^{232} \mathrm{U},{ }^{228} \mathrm{Th}$, and other daughter activities, fission products, and niobium, which was present as an impurity in the original material. Processing was carried out in a hot cell in the High Level Radiation Analytical Facility, Building 3019.

The purification process was based on loading protactinium on an anion exchange resin from
$\mathrm{HCl}-\mathrm{HF}$ solution in which the fluoride has been complexed with boric acid. The resin was Dowex 1-X8 (50 to 100 mesh) and the feed composition was $9 M \mathrm{HCl}-0.2$ to $0.3 M \mathrm{HF}$, saturated with boric acid. The protactinium was eluted from the resin with $\mathrm{HCl}-\mathrm{HF}$ solutions, and the protactinium products were precipitated with ammonium hydroxide, filtered, washed, and finally ignited to the oxide.

The total amount of protactinium recovered was approximately $39 \mathrm{~g}$ (probably $\pm 1 \mathrm{~g}$ ), which was obtained in three products (Table 9.1). Product A resulted from elution of a column on which the protactinium loading was incomplete (due to insufficient boric acid to complex the fluoride completely), and it contained remarkably little niobium. The silicon and calcium impurities are believed to have been introduced with the ammonium hydroxide used for precipitation. Product $B$ resulted from elution of a column on which the rest of the protactinium had been loaded quantitatively, and it contained appreciable amounts of niobium. Product $\mathrm{C}$ was recovered from various liquid and solid wastes that had accumulated during the ${ }^{232} \mathrm{U}$ program, and it is the least-pure fraction.

A major difficulty during this work resulted from solids that appeared in the various solutions, leading in many cases to reduced flow or plugging of the ion exchange column. In some cases a white solid appeared in $\mathrm{HCl}-\mathrm{HF}$ product solutions after standing for several days. It redissolved upon addition of boric acid and appeared to follow protactinium through the ion exchange cycle. Analysis of this material showed only aluminum and silicon.

\subsection{PROCESS DEVELOPMENT}

Prior to the protactinium recovery, some scouting tests were undertaken to investigate the 
Table 9.1. Analytical Data Summary for ${ }^{231} \mathrm{~Pa}_{2} \mathrm{O}_{5}$ Products

\begin{tabular}{|c|c|c|c|}
\hline Product & A & B & C \\
\hline Weight, g & 22.45 & 22.57 & 6.70 \\
\hline Pa content, ${ }^{a} \mathrm{~g}$ & 18.9 & 16.5 & 2.83 \\
\hline $\mathrm{Nb} / \mathrm{Pa} \gamma$ ratio (February 1964$)^{b}$ & $10^{-3}$ & $4 \times 10^{-2}$ & \\
\hline \multicolumn{4}{|l|}{ Spectrographic ana lysis } \\
\hline $\mathrm{Ca}$ as oxide, $\%$ & 0.75 & 2.1 & $2-6$ \\
\hline $\mathrm{S} 1$ as oxide, $\%$ & 07 & 1.3 & $4-13$ \\
\hline $\mathrm{Nb}$ as oxide, \% & $>0.1^{c}$ & 3.1 & $1-4$ \\
\hline Al as oxide, $\%$ & N.D. ${ }^{d}$ & $\sim 2.4$ & $2-7$ \\
\hline \multicolumn{4}{|l|}{ Radiation at contact, $\mathrm{r} / \mathrm{hr}$} \\
\hline January 1964 & 3.7 & 6.2 & \\
\hline April 1964 & 5.0 & 6.9 & 1.3 \\
\hline
\end{tabular}

${ }^{a}$ Based on specific activity of $5.28 \times 10^{7}$ counts $\mathrm{min}^{-1} \mathrm{mg}^{-1}$.

${ }^{b}$ Ratio of 0.75 - and $0.3-\mathrm{Mev}$ gamma peak heights. Beta analysis indicated that $\mathrm{Zr}-\mathrm{Nb}$ activity was $>80 \% \mathrm{Nb}$.

${ }^{c}$ Estimated from relative content of fission product $\mathrm{Nb}$.

${ }^{d}$ Not detected.

applicability of alternative procedures, compared with the usual $\mathrm{HCl}-\mathrm{HF}$ anion exchange method that had been used in the past. The contaminants of primary concern were nioblum (an impurity in the material originally obtained from UKAEA), ${ }^{232} \mathrm{U}$ (from the 1rradiation), 1ts daughter ${ }^{228} \mathrm{Th}$, and aluminum (used to can the protactinium during irradiation) The ${ }^{232} \mathrm{U}$ was readily removed by passing the HCl-HF solution containing the ${ }^{231} \mathrm{~Pa}$ through a Dowex 1 resin column, and this was used as the first step of the process. Aluminum was essentially eliminated by using boric acid to complex the fluoride ion instead of using $\mathrm{AlCl}_{3}$, which had been used in most of the past work. Were some boric acid to follow the protactinium into the product solutions, it could be removed by volatilization from the protactinium oxide by adding methyl alcohol and heating.

Thorium does not load on Dowex 1 resin from high concentrations of $\mathrm{HCl}$ (or $\mathrm{HCl}-\mathrm{HF}-\mathrm{H}_{3} \mathrm{BO}_{3}$ in this case), but protactinium does load, and this is the basis of the usual separation. An alternative procedure was developed to separate protactinium and thorium based on diluting the $\mathrm{HCl}-\mathrm{HF}$ feed solution with water to reduce the hydrochloric acid concentration to about $2 N$, complexing the fluoride ion with boric acid, and passing the solution through a cation (Dowex 50 ) resin column.
In tests of this procedure, thorium loaded quantitatively on the column and protactinium passed through. There was no separation of protactinium from niobium since it also passed through the column.

The most difficult separation is that of niobium from protactinium. It was found that some separation could be obtained by eluting protactinium from Dowex 1 resin with $8 N \mathrm{HCl}-02 N \mathrm{HF}$, the separation apparently improved with decreasing $\mathrm{HF}$ and increasing $\mathrm{HCl}$ concentrations. In one test with ${ }^{95} \mathrm{Nb}$ tracer, more than $95 \%$ of the protactinium was eluted with $8 \mathrm{~N} \mathrm{HCl}-0.2 N \mathrm{HF}$ before nobium could be detected in the eluate. It was also observed, both during development work and during processing, that whenever protactinium loading on the resin was incomplete (due to low $\mathrm{HCl}$ concentration or insufficient boric acid to complex the fluoride), the eluted product contained relatively little niobium impurity.

During both the process development and the actual processing of the ${ }^{231} \mathrm{~Pa}$, there was never any evidence for irreversible formation of protactinium species that would not load on the resin. When poor loading of protactinium was observed, the addition of boric acid and/or hydrochloric acid invariably resulted in a better than 99\% loading subsequently. This observation 
includes cases in which solutions containing more than $1 \mathrm{~g}$ of protactinium per liter and excess boric acid were stored for weeks before processing. It is not clear whether the poor protactinium loading observed in some cases was the result of the formation of inextractable species or the result of the extraction coefficient being too small because of poor control of process conditions. Whatever the reason, in every case the protactinium was made extractable by addition of boric acid and hydrochloric acid. In some cases it was necessary to raise the hydrochloric acid concentration substantially above $8 \mathrm{~N}$, a value often used in the past. In the range 9.5 to $10.5 \mathrm{~N}$, quantitative loading was always observed.

\subsection{PROTACTINIUM CHEMISTRY IN SULFURIC ACID}

Study of the extraction of protactinium from sulfuric acid solutions has continued, with emphasis on the increase in extraction with increasing protactinium concentration. This behavior was described last year ${ }^{1}$ for the extraction of protactinium from $5 \mathrm{~N} \mathrm{H}_{2} \mathrm{SO}_{4}$ with both trilaurylamine and Dowex 1 resin.

The extraction of protactinium from $8.4 \mathrm{~N} \mathrm{H}_{2} \mathrm{SO}_{4}$ with $0.03 N$ trilaurylamine in diethylbenzene (Fig. 9.1) demonstrated a somewhat more complicated behavior than that reported for $5 \mathrm{~N}$ acid. At low protactinium concentrations, the concentration of extracted protactinium increases approximately linearly with the concentration remaining in the aqueous phase; thus the extraction coefficient is nearly constant, lying between 4.2 and 4.5. At high protactinium concentrations, the extraction coefficient is inversely proportional to the $1 / 3$ power of the aqueous protactinium concentration. Between these two linear portions of the curve there is a sharp increase in extraction with a very small increase in the aqueous protactinium concentration. Distribution measurements along the linear portions of the curve re-

19. L. Culler et al., Chem. Technol. Div. Ann. Progr. Rept. May 31, 1963, ORNL-3452, pp. 199-202. mained unchanged for equilibration periods between 1 and 21 days. However, the steep portion of the curve (Fig. 9.1) moved substantially to the left (i.e., lower aqueous protactinium concentration) for measurements made at 12 and 21 days compared with measurements after only 1 day.

A similar set of experiments with a $6.6 \mathrm{~N} \mathrm{H}_{2} \mathrm{SO}_{4}$ aqueous phase indicated greater extraction than that from either 5 or $8.4 \mathrm{~N}$ acid. The extraction coefficient increased slightly (from 12 to 16) with aqueous protactinium concentration in the low concentration range; it increased sharply at about $2 \times 10^{5}$ alpha counts $\mathrm{min}^{-1} \mathrm{ml}^{-1}$ concentration in the aqueous phase, and, at higher concentrations of protactinium, the extraction coefficient was again nearly constant (80 to 100). The experimental results are subject to a larger uncertainty in this series of experiments than in the others because of sampling difficulties.

The distribution behavior in these experiments is rather unusual, and the explanation of it is only tentative. Distribution curves obtained for any one acid concentration, such as $8.4 \mathrm{~N} \mathrm{H}_{2} \mathrm{SO}_{4}$ (Fig. 9.1), are reasonably consistent with a mechanism involving the formation of one or more

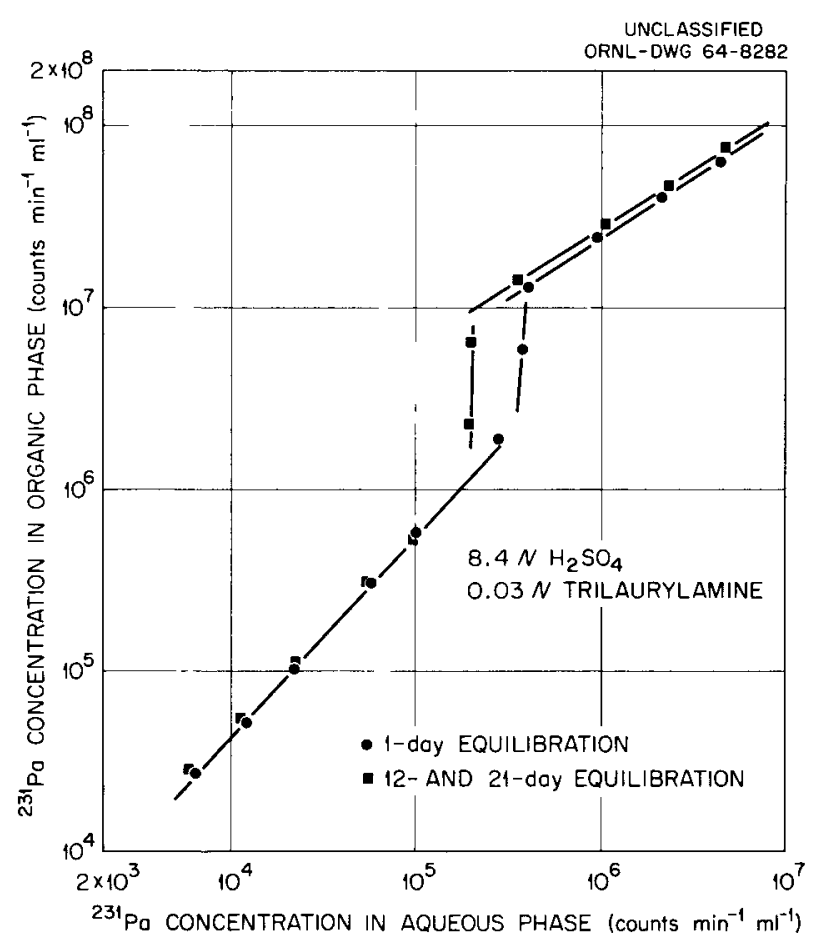

Fig. 9.1. Effect of Protactinium Concentration on Its Extroction into Trilaurylamine from $8.4 \mathrm{~N} \mathrm{H}_{2} \mathrm{SO}_{4}$. 
fairly small polymers of protactinium. The effect of changing the aqueous acid concentration is a further complication, since extraction at the low protactinium concentration is higher from 6.6 $N$ sulfuric acid than from either 5 or $8.4 \mathrm{~N}$ acid. A great deal more information will be required to permit a firm explanation of this behavior.

\subsection{SPECIFIC ACTIVITY OF ${ }^{232} \mathrm{U}$}

In collaboration with personnel of the Chemistry and Analytical Chemistry Divisions, the specific activity of ${ }^{232} U$ was determined with high-purity samples produced by the neutron irradiation of ${ }^{23} \mathrm{~Pa}$. Calorimetric measurement of the heatevolution rate and alpha counting were used. The average value obtained by these two methods was $4.77 \times 10^{10}$ dis $\mathrm{min}^{-1} \mathrm{mg}^{-1}$, which corresponds to a half-life of $71.7 \pm 0.9$ years at an estimated $95 \%$ confidence level. ${ }^{2}$

${ }^{2}$ J. M. Chilton et al., J. Inorg. Nucl. Chem. 26, 395-99 (1964). 


\section{Radiation Effects on Catalysts}

\subsection{DECOMPOSITION OF FORMIC ACID ON METAL AND OXIDE CATALYSTS}

The study of the effects of radiation on solid catalysts was continued by using the vapor-phase decomposition of formic acid as the test reaction. The microcatalytic-chromatographic technique ${ }^{1}$ was used, and the activity and selectivity of copper, nickel, stainless steel, silica gel, activated alumina, $\mathrm{ZnO}, \mathrm{UO}_{2}, \mathrm{ThO}_{2}$, silica-alumina, and chromia-alumina were studied before and after beta irradiation. The beta rays were supplied by an 80 -curie ${ }^{90} \mathrm{Sr}-{ }^{90} \mathrm{Y}$ source especially designed for this program. Transient effects due to irradiation were found with silica gel, $\mathrm{ZnO}$, and $\mathrm{UO}_{2}$. No permanent effects were found in any case.

\section{Progress and Status}

The study of the effect of beta radiation on catalysts for the decomposition of formic acid was concluded, and attention will now be turned to an investigation of energy transfer phenomena between solids and adsorbed materials in a radiation field.

\section{Experimental Work}

Design of the Equipment. - The radiation source used in these studies contains 80 curies of ${ }^{90} \mathrm{SrTiO}_{3}$ in the form of a disk approximately $2 \mathrm{~cm}$ in diameter and $4 \mathrm{~mm}$ thick. This disk is encapsulated in a stainless steel container having a 5-mil-thick stainless steel window which is in turn held in a lead shield, with the window facing up. A sliding drawer in the lead shield, operated

\footnotetext{
${ }^{1}$ R. J. Kokes, H. Tobin, Jr., and P. H. Emmett, J. Am. Chem. Soc. 77, 5860 (1955).
}

by a crank, allows positioning of the catalyst holder directly above the source window (Fig. 10.1). The catalyst holder, also of stainless steel, has a 2.5-mil-thick window on the bottom to allow the entrance of the beta particles, a thermocouple well, an electric heater, and gas inlet and outlet lines. The wires and lines are brought out of the shield through an offset channel in the sliding drawer.

Dosimetry. - The dose rate (due primarily to the energetic beta particles emitted from ${ }^{90} \mathrm{Y}$, which is in equilibrium with the ${ }^{90} \mathrm{Sr}$ ) was measured by the reduction of a $\mathrm{Ce}(\mathrm{IV})$ solution in a gold-foil cup. A value of $4.45 \times 10^{18} \mathrm{ev} \mathrm{min}^{-1}$ $\mathrm{ml}^{-1}$ was obtained. The absorption in the 1 -milthick gold foil should not be much different from that in 2.5 mils of stainless steel, so the dose rate inside the catalyst holder should be about the same. Attempts to measure the dose rate inside the catalyst holder directly by using $\mathrm{NaCOOH}$ solutions ${ }^{2}$ gave lower and highly erratic results, probably because of difficulty in analyzing for the very small total amount of oxalate ion produced.

Reaction Rate Measurements. - Method. - The catalysts were placed in the catalyst holder as pressed porous disks, in the case of the metals, and as 30- to 40-mesh granules, in the case of the oxides. The holder was mounted in the sliding drawer and brought to about $200^{\circ} \mathrm{C}$ in a stream of helium carrier gas. Then a "slug" of helium, saturated at room temperature with $\mathrm{HCOOH}$, was introduced into the carrier stream by the operation of a linear valve of the type used to inject samples into a gas chromatograph. The $\mathrm{HCOOH}$ was carried over the catalyst, through a cold trap to remove unreacted $\mathrm{HCOOH}$ and water, and into a

\footnotetext{
${ }^{2}$ T. J. Hardwick and w. S. Guentner, J. Phys. Chem. 63, 896 (1959).
} 


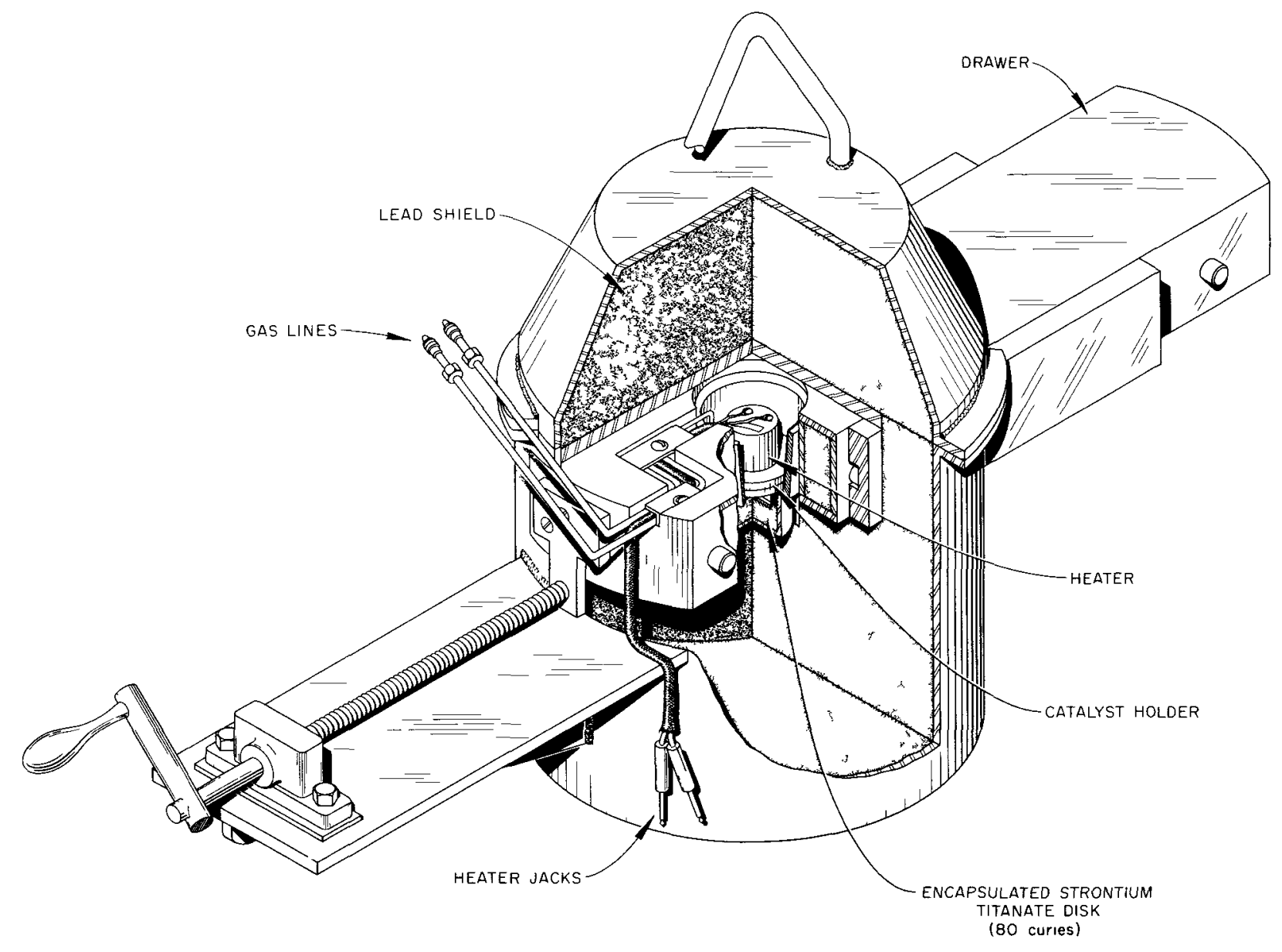

Fig. 10.1, Eighty-Curie Beta Radiation Source.

gas chromatograph for analysis of $\mathrm{CO}$ and $\mathrm{CO}_{2}$ This procedure was repeated at several temperatures, after which the system was cooled and stored under a slight, positive helium pressure After the system had stood overnight, the measurements were repeated to see if storage, use, or thermal cycling had affected the catalytic activity Then the sample was cooled and placed in the source for an overnight irradiation, and the measurements were repeated The sample was then given a 2- to 3-day irradiation, and the catalytic activity was again measured at various temperatures In these experiments, the catalyst was removed from the radiation field before the measurements were made Measurements were made of the catalytic activity in the presence of the radiation field, but no effects were found in any of these cases

Results - The results obtained for the unirradiated oxide catalysts are given in Table 101 
They are, in general, in agreement with results reported in the literature. ${ }^{3}$ No effect of radiation was found for the chromia-alumina, silica-alumina, thoria, or activated alumina. For thoria and activated alumina, the extent of decomposition of $\mathrm{HCOOH}$ was only slightly greater in the presence of the catalyst than in its absence, necessitating a large correction; so the results can only be considered semiquantitative. The effects of overnight irradiation on silica gel, $\mathrm{ZnO}$, and $\mathrm{UO}_{2}$ are shown by the triangular points in Figs. 10.2, 10.3, and 10.4 respectively. In all cases, the effect observed was a temporary increase in the rate of the minor reaction: dehydrogenation in the case of silica gel and $\mathrm{UO}_{2}$ and dehydration in the case of $\mathrm{ZnO}$. Upon use, the radiation-induced activity declined as indicated by the dashed lines. For $\mathrm{UO}_{2}$ and $\mathrm{ZnO}$, the activity dropped below its original value and became undetectable at the lower temperatures. For silica gel, the activity returned to its original level. The second, and longer, irradiation restored the original activity to $\mathrm{ZnO}$ and enhanced the activity of silica gel and $\mathrm{UO}_{2}$, as shown by the square points in Figs. 10.2-10.4. Whether even higher radiation doses

${ }^{3}$ P. Mars, J. J. F. Scholten, and P. Zweitering, "The Catalytic Decomposition of Formic Acid," p. 35 in Advances in Catalysis, vol. 14, Academic, New York, 1963. would give greater enhancement was not determined.

The study of the metal catalysts copper and nickel was complicated by the fact that the reaction products poison the catalysts, and the

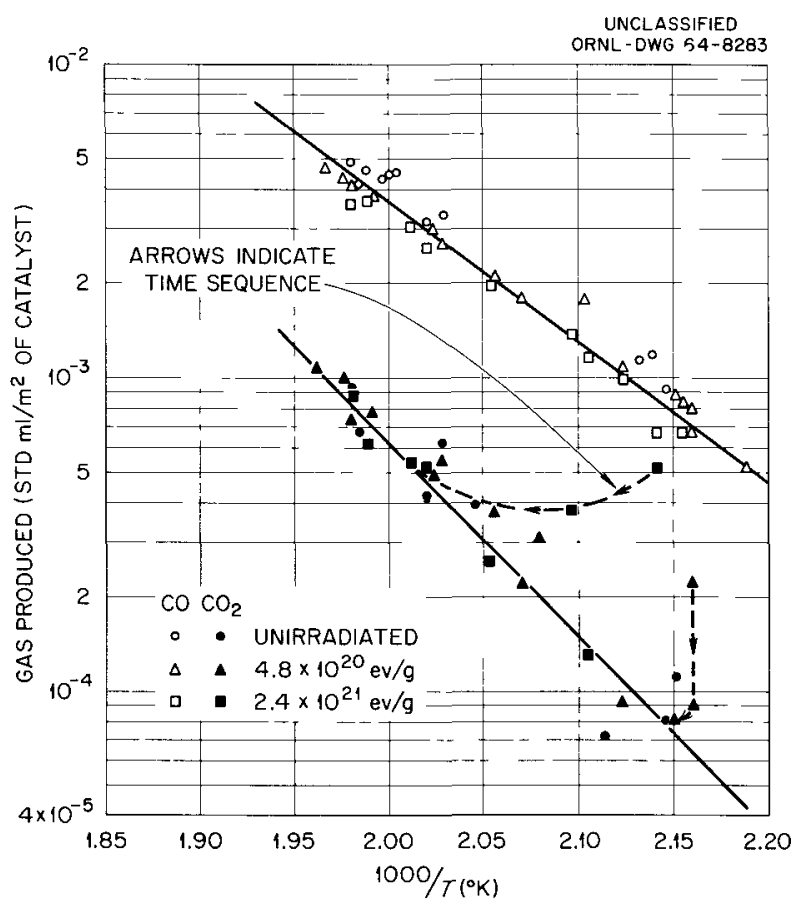

Fig. 10.2. The Effect of Beta Radiation on the De. composition of Formic Acid on Silica Gel.

Table 10.1. The Decomposition of Formic Acid on Oxide Catalysts

\begin{tabular}{|c|c|c|c|c|c|c|}
\hline \multirow{3}{*}{ Catalyst } & \multirow{3}{*}{$\begin{array}{l}\text { Weight } \\
\text { (g) }\end{array}$} & \multirow{3}{*}{$\begin{array}{l}\text { Surface Area } \\
\qquad\left(\mathrm{m}^{2} / \mathrm{g}\right)\end{array}$} & \multicolumn{2}{|c|}{ Selectivity at $220^{\circ} \mathrm{C}$} & \multirow{2}{*}{\multicolumn{2}{|c|}{$\begin{array}{l}\text { Apparent Activation Energy } \\
\text { (kcal/mole) }\end{array}$}} \\
\hline & & & \multirow{2}{*}{$\begin{array}{c}\text { Percent } \\
\text { Dehydration }\end{array}$} & \multirow{2}{*}{$\begin{array}{c}\text { Percent } \\
\text { Dehydrogenation }\end{array}$} & & \\
\hline & & & & & Dehydration & Dehydrogenation \\
\hline $\mathrm{SiO}_{2}-\mathrm{Al}_{2} \mathrm{O}_{3}$ & 0.4709 & 375 & $99+$ & $\sim 0$ & 19.1 & \\
\hline $\mathrm{UO}_{2}$ & 1.0255 & 6.8 & 97 & 3 & 29.1 & 17.4 \\
\hline $\mathrm{SiO}_{2}$ (silica gel) & 0.6100 & 210 & 87 & 13 & 20.5 & 28.3 \\
\hline $\mathrm{Al}_{2} \mathrm{O}_{3}$ & 1.2928 & 126 & $67^{a}$ & $33^{a}$ & $25^{a}$ & $18^{a}$ \\
\hline $\mathrm{ZnO}$ & 0.5499 & 25.7 & 6 & 94 & 26.8 & 17.4 \\
\hline $\mathrm{Cr}_{2} \mathrm{O}_{3}-\mathrm{Al}_{2} \mathrm{O}_{3}$ & 1.0722 & 71 & $\sim 0$ & $99+$ & & 6.9 \\
\hline $\mathrm{ThO}_{2}$ & 2.0393 & 28 & $b$ & $b$ & $16^{a}$ & $b$ \\
\hline
\end{tabular}

${ }^{a}$ Catalyst not very active. Precision very poor.

${ }^{b}$ Data badly scattered for dehydrogenation reaction. Values could not be calculated. 


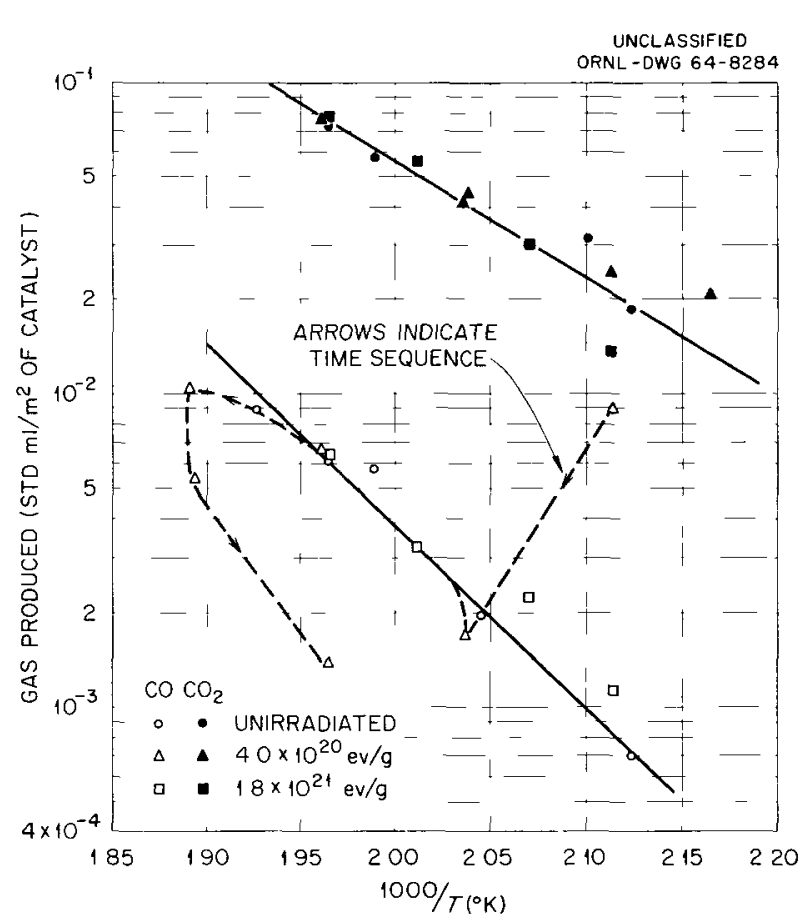

Fig. 10.3. The Effect of Beta Radiation on the Decomposition of Formic Acid on Zinc Oxide.

extent of reaction became a function of the time between injections of $\mathrm{HCOOH}$ vapor as well as of temperature. As well as could be determined, however, no radiation effects occurred.

Measurements made with the stainless steel container alone (needed to provide corrections to the measurements made on the various catalysts) showed it to be a quite effective catalyst, considering the fact that only a few square centimeters of surface was exposed. The reaction was about $84 \%$ dehydrogenation and $16 \%$ dehydration, with apparent activation energies of 22.8 and

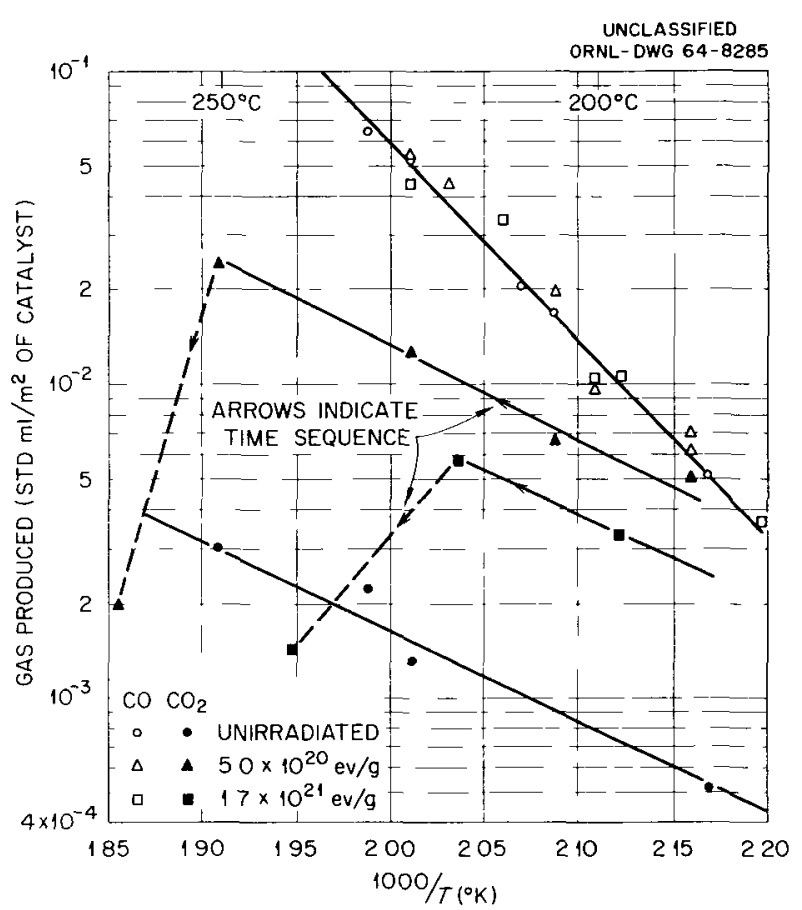

Fig. 10.4. The Effect of Beta Radiation on the De. composition of Formic Acid on $\mathrm{UO}_{2}$.

$24.6 \mathrm{kcal} / \mathrm{mole}$ respectively. There was no irradiation effect.

\section{Conclusions}

Beta radiation can induce changes in some oxide catalysts for the decomposition of $\mathrm{HCOOH}$. The changes found were always transient increases in the catalytic activity for the minor mode of reaction. The microcatalytic-chromatographic technique, coupled with the ${ }^{90} \mathrm{Sr}-{ }^{90} \mathrm{Y}$ beta source designed for use in this study, provides a rapid method for scanning reactant-catalyst systems for possible useful radiation effects. 


\section{High-Temperature Chemistry}

The purpose of this program is to develop and exploit varıous spectrophotometric techniques for studying the properties of aqueous solutions, primarily of uranium, transuranium, rare-earth, and transition-group elements. The principal effort is directed at construction of a spectrophotometer that can be used to study spectra of these elements in solutions up to $330^{\circ} \mathrm{C}$.

\subsection{HIGH-TEMPERATURE, HIGH-PRESSURE SPECTROPHOTOMETER SYSTEM}

The program for the absorption spectrophotometric study of aqueous solutions at high temperature and high pressure has been discussed in recent reports. ${ }^{2-4} \mathrm{~A}$ high-pressure, high-temperature spectrophotometer has been especially designed for the Laboratory under subcontract by the Applied Physics Corporation (APC) of Monrovia, Calıfornia. The design is such that, ultimately, solutions containing high levels of alpha-radioactive elements of interest in heavy-element chemistry can be studied. The high-temperature, high-pressure spectrophotometer system will permit the study of the solution chemistry behavior, reaction kinetics, and spectra of elements and

\footnotetext{
${ }^{1}$ Joint program with the Analytical Chemistry Division.

${ }^{2}$ F. L. Culler et al., Chem. Technol. Div. Ann. Progr. Rept. May 31, 1963, ORNL-3452, p. 213.

${ }^{3}$ Anal. Chem. Div. Ann. Progr. Rept. Nov. 15, 1963, ORNL-3537, pp. 39-45.

${ }^{4}$ R. E. Biggers and R. Eno, "The Design and Development of a Spectrophotometer System for Optical Measurements on Liquids at High-Temperatures and High-Pressures", presented at the Symposium on High Temperature Solution Chemistry, 141st meeting of the American Chemical Society, Washington, D.C., March $20-24,1962$, and also at the Symposium on Molecular Structure and Spectroscopy, Department of Physics and Astronomy, Ohio State University, Columbus, June 11-15, 1962. To be published.
}

substances in solution up to at least $330^{\circ} \mathrm{C}$. The system will be operable at pressures to at least 5000 ps 1 with the highly radioactive solutions.

During this report period, the prototype hightemperature, high-pressure spectrophotometer cell that was constructed for ORNL by APC has been given a series of tests utilizing various sets of sapphire windows that were made for the cell by the Linde Company, both c-axis $\left(0^{\circ}\right)$ and $60^{\circ}$ windows were used in the test series. Tests made here showed that the sapphire windows made by Linde conform to our specifications for surface finish and flatness. The prototype cell has been subjected to operating and assembly procedures, and its performance has been evaluated at $350^{\circ} \mathrm{C}$ and 5000 psi. A leak-rate specification of not more than $1 \mu 1$ of water per hour from the pressurized end chambers of the cell, at the maximum conditions of temperature and pressure, was imposed to permit ultımate operation with high levels of alpha radioactivity.

A number of dimensional measurements and interferometric flatness and finish measurements of the cell and all of its components were made in order to verify conformity to design. Some of the measurements were made as a function of pressure up to $5000 \mathrm{ps} 1$. As a result of these tests, several minor changes were made in the cell design.

A new spring was designed for loading the inner Haskel seals of the cell. The spring must develop approximately $200 \mathrm{lb}$ of force, at $400^{\circ} \mathrm{C}$, within a total linear space of $0.240 \mathrm{in}$., and with a very small deflection of approximately $0.020 \mathrm{in}$. This requirement was met with a Bellville type of spring. Four such springs were designed and constructed from 17-4-PH precipitation-hardened stainless steel. Calibrations at room temperature confirmed the design, and the springs have been tested at full temperature and pressure, they perform according to design specifications. 
The design of the window mounting plate was changed, and the thickness was increased considerably, to provide one that will withstand the temperature and pressure requirement without flexing beyond a tolerable limit. In tests carried out during this past year, it was found that, at elevated-temperature operation, flexure of the thinner plates led to a condition in which the sapphire windows were unsupported near their centers and were subjected to very high stresses. These stresses can exceed the rupture strength of sapphire, and sapphire windows have, on occasion, fractured.

\subsection{SPECTRAL STUDIES OF IONIC SYSTEMS AT ELEVATED TEMPERATURES}

One of the purposes of this program is to develop and exploit varıous spectrophotometric technıques for studying the properties and reactions in aqueous solutions, primarily of uranium, the higher transuranium, rare-earth, and other transition-group elements. A Cary model 14 CMR spectrophotometer system is now fully equipped for routine spectral studies of solutions up to about $97^{\circ} \mathrm{C}$, using essentially conventional equipment. The pressurized, circulating, closed-loop system and instrumentation has been installed and is being readied for operation at temperatures beyond $100^{\circ} \mathrm{C}$, up to approximately 150 to $175^{\circ} \mathrm{C}$.

Work was started on studies of the environmental effect of ronic species (complexing ions) and temperature on the spectra of $\mathrm{U}(\mathrm{VI})$ systems, beginning with uranyl ion in perchlorate systems at fixed 1onic strengths in both light and heavy water. Preliminary experiments were carried out at $1 \mathrm{M}$ $\mathrm{HClO}_{4}$ and an 1onc strength of 3.0 over the temperature range 25 to $95^{\circ} \mathrm{C}$. The experimental variables of interest are temperature, U(VI) concentration, acidity, and heavy-water effects (solvent isotope effects). The effects of sulfate and nitrate ions as complexing ions will be studied subsequently. Studies at temperatures from this point to the vicinity of the critical point will have to await completion of the high-temperature, highpressure spectrophotometer system.

All the work is being performed in series of experiments at invariant ionic strength, insofar as this is possible. The work has been extended into the region of low acidity, where hydrolysis is an important effect. All the experimental spectral data are being obtained, digitized, and punched as IBM card decks, simultaneously with the stripchart spectral-data output. Smoothing, resolution, analysis of reacting systems, and other types of analysis of the data will, for the most part, be carried out with computer techniques and programs that we have been developing. The spectrophotometer digital data output system has been discussed previously. ${ }^{2,3}$

The uranyl ion exhibits 14 absorption bands in the region 3300 to $5000 \mathrm{~A}$. A change in the 1onic strength from 2 to 3 does not affect the absorption of $0.01 M$ uranyl solution at $1 \mathrm{MHClO}_{4}$. There appear to be small changes in the absorption spectra between an ionic strength of 1 to 2 . An ionic strength of 3 has been selected for the initial studies. We have observed no significant changes in the absorptivity of $0.01 \mathrm{M}$ uranyl ion at an ionic strength of 3.0 when the acidity is changed from $1 M$ to $3 \mathrm{M} \mathrm{HClO}_{4}$. These experiments in perchloric media are being carried out to serve as reference measurements for subsequent work on the effects of solvent and temperature on the complexation of uranyl ion by sulfate, nitrate, and other 1ons.

Several series of measurements have now been made on stoichiometric solutions of uranyl perchlorate (no excess acid), on solutions containing excess acid, and on solutions which were extensively hydrolyzed. Each solution was studied over the temperature range 25 to $95^{\circ} \mathrm{C}$ for each change of the experimental variable.

The effects of acid and temperature on the spectra of the uranyl solution are quite marked. In many cases, similar results are obtained with either an increase in alkalinity or an increase in temperature. The molar absorptivities increased as the basicity or the temperature increased. Solutions of $0.01 \quad M \quad \mathrm{UO}_{2}\left(\mathrm{ClO}_{4}\right)_{2}$ precipitated immediately when the $\mathrm{U}(\mathrm{VI})$ to $\mathrm{OH}$ ratio was greater than 1.1 at $25^{\circ} \mathrm{C}$, and with $24 \mathrm{hr}$ when the ratio was 1.0 . With a ratio of 0.9 , the $0.01 \mathrm{M}$ uranyl solution precipitated at approximately $60^{\circ} \mathrm{C}$. At a ratio of 0.7 , the solution precipitated at approximately $95^{\circ} \mathrm{C}$. The molar absorptivities changed very 1 ittle with acid concentration in the range 2.5 to $0.1 M \mathrm{HClO}_{4}$, however. Work at uranyl ion concentrations up to about $0.8 M$ is in progress. It has been observed that at high uranyl perchlorate concentrations, there is a slow approach to equilibrium when the temperature is raised, even in the presence of excess acid. The 
magnitude of the effect is surprising, and it will be studied further.

\subsection{SPECTROPHOTOMETRIC STUDIES OF Pu(IV) IN AQUEOUS NITRATE MEDI ${ }^{5}$}

The analysis of data from spectrophotometric studies has continued. An objective of this work was to determine the kinetics of the polymerization and depolymerization of $\mathrm{Pu}(\mathrm{IV})$ and the properties of $\mathrm{Pu}(\mathrm{IV})$ polymer in solution under conditions of acidity, temperature, and solution composition encountered in fuel processing. An internal memorandum on the plutonium work was reissued ${ }^{6}$ for external distribution. Preliminary data analyses by approximation methods have been summarized. ${ }^{7}$

\section{Polymerization and Precipitation Behavior of Pu(IV) in Acid Nitrate Media}

The recovery of plutonium from irradiated nuclear fuels by aqueous processing methods normally involves dissolution of the fuel in nitric acid followed by solvent extraction or ion exchange purification of tetravalent plutonium from the acid nitrate medium. Hydrolysis and subsequent polymerization of the tetravalent plutonium can cause difficulty because polymeric plutonium is neither extracted by usual solvents nor sorbed on ion exchange resins. In addition, increasing the temperature of the collordal polymer causes it to precipitate if the temperature exceeds a critical value for any given polymeric solution. Precipitation could result in serious criticality problems,

\footnotetext{
${ }^{5}$ In collaboration with D. A. Costanzo, Analytical Chemistry Division.

${ }^{6}$ R. E. Biggers and D. A. Costanzo, Hazards and Experimental Evaluation for: Studies on the Polymerization and Hydrolysis of Plutonium in Uranyl Nitrate Acid Solutions at Elevated Temperatures, ORNL-TM580 (May 22, 1963).

${ }^{7}$ D. A. Costanzo and R. E. Biggers, A Study of the Polymerization, Depolymerization and Precipitation of Tetravalent Plutonium as Functions of Temperature and Acidity by Spectrophotometric Methods: Preliminary Report, ORNL-TM-585 (July 1, 1963).
}

and inadequate extraction or sorption could result in loss of plutonium to process waste streams. The present work was undertaken to provide more extensive data on the kinetics of polymerization of plutonium in acid nitrate media.

The polymerization of $\mathrm{Pu}(\mathrm{IV})$ was studied as a function of plutonium and nitric acid concentrations and of temperature. The disproportionation of $\mathrm{Pu}(\mathrm{IV})$ and the oxidation of $\mathrm{Pu}(\mathrm{IV})$ by nitrate ion were also studied. Colloidal polymer formation is favored by an increase in plutonium concentration, by temperature, and by a decrease in acidity. Temperature markedly increases the rate and extent of polymer formation at any particular acidity. Figure 11.1 shows the concentration-time plot for the five-component plutonium system in $0.06 M$ $\mathrm{HNO}_{3}$ at $25^{\circ} \mathrm{C}$. This figure represents one of the final results of the computer analyses of the dynamic spectral data of Sect. 11.4. This figure was prepared as part of the computer output for plotting on the Calcomp off-line plotter. Other types of data and plots obtaned are discussed also in Sect. 11.4. Similar results have been obtained for other acidities, media, and temperatures.

For solutions containing initially $\mathrm{Pu}(\mathrm{III})$ and $\mathrm{Pu}(\mathrm{VI})$ resulting from the rapid disproportionation of $\mathrm{Pu}(\mathrm{IV})$ at low acidity, the removal of $\mathrm{Pu}(\mathrm{IV})$ from solution by polymerization of the $\mathrm{Pu}(\mathrm{IV})$ reversed the disproportionation reaction. This effect is more pronounced the lower the acidity. The effects of $\mathrm{UO}_{2}\left(\mathrm{NO}_{3}\right)_{2}, \mathrm{Al}\left(\mathrm{NO}_{3}\right)_{3}, \mathrm{NaNO}_{3}$, and $\mathrm{NaF}$ on the kinetics of polymer formation in acid nitrate media were also determined at low acidities and at various temperatures. In the presence of high concentrations of a nitrate salt, the colloidal Pu(IV) polymer precipitated.

The precipitation of "aged" Pu(IV) polymer by nitrate-containing electrolytes (e.g., $\mathrm{HNO}_{3}$, $\mathrm{Al}\left(\mathrm{NO}_{3}\right)_{3}, \mathrm{NaNO}_{3}$, and $\mathrm{LiNO}_{3}$ ) was studied as a function of nitrate ion concentration at $25^{\circ} \mathrm{C}$. (The term "aged" $\mathrm{Pu}(\mathrm{IV})$ polymer is applied to polymer solutions that have set for several weeks at room temperature or that have been subjected to boiling for $24 \mathrm{hr}$.) The amount of polymer precipitated in the nitrate media reached a maximum at 2 to $3 \mathrm{M}$ nitrate and decreased thereafter $w 1$ th an increase in nitrate concentration. Precipitation did not occur above a nitrate concentration of $4 \mathrm{M}$. These studies show that polymer formation and precipitation can be prevented in reactor fuel processing by the proper control of conditions. 


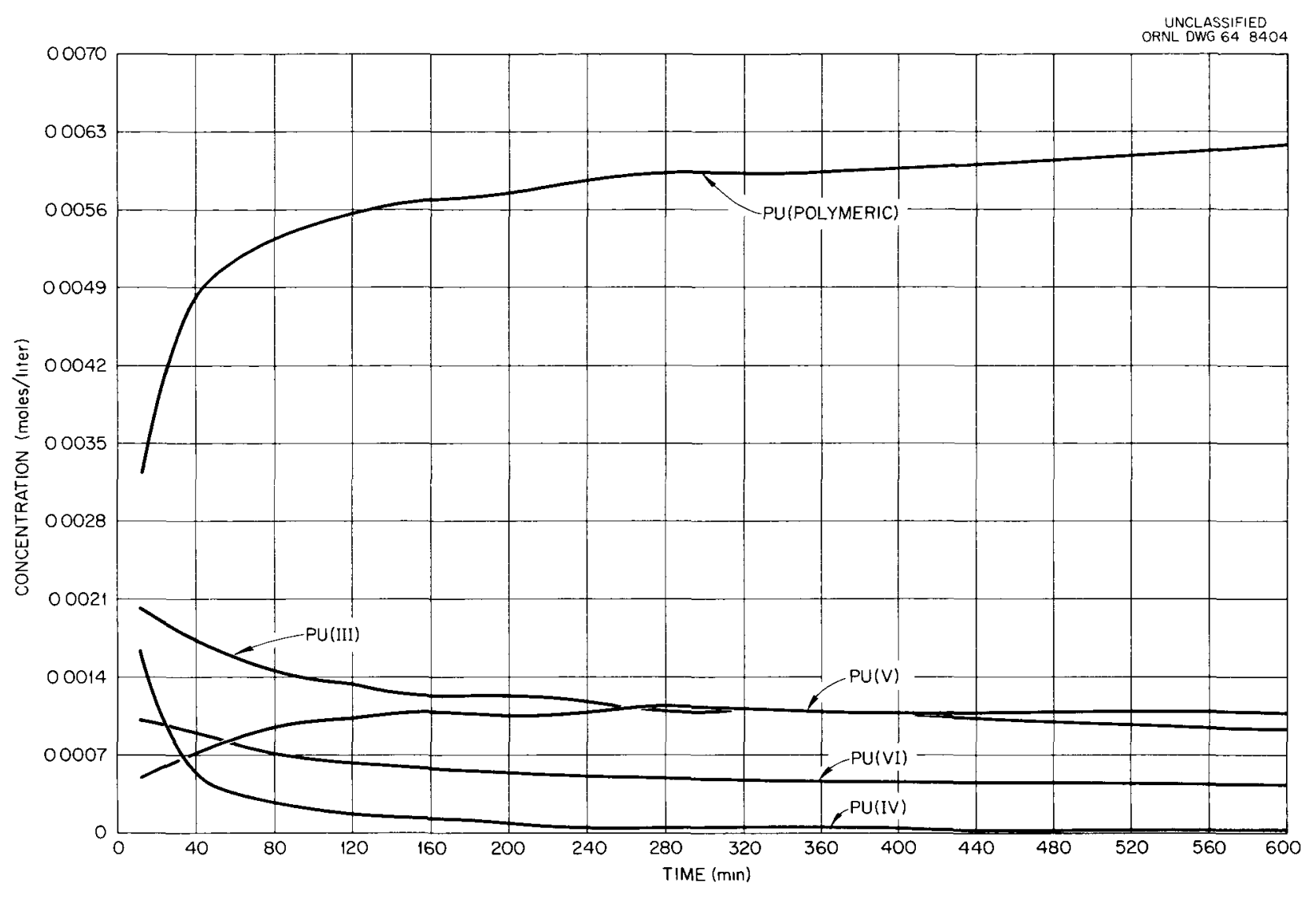

Fig. 11.1. Reactions of Plutonium in $0.06 \mathrm{MHO}_{3}$ at $25^{\circ} \mathrm{C}$ (Concentration-Time Plots for the Five-Component System), Showing Disproportionation of Pu(IV) and Polymer Formotion.

\section{Kinetics of the Depolymerization of Polymeric Pu(IV) in Acidic Nitrate Media and in the Presence of Complexing Agents}

The work that was briefly summarized in the previous section showed that the polymerization of $\mathrm{Pu}(\mathrm{IV})$ can be very rapid. Experiments carried out during the early plutonium project work show that the depolymerization by increased acid concentration is very slow, and drastic conditions are required for the depolymerization. In addition, since the depolymerization is very slow at even high acidities, the solutions and precipitates require drastic treatment before becoming suitable for further processing.

The kinetics of the depolymerization of freshly prepared polymeric $\mathrm{Pu}(\mathrm{IV})$ to ionic plutonium have been studied at acidities from 1 to $15 \mathrm{MHNO}_{3}$.
As a typical example, Fig. 11.2 shows the rate of depolymerization of polymeric plutonium in $1 M$ $\mathrm{HNO}_{3}$. The data do not indicate first-order depolymerization kinetics. Figure 11.3 is a threedimensional surface, representing the interrelated effects of reaction rate, time, and the $\mathrm{H}^{+}$activity.

The rates of depolymerization of aged polymeric $\mathrm{Pu}(\mathrm{IV})$ were determıned in $5 \mathrm{M} \mathrm{HNO}_{3}$ and at elevated temperatures. In $5 \mathrm{MHNO}_{3}$, the depolymer1zation rate is about five times slower than for freshly prepared polymer. A 600 -fold increase in rate was observed for a $70^{\circ}$ increase in temperature. Approximate activation energies for the depolymerization of aged and fresh polymer were calculated to be 16.7 and $14.2 \mathrm{kcal}$ respectively.

The effects of fluoride, sulfate, and fluoride in the presence of a 4.1 mole ratio excess of alum1num on the depolymerization kinetics were also 


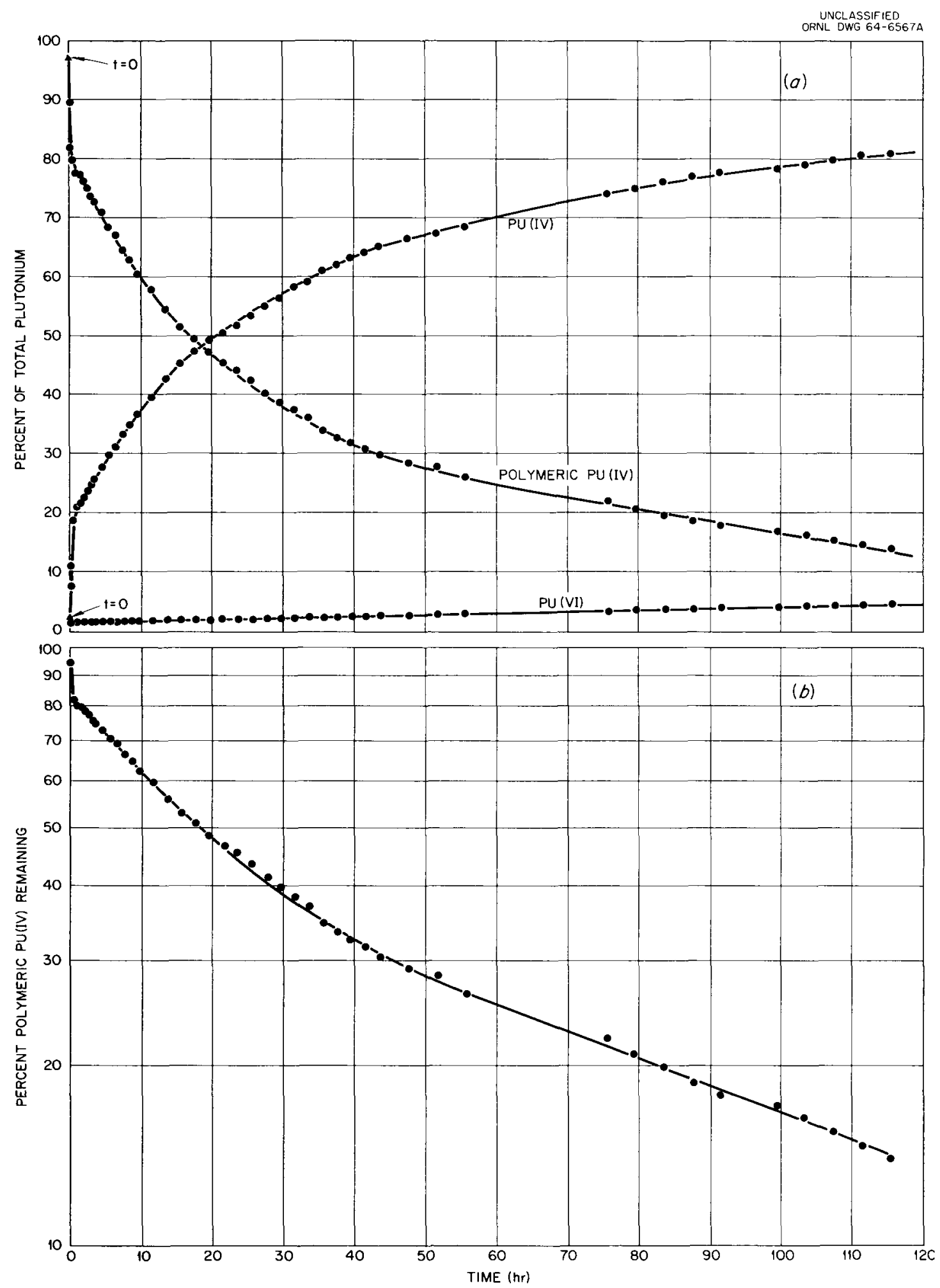

Fig. 11.2. Concentration-Time Curves for the Conversion of Freshly Prepared Polymeric Pu(IV) to lonic Plutonium in $1 \mathrm{M} \mathrm{HNO}_{3}$ at $25^{\circ} \mathrm{C}$. Total Pu, $7.448 \times 10^{-3} \mathrm{M}$. (a) Distribution between the various states during the depolymerization reaction (triangular points show concentrations of various states at $t=0$ ); $(b)$ concentration-time logarithmic plot for polymer, corrected for amount of ionic plutonium initially present (3\%). 


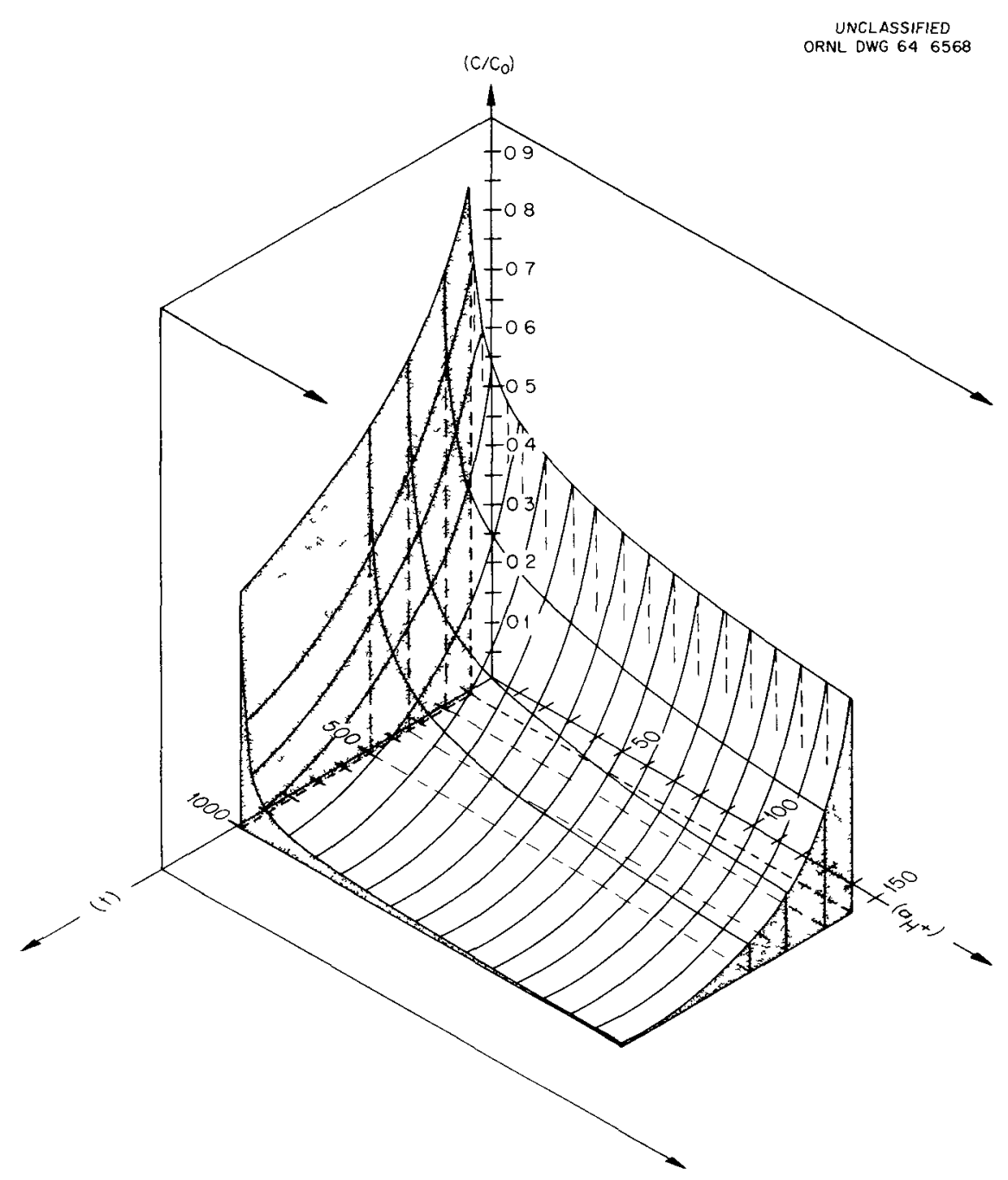

Fig. 11.3. Three-Dimensional Representation of the Depolymerizotion Surface for Fresh Polymeric Pu(IV), Interrelating the Following: Polymeric Pu(IV) Fraction Remaining $\left(C / C_{0}\right)$, Time $(t)$, and the Stoichiometric Nitric Acid Activity $\left(\mathrm{a}_{\mathrm{H}^{+}}\right)$. Temperature, $25^{\circ} \mathrm{C}$, plutonium concentration, $7.45 \times 10^{-3} \mathrm{M}$.

studied. The effects of fluoride were shown to exert up to an 8000 -fold decrease in the time required to convert $50 \%$ of the plutonium present as polymeric $\mathrm{Pu}(\mathrm{IV})$ to ionic plutonium, over that in pure acid.

\subsection{COMPUTER PROGRAMS FOR SPECTROPHOTOMETRIC STUDIES}

\section{Computer Program for the Analyses of Spectrophotometric Absorption Data from Dynamic Multicomponent Systems ${ }^{5}$}

A study of the reaction kinetics of the plutonium polymer system by spectrophotometric means has prompted the development of methods that could be used for the analysis of data from such systems. The complexity of the mathematical computations requires the use of digital computing techniques for a reasonably quick and statistically meaningful analysis of the data. In order to make possible the analysis, a number of FORTRAN computer programs and subroutines have been prepared for the IBM 7090 or CDC 1604-A computers. ${ }^{8}$ The main program (calling title AØDSD) is complete. All the subprograms are finished and oper-

\footnotetext{
${ }^{8}$ In collaboration with A. A. Brooks, E. C. Long, and O. W. Russ of the Central Data Processing Center, ORGDP.
} 
ating. A general discussion of the computer program has already been presented. ${ }^{2,3}$

Considerable effort was applied to the problem of finding various methods to accurately fit, automatically, the absorption-time data in order to permit the calculation of time-independent spectra from the experiment results obtained with dynamic systems.

It appears that a polynomial curve-fitting technique is applicable to those cases where the absorption-time curve has a relatively large number of data points per unit time interval, and especially for cases of this type that show significant statistical scatter of the experimental data. For those cases where the scatter is not significant and where a large number of data points are not available, a moving-point-group interpolation technique must be used. The moving-point-group or interpolation technique will not handle very significant statistical scatter as well, but will help remove a small amount of scatter; under these conditions, in general, this technique gives results superior to those provided by the single polynomial curve-fitting technique. The exact number of data points or spacings necessary are strongly dependent on the particular characteristics and reaction kinetics of the system under study. Lagrangian interpolation appears to be significantly better than most of the other approaches applied to this problem for much of the work studied.

The computed reaction-rate data and various other types of statistical data are tabulated for each component and species, if desired, and the reaction rate curve for each species and the absorption-time functions can be plotted on the Calcomp curve plotter as direct output from the computer. The program also calculates the instantaneous reaction rate, or slope, at each data point on the curve of the concentration vs time for each species of the system. This facilitates the kinetic analysis of proposed reaction mechanisms for all the species present in the solution under study and which may be involved in reactions along several different paths at the same time. The data may also be punched out to be used as input for a more detailed kinetic analysis by subsequent programs. 


\section{Mechanisms of Separations. Processes}

The development of mathematical equations to describe the extraction of uranyl nitrate from aqueous nitric acid by tributyl phosphate-hydrocarbon diluent solutions requires a knowledge of the activities of the various chemical species in the multicomponent systems. These are being obtained from measurements of the vapor pressures of water, nitric acid, and tributyl phosphate (TBP), and from analyses of literature data.

\subsection{ACTIVITIES OF WATER, NITRIC ACID, AND URANYL NITRATE IN THE THREE. COMPONENT SYSTEM}

The transpiration technique for the dynamic measurement of vapor pressure was used to obtain the partial pressures of water and nitric acid over the three-component system water-nitric acid-uranyl nitrate at $25^{\circ} \mathrm{C}$. The concentration of nitric acid was varied from 1 to $14 \mathrm{~m}$, while the concentration of uranyl nitrate hexahydrate (UNH) was varied from 0 to $2.3 \mathrm{~m}$. The activities of UNH were calculated by means of the Gibbs-Duhem relation,

$$
n_{1} d \ln a_{1}+n_{2} d \ln a_{2}+n_{3} d \ln a_{3}=0 \text {. }
$$

Subscripts 1,2 , and 3 refer to water, nitric acid, and uranyl nitrate, respectively, and the terms $n$ and $a$ refer to the number of moles and the activity.

After integration of Eq. (1) and appropriate substitutions, the ratios of activities of nitric acid in the three-component system to corresponding values in the two-component system water-nitric acid were fitted to a four-parameter empirical function. By use of cross-differentiation terms, the ratios of the activities of water in the three-component system to the product of the activities in the two two-component systems were also used to evaluate these four parameters. Since the final calcula- tions involve the two two-component systems, activity coefficients of nitric acid solutions and water activities in aqueous uranyl nitrate solutions were fitted to appropriate semitheoretical equations using data in the literature. ${ }^{1,2}$

The activities of water and the activity coefficients of nitric acid and UNH in the three-component system were calculated according to the following:

$$
\begin{gathered}
a_{1}\left(m_{s}, m_{u}\right) \\
=a_{1}\left(m_{s}, 0\right) a_{1}\left(0, m_{u}\right) \exp \left[( - m _ { s } m _ { u } / n _ { 1 } ) \left(P_{1}\right.\right. \\
\left.+2 P_{2} m_{u}\right)\left(1+P_{3} m_{s}+P_{4} m_{s}^{2}\right) \\
\left.+\left(P_{2} m_{s}^{2} m_{u}^{2} / n_{1}\right)\left(P_{3} / 2+2 P_{4} m_{s} / 3\right)\right], \\
\gamma_{2}\left(m_{s}, m_{u}\right)=\gamma_{2}\left(m_{s}, 0\right) \exp \left[( m _ { u } / 2 ) \left(P_{1}\right.\right. \\
\left.\left.\quad+P_{2} m_{u}\right)\left(1+P_{3} m_{s}+P_{4} m_{s}^{2}\right)\right] \\
\gamma_{3}\left(m_{s}, m_{u}\right) \quad \\
=\gamma_{3}\left(0, m_{u}\right) \exp \left[\left(m_{s} / 3\right)\left(P_{1}+2 P_{2} m_{u}\right)(1\right.
\end{gathered}
$$

The quantities $m_{s}$ and $m_{u}$ are the molalities of nitric acid and UNH respectively; $\gamma_{2}\left(m_{s}, 0\right)$, for example, is the activity coefficient of nitric acid in the two-component, water-nitric acid system containing $m_{s}$ moles of acid per kilogram of water, and $\gamma_{3}\left(m_{s}, m_{u}\right)$ is the activity coefficient of $\mathrm{UNH}$ in the three-component system containing

\footnotetext{
${ }^{1}$ W. Davis, Jr., and H. J. de Bruin, J. Inorg. Nucl. Chem. 26, 1069 (1964).

${ }^{2}$ R. A. Robinson and C. K. L1m, J. Chem. Soc. 1951, p. 1840 .
} 
$m_{\mathrm{s}}$ moles of acid and $m_{u}$ moles of UNH per kilogram of water. The $P$ 's are the four parameters obtained by fitting the data by the method of least squares. Values of these parameters, their standard deviations, and the standard deviation of the fit are listed in Table 12.1. Equation (4) was used to calculate a table of the activity coefficients of uranyl nitrate hexahydrate, which is summarized in Fig. 12.1. Activity coefficients presented in this figure for uranyl nitrate hexahydrate and nitric acid concentrations greater than 2.3 and $14 \mathrm{~m}$, respectively, represent extrapolations of the experimental data.

Table 12.1. Parameters of Equations (2), (3), and (4), Obtained by the Method of Least Squares

\begin{tabular}{ccc}
\hline Parameter & Value & $\begin{array}{c}\text { Standard } \\
\text { Deviation }\end{array}$ \\
\hline$P_{1}$ & 1.65560 & 0.0771 \\
$P_{2}$ & -0.11263 & 0.0440 \\
$P_{3}$ & -0.15247 & 0.0030 \\
$P_{4}$ & 0.00579 & 0.0003 \\
\hline
\end{tabular}

${ }^{a}$ Standard deviation of the fit is 0.2582 .

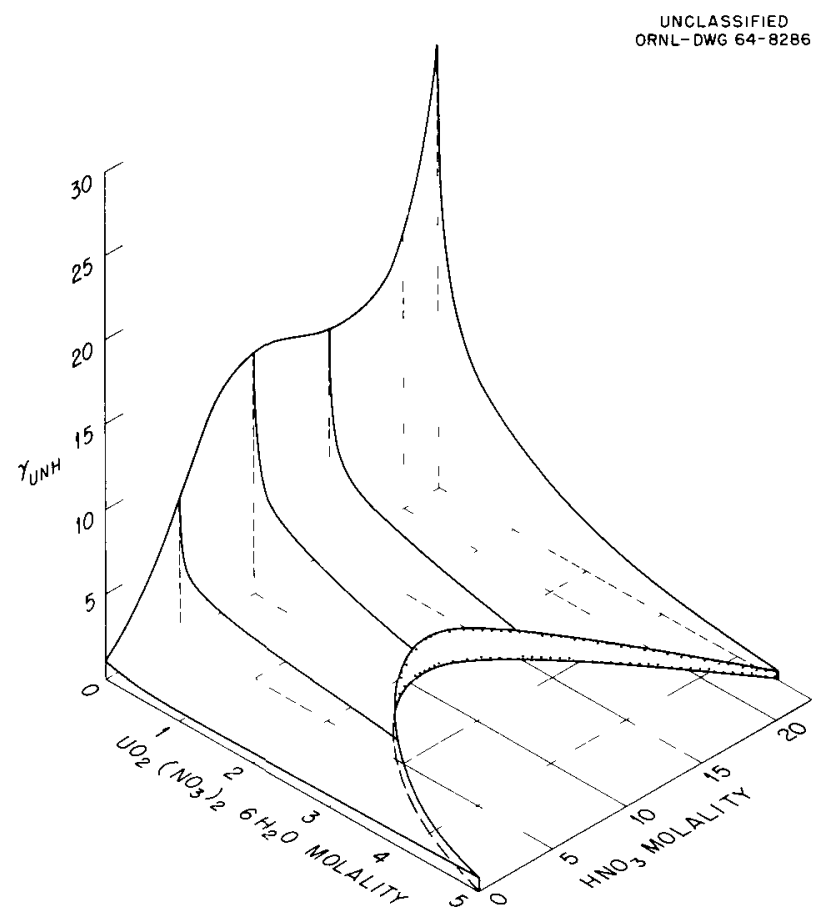

Fig. 12.1. Activities of $\mathrm{UO}_{2}\left(\mathrm{NO}_{3}\right)_{2} \cdot 6 \mathrm{H}_{2} \mathrm{O}$ in Aqueous Nitric Acid Solutions.

\subsection{VAPOR-PRESSURE AND PARTITION DATA FOR THE TWO-PHASE SYSTEM $\mathrm{H}_{2} \mathrm{O}$. $\mathrm{UO}_{2}\left(\mathrm{NO}_{3}\right)_{2}$-TBP}

Vapor pressures of TBP and water over twophase $\mathrm{H}_{2} \mathrm{O}-\mathrm{UO}_{2}\left(\mathrm{NO}_{3}\right)_{2}-\mathrm{TBP}$ systems, at $25^{\circ} \mathrm{C}$, were measured by the transpiration technique using ${ }^{32}$ P-labeled TBP. Partition data were also obtained for this system at identical aqueous uranyl nitrate concentrations. Experimental data were obtained for uranyl nitrate molalities ranging from 0.04 to 1.82 in the aqueous phase.

The combined vapor pressure and partition data were found to fit Eq. (5), and the partition data alone, Eq. (6).

$$
\begin{gathered}
\log \left(K / \gamma_{\mathrm{U} 2 \mathrm{~T}}\right)=A+B m_{3}(o r g) \\
\log \left(K \gamma^{2}{ }_{\mathrm{T} \mathrm{BP}} / \gamma_{\mathrm{U} 2 \mathrm{~T}}\right)=A^{\prime}+B^{\prime} m_{3}(o r g)
\end{gathered}
$$

The constant $K$ is the thermodynamic equilibrium constant for the formation of the bisolvated $\mathrm{UO}_{2}\left(\mathrm{NO}_{3}\right)_{2} \cdot 2 \mathrm{TBP}$ complex; $m_{3}$ (org) is the molality of uranyl nitrate in the organic phase; and $\gamma_{\mathrm{TBP}}$ and $\gamma_{\mathrm{U} 2 \mathrm{~T}}$ are the activity coefficients of TBP and $\mathrm{UO}_{2}\left(\mathrm{NO}_{3}\right)_{2} \cdot 2 \mathrm{TBP}$ respectively. Solution of these two simultaneous equations theoretically permits the calculation of $\gamma_{\text {TBP }}$ as a function of the molality of uranium in the organic phase, Eq. (7).

$$
\gamma_{\text {T B P }}=\exp \left[\alpha+\beta m_{3}(\text { org })\right]
$$

The value of $a$ so obtained appears to be sufficiently precise (standard deviation of $2.8 \%$ ); however, the uncertainty in the value of $\beta$ (standard deviation greater than $100 \%$ ) suggests that further refinement of the data is necessary before attempting to use Eq. (7) for the calculation of activity coefficients of TBP in this three-component system. This refinement includes checking for consistency of data by comparing the quantity $d \ln$ $a_{\text {Т В }} / d m_{3}(a q)$ calculated from partition data (by means of the Gibbs-Duhem relation) with that calculated from vapor-pressure data. 


\section{Ion Exchange: Radiation Damage to Ion Exchange Resins}

Although ion exchange is widely used in radiochemical processing for such operations as separation, purification, and radioactive waste treatment, the limitations imposed by radiation damage to the organic resins are poorly defined. The object of this work was to study the changes in the properties of a strong-acid cation exchange resin under conditions similar to those used in processing.

Data analysis of previously reported flowingwater irradiation experiments ${ }^{1}$ indicate that, after a dose of $0.75 \times 10^{9} \mathrm{r}$ ( 2 whr per gram of dry resin), the rate of loss of strong-acid capacity of Dowex $50 \mathrm{~W}$ cation resin was about 20 to $25 \%$ per watthour per gram of dry resin. This loss rate is about double that reported in the literature for air-dried resin exposed in a static system. ${ }^{2}$

Instead of increasing cross-linkage, as reported for atr-dried material exposed statically, ${ }^{2}$ there is evidence that de-cross-linking of the resin matrix occurred during exposure under simulated chemical processing conditions (Table 13.1). It is estimated, from determinations of moisture content and titrated capacity, that the number of water molecules retained per sulfonate (- $\mathrm{SO}_{3} \mathrm{H}$ ) group remaining on the resin after irradiation was $120 \%$ greater than that for the original material. Similar analyses of unirradiated Dowex $50 \mathrm{~W}$ resin $(20 \%, 16 \%, 12 \%$, and $8 \%$ cross-linked) showed a maximum increase of only $30 \%$ in this ratio for each $4 \%$ decrease in cross-linkage. The loss of polar sulfonate groups during irradiation would tend to reduce the water content of the resin. Accordingly, the observed increase in water uptake is attributed to more than $4 \%$ de-cross-linkage of the resin matrix.

De-cross-linking appears to play a major role in the damage that has been reported ${ }^{3}$ for resin used for radiochemical processing. Apparently, when a resin bed is exposed both to radiation and to a flowing aqueous stream, the cross-links that make the material "absolutely" insoluble are severed, and this results in detrimental effects such as (1) increased solubility of the resin and loss of capacity and (2) the introduction of soluble and insoluble contaminants in the eluted product.

\footnotetext{
${ }^{1}$ Chem. Technol. Ann. Progr. Rept. May 31, 1963, ORNL-3452, p. 218.

${ }^{2}$ J. W. Utley, The Chemical Effects of Low Energy $X-R a d i a t i o n$ on Ion Exchange Resins, thesis, Vanderbilt University, Nashville, Tenn., June 1959.

${ }^{3} \mathrm{P}$. B. Orr, private communication.
} 
Table 13.1. The Matrix of the Cation Exchange Resin Dowex 50W De-cross-links when Exposed to Gamma Radiation in a Flowing Stream of Water

\begin{tabular}{|c|c|c|c|c|c|c|c|c|c|c|}
\hline \multirow{4}{*}{$\begin{array}{c}\text { Cross-Linkage } \\
(\%)\end{array}$} & \multirow{4}{*}{$\begin{array}{l}\text { Mesh } \\
\text { Size }\end{array}$} & \multirow{4}{*}{$\begin{array}{c}\text { Radiation Dose } \\
\text { (r) }\end{array}$} & \multicolumn{2}{|c|}{ Water Content } & \multirow{3}{*}{\multicolumn{2}{|c|}{$\begin{array}{c}\text { Strong-Acıd } \\
\text { Capacity } \\
\text { (meq per dry gram) }\end{array}$}} & \multicolumn{4}{|c|}{ Cross-Linkage and Water Retention } \\
\hline & & & \multirow{2}{*}{\multicolumn{2}{|c|}{$\left(\frac{\text { gram } \mathrm{H}_{2} \mathrm{O}}{\text { gram dry resin }}\right)$}} & & & \multirow{2}{*}{\multicolumn{2}{|c|}{$\left(\frac{\text { molecules } \mathrm{H}_{2} \mathrm{O}}{-\mathrm{SO}_{3} \mathrm{H} \text { group }}\right)$}} & \multicolumn{2}{|c|}{$\%$ Increase } \\
\hline & & & & & & & & & \multirow{2}{*}{$\begin{array}{l}\text { Gain due to Lower } \\
\text { Cross-Linkage of } \\
\text { Orıginal Resin }\end{array}$} & \multirow{2}{*}{$\begin{array}{l}\text { Gain due to } \\
\text { Irradiation }\end{array}$} \\
\hline & & & Origina 1 & Exposed & Original & Exposed & Original & Exposed & & \\
\hline & & $\times 10^{-9}$ & & & & & & & & \\
\hline 8 & $20-50$ & 0.76 & 1.01 & 1.54 & 4.8 & 3.2 & 11.7 & 27.1 & 28 & 130 \\
\hline 12 & $20-50$ & 0.77 & 0.80 & 1.28 & 4.9 & 3.4 & 9.2 & 20.8 & 7 & 126 \\
\hline 16 & $20-50$ & 0.75 & 0.74 & 1.28 & 4.8 & 3.5 & 8.6 & 20.5 & 28 & 138 \\
\hline 20 & $20-100$ & 0.77 & 0.55 & 0.72 & 4.6 & 3.3 & 6.7 & 12.2 & & 82 \\
\hline
\end{tabular}

${ }^{a}$ Irradiated in a ${ }^{60} \mathrm{Co}$ gamma-radiation field of $0.012-0.013 \mathrm{w}$ per gram of dry resin. 


\section{Chemical Engineering Research}

Chemical engineering research is an aggregate of studies which, while intimately tied in with the objectives of the Division's programs, are generally long range and fundamental, or involve the pursuit of new concepts which hold the promise of large returns in application, but which, because of the lack of established technology, embody uncertain prospects for success. It is in this program that interesting effects noted during the pursuit of more specific commitments are isolated, studied, and made part of technology. It is also from this program that new ideas arise to later grow into programs in their own right or to change the direction of existing programs.

The work reported for this year includes: definitive studies on design parameters for a highperformance solvent extraction contactor which uses liquid cyclones for stages; the quantitative verification of the effect of ionizing radiation on coalescence in liquid-liquid systems and attempts to formulate an explanation for it; progress in attempts to use light scattering as a method for particle-size analysis in radioactive gas streams; an unsuccessful attempt to use magnetically induced current for the electrolytic dissolution of stainless steel fuel elements; and progress in an attempt to develop a model to describe the transient behavior in gas-absorption towers.

\subsection{THE STACKED.CLONE CONTACTOR}

A high-speed solvent extraction device that features high throughput, high extraction efficiency, short contact time per stage, and low holdup, has been developed for application to radiochemical processing. The stacked-clone contactor consists of a cascade of axially aligned liquid cyclones, each of which acts as a single countercurrent extraction stage. Counterflow in each stage is created from the application of the induced underflow effect. The contactor develop- ment has progressed to the identification of an optimum configuration, shown schematically in Fig. 14.1. Figure 14.2 is an exploded view of the functioning components, and Fig. 14.3 is a photograph of the assembled contactor.

UNCLASSIFIED ORNL-DWG 64-8277

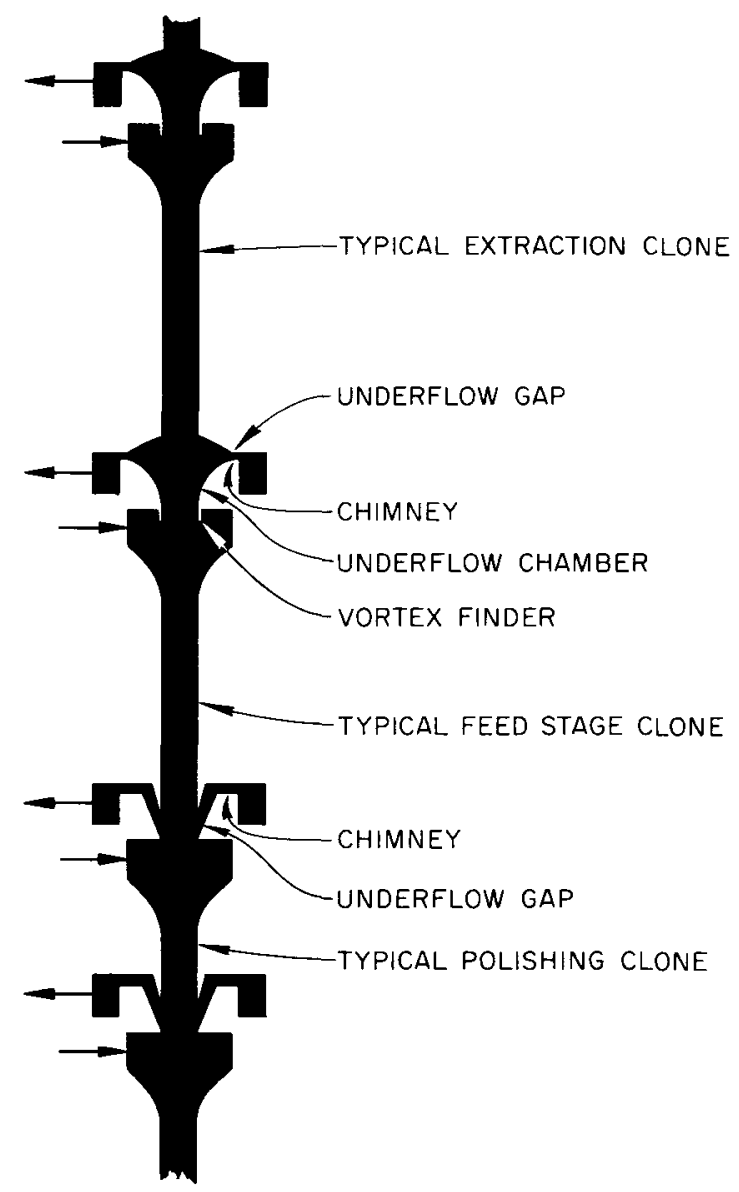

Fig. 14.1. Clone Shapes, Underflow Chambers, and other Functioning Components of the Stacked-Clone Contactor. 


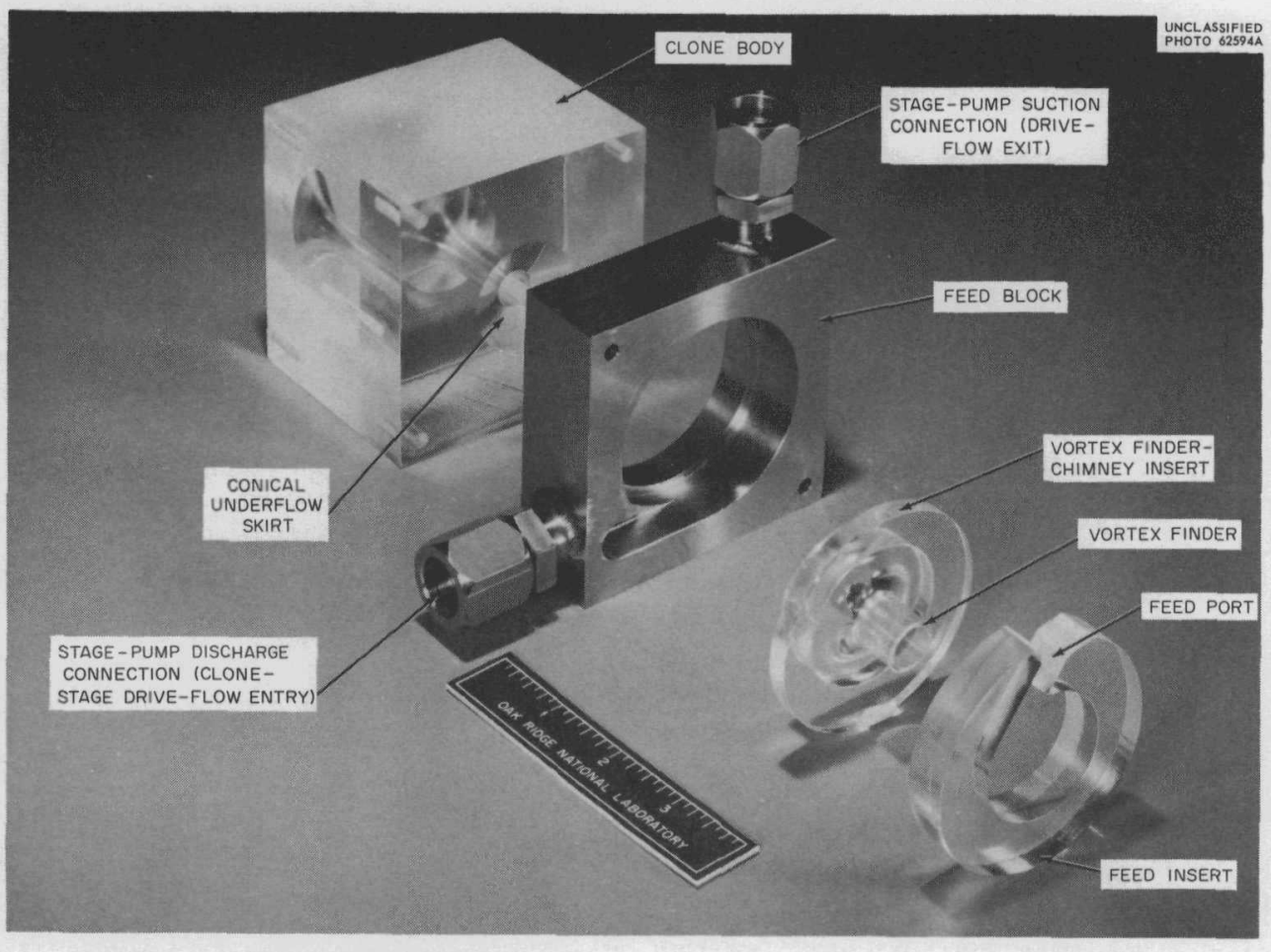

Fig. 14.2. Exploded View of Recycle Plate, Inserts, and Clone Body.

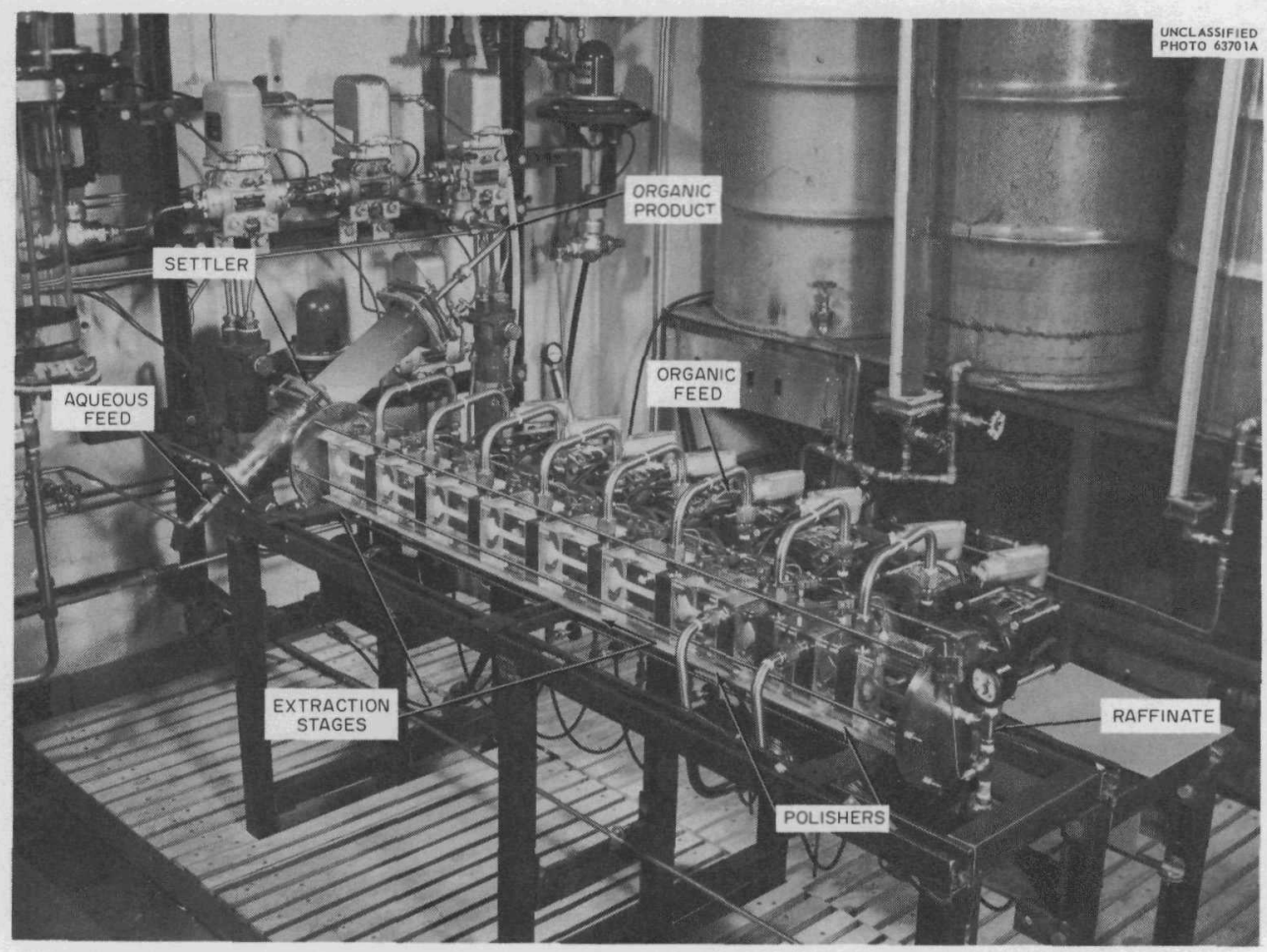

Fig. 14.3. The Stacked-Clone Contactor. 
The stacked-clone contactor, in its present state of development, appears to be a useful and practical device for application to radiochemical processing.

Variables examined were clone length, underflow chamber depth and gap, vortex finder extension, and feed port size. The effects on flow capacity and stage efficiency were determined with the system uranyl nitrate-1 $M$ sodium nitrate$18 \%$ TBP in Amsco at an aqueous-to-organic flow ratio $(\mathrm{A} / \mathrm{O})$ of about 3 to give an extraction factor near unity. Typical test results, averages taken over several runs from 50 to $95 \%$ of flooding, are shown in Table 14.1. At $40^{\circ} \mathrm{C}$, the test results clearly show the effect of clone length (Fig. 14.4), optimum performance being achieved with about 4-in. clones to produce stage efficiencies as high as $80 \%$ at a flow capacity up to 4.0 liters $/ \mathrm{min}$. Although zero vortex finder extensions appear to have a slightly higher performance factor than the $3 / 8$-in. extensions and changes in other variables produce little effect on performance in the ranges tested, the need for an underflow chamber with a limited gap and for some vortex-finder extension is based on other criteria and has been demonstrated previously.

Operability of the device at flow ratios (A/O) as high as 40 has been demonstrated. Tests at a ratio of 20 using a system salted with $2 M$ sodium nitrate indicated that the performance was equivalent to that at a ratio of 3 , with a maximum entrainment of $5 \%$ of the total organic feed. These results are reported in Table 14.2, which also shows the effect of temperature on performance. The effect of temperature on performance is startling at first glance; however, comparison with other types of contactors shows that pulsed columns and mixer-settlers behave similarly, if to a smaller degree.

Due to the rapid generation of data, a computer program has been employed for stage-efficiency calculations. This program uses an equilibrium expression that recognizes the variation of the solute distribution over an applicable concentration range. Equilibrium data obtained with each series of clone runs are used in the expression. Each series of runs includes operation in both the extraction and stripping modes. As part of the calculation, a parameter in the equilibrium relation is adjusted to make the calculated average stage efficiency for the extraction mode equal to the average stage efficiency for the stripping mode. It has been found that the adjustment has been random around zero, signifying that the stage efficiency is the same in each mode. These average or normalized efficiencies are reported.

AQUEOUS PHASE $1 M \mathrm{NaNO}_{3}$ ORGANIC PHASE $18 \%$ TBP IN AMSCO 125-82 DISTRIBUTING SPECIES URANYL NITRATE EXTRACTION FACTOR APPROX UNITY MARK $X$ EXTRACTION CLONES WITH $1 / 4-$ In UNDERFLOW CHAMBER DEPTHS, $1 / 8^{-}$in UNDERFLOW CHAMBER GAPS, $1 / 4$-in FEED PORTS VORTEX FINDER EXTENSION ( in)

\begin{tabular}{ccl}
0 & $3 / 8$ & \\
\hline 0 & $\bullet$ & EFFICIENCY \\
0 & - & FLOODING THROUGHPUT \\
$\Delta$ & $\bullet$ & PERFORMANCE FACTOR
\end{tabular}
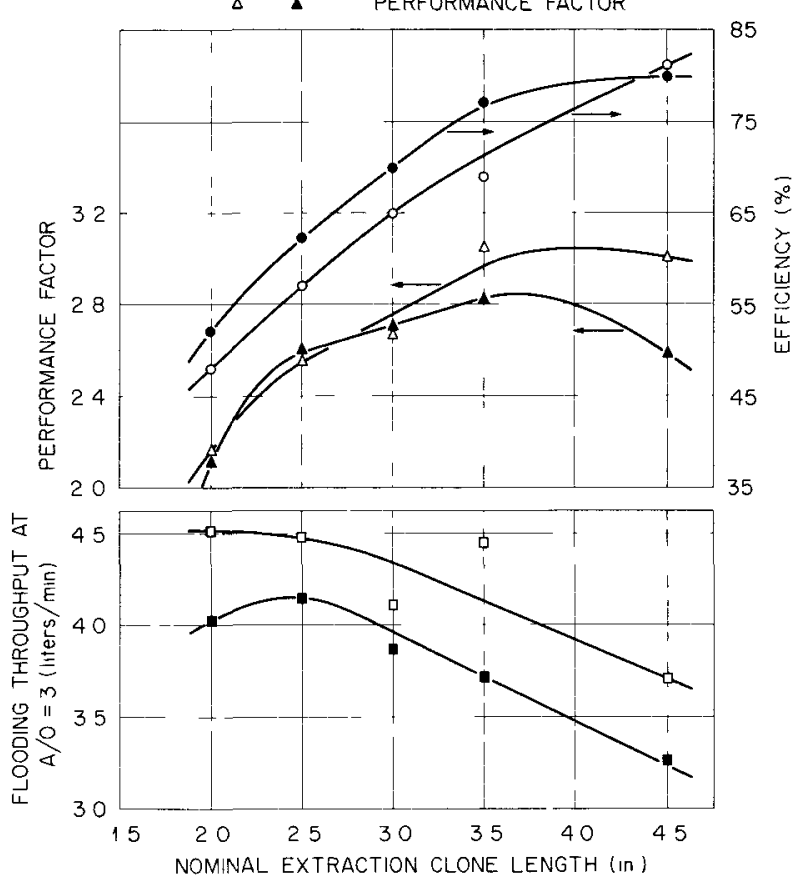

Fig. 14.4. The Effect of Clone Length and Vortex Finder Extension on the Performance of the Stacked. Clone Contactor at $40^{\circ} \mathrm{C}$. 
Table 14.1. Summary of Typical Performance of the Stacked-Clone Contactor at $40^{\circ} \mathrm{C}$

Conditions: Mark X extraction clones used

Aque ous phase: $1 M \mathrm{NaNO}_{3}$

Organic phase: $18 \%$ TBP in Amsco 125-82

Distributing species. Uranyl nitrate

Extraction factor: Approximately unity

Polishing section: Mark XII clones, 0.40-1n.-d tam vortex finders

w ith no extensions, no underflow chambers, $1 / 8$-in. underflow gaps, $3 / 16^{-1 n}$. feed ports.

\begin{tabular}{|c|c|c|c|c|c|c|c|}
\hline \multirow{2}{*}{$\begin{array}{l}\text { Nominal Extraction } \\
\text { Clone Length } \\
\text { (in.) }\end{array}$} & \multirow{2}{*}{$\begin{array}{l}\text { Vortex } \\
\text { Finder } \\
\text { Extension } \\
\quad \text { (in.) }\end{array}$} & \multicolumn{2}{|c|}{$\begin{array}{l}\text { Underflow } \\
\text { Cha mber }\end{array}$} & \multirow{2}{*}{$\begin{array}{l}\text { Feed Port } \\
\text { W1dth } \\
(\text { in, })\end{array}$} & \multirow{2}{*}{$\begin{array}{c}\text { Flow Capacity, } \\
\text { Flooding } \\
\text { (1iters } / \text { min) } \\
\text { at } A / O=3\end{array}$} & \multirow{2}{*}{$\begin{array}{c}\text { Average } \\
\text { Stage } \\
\text { Eff } 1 \text { 1c 1ency } \\
(\%)\end{array}$} & \multirow{2}{*}{$\begin{array}{c}\text { Performance } \\
\text { Factor }\end{array}$} \\
\hline & & $\begin{array}{l}\text { Depth } \\
\text { (in.) }\end{array}$ & $\begin{array}{l}\text { Gap } \\
\text { (in.) }\end{array}$ & & & & \\
\hline 2.0 & 0 & $1 / 4$ & $1 / 8$ & $1 / 4$ & 4.51 & 48 & 2.16 \\
\hline 2.0 & $3 / 8$ & $1 / 4$ & $1 / 8$ & $1 / 4$ & 4.03 & 52 & 2.11 \\
\hline 2.0 & 0 & $1 / 2$ & $1 / 8$ & $1 / 4$ & 4.53 & 52 & 2.34 \\
\hline 2.0 & $3 / 8$ & $1 / 2$ & $1 / 8$ & $1 / 4$ & 3.23 & 62 & 2.01 \\
\hline 2.0 & 0 & $1 / 2$ & $1 / 16$ & $1 / 4$ & 4.83 & 52 & 2.53 \\
\hline 2.0 & $3 / 8$ & $1 / 2$ & $1 / 16$ & $1 / 4$ & 3.29 & 58 & 1.90 \\
\hline 2.0 & 0 & $3 / 4$ & $1 / 8$ & $1 / 4$ & 4.42 & 56 & 2.48 \\
\hline 2.0 & $3 / 8$ & $3 / 4$ & $1 / 8$ & $1 / 4$ & 3.37 & 60 & 2.03 \\
\hline 2.5 & 0 & $1 / 4$ & $1 / 8$ & $1 / 4$ & 4.48 & 57 & 2.56 \\
\hline 2.5 & $3 / 8$ & $1 / 4$ & $1 / 8$ & $1 / 4$ & 4.15 & 62 & 2.59 \\
\hline 3.0 & $3 / 8$ & $1 / 4$ & $1 / 8$ & $3 / 16$ & 3.70 & 75 & 2.79 \\
\hline 3.0 & 0 & $1 / 4$ & $1 / 8$ & $1 / 4$ & 4.12 & 65 & 2.67 \\
\hline 3.0 & $3 / 8$ & $1 / 4$ & $1 / 8$ & $1 / 4$ & 3.88 & 70 & 2.70 \\
\hline 3.0 & 0 & $1 / 2$ & $1 / 8$ & $1 / 4$ & 4.63 & 68 & 3.15 \\
\hline 3.0 & $3 / 8$ & $1 / 2$ & $1 / 8$ & $1 / 4$ & 3.89 & 70 & 2.73 \\
\hline 3.0 & 0 & $3 / 4$ & $1 / 8$ & $1 / 4$ & 4.54 & 67 & 3.05 \\
\hline 3.0 & $3 / 8$ & $3 / 4$ & $1 / 8$ & $1 / 4$ & 3.88 & 69 & 2.67 \\
\hline 3.5 & 0 & $1 / 4$ & $1 / 8$ & $1 / 4$ & 4.45 & 69 & 3.06 \\
\hline 3.5 & $3 / 8$ & $1 / 4$ & $1 / 8$ & $1 / 4$ & 3.71 & 77 & 2.84 \\
\hline 4.0 & 0 & 0 & $1 / 8$ & $3 / 16$ & 4.55 & 64 & 2.92 \\
\hline 4.0 & $3 / 8$ & 0 & $1 / 8$ & $3 / 16$ & 3.80 & 70 & 2.66 \\
\hline 4.5 & 0 & $1 / 4$ & $1 / 8$ & $1 / 4$ & 3.72 & 81 & 3.01 \\
\hline 4.5 & $3 / 8$ & $1 / 4$ & $1 / 8$ & $1 / 4$ & 3.26 & 80 & 2.60 \\
\hline
\end{tabular}


Table 14.2. Summary of the Effects of Temperature and Flow Ratio on the Performance of the Stacked-Clone Contactor

Conditions " 4-in. Mark X extraction clones with $3 / 16^{-1 n}$. vortex finder extensions, $1 / 4-1$. underflow chamber depths, $1 / 16^{-1 n}$. underflow gaps, $3 / 16^{-1 n}$. feed ports.

Aqueous phase: Sodium nitrate

Organic phase: $18 \%$ TBP in Amsco 125-82

Distributing species: Urany1 nitrate

Extraction factor: Approximately unity

\begin{tabular}{|c|c|c|c|c|c|}
\hline $\begin{array}{l}\text { Temperature } \\
\qquad\left({ }^{\circ} \mathrm{C}\right)\end{array}$ & $\begin{array}{c}\text { Flow Ratio Range } \\
\text { for Efficiency } \\
\text { Test }(A / O)\end{array}$ & $\begin{array}{c}\mathrm{NaNO}_{3} \text { in } \\
\text { Aqueous Feed } \\
(M)\end{array}$ & $\begin{array}{c}\text { Flow Capacity, } \\
\text { Flooding } \\
(1+\text { ters } / \text { min) } \\
\text { at } \mathrm{A} / \mathrm{O}-3\end{array}$ & $\begin{array}{l}\text { Average Stage } \\
\text { Efficiency } \\
(\%)\end{array}$ & $\begin{array}{c}\text { Performance } \\
\text { Factor }\end{array}$ \\
\hline 25 & & 1.0 & 1.57 & & \\
\hline 30 & $2.0-5.3$ & 1.0 & 2.03 & 52 & 1.06 \\
\hline 35 & $2.0-5.5$ & 1.0 & 2.53 & 57 & 1.45 \\
\hline 40 & $1.5-6.0$ & 1.0 & 3.13 & 65 & 2.03 \\
\hline 45 & $1.9-4.6$ & 1.0 & 3.75 & 75 & 2.81 \\
\hline 50 & $1.8-4.5$ & 1.0 & 4.25 & 79 & 3.38 \\
\hline 40 & $13-20$ & 2.0 & 3.43 & 60 & 2.06 \\
\hline 45 & $12-19$ & 2.0 & 4.27 & 70 & 2.99 \\
\hline 50 & $10-15$ & 2.0 & 4.91 & 67 & 3.27 \\
\hline
\end{tabular}

${ }^{a}$ Because flow capacity is dependent on flow ratio, performance at different conditions must be compared at a standard flow ratio. A linear correlation is used to make this correction.

\subsection{MECHANISM OF COALESCENCE IN SOLVENT EXTRACTION SYSTEMS}

The effect of ionizing radiation on coalescence of the dispersed phase in liquid-liquid systems is being studied. It is known that strongly alphaactive solutions usually give no settling problems in solvent extraction equipment. It is desired to elucidate the mechanism of this phenomenon with the hope of exploiting it.

To this end an apparatus has been constructed to measure the lifetime of single drops of dispersed phase resting on a plane interface under various conditions of temperature, pressure, and radiation, and isolated mechanically, acoustically, and thermally from the environs. The interface under study can be irradiated with alpha particles or fission fragments by including in the aqueous phase a salt of ${ }^{6} \mathrm{Li}$ or ${ }^{235} \mathrm{U}$, respectively, and exposing the whole system to a flux of thermal neutrons.

The apparatus is shown schematically in Fig. 14.5. Drops of heavy phase are generated on the dropping tip by pneumatically expressing the liquid in the dropping buret (by advancing syringe 1). Syringe 2 is simultaneously backed of to maintain a level interface. Figure 14.6 is a photograph of the apparatus. The emitting end of the Texas Instruments' Cockcroft-Walton neutron generator is visible in the bottom center of the 


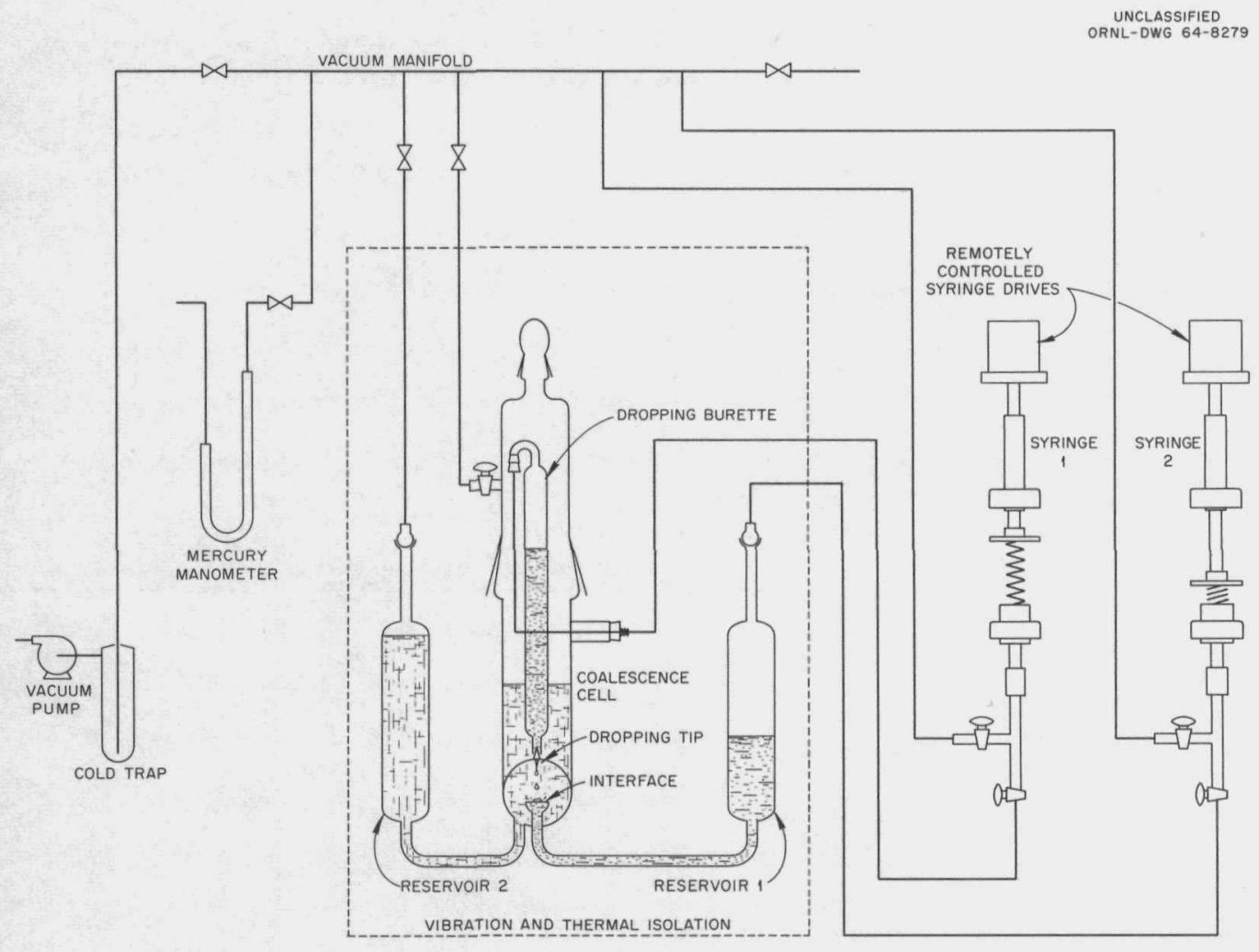

Fig. 14.5. Schematic of Coalescence Apparatus.

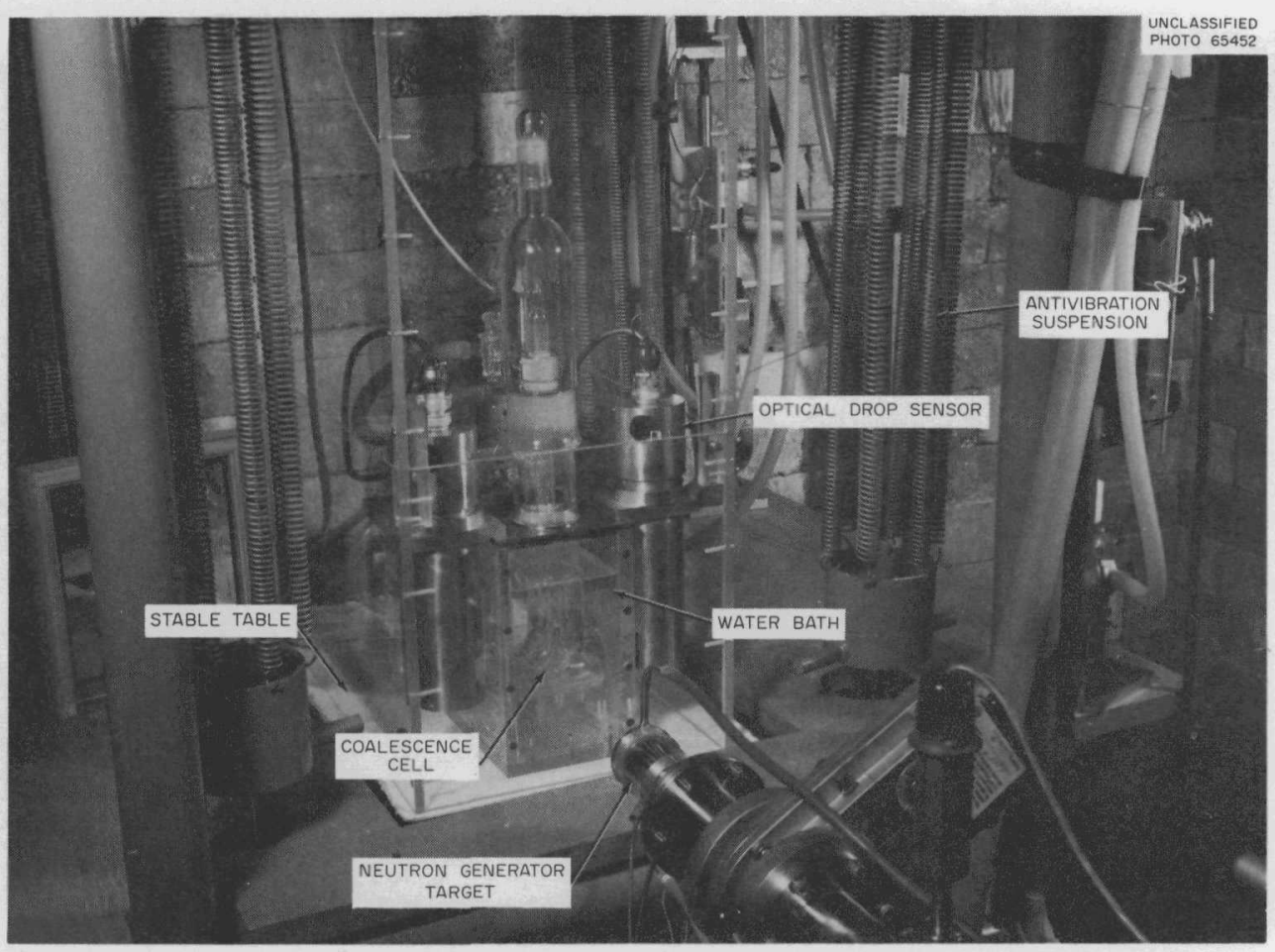

Fig. 14.6. Coalescence Apparatus. 
photograph. The data from the runs to date are shown in Figs. 14.7-14.9. The results are summarized in Table 14.3.

The only observed effect of charged-particle irradiation is coalescence on impact caused by fission fragments and, in some cases, alpha particles. The mechanism is not yet understood. It was at first believed to be the result of bubble nucleation on the particle track between the drop and the interface. However, going to a more volatile organic phase (n-hexane) and "pulling" a vacuum on the system did not increase the coalescence probability, which one would expect if bubble nucleation were occurring. There was probably some surfactant contamination present, as evidenced by the long drop life.

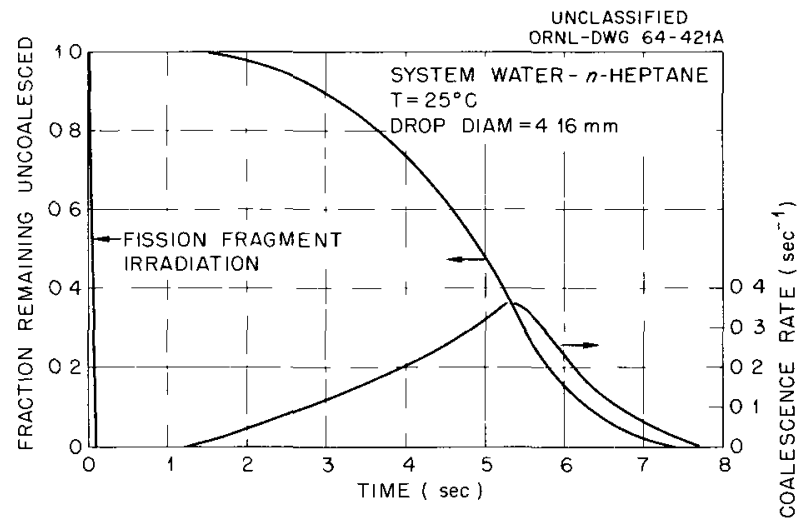

Fig. 14.7. Effect of Fission Fragments on Coalescence Rate of Drops in the System n-Heptane-0.3 $M$ ${ }^{235} \mathrm{UO}_{2}\left(\mathrm{NO}_{3}\right)_{2}$. Atmospheric pressure.

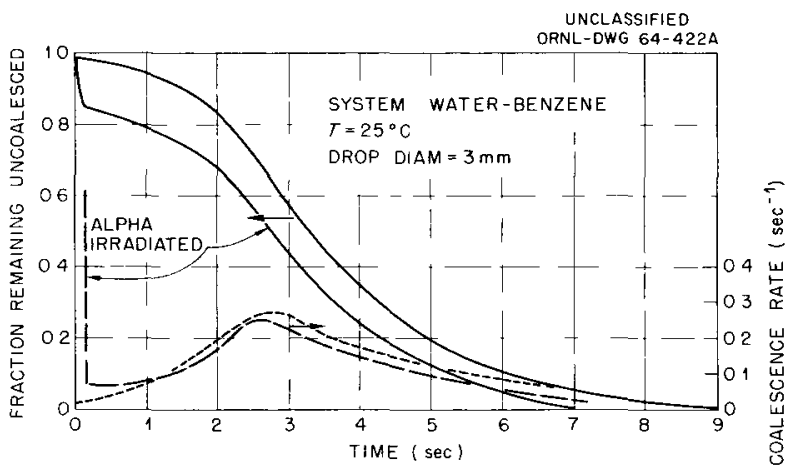

Fig. 14.8. Effect of Alpha Particles on Coalescence Rate of Drops in the System Benzene-0.5 $\mathrm{M}^{6} \mathrm{LiNO}_{3}$. Atmospheric pressure.

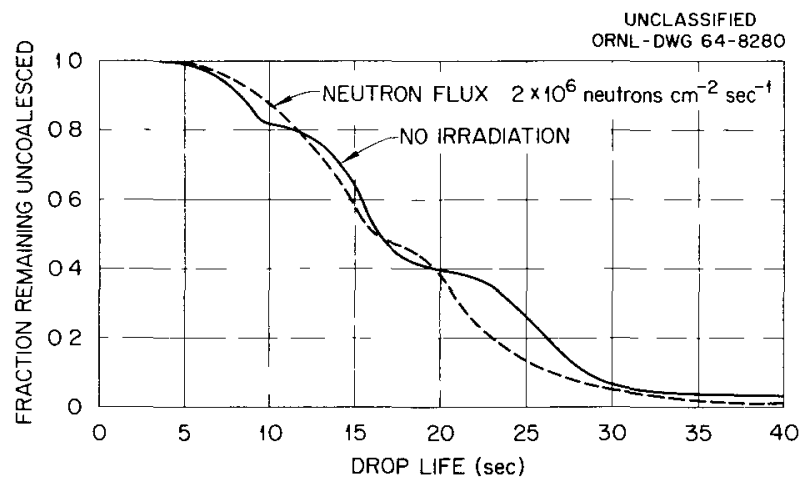

Fig. 14.9. Effect of Alpha Particles on Coalescence Rate of Drops in the System $n-H$ exane-0.5 $\mathrm{M}^{6} \mathrm{LiNO}_{3}$. Diameter of drops, $5 \mathrm{~mm}$; vacuum, $11 \mathrm{in.} \mathrm{Hg}$.

Table 14.3. Summary of Results

\begin{tabular}{|c|c|c|}
\hline System & Results & Comments \\
\hline $\begin{array}{l}n-\mathrm{He} \text { ptane, aque ous } \\
{ }^{235} \mathrm{UO}_{2}\left(\mathrm{NO}_{3}\right)_{2}\end{array}$ & $\begin{array}{l}100 \% \text { coalescence on impact under } \\
\text { neutron urradiation }\end{array}$ & $\begin{array}{l}\text { Clean system; } t_{a v} \text { about } \\
4.5 \mathrm{sec}\end{array}$ \\
\hline $\begin{array}{c}n \text {-Heptane, } 0.2 M \\
\text { aque ous }{ }^{6} \mathrm{~L}_{1 \mathrm{Cl}}\end{array}$ & $\begin{array}{l}20 \% \text { coa lescence on impact under } \\
\text { neutron irradiation }\end{array}$ & $\begin{array}{l}\text { Clean system; } t_{a v} \text { about } \\
3.5 \mathrm{sec}\end{array}$ \\
\hline $\begin{array}{c}n \text {-Hexane, } 0.5 M \\
\text { aque ous }{ }^{6} \mathrm{~L}_{1} \mathrm{NO}_{3}\end{array}$ & $\begin{array}{l}\text { No effect of neutron uradiation }{ }^{a} \text { at } \\
\text { atmos pheric pressure or at } 11-1 \text {. } \\
\text { Hg vacuum }\end{array}$ & $\begin{array}{l}\text { Organic contamination from } \\
\text { sealants; } t_{a v} \text { about } 20 \mathrm{sec}\end{array}$ \\
\hline
\end{tabular}

${ }^{a}$ Neutron flux in vicinity of interface: $2 \times 10^{6}$ ne utrons $\mathrm{sec}^{-1} \mathrm{~cm}^{-2}$, according to maganese activation. 


\subsection{IN-LINE DETECTION OF PARTICLES IN GAS STREAMS BY SCATTERED LIGHT}

The principle of operation of the light-scattering device is the measurement of the frequency and intensity of light scattered by individual particles in a gas stream which passes through a known, optically sensitive volume when the gas stream is subjected to a light source of known properties. Knowledge of the distribution of scattered-light intensity measured from a number of particles over a known length of time and with known fluid dynamics will allow determination of the aerosol concentration and particle-size distribution. No in-line instrument using this principle where there was turbulent flow has been reported in the literature, although one instrument manufacturer reports that limited work was done for such an application. ${ }^{1}$

\section{Detection Cell}

An in-line detection cell for $1 \frac{1}{2}$-1n.-diam pipe was designed and fabricated, and the detection cell from a commercial unit built for side stream use was also procured and adapted for testing purposes. Associated with each detection cell are two to four optical windows arrayed radially at $90^{\circ}$. One of these windows allows light from a primary source to focus at the center point of the cell. The other windows are used to allow scattered light, either at $90^{\circ}$ from the source or near forward, to reach photomultiplier tubes, which are the detectors. Lens systems are used to focus the primary light and to permit scattered light from only a sensitive volume in the center of the cell to enter the detectors.

Initial results from tests with the avallable detection cells showed that one of the critical problems was introduction of a high-intensity, well-defined light source into the detection cell. When a tungsten light was used as the primary light source with the best avalable optical system, a signal-to-noise ratio from the photomultiplier of about 8 to 1 was achieved with $1.3-\mu$-diam aerosol particles. Limited tests with a continuous, neon-helium laser as the primary light source

\footnotetext{
${ }^{1}$ D. Coxe, Royco Instruments, Inc., personal communication (June 3,1963 ).
}

coupled with optical focusing gave a signal-tonoise ratio of about 25 to 1 for the $1.3-\mu$-diam particles.

\section{Electronic Analysis of the Detector Signal}

In order to analyze the signals from the photomultiplier tubes and relate them to aerosol particle size, an electronic system is necessary. Modern radiation-counting techniques are being adopted to determine and record the intensity and frequency of the light pulses which result from light scattered from aerosol particles.

Photomultiplier (PM) tubes are being used as the detecting devices. These will be coupled through preamplifiers, amplif $f_{1}$ ers, and a triggerıng device to a multichannel pulse-height analyzer which has the capability of determining the voltage of the signal from the PM tube, sorting it according to magnitude, and storing the number of such signals which occur during a specific time interval. This spectrum of voltage pulse heights will be the basis for determining the concentration and particle size distribution of the aerosol passing through the detector. At a later time, two $90^{\circ} \mathrm{PM}$ tubes may be connected through coincidence circuitry to reduce the background noise.

\subsection{STUDIES ON MAGNE TICALLY INDUCED ELECTROLYTIC DISSOLUTION OF STAINLESS STEEL FUEL ELEMENTS}

A study was made of the possibility of avolding the contact problem in the electrolytic dissolution in nitric acid of stainless steels by inducing the required potential in the prece by a moving magnetic field.

Experıments show that a potential of about $3 \mathrm{v}$ is needed to maintain dissolution of a stainless steel anode in nitric acid (Fig. 14.10).

To obtain this voltage across a $1-\mathrm{cm}$ piece requires a velocity of $3000 \mathrm{~m} / \mathrm{sec}$ in a 1000-gauss field, if the prece is moved mechanically with res pect to the field. Due to the very large velocity and associated mechanical problems, this approach to the problem was abandoned.

The alternative, moving the field with respect to the prece, was chosen. The most feasible technıque was to discharge a capacitor bank 
through a coil around an appropriately shaped dissolver. It was calculated that a pulse of 1- to 10 -msec duration was required to allow migration of ions away from the anode before the voltage went to zero or below.

The solution of the differential equation describing the current in the circuit is available, but is not explicit in the circuit parameters: resistance $R$, inductance $L$, and capacitance $C$. To determine these parameters, a scaled analog of the proposed assembly was constructed. The inductor in the analog was scaled to unity, in order that the value of inductance of a coil mechanically similar to the proposed dissolver could be used. The circuit is shown in Fig. 14.11.

The scaling factors are given in Table 14.4. Charging voltage, capacitance, and inductance were varied until a voltage pulse of $3 \mathrm{v}$ lasting $10 \mathrm{msec}$ was obtained in a single-turn secondary, corresponding to a ring of stainless steel pieces in the dissolver. Charging voltage and capacitance were chosen so as to minimize the cost of the capacitor bank. The current vs time for the primary and single-turn secondary are shown in Figs. 14.12 and 14.13. The essential features of the dissolver are shown schematically in Fig. 14.14. The full-size dissolver would consist of a $0.1-\mathrm{f}$ capacitor discharging at $675 \mathrm{v}$ once per second into 150 turns of water-cooled copper tubing wrapped around a 2-in. Pyrex pipe containing the stainless steel. Power input to the primary would

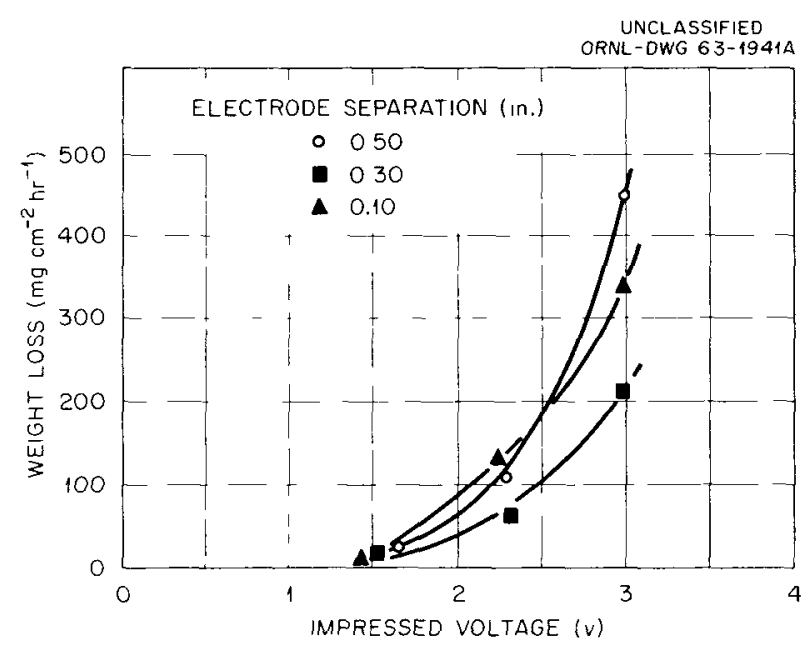

Fig. 14.10. Electrolytic Dissolution of Stainless Steel in Nitric Acid.

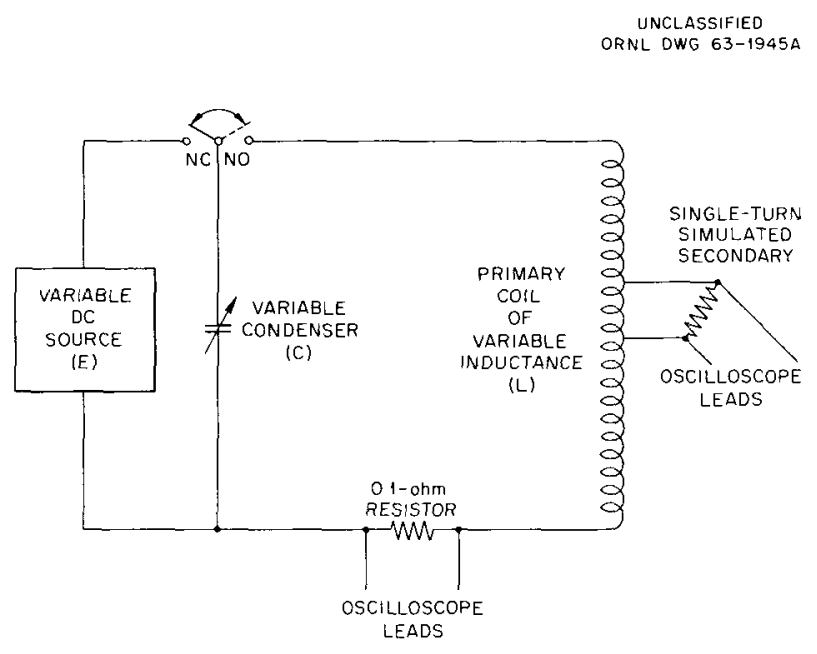

Fig. 14.11. Analog Computer Circuit.

Table 14.4. Scaling Factors of Analog of Dissolver Circuit

\begin{tabular}{lcc}
\hline & Analog & Dissolver \\
\hline Inductance & 1 & 1 \\
Current & 1 & 100 \\
Capacitance & 1 & 100 \\
Time & 1 & 10 \\
Potential & 1 & 10 \\
Resistance & 10 & 1 \\
\hline
\end{tabular}

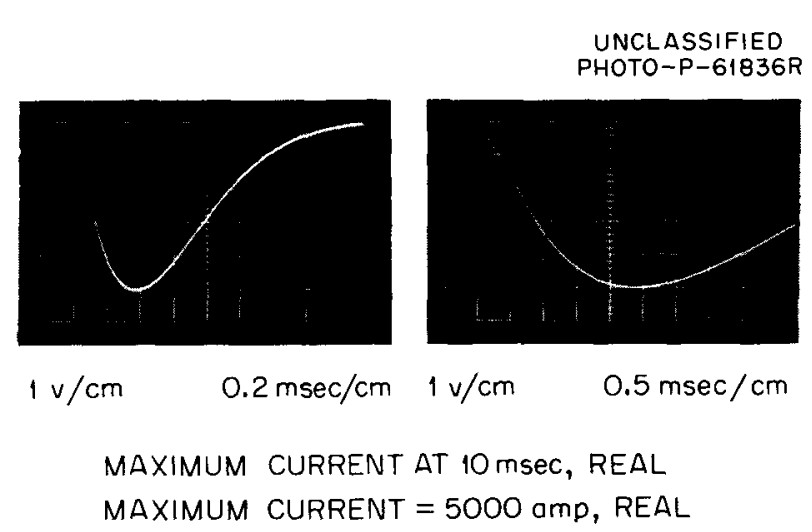

Fig. 14.12. Voltoge Across 0.1-ohm Resistor in Primary in Final Analog Computer Setup. 
UNCLASSIFIED

PHOTO-P-61837R

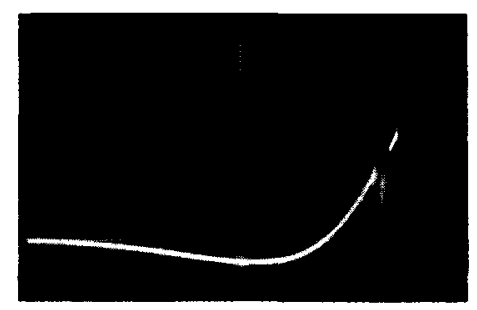

$$
\begin{gathered}
0.1 \mathrm{v} / \mathrm{cm} \quad 0.5 \mathrm{msec} / \mathrm{cm} \\
\text { REAL VALUES: } 3 \mathrm{v} \text { PEAK, } \\
10 \mathrm{msec} \text { LIFE }
\end{gathered}
$$

Fig. 14.13. Voltage Across Secondary in Final Anolog Computer Setup. be $22.8 \mathrm{kw}$, the efficiency $0.01 \%$, and the dissolution rate about $5 \mathrm{mg} / \mathrm{hr}$. Cost of the capacitor bank and silicon control rectifier bank would total about $\$ 5000$.

\subsection{SOLVENT EXTRACTION ENGINEERING STUDIES}

\section{Hydraulic Study of Pulsed Columns}

The lines connected to the bottom of a pulsed column for introducing and withdrawing the organic and aqueous streams must be properly sized to minimize pulse loss and yet permit gravity flow

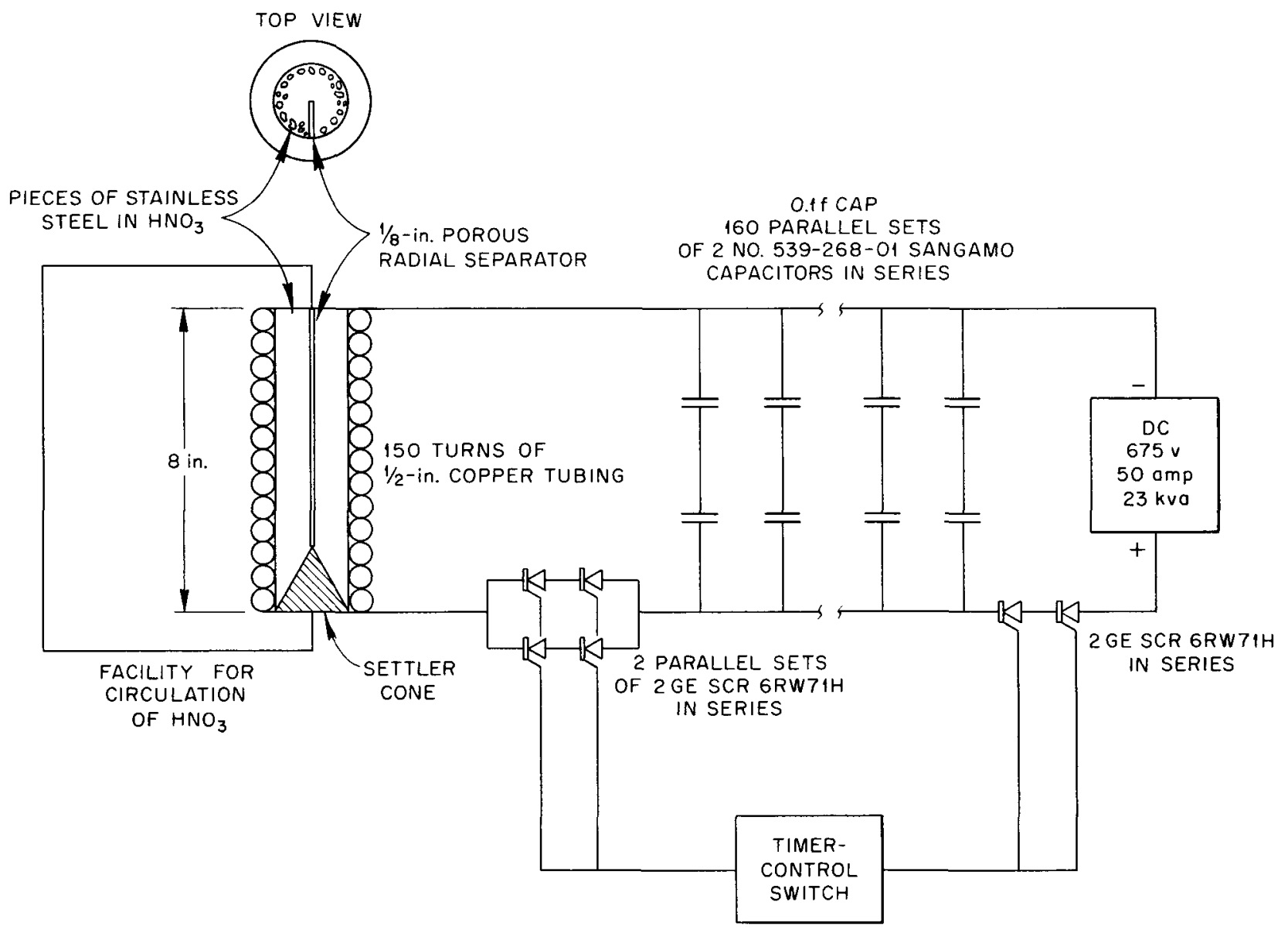

Fig. 14.14. Proposed Dissolver. 
through them. An analog simulation of the hydraulics, including several different models, has yielded a good approximation of the experimental pulse loss and pumping effect in these lines for pulsed columns containing nozzle plates. With a sinusoidal pulse wave having an amplitude of 1 in., the pulse loss was independent of pulse frequency from 30 to $80 \mathrm{cpm}$. For column lengths from 7 to $40 \mathrm{ft}$, and for line lengths equal to or greater than the column length, a line having a diameter one-eighth the column diameter caused less than a $5 \%$ pulse loss. When the diameter of the line was increased to $25 \%$ of the column diameter, the loss increased to about $15 \%$. The pulse in the line lagged the pulse in the column by about $75 \%$ because of the difference in impedance to flow. The pumping effect of the pulse in the nozzle column was insignificant (less than 4 in. of water head).

\section{Flooding of Pulsed Columns Caused by Insufficient Pulsation}

The flow capacity of pulsed columns limited by insufficient pulsation is dependent on the pulse velocity, the ratio of phase flow rates, and the method of introducing and withdrawing both liquid phases from the column. Four cases covering the most common modes of operation are shown in Fig. 14.15. Case 1 is constant introduction and withdrawal of both phases; case 2 is introduction of the light (L) phase during the pulse downstroke and constant withdrawal of the heavy $(\mathrm{H})$ phase; case 3 is constant introduction of the light phase and withdrawal of the heavy phase during the pulse upstroke; and case 4 is introduction of the light phase during the pulse downstroke and withdrawal of the heavy phase during the pulse upstroke.

\section{Development of Small Mixer-Settlers}

A small mixer-settler for use in solvent extraction flowsheet development studies with radioactive systems has been developed. It makes use of the good features of other designs, such as positive interface control, inclined settlers for increased capacity, and combination mixing and pumping impellers. In addition, the mixers are driven by a magnetic coupling that eliminates the need of liquid seals and/or exposure of bearings to corrosive liquids. A prototype constructed of plastic has been tested and proved satisfactory for an "easy" system - transfer of uranyl nitrate

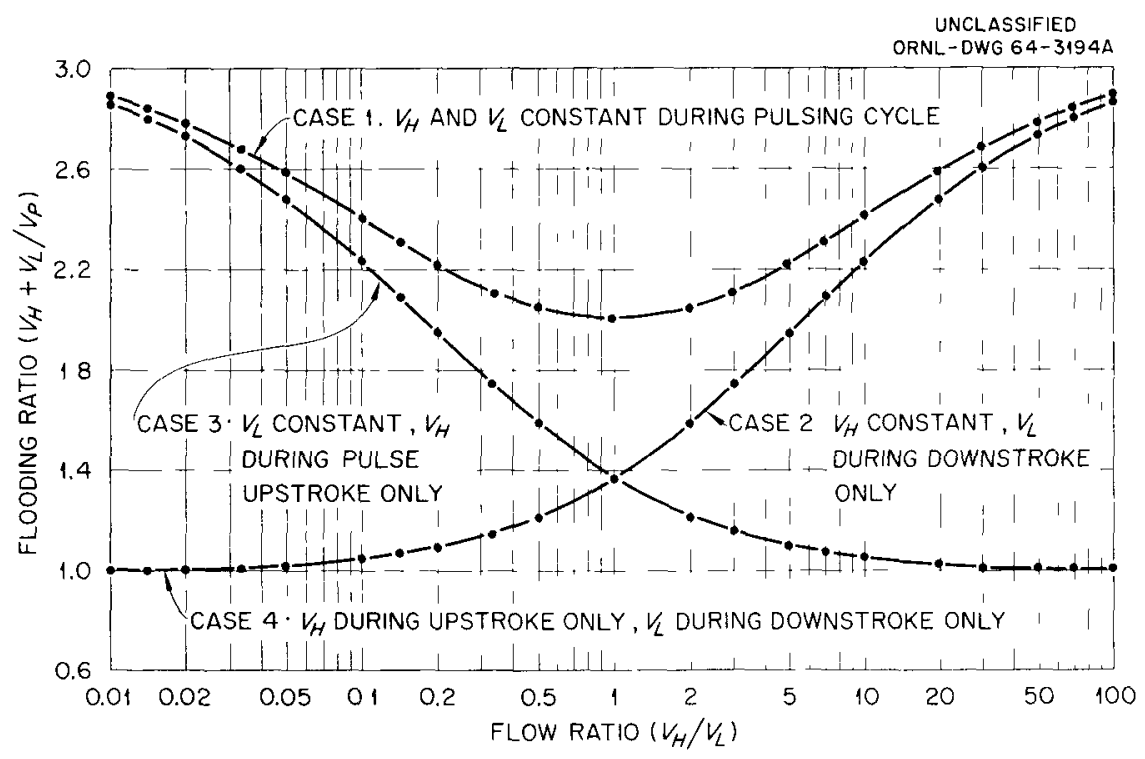

Fig. 14.15. Calculated Ratio of Throughput at Flooding Due to Insufficient Pulsation to Pulsed Velocity as a Function of Flow Ratio for Four Different Modes of Flow in a Pulsed Column. 
with tributyl phosphate. Tests with a more difficult system, transfer of uranium with an amine, showed that the stage efficiency was lower than desired ( 60 to $70 \%$ ) but was better than that obtained in a conventional box-type mixer-settler. ${ }^{2}$

\subsection{TRANSIENTS IN GAS-ABSORPTION TOWERS ${ }^{3}$}

The analysis of transients in processing equipment has recently received considerable attention, and rightly so. The reduction of costs which goes with reduction of process holdup volume and increased capacity requires advanced control techniques, which demand understanding of transient response. The countercurrent mass transfer operations are, as a class, among the most interesting and the most difficult to analyze of operations. Gas absorption is being studied in this program for two reasons: It is the simplest and most tractable of the countercurrent operations for experimental work, and it is used frequently in radiochemical plants as a safeguard against the accidental release of radioiodine, where it spends its entire time of functioning service in a transient mode of operation.

\footnotetext{
${ }^{2}$ Chem. Technol. Div. Ann. Progr. Rept. June 30 , 1962, ORNL-3314, p. 100

${ }^{3}$ This work was done at the University of Tennessee.
}

The experimental studies employ a 6-in.-diam glass column with $5 \mathrm{ft}$ of packed section using both $0.25-$ and $0.5125-i n$. Raschig rings. The present system uses $\mathrm{SO}_{2}$ distributed between air and water and runs at absorption factors up to 2 . The $\mathrm{SO}_{2}$ is introduced as a rectangular pulse into the inlet air, and the concentration of the outlet air is monitored. This concentration trace is then analyzed to produce a Bode plot of amplitude ratio and phase shift as a function of frequency. The pulse must be short compared with the characteristic time of the highest frequency of interest, and a Fourier analysis using a digital computer is required. However, this technique has proved superior to the previously used method of forcing the system with sinusoidal inputs over the whole range.

Similar studies reported last year using $\mathrm{CO}$ as a solute component produced results that were well described by a slug-flow model at least for moderate liquid flow rates. This was probably because the absorption factors were much less than unity. This elementary model does not fit the SO system. Apparently for systems with absorption factors in the range of unity it is necessary to account for mixing within the tower.

The mathematical model presently being tried takes into account axial mixing in both phases. When some of the necessary data are available it is intended to try a model which describes the internal mixing by a nonuniform flow over the tower cross section and radial diffusion. 


\section{Decontamination of Equipment}

The broad goal of all decontamination research programs is to develop and test reagents and methods for the rapid and efficient radioactive decontamination of metallic and nonmetallic surfaces, without unduly damaging these surfaces. Decontamination permits direct maintenance and recovery of equipment. Our group has been concerned primarily this year with the special problem of decontaminating metal surfaces that have been exposed to the coolant stream in gas-cooled nuclear reactors of the type using graphite-clad fuels. Oxalate-peroxide reagents continued to give favorable results in laboratory tests on gas-contaminated surfaces, as well as for other applications. Details have been reported elsewhere. ${ }^{1-3}$

\subsection{PROGRESS AND STATUS}

A new oxalic acid-hydrogen peroxide decontamination reagent for carbon steel, costing only $7 \phi$ a gallon, was developed for use at room temperature. Another oxalate-peroxide reagent was formulated for the simultaneous decontamination of Zircaloy-2, carbon steel, and stainless steel. Still another was effective on nickel and INOR-8 from the Fluoride Volatility Process.

A few laboratory-scale studies were made in order to investigate the transport, deposition, and adhesion of fission products from gas streams onto surfaces of various metals. Carrier-free ${ }^{131} \mathrm{I}$ and ${ }^{137} \mathrm{Cs}$ were volatilized, deposited from the gas phase, and decontaminated from metals in the laboratory. Fission products deposited on

\footnotetext{
${ }^{1}$ GCR Program Semiann. Proǵr. Rept. Sept. 30, 1963, ORNL-3523.

${ }^{2}$ GCR Program Semiann. Ptogr. Rept. Mar. 31, 1964, ORNL-3619.

${ }^{3}$ A. B. Meservey, Peroxide-Inhibited Decontamination Solutions, ORNL-3308 (Dec. 14, 1962).
}

metals in Oak Ridge Reactor gas loops were studied.

The deposition of fission products when the acid and neutral aqueous $Z$ irflex fuel dissolution processes are used were found to be different and characteristic.

\subsection{EXPERIMENTAL WORK}

\section{New Oxalate-Peroxide Decontamination Formulas and Applications}

A new room-temperature decontamination method for carbon steel consists in immersing the steel for about $5 \mathrm{~min}$ in $0.02 \mathrm{M}$ oxalic acid, then adding $30 \% \quad \mathrm{H}_{2} \mathrm{O}_{2}$ until the peroxide concentration is about $0.05 \mathrm{M}$, and soaking for another $5 \mathrm{~min}^{1}$ The first step dissolves light coatings of rust and activates the surface, and the second step brightens the surface and decontaminates it by factors of 400 to 800 . The depth of penetration of the metal is only about $0.05 \mathrm{mil}$. The treatment is halted by rinsing with water or by further increasing the peroxide concentration to about $0.25 \mathrm{M}$.

The useful life of $0.5 M$ oxalic acid solution $0.1 \mathrm{M}$ in fluoride and $0.2 \mathrm{M}$ in hydrogen peroxide, a formula effective in the noncorrosive decontamination of stainless steels at 90 to $95^{\circ} \mathrm{C}$, was extended indefinitely by hourly replacement of decomposition losses (20\% of the oxalic acid and half the peroxide are lost each hour).

An oxalate-peroxide mixture $(0.4 \mathrm{M}$ ammonium oxalate-0.16 $M$ ammonium citrate-0.05 $M$ NaF$0.8 \mathrm{M} \mathrm{H}_{2} \mathrm{O}_{2}$ ) at an initial $\mathrm{pH}$ of 4.0 was effective for simultaneously decontaminating $Z$ ircaloy-2, stainless steel, and carbon steel at 90 to $95^{\circ} \mathrm{C}{ }^{2}$ The contaminated metals had been baked in helium at $500^{\circ} \mathrm{C}$. Initial corrosion rates, which decreased with time as the $\mathrm{pH}$ of the solution rose during 
use, were $0.5 \mathrm{mil} / \mathrm{hr}$ for $\mathrm{Zircaloy}-2$ and $0.09 \mathrm{mil} / \mathrm{hr}$ for carbon steel.

The oxalate-citrate-peroxide formula recommended for decontaminating carbon steel (the Gas-Cooled Reactor Program ${ }^{3}$ ) was also quite effective on specimens of nickel and INOR-8 used in the Fluoride Volatility Hot Cell Facility. ${ }^{2}$ The reagent did not attack nickel weld metal as much as the aluminum nitrate previously used, but it was not suitable for use with copper and its alloys.

\section{Laboratory Volatilization, Deposition, and Decontamination of ${ }^{131_{1}}$ and ${ }^{137} \mathrm{Cs}$ (ref 1 )}

Carrier-free ${ }^{131} \mathrm{I}$ was volatilized in hydrogen and in helium and deposited on stainless steel at 200 to $500^{\circ} \mathrm{C}$. The deposits were easily removed from the steels contaminated at temperatures up to about $450^{\circ} \mathrm{C}$, but the steels contaminated at about $500^{\circ} \mathrm{C}$, which retained only slight activity, resisted decontamination. Carrier-free ${ }^{137} \mathrm{Cs}$ deposited from helium at 500 to $1000^{\circ} \mathrm{C}$ was also relatively tenacious, presumably due to penetration of the cesium into the steel. For cesium deposited at about $200^{\circ} \mathrm{C}$, however, decontamination factors (DF's) in various reagents were in the range of $10^{3}$ to $10^{5}$.

\section{Fission Products Deposited in Gas-Loop Tests 1,2}

In several experiments on the deposition of fission products in the Oak Ridge Reactor, the deposition level from circulating helium was below the level of contamination that occurs in handling the neutron-activated metal samples in hot-cell facilities. The fuel elements were thus shown to be highly retentive. Several metal specimens, remote from the neutron flux when contaminated at $270^{\circ} \mathrm{C}$, were decontaminated by factors of about 100 in $1 \mathrm{hr}$ at $95^{\circ} \mathrm{C}$ in dilute nitric acid and in oxalate-peroxide at $\mathrm{pH} 4$. Contamination that was deposited at $540^{\circ} \mathrm{C}$ was more resistant to removal; but, with the aid of a fluoride-containing oxalate-peroxide solution, the DF after several hours at $95^{\circ} \mathrm{C}$ was a satisfactory value of about 50. Investigation of fission product deposition on in-pile gas loops and methods of removing the fission products will continue. Metal surfaces remote from the neutron flux will be studied to eliminate the high gamma-radiation background caused by neutron activation.

\section{Decontamination of Equipment Used in the Zirflex Process}

A gamma scintillation spectrometer was used in an investigation of the types of fission products deposited on stainless steels in the STR and modified-Zirflex fuel dissolution processes and the effects of different decontamination reagents. In the acid fluoride STR process (nitric and hydrofluoric acids), the only gamma-emitting fission product deposited from a solution of mixed fission products was ruthenium. Similarly, the only deposit on stainless steels in the neutral fluoride Zirflex process was cerium; only zirconium-niobium and ruthenium appeared on steels exposed to contaminated, dilute nitric acid as a control. In comparative decontamination tests $(30 \mathrm{~min}$ at $95^{\circ} \mathrm{C}$ ), the cerium was easily removed by dilute nitric acid $\left(\mathrm{DF}=8 \times 10^{3}\right.$ ) and by oxalate-peroxide reagent at $\mathrm{pH} 4\left(\mathrm{DF}=3 \times 10^{3}\right)$. The ruthenium deposited when the STR process was used was best removed with oxalate-peroxide (DF $=900$, compared with 18 in $3 \mathrm{MHNO}_{3}$ ). The gamma activity of the steels contaminated by radioactive impurities in nitric acid was only about $4 \%$ as high as that of the steels from the STR and Zirflex processing solutions, but they were more resistant to decontamination (DF about 14 when oxalateperoxide was used, compared with about 10 when $3 \mathrm{MHNO}_{3}$ was used). 


\section{Reactor Evaluation Studies}

This program, which is supported jointly by the Reactor Division and the Chemical Technology Division, involves studies on various proposed advanced reactor and fuel cycle systems to determine the feasibility and economics of such systems. The work in the Chemical Technology Division during the past year included the initiation of drop tests with unshielded shipping containers for fissionable material; development of two computer codes, MYRA and NORA, for the estimation of reactor fuel shipping costs; the preparation of several studies on the costs of processing irradiated fuel; and the preparation of a criticality report summarizing all available criticality data of interest to fuel processors.

\subsection{STUDIES OF THE COST OF SHIPPING SPENT FUEL}

The cost of shipping irradiated fuel elements from a reactor to a fuel-processing plant is an appreciable part of the total fuel-cycle cost. Shipping cost is often difficult to calculate, because of the necessity of first designing an adequately shielded and cooled shipping cask. Fuel-cycle optimization requires the determination of costs under a variety of reactor conditions and the selection of conditions that give the minimum total cost. The shipping cost will, in general, be different for each set of conditions. A further difficulty arises when inventory charges are taken into account. A longer cooling time before shipping reduces the shielding requirements and gives lower shipping costs, but this reduction may be offset by increased inventory charges for the cooling period. The existence of an optimal cooling time may therefore be expected.

As a step in the direction of fuel-cycle optimization, a computer code was written that designs a cask and calculates shipping and cooling costs for any desired set of reactor conditions. This code, MYRA, may be run on either the CDC-1604A or the IBM 7090. In each problem, the number of elements per cask is automatically varied from one up to the maximum that can be carried without exceeding the total allowable weight, as set by carrier or handling limitations. The cooling time also is varied within specified limits. The costs are shown in each case. The resulting output is a parametric study that enables the user to select the conditions that give minimum total cost of cooling and shipping.

By means of the MYRA code, shipping costs were determined for several reactor fuels under various conditions of burnup and specific power. Costs of $\$ 2.00$ to $\$ 4.00$ per kilogram of uranium were found to be typical for stainless-steel-clad or Zircaloy-2-clad fuel elements of low enrichment. This includes freight, handling costs, fixed charges on casks, and insurance against damage to fuel in transit. Some of the results are shown in Table 16.1. These costs are based on a freight rate of $\$ 1.93$ per $100 \mathrm{lb}$ (full) and $\$ 1.81$ per $100 \mathrm{lb}$ (empty), a shipping distance of 1000 miles each way, a handling cost of $\$ 500$ per round trip, an insurance rate of $0.2 \%$ of the fuel value, a fixed-charge rate on casks of $15 \%$ per year, a cask cost of $\$ 1.00$ per $1 \mathrm{~b}$, and a maximum shipping weight of $140,000 \mathrm{lb}$. In each case, the number of casks used was the minimum number needed to keep up with the rate of discharge of fuel from the reactor.

Typical optimization curves are shown in Figs. 16.1 and 16.2. Figure 16.1 shows the variation of shipping cost with the number of elements per cask for a desalination study based on three reactors with a total capacity of $25,000 \mathrm{Mw}$ (thermal). Cooling time was 90 days. Minimum cost was obtained at about 26 elements per cask. As this number is raised, the increasing difficulty of heat removal tends to outweigh other factors 
Table 16.1. Typical Calculated Fuel Shipping Cosis According to the MYRA Code

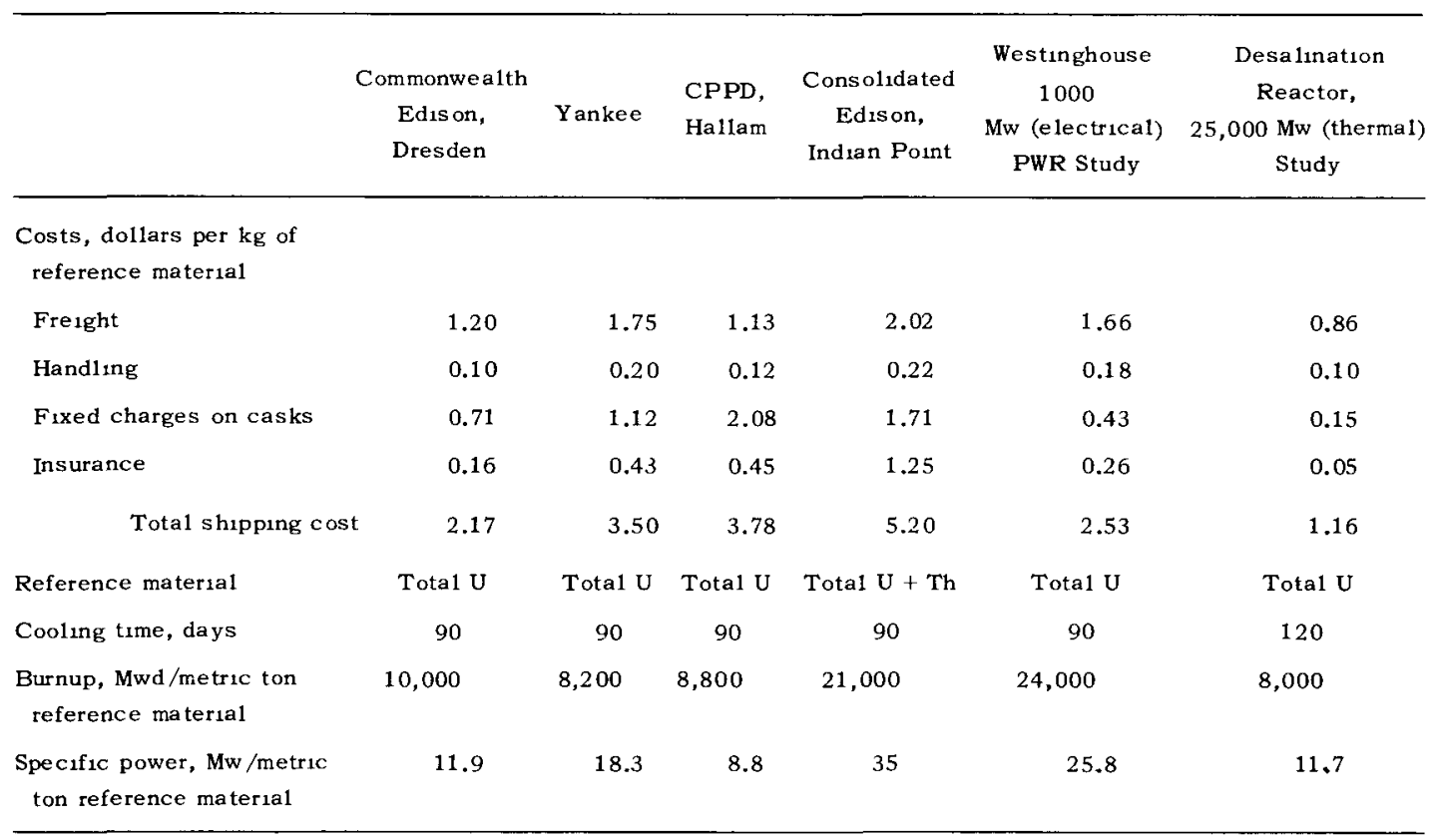

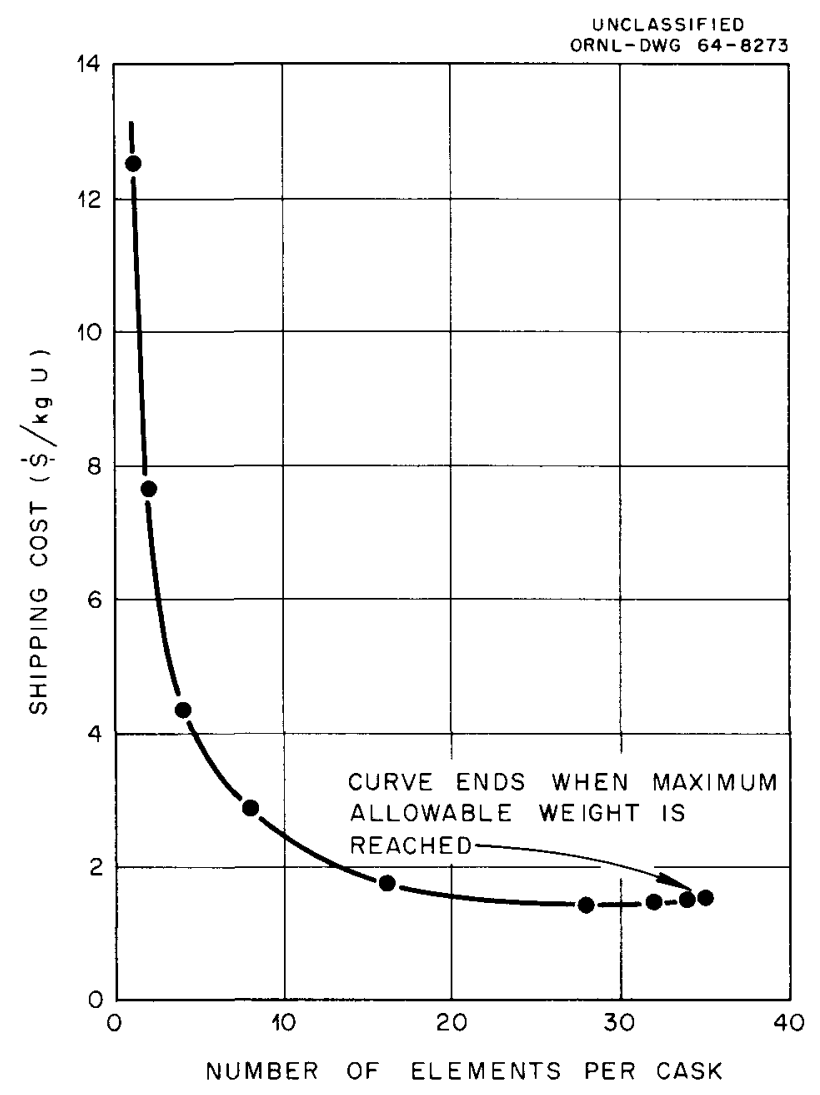

Fig. 16.1. Optimal Number of Elements per Cask. Desalination reactors, $25,000 \mathrm{Mw}$ (thermal) total; cooling time, 90 days.

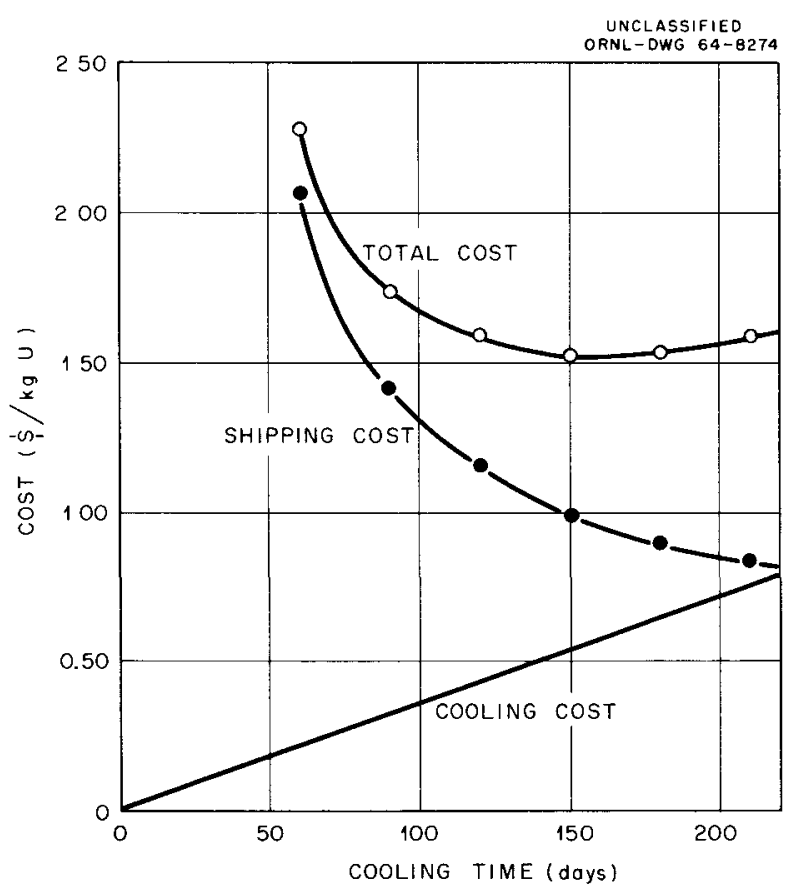

Fig. 16.2. Optimal Cooling Time. Desalination reactors, 25,000 $\mathrm{Mw}$ (thermal) total; inventory rate, $10 \%$ /year; fuel value, $\$ 13$ per kilogram of uranium (plutonium value minus reprocessing cost). 
and causes an increase in cost. Figure 16.2 shows the total cost of cooling and shipping for the same reactors, as cooling time is varied. An optimal cooling time of about 150 days is indicated. This work is reported in deta1l in ORNL$3648 .^{1}$

During this investigation it became apparent that the optimal conditions for shipment cannot be determined without taking into account the

\footnotetext{
${ }^{1}$ Royes Salmon, A Computer Code (CDC 1604A or IBM 7090) for Calculating the Cost of Shipping Spent Reactor Fuels as a Function of Burnup, Specif $1 \mathrm{c}$ Power, Cooling Time, Fuel Composition, and Other Variables, ORNL-3648 (August 1964).
}

processing batch size, since the batch size influences both the reprocessing cost per kilogram and the inventory charges for the shipping period. The existence of an optimal batch size was anticipated, because larger batch sizes tend to reduce processing costs by minimizing turnaround cost.

With total fuel-cycle optimization again in mind, a second computer code, NORA, was written, it includes the features of MYRA plus the calculation of reprocessing costs and inventory charges for various processing batch sizes. The inventory charges are for the entire period from reactor $d_{1} s-$ charge to start of reprocessing. The NORA code finds conditions that minimize the total of the

Table 16.2. Preliminary Shipping Costs: Advanced Converter Study

\begin{tabular}{|c|c|c|c|c|}
\hline Reactor & $\begin{array}{l}\text { Average Burnup } \\
\text { (Mwd/metric ton } \\
\text { of reference material) }\end{array}$ & $\begin{array}{l}\text { Cooling Time } \\
\text { (Days) }\end{array}$ & $\begin{array}{l}\text { Shipping Cost } \\
\text { (dollars per } \mathrm{kg} \text { of } \\
\text { reference material) }\end{array}$ & $\begin{array}{c}\text { Reference } \\
\text { Material }\end{array}$ \\
\hline \multirow[t]{4}{*}{ PWR } & 20,000 & 150 & 3.94 & U \\
\hline & 25,000 & 180 & 4.08 & \\
\hline & 30,000 & 180 & 3.71 & \\
\hline & 35,000 & 180 & 4.02 & \\
\hline \multirow[t]{5}{*}{ Seed-Blanket } & 50,000 & 240 & 9.69 & Th \\
\hline & 60,000 & 240 & 9.67 & \\
\hline & 70,000 & 240 & 9.78 & \\
\hline & 80,000 & 270 & 9.86 & \\
\hline & 90,000 & 270 & 10.20 & \\
\hline \multirow[t]{5}{*}{ SSCR } & 20,000 & 240 & 3.94 & Th \\
\hline & 25,000 & 240 & 4.64 & \\
\hline & 30,000 & 270 & 4.04 & \\
\hline & 35,000 & 270 & 4.69 & \\
\hline & 40,000 & 300 & 4.12 & \\
\hline \multirow{4}{*}{$\mathrm{D}_{2} \mathrm{O}-\mathrm{UO}_{2}$} & 14,000 & 360 & 2.02 & $\mathrm{U}$ \\
\hline & 15,400 & 360 & 2.09 & \\
\hline & 17,000 & 360 & 2.37 & \\
\hline & 20,000 & 360 & 2.85 & \\
\hline \multirow{3}{*}{$\mathrm{D}_{2} \mathrm{O}-\mathrm{ThO}_{2}$} & 15,000 & 270 & 3.35 & $\mathrm{Th}$ \\
\hline & 22,000 & 300 & 3.98 & \\
\hline & 30,000 & 330 & 4.44 & \\
\hline \multirow[t]{4}{*}{ TARGET } & 40,000 & 120 & 33.04 & Th \\
\hline & 51,400 & 150 & 32.67 & \\
\hline & 60,000 & 150 & 32.70 & \\
\hline & 70,000 & 150 & 32.92 & \\
\hline \multirow[t]{3}{*}{ SGR } & 25,000 & 150 & 3.78 & $\mathrm{U}$ \\
\hline & 35,000 & 90 & 5.01 & \\
\hline & 45,000 & 60 & 5.51 & \\
\hline
\end{tabular}


shipping, reprocessing, and inventory charges. The number of cask purchases is optimized, that is, the number of casks may be greater than the minımum requirement, provided that the reduction in inventory charges for the delivery period just1fies the additional cask cost. Because of this, the shipping cost may be larger than it would be if it were calculated to minımize the total of cooling and shipping costs only.

Typical shipping costs calculated by the NORA code are shown in Table 16.2. This work was done for the Reactor Division in connection with the study of advanced converters. Costs tend to be somewhat higher than those shown in Table 16.1, for the following reasons: (1) optimization required the use of a larger number of casks, (2) the average exposures shown were increased by peaking factors of from 1.1 to 1.5 , and (3) allowable temperatures were reduced in some cases.

\subsection{COST STUDIES FOR PROCESSING CONVERTER-REACTOR FUEL}

As part of an overall comparative evaluation of advanced converter reactors, ${ }^{2}$ especially thonum-fueled converters, costs were estımated for processing irradiated fuel from the reactor types listed in Table 16.3, for a range of burnup values around the reference figure shown. These estimates were supplied to the ORNL Technical Assistance Group, where they were combined with shipping costs (Sect. 16.1), fabrication costs (Metals and Ceramics Division), and reactor capital and operating costs (Reactor Division), to give optımized power costs for each reactor in a hypothetical 1975-80 nuclear economy.

Under the ground rules of this study, each fuel type was considered separately for the case of processing in a single-purpose plant designed to service fifteen 1000-Mw (electrical) reactors of that type. Alternatively, the case of a dualpurpose processing plant designed to service ten $1000-\mathrm{Mw}$ (electrical) reactors of the particular type plus ten 1000-Mw (electrical) PWR-type reactors was also considered. Capital and operatıng costs were estımated for each hypothetical processing plant. The rules specified a fixedcharge rate of $22.5 \%$, with alternative values of

\footnotetext{
${ }^{2} \mathrm{~J}$. A. Lane et al., A Comparative Evaluation of Advanced Converters (in preparation).
}

15 and $30 \%$, to be applied to capital investment to cover the annual cost of depreciation, interest on debt capital, return on equity capital, federal income taxes for corporations, other taxes, and property and liability insurance for privately owned plants. ${ }^{3}$

The calculated costs were based on the estimates of Farrow, ${ }^{4}$ with modifications as deemed appropriate for each fuel type to allow for differences in head-end treatment and fertıle and fissile throughput rates, plus added costs for krypton removal from off-gases, ultımate waste disposal, and escalation to 1964 price levels. The estimates are comparable to those previously made for a large nuclear water-desalination industry, ${ }^{5,6}$ except that the former study did not include the extra waste disposal and escalation costs and used a $7.7 \%$ fixed-charge rate under public-ownership ground rules. As has already been pointed out, ${ }^{7,8}$ the relative insensitivity of total fuel-processing capital and operating costs to production rate gives rapidly decreasing unit production costs with increasing plant size. In the present study, however, fixing the size of a nuclear power industry served by one singlepurpose processing plant at a constant $15,000 \mathrm{Mw}$ (electrical) tended to minimize the difference between reactor types as far as processing-cost contribution to unit electricity costs [m1lls/kwhr (electrical)] is concerned, since wide differences in the amount of fuel to be processed per year are associated with smaller differences in the total annual processing costs.

Table 16.3 gives typical calculated processing costs for the various reactor fuels in singlepurpose plants. As might be expected, the highburnup High-Temperature Graphite Reactor has the highest cost in dollars per metric ton but one of

${ }^{3} \mathrm{~J}$. T. Roberts, Fixed-Charge Rates Applicable to Capital Investment in Spent Fuel Processing Plants (in preparation).

${ }^{4}$ W. H. Farrow, Jr., Radiochemical Separations Plant Study, Part II - Design and Cost Estimates, DP-566 (March 1961).

${ }^{5}$ Chem. Technol. Div. Ann. Progr. Rept. May 31, 1963, ORNL-3452, p. 243.

${ }^{6} \mathrm{~F}$. E. Harrington et al., Fuel Cycle Costs for a Plutonium Recycle System, ORNL-3501 (Jan. 6, 1964).

${ }^{7} \mathrm{~F}$. L. Culler, Jr., The Effect of Scale-Up on Fuel Cycle Costs for Enrtched Fuel and Natural Uranium Fuel Systems, ORNL-TM-564 (A pr. 16, 1963).

${ }^{8}$ F. L. Culler, Jr., Partially Enriched Fuel Cycles, ORNL-TM-678 (Sept. 3, 1963). 
Table 16.3. Spent Fuel Processing Costs for Advanced Converter Study: Single-Purpose Plants

Basis · $15,000 \mathrm{Mw}$ (electrical) total capacity, $80 \%$ load factor

$1,000 \mathrm{Mw}$ (electrical) per reactor except $500 \mathrm{Mw}$ (electrica1) for seed-blanket reactor 150 days minimum cooling time before processing

310 operating days per year (processing plus turnaround)

\begin{tabular}{|c|c|c|c|c|c|c|c|}
\hline & \multicolumn{7}{|c|}{ Type of Reactor } \\
\hline & PWR & SBR & SSCR & $\mathrm{D}_{2} \mathrm{O}-\mathrm{U}$ & $\mathrm{D}_{2} \mathrm{O}-\mathrm{Th}^{\mathrm{a}}$ & TARGET & SGR \\
\hline $\mathrm{Mwd} /$ metric ton $\mathrm{U}$ or $\mathrm{Th}^{b}$ & 25,000 & $70,000^{*}$ & $30,000^{*}$ & 15,400 & $22,000^{*}$ & $51,400^{*}$ & 35,000 \\
\hline Thermal efficiency, $\%$ & 31.1 & 28.8 & 31.2 & 26.8 & 26.8 & 45.8 & 43.6 \\
\hline $\begin{array}{l}\text { Metric tons/batch, } \mathrm{U} \text { or } \\
\operatorname{Th}^{b}\end{array}$ & 38.7 & $77.4^{*}$ & $66.3 *$ & 23.0 & $12.2^{*}$ & $12.9 *$ & 12.8 \\
\hline $\mathrm{Kg} /$ batch, $\mathrm{Pu}$ or $\mathrm{U}^{b}$ & 380 & $3,230^{*}$ & $2,635^{*}$ & 92.0 & $215^{*}$ & $445^{*}$ & 88.0 \\
\hline $\begin{array}{l}\text { Metric tons/year, } U \text { or } \\
\mathrm{Th}^{b}\end{array}$ & 563 & $217^{*}$ & $468^{*}$ & 1,060 & $784^{*}$ & $186^{*}$ & 287 \\
\hline $\mathrm{Kg} /$ year, $\mathrm{Pu}$ or $\mathrm{U}^{b}$ & 5,520 & $9.040 *$ & $18,600^{*}$ & 4,240 & $13,800^{*}$ & $6,410^{*}$ & 1,970 \\
\hline $\mathrm{Kg} /$ year, fission products & 14,100 & 15,200 & 14,000 & 16,300 & 16,300 & 9,560 & 10,000 \\
\hline Batches /year & 14.5 & 2.80 & 7.06 & 46.1 & 64.3 & 14.4 & 22.4 \\
\hline Processing days $/ y r$ & 194 & 288 & 254 & 155 & 155 & 195 & 155 \\
\hline \multicolumn{8}{|l|}{ Processing rates: } \\
\hline $\begin{array}{l}\text { Metric tons /day, U or } \\
\mathrm{Th}^{b}\end{array}$ & 2.90 & $0.753^{*}$ & $1.84 *$ & 6.85 & $5.06 *$ & $0.954^{*}$ & 1.85 \\
\hline $\mathrm{Kg} /$ day, $\mathrm{Pu}$ or $\mathrm{U}^{\mathrm{b}}$ & 28.5 & $31.4^{*}$ & $73.2^{*}$ & 27.4 & $89.0^{*}$ & $32.9^{*}$ & 12.7 \\
\hline $\begin{array}{l}\text { Cost of processing plant, } \\
\text { millions of dollars }\end{array}$ & 67.2 & 56.6 & 66.8 & 74.8 & 76.7 & 59.9 & 62.2 \\
\hline $\begin{array}{l}\text { Land, startup, and working } \\
\text { capital, millions of } \\
\text { dollars }\end{array}$ & 4.5 & 3.8 & 4.4 & 5.1 & 5.2 & 3.7 & 3.9 \\
\hline $\begin{array}{l}\text { Tota } 1 \text { capital investment, } \\
\text { millions of dollars }\end{array}$ & 71.7 & 60.4 & 71.2 & 79.9 & 81.9 & 63.6 & 66.1 \\
\hline $\begin{array}{l}\text { Annual operating cost, } \\
\text { millions of dollars }\end{array}$ & 6.7 & 5.1 & 6.5 & 7.6 & 7.9 & 5.5 & 5.8 \\
\hline $\begin{array}{l}\text { Annual charge for ultimate } \\
\text { disposal, millions of } \\
\text { dollars }\end{array}$ & 3.2 & 3.3 & 3.2 & 3.4 & 3.4 & 2.5 & 2.6 \\
\hline \multicolumn{8}{|l|}{ At $15 \%$ fixed-charge rate: } \\
\hline Millions of dollars /year & 20.7 & 17.5 & 20.4 & 23.0 & 23.6 & 17.5 & 18.3 \\
\hline Dollars /metric ton & 36,800 & 80,600 & 43,600 & 21,700 & 30,100 & 94,100 & 63,800 \\
\hline Mills /kwhr (electrical) & 0.197 & 0.166 & 0.194 & 0.219 & 0.224 & 0.166 & 0.174 \\
\hline \multicolumn{8}{|l|}{ At $22.5 \%$ fixed-charge rate: } \\
\hline Millions of dollars /year & 26.0 & 22.0 & 25.7 & 29.0 & 29.7 & 22.3 & 23.3 \\
\hline Dollars /metric ton & 46,200 & 101,000 & 54,900 & 27,300 & 37,900 & 120,000 & 81,200 \\
\hline Mills / kwhr (electrical) & 0.247 & 0.209 & 0.244 & 0.276 & 0.283 & 0.212 & 0.222 \\
\hline \multicolumn{8}{|l|}{ At $30 \%$ fixed-charge rate: } \\
\hline Millions of dollars /year & 31.4 & 26.5 & 31.1 & 35.0 & 35.9 & 27.1 & 28.2 \\
\hline Dollars/metric ton & 55,800 & 122,000 & 66,500 & 33,000 & 45,800 & 146,000 & 98,300 \\
\hline Mills/kwhr (electrica1) & 0.299 & 0.252 & 0.296 & 0.333 & 0.341 & 0.258 & 0.268 \\
\hline
\end{tabular}

${ }^{a}$ The burnup for the $\mathrm{D}_{2} \mathrm{O}-\mathrm{Th}$ case is for the core only, but the number of metric tons per batch and the number of metric tons per year include the blanket also. For all the other reactors, the numbers represent averages over one reactor-discharge batch.

${ }^{b}$ The asterisk indicates that the fertile material is thorium and that the fissionable material is uranium. 
the lowest costs in mills per kwhr (electrical), with the reverse being the case for the low-burnup $\mathrm{D}_{2} \mathrm{O}-\mathrm{U}$ reactor. It should be emphasized, however, that the processing cost is not necessarily the controlling factor in the overall cost evaluation. In this study, for example, fabrication costs generally were higher than processing costs and varied more between reactors.

In dual-purpose plant cases, some unit-cost advantages were obtained in scaling up from 15,000 to $20,000 \mathrm{Mw}$ (electrical), though these were partially offset by the extra costs associated with designing for two different fuel types, especially when the second fuel type was sufficiently different from PWR (Pressurized-Water Reactor) fuel to require separate head-end and/or tall-end facilities. The total costs can be calculated in a fairly straightforward manner, but division of the costs between the two fuel types is not necessarily straightforward. Actually, since the PWR load is held constant the comparison of the totals gives the correct relative ranking between the various advanced converters as far as processing is concerned, but, in order to be able to calculate a total unit-power cost for each reactor for intercomparing them with each other and with PWR, a cost division is necessary. The "revenue-day" cost-assignment formula used for the AEC reference fuel reprocessing plant ${ }^{9}$ and the Nuclear Fuel Services proposal $1^{10}$ is straightforward in that it divides total costs in proportion to (processing plus turnaround) plant time assigned to a fuel, but is arbitrary in that, for a plant designed to match a specific load, it does not necessarily reflect the manner in which each different fuel type actually contributes to total costs. In this study it had the further disadvantage of giving a different PWR-processing cost for each of the six dual-purpose plants, which may or may not be justified but which complicates intercomparisons. Alternative methods of cost division were proposed, ${ }^{11}$ but, for simplicity, it was decided to use the single-purpose plant unit costs for intercomparis on purposes in this study and to list the

\footnotetext{
${ }^{9}$ AEC Reference Fuel-Reprocessing Plant, WASH-743 (October 1957).

10 "Chemical Processing Plant," hearing before the Joint Committee on Atomic Energy, 85th Congress of the U.S., May 14, 1963.

$11 \mathrm{~J}$. T. Roberts, Fuel Reprocessing Costs for Advanced Converter Reactors (in preparation).
}

dual-purpose plant costs only as supplementary information.

\subsection{MANUAL FOR SHIPPING SPENT REACTOR FUEL}

Over the past several years the Laboratory and other sites have conducted a series of investigations concerned with the design of a safe shipping cask for transporting radioactive material and, more specifically, spent reactor fuel elements. These experimental and study-type investigations have encompassed basic engineering problems such as shielding, heat transfer, energy absorption characteristics of structural materials, and scaleup and criticality studies. The goal of the program has been to take the results of these studies, including those done at other sites, and combine them into a comprehensive report that will cover all aspects of shipping cask design.

The report has been written and is being prepared in second-draft form. The topics discussed in the report include criticality and nuclear safety, heat transfer problems in cask design, structural integrity of casks, shielding, contamination, regulations, and accidents.

\subsection{DROP TESTS ON CONTAINERS FOR SHIPPING SOLUTIONS OF REACTOR FUELS}

Shipments of unırradiated fissile material are normally made in containers with a surrounding framework called a "bird cage" to ensure a definite spacing between containers. The purpose of controlled spacing is to minimize neutron interaction, in order to prevent an accidental and uncontrolled criticality incident when a number of such contaners are shipped together. Since spacing is mandatory, it is important to know what effect an impact accident would have on such a container. Such tests, simulating possible accident conditions, have been made to and in designing bird cages to withstand such impacts.

In a recent investigation, several 55-gal steel drums (ICC specification 17H), each of which held the simulated fissile material in an 8-1n.-diam pipe positioned in the center of the drum, were dropped from heights up to $30 \mathrm{ft}$. The pipe, which weighed $200 \mathrm{lb}$, was held in place by two rows of 
angle-iron spokes welded to the pipe and to a steel band that $f_{1}$ tted snugly inside and was welded to the drum. Results indicate that such bird cages can withstand horizontal drops without completely destroying the spacing.

\subsection{CRITICALITY CONTROL IN FUEL-CYCLE PLANTS}

A study was made in order to define design criteria for methods for controlling criticality in fuel-cycle plants. The primary stress was placed on determining the $l_{1}$ mits and allowable procedures for newer and more economical methods for controlling criticality as they apply to large plants for recoverng unburnt fuel and making new powerreactor fuels.
Present criticality data applicable to configuration, mass, concentration, and control of fixed and soluble poisons in fuel-cycle processes were supplemented by multigroup neutron diffusion and transport calculations. Allowable configurations and $f_{1} s_{1} 1$ e masses were determined for typical homogeneous and heterogeneous systems of $f_{1 s-}$ sile, fertile, and moderator materials that occur in fuel processing and fabrication. Limiting critical concentrations were calculated for aqueous solutions of mixtures of ${ }^{23}{ }^{3} \mathrm{U}-{ }^{232} \mathrm{Th},{ }^{235} \mathrm{U}-{ }^{238} \mathrm{U}$, ${ }^{235} \mathrm{U}-{ }^{232} \mathrm{Th}, \quad{ }^{23}{ }^{9} \mathrm{Pu}-{ }^{232} \mathrm{Th}$, and ${ }^{23}{ }^{9} \mathrm{Pu}-{ }^{23}{ }^{8} \mathrm{U}$. Criticality parameters and safeguard techniques were derived for use with fixed-poison arrays of borosilicate glass and boron-stanless steel and for use with the soluble porsons boron, cadmium, samarıum, and gadolinium. The effect of various external neutron absorbers and reflectors on the reactivity of fissile systems and arrays of fissile systems was calculated. The results of this study are to be issued as a topical report. 


\section{Chemical Applications of Nuclear Explosions}

The Chemical Applications of Nuclear Explosions (CANE) Program at ORNL centers about a study of the various ways in which nuclear explosions may be used to produce chemical reactions, new products, or radioisotopes which are either difficult or impossible to obtain by other means. The major effort this year was devoted to the development of a chemical flowsheet for the recovery of transplutonium elements from salt debris produced in Project Coach, a planned underground nuclear explosion. Smaller efforts were devoted to studies on the production and recovery of radioisotopes by "jet sampling" and on the feasibility of a "bubble-tapping" line to obtain samples from the blast zone immediately after the explosion.

\subsection{PROJECT COACH}

In Project Coach, it is proposed that a 5- to 10kiloton nuclear device designed for producing maximum neutron fluxes be detonated underground in a bedded-salt formation near Carlsbad, New Mexico, for producing milligram or larger quantities of transcurium elements. Project Coach is a part of the Plowshare Program. The Coach detonation was originally planned for 1963 , but it was postponed because of technical difficulties related to developing a suitable neutron-producing device. Further work on the device is under way at Lawrence Radiation Laboratory at Livermore, California. Lawrence Radiation Laboratory is responsible for conducting the detonation, for mining and crushing the debris to be processed, and for on-site processing. Our responsibility in Project Coach is to aid in the development of chemical flowsheets for isolating transplutonium elements from the debris.

The isotopes produced in the Coach shot will be dispersed into 10,000 to 35,000 tons of debris. The debris will be mined about a year after the detonation in order to allow time for fission product decay. Because shipping costs for large tonnages of the radioactive debris are high, an on-site chemical plant for concentrating the actinides to a primary concentrate is required. The primary concentrate will then be shipped to ORNL or to other AEC sites for final processing.

Work performed on Project Coach at ORNL this year was concerned with chemical processing methods for obtaining a primary concentrate of actinides from the salt debris. Laboratory chemistry studies were performed on radioactive samples from the Gnome underground detonation in bedded salt, and engineering data were obtained on salt samples from the tunnel excavation prior to the Coach shot.

In the proposed process for primary concentration, 10,000 to 35,000 tons of the mined and crushed salt debris is water-leached, leaving a water-insoluble residue that contains more than $99 \%$ of the desired actinides. Next, the insoluble material is separated from the brine and leached with acid to bring the desired elements into solution. A primary concentrate of actinides is then obtained by "carrying" with a calcium oxalate precipitate. The concentration factor achieved is about 1000. All liquid and solid wastes will be disposed of at the Coach site.

\section{Chemical Studies of Samples from the Gnome Site}

A 3 to 1 weight ratio of water to salt "ore" is sufficient to leach all the salt from the debris at room temperature. About $10 \%$ of the ore remains insoluble in water under these conditions. The insoluble residue is composed mainly of anhydrite, olivine, quartz, magnetite, and various silicates and clays, plus the actinide elements sought. The only significant quantities of radioactive elements leached by water are ${ }^{90} \mathrm{Sr}$ and ${ }^{137} \mathrm{Cs}$, which are 
expected to be, respectively, 10 and 500 times the maximum permissible concentration for water $\left(\mathrm{MPC}_{\mathrm{w}}\right)$ for occupational exposure.

Either nitric or hydrochloric acid is effective for leaching the actinides from the water-insoluble residues. Different leaching conditions are required for different types of residues, depending on whether anhydrite or silicates are the major component of the residue. For residues that are mainly anhydrite, leaching with $1 \mathrm{~N} \mathrm{HCl}$ or $1 \mathrm{~N}$ $\mathrm{HNO}_{3}$ (10 to 30 parts per unit of water-insoluble material) at room temperature for $4 \mathrm{hr}$ is sufficient for 80 to $90 \%$ recovery of the actinides. On the other hand, with residues that are mainly silicates of calcium, magnesium, and iron, leaching with 3 to $6 N$ acid (about 20 parts per unit of waterinsoluble material) at reflux temperatures for 4 to $6 \mathrm{hr}$ is required for the same percentage recovery of actinides. A leaching efficiency of about $90 \%$ can be achieved at room temperature with the high-silicate residues, but leaching times of two to three days are required. A leach-liquor clarification step is required for liquors obtained from acid leaching of the high-silicate residues. Clarification is effected by adding gelatin ( $1 \%$ by weight) to the leach liquor, digesting at $80^{\circ} \mathrm{C}$ for $1 \mathrm{hr}$ to coagulate the colloidal silica, and then separating the silica by filtration. Silicate decomposition by acid is necessary for good leaching efficiency because the radioactivity in the water-insoluble residues is associated mainly with the silicates. Acid consumption by the water-insoluble residue varies from 10 to $25 \mathrm{meq} / \mathrm{g}$, depending on the silicate content. Acid consumption increases with increasing silicate content of the residues.

Partial precipitation of calcium as oxalate at $\mathrm{pH} 1$ to 2 is effective for obtaining a primary concentrate of the actinides, which are carried on the oxalate precipitate. Experiments on the carrying of ${ }^{241} \mathrm{Am}$ tracer from acid leach liquors of water-insoluble residues showed that 90 to $95 \%$ of the tracer was carried by precipitating about $5 \%$ of the soluble calcium. It is estimated that the total actinide concentration factor achieved in the steps going from salt debris to calcium oxalate is about 1000 .

Radiochemical analyses of several Gnome samples indicate that simple gamma counting might be used to select the salt debris to be processed. In this way the quantity of debris to be processed could be reduced by half or more by simple gamma counting. In the samples thus far examined, the ratio of gamma radioactivity to transplutonium element concentration is fairly constant.

\section{Engineering Data from Coach Excavation Salt}

A large sample of salt from the excavation site of the proposed Coach detonation was used to obtain engineering data on the liquid-solids separation in the water and acid leach steps of the proposed process. The sample contained mineral concentrations nearly typical for the Salado formation in which the site is located, except for the concentrations of magnesium and sulfate, which are significantly higher, and of aluminum, which is lower.

The total water-insoluble material resulting from leaching with 3 parts of water was $21 \%$, most of which was calcium sulfate. About $40 \%$ of the insoluble residue passed through a 50 -mesh screen. Sedimentation and filtration tests with the waterleach slurry showed that the rates were greatly improved by the addition of the flocculating agent, Separan. The sedimentation rate was $5 \mathrm{ft} / \mathrm{hr}$ without Separan, and $36 \mathrm{ft} / \mathrm{hr}$ with $0.4 \mathrm{lb}$ of Separan per ton of water-insoluble material. The thickener for processing 100 tons of salt per day should be $5 \mathrm{ft}$ in diameter and $3 \mathrm{ft}$ high if Separan is used. The required filter area is $200 \mathrm{ft}^{2}$ under the same conditions.

Leaching the water-insoluble residue with $1 \mathrm{~N}$ $\mathrm{HCl}$ (30 parts per unit of residue) dissolved about $50 \%$ of the solids. The major constituents of the acid leach liquor were calcium, magnesium, and sulfate, with low concentrations of iron, aluminum, and silicon. The acid consumption was $3.6 \mathrm{meq}$ per gram of water-insoluble residue. The required thickener and filter sizes were very nearly the same as those for use with the water-leach slurry.

It is expected that about a fourth of the salt in the debris of the Coach detonation will have been melted. To simulate such debris, a sample of salt was heated at $850^{\circ} \mathrm{C}$ for $4 \mathrm{hr}$. The most significant effects of melting were that nearly all the waterinsoluble matter was smaller than 50 mesh, compared with the $40 \%$ that passed the 50 -mesh screen when the salt had not been melted, and that the acid consumption was more than doubled, $7.8 \mathrm{meq}$ per gram of water-insoluble residue. 


\subsection{PROMPT-SAMPLER STUDIES FOR RECOVERING SAMPLES AND IRRADIATED SPECIMENS FROM NUCLEAR EXPLOSIONS}

A study of samples of the products of contained, underground nuclear explosions is necessary to understand the chemical and nuclear reactions that occur. Since the nature of the samples depends upon the time at which they are withdrawn, they must be taken at several intervals of time to establish all the reactions that occur. Core samples obtained by drilling into the debris a few weeks after detonation establish final products, but they do not permit the investigation of intermediate chemical reactions or of radionuclides that have decayed beyond their limit of detection. Present prompt samplers, such as the Gnome sampler, ${ }^{1}$ allow gas samples of debris plus any irradiated target material to be taken for a few milliseconds after detonation, before the sampling system is destroyed by the explosion. The Gnometype sampler recovers only about $3 \times 10^{-12}$ of any irradiated specimen, and the specimen is mixed with the debris of the explosion.

We are investigating two types of samplers that supplement the Gnome type. One is a jet sampler for recovering neutron-irradiated targets free of explosion debris in about $50 \%$ yield, and the other is a bubble-tapping sampler whereby gaseous and aerosol samples from the underground cavity can be withdrawn over periods of hours or days, starting a few hundred milliseconds after the nuclear explosion. The Pitman-Dunn Institute for Research (PDIFR) at Frankford Arsenal, under subcontract, is aiding in a study of these samplers. Experimental work utilizing high explosives has been started by PDIFR on the jet sampler, but the bubble-tapping sampler is still in the conceptual stage.

The unique feature of the jet sampler is that it allows a target to be irradiated by the large neutron flux of a nuclear explosion and to be jetted through an evacuated pipe at velocities of 10 to $100 \mathrm{~km} / \mathrm{sec}$ ahead of the shock wave to a recovery station about $100 \mathrm{~m}$ from the explosion point. The irradiated target could then be recovered within a few minutes after the explosion and would be free of explosion debris. Such a sampler, if successful,

${ }^{1} \mathrm{~J}$. W. Landry, The Sequenced Gas-Sampling Experiment, Project Gnome, Carlsbad, N. Mex., Dec. 10, 1961, USAEC Plowshare Program, PNE-103F (Sept. 26, 1962). would be very useful in isotope studies and fastneutron cross-section measurements. An outdoor firing range utilizing a vacuum chamber has been constructed at PDIFR for firing high-explosive shaped charges to form target specimens into longrange hypervelocity jets. Uranium specimens simulating heavy metals have been jetted at velocities of about $10 \mathrm{~km} / \mathrm{sec}$, but the range was only $10 \mathrm{ft}$, and the recovery was less than $50 \%$. The specimens were $25 \mathrm{~mm}$ in diameter. Range and yield are expected to improve with larger and more accurately fabricated target specimens. Studies are being conducted to determine the necessary scaling factors for the transition from high explosive to nuclear energy to form jets of various specimens. After successful demonstration of the proper range, velocity, and recovery of jets formed from special targets by high explosives, an experiment in an underground nuclear explosion will be proposed.

The important feature of the bubble-tapping sampler is that the contents of the cavity formed by an underground nuclear explosion can be sampled in a continuous and controlled manner, starting a few hundred milliseconds after the detonation and continuing for days or weeks, if desired. The sampling is accomplished by initially installing the sampling pipe inlet several meters from the detonation point, such that the end of the sampling pipe is protected by intervening rock. Upon detonation of the device, the cavity that is formed expands to within a few feet of the pipe inlet. At the time of maximum bubble size or cavity radius, connection is made between the pipe and the bubble by special means, and the bubble is sampled. The expansion of the bubble bends the pipe in a slight arc, but it is postulated that the axial compression will not be sufficient to break or close the pipe, and a permanent connection to the cavity will be attained. No part of the sample pipe passes through the zone of earth above the cavity in which collapse and fall of earth material occur. The pipe will require protection from the shock wave, heat, and earth movement that occur outside the collapse zone. It is believed that the pipe could be protected from the shock wave by surrounding the pipe with high explosives and filling it with water to counteract and absorb the shock energy. Feasibility and cost studies of the bubble-tapping sampler are being made, but no tests have been conducted. 


\section{Assistance Programs}

The Chemical Technology Division provided assistance to others on several projects. The Eurochemic Assistance Program was continued. Under this program, the Laboratory is coordinating the exchange of information between Eurochemic and the various AEC sites and is currently supplying the U.S. Technical Advisor to Eurochemic during the construction and startup periods. The Division continued to supply technical liaison between the Laboratory, the AEC, and the construction contractor for the High Radiation Level Analytical Laboratory. Consultation on construction of the two plant-waste-improvement projects was continued. Assistance on alpha laboratory design and construction included completion of the Interim Alpha Laboratory in the basement of Building 3019 and the preparation of a design study for a 32-laboratory Alpha Laboratory Facility. Engineering assistance was provided the Health Physics Division on two large experiments: intermediate-level radioactive waste disposal by hydrofracturing and high-level radioactive waste disposal in salt. In order to provide additional ${ }^{233} \mathrm{U}$ storage space, an interim facility for storing $60 \mathrm{~kg}$ of ${ }^{23}{ }^{3} \mathrm{U}_{3} \mathrm{O}_{8}$ was designed and built, and the design of a facility for storing $300 \mathrm{~kg}$ of ${ }^{233} \mathrm{U}$ as uranyl nitrate solution was begun. Both facilities will be in Building 3019. A shielded interim alphagamma facility was designed and is being installed in Building 3508. A study was made on the shielding of isotopic power sources for space missions. Finally, a proposal was made to the AEC to process fuel from the Elk River reactor in our facilities as a means of accelerating engineering evaluation of the overall $\mathrm{Th}-{ }^{23} \mathrm{U}$ fuel cycle.

\subsection{EUROCHEMIC ASSISTANCE PROGRAM}

The Laboratory continued to coordinate the Eurochemic Assistance Program for the exchange of information between Eurochemic and the several
AEC sites participating in the program. In addition, the Laboratory is supplying the U.S. Technical Advisor, E. M. Shank, who will remain at Mol, Belgium, during the construction and startup phases of the Eurochemic plant.

During the past year, 509 USAEC-originated documents and 55 drawings and miscellaneous items were sent to Eurochemic. About 48 Eurochemic documents written in English were received, reproduced, and distributed. Also, 4 Eurochemic documents written in French were translated and distributed.

At the end of 1963, the Eurochemic staff had increased to 271 people from 14 countries; expansion will continue until the full complement of 450 is reached. E. Pohland, General Manager since the beginning of the project, retired, and R. Rometsch, Research Director, was appointed acting General Manager. Based on a new estimate, the total cost of the completed facility will be $\$ 27.2$ million. Expenses for the next four years, including construction completion, are estimated to be $\$ 21$ million. The plant is now scheduled for "hot" startup in December 1965.

All main process engineering flowsheets have been approved except for the rework and the final plutonium systems. Detailed equipment design (by the architect-engineer) is nearly complete, and $90 \%$ of the equipment has been ordered; two longdelivery items, the second dissolver and the $1 \mathrm{WW}$ evaporator, have not been ordered. A systematic criticality review is $90 \%$ complete. Handling requirements for EL-3 fuel (the first fuel expected) were studied, and the special tools were ordered. The engineering flowsheets for the effluenttreatment station have not been approved; this facility may control the plant startup date, since it is the final control point for all radioactive liquid wastes discharged from the site. Pre-project studies have continued for medium-level radioactive waste (MLW) storage and solid-waste 
handling; the MLW storage facility may also control the plant startup date. The preparation of the analytical procedures and the high-activitylevel glove box equipment is well advanced.

Laboratory-scale studies were continued on processes not immediately applicable to the main process. These studies concern graphite-based fuels, the Citriflex head-end, air-pulsed mixersettlers, and the pre-project design study for the 500-curie hot cells. Similar studies are continuing on various feed preparation systems, the solvent extraction flowsheets, preparation of U(IV) nitrate, and final product purification. Pilot-scale studies were continued on dissolution, bottom interface control, effects of purge air on pulsed columns, air pulsation, evaporation, and slab-tank mixing. In-line instrumentation development has continued on the beta-ray monitoring of low-level radioactive waste, the alpha liquid-film monitor, a beta-gamma in-line sample monitor, conductivity, and the ${ }^{241} \mathrm{Am}$ absorptiometer.

\subsection{CONSTRUCTION AND STARTUP OF THE HIGH RADIATION LEVEL ANALYTICAL FACILITY}

The construction of the Analytical Chemistry Division's High Radiation Level Analytical Laboratory was completed in April 1964. This facility is a $225,000-\mathrm{ft}^{3}$, two-story building housing one unloading cell, one storage cell, six work cells, three analytical laboratories, and such necessary supporting areas as cell-equipment assembly and decontamination rooms, change rooms, offices, a conference room, and a serviceequipment area. Construction was done under an AEC fixed-price contract by the Foster and Creighton Company of Nashville, Tennessee. Field supervision and inspection of construction were done by the Vitro Engineering Company, New York, who prepared the contract drawings and specifications for the project.

Considerable additional work still remains to be performed before the facility will be ready for high-radiation-level analytical operations toward the end of this calendar year. This involves the Laboratory and H. K. Ferguson Company phases of the overall construction project. Afterward, certain modifications and additions to existing construction will be required to improve the ease of maintenance and operating reliability of me- chanical equipment and ventilation controls, particularly within the radiation confinement areas of the building.

Project construction work remaining to be completed by Ferguson includes the installation of tie-in connections between the construction site and the ORNL tank farm for two building drain lines. The radiochemical drain will be of Hastelloy $\mathrm{C}$, and a process-waste drain will be of vitrified tile. Work at the construction site will include improvements in site drainage, a new paved road around the building, a protective fence around the cell-ventilation exhaust equipment located outside the building, and facilities for housing the filter pit, fans, and stack.

Project construction work remaining to be completed by the Laboratory includes the procurement of Hastelloy C pipe required for H. K. Ferguson Company installation of the radiochemical drain (RCD) tie-in connection; placement of topsoil, seeding of the construction site, and backfilling of trench areas following Ferguson installation of drain-line connections; installation of model 8 standard-duty manipulators for cell and special work areas; installation of health physics instrumentation; installation of stack, RCD, and process-water drain monitoring and telemetering instrumentation; and installation of filters in the cell-exhaust filter pit and sealing of pit covers in the cell-exhaust filter and off-gas system pits.

\subsection{ALPHA LABORATORY FACILITIES}

A three-laboratory Interim Alpha Facility (Fig. 18.1) was built in the equipment and mechanical room of the Chemical Technology Division Radiochemical Pilot Plant, Building 3019, and placed in operation. The interior of the building was completely renovated, and the containment was upgraded. A once-through conditioned-air ventilation system with appropriate filters and backflow preventers was installed. The system now exhausts to the Building 3019 cell-ventilation system. Ventilation exhaust from the glove boxes is filtered through absolute filters and discharged into the Building 3019 dissolver off-gas system. Liquid-waste-disposal facilities have been extended into the area. Each laboratory has instruments for continuous monitoring of alpha activity, detection of fire, and detection of loss of vacuum in the ventilation and off-gas headers. 
UNCLASSIFIED

ORNL-DWG $64-419 R I A$

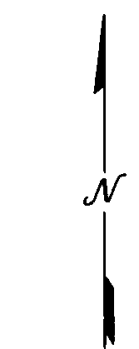

UP TO

FIRST FLOOR
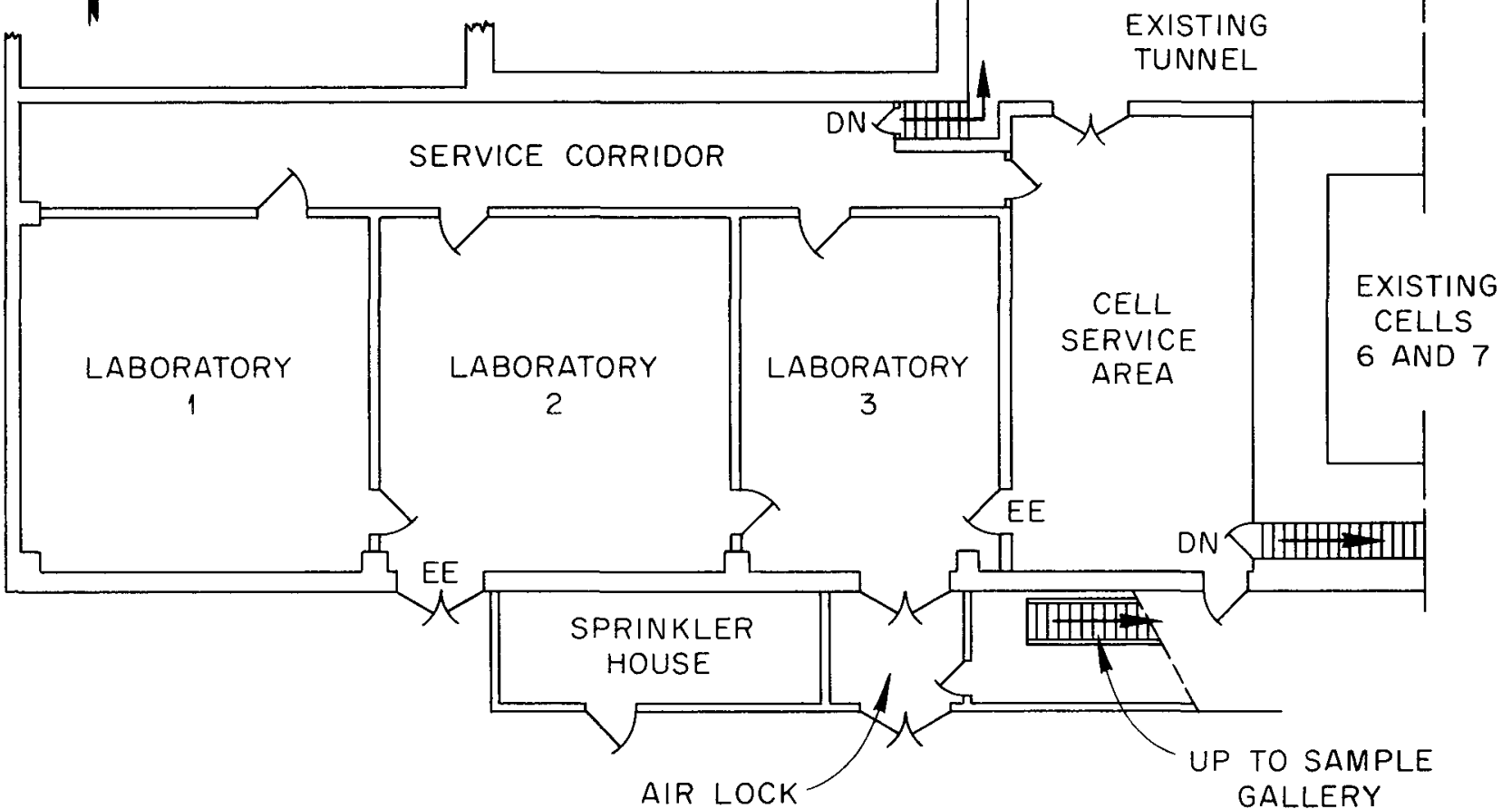

$E E=E M E R G E N C Y E X I T$

Fig. 18.1. Floor Plan of Interim Alpho Laboratory, Basement of Building 3019.

Alarm signals are transmitted to the Building 3019 containment panel. The laboratory facility is also tied into the Building 3019 communication and evacuation system.

The facility is being used for the fabrication of ${ }^{242} \mathrm{Pu}$ targets for irradiation in the Savannah River reactors and later in the High Flux Isotope Reactor, in suppost of the Transuranium Program. Other process investigations scheduled for the near future include the development of a sol-gel process for $\mathrm{PuO}_{2}$, testing of the Tramex process in small-scale pulsed columns, and chemical studies on americium and curium oxide.

A preliminary design and cost study was made for a new Alpha Laboratory Facility for joint use by the Analytical Chemistry, Chemical Technology, Reactor Chemistry, and Metals and Ceramics Divisions. The laboratory would contain twentyeight 16- by $32-\mathrm{ft}$ alpha laboratories, four supporting "cold" laboratories, a 32- by 64-ft-deep bay area for large alpha experiments, and supporting office and service facilities. The facility is estimated to cost approximately $\$ 5,000,000$.

\subsection{PROJECTS FOR IMPROVING THE PLANT-WASTE SYSTEM}

The Chemical Technology Division continued to supply consultation to the General Engineering 
and Construction and the Operations Divisions during construction of two plant-waste-system improvement projects. The first of these, the Melton Valley waste collection and transfer system, was completed in February 1964, except for connections into the main ORNL waste system. This system will serve the High Flux Isotope Reactor, the Transuranium Processing Plant, the Thorium-Uranium Fuel Cycle Development Facility, and the Molten-Salt Reactor Experiment. A wastetransfer line has been installed to each of these facilities for connection as each facility is completed.

The second improvement project is the construction of an intermediate-level waste evaporator and two 50,000-gal high-level-waste storage tanks. The building to house this facility was completed in February 1964, and installation of the evaporator began in March. The facility is scheduled for completion in February 1965 because of a delay in fabrication of the storage tanks. Because the sampling room for the entire facility is to be situated above the storage-tank vault, the evaporator cannot be operated until the storage tanks have been installed and their vault has been sealed.

The evaporator and its auxiliaries and the storage tanks are being made of type $304 \mathrm{~L}$ stainless steel to permit the handling of acid wastes. Although the major function of the evaporator will be to concentrate 10,000 gal per day of ORNL intermediate-level alkaline waste containing less than 10 curies/gal, the facility has adequate shielding to process and store waste containing 2800 curies/gal. Total cost of the two wastesystem-improvement projects will be $\$ 1.7$ million.

\subsection{DEMONSTRATION OF THE DISPOSAL OF SOLID, HIGH-LEVEL RADIOACTIVE WASTE IN SALT MINES}

The engineering design, development, and fabrication of the required equipment for handling the radioactive materials for the high-level waste solids demonstration in salt are being coordinated in the Process Design Section of this Division. The demonstration is directed by the Health Physics Division, with the objectives of demonstrating equipment and techniques for safely handling and storing of high-level radioactive waste in solid form and of studying the effect of radiation and heat on the salt. Fuel elements from the ETR will be used to simulate the pots of calcined waste that will be produced at the Hanford High-Activity-Level Waste Calcination Pilot Plant at a future date. The present operation includes canning and shipping short-cooled ETR fuel elements from the NRTS in Idaho to the Carey salt mine in Lyons, Kansas; transferring the elements from the surface to the mine; charging the fuel to shielded storage holes; and recovering the fuel after completion of the demonstration. Data will be collected during a two-year period, starting early in 1965.

In addition to the responsibilities above, work in the design section includes evaluating the hazards involved in shipping and operations in the mine, installing the equipment, and planning the operating procedures for handling radioactive materials. The design of the equipment was completed this year, and the majority of the equipment is now being built or purchased.

The Health Physics Division is in charge of renovating the mine, mining the experimental area, instrumentation, and collecting the data over the two-year demonstration period.

\subsection{DISPOSAL OF RADIOACTIVE WASTE BY HYDROFRACTURE}

The engineering on the Health Physics Division experiments on disposal of intermediate-activitylevel aqueous wastes by hydrofracturing is being coordinated by the Process Design Section of this Division. In this program, the aqueous wastes are mixed with cement and clay and pumped at high pressure into an approximately 1000 -ftdeep well in the ORNL test area in lower Melton Valley. When sufficient pressure is exerted, the rock strata is fractured at the bottom of the well, and the waste is distributed in a thin slab of large diameter around the well, where it sets up as a concrete sheet.

Our responsibilities on this project included the design, fabrication, and installation of the cement, clay, and waste storage areas, and the mixing cell and its equipment. The Halliburton Company was responsible for the high-pressure pumping equipment and the well operations. During the past year, the facility design and installation were completed. A series of four 
injections were made in order to test the performance of the surface plant and to determine the underground behavior of the grout sheets with waste solutions and solid mixes of different compositions. Synthetic waste solutions were used in the first injections so that the composition would be similar to that of the concentrate from the ORNL waste evaporator.

In the first injection (February 13, 1964), 37,000 gal of synthetic concentrated waste solution was mixed with $23,400 \mathrm{lb}$ of attapulgite drilling clay and injected at a depth of $945 \mathrm{ft}$. This injection was made in order to test the operation of the surface plant and to evaluate a nonsetting mix.

In the second injection (February 21), 27,300 gal of synthetic concentrated waste solution with 30 curies of ${ }^{198} \mathrm{Au}$ tracer was mixed with about $170,000 \mathrm{lb}$ of a cement-base mix and injected at a depth of $924 \mathrm{ft}$. This injection was made to evaluate a mix with a low concentration of cement and to determine whether the activity in the grout sheet could be detected at the observation well.

In the third injection (April 8), 33,500 gal of a mixture of synthetic concentrated waste solution and actual intermediate-level radioactive waste was mixed with about $518,000 \mathrm{lb}$ of a cement-base mix and injected at a depth of $912 \mathrm{ft}$. This injection was made to demonstrate that concentrated radioactive waste solutions similar to those to be produced by the ORNL waste evaporator can be fixed permanently underground.

In the fourth injection (April 17), 36,000 gal of intermediate-level waste solution was mixed with about $381,000 \mathrm{lb}$ of a cement-base mix and injected at a depth of $900 \mathrm{ft}$. This injection was made to evaluate a mix for dilute waste solutions.

Minor difficulties were encountered with various components of the surface plant during the series of injections and were corrected as they appeared. In general, the operation of the injection plant has been smooth and satisfactory.

Evaluation of the mixes used in the four injections and determination of the underground behavior of the grout sheets cannot be accomplished until cores of the formation have been recovered.

\subsection{STORAGE FACILITY FOR ${ }^{233} \mathrm{U}$, BUILDING 3019}

A facility is being designed for installation in the pipe tunnel of Building 3019 for the handling and critically safe storage of up to $300 \mathrm{~kg}$ of ${ }^{233} \mathrm{U}$ as the nitrate solution. A smaller storage and handling system was designed and installed in the penthouse of Building 3019 for the handling and critically safe storage of more than $60 \mathrm{~kg}$ of ${ }^{233} \mathrm{U}$ as dry $\mathrm{U}_{3} \mathrm{O}_{8}$.

The facility for handling nitrate solutions in the pipe tunnel will consist of five type 316 stainless steel tanks, 36 in. OD, $61 \mathrm{in.} \mathrm{long,} \mathrm{and} \mathrm{having} \mathrm{a}$ $3 / 16^{-i n}$. wall thickness. The part of the pipe tunnel in which these tanks are to be located will be a shielded, doubly contained area. Each tank is to be separately installed and individually shielded to permit maintenance independent of the other tanks. The criticality problem is met by using borosilicate-glass Raschig rings (1.75 in. long, 1.50 in. $\mathrm{OD}, 1.042$ in. ID) with a $\mathrm{B}_{2} \mathrm{O}_{3}$ content of 11.8 to $12.8 \%$ and a total glass volume of $31 \%$ of the space occupied by the randomly packed rings.

When needed, solution from these tanks will be routed to the Thorex solvent extraction facility located in cells 5, 6, and 7 of Building 3019 for decontamination of the ${ }^{233} \mathrm{U}$ from the decay daughters of ${ }^{232} \mathrm{U}$, or to a laboratory-scale ${ }^{233} \mathrm{U}$ purification and packaging area located in the former solvent room in the makeup area of Building 3019 for handling quantities of ${ }^{23} \mathrm{U}$ up to several hundred grams. Figures 18.2 and 18.3 show schematically the location, arrangement, and some details of this facility.

With this facility, the Laboratory will serve as a national depository for the ${ }^{233} \mathrm{U}$ being produced at Savannah River and elsewhere, and possibly for the ${ }^{235} \mathrm{U}-{ }^{233} \mathrm{U}$ to be produced in power reactors [Consolidated Edison (core A) and Elk River].

Interim storage was provided for about $60 \mathrm{~kg}$ of ${ }^{23}{ }^{3} \mathrm{U}_{3} \mathrm{O}_{8}$ obtained from Savannah River as a dry powder contained in welded aluminum cans 2.77 in. OD, 6.5 in. long, and with a wall thickness of 0.04 in. Storage was provided by core drilling nine 5 -in.-diam by 8 -ft-3-in.-long holes into the concrete dividing wall between cells 3 and 4 in the Building 3019 penthouse and lining the holes with a 4-in.-IPS (iron pipe size) type 316 stainless steel pipe. 


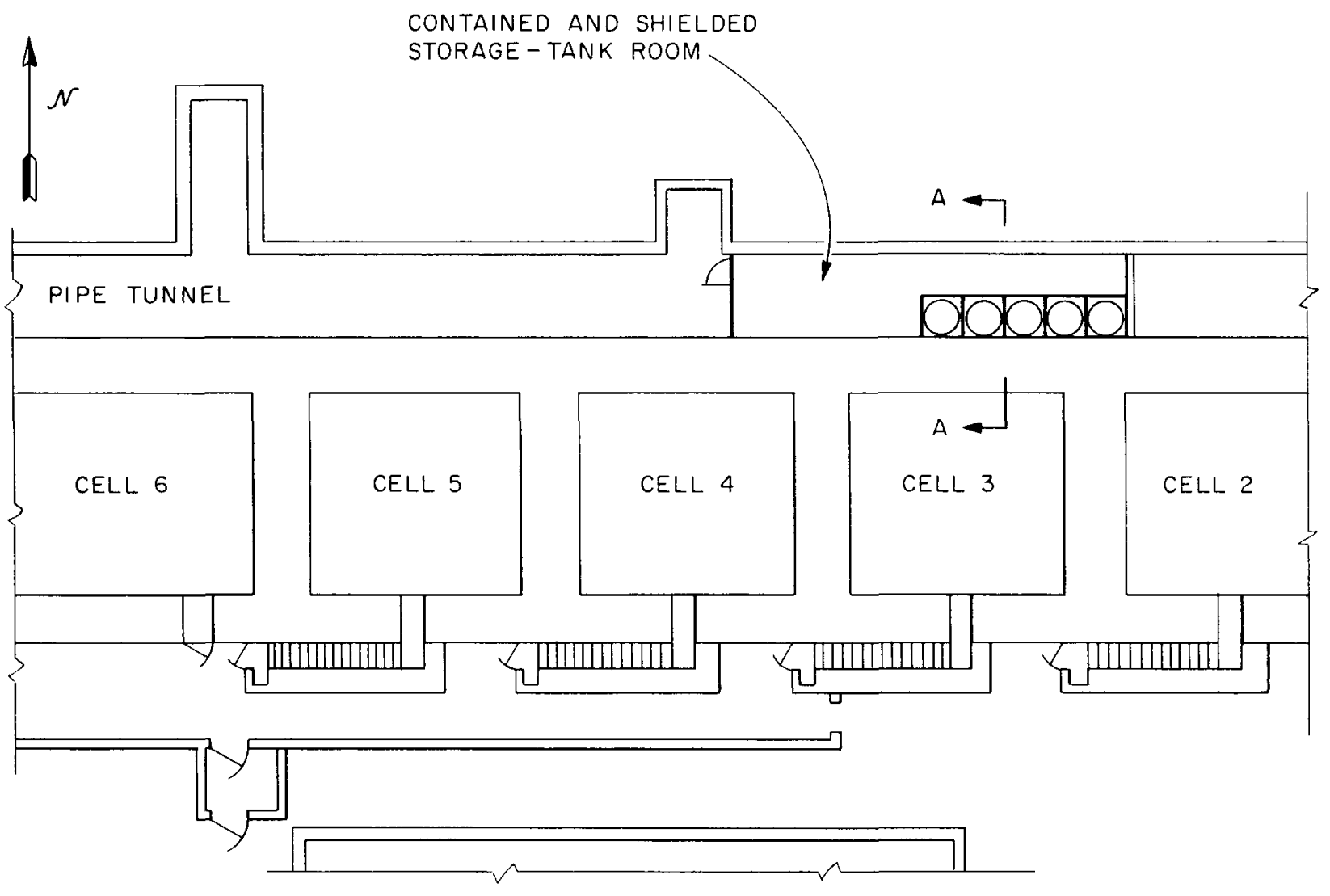

Fig. 18.2. Location and Arrangement of Five ${ }^{233} \mathrm{U}$ Storage Tanks in Pipe Tunnel of Building 3019 (Section A-A is shown in Fig. 18.3). 
UNCLASSIFIED ORNL-OWG 64-8276

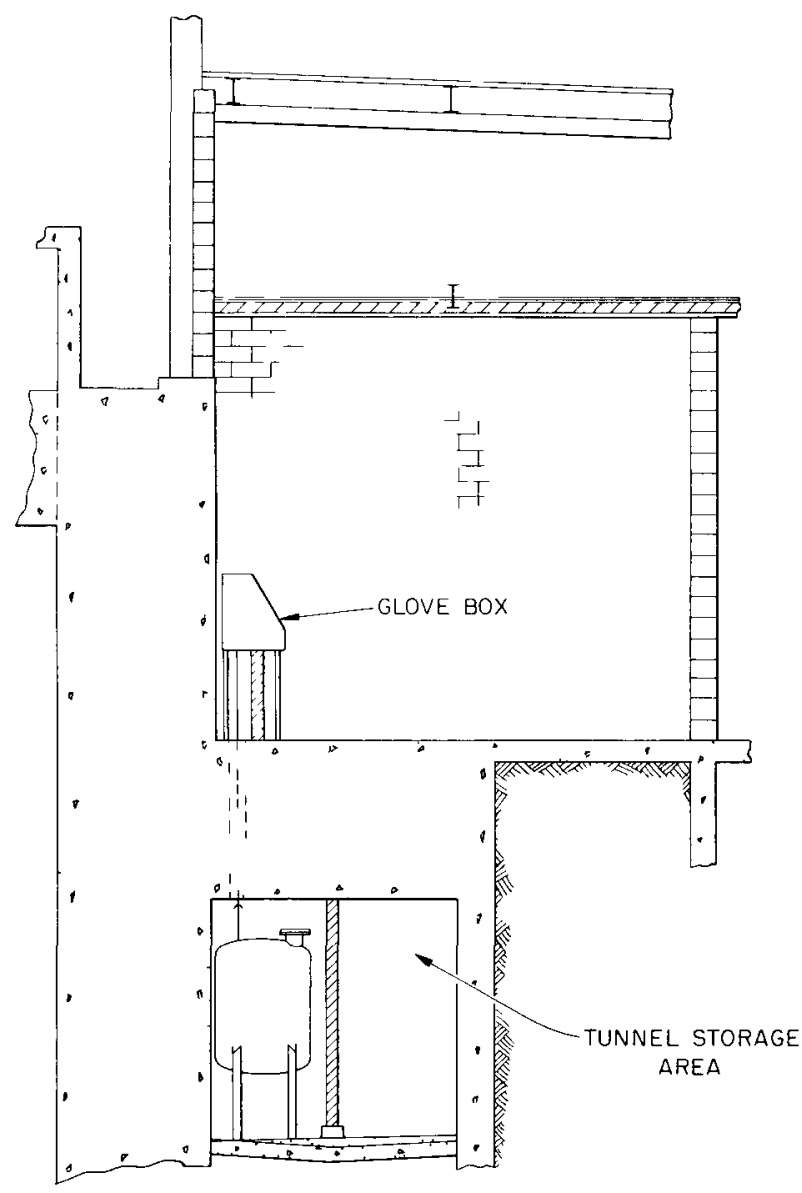

Fıg. 18.3. One of Five Storage Tanks and Its Relation to Small-Scale Purification Facility (Section A-A of Fig. 18.2).

\subsection{SHIELDED ALPHA-GAMMA FACILITY}

A shielded alpha-gamma facility was designed and is being installed in laboratory 1, Building 3508 , to provide an interim area in which chemical research and development with substantial amounts of transuranium isotopes can be done prior to the startup of the Transuranium Processing Plant.

The proposed installation will consist of structural alterations and relocation of existing facilities, an alpha box, concrete-block shielding enclosure, and miscellaneous auxiliary equipment.

The alpha box (approximately 5 by 5 by $5 \mathrm{ft}$ ) will be made of mild steel, coated with liquid tile, and equipped with a Plexiglas viewing window, safety glass ports for lighting, manipulator booting, and bag-out ports. The alpha box will be suspended inside the shielding enclosure and locked in position by use of a mechanical hoisting device. The box will be completely sealed to prevent the spread of alpha contaminants.

The shielding enclosure (inside dimensions, about 6 by 6 by $9 \mathrm{ft}$ ) will be made of solid concrete blocks with mortared joints to form a wall about $2 \mathrm{ft}$ thick. The interior will be coated with an acid-resistant sealing material. The roof of the enclosure will be a precast concrete slab about 8 in. thick. A $z$ inc bromide viewing window and one pair of specially built manipulators will be installed in the west wall of the enclosure. A removable steel plate with dry stacked concrete block will be installed in the south wall to permit the removal of the alpha box. A transfer port and a carrier loading port, each with lead shield doors, will be installed in the north wall. A glove box bag-out arrangement will be connected to the transfer port.

Inlet air and exhaust will be connected to the nearby off-gas and cell-ventilation system for the building. Auxiliary high-efficiency filters and dampers will be installed to maintain a negative pressure within the enclosure of $0.3 \mathrm{in}$. water gage, and within the alpha box, 0.4 in. water gage. A vacuum breaker will be installed to prevent the collapse of the box.

Electrical services, a hot drain, distilled water, process water, gages and alarms, and air supply will be installed as required. The facility is estimated to cost $\$ 70,000$.

\subsection{SHIELDING OF ISOTOPIC POWER SOURCES FOR SPACE MISSIONS}

Power-producing isotopes all emit penetrating radiation to some degree. Among the eight isotopes considered for space-power application $\left({ }^{137} \mathrm{Cs},{ }^{90} \mathrm{Sr}, \quad{ }^{238} \mathrm{Pu}, \quad{ }^{244} \mathrm{Cm}, \quad{ }^{127} \mathrm{Pm},{ }^{144} \mathrm{Ce}\right.$, ${ }^{242} \mathrm{Cm}$, and ${ }^{210} \mathrm{Po}$ ), all produce gamma rays as part of their natural decay scheme, and the beta emitters produce a bremsstrahlung flux in addition. Moreover, four of the isotopes are neutron emitters, the neutrons coming from spontaneous fission or from $\alpha, n$ reactions in the fuel material. As a result, protective measures would be required on space missions in which astronauts or 
long-life electronic equipment is exposed to power generators that use any of the eight isotopes.

Shield weights and separation distances were calculated for each of the eight isotopes as a function of power level. If material shielding is employed (uranium metal and lithium hydride), the calculations indicate shield weights ranging from about $20 \mathrm{lb}$ for ${ }^{238} \mathrm{Pu}$ to over $500 \mathrm{lb}$ for ${ }^{137} \mathrm{Cs}$ at a power level of $10 \mathrm{kw}$ (thermal). These weight penalties can be avoided, according to the calculations, if separation distances ranging from $2 \mathrm{ft}$ for ${ }^{238} \mathrm{Pu}$ to $40 \mathrm{ft}$ for ${ }^{137} \mathrm{Cs}$ give protection equivalent to the shield weights quoted.

\subsection{PROPOSAL FOR THE ELK RIVER REACTOR FUEL CYCLE}

In order to further the engineering development of the $T h-{ }^{23} \mathrm{U}$ fuel cycle, a proposal was made to the AEC for processing and reconstituting the fuel from the Elk River reactor in our facilities. This proposal is based on the present Elk River reactor fuel-discharge schedule, in which the core will be discharged in thirds (July 1965, July 1966, and July 1967). The first spent fuel would be cooled six months and be available for processing in January 1966 .

Under the proposed demonstration program, the Laboratory would receive, store, and mechanically and chemically process all or part of the fuel from the Elk River reactor to effect complete recovery of the ${ }^{233} \mathrm{U}-{ }^{235} \mathrm{U}$ from the fuel. The used thorium would be stored as a partially decontaminated byproduct. The recovered uranium would be combined with new thorium and converted to $\mathrm{ThO}_{2}-$ $\mathrm{UO}_{2}$ by the sol-gel process. The $\mathrm{ThO}_{2}-\mathrm{UO}_{2}$ would be loaded into tubes and vibratorily compacted to produce new fuel rods. Then, the rods would be assembled into new fuel elements and returned to the Elk River reactor. All metal waste would be sent to the ORNL burial ground, and all aqueous wastes would be handled in existing ORNL waste facilities.

The various operations would be handled in several existing ORNL facilities. The fuel would be received and stored at Building 3026, the reactor fuel dismantling facility, where it would also be disassembled, chopped, and leached in cell $\mathrm{A}$ to produce a thorium-uranium nitrate fuel solution. The resulting solution would be transferred through a pipeline to the Thorex pilot plant in cells 5, 6, and 7 of Building 3019, where it would be adjusted and solvent extracted to achieve separation of fission products from thorium and uranium and the separation and recovery of the uranium from the thorium by the Acid Thorex Process. The product ${ }^{233} \mathrm{U}-{ }^{235} \mathrm{U}$ would be stored temporarily in the new ${ }^{233} \mathrm{U}$ storage facility currently being installed in the pipe tunnel of Building 3019. The recovered ${ }^{233} \mathrm{U}$ with fresh thorium will be fabricated into fuel rods by the sol-gel-vibratory compaction procedure in the Kilorod Facility. The completed rods would be inspected and cleaned and delivered to the fuel element reassembly area to be provided in a vacant laboratory in Building 3019 . Here, each group of 25 rods would be reassembled to make reconstituted fuel assemblies according to Elk River reactor fuel specifications and, after inspection, shipped to the Elk River reactor at Elk River, Minnesota, in the same carrier in which spent fuel was delivered to us.

The Kilorod Facility changes and the installation of a new fuel element assembly facility would be done immediately in order to make several Elk River fuel rods and one complete assembly in time for placement in the reactor in July 1965. The other changes and additions would be scheduled for completion prior to January 1966.

The cost of equipment and facility modifications has been estimated to be $\$ 900,000$, and the annual operating cost for handling one-third of a core to be $\$ 800,000$. 


\section{Chemical Processing for the Molten-Salt Reactor Experiment}

Details of this work have been reported in progress reports, ${ }^{1,2}$ and only a brief summary is included here.

The flowsheet for the chemical processing system for the Molten-Salt Reactor Experiment (MSRE) is shown in Fig. 19.1. Feed to the plant can be either fuel salt or flush salt ( $\mathrm{LiF}-\mathrm{BeF}_{2}, 66-34$

${ }^{1}$ Molten-Salt Reactor Program Semiann. Rept. July 31 , 1963, ORNL-3529. mole \%). The salt is transferred from an MSRE drain tank to the INOR-8 fuel storage tank, which is large enough to hold a full batch with $40 \%$ freeboard. Oxides are removed by sparging with an $\mathrm{H}_{2}-\mathrm{HF}$ mixture. The hydrogen maintains a reducing condition in the salt to prevent corrosion of the vessel. The $\mathrm{H}_{2}-\mathrm{HF}-\mathrm{H}_{2} \mathrm{O}$ off-gas passes through a

${ }^{2}$ Molten-Salt Reactor Program Semiann. Rept. Jan. 31 , 1964, ORNL-3626.

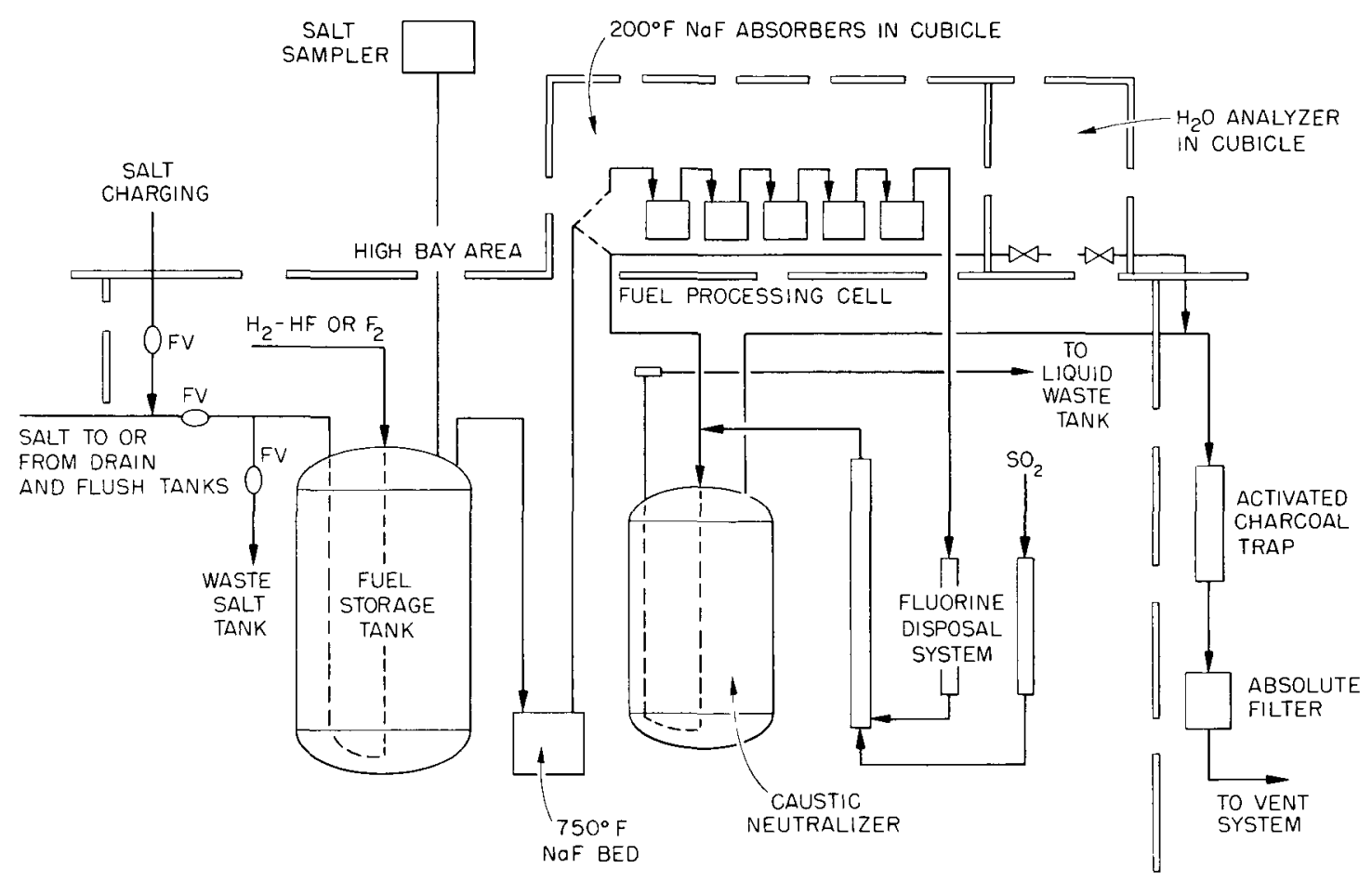

Fig. 19.1. Equipment Flowsheet for the Purification of Molten Salt Used in the Molten-Salt Reactor Experiment. Here, oxides are converted to fluorides by $\mathrm{H}_{2}-\mathrm{HF}$ gas, and uranium is recovered by converting it to $U F_{6}$ by sparging with $\mathrm{F}_{2}$. 
$750^{\circ} \mathrm{F}$ bed of $\mathrm{NaF}$ pellets for removing the fluorides of fission products and chromium, to a cold trap for condensing and measuring the amount of water removed, and then to a caustic neutralizer for removing the excess HF.

Uranium can be recovered from the molten salt by sparging with fluorine to produce $\mathrm{UF}_{6}$. The $\mathrm{UF}_{6}$ gas is decontaminated by passing through the hot $\mathrm{NaF}$ bed before sorption on low-temperature
$\mathrm{NaF}$ in a series of absorbers. These absorbers are located in a sealed cubicle above the processing cell and will be transported to the Volatility Pilot Plant for desorption and collection of the $\mathrm{UF}_{6}$ in product cylinders. Excess fluorine is disposed of by contacting it with $\mathrm{SO}_{2}$ to form an inert gas, $\mathrm{SO}_{2} \mathrm{~F}_{2}$. An activated-charcoal trap and separate off-gas filter provide final cleanup of the off-gas.

\section{Water Research Program}

Work by the Chemical Technology Division on the Water Research Program is reported directly to the Office of Saline Water, and only an abstract appears in this report (see the Summary). 


\title{
Publications, Speeches, and Seminars
}

\author{
POWER REACTOR FUEL PROCESSING
}

Blanco, R. E., G. I. Cathers, L. M. Ferris, T. A. Gens, R. W. Horton, and E. L. Nicholson, Processing of Graphite Reactor Fuels Containing Coated Partıcles and Ceramıcs, ORNL-TM-667, rev. 1 (1n press), presented at the American Chemical Society National Meeting, New York, Sept. 8-13, 1963, Nucl. Sci. Eng. 20, 13-22 (1964).

Bradley, Mildred J., and L. M. Ferris, "Hydrolysis of Uranium Carbides Between 25 and 100". II. Uranium Dicarbide, Uranıum Metal-Monocarbide Mixtures and Uranium Monocarbide-Dicarbide Mixtures," presented at the American Chemical Society Meetıng, Philadelphia, Pa., April 1964, Inorg. Chem. 3, 189 (1964).

Bradley, Mildred J., and L. M. Ferris, "Hydrolysis of Uranium Carbides Between 25 and 100'. III. Uranium Sesquicarbide and Mixtures of the Sesquicarbide with Monocarbide or Dicarbide," Inorg. Chem. 3, 730 (1964).

Bradley, Mildred J., L. M. Ferris, J. R. Flanary, J. H. Goode, and J. W. Ullmann, "Hydrolysis of NeutronIrradiated Uranium Monocarbide," Inorg. Chem. 3, 454 (1964).

Bradley, Mildred J., L. M. Ferris, J. R. Flanary, J. H. Goode, and J. W. Ullmann, "The Reactions of Neutron-Irradiated Uranium Monocarbide with Water and Aque ous Solutions of $\mathrm{NaOH}_{2} \mathrm{HCl}_{1}$ and $\mathrm{H}_{2} \mathrm{SO}_{4}$," presented at the American Institute of Chemical Engineers Meeting, Memphis, Tenn., Feb. 3-6, 1964.

Bresee, J. C., Bibliography of Rover Fuel Processing and Molten Salt Fluoride Volatrlity Process Development Studies at ORNL, ORNL-TM-800 (Apri1 1964).

Culler, F. L., Jr., "Reactor Fuel Processing," presented at the 14th Annual Nuclear Science Seminar, Oak Ridge, Tenn., Dec. 1-14, 1963.

Flanary, J. R., Mıldred J. Bradley, L. M. Ferrıs, J. H. Goode, J. W. Ullmann, and G. C. Wall, "Hot Cell Studies of Aqueous Processes for Irradiated Carbide Reactor Fuels," presented at the American Institute of Chemical Engineers Meeting, Memphis, Tenn., Feb. 4, 1964.

Gens, T. A., Laboratory Development of Methods for Precrpitating Uranium Peroxide from Zirflex Waste Solutions and Converting the Waste to Alkaline Solutions, ORNL-TM-780 (Feb. 3, 1964).

Gens, T. A., "The Use of Chlorination and Chloride Volatility Methods in Processing Nuclear Fuels," presented at the American Institute of Chemical Engineers Meeting, Memphis, Tenn., Feb. 4, 1964.

Gens, T. A., Laboratory Development of a Process for Chlorinating the Combustion Ash from Graphite Fuels Containing $T h C_{2}$ and $U_{2} C_{2}$ and Recovering the Uranium by Solvent Extraction from a Solution of the Chlorination Products, ORNL TM-789 (April 1964).

Guthrie, C. E., and J. P. Nichols, Theoretical Possibilities and Consequences of Major Accidents in $U^{233}$ and $P^{239}$ Fuel Fabrication and Radroisotope Processing Plants, ORNL-3441 (April 1964).

Kitts, F. G., Evaluation of an Engineering Demonstration of the Modified Zirflex and Neuflex Processes for the Preparation of Solvent Extraction Feeds from Unirradiated Zirconium-Base Reactor Fuels, ORNL-3465 (Mar. 11, 1964). 
Nichols, J. P., The Effect of Various External Neutron Absorbers and Reflectors on the Reactivity of Solutions of ${ }^{239} \mathrm{Pu}^{240} \mathrm{Pu}$ in Slabs, ORNL-TM-821 (Mar. 31, 1964).

Nichols, J. P., "Criticality Control in Fuel Processing Plants," Nucl. Safety 4(4), 87-90 (June 1963).

Scott, C. D., J. B. Adams, and J. C. Bresee, Production of Uranium Hexafluoride in a Fluidized Bed Reactor by the Reaction of Uranium Tetrafluoride with Oxygen, ORNL-TM-544 (Aug. 8, 1963); to be published in Industrial and Engineering Chemistry, Process Design and Development (in press).

Uriarte, A. L., and R. H. Rainey, "Dissolution of High Density $\mathrm{UO}_{2}, \mathrm{PuO}_{2}$, and $\mathrm{PuO}_{2}$-UO $\mathrm{UO}_{2}$ Pellets in Inorganic Acids," presented at the American Nuclear Society Meeting, New York, Nov. 18-21, 1963.

Watson, C. D., B. C. Finney, G. A. West, and B. A. Hannaford, "The Shear-Leach Process for Spent Nuclear Fuels," presented at the American Nuclear Society Winter Meeting, New York, Nov. 19-21, 1963, and published in the American Nuclear Society Transactions of the American Nuclear Society Winter Meeting, New York, Nov. 19-21, 1963.

Watson, C. D., and W. W. Parkinson, "Irradiation of Bituminous Materials," Chapter 6 in Bituminous Materials, Tars, and Pitches, Vol. I, ed. by A. J. Hoiberg, Wiley and Interscience Books, New York, 1964.

Watson, C. D., G. A. West, and W. F. Schaffer, Jr., "Mechanical Dejacketing of Liquid-Metal-Bonded Nuclear Fuels: An Evaluation of a Hydraulic Method and Two Alternative Methods with Spent Fuel from Core I of the Sodium Reactor Experiment," Nucl. Sci. Eng. 17(1) 149-64 (1963).

West, G. A., and C. D. Watson, Gamma Radiation Damage and Decontamination Evaluation of Protective Coatings and Other Materials for Hot Laboratory and Fuel Processing Facilities, ORNL-3589 (in press).

\section{FLUORIDE VOLATILITY PROCESSING}

Carr, W. H., "Pilot Plant Processing of Uranium-Zirconium Alloy Nuclear Fuels by a Molten-Salt FluorideVolatility Method,"' J. Tenn. Acad Sci. 39(2), 44-49 (1964).

Carr, W. H., S. Mann, and E. C. Moncrief, "Uranium-Zirconium Alloy Fuel Processing in the Oak Ridge National Laboratory Volatility Pilot Plant," pp. 56-61 in Nuclear Engineering - Patt X, American Institute of Chemical Engineers, New York, 1964 [Chem. Eng. Progt., Symp. Ser. 60(47) (1964)].

Horton, R. W., "Fluoride Volatility Processing for Recovery of Uranium from Rover Fuel," presented at the classified portion of the 1963 Annual Chemical Technology Division Information Meeting, Sept. 23-25, 1963.

Katz, Sidney, Apparatus for the Gasometric Study of Solid-Gas Reactions: Sodium Fluoride and Hydrogen Fluoride and Uranium Hexafluoride, ORNL-3497 (October 1963).

McNeese, L. E., An Experimental Study of Sorption of Uranium Hexafluoride by Sodium Fluoride Pellets and a Mathematical Analysis of Diffusion with Simultaneous Reaction, ORNL-3494 (Nov. 14, 1963), submitted to the University of Tennessee for a Master of Science Degree in Chemical Engineering, August 1963.

Milford, R. P., Process Developments in the ORNL Fluoride Volatility Program October 1962 to September 1963, ORNL-TM-717 (Oct. 25, 1963).

\section{WASTE TREATMENT AND DISPOSAL}

Blanco, R. E., Low Level Waste Treatment (ORNL-TM-861), presented at the Annual Meeting of the National Technical Task Committee on Industrial Wastes, St. Louis, Mo., Dec. 11-13, 1963. 
Blanco, R. E., J. O. Blomeke, W. E. Clark, E. J. Frederıck, H. W. Godbee, C. W. Hancher, J. M. Holmes, and J. C. Suddath, Status of the ORNL Potcal and Potglass Processes for the Conversion of Highly Radroactive Liquid Wastes to Solids, ORNL-TM-857 (May 8, 1964).

Blomeke, J. O., "Waste Management Economics in a Future Atomic Energy Industry," presented at the Annual Meeting of the National Technical Task Committee on Industrial Wastes, St. Louis, Mo., Dec. 11-13, 1963.

Blomeke, J. O., J. J. Perona, R. L. Bradshaw, ${ }^{1}$ and J. T. Roberts, Estrmated Costs for Management of High-Actrvity Power Reactor Processing Wastes, ORNL-TM-559 (May 13, 1963).

Blomeke, J. O., J. J. Perona, H. O. Weeren, and R. L. Bradshaw, ${ }^{1}$ Evaluation of Ultrmate Drsposal Methods for Liquid and Solıd Radroactive Wastes. Part III. Interim Storage of Solıdified Wastes, ORNL-3355 (Oct. 14, 1963).

Bradshaw, R. L., ${ }^{1}$ J. J. Perona, and J. O. Blomeke, Demonstration Disposal of High-Level Radroactive Solids in Lyons, Kansas, Salt Mine Background and Prelıminary Desıgn of Experimental Aspects, ORNL-TM-734 (Jan. 10, 1964).

Brooksbank, R. E., L. J. King, and J. T. Roberts, "P1lot Plant Demonstration of the Removal of Radioactivity from Low Level Process Waste Water by a Scavenging-Precipitation Ion-Exchange Process," presented at the Symposium on Radionuclide Exchange on Soils, Minerals, and Resins, Philadelphia, Pa., Apr. 10, 1964.

Clark, W. E., and C. L. Fitzgerald, Proposed Methods for the Removal of Mercury from Radioactrve Waste Solutions, ORNL-TM-827 (Mar. 31, 1964).

Davis, W., Jr., Softening and Decontaminatıng Waste Water by Caustıc Carbonate Precipitants and Filtratron in a Slowly Stirred Sludge-Blanket Clarufier Laboratory Development and Semi Pilot-Plant Testing, ORNL-TM-835 (January 1964).

Frederick, E. J., and J. M. Holmes (technical advisors), "Pot Calcination Process," motion picture produced by ORNL (S. Sinichak, ${ }^{2}$ director, and E. Sienknecht, ${ }^{2}$ cameraman), March 1964.

Hancher, C. W., and E. J. Frederick, Waste Processing Pump Test Loop Progress Report, July 1, 1963, ORNL TM-648 (Aug. 7, 1963).

Hancher, C. W., J. C. Suddath, L. J. King, and M. E. Whatley, Engineering Studies on Pot Calcination for Ultimate Disposal of Nuclear Waste from TBP-25, Darex, and Purex Processes. Part II. Collection of Performance Data and Analysis, ORNL-TM-619 (Sept. 20, 1963).

Hancher, C. W., J. C. Suddath, and M. E. Whatley, Engineering Studies on Pot Calcination for Ultimate Disposal of Nuclear Waste from the TBP-25, Darex, and Purex Processes. Part I. The System Evaluation, ORNL-3277 (revised) (Sept. 9, 1963).

Hancher, C. W., J. C. Suddath, and M. E. Whatley, Engineering Studies on Pot Calcrnation for Ultimate Disposal of Nuclear Waste Formaldehyde-Treated Purex Waste for 1965 (FTW-65), ORNL-TM-715 (Jan. 4, 1964).

Holcomb, R. R., Low-Radioactivity-Level Waste Treatment. Part I. Laboratory Development of a Scavenging-Precipitation Ion-Exchange Process for Decontamination of Process Waste, ORNL-3322 (June 1963).

Holmes, J. M., "Pot Calcination Process for Convertıng Highly Radioactive Wastes to Solıds," pre sented at the IAEA Symposium on the Treatment and Storage of High-Level Radioactive Wastes, Vienna, Austria, Oct. 8-13, 1962.

\footnotetext{
${ }^{1}$ Health Physics Division.

${ }^{2}$ Public Information Office.
} 
Holmes, J. M., H. Pfohl, ${ }^{3}$ and E. D. Arnold, Shielding Calculations - Pot Calcination Demonstration at Hanford, ORNL-TM-595 (June 21, 1963).

Horner, D. E., K. B. Brown, D. J. Crouse, and B. Weaver, Recovery of Fission Products from Waste Solutions by Solvent Extraction, ORNL-3518 (Nov. 22, 1963).

Horner, D. E., D. J. Crouse, K. B. Brown, and B. Weaver, "Fission Product Recovery from Waste Solutions by Solvent Extraction," Nucl. Sc1. Eng. 17, 234-46 (1963).

Jury, S. H., The Programming of Pot Calciner Wall Temperature to Ensure Calcination at $1650^{\circ} \mathrm{F}$ Under Optrmum Economic Conditions, ORNL-TM-600 (Aug. 12, 1963).

Jury, S. H., The Theory of Optimized Induction Heating Design for Hollow Cylindrical Loads, ORNL-TM694 (Nov. 22, 1963).

Perona, J. J., R. L. Bradshaw, ${ }^{1}$ and J. O. Blomeke, Comparative Costs for Final Disposal of Radroactive Solıds in Concrete Vaults, Granite, and Salt, ORNL-TM-664 (Oct. 23, 1963).

Schonfeld, E., Use of Alkalı Carbonate and Alkalı Phosphate to Eliminate Inhibitory Effects of Some Impurities on the Precipitation of Calcium and Magnesium from Process Waste Water, ORNL-TM-505, J. Am. Water Works Assoc 56(6), 767-73 (June 1964).

Suddath, J. C., and C. W. Hancher, "Status of Engineering Development of Pot Calcination at ORNL," presented at the High Level Waste Treatment Meeting at Brookhaven National Laboratory, Feb. $12-13,1964$.

Weeren, H. O., "Waste Disposal by Shale Fracturing," presented at a meeting of the Knoxville Society of Professional Engineers, Knoxville, Tenn., Mar. 23, 1964.

Weeren, H. O., "Shale-Fracturing Disposal Experiments at ORNL," presented at the ORNL Health Physics Information Meeting, Oct. 2-4, 1963.

Whatley, M. E., C. W. Hancher, and J. C. Suddath, Engineering Development of Nuclear Waste Pot Calcination, ORNL-TM-549 (Apr. 24, 1963), also presented as paper No. 7 at the Symposium on Utilization and Disposal of High Level Radioactive Materials of the American Institute of Chemical Eng1neers Meetıng, Buffalo, N.Y., May 5-8, 1963.

\section{TRANSURANIUM ELEMENT PROCESSING}

Bottenfield, B. F., J. P. Nichols, W. D. Burch, O. O. Yarbro, and W. E. Unger, "Containment and Ventılation Systems in the Transuranium Processing Plant," presented at the E1ghth AEC Air Cleaning Conference Held at Oak Ridge National Laboratory, Oct. 22-25, 1963, TID-7677, pp. 86-100.

Brooksbank, R. E., and W T. McDuffee, Recovery of Plutonium and Other Transuranium Elements from Irradiated Plutonium-Aluminum Alloy by Ion Exchange Methods, ORNL-3566 (May 1964).

Burch, W. D., E. D. Arnold, and A. Chetham-Strode, " ${ }^{4}$ "Production of the Transuranium Elements," Nucl. Scr. Eng. 17(3), 438-42 (November 1963).

Ferguson, D. E., "The Production of Transuranium Elements," Nucl. Scr. Eng. 17(3), 435-37 (November 1963).

Nichols, J. P., E. D. Arnold, and D. K. Trubey, "Evaluation of Shieldıng and Hazards in the Transuranıum Processing Plant," Nucl. Scr. Enǵ. 17(3), 486-91 (1963).

\footnotetext{
${ }^{3}$ Co-op student.

${ }^{4}$ Chemistry Division.

${ }^{5}$ Neutron Physics Division.
} 
Unger, W. E., B. F. Bottenfield, and F. L. Hannon, "Transuranıum Processing Facility Design," Nucl. Scı. Eng. 17(3), 479-85 (1963).

Yarbro, O. O., J. L. English," and T. S. Mackey, "Process Equipment Design and Development for Transuranium Processing Plant," Nucl. Sc1. Eng. 17(3), 492-97 (November 1963).

\section{DEVELOPMENT OF THE THORIUM FUEL CYCLE}

Dean, O. C., R. E. Brooksbank, and A. L. Lotts, A New Process for the Remote Preparation of Fuel Elements Containing Uranium-233 Oxide-Thorium Oxide (ORNL-TM 588), presented at the Ceramic Fuel Particles Symposium in the Eighth Nuclear Congress, Rome, Italy, June 19, 1963.

Dean, O. C., R. E. Brooksbank, and A. L. Lotts, "Preparation and Fabrication of Uranium-233-Thorium Oxide Fuels," presented at the Eighth Nuclear Congress, Rome, Italy, June 17-23, 1963.

Dean, O. C., C. C. Haws, Jr., A. T. Kleinsteuber, and J. W. Snıder, "The Sol Gel Process for Preparation of Thoria Base Fuels," pp. 519-42 in Proceedings of the Thorium Fuel Cycle Symposium December 5-7, 1962, Sessions IV-VII, Book II, TID-7650, book II.

Ferguson, D. E. (compiler), Status and Progress Report for Thorium Fuel Cycle Development for Period Ending December 31, 1962, ORNL-3385 (October 1963).

Ferguson, D. E., O. C. Dean, and D. A. Douglas, "The Sol-Gel Process for the Remote Preparation and Fabrication of Recycle Fuels," Third United Nations Intemational Conference on the Peaceful Uses of Atomic Energy, Geneva, Switzerland, Aug. 31-Sept. 9, 1964, to be published in the Proceedings.

Ferguson, D. E., and J. A. Lane, "Technical Status of the ORNL Thorium Utılization Program," presented at the AEC Symposium on Advanced Converter Reactor Prototypes, Washington, D.C., Mar. 19-20, 1964, ORNL-TM-859 (May 1964).

Haws, C. C., Jr., "Pilot Plant Preparation of ${ }^{233} \mathrm{U}-\mathrm{O}-\mathrm{ThO}_{2}$ Shards by the Sol-Gel Method," presented at the Powder Filled UO Symposium, Worcester, Mass., Nov. 5-6, 1963, to be published in the Proceedings.

Kelly, J. L., O. C. Dean, and A. T. Kleinsteuber, "The Preparation of Thorium Dicarbide and UraniumThorium Dicarbide Spheres by a Sol Gel Process," presented at the Eighth Nuclear Congress, Rome, Italy, June 17-23, 1963.

Kelly, J. L., O. C. Dean, and A. T. Kleinsteuber, "A New Procedure for the Preparation of Spheroidal Particles of Thorium and Uranium-Thorium Dicarbides," presented at the American Chemical Society Meetıng, New York, Sept. 8-13, 1963.

Kelly, J. L., A. T. Kleinsteuber, S. D. Clınton, and O. C. Dean, "Sol-Gel Process for Preparıng Sphero1dal Particles of the Dicarbides of Thorium and Thorıum-Uranıum Mixtures," accepted for publication by Industrial and Engineering Chemistry, Process Design and Development.

McBrıde, J. P., S. D. Clinton, and W. L. Pattıson, "Reactor Irradiation of Thoria Powders and Pellets," pp. 675-95 in Proceedings of the Thorium Fuel Cycle Symposium December 5-7, 1962, Sessions $I V-V I I$, Book II, TID-7650, book II.

Rabın, S. A., S. D. Clinton, and J. W. Ulimann, "The Radiation of Nonsintered Thoria-UO and Thona$\mathrm{PuO}_{2}$ Fuel Rods for Power Reactor Applications," presented at the Powder Filled UO Fuel Element Symposium, Worcester, Mass., Nov. 5-6, 1963, to be published in the Proceedings.

\footnotetext{
${ }^{6}$ General Engineering and Construction Division.

${ }^{7}$ Reactor Chemistry Division.
} 


\section{SEPARATIONS CHEMISTRY RESEARCH}

Blake, C. A., Jr., "Separation of Diethylbenzenes by Gas Chromatography Using Packed Columns," Anal. Chem. 11(35), 1759-60 (October 1963).

Blake, C. A., Jr., "Chemical Separations in the Atomic Energy Field," presented, under the ORNL Traveling Lecture Program, at the University of Mississippi, University, Miss., Dec. 9-10, 1963, at North Carolina State University, Raleigh, Dec. 11-13, 1963, at Mississippi State University, State College, Miss., Apr. 7, 1964, and at LeMoyne College, Memphis, Tenn., Apr. 9, 1964.

Blake, C. A., Jr., W. Davis, Jr., and J. M. Schmitt, Properties and Cleanup of Degraded Tributyl Phosphate-Amsco Solutions and the Relative Stabilities of Alternative Extractant-Diluent Systems, ORNL3524 (Nov. 25, 1963).

Blake, C. A., Jr., W. Davis, Jr., and J. M. Schmitt, "Properties of Degraded TBP-Amsco Solutions and Alternative Extractant-Diluent Systems," Nucl. Sci. Eng. 17, 626-37 (1963).

Brown, K. B., "Introduction - Solvent Extraction Che mistry Symposium," Nucl. Sci. Eng. 16, 381 (1963).

Coleman, C. F., "Amines as Extractants," Nucl. Sci. Eng. 17, 274-86 (1963).

Coleman, C. F., Amines as Extractants - Survey of the Descriptive and Fundamental Extraction Chemistry, ORNL-3516 (Nov. 12, 1963).

Egan, B. Z., "Extraction of Alkali Metals by Substituted Phenols - Descriptive Chemistry," presented to Technical Staff, U.S. Rubber Company, Wayne, N.J., by R. A. Zingaro, Apr. 8, 1964.

Myers, A. L., W. J. McDowell, and C. F. Coleman, Degree of Polymerization of Di(2-ethylhexyl)phosphoric Acid and Sodium Di(2-ethylhexyl)phosphate in Wet Benzene by Differential Vapor Pressure Measurements, ORNL-TM-695 (Dec. 2, 1963).

Schmitt, J. M., and C. A. Blake, Jr., Purification of Di(2-ethylhexyl)phosphoric Acid, ORNL-3548 (Feb. 17, 1964).

Weaver, B., "New Methods for Separation of Actinides and Lanthanides," presented at Texas Women's University, Denton, Tex., under Traveling Lecture Program, Jan. 13, 1964.

Weaver, B., "Chemical Differences Between the Lanthanides and Trivalent Actinides," presented at the Fourth Rare Earth Research Conference at Phoenix, Ariz., Apr. 22-25, 1964.

Weaver, B., "Liquid-Liquid Extraction of the Rare Earths," in Progress in the Science and Technology of the Rare Earths, Vol. 1, ed. by LeRoy Eyring, Pergamon, New York, 1964.

Zingaro, R. A., "Separation of Alkali Metals by Solvent Extraction with Phenols," presented, under the ORNL Traveling Lecture Program, at Alabama College, Montevallo, Feb. 21, 1964, at the University of South Carolina, Columbia, May 11, 1964, and at Clemson University, Clemson, S.C., May 12, 1964.

\section{CHEMISTRY OF PROTACTINIUM}

Campbell, D. O., "The Chemistry of Protactinium in Sulfuric Acid Solutions," in Proceedings of the Protactinium Chemistry Symposium, Gatlinburg, Tenn., Apr. 25-26, 1963, Sessions 1-3; TID-7675.

Chilton, J. M., "Some Observations on the Behavior of Protactinium in Hydrochloric Acid-Hydrofluoric Acid Solutions," in Proceedings of the Protactinium Chemistry Symposium, Gatlinburg, Tenn., Apr. 25-26, 1963, Sessions 1-3; TID-7675. 


\section{RADIATION EFFECTS ON CATALYSTS}

Krohn, N. A., An Annotated Bibliography on the Effects of Radiation on Heterogeneously Catalyzed Reactions and on Chemisorption, ORNL-3461 (July 3, 1963).

Krohn, N. A., and H. A. Smith, "The Influence of Incorporated Radioactivity and External Radiation on the Dehydration of Cyclohexanol over Sulfate Catalysts," J. Phys. Chem. 67, 1497 (1963).

\section{CHEMICAL ENGINEERING RESEARCH}

Chester, C. V., and H. F. Johnson, "Transfer of Uranyl Ion Across the Water-Tri- $n$-Butyl Phosphate Interface," presented at the 53d National American Institute of Chemical Engineers Meeting, Pittsburgh, Pa., May 17-20, 1963.

Erdman, C. A., and C. V. Chester, A Study of the Electrodeless Electrolytic Dissolution of Stainless Steel in Nitric Acid Using a Magnetically Induced Potential, ORNL-TM-598 (Sept. 3, 1963).

Fisher, G. T. and J. W. Prados, "A Differential Stage Cascade Design for Separation of Two Components in a Dilute Solution" (under subcontract No. 1056 with the University of Tennessee), Ind. Eng. Chem., Fundamentals 2, 300-304 (1963).

Fisher, G. T., J. W. Prados, and L. P. Bosanquet, "Thermal Diffusion of Salt Solutions in Single Stage Cells and in Continuous Horizontal Cells: The System Copper Sulfate-Cobalt Sulfate-Water" (under subcontract No. 1056 with the University of Tennessee), A.I.Ch.E. (Am. Inst. Chem. Engrs.) J. 3, 786-93 (1963).

Whatley, M. E., "Countercurrent Liquid-Liquid Extraction by Exploiting the Induced Underflow Effect in the Stacked-Clone Contactor," presented at the Annual Meeting of the Tennessee Academy of Science, Chattanooga, Tenn., Nov. 29, 1963, and published in the Proceedings.

Whatley, M. E., and W. M. Woods, The Performance of an Advanced Experimental Stacked-Clone Contactor: A High-Performance Solvent Extraction Machine with Potential for Application to Very Highly Radioactive Solutions, ORNL-3533 (April 1964).

\section{ASSISTANCE PROGRAMS}

Goeller, H. E., E. M. Shank, and W. M. Sproule, List of Information Sent to and Received from the Eurochemic Co., Jan. 1, 1963, through June 30, 1963 (Categorized), ORNL-TM-685 (Aug. 5, 1963).

Goeller, H. E., E. M. Shank, and W. M. Sproule, List of Information Sent to and Received from the Eurochemic Co., July 1, 1963, through Dec. 31, 1963 (Categorized), ORNL-TM-685, supp1. 1 (Feb. 3, 1964).

Nichols, J. P., and E. D. Arnold, Radiation Characteristics and Shielding Requirements of Isotopic Power Sources for Space Missions, ORNL-TM-591, Revised (Aug. 13, 1963); presented at the Symposium on Isotopic Power Fuels at ORNL, June 25-26, 1963.

Nichols, J. P., and E. D. Arnold, "Shielding Isotopic Power Sources for Space Missions," Nucleonics 22(2), 52-56 (February 1964).

Shank, E. M., USAEC - Eurochemic Assistance Program Progress Report for January-June 1963, ORNLTM-704 (Oct. 10, 1963).

\footnotetext{
${ }^{8}$ University of Tennessee.
} 


\section{MISCELLANEOUS}

Arnold, E. D., Shrelding Requirements and Radiation Characteristrcs of Isotoprc Power Sources for Space Applications, ORNL-3576 (Apri1 1964).

Arnold, W. D., and D. J. Crouse, "Radium Removal from Uranium Mill Effluents with Inorganic Ion Exchangers," presented at the American Chemical Society Meetıng, Philadelphia, Pa., Apr. 6-10, 1964.

Arnold, W. D., D. J. Crouse, and K. B. Brown, "Solvent Extraction of Cesium from Ore Liquors," presented at the 19th Southwest Regional Meeting of the American Chemical Society, Houston, Tex., Dec. 5-7, 1963.

Bennett, M. R., "Chemistry in Fused Salt Processing," presented at the University of Chat tanooga, Chattanooga, Tenn., Nov. 29-30, 1963.

Blanco, R. E., Production of Fertilizer in a Multipurpose Atomic Power Reactor Complex for Distrllation of Sea Water: A Survey, ORNL-TM-609 (July 3, 1963).

Brown, K. B., F. J. Hurst, D. J. Crouse, and W. D. Arnold, Review of Thorium Reserves in Granitic Rock and Processing of Thorium Ores, ORNL-3495 (Nov. 22, 1963).

Chilton, J. M., R. A. Gilbert, R. E. Leuze, and W. S. Lyon, "A Redetermination of the Half-Life of Uranium-232," J. Inotg. Nucl. Chem. 26, 395 (1964).

Corbin, L. T., ${ }^{9}$ W. R. Winsbro, C. E. Lamb, ${ }^{9}$ and M. T. Kelley, ${ }^{9}$ "Design and Construction of ORNL High-Radiation-Level Analytical Laboratory," presented at the 11th Conference on Hot Laboratories and Equipment, Winter Meeting of the American Nuclear Society, New York, Nov. 18-21, 1963, also in the Proceedings.

Culler, F. L., Jr., "Potential Processes for the Production of Liquid Fuels and Chemical Raw Materials from Coal," presented at the Symposium on Application of Advanced Technology to Coal Research, University of Kentucky, Lexington, June 1963.

Culler, F. L., Jr., "Partially Enriched Fuel Cycles," presented at the European Atomic Energy Society Symposium on Fuel Cycles for Power Reactors, Baden-Baden, Germany, Sept. 9-14, 1963.

Davis, W., Jr., and P. S. Lawson, Activities and Other Thermodynamic Properties from Measurements of Partial Pressures of Water-Nitric Acıd-Tributyl Phosphate Solutions at 25 C, ORNL-TM-651 (Sept. 19, 1963).

Godbee, H. W., and W. T. Ziegler, "The Thermal Conductivity of $\mathrm{MgO}, \mathrm{Al}_{2} \mathrm{O}_{3}$ and $\mathrm{ZrO}_{2}$ Powders to $850^{\circ}$," presented at the 1963 Thermal Conductivity Conference, Gatlinburg, Tenn., Oct. 16-18, 1963.

Goodpasture, D. W., ${ }^{8}$ and L. B. Shappert, Energy Absorption Capability of Steel Determined from Cask Impact Tests, ORNL-TM-680 (Jan. 7, 1964).

Guthrie, C. E., and J. P. Nichols, "Theoretical Possibilities and Consequences in Major Accidents in $\mathrm{U}^{233}$ and $\mathrm{Pu}^{239}$ Fuel Fabrication and Radioisotope Processing Facilities," presented at a meeting of the American Nuclear Society, Philadelphia, Pa., June 1964.

Harrington, F. E., E. D. Arnold, D. C. Brater, ${ }^{10}$ D. A. Douglas, ${ }^{11}$ S. H. Smlley, ${ }^{10}$ W. G. Stockdale, J. W Ullmann, and A. L. Lotts, ${ }^{11}$ Fuel Cycle Costs for a Plutonium Recycle System, ORNL-3501 (Jan. 6, 1964).

Harrington, F. E., D. H. Newman, and A. B. Meservey, Laboratory Study of Zirconium-Uranium Processing Equipment Contamination and Decontamination, ORNL-TM-837 (Apr. 29, 1964).

\footnotetext{
${ }^{9}$ Analytical Chemistry Division.

${ }^{10}$ ORGDP.

11 Metals and Ceramics Division.
} 
Helton, D. M., A Preliminary Study on Uranıum Carbide Synthesis, Using a Plasma Jet, ORNL-TM-872 (May 25, 1964).

Landry, J. W., "Peaceful Nuclear Explosives and the Nuclear Test Ban," presented to the exhibit managers of the American Museum of Atomic Energy at Oak Ridge Institute of Nuclear Studies, Oak Ridge, Tenn., Aug. 15, 1963.

Landry, J. W., "Project Plowshare," presented at the U.S. Army Nuclear Science Seminar, Oak Ridge, Tenn., Aug. 21, 1963.

Landry, J. W., "Excavation with Nuclear Explosives," presented to the Blount County Medical Society, Maryville, Tenn., Oct. 24, 1963.

Landry, J. W., "Project Plowshare," presented at the U.S. Naval Reserve Research Semınar, Oak Ridge, Tenn., Dec. 4, 1963.

Landry, J. W., "Peaceful Uses of Nuclear Explosives," presented to the Knoxville-Oak Ridge Section of the American Institute of Chemical Engineers, Oak Ridge, Tenn., Dec. 11, 1963.

Landry, J. W., "Peaceful Uses of Nuclear Explosives," presented to the exhibit managers of the Amer1can Museum of Atomic Energy at Oak Ridge Institute of Nuclear Studies, Oak Ridge, Tenn., Jan. $10,1964$.

Landry, J. W., "Peaceful Uses of Nuclear Explosives," presented to the University of Tennessee Student Chapter of the American Institute of Chemical Engineers, Knoxville, Tenn., Jan. 22, 1964.

Landry, J. W., "Peaceful Uses of Nuclear Explosives," presented to the Oak Ridge Lions Club, Oak Ridge, Tenn., Jan. 27, 1964.

Leuze, R. E., and J. M. Chilton, "Production and Isolation of Uranium-232," presented at the 15th Annual Southeastern Regional Meeting of the American Chemical Society, Charlotte, N.C., Nov. 14, 1963.

McAllister, R. A., and A. D. Ryon, A Review of Pulse-Column Flooding Data and Correlations with Proposed Methods of Correlation, ORNL-TM-634 (Sept. 9, 1963).

Meservey, A. B., "Decontamination Research," presented at the Winter Meeting of the Reactor Decontamination Information Exchange Group (RDIEG), Pittsburgh, Pa., Feb. 26-28, 1964.

Nıchols, J. P., and E. D. Arnold, Radiation Characterıstıcs and Shielding Requirements of Isotopıc Power, ORNL-TM-591 (revised), Nucleonics 22(2), 52 (February 1964).

Olsen, A. R., ${ }^{11}$ J. P. Nichols, and Sigfred Peterson, ${ }^{11}$ Safety Analysis of the Operation of the HighRadiation-Level Examination Laboratory, ORNL-3479 (Nov. 20, 1963).

Salmon, Royes, A Computer Code (CDC 1604A or IBM 7090) for Calculating the Cost of Shipping Spent Reactor Fuels as a Function of Burnup, Specific Power, Cooling Time, Fuel Composition, and Other Variables, ORNL-3648 (August 1964).

Shappert, L. B., An Economic Analysis of the Domestic and Overseas Shipment of Spent Reactor Fuel, ORNL-TM-590 (June 27, 1963).

Shappert, L. B., Drop Tests Performed on the Franklin Institute's 1/4-Scale Model of a 40-Ton Cask, ORNL-TM-629 (Aug. 19, 1963).

Shappert, L. B., "Review of Incidents Which Have Occurred in AEC Shipments of Radioactive Materıal," Nucl. Safety 5(1), 123-27 (September 1963).

Shappert, L. B., "Cask Drop Tests Performed at Oak Ridge National Laboratory," presented at the Paducah Gaseous Diffusion Plant, Paducah, Ky., Oct. 2, 1963.

Shappert, L. B., "Progress Report on Shipping Cask Impact Tests and the Shipping Cost Code," presented to the U.S. Atomic Energy Commission, Germantown, Md., Nov. 14, 1963.

Shappert, L. B., A Gurde to the Design of Shipping Casks for the Transport of Radioactive Materials, ORNL TM-681 (in press). 
Shappert, L. B., and K. W. Haff, ${ }^{12}$ "Standards and Tests for Radioactive Materials Shipping Casks," Nucl. Safety 4(4), 18-21 (June 1963).

\section{PROGRESS REPORTS}

\section{Unit Operations Section}

Whatley, M. E., et al., Unit Operations Section Monthly Progress Report, January 1963, ORNL-TM-541 (Aug. 13, 1963).

Ibid., February 1963, ORNL-TM-581 (Oct. 8, 1963).

Ibid., March 1963, ORNL-TM-586 (Sept. 23, 1963).

Ibid., April 1963, ORNL-TM-608 (Oct. 17, 1963).

Ibid., May 1963, ORNL-TM-613 (Oct. 21, 1963).

lbid., June 1963, ORNL-TM-628 (Sept. 12, 1963).

Ibid., July 1963, ORNL-TM-642 (Nov. 8, 1963).

Ibid., August 1963, ORNL-TM-776 (June 29, 1964).

Ibid., September 1963, ORNL-TM-785 (Aug. 17, 1964).

Ibid., October 1963, ORNL-TM-823 (Aug. 17, 1964).

Ibid., November 1963, ORNL-TM-756 (Apr. 28, 1964).

Ibid., December 1963, ORNL-TM-775 (Apr. 22, 1964).

\section{Transuranium Element Processing}

Burch, W. D., Transuranium Quarterly Progress Report for Period Ending February 28, 1963, ORNL-3482 (Oct. 1, 1963).

Ibid., for Period Ending August 31, 1963, ORNL-3558 (March 1964).

Ibid., for Period Ending November 30, 1963, ORNL-3597 (May 1964).

Ibid., for Period Ending February 29, 1964, ORNL-3651 (in preparation).

\section{Chemical Development Section C}

Brown, K. B., Chemical Technology Division, Chemical Development Section C, Progress Report on Separations Process Research for January-June 1963, ORNL-3496 (Oct. 18, 1963).

\section{SEMINARS}

1963

July 16 Effects of Reactor Irradiation on $\mathrm{ThO}_{2}$

J. P. McBride

July 23

Use of Radio-Frequency-Excited Oxygen for Low-

C. E. Gleit

Temperature Burning of Organic Substances

(Tracerlab)

\footnotetext{
${ }^{12}$ Is otopes Division.
} 
July $30 \quad$ Thermoconductivity of Powders High-Level Waste Disposal

Aug. 6

Aug. 13

Aug. 20

Aug. 27

Sept. 3

Oct. 8

Nov. 5

Nov. 12

Nov. 19

Nov. 26

Dec. 3

Dec. 10

Dec. 17

1964

Jan. 21

Jan. 28

Feb. 11

Feb. 18

Mar. 3

Mar. 10 International

\section{Laser Demonstration}

Pellets in Nitric Acid Systems Studies with Solid Fluorides Pilot Plant Columns

Status of BNL-Kilorod Program with Amines

Drop Coalescence Studies

Laser Demonstration

"Bouclier Liquide" (movie)
Uranium Carbide Development at Atomics

Sodium and Strontium Extraction by D2EHPA

Adsorption of Protactinium on Unfired Vycor Dissolution of $\mathrm{UO}_{2}, \mathrm{PuO}_{2}$, and $\mathrm{UO}_{2}-\mathrm{PuO}_{2} \mathrm{Fuel}$

Processing of Al-U Fuel by Fused Salt Process Volatilization of $\mathrm{PuF}_{6}$ from Fused Salt Sorption

Solvent Extraction Properties of Amines

Uranium-Zirconium Processing in the Volatility

Absorption of $\mathrm{UF}_{6}$ in Sodium Fluoride Pellets

Engineering Development of Foam Separation

Extraction of Metals from Chloride Solutions

Small Angle X-Ray Scattering as a Research Tool

Turbulence Promotion with Flow Elements

Located Away from the Surface

Alkylbenzenes - Structure Versus Stability

Rover Fuel Processing (classified)

The Outlook for Thorium Utilization

Project Plowshare, Part I: The Peaceful Uses of Nuclear Explosives

Nevada Test (movie)
H. W. Godbee

W. E. Clarke

Keith Magnus

(Atomics International)

P. M. Griffin

(Physics)

W. J. McDowell

J. G. Moore

Armando Uriarte

(Spain)

M. R. Bennett

R. L. Jolley

Sidney Katz

C. A. Blake

W. H. Carr

S. Mann

E. L. Youngblood

L. E. McNeese

P. A. Haas

C. C. Haws

J. L. Matherne

J. E. Van Cleve

(Metals and Ceramics)

F. G. Seeley

P. W. Schmidt

(University of Missouri)

D. G. Thomas

(Reactor)

C. O. Chester

D. E. Ferguson

C. A. Blake

Robert Souvognac, Narrator (Isotope)

R. W. Horton

J. A. Lane

(Directors)

J. W. Landry 
Mar. 31

Energy Absorption Capabilities of Lead and Steel Shipping Costs of Spent Fuel Elements

Apr. 7

Chemonuclear and Radiation Process Development at $\mathrm{BNL}$

Apr. 14

Project Plowshare, Part II: “Project GNOME Technical Report" (movie)

May 12

The Kilorod Program

Evaluation of Powder-Packed Fuel Rods

May 19

Remote Fuel Fabrication Studies

The TUFCDF

May 26
Preparation of Carbides by Sol-Gel (classified)

Preparation of $\mathrm{UO}_{2}$ and Mixed Oxides (classified)
L. B. Shappert

Royes Salmon

M. Steinberg

(Brookhaven National Laboratory)

J. W. Landry

R. E. Brooksbank

S. A. Rabin

(Metals and Ceramics)

A. L. Lotts

(Metals and Ceramics)

A. R. Irvine

J. L. Kelly

R. G. Wymer 
ORNL-3627

UC. 10 - Chemical Separations Processes for Plutonium and Uranium TID.4500 (33rd ed.)

INTERNAL DISTRIBUTION

1. Biology Library

2-4. Central Research Library

5. Laboratory Shift Supervisor

6. Reactor Division Library

7-8. ORNL - Y-12 Technical Library Document Reference Section

9-28. Laboratory Records Department

29. Laboratory Records, ORNL R.C.

30. S. E. Beall

31. D. S. Billington

32. C. A. Blake

33. R. E. Blanco

34. E. P. Blizard

35. J. O. Blomeke

36. C. J. Borkowski

37. R. E. Brooksbank

38. G. E. Boyd

39. J. C. Bresee

40. R. B. Briggs

41. K. B. Brown

42. F. R. Bruce

43. W. H. Carr

44. G. I. Cathers

45. J. M. Chandler

46. W. E. Clark

47. C. F. Coleman

48. J. A. Cox

49. D. J. Crouse

50-79. F. L. Culler

80. W. Davis, Jr.

81. O. C. Dean

82. D. A. Douglas

83. D. E. Ferguson

84. L. M. Ferris

85. J. R. Flanary

86. J. L. Fowler

87. J. H. Frye, Jr.

88. J. H. Gillette

89. H. E. Goeller

90. A. T. Gresky

91. W. R. Grimes

92. P. A. Haas
93. J. P. Hammond

94. C. S. Harrill

95. A. Hollaender

96. R. W. Horton

97. A. R. Irvine

98. W. H. Jordan

99. M. T. Kelley

100. J. A. Lane

101. C. E. Larson

102. R. E. Leuze

103. M. H. Lloyd

104. R. S. Livingston

105. H. G. MacPherson

106. R. A. McNees

107. R. P. Milford

108. E. C. Miller

109. K. Z. Morgan

110. L. Nelson

111. E. L. Nicholson

112-113. R. B. Parker

114. R. H. Rainey

115. A. D. Ryon

116. A. F. Rupp

117. H. E. Seagren

118. M. J. Skinner

119. A. H. Snell

120. J. C. Suddath

121. J. A. Swartout

122. E. H. Taylor

123. V. C. A. Vaughen

124. W. E. Unger

125. B. J. Young

126. C. D. Watson

127. B. S. Weaver

128. A. M. Weinberg

129. M. E. Whatley

130. G. C. Williams

131. R. G. Wymer

132. J. J. Katz (consultant)

133. C. W. J. Wende (consultant)

134. P. H. Emmett (consultant)

135. C. E. Winters (consultant) 


\section{EXTERNAL DISTRIBUTION}

136. R. W. McNamee, Union Carbide Corporation, New York

137. Sylvania Electric Products, Inc.

138. Research and Development Division, AEC, ORO

139. Dr. Barendregt, Eurochemic, Mol, Belgium

140. Giacomo Calleri, CNEN, c/o Vitro via Bacdisseras, Milano, Italy

141. D. J. Carswell, Radiochemical Laboratory, The New South Wales University of Technology, P.O. Box 1, Kensington, Sydney, N.S.W., Australia

142. E. Cerrai, Laboratori CISE, Casella Postale N. 3986, Milano, Italy

143. David Dyrssen, The Royal Institute of Technology, Department of Inorganic Chemistry, Kemisträgen 37, Stockholm 70, Sweden

144. Syed Fareeduddin, Indian Rare Earths Ltd., Army and Navy Building, 148 Mahatma Gandhi Road, Bombay 1, India

145. J. M. Fletcher, United Kingdom Atomic Energy Authority, Atomic Energy Research Establishment, Harwell, Berks, England

146. H. Irving, Department of Inorganic Chemistry, University of Leeds, Leeds, England

147. T. Ishihara, Chemical Engineering Laboratory, Japan Atomic Energy Research Institute, Tokyo, Japan

148. A. S. Kertes, Hebrew University, Jerusalem

149. Y. Marcus, Israel Atomic Energy Commission, Tel Aviv, Israel

150. E. Glueckauf, Atomic Energy Research Establishment, Harwell, Berks, England

151. P. Regnaut, C.E.N. Fontenay-aux-Roses, Boite Postale No. 6, Fontenay-aux-Roses, Seine, France

152. R. Rometsch, Eurochemic, Mol, Belgium

153. A. J. A. Roux, Director of Atomic Energy Research, South African Council for Scientific and Industrial Research, Box 395, Pretoria, South Africa

154. Jan Rydberg, Department of Nuclear Chemistry, Chalmers Tekniska Hogskola, Gibraltargatan $5 \mathrm{H}$, Goteborg, Sweden

155. Erik Svenke, Director, Department of Chemistry, Atomic Energy Company, Stockholm 9, Sweden

156. D. G. Tuck, University of Nottingham, Nottingham, England

157. B. F. Warner, United Kingdom Atomic Energy Authority, Production Group, Windscale and Calder Works, Sellafield, Seascale, Cumberland, England

158. R. A. Wells, Dept. of Scientific and Industrial Research, National Chemical Laboratory, Teddington, Middlesex, England

159. M. Zifferero, Comitato Nazionale per l'Energia, Nucleare, Laboratorio Trattamento Elementi Combustibili, c/o Instituto di Chemica Farmaceutica e Tossicologica dell 'Universita, Piazzale delle Scienze, 5, Rome, Italy

160. M. Claude Jean Jouannaud, Department Head, Plutonium Extraction Plant, Marcoule (Gard), France

161. Prof. Louis Gutierrez-Jadra, Director de Planta Pilotos e Industriales, Junta de Energia Nuclear, Ciudad Universitaris, Madrid (3), Spain

162. W. G. Belter, AEC, Washington

163. J. A. Lieberman, AEC, Washington

164. W. H. Regan, AEC, Washington

165. H. Bernard, AEC, Washington

166-672. Given distribution as shown in TID-4500 (33rd ed.) under Chemical Separations Processes for Plutonium and Uranium Category (75 copies - CFSTI) 
CHEMICAL TECHNOLOGY DIVISION

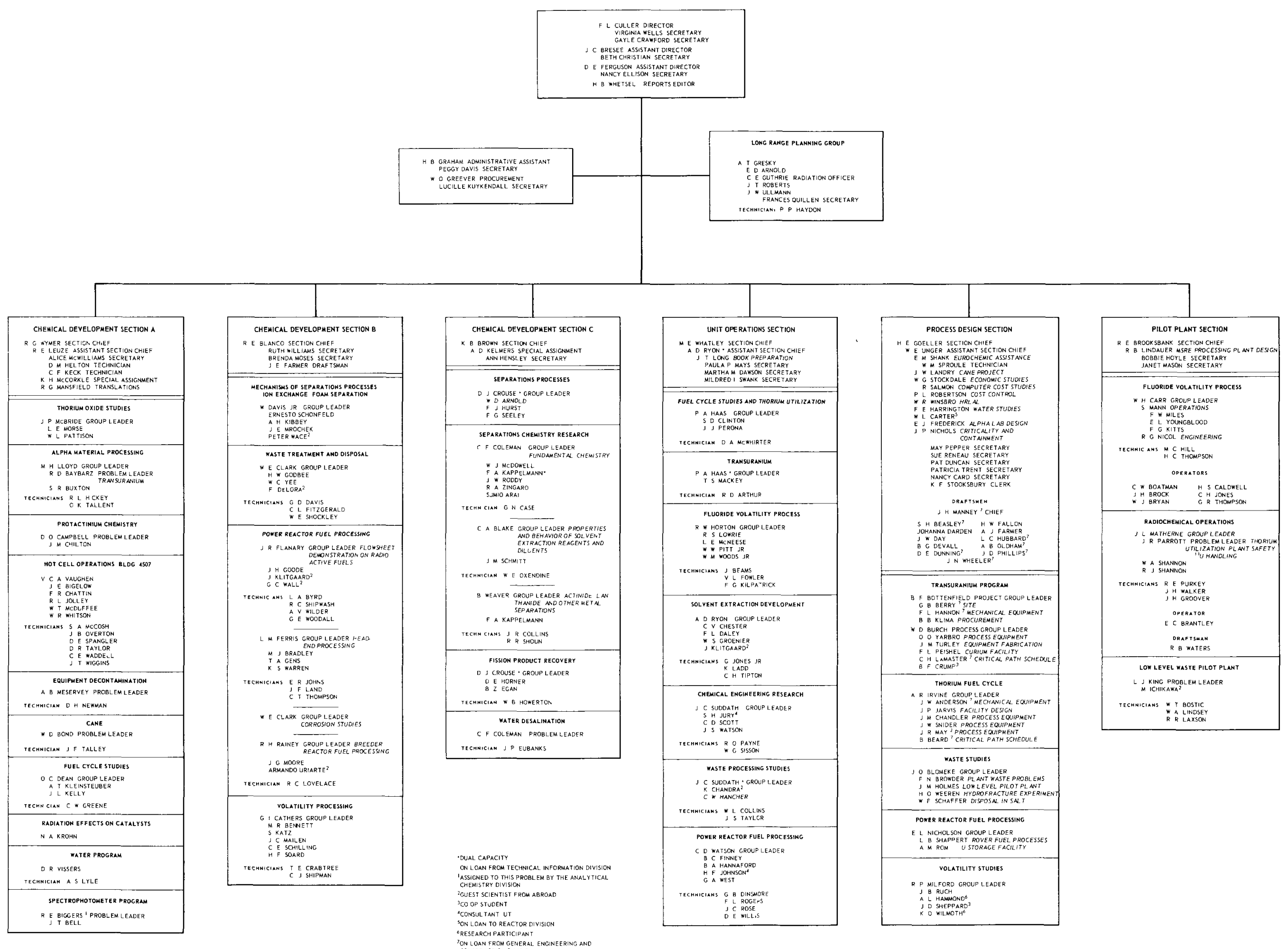

